\title{
DEVELOPING A LABEL FOR EXECELLENCE IN DESIGN FOR URBAN SUSTAINABILITY
}

\author{
By \\ Fabricio Ribas Chicca \\ A thesis submitted to the Victoria University of Wellington \\ in fulfilment of the requirements for the degree of \\ Doctor of Philosophy \\ in Architecture
}

Victoria University of Wellington

2013 



\begin{abstract}
The thesis investigates the impact caused by urban development on the environment. In addition, the thesis proposes and tests a methodology and a prototype tool for assessing the environmental performance of urban environments.
\end{abstract}

The first section of the research briefly discusses some of the important environmental performance rating systems available on the market, such as USGBC-LEED, BREEAM, ISO 14000, NABERS and CASBEE. Their use for assessing urban developments is investigated critically. The thesis points out relevant flaws in the methods of these institutions, exposing a gap in knowledge of urban environmental assessment.

The next step of the thesis begins by considering some historical societies and their urban models in order to understand how those making urban developments have approached the environment and its limitations. Indeed, the analysis of these historical models was based on selected speculative aspects, since confirmed by the investigation, as being essential for an ecologically balanced society. The thesis dedicates a chapter to describing the impact caused by the progressive monetarization of ancient society on the relationship between the urban environment and nature. The chapter introduces a discussion about how money has interfered with and speeded up the process of job specialization in urban areas, and how it has been shaping urban areas today.

The thesis then reflects on important urban problems from an ecological point of view, pointing out relevant issues in modern urban development. Additionally, the research connects the problems of modern urbanism and the economics that have acted as a major force in shaping cities and their expansions.

Finally the research proposes a methodology for environmental assessment, based on the ecological footprint. The prototype tool developed puts together all relevant environmental aspects. It also includes personal habits, combining these with urban design, transportation, consumption and energy resources to measure the footprint impact. The research recognises that the footprint cannot be treated as a static number; therefore, the research also presents a second instrument, which 
calculates the biocapacity per capita, according to population and economic growth, serving as a numerical ecological parameter for the first prototype tool. This enables the environmental impact of proposed changes, such as urban growth, to be assessed.

A number of case studies using the tools are presented. These include three new urban developments which have a label for more sustainable urban design (LEED). The measurement prototype tool is also applied to some of the ancient societies previously studied, in order to compare the present urban and life style model with that of ancient urban societies. The thesis ends by comparing results from LEED for Neighbourhood Development with those of the new prototype tool, including comparison of modern and historical urban models. 


\section{Abbreviations}

ABNT - Associacao Brasileira de Normas Tecnicas - Brazilian Association for Technical Standards

ANSI - American National Standards Institute

ASHRAE - American Society of Heating, Refrigeration, and Air-Conditioning Engineers

BEE - Building Environmental Efficiency

BEES - Building for Environmental and Economic Sustainability

BREEAM - Building Research Establishment Environmental Assessment Method

BRE - Building Research Establishment

CASBEE - Comprehensive Assessment System for Building Environmental Efficiency

CBECS - Commercial Building Energy Consumption Survey

CNU - Congress for New Urbanism

DfE - Design for Environment

DIS - Draft International Standard

EBTIDA - Earnings Before Interest, Taxes, Depreciation, and Amortization

EMS - Environmental Management Systems

ESCO - Energy Service Company

EYR - Energy Yield Ratio

FDIS - Final Draft International Standard

FIESP - Federacao das Industrias de Sao Paulo - Federation Industries of Sao Paulo

G\&A - General and Administration costs

GAEF - Global Average Ecological Footprint

gha - Global Hectare

GJ - Gigajoule

GWh - Gigawatts Hours

IESNA - Illuminating Engineering Society of North America 
ha - Hectare

IBGE - Instituto Brasileiro de Geografia e Estatistica - Brazilian Institute of Geography and Statistics

ISA - International Federation of National Standardizing Associations

ISO - International Organization for Standardization

IUCN - International Union for Conservation of Nature

JSBC - Japan Sustainable Building Consortium

kcal - Kilocalorie

LCA - Life Cycle Assessment

LEED - Leadership in Energy and Environmental Design

LSC - LEED Steering Committee

MJ - Megajoule

MLIT - Ministry of Land, Infrastructure and Transport - Japan

NABERS - National Australian Building Environmental Rating System

NPD - Neighbourhood Pattern and Design

p. L - Page Location (for Digital Book version)

PV - Photovoltaic

ROE - Return on Equity

ROI - Return on Investment

SLL - Smart Location and Linkage

SNZ - Standards New Zealand

TAG - Technical Advisory Group

UN - United Nations

USGBC - United States Green Building Council 


\section{List of Contents}

$\begin{array}{ll}\text { Abstract } & 03\end{array}$

$\begin{array}{ll}\text { Abbreviations } & 05\end{array}$

1. Introduction

1.1. What is the Research about and why is it necessary?

1.1.1. Defining Sustainability 27

1.1.2. Biocapacity and Ecological Footprint 30

1.1.3. Definition of Urban Sustainability 31

1.1.3. Definition of Urban Area 31

1.2. Gap in Knowledge $\quad 31$

1.2.1. Labelling and Standardization 33

1.2.2. International Organization for Standardization (ISO) 35

1.2.2.1. ISO Members 36

1.2.2.2. The ISO Standardization Process 37

1.2.2.3. ISO 14000 and ISO 14001

1.2.3. Leadership in Energy and Environmental Design (LEED) and United States Green Building Council (USGBC) 41

1.2.3.1. The LEED Steering Committee 43

1.2.3.2. Implementation Advisory Committee $\quad 44$

1.2.3.3. LEED Market Advisory Committee Charge $\quad 44$

1.2.3.4. Technical Committee $\quad 45$

1.2.3.5. LEED Technical Advisory Groups Charge $\quad 46$ 
1.2.4. CASBEE - Comprehensive Assessment System for Building

1.2.4.3. CASBEE for New Construction (CASBEE-NC) 54

1.2.4.4. CASBEE for Existing Building (CASBEE-EB) 54

1.2.4.5. CASBEE for Renovation (CASBEE-RN) 55

1.2.4.6. CASBEE for Specific Purposes 56

1.2.4.7. Regional Scale Assessment 56

1.2.5. BREEAM

1.2.5.1. BREEAM Methods 58

1.2.5.2. The Scope of BREEAM 59

$\begin{array}{ll}\text { 1.2.6. NABERS } & 60\end{array}$

1.2.6.1. NABERS Office $\quad 63$

1.2.6.2. NABERS Homes 67

1.2.6.3. NABERS Hotels $\quad 67$

1.2.6.4. NABERS Retail $\quad 67$

$\begin{array}{ll}\text { 1.2.7 Discussion } & 67\end{array}$

$\begin{array}{lr}\text { 2. Research Design and Methodology } & 69\end{array}$

2.1. Research Design $\quad 69$

$\begin{array}{ll}\text { 2.2. Methodology } & 72\end{array}$ 
2.3 Historical Data $\quad 72$

2.3.1.1. From Historical Data to Modern Indicators 73

2.3.1.2. Providing a Label for Urban Environmental Sustainability 75 
3.5.2. The burgs and the expansion of countryside production 126

3.5.3. Conclusion

3.6. Early Modernism, the Garden City Concept and Contemporary

Urbanism

3.6.1. Early Stages

3.6.2. The Garden City - Ebenezer Howard 128

3.6.3. Functional Zoning: Tony Garnier

3.6.4. The City for Three Million People and La Ville Radieuse: Le Corbusier

3.6.5. Broadacre City: Frank Lloyd Wright

3.6.6. Conclusion

3.7. General Conclusion

131

\section{Monetarization in the Ancient World and the Impact on Urban Design}

132

4.1. Introduction

4.2. Monetarization as a Catalyst for the Process of Urbanization

4.3. From the Pre-Monetary Stage to the Monetary Economy

133

4.4. The Mesopotamian Economy and the Invention of Money

4.5. The Development of the Ancient Mediterranean Monetary Economy 
4.5.2. Monetarization in the Roman Empire and the Urban Character of Ancient Rome

4.6. Conclusion

5.1. Introduction 153

5.2. Defining the Modern Concept of Rural and Urban

154

5.2.1. Main Urban Areas

155

5.2.2. Satellite Urban Areas

155

5.2.3. Independent Urban Community

155

5.2.4. Rural Area with High Urban Influence

155

5.2.5. Rural Area with Moderate Urban Influence

156

5.2.6. Rural Area with Low Urban Influence 156

5.2.7. Highly Rural/Remote Area

156

5.3. Global Urbanisation

157

5.4. Regional Imbalance -Origin and Consequence for Urban Design

159

6. Eco-Social Urban Design and Urban Social Efficiency

6.1.1. Equal access to green areas and urban infra-structure

6.1.3. Walkability and Local Commerce 
6.1.4.1.1. Priority Given to Public Transportation over Private Transportation

6.1.4.1.2. Reduction of Private Areas over Common

Areas

6.1.4.1.3. Preservation of Ecosystems and Green

Corridors

6.1.4.1.4. Urban Food Production 198

6.1.4.1.4.1. The Social Function of Urban Agriculture

200

6.1.4.1.5. Integrated Transportation Planning and

Design

203

6.1.4.2. Urban Energy Consumption and Local Production 208

6.1.4.3. Water

6.2 Conclusion

220

\section{How the Economic Status quo affects Urban Environmental}

\section{Inequality}

7.1. The Inconsistent Relationship between Economy, Economic Growth and Environmental Limits 224

7.2. Urban Sustainability in an Economic Environment 229

7.2.1. The Unsustainable Real Estate Approach to Urban Growth; the Myth of Profit 230

7.3. Conclusion 235 
8.2. The Unreal Handiness of the Car Exchanged for the Real Convenience of not Going

8.3. Urban Environments towards Walkability 244

8.4. Food - Integrating Food in Urban Planning 250

8.5. Mobility: Circulation of People and Goods 255

8.6. The Matter of Distance-High-Density or Low Density-Transportation and Urban Design

8.7. Energy and Consumption 262

9. General Global Footprint: Results and Analysis

9.1. Urban Ecological Footprint Measurement Prototye Tool

9.1.1 Description of Prototype Tool 1 Components

9.1.1.1. Advantages and Disadvantages of Prototype Tool 1

9.1.2 Description of Prototype Tool 2 Components

9.2. Cases Studies - Contemporary Urban Developments

9.3.1. First Group of Analyses - Ancient Societies, Incas, Medieval Milan, Contemporary Rural India and China 
9.3.1.4. Rural China - Ping'an and Weigan, Guangxi Province, July 2006

9.3.1.5. Rural India - Khajuharo, Madhya Pradesh , January 2011

9.3.1.6. Medieval Milan 284

9.3.2. Ecological Footprint Comparison 284

9.4. Second Group of Analyses - Contemporary LEED Certified Projects

9.4.1. Tassafaronga, SALT District and Mapleton-Fall Creek - Analysis of the scores from LEED 286

9.4.1.1 Seaside 294

9.4.2. LEED: Revealing Important Flaws 294

9.4.2.1. SLL - Credit 1 - Preferred Location 1-10 points 295

9.4.2.2. SLL Credit 3: Locations with Reduced Automobile Dependence 1-7 points 297

9.4.2.3. SLL Credit 5: Housing and Job Proximity 1 - 3 points 298

9.4.2.4. NPD Credit 13: Local Food production - 1 point 299 9.4.2.5. NPD Credit 4: Mixed-Income Diverse Communities

1 - 7 points 299

9.4.3. Conclusions about LEED-ND as a Tool for Environmental Assessment

9.5. Using LEED to Environmentally Assess Low Ecological Footprint Communities 
9.5.2. Imperilled Species and Ecological Communities

Conservation

9.5.3. Wetland and Water Body Conservation

303

9.5.4. Agricultural Land Conservation

9.5.5. Floodplain Avoidance

9.5.6. Walkable Streets

304

9.5.7. Compact development

304

9.5.8. Connected and Open Community 304

9.5.9. Certified Green Building 305

9.5.10. Minimum Building Energy Efficiency 305

9.5.11. Minimum Building Water Efficiency 305

9.5.12. Construction Activity Pollution Prevention

9.5.13. Conclusion on Using LEED for Low Ecological Footprint Communities 305

9.6. General Conclusion 308

10. General Conclusion 312

Bibliography 326

Appendices

342 


\section{List of Figures}

Figure 1- Definition of $Q$ and $L$ through a theoretical boundary (Japan Sustainable Building Consortium, 2011, p. 02)

Figure 2 - Simplified research chart showing the research design and its main stages: Research problem investigation (Problems), Gap in Knowledge (Need), Ecological Footprint Measurement tools (Prototype Tools) and the case studies (Testing)

Figure 3 - Simplified comparison between the ancient Chinese (left) and European (right) models of urbanization

Figure 4 - Xi'an - China, sector 5 Photo: Author: July 2008

Figure 5 - Diagram of ancient Chinese urban modulation, the "holy system":

Image: Author

Figure 6 - Left - Access to group of Residences. Hutong - Beijing -June 2008-Photo: Author 120

Figure 7 - Right top - Internal courtyard, Hutong - Beijing - June 2008 - Photo: Author

Figure 8 - Right bottom - Street of a Hutong - Beijing - June 2008 - Photo: Author

Figure 9 - Percentage of urban population in Europe (Estimated) (Pounds, 2005, p. 81)

Figure 10 - Simplified model of the urban development of ancient Rome

Figure 11 - Timeline representing the development of Mesopotamia, ancient Greece and Rome relating to historical economic milestones

Figure 12 - Urban and rural populations from 1950 to 2050 in billions

(United Nations, 2011)

Figure 13 - Urban and rural populations from 1950 to 2050 in billions in the least developed countries. "The group of least developed countries, as defined by the United Nations General Assembly in 2003, comprises 50 countries, of which 34 are in Africa, 10 in Asia, 1 in Latin America and the Caribbean, and 5 in Oceania. The group includes 50 countries - Afghanistan, Angola, Bangladesh, Benin, Bhutan, Burkina Faso, Burundi, Cambodia, Cape Verde, Central African Republic, Chad, Comoros, Democratic Republic of the Congo, Djibouti, Equatorial Guinea, Eritrea, Ethiopia, Gambia, Guinea, Guinea-Bissau, Haiti, Kiribati, Lao People's Democratic Republic, Lesotho, Liberia, Madagascar, Malawi, Maldives, Mali, Mauritania, Mozambique, Myanmar, Nepal, Niger, Rwanda, Samoa, Sao Tome and Principe, Senegal, Sierra Leone, Solomon Islands, Somalia, Sudan, TimorLeste, Togo, Tuvalu, Uganda, United Republic of Tanzania, Vanuatu, Yemen and Zambia. These countries are also included in the less developed regions." (United Nations, 2011) 
Figure 14 - Urban and rural populations from 1950 and 2050 in billions in the more developed countries which comprise all regions of Europe plus Northern America, Australia/New Zealand and Japan (United Nations, 2011)

Figure 15 - Regional imbalance and the commercial relationship between cities with different characteristics - static model

Figure 16 - Regional imbalance and the commercial relationship between cities with different characteristics - non static model (population growth)

Figure 17 - Regional imbalance and the commercial relationship between cities in a scenario of great population growth and large commercial expansion, increase in poverty, environmental degradation etc.

Figure 18 - The consequence of population growth in a stable and sufficient region. The grey area indicates one of the probable effects of population decrease

Figure 19 - Contrast between two regions in São Paulo, Brazil. Site 1 is located in a wealthy region in contrast with site 2 which is located in a recently urbanized slum. - (C) 2011 Google@ 2011 Tele Atlas

Figure 20 - Family income distribution according to the national 2001 census. Although the distance between Sites 1 and 2 is less than 400 metres the map shows the social gap in this part of the town. MW - Minimum Wage in Brazil in 2011 is NZD\$ 354 / month - (c) 2011 Google (c) 2011 Tele Atlas

Figure 21 - Site 01, low density, and no commerce - Image: (c) 2011 Google

Figure 22 - Site 2 - Higher density than site 1, commerce - (c) 2011 Google

Figure 23-Commercial outlets available around sites 1 and 2. Strip centres are small commercial centres ( 2 or 3 shops), in Sao Paulo, Brazil, with parking places in front of the stores. The yellow rings represents $2 \mathrm{~km}$ radii steps (c) 2011 Google (C) 2011 Tele Atlas

Figure 24 - Western Sao Paulo, including Barueri, Carapicuiba, Osasco Santa do Parnaiba, Itapevi, first Alphaville (orange), and second Alphaville (yellow): Sao Paulo is in the lower right corner (C) 2011 Google (C) 2011 Tele Atlas (Imagery from Dec 15, 2008)

Figure 25 - Junction between one of the Alphaville gated communities and Carapicuiba - The details shows the property division made by a high wall (c) 2011 Google (c) 2011 Tele Atlas 180 Figure 26 - Distance between the community attached to Alphaville and the closest condominium entry (C) 2011 Google (C) 2011 Tele Atlas 
Figure 27- Distances between residential condominiums and the closest commercial area (marked in Yellow) (C) 2011 Google (C) 2011 Tele Atlas

Figure 28 - The walkable route forces the pedestrian to take a longer path. (C) 2011 Google (C) 2011

Tele Atlas

Figure 29 - Greater Sao Paulo GDP (In New Zealand Dollars) (IBGE, 2009)

Figure 30 Comparison between government investment in public transportation and highways in NZ (Ministry of Transport - New Zealand, 2010)

Figure 31 Comparison between government investment in public transportation and highways in NZ between 2011 - 2018 (Ministry of Transport - New Zealand, 2010) in million NZ dollars

Figure 32 Amount of investment in Roads compared with Public transportation in NZ (Ministry of

Transport - New Zealand, 2010) - in million dollars

Figure 33 - Transportation cycle and impacts on social and urban environment

Figure 34 - Subdivision at Ribeirao Preto, Sao Paulo, Brazil developed by the join-venture CIPASA, SCOPEL and WTB, with 23.63 per cent road cover in its original design

Figure 35 - Subdivision at Mogi das Cruzes, Sao Paulo, Brazil developed by the join-venture CIPASA, SCOPEL and Helbor has 20.78 per cent road cover in its design

Figure 36 - Common urban block design. Residential site, sidewalk and road. An Example of high level of water impermeability

Figure 37 - Example of urban design integrating the principle of green areas and minimizing the importance of roads, therefore cars, in a subdivision

Figure 38 - Present hypothetical model of urban development. Urban area almost totally taken by built-up areas making the city reliant on outsourced food suppliers

Figure 39 - Distribution chart showing the process of goods distribution and illustrating the importance of distribution for retailers

Figure 40 - Comparison between three different models of urban design according to food production and local supply system

Figure 41 - Conceptual model chart for regional transportation system 
Figure 44 - Theoretical graph showing the relationship between population growth and footprint and transformation after Energy and Land crisis, the vertical axis indicates the growth while the horizontal axis indicates timeline

Figure 45 - Connectivity comparing the number of intersections in different models of urban environment

Figure 46 - Comparison of the urban intersection dispositions in different urban models - the analysis was made using google earth (C) 2011 Google Earth

Figure 47- The graph compares different countries and their ecological footprint and its components (Global Footprint Network, 2012)

Figure 48 - The bar chart compares the capacity of different countries to produce food according to their diet habits and ecological footprint. It means that, in India for example, a region with low density (386 p/ha) would be able to produce 66 per cent of their food, while in Australia, due to the diet, even using the free space in regions with low density, only 11 per cent would be locally produced

Figure 49 - World energy uses by source (ExxonMobil, 2012)

Figure 50 - Ecological footprint by energy source (Chambers, Simmons, \& Wackernagel, 2000, p. 83 Wackernagel \& Rees, 1996, p. 69)

Figure 51 - Comparison between EROEI from different energy sources - (Murphy \& Hall, 2010, p. 109; Wackernagel \& Rees, 1996, p. 69)

Figure 52 - The bar chart shows the comparison between the Ecological Footprints of different ages and communities all around the world. The red line represents the group average

Figure 53 - Top Left - Every day meal - Rice and Pork Cooked inside bamboo

Figure 55 - Top middle - Pork Slaughter and commerce - Barter is largely accepted

Figure 58 - Khajuharo region, including the old city and production fields (C) 2012 Google (C) 2011 
Figure 59 - Overview of an analysed family from Khajuraho. Left middle, woman working on the family harvest. Bottom right a communal well, and beside a small reservoir to collect rain water 


\section{List of Tables}

Table 1 - Definitions of Sustainability and Sustainable Development References: 1 - (Bosselman, 2008, pp. 17-22), 2 - (Danzer Group, 2012), 3 - (Environment \& Society Portal, 2011), 4 - (United Nations, 2012), 5 - (McFarland, Guerti, \& Pelizza, 1996, p. 373), 6 - (Elkington, 2012), 7 -

(Wohlmeyer \& Quendler, 2002, p. 197), 8 - (Beckerman, 1994, p. 191), 9 - (Wackernagel \& Rees, 1996), 10 - (Gilding, 2011, p. 149), 11 - (Common \& Stagl, Ecological Economy - An Introduction, 2005, p. 08), 12 - (Sheehan, 2009, p. 12), 13 - (Kuhlman \& Farrington, 2010, p. 3441), 14 - (LeGates \& Stout, 2011, p. 381), 15 - (United States Environmental Protection Agency, 2012)

Table 2 - Distances between residential condominiums and the closest commercial area

Table 4 - The table describes the minimum requirements for urban sustainability related to walkability

Table 6 - World Biocapacity and the ideal share that each item should have in order to have a zero land deficit (Global Footprint Network, 2012)

Table 7 - The relationship necessary between Urban Density and Local Food Production in order to achieve local food production sustainability. Lower densisties have to have high levels of food production

Table 8 - Land used to supply the demand for energy for daily transportation (220 days a year) including embodied energy. Electric commuter train has $\mathrm{MJ} /$ passenger calculated from a renewable energy model multiplied by 1.25 (for diesel) and then multiplied by 3 for a non-renewable electricity value (Vale \& Vale, 2009, p. 111) .

Table 9 - Typical Ancient Roman diet* kcal and gha of 7 different vegetables and fruits (carrots, asparagus, tomatoes, cabbage, apples, fig and banana - (Berners-Lee, 2010, pp. L 580, 839, 1359; Calorie Count, 2012; Global Footprint Network, 2011)

Table 10 - Typical Ancient Greek diet * kcal and gha of 7 different vegetables and fruits (carrots, asparagus, tomatoes, cabbage, apples, fig and banana - (Berners-Lee, 2010, pp. L 580, 839, 1359; Calorie Count, 2012; Global Footprint Network, 2011)

Table 12 - Typical Rural China Diet (Guangxi - Province) * kcal and gha of 7 different vegetables and fruits (carrots, asparagus, tomatoes, cabbage, apples, fig and banana - (Berners-Lee, 2010, pp. L 580, 839, 1359 ; Calorie Count, 2012; Global Footprint Network, 2011) 
Table 13 - Typical Rural Indian Diet (Madhya Pradesh - State) * kcal and gha of 7 different vegetables and fruits (carrots, asparagus, tomatoes, cabbage, apples, fig and banana - (Berners-Lee, 2010, pp. L 580, 839, 1359; Calorie Count, 2012; Global Footprint Network, 2011)

Table 14 - Food ecological footprint (global average) and Calorie Comparison - Final Footprint (global average) ${ }^{* *}$ Number computed from productivity - tonne/ha

Table 15 - Comparison between 3 real estate developments certified with LEED-ND. The table shows the total score by blocks and the highest scores for each block of credits

Table 16 - Combined results of the prototype tools developed in this thesis. The right column explores the results from the second prototype tool, calculating the scenarios of land deficit or surplus according to the ecological footprint of the case studies 


\section{Introduction}

\subsection{What is the Research about and why is it necessary?}

This research investigates sustainability in urban environments. The ultimate intent is to produce an assessment prototype tool capable of measuring sustainability in urban regions. A perception of the existence of a profound social and environmental inequality, developed during a period of being involved in delivery of new urban environments in Brazil, has driven this research to analyse the urban environment and its environmental impact, in an effort to find a way to categorize the urban environment as being sustainable or not. Sustainability here is applied in its broadest sense of the continuous living of humanity within the resources of one planet (see table 1).

Urban areas normally accrue and consume more resources than rural areas; it has been suggested that urban areas have a larger impact than rural communities (Kahn, 2006, p. 11). According to the United Nations (UN), the world urban human population trends indicate an increase of 72 per cent by 2050 , from 3.6 billion in 2006 to a staggering 6.3 billion by 2050 . The rural population will also steadily increase until 2021 reaching a peak of 3.4 billion. In 2050, the UN suggests a total human population of 9.31 billion, a substantial growth when compared with the 6.97 billion inhabitants in 2011 (United Nations, 2012, pp. 3-4). Cities are, therefore, the predominant human habitat today, although this is fairly recent phenomenon. In 1950, only 29.5 per cent of the population lived in cities (United Nations, 2012, p. 04). Cities were smaller in the past; in 1900, only four cities had around one million inhabitants (Beijing, Tokyo, Delhi and London). By 2000 there were around 200 cities of more than one million, 100 between one million and ten million, and 20 megacities with more than ten million (Giradert, 2004, p. 03). The human species has thus become eminently urban. This highlights one of the reasons it is essential to assess environmental performance in urban areas. As the urban population is growing faster than the total population, and urban areas commonly consume more resources, the straightforward conclusion is the environmental impact caused by this urbanization will proportionally raise the total human environmental impact at a faster rate than that of today. Urbanization 
itself will cause an increase in the environmental impact even without population and consumption growth. However, the total human population will also increase by around 50 per cent, and the current economic model depends on expansion, with a consequent demand for more resources (Vale \& Vale, 2009, p. 11; Heinberg, 2011, p. L 273).

This research is essentially about the environmental impact caused by urban environments and the best way to measure their impacts. Because of population and economic growth the ecological problems faced by the world justify the research focus.

Consequently, the first step in this research is focused on the definition of sustainability. Many sustainability definitions were analysed (see Table 1), and it emerged that as a consequence of the proliferation of definitions of sustainability, the term has been perceived as a vehicle to perpetuate corporate interests while giving the impression of using environmentally sound principles. It was estimated that in 2007 there were around three hundred definitions of sustainability (Johnston, Everard, Santillo, \& Robert, 2007, p. 60). Perhaps, the definition of sustainable development from the World Commission on Environment and Development, "meeting the needs of the present generation while not compromising the ability of future generations to meet their needs" (World Commission on Environment and Development, 1987, p. 40) remains one of the most commonly cited definitions. However, this definition is too broad for assessing sustainability in urban areas, and too conveniently vague to be used for assessing commercial proposals. Moreover, the definition is ambiguous because it includes the term 'development'. The simple inclusion of development leads to interpretations of the definition that are focused on growth. According to Wackernagel and Rees (1996, p. 33), the confusion is intentional as it is a reflection of power politics and political bargaining". Even though investigating this confusion was not the core of this research, the findings from looking at what has driven urban development suggest agreement with this view of Wackernagel and Rees. The thesis suggests that the lack of accuracy in defining sustainability has been useful for developers and other economic players acting in the urban 
environment. Indeed, development and environment have been in conflict at all scales from the regional to global (Owens, 2003, p. 05).

\subsubsection{Defining Sustainability}

Because of the wide range of definitions of sustainability and the influence that the real estate market has in expropriating the term as a means to increase sales, it was imperative to find a definition of sustainability which would be suitable for this research proposal. Although, the main goal was not to untangle the misunderstandings concerning with the misuse of the term sustainability, some investigation was needed in order to start the process, and effectively to measure sustainability in a scientific way. As a result, detachment of the terms development and sustainability was a mandatory first step.

The idea of having the terms sustainable development and sustainability as synonymous was not thought suitable for this research. The conflict between the present models of development and sustainability were perceived early in this investigation. Hence, it was necessary to research more into definitions about sustainability. At the dictionary level, sustainability simply describes an activity which is capable of being permanently sustained. However, the dictionary meaning does not explore what is necessary to maintain the activity and the consequences (whether restorative or damaging) caused by this activity. Under the dictionary meaning, companies can create long cycle profit, in a very sustainable way, but in doing so could cause sustained environmental harm. The broad definition of sustainable development suggested that a clear separation between economic and environmental interests is necessary.

\begin{tabular}{|l|l|}
\hline \multicolumn{2}{|l|}{ Definitions of Sustainability and Sustainable Development } \\
$\begin{array}{l}\text { Medieval Idea of } \\
\text { Sustainability }{ }^{1}\end{array}$ & $\begin{array}{l}\text { Live from the yields, but not from the substance. Perception of the } \\
\text { importance of the forest }\end{array}$ \\
\hline $\begin{array}{l}1662 \text { - John Evelyn and the } \\
\text { British Royal Society }\end{array}$ & Investigation of a sustained supply of timber \\
\hline 1662 - Louis XIV1 & $\begin{array}{l}\text { "bon usage de la nature" (good use of nature), restrict tree felling, } \\
\text { cattle grazing, and have a tree planting programme. This was the } \\
\text { essence of forest management }\end{array}$ \\
\hline
\end{tabular}




\begin{tabular}{|c|c|}
\hline $\begin{array}{l}1714 \text { - Hans Carl von } \\
\text { Carlowitz }{ }^{1,2}\end{array}$ & $\begin{array}{l}\text { "Nachhaltigkeit" (Sustainability) - Forest Economy or Guide to } \\
\text { Tree Cultivation Conforming with Nature" }\end{array}$ \\
\hline $\begin{array}{l}1757 \text { - Wilhelm Gottfried } \\
\text { Moser } 1,3\end{array}$ & $\begin{array}{l}\text { Modifying Carlowitz's term sustained to sustainable. Definition of } \\
\text { forest management. Introduction of the expression 'sustainable } \\
\text { economy for forests'. }\end{array}$ \\
\hline $\begin{array}{l}1972 \text { - Club of Rome - Limits } \\
\text { of Growth }{ }^{1}\end{array}$ & $\begin{array}{l}\text { Sustainability as a counter-model to economic dominance. It } \\
\text { explores how exponential population growth interacts with finite } \\
\text { resources. }\end{array}$ \\
\hline $\begin{array}{l}1972 \text { - UN Conference on } \\
\text { Human Environment }{ }^{4}\end{array}$ & $\begin{array}{l}\text { Introduction of the concept of sustainable development concealing } \\
\text { economic development and environment. }\end{array}$ \\
\hline 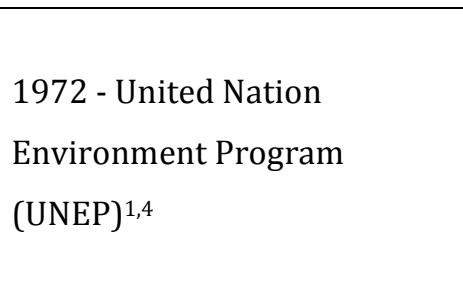 & $\begin{array}{l}\text { Leading the efforts of the United Nations family on behalf of the } \\
\text { global environment. Its current priorities are environmental } \\
\text { aspects of disasters and conflicts, ecosystem management, } \\
\text { environmental governance, harmful substances, resource } \\
\text { efficiency, and climate change. }\end{array}$ \\
\hline $\begin{array}{l}1980 \text { - World Conservation } \\
\text { Strategy produced by IUCN }{ }^{4}\end{array}$ & $\begin{array}{l}\text { World Conservation Strategy produced by IUCN put forward the } \\
\text { concept of 'sustainable development' meaning development that } \\
\text { would allow ecosystem services and biodiversity to be sustained. }\end{array}$ \\
\hline $\begin{array}{l}1987 \text { - Gro Harlem } \\
\text { Brundtland }^{4}\end{array}$ & $\begin{array}{l}\text { "Our Common Future" - "Sustainable development is development } \\
\text { that meets the needs of the present without compromising the } \\
\text { ability of future generations to meet their own needs." }\end{array}$ \\
\hline $\begin{array}{l}1993 \text { - US. Council on } \\
\text { Sustainable Development }{ }^{5}\end{array}$ & $\begin{array}{l}\text { "to bring people together to meet the needs of the present without } \\
\text { jeopardizing the future" }\end{array}$ \\
\hline $\begin{array}{l}1993 \text { - David Pearce and Giles } \\
\text { Atkinson }^{1}\end{array}$ & $\begin{array}{l}\text { An economy is considered sustainable if its savings rate is } \\
\text { greater than the combined depreciation rate on natural and } \\
\text { man-made capital. They define sustainability as implying } \\
\text { maintaining the level of human welfare (or well-being) so that it } \\
\text { may improve, but never decline (or, not more than temporarily, } \\
\text { anyway). In this sense, sustainable development can be viewed as } \\
\text { the non-decline of human welfare over time. }\end{array}$ \\
\hline $\begin{array}{l}1994 \text { - John Elkington - The } \\
\text { triple Bottom Line } 6\end{array}$ & People, Planet and Profit \\
\hline 1996 - Herman Edward Daly ${ }^{7}$ & $\begin{array}{l}\text { Sustainability is the view that no species should ever go extinct, } \\
\text { nor any non-renewable resource should ever be taken from the } \\
\text { ground, no matter how many people are starving }\end{array}$ \\
\hline 1997 - Wilfred Beckerman ${ }^{8}$ & $\begin{array}{l}\text { Some natural resources to be run down as long as sufficient } \\
\text { compensation is provided by increases in use of other resources, } \\
\text { usually in the form of human capital. }\end{array}$ \\
\hline
\end{tabular}




\begin{tabular}{|c|c|}
\hline $\begin{array}{l}1997 \text { - Mathis Wackernagel } \\
\text { and William Rees }\end{array}$ & Concept of ecological footprint \\
\hline $\begin{array}{l}2002 \text { - Don Reed and Murray } \\
\text { Hogarth }^{10}\end{array}$ & $\begin{array}{l}\text { Single Bottom Line - companies should take only those actions in } \\
\text { sustainability that deliver definable financial benefit to companies. }\end{array}$ \\
\hline 2005 - Michael Common ${ }^{11}$ & $\begin{array}{l}\text { Sustainability is: maintaining the capacity of the joint economy- } \\
\text { environment system to continue to satisfy the needs and desires of } \\
\text { humans for a long time into the future }\end{array}$ \\
\hline 2009 - Brendan Sheehan ${ }^{12}$ & $\begin{array}{l}\text { The principles of sustainability integrate three closely interlinked } \\
\text { elements the environment, the economy, and the social system- } \\
\text { into a system that can be maintained in a healthy state indefinitely. } \\
\text { In parallel, running a successful and sustainable plant operation } \\
\text { includes factors in three categories: energy and environmental } \\
\text { stewardship, corporate stewardship and human resources, and } \\
\text { achieving operational and financial goal }\end{array}$ \\
\hline $\begin{array}{l}2010 \text { - Tom Kuhlman and } \\
\text { John Farrington } 13\end{array}$ & $\begin{array}{l}\text { Sustainability may be defined as maintaining well-being over a } \\
\text { long, perhaps even an indefinite period. }\end{array}$ \\
\hline $\begin{array}{l}2011 \text { - Richard LeGates and } \\
\text { Frederic Stout }{ }^{14}\end{array}$ & $\begin{array}{l}\text { In essence, sustainable development is a process of change in } \\
\text { which the exploitation of resources, the direction of investments, } \\
\text { the orientation of technological development, and institutional } \\
\text { change are all in harmony and enhance both current and future } \\
\text { potential to meet human needs and aspirations }\end{array}$ \\
\hline $\begin{array}{l}2012 \text { - EPA - UN } \\
\text { Environmental Protection } \\
\text { Agency }^{15}\end{array}$ & $\begin{array}{l}\text { Sustainability is based on a simple principle: everything that we } \\
\text { need for our survival and well-being depends, either directly or } \\
\text { indirectly, on our natural environment. Sustainability creates and } \\
\text { maintains the conditions under which humans and nature can } \\
\text { exist in productive harmony, that permit fulfilling the social, } \\
\text { economic and other requirements of present and future } \\
\text { generations. Sustainability is important to making sure that we } \\
\text { have and will continue to have, the water, materials, and } \\
\text { resources to protect human health and our environment }\end{array}$ \\
\hline
\end{tabular}

Table 1 - Definitions of sustainability and sustainable development - References: 1 - (Bosselman, 2008, pp. 17-22), 2 - (Danzer Group, 2012), 3 - (Environment \& Society Portal, 2011), 4 - (United Nations, 2012), 5 - (McFarland, Guerti, \& Pelizza, 1996, p. 373), 6 - (Elkington, 2012), 7 - (Wohlmeyer \& Quendler, 2002, p. 197), 8 - (Beckerman, 1994, p. 191), 9 - (Wackernagel \& Rees, 1996), 10 - (Gilding, 2011, p. 149), 11 - (Common \& Stagl, 2005, p. 08), 12 - (Sheehan, 2009, p. 12), 13 - (Kuhlman \& Farrington, 2010, p. 3441), 14 - (LeGates \& Stout, 2011, p. 381), 15 - (United States Environmental Protection Agency, 2012)

What table 1 demonstrates could be summarised as two views of sustainability. The first is that economic goals are still key and sustainability has to work around these. The second, exemplified in the early definitions that predate the concept, is humanity should not overharvest the resources supplied by nature. However, this 
thesis does not suggest an anti-economic process, or a permanent recession. It does, however, strongly contest the economic model and its concepts including the need for permanent expansion. Preliminary results from the investigation into the meaning of sustainability exposed the importance of the term for today's market. It has been used as part of the marketing policies for companies in most segments of the economy, including real estate. The importance that the term sustainability has gained among all sorts of consumers has also been perceived by Rutherford (2012). Consequently, it became important to associate the environmental performace of an urban area with a definition of sustainability which was not commited to any corporate interest. As a result, two independent principles have been studied and introduced as essential aspects for a definition of sustainability; biocapacity or biological capacity; and ecological footprint.

\subsubsection{Biocapacity and Ecological Footprint}

According to the Global Footprint Network (2011), biocapacity can be defined as:

"The capacity of ecosystems to produce useful biological materials and to absorb waste materials generated by humans, using current management schemes and extraction technologies. Biocapacity is usually expressed in global hectares."

(Global Footprint Network, 2011)

In this definition global hectares measure global average land productivity. Biocapacity can also be described as the global total of all biologically productive areas, where these are defined as areas with quantitatively significant plant and animal productivity. Arable land is potentially the most productive land type (Chambers, Simmons, \& Wackernagel, 2000, p. 177). The idea of continuity and permanence can be taken from the broad meaning of sustainability. The maximum amount of resources that can safely and persistently be imposed on the environment by humans was also called carrying capacity by William Cotton (Wackernagel \& Rees, 1996, p. 158). The amount (or area) of biologically productive land and water an individual, population, or activity required to 
produce all the resources it consumes and absorb the waste it generates is called the ecological footprint by the Global Footprint Network (Global Footprint Network, 2012). Similarly Wackernagel \& Rees (1996, p. 09) have defined ecological footprint as an accounting tool that allows estimation of the resource consumption and waste assimilation requirement of an individual, population or activity in terms of a corresponding biologically productive land area. The importance of these tools is that they are quantitative methods of assessing environmental impact. Although ecological footprint has been criticised (Costanza, 2000 ) it remains a tool that gives a different definition of sustainability, that of being able to sustain human life within the available resources of one planet. The question then becomes not one of defining sustainability, but rather one of deciding what sort of life is possible under those conditions.

\subsubsection{Definition of Urban Sustainability}

The modern urban environment does not often have arable areas, the most productive land category, and they are, therefore, unable to provide themselves with essential products such as food, goods, and water. Under the concepts and principles above, the definition of urban sustainability proposed by this thesis is an urban environment in which its ecological footprint is, at every point of its history, lower than the available share of world total biocapacity, assuming everyone is entitled to equal access to resources. Because of population growth, the world biocapacity per person progressively decreases and therefore, the urban environment assessed has to have the capacity to proportionally reduce its environmental demand and impact in order to keep itself sustainable.

\subsubsection{Definition of Urban Area}

In this thesis an urban area is defined as a specific part of a city, such as might be produced by an urban developer. Where cities are very small, as in some eras of history, the urban area is effectively the whole city. However, the intention in developing a label for urban sustainability is related to the scale at which modern 
developers operate within a city. How this definition is used will become clear in the case studies (chapter 3.6)

\subsection{Gap in Knowledge}

Based on the concepts and principles of sustainability previously discussed, an investigation into the environmental assessment effectiveness of selected existing environmental impact measurement tools available in the market was undertaken. The number of tools specifically addressed at urban areas is limited, so to understand how the existing tools work, the study was widened to include available neighbourhood rating tools and other tools that rated appropriate environmental impact issues.

There is no consensus about the indicators used to evaluate environmental performance (Delgado, 2010; Seo, 2002). Each label has its own criteria and method connected with who operates the institution that offers the label. The institutional focus normally determines which direction the label takes according to each institution's broad natural interest and position (Delgado, 2010). Labels generally offer a classification, based on some performance criteria that in turn are part of a life cycle assessment (LCA). However, some such as BEES (USA) (Building for Environmental and Economic Sustainability) and Eco-quantum (Dutch) are focused on building products and equipment (Campbell \& Hood, 2006, p. 05). However, most models emphasize environmental loadings such as emissions with global warming potential, fossil fuel related energy consumption, and resource consumption, as well as human issues such as indoor air quality, lighting, salubrity, and green areas.

The key point to understanding the role of each environmental label is identification of who is the final client for that label. This client is not normally declared in brochures or websites of the label institutions. In the few last years, many companies have self-declared themselves as being sustainable or ecofriendly (Felix, 2005, p. 2). While the users have just started recognizing and responding to this self-declaration (Vasconcelos, 2008), the market has moved on 
to institutions which operate eco-certification. This all started to happen during the 1970s and 1980s when public awareness increased significantly due to media discussion of a great number of environmental issues such as ozone depletion, acid rain, and climate change (Castro, Castilho, \& Miranda, 2004).

Most available environmental labels are currently operated by private institutions because the public authorities have felt unable to run eco-labels due to the pressures made by real estate developers and other interested parties. However, some public institutions have developed labels (such as the NZ Eco-labelling Trust which, until the recent change in government, was in part funded by the Ministry of the Environment). However, because of the complexity of evaluation most of these governmental institutions have not been competent to assure the labelled products are truly eco-friendly (Tomé, 2007, p. 24).

However, the main flaw, or gap in knowledge, caused by the labels and standards providers is the lack of capacity to assess any sort of built environment taking into account the holistic principles of biocapacity and ecological footprint. Most of the certifications available in the market only analyse part of the problem. In order to truly assess sustainability a holistic assessment is needed. Because of the universal characteristics of the ecological footprint concept, it is considered in this thesis to be an ideal way for evaluating an urban environment. In contrast, the labels analysed here do not encompass the principles enshrined in the ecological footprint and do not present any other way of dealing with these fundamental concepts.

\subsubsection{Labelling and Standardization}

Today there are several institutions assessing sustainability in the built environment, normally distributing certification or labels based on the idea of environmental standardization. Labelling and certification are processes undertaken to confirm the selected characteristics of an object, person or organization meet preset performance criteria. This confirmation can be provided by an external reviewer or reviewers through examination of the product or 
service. Labels or certificates can be offered by an institution, public authority, person, private company, or any type of institution. The items or criteria on which the label is based are an important part of the whole certification process. The label provider has to create an ideal product (or any other item) against which the real product or service can be compared, and hence a ranking made. A ranking can also be used for standardization, as a production guide, and for general improvements through encouraging competition to improve rankings.

Standardization is the process of developing an assessment from a technical ranking. A standard is a final ranking transformed into a document that establishes uniform engineering, technical standards, criteria, methods, processes, and practices. The standard is an idealized product, being a perfect model which the assessed products have to try to achieve. A certification or label is given when any sort of product achieves a minimum pre-established score which represents a point on the path to having the perfect model.

During the last century standardization became both popular and necessary. Standards have been important in international trade, and have thus become part of the increasing consumer market (International Organization for Standardization, 2012). However, different standards can be barriers to trade and general commerce, creating some regional monopolies. This can be an advantage for some organizations. Standards provide clear identifiable references that are recognized internationally. They encourage fair competition in free-market economies.

In theory, standards can be offered by anybody. Having them used and recognized, however, is much harder. The majority of the recognized standards were created by companies which got together to develop a common standard for their industry. The first significant example occurred in 1886, when the US government worked with railroads to promote use of the most common gauge in US under the slogan 'Switching tracks, but not the trains' (Achsah Nesmith, 1985). Industry standardization happens when competitors decide that it does not make sense to compete at the level of the basic technical platform. They prefer to compete at a 
more value-added level, usually because they feel that this will enhance the overall market.

Recently interest in and research related to the development of environmental evaluation has increased significantly. Measurement models are constantly being reviewed to improve the analyses. Some models are used widely throughout the world (Seo, 2002, p. 12). Although ISO and LEED are probably the most wellknown among the labels, different institutions and labels have gained ground in the labelling market (Warren C. , 2009, p. 1). These include NABERS (National Australian Building Environmental Rating System), CASBEE (Comprehensive Assessment System for Building Environmental Efficiency), and BREEAM (Building Research Establishment Environmental Assessment Method). Based on their visibility, media coverage, and the opinion of a real estate developer (Napoli F. , 2009) five labels have been selected to be analysed here: ISO, LEED, NABERS, CASBEE and BREEAM.

\subsubsection{International Organization for Standardization (ISO)}

Standards organizations such as the International Organization for Standardization (ISO) or America National Standards Institute are partially independent of the manufacturers for which they publish standards. The members of ISO come from 163 from different countries, but most of them are still somehow linked with industries that will receive the ISO certification. Although the influence of one single member will be relatively small, there is no way to consider this institution as totally independent (International Organization for Standardization, 2012).

The nomination for a committee is done when a member body has an interest in a certain area. This member is automatically entitled to be a member of that new committee. The standards are reached by consensus. The multidisciplinary committees are made up of people with diverse interests and backgrounds, such as vendors, manufactures, consumers, professionals, and governments, and all have to agree about the final criteria. 
The organization called ISO started in 1926 as the International Federation of National Standardizing Associations (ISA). This organization was heavily focused on mechanical engineering. This organization had its processes interrupted during World War II and in 1946 was recreated under the current name, ISO. The name ISO is also standardized. It is not an acronym but came from the Greek word "isos" which means "equal". Essentially when two objects reach the same "standard" they should be equal. The name ISO eliminates any confusion resulting from the translation of International Organization for Standardization into different languages. Such translation would lead to different acronyms.

\subsubsection{ISO Members}

ISO is made up of 163 members representing different countries. There are three categories of members:

- Member bodies are national bodies that are considered to be the most representative standards body in each country. These are the only members of ISO that have voting rights.

- Correspondent members are countries that do not have their own standards organization. These members are informed about ISO's work, but do not participate in standards promulgation.

- Subscriber members are countries with small economies. They pay reduced membership fees, but can follow the development of standards.

For example, Brazil is represented by ABNT (Associacao Brasileira de Normas Tecnicas - Brazilian Association for Technical Standards). Its internal council is composed of FIESP (Federacao das Industrias de Sao Paulo - Federation Industries of Sao Paulo). Siemens and Petrobras (Brazilian National Oil Company) are also currently represented on the ABNT council. New Zealand is represented by Standards New Zealand (SNZ) in the ISO council. Its chairman has a background linked with banking and real estate companies (Quotable Value Ltd and Holmes Consulting). The USA is presently represented by the American National Standards Institute (ANSI) (International Organization for Standardization, 2010). This 
organisation coordinated the development of voluntary consensus standards in the United States. Since it was founded in 1918, ANSI has represented the needs and views of USA stakeholders in standardization forums around the globe. According to ANSI`s web site:

\footnotetext{
"As the voice of the U.S. standards and conformity assessment system, the American National Standards Institute (ANSI) empowers its members and constituents to strengthen the U.S. marketplace position in the global economy while helping to assure the safety and health of consumers and the protection of the environment."
}

(American National Standards Institute, 2008)

This brief look at membership suggests that private industry forms a large part of those involved in developing the ISO system, and this is confirmed by the ISO membership Manual (International Organization for Standardization, 2012, p. 05).

\subsubsection{The ISO Standardization Process}

According to the ISO process, a "standard" goes through six different stages before being published and recognized as an ISO standard.

The first stage occurs when a work group determines the need to create a standard. Afterwards, members are selected to work on it. A preparatory stage starts when the selected members draw a draft standard. As soon as the draft is completed it goes to committee stage. The committee stage has the obligation to debate the draft and the issues it raises until a consensus is reached. The result of this stage is known as a DIS (Draft International Standard).

After the first stage, the DIS is circulated among all member bodies and then voted on. The minimum vote to be accepted is 75 per cent and if this is not reached it returns to a lower stage to be redone and the process starts again. On the other hand, if the DIS achieves 75 per cent or more, it becomes a FDIS (Final Draft International Standard), and goes straight to the approval stage. 
The approval stage is similar to the previous one. Again, the FIDS is circulated among all bodies, and it has to get at least 75 per cent acceptance. If it fails in this, the FDIS goes back to the stage before. When the FDIS achieves 75 per cent or more, it goes to the Central Secretariat for publication.

Standards from ISO (both 9000 and 14000) have frequently been challenged. One of the most famous ISO concessions resulted from a challenge that ISO 9000 cannot guarantee the total quality of the products. For example, ISO does not concern itself with product related aspects like profit, a good work environment, energy efficient performance or sewage treatment to avoid pollution. Therefore, practical use of this concession has been very controversial during the last 20 years for ISO 9000 and more recently for ISO 14000. Quality management is what determines ISO 9000 but this does not necessarily have any relationship with profit or product quality. As a result, ISO 9000 became virtually useless, being only useful for advertising and marketing strategies. The ISO 14000 has the same issue. It cannot guarantee that the organization or final product will not damage the environment.

The process to create a new ISO is complicated but democratic. It requires a significant amount of time, financial resources, personnel and infra-structure. In practice, management technologies and tools improve faster than the capacity of ISO to provide a new standard.

Both 9000 and 14000 require a complementary certification for items such as energy performance, quality management, or any sort of restricted item to be analyzed. Because of the popularity of ISO, the certification business is flourishing. The consequence is ISO is not able to provide the reliability that the market currently requires.

Obviously, its proponents claim that increased profit and economic benefits can be gained by putting the standards into practice. Certified products can easily reach new markets. This allows the companies involved to increase market share, gain new consumers, and make the company international. Above all, this raises profits. In addition, companies have non-tangible supplementary benefits, such as, 
improved morale, improved corporate image, and the feeling of doing the right thing.

\subsubsection{ISO 14000 and ISO 14001}

The Technical Committee 207 is responsible for the ISO 14000 standards series. ISO 14000 is based on the British BS 5750 standard (1992). ISO 14000 was created to meet a market demand. Environmental activism in the 1980s helped to increase the awareness of environmental issues and ecological regulations were ratified all over the world. Companies were obligated to adhere to these regulations but soon found they could use them as marketing tools.

ISO 14000 is a series of standards providing a framework that organizations can use to regulate the environmental impact of their activities. ISO 14000 is a management system rather than a performance standard. It does not identify specific goals but gives a framework for carrying out environmental management. The ISO 14000 series standards were created to achieve a perfect integration of environmental and business management. The ISO 14000 series allows companies to take a proactive approach to managing their environmental issues. They make the companies committed to keeping these issues under control.

Because ISO 14000 series is a management tool not a set of performance standards it excludes some relevant aspects of global environmental issues. It is not concerned with pollutant emissions, setting limit values regarding pollutants and effluents, or setting environmental performance levels and energy efficiency.

The ISO 14000 series evaluates process and not results. This management index does not tell organizations what environmental performance they must achieve. Instead, to determine environmental goals, the standards describe a system that will help to achieve the organization's objectives. ISO do not guarantee any environmental benefit. The assumption is that better environmental management will improve environmental performance. 
The ISO 14001 standard contains the actual requirements that an organization has to comply with to become certified to the ISO 14000 standard. The "2004" designation indicates that the standard was last revised in the year 2004. ISO 14000 is not a label but is the name of the series. The ISO 14001 system can be moulded to be suitable for any company's particular needs and operational conditions. ISO 14001 suggests that a successful Environmental Management System (EMS) should fit with the nature of the company's activities, products, services and users.

The obligation to obey relevant environmental legislation and regulations is an important item related to ISO 14001. In addition, another important recommendation is to keep all employees and partners fully informed about all processes. Although ISO 14001 has a great number of recommendations, it does not have a series of requirements. ISO 14001 essentially measures a firm's adherence to its own environmental policy, not its environmental impacts.

The complete ISO 14000 is composed of:

- ISO 14001 - Specification of Environmental Management Systems (EMS)

- ISO 14004 - Guideline Standard

- ISO 14010 through ISO 14015 - Environmental Auditing and Related Activities

- ISO 14020 through ISO 14024 - Environmental Labelling

- ISO 14031 through ISO 14032 - Environmental Performance Evaluation

- ISO 14040 through ISO 14043 - Life Cycle Assessment

- $\quad$ ISO 14050 - Terms and Definitions

ISO 14001 is the only standard in the 14000 series with a direct environmental application. This ISO gives an entire framework for identifying operations, processes and products which impact on the environment. Afterwards, the impact is analyzed and the results obtained determine the setting of objectives and targets to reduce any problem with the environment. Moreover, as result of the whole analysis, ISO 14001 indicates activities for achieving the targets. 
To become ISO 14001 certified, a company can audit itself or undergo a third party audit of its processes. If its processes were submitted to a third party, the auditor is given the discretion to make recommendations to the registering body about what is required for certification. ISO 14001 provides the core requirements for developing and implementing an EMS.

All other documents of the series are guidance standards. They are only intended to be used as internal management tools by an organization. For example, ISO 14004 provides practical advice for an organization on implementing and enhancing the EMS. ISO 14004 includes examples, descriptions and options that aid in the implementation of EMS.

The ISO 14000 series cannot be considered an end in itself, it is just a tool. Considering environmental issues, this series may be seen as a sort of "diploma". It is earned after preparatory work but is not a final test audit of true environmental impact.

\subsubsection{Leadership in Energy and Environmental Design (LEED) and United States Green Building Council (USGBC)}

LEED - Leadership in Energy and Environmental Design - is a green building certification system and so has a narrower focus than ISO. While ISO includes management and efficiency issues, LEED is focused on energy efficiency and, according to the USGBC, sustainability. LEED certification is provided by the United States Green Building Council (USGBC). The USGBC was founded in 1993 and it is a non-profit trade organization that became best known for the development of the LEED program. Certification was developed in 1998 and rapidly became recognized around the world. Since its inception, more than 35,000 projects have been part of the LEED system, comprising over 4.5 billion square feet (418million $\mathrm{m}^{2}$ ) of construction space in 91 countries in 2010. 
This certification offers building owners and operators a framework whereby USGBC evaluates environmental efficiency. It was supposedly created to make buildings more ecologically efficient compared to conventional ones.

LEED certification started in 1998 as a new method for evaluating environmental issues in buildings. It was originally planned to define "green building" through establishing a common standard of measurement. The first intention was to transform the building market by raising consumer awareness of green construction methods. The first task of this group was research into existing green building metrics and rating systems. The initial composition of the committee included representatives from the real estate industry, such as architects, realtors, and a building owner (Wiser, 2008). Perhaps surprisingly this group did not have any representative from an academic institution. Universities in the USA have a long history of being involved in research into low energy buildings, such as the series of solar houses built by MIT in the second part of the 20th century (MIT Massachusetts Institute of Technology, 2012).

The LEED rating system is essentially voluntary, consensus based, and marketdriven. The rating has expanded since its inception and now tries to evaluate environmental performance from the scale of a building to the life-cycle of a neighbourhood, making it an important comparison for this thesis. It can now be used for rating new and existing buildings, and commercial, institutional, and residential buildings as well as neighbourhood development.

The pilot program, known as LEED Version 1.0., was launched in 1998. USGBC released version 2.0 in March 2000 after more research and some rating changes, including changes to levels according to the points reached: Certified (26-32), Silver (33-38), Gold (39-51), and Platinum (52-69) (Wiser, 2008). The next version, LEED V3., was launched in April 2009. This new version incorporates some technical advancement in the LEED system`s credits and points, recognising new technologies and advancements in building science, water efficiency, material and resources, and indoor air quality. LEED V3 prioritizes energy efficiency and $\mathrm{CO}_{2}$ emissions reductions. 
The first LEED committee was composed of six volunteers but the LEED organization in 2010 had more than 200 members on 20 different committees and more than 150 professional staff. LEED committees have a primary function around the development, implementation and revision of LEED rating systems as part of the USGBC organization. LEED committees are the main resource for developing consensus-based actions in the green-building industry. As LEED is still made up of market representatives, they have undertaken new initiatives to respond to the market. The rating system relies on volunteers, who are representatives from companies affiliated to USGBC, to provide the technical and market expertise. By using this "market expertise" the intention is to connect LEED to the market demand. The internal committee structure was designed for USGBC members to utilize their relevant market expertise to build a suitable label for real estate developers. This thesis has used LEED Neighbourhood Development for case studies (see chapter 9) to compare the results obtained from the prototype tool developed in this research with the certification provided by LEED, to reveal whether the market approach has truly delivered low environmental impact.

The LEED structure is made up of the following committees:

- LEED Steering Committee

- Implementation Advisory Committee

- Market Advisory Committee

- Technical Committee

- Rating System Committee

In Addition, Technical Advisory Groups provide technical advice to LEED committees. Committee Membership is currently formed by representatives from private companies.

\subsubsection{The LEED Steering Committee}

The LEED Steering Committee (LSC) is in effect a Board of Directors for the other LEED committees. The main function of this group is keeping LEED a leadership 
tool. In addition, the LSC is charged with preserving the integrity of the LEED rating system, and ensuring the use of the consensus approach.

\subsubsection{Implementation Advisory Committee}

The LEED Implementation Advisory Committee is responsible for recommending solutions to the LSC for review and approval. Its principle is to advise on the scope, content and rigor of technical resources and tools supporting LEED programs.

The Committee's overall objectives are:

- To collaborate with staff to provide feedback loops to and from LEED customers to help with continuous improvement of the active versions of LEED.

- To bring project expertise to help inform the improvement of LEED supporting tools and resources.

- To provide a readily available sounding board for new ideas related to LEED supporting tools and resources.

- To advise on Technical Advisory Group (TAG) recommendations for precedent setting credit interpretation rulings.

LEED customers are basically building owners and constructors. These consumers provide substantial levels of information to the committee. The committee essentially processes the information collected from LEED customers and suggests changes to the LSC. This committee, made up of market representatives, works to understand the LEED customer as, in effect, they have the same interests. The committee must be made up of members who represent a diversity of viewpoints. Because the members have to consider all aspects of the real estate market the LSC must necessarily include representatives with real estate knowledge.

\subsubsection{LEED Market Advisory Committee Charge}

The Market Advisory Committee's principle focus is ensuring that LEED is updated as the market transforms. The members apply their market expertise to ensure that all LEED ratings are practicable, viable, flexible, and represent leadership in 
the market. This seems a key point as what might be expected from LEED is leadership in reducing environmental impacts, or leadership in combatting climate change (see 1.2.3.4). The diversity of members is intended to make LEED applicable to a wider range of building types increasing its presence in the marketplace. Another important function of this committee is regularly identifying new market opportunities. This normally happens when the committee finds significant barriers to LEED, for example through showing the market sectors where LEED is not applicable. As soon as a new market prospect is found, this committee acts through developing a new sub-committee to produce an extension to the LEED portfolio. This committee is made up of representatives of all aspects of the real estate industry. The members are experts in market transformation strategies, LEED development, green building, and represent almost all building sectors in the United States. The committee members also represent a wide range of private companies such as Goldman, Sachs \& Co, LaSalle Investment Management and C.B. Richard Ellis. Universities are only represented as treasurer of the committee through the university treasurer's office from UCLA, which is not an influential position in the committee.

\subsubsection{Technical Committee}

The supposed purpose of the technical committee is to make the LEED certification process enhance the natural environment and human well-being. However, it works under the USGCB management, which is extremely committed to the market approach. The operational objective imposed by the USCGB means effectively the Technical Committee works just to oversee the LEED rating system. It normally suggests changing the rating system to adapt it according to market needs. Another relevant function of the Technical Committee is to sustain technical rigor, fairness and transparency in the LEED process.

Although this committee has members from some government institutions, the majority is made up of representatives from private companies such as Tischman Speyer, Sasaki Associates and Constructive Technologies Group. Despite the 
technical significance of this committee there are currently no university representatives on it.

\subsubsection{LEED Technical Advisory Groups Charge}

The Technical Advisory Groups, internally known as TAG(s), are responsible for giving a consistent foundation to the technical advice to LEED committees. They work to assure that any LEED rating will be made with scientific consideration. These groups are directly in charge of establishing the indicators on which the LEED ratings are based. The Technical Advisory Groups have considered an extensive variety of measureable and immeasurable factors such as: sustainable sites, water efficiency, energy and atmosphere, materials and resources, indoor environmental quality and location and planning. Each topic is given to a specific group of experts. This process of expertise by division means that the holistic viewpoint is lost, and universal indicators, like ecological footprint, will never be considered.

\subsubsection{LEED Rating System Committees}

These Committees are temporary groups made up of members of other groups. They are created to develop and implement LEED rating for a specific type of building or market sector. Once it is done, the new rating system is approved by USGBC and the committee is disbanded.

A LEED Rating System is the result of the committee work. The Rating Systems need to cover all sectors of the real estate market acting intensively to keep the USGCB as the leaders in US market. As soon as an opportunity is found the process of creating a new LEED rating starts. The LEED portfolio in 2009 had the following products:

- New Construction - this is designed for new buildings or substantial renovations. It is focused on commercial and institutional projects. 
- Existing Buildings - this was created to analyze the operation and maintenance of buildings.

- Commercial Interiors - this was implemented to analyze tenant improvements.

- Core and Shell - this analyzes design for new core and shell constructions.

- Schools - this was made recognizing the specific needs of school spaces.

- Retail - this is focused on retail design and construction projects analyzing the specific needs of such spaces.

- Healthcare - this was designed to analyze healthcare facilities.

- Homes - this is focused on residences

- Neighborhood Development - this analyzes the principle of growth, urban design and use of green buildings in urban areas.

\subsubsection{LEED and the Real Estate Market.}

Through marketing to create public awareness USGBC has achieved an enormous presence in the ratings market. In itself it has representatives from a great number of parts of the real estate market. Therefore, a label that responds to the market has been relatively easy to achieve. The ratings were designed to cope with the market needs. Environmental problems are basically the 'products' by which USGBC/LEED have consolidated a green market strategy. Green building labels have helped developers to achieve public recognition for the product, while designers and builders have been given credit for using them. This tacit arrangement is important to increasing the use of LEED certification, as LEED and USGBC are committed to work with the real estate market, "to accelerate the adoption and business advantages of green building" (USGBC, 2011).

USGBC has emphasized the benefits of green buildings. It has publicized successfully, under its own criteria, the fact that LEED is a process that will produce buildings able to conserve resources, reduce operating costs, help to address global warning, protect occupant health, and improve occupant productivity. All these items improve the marketability of the product because they are probably the answer expected by consumers but of themselves they will not necessarily be a true strategy for greening the built environment. They are also all 
focussed on the building as a product, not as a system that includes users and user behaviour.

Energy saving seems to be one easily measurable item considered by LEED. As the world population increases dramatically, the need for buildings also rises. To declare that a green building is saving energy it would be need to be compared with buildings of the same age, location and use. Most of LEED measures are based on data from the Commercial Building Energy Consumption Survey (CBECS) which includes all buildings in the database (including those built before 1920 when energy efficiency was not an issue).

However, even energy efficiency is not a unanimous goal for green buildings as defined by LEED. Analyzing LEED certified buildings with counterparts from CBECS, LEED buildings use 18-39 per cent less energy per unit of floor area than non-certified ones. However, 28-35 per cent of LEED buildings use more energy than non-certified ones (Newsham, Mancini, \& Birt, 2009, p. 904). This may happen because energy performance is estimated at the design stage and before the building has been constructed and occupied. There is no reference in LEED to post-occupancy evaluations and energy efficiency achievements after the building is occupied. Because LEED only evaluates during the project stage, construction changes and users can lead the building to a different level of energy consumption.

The ecological benefits attained from LEED are very restricted and the root of the system may be the initial problem here. USGBC was founded in 1993 by a real estate developer and an executive of an air-conditioning company (Gifford, 2009, p. 19). Its membership is totally open to the largest real estate developer players. USGBC is a construction group making rules for itself. Considering this, LEED certification has apparently been designed to be reasonably reachable rather than stringent.

The real estate market has assumed the marketability brought through using LEED. The final users have gradually come to demand some sort of green label to increase the public recognition of the building. The real estate developers understood this demand. The sum of users' demands, public environmental awareness, and lack of organized players has contributed to the LEED boom. 
USGBC was tremendously insightful in understanding current real estate production. Recent developments have highlighted a wide range of concerns, including the money restriction caused by the international crisis in 2008 and availability of credits, and clearly the environment has not been considered a high priority. The USGBC tacitly invited the real estate producers to design a label able to answer the environmental awareness of the public. By creating a single green building certification scheme the companies involved have gained considerable media attention, which is another marketing push.

The expression 'green building' attained significance after the flourishing of LEED. However, this importance is frequently challenged. Although the public has become more worried about environmental problems this label wrongly drives it to consider all buildings without a LEED label as not being environmentally committed. Moreover, it spreads the wrong concept that good architecture and urban design can be done without a rigorous engagement with environmental principles.

A green building label has become an extra achievement for a good architect and urban designer. In a similar manner, increasing the disconnection between green building and other architectural knowledge implies the erroneous idea that good architecture does not include addressing environmental issues. The commercial idea that a building is good only if it has a label is totally wrong. The correct thought should be that a building is good even without a green label if it has a green approach. Any good architecture or urban design project can obviously be a green product, even if it does not get a green label.

A rating achieved through points related to a checklist, the basis of LEED, can lead to several erroneous conclusions. There is no logical reason not to go for easy points, such as including a bike rack, instead of introducing sophisticated and expensive equipment like photovoltaic panels. Points and checklists lull architects into thinking that by designing to achieve points they will make an environmentally engaged project. LEED also gives more value for some criteria guided by the fact the first topic for developers is the economic margin. The guidance thus becomes monetary instead of environmental. 
The real estate market has realized the monetary benefits gained from using LEED certification (Zheng, Wu, Kahn, \& Deng, 2011, p. 04). The return on investment (ROI) normally increases for a green building. Energy efficiency decreases the occupation costs leaving the rental prices more flexible. Reducing occupation costs means the real estate developers answer user demand. Therefore, USGBC has found the perfect equation to ensure its leadership in the green building standard market.

When a developer does adopt LEED in a project, this may increase the construction cost. The main reason for the increase in costs is the time needed to research products and technologies. Environmentally friendly technology requires more time at the design stage for finding product sources. Certified products are normally harder to find than non-certified products, and often require market research. The lack of products and additional research time may mean an extended project time which directly impacts on the financial result. The LEED evaluation adds a cost in itself. The additional costs come from hiring the required commissioning authorities and LEED design-aide consultants. The popularity obtained by LEED has thereby created a secondary market for these new skills.

However, some environmental advantages have undeniably been achieved. Constructors and real estate developers have finally been including the environment in their agenda. Unfortunately having the certification is still more important than helping the environment.

\subsubsection{CASBEE - Comprehensive Assessment System for Building Environmental Efficiency}

The Japanese real estate market has progressively demanded products with more concern for sustainability (Endo, Murakami, Ikaga, Iwamura, Yashiro, \& Bogaki, 2005, p. 1865). In 2002 the Tokyo Metropolitan Government became the first local authority that obliged all building owners intending to build new or rebuild with areas over $10,000 \mathrm{~m}^{2}$ to submit the plans to be evaluated for the environmental performance of the building. The Housing Japanese Bureau and the Ministry of 
Land, Infrastructure and Transport (MLIT) supported a joint industrial / government / academic initiative, which led to the establishment of a new organization called the Japan Sustainable Building Consortium (JSBC). It was administered by another government organization called the Institute for Building Environment and Energy Conservation. As result of the effort between the JSBC and its committees the Comprehensive Assessment System for Building Environmental Efficiency (CASBEE) was launched in 2002 (Institute for Building Environment and Energy Conservation, 2007, p. introduction). The first evaluation tool was CASBEE 2002. It was followed by CASBEE for New Construction in July 2003, CASBEE for Existing Buildings in July 2004 and CASBEE for Renovation in July 2005. Consequently from 2002, because of an environmental protection ordinance, the Japanese market demanded that buildings be analyzed using CASBEE.

The criteria adopted by CASBEE were published on the internet to disclose information about the environmental performance of the buildings assessed. This process indicated the degree of effort for environmental protection made by the building owners, users and designers. Since then, because the information was available on the internet, other local governments have also followed this policy (Endo, Murakami, Ikaga, Iwamura, Yashiro, \& Bogaki, 2005, p. 1857). In April 2004, Nagoya introduced a building environmental evaluation system called CASBEE Nagoya, which was based on the original CASBEE. In May 2004, Osaka adopted guidelines for Osaka CASBEE and the system was permanently in use by October 2004. CASBEE has been used for regional governments throughout Japan since 2004.

\subsubsection{CASBEE Principles}

CASBEE is based on three main principles, and all its developments and extensions are linked with these basic concepts. Firstly, CASBEE was designed for evaluation of a building's environmental performance. CASBEE comprises four basic tools, tailored to the building life cycle such as Tool-0 CASBEE for pre-design, Tool -1 CASBEE for new construction, Tool 2 - CASBEE for existing buildings, and Tool 3 - 
CASBEE for renovation. These tools are then expanded for specific purposes. These are collectively known as the CASBEE Family.

Secondly, it was based on a concept that clearly distinguishes Building Environmental Quality and Performance (Q) and Environmental Load (L).

Building Environmental Quality and Performance (Q) include the following items:

- Indoor environment (noise and acoustics, thermal comfort, lighting and air quality)

- Quality of services (functionality, amenities, durability and reliability and flexibility)

- Outdoor environment on site (preservation and creation of biotope, landscape, and outdoor amenities)

And Building Environmental Load (L) items are:

- Energy (thermal load, use of natural energy, efficiency of systems, and efficient operations)

- Resources and materials (water conservation, recycled materials, sustainably harvested timber, materials with low health risks).

- Reuse and reusability, and avoidance of CFCs

- Off-site environment (air pollution, noise and vibration, odour, sunlight obstruction, light pollution, heat island effect, and local infrastructure).

The results are plotted on a graph, with $\mathrm{L}$ and $\mathrm{Q}$ in different axes. A good 
environmental performance will give a high score for $\mathrm{Q}$ and a low score for $\mathrm{L}$. Each criterion scores from level 1 to level 5 , level 1 being the minimum requirement.

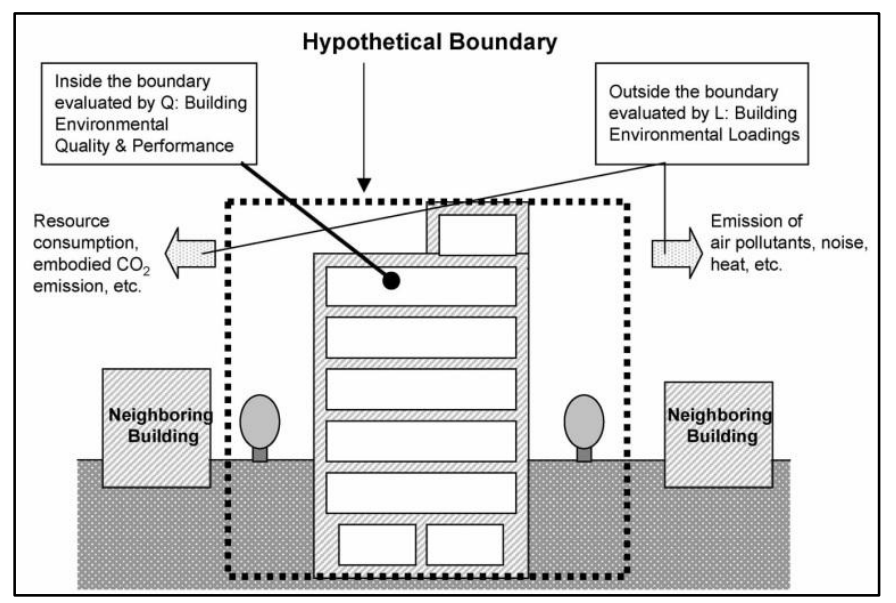

Figure 1 - Definition of $Q$ and $L$ through a theoretical boundary. (Japan Sustainable Building Consortium , 2011, p. 02)

Thirdly, CASBEE considers Building Environmental Efficiency (BEE) as the important outcome. When $\mathrm{L}$ and $\mathrm{Q}$ are known, BEE is defined by $\mathrm{Q} / \mathrm{L}$ to indicate the overall result for the environmental evaluation of a building. A building will be evaluated by CASBEE in five grades: Excellent (S), Very Good (A), Good (B+), Fairly Poor (B-), and Poor (C).

The evaluation process is managed in accordance with certain principles. The most remarkable is that it should be a positive assessment tool for designers, rather than a check-list, to motivate clients to be more interested. Secondly, the evaluation system should be kept simple and be as comprehensible as possible (Endo, Murakami, Ikaga, Iwamura, Yashiro, \& Bogaki, 2005, p. 1857). However, the market has considered CASBEE a complex tool. Indeed, the scoring criteria are relatively simple but the process as a whole is extremely complex and demands great effort (Campbell \& Hood, 2006, p. 26). Thirdly, the tool has to include a wide range of buildings, of different sizes, types, uses and materials, such as schools, retail outlets, restaurants, halls, factories, hospitals, hotels and apartments. To ensure widespread use, it was designed to have a flexible structure able to reflect innovative initiatives taken by users based on their organizational circumstances 
(Endo, Murakami, Ikaga, Iwamura, Yashiro, \& Bogaki, 2005, pp. 1857 - 1860). Finally, CASBEE is a tool for Japan and Asia.

\subsubsection{The CASBEE Family}

The first CASBEE move into the environmental label market was through four basic tools (American National Standards Institute, 2008); "CASBEE for Predesign"(CASBEE-PD), "CASBEE for New Construction"(CASBEE-NC), "CASBEE for Existing Buildings" (CASBEE-EB) and "CASBEE for Renovation" (CASBEE-RN).

With its restricted scope, CASBEE was not able to spread quickly in the Japanese market. Since its inception CASBEE has been struggling to increase its market share in Japan and Asia. New members have been included in the CASBEE family in accordance with demand from the Asian market, such as CASBEE for Heat Island, CASBEE for Urban Development, CASBEE for an Urban Area + Buildings and CASBEE for home only for detached houses (Japan Sustainable Building Consortium, 2011). CASBEE for Pre-design is not used today and has been merged with CASBEE for New Construction.

\subsubsection{CASBEE for New Construction (CASBEE-NC)}

CASBEE for New Construction is a self-evaluation check system. It enables architects and engineers to raise the BEE rate of the building while it is being designed. This tool was formerly called the DfE (Design for Environment) tool. Its goal is to evaluate the building performance based on the design specification and anticipated performance. It can also serve as a labelling tool when the building is subjected to expert third-party assessment.

\subsubsection{CASBEE for Existing Building (CASBEE-EB)}

This member is focused on the existing building stock. It analyses the building performance through records for at least a year after completion. It was also developed to be applicable to assist with assessment. 


\subsubsection{CASBEE for Renovation (CASBEE-RN)}

Tokyo has been struggling to find new areas for new buildings since the 1960s. As a result, the retrofit market has flourished since then (Manfredini, 2007, p. 165). International companies and local developers began a hostile competition for a market-share of the retrofit sector (Manfredini, 2007, p. 188). This market is still strong and, although there have been some fluctuations, it has tended to increase. CASBEE decided to accept this sector as part of its portfolio of evaluation. It can be used to generate proposals for building operation monitoring, commissioning and upgrade design with a view to using an Energy Service Company (ESCO):

"which is a professional business providing a broad range of comprehensive energy solutions including designs and implementation of energy savings projects, energy conservation, energy infrastructure outsourcing, power generation and energy supply, and risk management."

(ESCO, 2012)

The ESCO identifies and evaluates energy-saving opportunities and then suggests some improvements to be paid for through savings. These will be increasingly important in the future, and for building stock renovation (Endo, Murakami, Ikaga, Iwamura, Yashiro, \& Bogaki, 2005, p. 1858).

\subsubsection{CASBEE for Specific Purposes}

This member of the CASBEE family is the basic CASEEB-NC moulded to be applicable to a wide range of individual applications. CASBEE - NC for specific purposes has several extended tools such as: CASBEE for temporary construction and CASBEE Heat Island (Endo, Murakami, Ikaga, Iwamura, Yashiro, \& Bogaki, 2005, p. 1858). 


\subsubsection{Regional Scale Assessment}

CASBEE considers individual buildings, but can also assess building groups. Part of Japanese development is based on retrofit (Manfredini, 2007, p. 199). Many recent city centre redevelopment projects have included plans taking into account the urban surroundings as one unit (Endo, Murakami, Ikaga, Iwamura, Yashiro, \& Bogaki, 2005, p. 1863). However, the assessment processes are not easily understood (Manfredini, 2007, p. 201). General restrictions imposed on all buildings on a site, even if each one has a different owner, can be regarded as efforts to improve the environmental performance of the urban area as a whole. This proposal will be called "CASBEE for district / regions (provisional name in 2005). Here the main goal is to assess the built enviroment from the scale of a group of buildings to a large neighboorhood for thousands of people. This is the part of CASBEE most directly relevant to this research.

CASBEE has a different approach to LEED. It tends to include more than real estate interest. Some universities are directly involved, and some local CASBEEs also invite local universities to participate (Manfredini, 2007, p. 145). However, the process for analysis and evaluation is very complex and sometimes very slow (Manfredini, 2007, p. 165; Napoli F. , 2009). Furthermore, the real estate market outside of Japan and Asia has not accepted CASBEE easily. CASBEE was originally designed for Japanese markets, and afterwards used for Asia as well. The assessments are complex and normally require an external consultant and, due to the complex items evaluated, this part is normally very expensive. These factors keep CASBEE almost exclusively for Japan and parts of Asia where Japan has an influence over the construction sector (Campbell \& Hood, 2006, p. 27; Napoli F. , 2009).

\subsubsection{BREEAM}

The UK Building Research Establishment (BRE) developed its assessment method (Building Research Establishment Environmental Assessment Method or BREEAM) in 1990. It has become one of the most widely recognized international environmental labels (Seo, 2002, p. 16). BREEAM was primarily implemented to provide an authoritative guidance on ways of minimizing the adverse effect of 
buildings on local and global environments (Seo, 2002, p. 16). For example, the introduction to BREEAM for offices (Baldwin et al, 1990, p. 1) states, "The assessment method described here specifies criteria for a range of issues concerning the global, neighbourhood and internal environment." The evaluation is based on "credits" gained for a certain number of criteria. The result is a single score, which enables users or buildings to achieve recognition for their environmental performance. However, BREEAM has also become a strong instrument for dramatically increasing the marketability of a building (Napoli F. , 2009).

BREEAM is used by clients, planners, development agencies, funders, and developers to specify the potential sustainability performance of a building and to make this highly visible in the marketplace. It also provides a level playing field for comparisons (BRE, Building Research Establishment, 2009). BREEAM is the leading environmental assessment method for buildings, with over 110,000 buildings and (in 2009) over half a million registered for certification (BRE, Building Research Establishment, 2009). BREEAM is most recognized in Europe. However, lately its leadership has been threatened by LEED. LEED has tailored itself to meet market needs faster than BREEAM (Napoli F. , 2009). BREEAM, however, has worked to adapt rapidly to local regulations and conditions (BRE, Building Research Establishment, 2009). Its strong focus on adaptability is part of a process to gain marketshare in new markets under development such as those of South America, Asia and Central America (Delgado, 2010; Napoli F. , 2009).

Within BREEAM, the sustainable board was formed in order to meet the needs of its stakeholders (BRE, Building Research Establishment, 2009). The board oversees the development of BREEAM as well as the production of material, criteria, indicators and market position. BREEAM intends that a benchmark in its systems is always higher than that of local regulations (BRE, Building Research Establishment, 2009; Napoli F. , 2009).

The most important tool used by the BRE to increase its market share is labelling related to a decrease in the general occupation cost of a building. Occupation cost 
is the result of rents or instalment costs plus on-going maintenance fees. When occupation costs are lowered through the environmental labelling process, property owners or investors can obtain more revenue by increasing the rental cost. In talking to developers in new markets BREEAM has focused on how labelling can keep occupation costs lower for conventional buildings (Napoli F. , 2009).

\subsubsection{BREEAM Methods}

BREEAM evaluates buildings according to performance to deliver higher comfort for the users and environmental and health benefits (BRE, Building Research Establishment, 2009). BREEAM gives points and classifies the products according to the summarized sections below:

- Energy: operational energy and carbon dioxide emissions $\left(\mathrm{CO}_{2}\right)$

- Management: management policy, commissioning, site management and procurement

- Health and Wellbeing: indoor and external issues (noise, light, air quality etc)

- Transport: transport-related $\mathrm{CO}_{2}$ and location related factors

- Water: consumption and efficiency inside and out

- Materials: embodied impacts of building materials, including lifecycle impacts like embodied carbon dioxide

- Waste: construction resource efficiency and operational waste management and minimisation

- Land Use: type of site and building footprint

- Pollution: external air and water pollution

- Ecology: ecological value, conservation and enhancement of the sites.

(BRE, Building Research Establishment, 2009)

BREEAM has specific versions for the UK, the Gulf, and Europe. However, it can be tailored for use for any region and will address topics such as details of the local construction methods, products and materials, and make reference to local codes, standards and good practice. 
The result of a BREEAM evaluation is that the final numbers are converted to credits and these are multiplied by an environmental weighting. The weighting is determined by considering many factors, ranged according to different topics such as location, climate and the public transportation available. This means BREEAM has no absolute value in it of what a low environmental impact building should be. The item's scores are then added together to produce a single overall score. When the score is known it is then checked with a classification scale to give one of the following:

Pass - Good - Very Good - Excellent - Outstanding.

\subsubsection{The Scope of BREEAM}

BREEAM has one of the largest label portfolios. It is part of a BRE strategy to cover all gaps in the environmental label market (Delgado, 2010). Although covering the great part of all building types, BREEAM still declares itself able to tailor a specific label for a non-related building activity, so theoretically could rate a neighbourhood, although at present it is focussed on buildings. BREEAM currently has six labels for non-residential and three labels for residential buildings.

The BREEAM portfolio in 2010 was is made up of the following:

Non residential

- Offices

- Retail

- Education

- Prisons

- Courts

- Healthcare

- Industrial 


\section{Residential}

- EcoHomes for the assessment of new housing in England which has replaced the UK Government's Code for Sustainable Homes (CSH)

- EcoHomes for new homes outside England

- Multi-Residential covering buildings housing many individuals and offering shared facilities

Outside the UK BREEAM has had some problem in gaining market share. North America has watched a dramatic increase in the use of LEED and the LEED organization has virtually closed access to this very important market. South America and Asia, except for Japan, still have a very limited demand for eco-labels. Because LEED is more flexible, quicker and better organized than BREEAM, it has gained more of these new label markets than BREEAM (Delgado, 2010).

\subsubsection{NABERS}

The National Australian Building Environmental Rating System (NABERS) project was set up to develop Australia's first comprehensive Building Environmental Rating System (Beyer, 2002, p. 61). The system development was based on the belief that rating should encourage improvements in the environmental performance of buildings. It was launched in April 2001 with funding from Environment Australia and was developed by a team from the Universities of Auckland and Tasmania. The original project authors were Robert and Brenda Vale and Roger Fay (Beyer, 2002, p. 62). NABERS in its commercialized form is now managed by the NSW Department of Environment, Climate Change and Water (NABERS - Home Page, 2008).

Commercialized NABERS has been developed to:

- Rate the environmental performance of buildings and homes in use.

- Provide separate ratings for the different stakeholders within a building (such as landlords and tenants) where appropriate. 
- Provide an explicit and consistent rating system methodology, with a clear performance-based structure and methodologies and defaults where necessary.

- Provide a realistic rating scale that recognises and rewards current performance levels, and encourages and promotes best practice.

- Allow for voluntary self-assessment, with the option of seeking a certified rating from an accredited provider if desired.

NABERS uses measured quantities as the primary means of assessment. Where measurement is not feasible, then practice-based or default scores may be acceptable in some categories (NABERS - Home Page, 2008).

NABERS is one of the most independent labels available in the environmental certification market. The key point is it is related with evaluation post-occupancy, thus keeping the building, developer and tenants responsible for the building in the long term (Napoli F. , 2009).

The original NABERS had specific concepts in it which included the following.

- Prioritizing environmental impacts, with allowance for re-prioritizing over time, if required.

- Performance based assessment, instead of use of a checklist or prescriptive codes, to offer the possibility for creative solutions based on behaviour and thus a deeper understanding of environmental issues. Prescription can suffocate creativity and can impede the introduction of emerging construction technologies and changes that can be achieved through behaviour, such as better running of a building.

- Adaptability as the whole system is designed to be updated to take account of environmental changes, and social and economic factors.

- Ease of application and avoidance of complexity to allow the system to be available to a wide audience, both professional and public, and also to reduce assessment costs.

- Aspirational scoring to achieve an 'aspirational quality' in having targets to aim for rather than a predetermined number to beat. This addresses the 
issue of how to rate true sustainability and what constitutes an acceptable result.

Point of application is varied as this determines the effectiveness of the system, whether it is at pre-design, design, or occupancy phase. There was a public profile that allowed NABERS to become a widely known and well understood system. All the development phases of NABERS were exposed and discussed in public meetings throughout Australia (Beyer, 2002, p. 63; NABERS Project Scope, 2001). Since its original development NABERS has been taken over and commercialized by the NSW Department of Environment, Climate Change and Water. Napoli (2009) considers this means NABERS is not able to keep itself updated with market technological advancement. Furthermore, although Australia has a wide range of climates, commercialised NABERS is strongly related to New South Wales, and cannot provide a consistent label for the whole of Australia. It is also not designed to be an international certification system (Napoli F. , 2009), although this was never part of its original concept. However, the NABERS concept can be used on a similar basis in other countries.

While questions and pressure around NABERS have been increasing dramatically for the NSW Department of Environment, Climate Change and Water, part of the market recognizes that NABERS is one of the most independent labels currently available (Napoli F. , 2009). This is one of the most relevant differences between NABERS and other labels. In addition, the academic origins (Universities of Auckland and Tasmania) gave a different conceptual approach rather than just considering the market. The NSW Department of Environment, Climate Change and Water is also in a different position, being a public institution. It acts as both "inspector" and "evaluator" and real estate developers are simply submissive in the face of the public institution (Napoli F. , 2009).

NABERS has been used as a maintenance performance analysis tool instead of for evaluating environmental performance at the design stage only (Napoli F. , 2009). However, when the items analyzed were reduced (Fay, 2003, p. 03), the evaluation process was diminished. Important environmental criteria are now out of the main NABERS scope such as resources and transport. 
When a rating system was first required by the Australian authorities, the association between Auckland and Tasmania universities won a research project and came up with a series of straightforward criteria that would recognize the fact a high rating, as a measure of sustainability, would be difficult to achieve. However, as soon as the rating was delivered to the Australian authorities the universities were put aside. The original rating, delivered by universities, cannot be consulted on the NABERS website and the lack of information about it has made it hard to analyze the history of NABERS and changes to it (Napoli F. , 2009). When the first rating system was delivered by the joint research group there was a great opportunity for building a label with an independent concept. However, the universities were contracted just to prepare the rating not to keep it updated (Vale R. , 2010).

Although NABERS Office includes waste and indoor environment for offices, a great amount of advertising material has been focused on water and energy performance. Scoping mainly based on energy and water has been considered important for the real estate market, because these factors impact directly on the maintenance costs, which are the second most important costs after rent or loan repayments (Big Switch Projects, 2008; Napoli F. , 2009).

One of the most important characteristics of the original label (as made by the research group) was that it was to be easy and simple. It was designed to allow any user to understand and apply the rating model. Only the formal rating process demanded a third party be involved (Napoli F. , 2009). The subsequent changes after commercialization have left NABERS with similar characteristics to other market labels. Users and owners have accepted NABERS as a measure of maintenance performance and this aspect is an important marketing tool (Napoli F. , 2009). NABERS has been used to undertake energy and water ratings of a portfolio of office buildings (Big Switch Projects, 2008). Afterwards, the knowledge gained has been used to complement the market material. Thus, the Australian real estate market has been using NABERS as a benchmark for energy and water performance, but some topics were lost, and some people think the criteria were adjusted according to market interest (Napoli F. , 2009). 
NABERS is currently divided in four categories according to the use of the building. The categories are offices, retail, homes and hotels.

\subsubsection{NABERS Office}

NABERS is tailored for use by building owners, managers and tenants. Building owners and managers will be able to report on those aspects of the environmental performance of the building. Today NABERS only includes Water, Waste and Indoor Environment (NABERS - Home Page, 2008). NABERS originally had a wider range of items analyzed. The initial project had the following categories with the brackets indicating whether the aspect relates to the building or the user as follows below.

"Land

- Nature of site (Building) for buildings under three years old

- Total site area per $\mathrm{m}^{2}$ of building total floor area (Building)

- Total site area per building user (Building)

- Area of site planted with beneficial plants (User)

- Impermeably paved area of the site (Building/User)

Materials

- Cost of building per $\mathrm{m}^{2}$ of floor area (Building)

- Material types for structure, walls, floors and roofs (Building) for buildings under three years old

- Building age (Building) for buildings over three years old

- Time since last major internal re-fit (User) for buildings over three years old

Energy

- Energy efficiency - total energy consumption in $\mathrm{kWh} / \mathrm{m}^{2}$

- Greenhouse emissions of the whole building (Building/User)

- Greenhouse emissions for high performance buildings (Building/User)

- Renewable electricity use (User) 
$\circ \quad$ Buildings that generate more energy than they use (Building)

Water

- Water consumption (for whole site) from public supply per person (User)

○ Source of on-site water supply (Building)

Interior

- Nature of internal fit-out, equipment and operation (Building/User)

- Percentage of workplaces within 5 metres of a window (Building)

- Percentage of workers able to control light levels (Building)

Resources

- Total building area per person (Building)

- Intended use of building - number of hours per day (User)

- Intended use of building - number of weeks per year (User)

Transport

- Distance to nearest local shop (Building)

- Distance to nearest urban centre (Building)

- Number of car park spaces provided on site (Building)

- Distance to public transport (Building)

- Provision of bicycle facilities (Building)

Waste

- Provision of on-site recycling facilities (Building/User)

- Provision of local collection for recyclables (Building)

- Wastewater re-use (Building)

- Use of more sustainable sewage treatment system (Building)."

(Beyer, 2002, p. 64) 
The analysis process and measurement did not intend the goal of a highly rated building would be easy to achieve. Although a NABERS assessment in the original form was based on data to which the building manager or user would have access as non-specialists are not able to undertake complex measurement (Fay, 2003, p. 02), the underlying concept of "Ease of application" (Beyer, 2002, p. 62) has been frequently challenged (Napoli F. , 2009).

After the project was handed over, the NSW Department of Environment, Climate Change and Water decided to develop NABERS into a different system. The issues to be measured now include:

- "Energy use and greenhouse emissions - Energy-related greenhouse emissions are a key factor in increasing the levels of carbon dioxide in the atmosphere, leading to human induced climate change. How buildings are operated can affect their energy demand significantly.

- Water use - Building users can be major water consumers, but users can also adopt practices to harvest water sustainably and effect considerable reductions in demand on existing constrained supplies.

- Waste - Waste contributes to resource depletion and a range of pollutants and emissions. The reduction of waste minimizes the area needed for landfill, and reduces the environmental impact of overall materials throughput

- Indoor environment - As well as minimizing impacts on the wider environment, it is important for the health, satisfaction and productivity of occupants that buildings provide a comfortable indoor environment for those who use them."

(NABERS - Home Page, 2008)

NABERS has four categories today which try to cover all the Australian real estate market. NABERS has apparently a stronger focus on offices and homes (Napoli F. , 2009). There is much more information available on the NABERS website about these items. 


\subsubsection{NABERS Homes}

On a per capita basis, residential energy and water consumption in Australia are amongst the highest in the world and continue to climb (NABERS - Home Page, 2008). Residential analyses are limited to this topic (Napoli F. , 2009). NABERS tries to decrease the energy and water waste by comparing values with those of existing eco-houses. NABERS also makes available an online rating system for householders.

\subsubsection{NABERS Hotels}

Hotel buildings have significant opportunities to reduce their energy and water consumption and greenhouse gas emissions (NABERS - Home Page, 2008). The NABERS focus for hotels is based on the fact an efficient hotel can reduce its impact on the environment, and save operating costs for the owner and manager (NABERS Project Scope, 2001).

\subsubsection{NABERS Retail}

NABERS can provide an accurate, comparable measure of a shopping centre's performance to improve industry and public understanding of its environmental impact. The main focus is again on energy and water use. NABERS is frequently used to measure a shopping centre's operational energy and water efficiency, on a scale from 1 to 5 stars, with 2.5 being the market median average.

\subsubsection{Discussion}

From the brief look at existing labels above two things emerge. The first is that LEED for neighbourhood is the only label that specifically sets out the measure the sustainable impact of urban developments. The second is that the existing labels do not deal with the fundamental issue of sustainability, which is how to live within the finite limits of the planet and what the contribution of the urban environment might be towards this. Through taking a market approach the labels 
examined assume that life can carry on in a present, albeit in a slightly more efficient, way when it comes to the use of energy and resources. This leads to the issues examined in this thesis, which is what a label that truly measures the sustainability of an urban development might be like, as set out below. 


\section{Research Design and Methodology}

\subsection{Research Design}

A map of the proposed research is given in Figure 2.

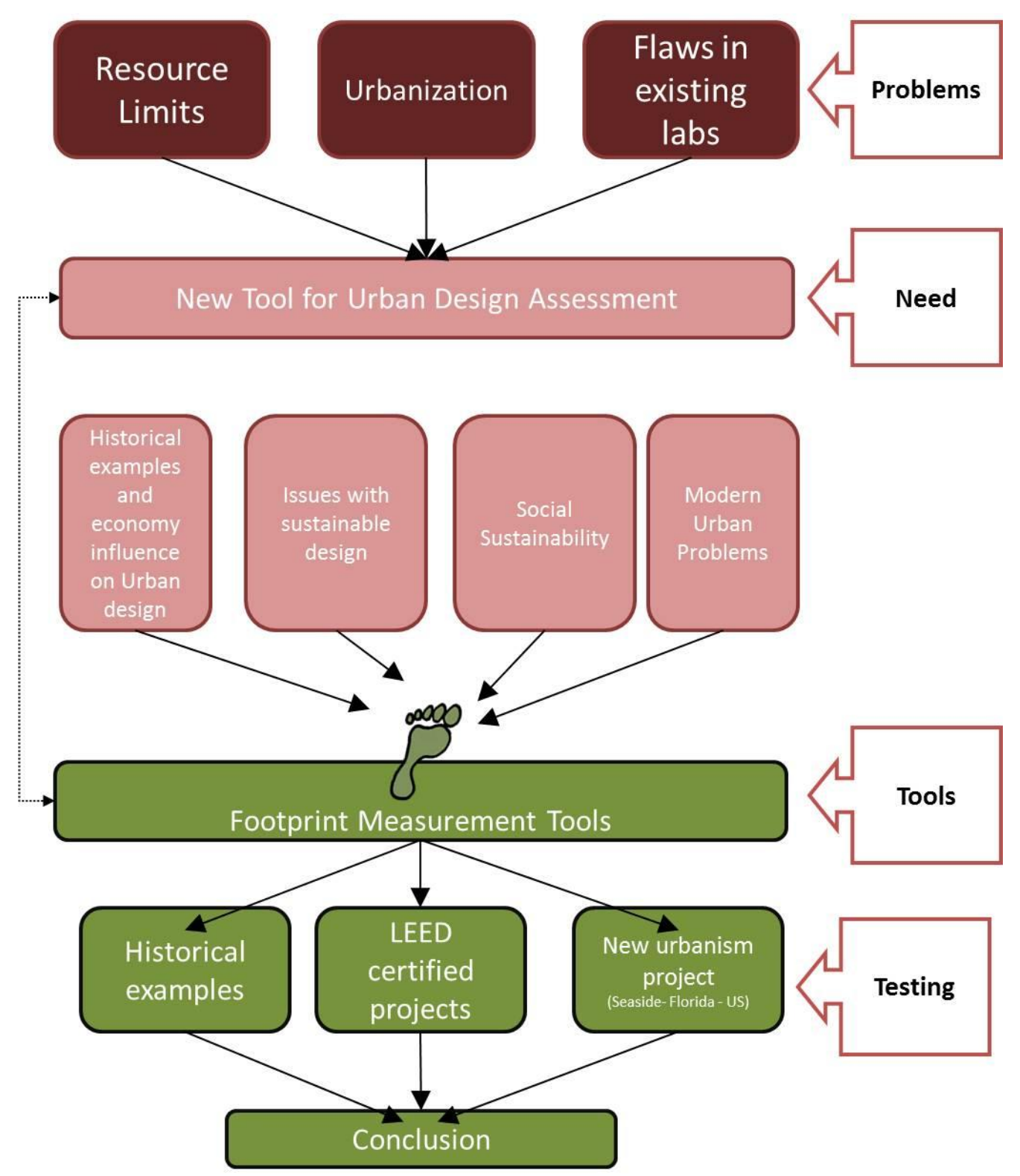

Figure 2- Simplified research chart showing the research design and its main stages: Research problem investigation (Problems), Gap in Knowledge (Need), Ecological Footprint Measurement tools (Tools) and the New Urbanism project (Testing)

The first stage in the research is to define the gap in knowledge through examination of existing problems with urban design and urban design labels (see sections 1.2 and 6.1.3). First what is meant by sustainability must be defined and 
why sustainability is important in a world that is increasingly becoming urbanised. However, the main gap in knowledge is revealed by an examination of existing urban design environmental labels. The fact that these labels are market driven rather than lying within the definition of strong sustainability as argued for in the thesis shows that there is room for a different type of label. The question then arises as to what tool or tools could be developed that would be able to produce a label of urban sustainability. However, as the diagram shows, the results of the first part of the investigation need to feed in parallel with the results from the second section of thesis research.

This second section begins with a brief historical investigation of different urban settlements, and their relationship with their hinterlands, environment, and economy. From this develops a discussion on the possible impacts and transformation that historical events have had on the urban environment. The historical analysis is essential to investigate whether, at some point in history, urban areas have been developed within the concept of environmental limitations, which is the definition of sustainability adopted in this research. Although more research would be necessary to measure accurately the environmental effects caused by ancient societies, the investigation gives an indication of how some ancient settlements were planned and developed within their environmental restrictions.

Even though the thesis is not aimed to be a historical report, it will make a chronological historical investigation of examples of cities, from ancient history to the medieval period, as selected city case studies. More research would be necessary to assess the different models of urban settlement in both ancient history and during the medieval period in Europe and Asia. The thesis also briefly explores aspects of the period after the medieval age, but, fundamentally the focus is on modern and contemporary urban problems. Instead of a theoretical analysis, the thesis will undertake a practical and exploratory analysis of the current urban environment, which includes the definition of rural and urban. Supported by the historical research, the thesis will also examine the influence of international trade 
on the urban economic system and the effect this had on urban design, which here is called 'regional imbalance'.

From this point on the intention is to concentrate on the urban aspects that are argued to be relevant for urban sustainability. Because the thesis has an explorative character, it will use examples to connect the social and environmental aspects in urban design. This step is made in order to reveal a number of aspects concerning sustainability, with a view to discovering which need to be included in the development of the proposed tool for measuring the sustainability of an urban development. The group of essential aspects which an urban design has to include should also positively affect the social characteristics of urban areas. The use of these concepts in an urban environment is here called 'urban social efficiency'. These investigations are particularly important for understanding what factors should be taken in account when environmentally assessing urban areas.

A final strand of this part of the investigation is to consider the role of economics in urban development, and particularly the role of the current economic paradigm, and the problems with the real estate approach towards sustainability. In addition, it talks about social aspects of sustainability and modern urban problems. This part of the investigation is important to confirm evidence in the literature that economic development runs counter to environmental interests and preservation (Brown, 2009; Common \& Stagl, 2005; Diamond, 2011; Meadows, Randers, \& Meadows, 2004; Heinberg, 2011; Tainter, 1988). It helps in reinforcing the need for an impartial model of urban assessment which cannot be subservient to the real estate market, with its inherent commitment to economic growth. This economic understanding provides an important conceptual input for the environmental measurement tool proposed by this thesis. Because of the divergent interest between economic growth and preservationist goals, it highlights the issues concerning the environmental certification institutions and their relationships with the market and its underlying economic principles, thus returning to the gap in knowledge previously identified.

Having argued for what needs to be assessed if an urban development is to be labelled as sustainable using the definition in this thesis, the final stages of the 
thesis work concern the creation of an assessment tool for urban design based on the concept of the ecological footprint. The latter is argued to be the best way of addressing and measuring sustainability as defined in the thesis. The aim is to make the tool universal and holistic, and to test it using selected historical models and neighbourhoods certified by LEED as case studies. LEED is argued to be the only true neighbourhood label. Obviously, given the scope of $\mathrm{PhD}$ work this cannot be a comprehensive and fully tested tool, however, the aim is rather to show that such a tool could be developed with more research. For this reason the proposed tool will be called a prototype tool. Another aim is to show it is possible to have an urban design label based on the concept of environmental limits. To this end a secondary prototype tool will also be developed to predict the progressive reduction of world biocapacity based on unchanging population and economic growth.

\subsection{Methodology}

The thesis has the final goal of providing a classification for urban developments according to their environmental performance. This classification, or label, will be based on the results provided by use of the prototype tools presented by the end of the thesis. The academic outcome is, therefore, to produce a prototype tool, which presupposes quantitative research. However, the first part of the thesis, the historical and urban investigation is largely qualitative and exploratory. The academic challenge is, therefore, how to move coherently from qualitative research towards a quantitative approach to generate a methodology (and prototype tool) based on environmental performance indicators related to resource limits.

\subsubsection{Building the Prototype Tools}

As a result of the understanding derived from forming the gap in knowledge (see section 1.2), environmental performance in urban areas should be approached holistically, and some of the indicators used by the environmental label providers available on the market should be measured differently. Additionally, the environmental assessment method should ideally be market independent, and thus not represent any financial or institutional interest. It should be designed only to measure environmental performance. The consequent need for a wider and independent assessment methodology has led to very specific academic research. 
Instead of simply reconfiguring any of the available tools on the market, new indicators have to be proposed and some of the existing indicators reassessed. There is no guarantee that market aspirations can be reconciled with environment preservation. As a result, a research methodology was constructed to produce the required environmental performance indicators. After the indicators have been defined a prototype tool will be developed, essentially putting these indicators together.

The requirement for an independent instrument for the environmental assessment of urban developments, combined with not being able to reconfigure an existing tool, confirms the need for an examination of historical urban societies and their settlements as a starting point. This is because in the past cities were smaller and probably better related to their environmental limits

However, this research does not demand an investigation of ancient urban planning and design models, nor urban fabric specificities, but rather an overview of the relationship of ancient societies and their environments and resource use. Essentially this research will fundamentally examine how ancient urban settlements have supplied themselves with natural resources, especially food, as the latter has played an essential whole in ancient urban societies (Gutkind, 1969, p. 467; Montillo, 1956, p. 25; Blanco, 1979, p. 11). It has driven the size of cities, stimulating their economic development, which in turn has led to the structuration of the monetarization process that dramatically increased international trade (see chapters 4 and 5).

\subsubsection{Historical Data}

The plan is qualitative research will be conducted to establish how ancient societies have handled environmental constraints. Secondarily, the aim is to study how they have coped with economic and social issues, as the environmental problems are often concomitantly present with social and economic problems, which could blur the analysis. A qualitative method has been used as there is insufficient data about urban societies to apply a quantitative method. More research than is possible here would be required to produce a measurable unit. However, to understand how urban settlements have developed, the historical research will extend at least to the medieval period. The intention is also to cover Western, Eastern and Mesoamerican societies. This wide framework aims to offer a holistic investigation rather than one which is Euro-centric. 
The first step will be to select a reasonable number of ancient societies, with some variation in location and historical period. These will be analysed in order to find out possible common problems and solutions, the economic and social impacts caused by environmental problems, resource and food shortages, and water supplies issues. Other topics will be added as they arise in the research.

Food supply plays an important environmental and economic role. As a result the initial investigation will include an economic overview. The initial phase of the research will introduce important economic and social aspects, and prepare for a philosophical exploration of the economic and social aspects of ancient societies and the impact caused by shifts in economic and social arrangements.

\subsubsection{From Historical Data to Modern Indicators}

The inherent relationship between the environmental impact caused by human action and the human economy means studying major economic shifts in ancient societies is unavoidable. As a result the plan is to study consequences of monetarization in these early societies. This is because when monetarization replaced the ancient barter system important changes occurred in societal activity and urban structure (Lévy, 1967, p. 21). The aim is to see whether and how this process caused relevant modifications in ancient urban communities. Philosophically, a system based on barter intrinsically supports the idea of limitation as the commercial transactions demand a physical product, the value of which is the product itself. This concept is highlighted when the dealer is also the producer. In this case, more than the just the notion of limitation is present, as the producers also know their capacity for production. This is perhaps one of the most important aspects to reinforce in the different phases of the research, being the idea of limitation and the economic process which led to the progressive loss of this idea. The idea of dependence on the immediate city hinterland or countryside partially opposes the idea of "the city is a settlement the inhabitants of which live primarily off trade and commerce rather than agriculture" (Weber, 1966, p. 66).

Monetarization is a process still present in modern societies. Therefore, the thesis will establish two priorities from its consideration. The first is the modern definition of urban and rural areas, in order to clarify the difference between the ancient and modern concepts of urban and urban development. The second, and perhaps more important, is to investigate the imbalance at local and regional scale caused by non-controlled commerce and the direct consequence this has for urban 
areas. This analysis will form a first step in the development of the new indicators based on resource limits.

The understanding and knowledge acquired from the historical and economic investigation will form the basis of an analysis of selected examples of modern urban societies. The two case studies are in Brazil, comparing two wealthy communities (Alphaville and Morumbi) with two poor neighbourhoods (Carapicuiba and Paraisopolis). These case studies were selected as they are known personally to the researcher and are also areas where urbanization has been seen as the societal goal. The aim of this part of the analysis is to establish some initial parameters of urban efficiency under a social and environmental analysis. However, further investigation will be undertaken to establish whether the current economic growth paradigm is even capable of supporting true urban sustainable development. This part of the investigation is important because there is an undeniable contradiction between the mathematical limits of the natural resources of the planet, and the need for economic growth (Heinberg, 2011, p. 280) .

From the combination of qualitative data from the investigation of ancient and medieval societies, that of the modern urban cases, and the theory and concepts of the modern economic paradigm and its implications for present cities, the thesis will have the conceptual support to propose indicators. Therefore, at this stage the thesis will move to a quantitative analysis. The ecological footprint will be used as a convenient method to concentrate all the indicators under a final measurement of sustainability (see section 1.1.2).

In order to establish the indicators the thesis will attempt to distinguish which aspects of urban design are vital when it comes to consideration of resource limits and which are desirable social aspects. The latter will be discussed as best urban practice but will not form part of the prototype tool.

At this stage the aim is to present the indicators using a method which reveals the concept of limitation when the indicators are being assessed, hence the proposed use of the ecological footprint. As result, the main prototype tool will essentially use data from several sources, in order to convert the different units of the indicators to a common unit that can produce an ecological footprint. The thesis also aims to consider how the assessment might be affected by global population growth, which is why a second prototype tool is proposed. Using this will enable a proposed urban development to be assessed not just at the beginning of its life but also under a number of world population growth scenarios and the affect these 
will have on world bio-capacity. Because of the scope of the planned research this will be a rudimentary tool based on secondary data. However, the aim here is to see the relative importance of developing such a tool when it comes to the environmental labelling of urban design. This approach makes this proposed urban design label different from any others currently available, since it will be able to rate sustainability in both the present and the future.

The final stage of the thesis will be to test the two prototype tools using a number of selected case studies and to match these with data from other ecological footprint studies, and then to reflect on any adjustments this testing suggests.

\subsubsection{Providing a Label for Urban Environmental Sustainability}

In order to offer a more complete methodology it is important to suggest a final classification of an urban design that will be both self-explanatory and relate to its sustainability performance over time. Although the results from the prototype tools will be expressed in the comprehensive unit of area (gha - global hectares), a simplification and classification is necessary for fully understanding the results of the prototype tools as the concept of gha could raise a measure of uncertainty regarding environmental impacts. This area will be addressed in the thesis.

The final classification will be intentionally defined simply, as the mathematical principle underlying the prototype tool does not allow a partial classification such as partially sustainable, or nearly sustainable. Therefore, the label should be presented under two classifications; sustainable or unsustainable followed by the year to which the analysis relates. For instance the label will state "the urban development is sustainable in 2013". Linking the assessment to the year it was carried out underlines the idea of permanent annual reassessment. In order to inform which environmental indicators should be enhanced to improve the classification, the assessment report will be presented showing the numerical breakdown, item by item. In this case, the final user will recognize why the development is unsustainable, because, for example, food has a higher impact than all other elements combined.

\subsection{Summary}

The methodology involving the development of prototype tools will be designed to cover fields normally ignored by the environment label providers, especially those 
factors directly related with economic growth (see section 1.2). For this reason, the evolution of the research will necessarily be backed by a discussion of economic theory, to explore why the idea of limits has been lost (see chapter 9). The methodological processes to achieve the final label will initially be based on a qualitative and exploratory critical analysis of ancient societies. The next stage will modify the qualitative data in a mathematical approach that will cover an extensive range of indicators. In order to reintroduce the concept of limitation, two prototype tools have to be developed, the main one measuring ecological footprint in urban areas and a secondary one which designed to provide biocapacity predictions based on several variables, including population growth.

Essentially the contribution to knowledge will be the label of sustainability for urban areas based on the environmental performance measure using the two proposed prototype tools. The deliberate decision to provide a label, instead of just the prototype tools, is done in order to simplify the information provided about the environmental performance and highlight the mathematical principles behind the tools. 


\section{Historical Analysis}

\subsection{Greece}

Greece is a territory of small plains and short rivers and of small valleys and low mountains. Its seashore is filled with deep bays and thousands of islands. The natural features of the country were reasonably important in shaping some of the important characteristics of the ancient cities of Greece. The cities arose isolated from each other thus maintaining individuality and a particular character. Water and productive soil, distance to the coast, and conditions of overseas trade were the most powerful agents that determined the fluctuation of the population in many settlements. Small villages were extremely dependent on these factors. (Gutkind, 1969, p. 445).

\subsubsection{Polis and Decentralized Power}

The term Polis, according to Aristotle, means "a union of clans and villages" (Halsall, 2000). Thus Polis means city-state, the city itself, and the region with its villages which belonged to the city. In Greece the Polis judicially was a state but emotionally was a country, while its people were a nation. This was one of the most important characteristics of ancient Greece. Ancient Greece did not have a central government; every city had its laws and specificity. This factor drove the ancient Greeks to live in relatively small cities compared with cities in other civilizations, especially in the East.

Most of the Polis in fact was a group of villages, preserving the relationship between city and country. Indeed the size of the cities was important for conserving this relationship. This association was lost in Rome when the citizen became a consumer instead a producer (see chapter 3.2). The cities in ancient Greece also show a gradient of density. The downtown area had a very high density, and moving out to suburbs the density decreased gradually, until a very low density was observed in the countryside. The Polis was clearly a set of connections between tribes and cities, creating a relationship where each party was provided with some quality of life. 
One important part of Greek thinking can be seen in her ancient cities. For a Greek, the human being was the centre of the universe, and for this reason, the whole city should be within reach of every citizen. The Greek city was considered a limited entity where the whole population could use the public buildings, such as the theatre, the agora, and the council house, and where the voice of the orator could be heard by every citizen. Temples were given a moderate elevation, and the council house was normally in the centre of the town, while the market was situated in the lower part of the city, where the roads from sea and countryside met. The houses were grouped around the central areas, becoming lower density as the distance from the central areas increased (Halsall, 2000).

All these factors, together with the usual reasons of water and food supplies, can explain why the cities did not increase and grow beyond narrow limits. Effectively the Polis supplied the resources, especially food, for all its citizens.

It was probably relatively late in the history of Greece (477 B.C.) during the Persian War (Newmann, 1967, p. 457) that people came together from many communities into the city. With two exceptions, Athens and Sparta, the cities in Greece were small and most of them were just villages interlinked under a local power. This means that several tribes or several clans had formed a confederacy and that their originally more-or-less discrete and self-sufficient units had gradually grown together, although without losing too much of their identity (Gutkind, 1969, p. 467).

The ideal of Aristotle was a static and balanced society which would retain a perfect equilibrium without dynamic transformation. However the reality was somewhat different, as a great number of disorders changed the Greek cities. The Polis was moulded and developed, as in the majority of cities in history, by migration, wars, and natural catastrophes, and it consisted of different and heterogeneous elements. Sometime, in accordance with Aristotle`s ideas, the movement from the countryside to city was prevented. This happened in Corinth about 600B.C. where the country people were forbidden to leave their land because this would risk food production and resources (Newmann, 1967, p. 115; Gutkind, 1969, p. 472). It should also be noted that families were deliberately kept small by abortion, and infanticide. Eventually the population of the whole country 
declined when there were conflicts, such as the Persian War and the Lelantine War (c.710-c.650 BC) (Cerchiai, Janelli, \& Longo, 2004, pp. 14-18).

The ideal citizen of the Polis was the landowner and cultivator. The rise of the Polis and the extension of its territory were directly dependent on the fertility of the soil and the available food supply.

Ancient Greece was not an urban society, and hence neither were its colonies. When colonizing, the Greeks tried to reproduce the same semi-urban format for their new towns. Their foundations had the same agrarian character as the Polis in the mother land. They were not really towns, but communities with some autonomy, and with a great number of peasants. Furthermore, the colonies were made to provide the new land (and hence resources) the homeland could no longer offer. The distribution of settlements and colonization are totally connected with the demographic aspects of Greek population fluctuation (Gutkind, 1969, p. 467).

The rural and urban settlements of a region are interdependent. There is no way to understand one without the other. One factor which makes the comprehending of the Greek rural structure hard is the ephemeral nature of rural buildings which were built for a short-life. Whatever the reasons for this lack of information, the fact is still the same that land availability and the way in which the rural population was distributed and the way villages were built were all extremely important to the Polis. The rural villages and some small Polis preserved the original idea behind the development of the Polis, in other words its origination in a union of families.

\subsubsection{Environmental Issues}

The clearing of forests changed not only the face of Greece but also her economic and social structure over the centuries. The growth of the cities and the increase in population gave rise to an intensive deforestation, especially around cities and towns. Originally large parts of Greece were well wooded, as numerous references by classical writers testify. Oak and beech groves were distributed over the mountains and highlands. According to Plato: 
"What now remains compared with what then existed is like the skeleton of a sick man, all the fat and soft earth having been washed away, and only the bare framework of the land being left."

(Boyle, 2004, p. 02)

Plato also describes how the bared slopes could not prevent the rapid runoff of the rain and the adverse effect this had on the soil and its fertility. When a city had any problem with attackers or during wars, the population would leave for the mountains and this gave rise to renewed clearing of the woods. This deforestation led to desert lowlands becoming swampy, and then the soil once fertile, would become unproductive.

Wood was needed for a very wide range of things. It was demanded for ships dedicated to trading and fishing, transport vessels, for the roofs of residences, and for public construction and temples. The more the cities increased in size the more timber had to be provided. However, there were huge areas which were still well wooded, because of the main characteristics of the land, with its mountains. For a time this aspect guaranteed a sufficient stock of wood for practically all the citystates in Greece. In fact, when the population started to migrate to colonies in Magna Graecia (Southern Italy and Sicily), and Asia Minor during the 8th and 7th centuries B.C. the demand for wood decreased (Cerchiai, Janelli, \& Longo, 2004, p. 18).

\subsubsection{Natural Resources - Solar Energy}

According to Socrates: "The ideal house should be cool in the summer and warm in the winter" (Rubnicu, 2012, p. 190). However, this was not easy to do 2500 years ago in Ancient Greece. Local fuel shortages probably exacerbated the problem. Near the populated areas people also devastated forests further for wood to heat their homes and for cooking. By the fifth century B.C., many parts of Greece were almost totally denuded of trees (Gutkind, 1969, p. 448). Many city-states regulated the use of wood and charcoal, and with wood scarce and the sources of supply getting farther away, fuel prices rose. Fortunately, the sun as an alternative source 
of energy was essentially free. Around ancient Greece, solar energy was used to help heat houses. The climate in Greece is sunny almost all year, and the Greeks learned to build their houses to take advantage of the sun's rays during the moderate winter and to avoid the sun's heat during the hot summer.

Basically solar architecture for the Greeks used the changing position of the sun during the different seasons. The Greeks knew about the sun's trajectory in the sky, and for this reason their houses were designed to capture a great amount of sun light in the winter, through a south-facing portico, similar to a covered porch.

\subsubsection{Olynthus: A Planned Solar City}

Olynthus was situated at approximately the same latitude as New York and Chicago, and the temperature often dropped below freezing in winter. Because of the pressures placed on the citizens of Olynthus by the Athenians, they revolted and erected a more defensible perimeter against the feared Athenians' revenge, by building a new community adjacent to the old city of Olynthus. The 5th century BC city was totally planned, as were most urban centres built in Greece at the time. The streets were perpendicular to each other, running north - south and east west. In this way, all the houses on a street could be built with a southern exposure. This lay-out helped assure equality of housing for all residents. According to Aristotle, “... it was a modern-fashion, it allowed a more convenient arrangement of homes to take maximum advantage of the sun" (Cerchiai, Janelli, \& Longo, 2004, p. 12).

\subsubsection{Labour Exchange between City and Countryside}

The Polis was firmly linked with the country, and the design of the city reflected this labour exchange. It meant the people lived in the city, near public services, temple and water, and the produce of the fields. Obviously this relationship was delicate, and fragile. Any change in population rates, invasion, war or simply the failure of the harvest could change the scenario and local atmosphere. These communities were originally self-contained and self-sufficient but this changed 
with the introduction of metal tools produced locally or supplied through trade. This led to greater efficiency and a certain division of labour (Gutkind, 1969, p. 467).

In the process of this development the self-sufficiency of the villages progressively changed. It was replaced by an inter-community exchange conducted by the chiefs and the artisans, which spread over Greece. Production for a person's own village was superseded by production for outside villages. The meeting place of the central village was used as a market square, and gradually the central village developed into a market town, and the villages depended more and more on the production of this economic unit in their centre, with their own agricultural industries continuing, although on a reduced scale. As a consequence of this change the chiefs grew richer and the clansmen poorer. A landed aristocracy came into being and with it the enclosure of its land. The tribal settlements became cities, and afterwards states, with the landed aristocracy as the dominant minority (Gutkind, 1969, p. 470).

The relationship between country and town changed steadily when the economic structure of the city began to be detached from the village economy. The natural relationship was based on the country providing food for the city, while the city concentrated on the political and cultural life, and industrial tasks. Together with this division of labour and stratification, both parties were still part of the Polis, although on the other hand the peasants were not full citizens. They were poor and their farms were normally fairly small. However this tacit social arrangement worked and was extremely convenient for the cities, as due to their size they could control food production. This balance was put under pressure and eventually broken down when the barter economy was replaced by a money economy. The country producers were not able to adapt themselves to these economic changes which increased their servitude and poverty. In contrast, the various Polis never lost their character as a dense agricultural village although they had many "industrial" activities. The majority of the population, even in Sparta and Athens, were cultivators who maintained contact with the countryside, rather than craftsmen or shopkeepers (Gutkind, 1969, p. 471). The agrarian character of the Polis was one of the reasons why trade guilds did not play the same decisive part 
as they did in the medieval towns. Moreover the small level of production and the use of slave labour made any association of free craftsmen (as happened in the guilds) difficult.

Greece did not have heavy industries, with the main industrial activities being mining and shipbuilding. The Greeks were superior artists and artisans in other fields, but they were definitely not industrialists. Their industries worked on a small scale and were only of secondary importance for the growth of the Polis. Trade, basically of grain, had an indirect influence on the rise of the cities although it made the city more or less independent of local supplies.

These interdependences of town and country operated in the economic and social, political and cultural fields. When immigration happened, caused by war or natural catastrophes, this changed the original urban spirit in a subtle and gradual process in which the Greeks themselves were transformed and swallowed by more rational urban thinking.

\subsubsection{City Planning and Design}

With the exception of the later planned solar cities discussed above, the streets in ancient Greek did not exist as planned space and they had no special importance. They were the intervals left over between the solid mass of buildings. The result is something without a planned shape. The main and general ideas of Greek planning were limitation, less space, inorganic internal arrangement and accretion. These characteristics made the ancient Polis not appropriate for carriages or horsedrawn vehicles of any kind, because the average width of the streets was four metres (Gutkind, 1969, p. 515). Almost every city had one or several main streets mostly running parallel to the main longitudinal axis of the settlement. They were the only roads that could be recognized as such in the normal way.

In general the layouts of the residential blocks were compact, the streets were narrow and sometimes very tortuous, and the houses crowded together. On the other hand, some important sites in the city were carefully planned. The Agora was above all a place for the congregation of the citizens of the Polis, and this was 
where they could meet and exchange news. This made the Agora the most important public space in Ancient Greek cities. It was the place when most of the political decisions were taken, being a kind of open air City Hall. It was the indispensable attribute of political and social union which was the essence of Greek thought. The Agora was also in many cases the market square, thus definitely making it the most original creation of Greek city planning (Gutkind, 1969, p. 471; Martin, 1945, p. 15).

By the beginning of the $5^{\text {th }}$ century the Polis had reached a final and classical form when the Agora gained its final complexity. After the Greek victory over the Persians the Greeks were more than ever convinced that their political organization should be in the form of small city-states. A small and controlled city was the ideal for the Greeks. However, the growth of the Polis and the Agora did not stop, and this raised new problems for which solutions had to be found (Martin, 1945, p. 18; Gutkind, 1969, pp. 469-471).

The Greek contribution to the art of city planning is much less than that of other countries at the same time, such as Mesopotamia, Egypt, China and India. The biggest Greek contribution concerns the importance of human beings, and meant the scales of the city, streets, and squares were suitable for the individual person. Despite a lack of development in city planning, the Greeks dedicated a great amount of time to choosing the place for new settlements. They preferred elevated sites which had good water supplies and that were surrounded by fertile, flat fields. Later they started to choose sites suitable for water and food supplies and military issues (Gutkind, 1969, p. 475).

The centre of these developments was the Acropolis, the fortified citadel, protected by several walls, and the religious buildings. The houses situated nearest the acropolis were occupied by the richer classes and with distance from the centre; the city became more rural and had lower density. The process of city formation was essential for some particular aspects of the future Polis. Gradually the most important and most favorably situated village assumed the function of the capital of these villages. This meant the leading village spread its social concepts to the others (Martin, 1945, p. 19). 


\subsubsection{Conclusion}

The decentralized government was a main factor in moulding the relationship between population and environment in ancient Greece. The Greeks were known for their ability not to unite: "At no time in antiquity was Greece a unified nation in the modern sense" (Nardo, 2000, p. 24). There were at least two main reasons for the Greeks' inability to unite, which are the geographical nature of the terrain where mountains and valleys separated land that could be easily settled, and the competitiveness of the cities that were based on different principles and concepts.

The geographic nature of Greece which made communication difficult was perhaps the main cause for the Greeks to develop their small cities, making "a nation built around a single city" (Nardo, 2000, p. 24). The coast of the entire area is jagged and the land broken by bays and gulfs and the interior is full of mountains and mountainous districts, producing many small separated regions. This made the cities grow up separated with their own social and cultural organization. "Although most of these towns were physically similar, their inhabitants developed different customs, governments, and traditions, and they came to think of themselves as separate nations" (Nardo, 1994, p. 33). In addition, the Greeks were extremely competitive, vying with each other in events from athletics to great drama festivals. The same thing happened with political and economic issues between cities.

This group of characteristics avoided large cities, and because there was not a central government, there was no capital of kingdom or empire. It meant the cities kept their rural relationship due to their size, and Aristotle's concepts about the unchanging ideal society that was always in perfect balance (Newmann, 1967, p. 485). However, despite this approach environmental degradation, especially deforestation, could not be avoided. Wood was necessary for construction, ships and military issues and the pressure on forests increased dramatically during the Bronze Age and continued during the Iron Age. Metallurgy demanded a great amount of wood, and demand also rose sharply during periods of war. 
The most important aspect related to environment and sustainability was the notion about the size of the city. The Greeks knew that the city could not rise over a certain limit that was related to the availability of their technology and natural resources. Obviously, because the Greeks did not have very effective birth control and other ways to keep the population stable, obtaining resources to support population growth was one of the main reasons for their creation of new colonies around the Mediterranean (Newmann, 1967, p. 496). However, their crude methods of birth control strongly suggest that the population had a tacit knowledge that they were part of a single natural system, which needed to be permanently controlled. In addition, they knew that quality of life depended on resources, which were limited.

However Greek society was not able to keep this balance for too long. War, especially the Peloponnesian War and Successors' War, and internal competition among cities were the main factors for the decline of Greece. Interestingly, both wars occurred after a period of unity and were followed by a unity that was enforced on Greece by outsiders (Martin, 1945, p. 65). The Peloponnesian War was the turning point of Greek civilization and the start of its decline. Just before the Peloponnesian War, the Greeks faced a war with Persia, and in an attempt to succeed, the Greeks united. With Greek city-states united, the Persians had no chance to conquer the land of Greece. This proved how strong the Greeks could be under unification (Martin, 1945, p. 66).

Macedonia, a country in the extreme north of Greece, attacked the once powerful southern Greece. The exhausted city-states failed to prevent the Macedonian conquest and easily fell. This was the first fall of ancient Greece. Under Alexander the Great, a Macedonian king, Greece was united and the nation was enlarged through conquests. However, this unity did not last long. After Alexander's death, his generals, who were called the Diadochoi meaning Successors, fought among themselves for the right to be king. Between 323 and 281BC, they fought a long series of costly wars that killed hundreds of thousands of people and exhausted all participants (Nardo, 1994, p. 87). This internal struggle would eventually lead to the decline of Greece. 


\subsection{Rome}

An analysis of the relationship between the environment and ancient Rome will be separated into different stages according to historical facts, and then chronologically organized. However the separation will be made considering the pressure on the environment, instead of following the normal Roman historical stages (Republic, Empire and decline).

\subsubsection{Urbanization and Environmental Issues}

Ancient Rome was probably the first civilization with a strong concept of urbanization. A traditional legend says that the city was founded by Romulus and Remus in 753BC. However, historically speaking and according to archeological evidence (Gutkind, 1969, p. 515), Rome grew from pastoral settlements around the Palatine Hill (located beside the current Roman Forum ruins).

With regard to location, Rome had every advantage for developing quickly. There was an abundant water supply provided by a convenient river, by which crops could be floated down from the hinterlands to the sea, which was near enough for use and far enough to keep the city protected from invasion. The terrain was relatively flat. Furthermore the site was in the middle of the current country of Italy, half way between south and north and highly suitable for trade (Newmann, 1967, p. 65).

The early urbanization of Rome and its surrounding areas was focused around the ability to obtain natural resources. Lowland areas and areas close to water transport were the first to be highly urbanized, but as population increased along with trade and manufacturing, imperial expansion and colonization of conquered territories was needed. Excessive use of wood made the forests one of the most important resources for the Roman Empire (Newmann, 1967, pp. 65-66; Montillo, 1956, p. 458). Wood was an essential resource because it was used for building houses, and hence was a key to urbanization. Although some Mediterranean houses were built with brick and stone, roof structures covered with tiles and floors were often made of wood. Timber was used in large quantities for military 
purposes, such as ships, and forests were also devastated to provide new areas for agriculture.

Some reasons for the increase in size of the ancient cities also can be seen in old Rome. Protection and commerce were the most important agents for its progressive urbanization. Protection was relatively important due to conflicts between foreigners and Romans around the $6^{\text {th }}$ century BC (Nash, 1944, p. 07). The expulsion of the Etruscans occurred in 509BC, and was followed by the establishment of the institution called the Republic, although in reality this meant the oligarchy of a few families (Gutkind, 1969, p. 29).

Before this expulsion, Rome had enjoyed two centuries of prosperity under the management of the Kings, although the Kings were elected rather than being part of a dynasty. However, this opulence steadily disappeared as part of a class struggle. Patricians were the higher class and they were represented in the Roman assemblies (comitia centuriata). These Patricians arrogated to themselves the important offices of the state and the exclusive right to interpret and ratify the laws. Eventually the Plebeians were represented for the first time in governance in 494BC (Sandys, 1910, p. 115), which created tension between the classes. Moreover, other facts added to and amplified the tension in Rome. As the population of Rome gradually increased, the conflicts between Patricians and Plebeians rose at the same rate. Migration was a notable factor in the making of the different peoples of Italy. This mainly took the form of urbanization as more people came into the city from the rural areas, thus increasing the number of Plebeians. Rome, being the capital, was for this reason the natural pole of attraction. Urbanization arose as a result of hostilities during the second Punic War (against Carthage) (Dupuy, 1993) and the wholesale abandonment of the areas of the countryside most at risk. This phenomenon assumed larger proportions in the decades that followed. The population in Rome at the end of the Republic was around 200,000 people (Gutkind, 1969, p. 29).

Rome demanded resources from a great part of modern Italy, however this was just the first step in a sharp increase in demand for resources. During the period when Rome enjoyed two centuries of prosperity, the concept of urbanization radiated steadily through the whole Republic. As the population of Rome increased 
dramatically, the Roman territories became insufficient to provide the resources for Rome and for the incipient urbanization elsewhere. The situation worsened when the competition against Carthage for naval commerce arose. This naval commerce was an important factor that increased the internal pressure in Rome. The production of food and others resources could not be increased at the same rate as the population in Rome and the other urban complexes, which had increased continually for three centuries. Carthage had some of the most important ports in the Mediterranean under its control, and because of this Rome could not use overseas commerce to minimize the internal crisis emanating from lack of food and resources.

How the citizens thought about food supplies was another relevant problem for Rome at that time. After the citizens lost contact with the constraints of rural production, they started to clamour for more and more provisions, increasing continually the demand for new arable areas. Rome together with the other cities of the Republic with an urban tradition, were definitely under pressure for supplies at this time.

Although there were a great number of cities around the ancient world, a strong relationship between city and countryside was essential for their survival. Basically the cities grew up from small settlements beside rivers, in arable regions, however part of the population moved from the city to the countryside during the day, or seasonally, thus providing labour for the countryside. This relationship between the citizen and the peasant, which was relatively common in the ancient world, was essential to keep the cities in balance. It meant the most important part of the required resources was produced by the city at least in part through the labour of its citizens, and therefore the cities had a layout suitable for this to happen. This meant the distances were short enough between the urban and the rural to be travelled in a day.

When Rome became the capital of a kingdom, and afterwards the capital of the empire, it acquired a population of around half a million people, and the exchange of labour was broken (Scheidel, 2007, p. 10). The city was big and travelling to the countryside was impossible. Some cultural Roman habits were definitely urban, 
such as the theatre or the amphitheatre for gladiatorial displays and other games, and the public baths, which were extremely dependent on a good water supply.

As the urbanization concept was consolidated in Roman culture, there were some relevant changes in the city which still remain until the present day. Before Rome it was relatively hard to find a citizen who did not have a consistent relationship with the countryside. A great number of people used to work in the countryside for part of the year, or even daily. This cultural habit provided the city with an inversion pressure to keep moderately small due to the necessity to be close to a food supply (Montillo, 1956, p. 25). Once the process of urbanization was totally spread all over the Roman Republic, trade became essential to maintain a fragile relationship between consumption and production. Any change could cause an increase in stress and internal tensions. For this reason, military expansion and the conquest of new lands through wars was essential to provide food, basic resources and moreover to spread the concept of urbanization all over North Africa and the Middle-east (Newmann, 1967, p. 109).

\subsubsection{Regional Environmental Degradation}

Obviously, Roman expansion and subjugation involved different factors beyond gaining food and other supplies, but new territories provided a temporary relief for the internal pressures. The Roman authorities quickly realized how important new conquests were for Roman balance; Rome was definitely consolidated during the Empire period.

Rome's expansion basically proceeded in three stages: the conquest of modern Italy, the victory against Carthage and her sovereignty over the western Mediterranean, and the supremacy over the east. As a result of these subjugations the city of Rome was strategically fed for four centuries. It was a cyclic process, new territories meant more resources and more opulence in the cities, which in turn raised expectations and produced the need for further expansion.

Between 400BC and 400AD the population of Rome underwent some fluctuation, always related to supplies and the economic situation (Newmann, 1967, p. 66). 
Urban developments in the Roman Empire became highly dependent on colonization and new territories. On the one hand, when Rome reached the peak of its expansion in $117 \mathrm{AD}$, the population of the empire was around 25 per cent of the world population (Januzzi, 2005, p. 80). Although the central government had been tolerant of the preservation of some aspects of the culture of the cities and nations subdued, the concepts of city and 'Urbis' were spread around the whole empire. Due to the need to organize and maintain local order, Rome brought to the new territories substantial parts of its state administration and military organization, thereby demanding more regional resources. Moreover the Romans brought with them the need to gain more resources to sustain a non-producer class, composed of authorities, the military, and government. This meant an additional number of people without any relationship with rural production.

For Romans in the new colonies and cities the factors of food, water, traffic and cleaning the streets were the most important items for measuring the quality of life. Other aspects were also important such as access to gold, silver, wood, iron, and copper. However the routine worries were definitely associated with urban issues.

The new Roman cities all over the empire had a Forum and temples as did the city of Rome itself. With regard to cultural habits, the cities subjugated were forced to reflect concepts from Rome. In addition the migration which happened in Rome also took place all over the Roman territories (Montillo, 1956, p. 23). Aqueducts were built to bring water to urban centres and wine and oil were imported from abroad. Landlords generally resided in cities and their estates were left in the care of farm managers. The labour in the farms became extremely dependent on slaves, as a rule often meaning low productivity (Montillo, 1956, p. 31).

The migration and the exodus from the countryside made slavery an essential element of the social order sustaining at least a part of the opulence and cultural habits in Roman cities. However many slaves were freed by their masters as a result of the services rendered. In addition some slaves could save money to buy their freedom. Although they could buy their freedom, slavery was still a very cruel system. Murder and mutilation were particularly common among slaves even though prohibited by legislation. Under some controversy, the number of slaves in 
Rome was estimated at over 25 per cent of the population (Bradley, 2009). Some experts also claim that during the Empire in the city of Rome alone, there were between 300,000 (Newmann, 1967, p. 55) and 500,000 slaves (Montillo, 1956, p. 12). The countryside was obligated to produce much more than before, so rural properties became larger, and the labour originally mixed between families and slaves became nearly all composed of slaves.

\subsubsection{The Importance of Water for the Romans}

Water was essential to keep the internal pressure under control in Rome due to the realization of the authorities that an increased water supply would lead to the improved health of the city. More water would mean the appearance of the city was cleaner, the air purer and the causes of an unwholesome atmosphere removed. The Censors were the Roman authority nominated to struggle again serious problems in Rome. During the time of the intervention of the Censors some aqueducts were built.

For several centuries Rome's natural supplies were enough to provide water for the city. The first crisis was partially solved when Aqua Appia, the first aqueduct was built in 312BC. During the next decades Rome had enough water to keep the internal pressure controlled (Frischer, 2008). The second aqueduct built was the Anio Vetus, 273B.C., started by the Censor M. Curius Dentatus, and finished by M. Fulvius Flaccus. It was a much more ambitious project. It drew its water from much further away, in the upper Anio Valley. This aqueduct had a much larger capacity than the first one, and made possible the distribution of water over a large area, particularly in the city's eastern regions, the area which received new inhabitants (Frischer, 2008).

For around 120 years Rome was able to cope with its water demand due to the huge capacity of the Anio Vetus. However the situation became unbearable when the population increased dramatically, particularly after the Second Punic War. Rome's third aqueduct, Marcia, was not introduced until 144BC. The Marcia was a line of much greater capacity then the first two aqueducts. The Marcia distributed drinking water of good quality at a high level throughout the city. The Marcia`s 
realization is evidence of the rapid growth of Rome during this period (Frischer, 2008).

Roman habits were definitely linked with the use of water. (Montillo, 1956, p. 22) Public baths and fountains were an indelible part of Roman culture and pride. However, the increase in population meant the need for more supply. In addition, as important as water was for Rome, the sewage disposal method through Cloaca (Channels) could not be accessed by most of the population.

As Rome partially solved the water problem, which meant bringing water from distant places, the other issues related with the city and its size were gradually solved. When the population increased the authorities (the Censors) were no longer able to provide water for the people. In this case, slaves brought water from fountains far from the city, sometimes from rivers in the countryside. Obviously during this time the social pressures rose sharply, due to the great number of the population who did not have enough slaves for this to happen. At its peak Rome was supplied by 11 aqueducts, and a large number of public water reservoirs spread all over the city. The Roman Empire was also responsible for producing a very sophisticated and efficient water supply system for other cities inside its boundaries.

\subsubsection{Roman Urban Design and Residential Architecture}

The character of original Roman city planning, as enshrined in its rigidity hallowed by religion and military tradition, sowed the seeds of its failure to cope with the intricate problems raised by the growth of the cities and by the change in their social and economic structures (Montillo, 1956, p. 101; Newmann, 1967, p. 65; Gutkind, 1969, p. 49). Every problem which Rome had to cope with for almost a thousand years was taken into account when a new city was established. Those involved analyzed the natural resources available and tried to improve the urban design by avoiding the problems faced in Rome in other urban developments (Gutkind, 1969, p. 50). 
The ancient city of Rome had some very current problems such as traffic jams and a garbage disposal problem (especially horse faeces). To cope with traffic, Rome created a law to restrict access for carriages at some times of the day (some exceptions were made to vehicles which brought materials for the construction of temples and aqueducts) (Newmann, 1967, p. 89).

Urban design in Rome was based on the cross formed by the decumanus and the cardo. The streets crossed each other at right angles and the gridiron plan was, as far as possible, the basic principle of the layout. The average width of the main streets, of the decumanus and cardo, was about 36 and 18 feet $(12 \mathrm{~m}$ and $6 \mathrm{~m})$. The streets were designed to receive military parades. In general, however, there were no hard-and-fast rules; the sidewalks, if there were any, differed in width according to whether or not they had an arcade or were open footpaths (Gutkind, 1969, pp. 49-55).

The city during the Roman Empire had a clearly defined separation between the different classes reflected in its residential architecture. Throughout the territory under Rome's control, residential architecture ranged from very modest houses (insula) to country villas (villas), and in the capital city of Rome, to the residences on the elegant Palatine Hill (Domus), from which the word "palace" is derived. The vast majority of the population lived in the city centre, packed into apartment blocks (also called insulas) (Benevolo, 1975, pp. 176-177).

The Romans were, above all, practical people and as such they were intensely proud of their material achievements. The Romans were more interested in acquiring existing knowledge and spreading it than in exploring new fields of learning (Gutkind, 1969, pp. 50-51). Due to the great number of achievements that were reached in architecture and urban living, it was natural that these concepts were spread to new colonies. Greece was one of the main intellectual resources for Romans who assimilated part of Greek knowledge for daily needs. They took over the elements of Greek architecture which they used or misused for their monumental buildings.

There were only a few cities with more than 10,000 inhabitants in ancient times, and they were normally smaller than $1 \mathrm{~km}^{2}$ (Montillo, 1956, p. 89). However, some 
of them were much larger and with a far greater population. When Athens reached its peak its population was estimated to be between 200,000 and 300,000 residents concentrated in around $10 \mathrm{~km}^{2}$ (Lanni, 2009, p. 698), which meant 20,000 people $/ \mathrm{km}^{2}$, a very high density even for modern cities. Paris currently has the same density at 20,696 people/ $\mathrm{km}^{2}$ (Paris City Council, 2009). However, most of the largest cities in the world have a lower density. São Paulo has 7247 people $/ \mathrm{km}^{2}$ (IBGE, 2009), New York has 6673 people $/ \mathrm{km}^{2}$ (NY City Council, 2009), and Tokyo has 5847 people $/ \mathrm{km}^{2}$ (Tokyo Metropolitan, 2009).

Rome during the peak of the Empire between 3 A.D. and 204 A.D. had more than one million inhabitants (Newmann, 1967, p. 25). Even allowing for some controversy most authors consider Rome the only city with more than one million before the Industrial Revolution, although some experts also believe that Alexandria could have had more than one million citizens before Rome (Rostovtzeff M. , 1986, pp. 1138-1139).

\subsubsection{Decline of the Western Empire}

According to many historians the sharp increase in the growth of the empire in a relatively short time and the economic problems caused by inflation could have contributed to the empire's fall (Newmann, 1967, p. 55). The huge dimensions of the Western Empire demanded a great budget to maintain its many essential elements, such as roads and aqueducts. At the time the empire was fighting against enemies on all sides due to its expansion throughout their lands, thus forcing these people to contribute great amounts of silver and gold in order to maintain the Roman war machine. Trying to solve both problems, the empire raised taxes both progressively and dramatically, causing inflation. This inflation was the cause of stress inside the cities, and the lack of essential goods.

In contrast some historians have argued that unstable economic policies played the main part in the impoverishment and fall of the western empire. By the 2nd century A.D. Rome had developed a sophisticated market economy in which commerce was partially free (Newmann, 1967, p. 55). At that time Rome controlled 
prices for foodstuffs, although those prices were not very much below their real market prices (Newmann, 1967, p. 56).

Afterwards, when Rome started to face the debasement of gold, silver and bronze (materials essential for coin production) this gradual process led to inflation, against which Rome fixed prices, but these were consistently cheaper than a real market price. The artificially low prices led to a scarcity of goods, particularly in cities. For an urban civilization keeping the city atmosphere calm was vital. The inhabitants of cities were totally dependent on trade in order to obtain goods, in particular foodstuffs, from the countryside. When starvation increased in the cities automatic migration to the countryside started. Despite the authorities passing laws to prevent migration to the hinterlands, the cities and urban surroundings gradually became smaller. The Roman citizens, highly specialized in trades, migrated to the country to practice subsistence agriculture. Thus Europe faced a counter movement, which meant that the people who had continually migrated to the city, started to go back to the rural areas, and the cities' populations decreased slowly but surely (Bloor, 1952, p. 23).

By the third century the monetary economy had collapsed. The end result was a form of state socialism. Monetary taxation was replaced by taking food and cattle from farmers. As the authorities struggled to increase the revenue, workers were organized into guilds and businesses into corporations called collegia (Bartlett, 1994). The collegias were organized for the state. The central government controlled and directed their members to work and produce for the state. In the countryside people attached themselves to the estates of the wealthy in order to gain some protection from state officials and tax collectors. These estates, the beginning of feudalism, operated as much as possible as closed systems, providing for all their own needs and not engaging in trade at all.

Some theories have pointed out that it was the environmental issues that steadily caused population and economic decline. Deforestation and monoculture led to erosion of cropland and loss of fertility and salinization was caused by irrigation. These human activities resulted in fertile land becoming nonproductive and finally to desertification in some regions. 


\subsubsection{Conclusion}

The Roman citizen became a consumer instead of a producer. Agricultural production was based on subsistence, with small properties and a wide range of products (meat, grains, and milk), when the city of Rome spread the concept of urbanization all over the new lands it had subjugated. The concept of 'Urbis' and the demands this entailed were also disseminated to new places.

Because the people in Rome lost the relationship with the effort involved in the production of food goods, they tended to consume more than they required to survive. Therefore they were no longer subsistence producers, they were just consumers.

The regulation of the price of food goods by the authorities was the catalyst for the increase in consumerism. Intending to keep a serene population the central government subsidized the price of food goods, without realizing the pressure this would create in the rural areas. The market politics were important in making the production cycle unstable. However consumerism is not regarded as a major reason for the decline of the Roman presence in the west. The main causes were the pressure on the borders (barbarians and invasions), corruption and internal fighting for influence and power (Bloor, 1952, p. 23; Newmann, 1967, p. 56)

During the more than 1000 years of Rome (500 BC to 400 AD) its technology and engineering overwhelmed some regions to the point that they could no longer keep and sustain population growth and urbanization (Montillo, 1956, p. 369).

The environment underwent drastic degradation as pollution from the burning of fuel wood filled the air and smelters that used wood as fuel transmitted heavy metals into the atmosphere. The creation of large cities contributed to deforestation in the classical world. Overcrowding forced citizens to move to the hillsides where forests once stood to build their homes. Wood was needed not only to build homes, but also theatres, public buildings, chapels and other fixtures of the modern cities as well as to keep them heated. Urbanization and the resulting degradation of the environment ultimately weakened the Roman Empire. 


\subsection{Mesoamerica}

\subsubsection{Introduction}

Part of Mesoamerican culture was based on urban settlements, and these traditions are best known in the form of public, ceremonial and monumental urban buildings and structures. However, the residential zone formed the transition between city and countryside. There is no similarity in urban design between Ancient Rome and Greece and the civilizations from America, but on the other hand the transition made from self-sufficient residences can be found in America, as well as the early Republic of Rome and Greece.

Mesoamerican building and urban design were based on solar principles. The sun was the most important factor for most cultures in America before Columbus arrived in 1492 A.D. (Blanco, 1979, p. 01). Civilizations before Columbus had a strong relationship with "cosmovision" which means to use astrological knowledge in religion, architecture, and urban design (Blanco, 1981, p. 100). Research seems to suggest that many traits of Mesoamerican architecture were governed by religious and mythological ideas. For example, the layout of most Mesoamerican cities seems to be influenced by the cardinal directions and their mythological and symbolic meanings in Mesoamerican culture (Blanco, 1979, p. 05).

There were different civilizations from the south of current Argentina to the north of Mexico, each one with a very particular culture and concepts. However most of them, especially in Central America, were significantly interrelated, such as the Mayas and Aztecs (Blanco, 1979, pp. 01-02).

This situation was completely different for the Incas. They were located over the Andes Mountains, and their food resources were obtained through harvest with the consequence that they were highly developed in food production, as this was the only accessible food resource (Blanco, 1979, p. 256). Obviously due to the fact they were situated over the Andes they had a different urban design approach. Each settlement had to be planned and every space had to be defined beforehand. 
This relationship between settlement spaces and similar development occurred in some cases due to intensive cultural exchange between the different cultures of Mesoamerica over thousands of years. Mesoamerican architecture is mostly noted for its pyramids which are the largest in America and some of the largest in the world. Although there is little information about residential zones, the public buildings, in particular the pyramids, were faced according to solar principles.

The civilizations had a great number of similarities due to exchange and trade, but they also had their specificities. Expect for the Incas, the other peoples developed in tropical areas, surrounded by forest and with large amounts of available resources. Basic goods, such as wood and water were abundant and this caused less tension for resources among American Pre-Columbian civilizations. The tropical forest could provide food and water when the harvest was not as good as planned. While the semi-urban population was relatively small, the forest was able to provide enough food although when it became larger some problems emerged (Blanco, 1979, p. 11).

\subsubsection{Olmec}

The Olmecs were located in the central coast of the Gulf of Mexico. The Olmecs developed the first major Mesoamerican civilization between about 1500 and 600 BC (Blanco, 1979, p. 66). Most of the cities were situated in the swampy jungle river basins of the current Veracruz state in Mexico. The Olmecs were responsible for many of the most characteristic elements of Mesoamerican civilization. These were especially evident at La Venta, which in this culture is the best known spiritual, intellectual and administrative capital. La Venta was planned with a north-south orientation, and because of that, the doors of their buildings opened east and west, according to the daily passage of the sun (Blanco, 1979, p. 71).

The Olmecs were one of the first to use stone architecturally and sculpturally, although it had to be laboriously quarried and transported from the Tuxtla Mountains $97 \mathrm{~km}$ to the west. Architectural stone mosaics were also created for the first time in the Americas. Although the Olmecs cropped and had some 
experience with agricultural production they were highly dependent on the forest and its resources. They did not have an urban centre with high density as their urban organization was only for religious and public buildings and the residences were spread around these sites (Blanco, 1979, p. 73).

\subsubsection{Teotihuacán}

Teotihuacán ("place of the gods") was the first truly urban Mesoamerican civilization. It was located 40km north from the current Mexico City. Teotihuacán grew into an important city during the 1st century $\mathrm{AD}$, prospered until about $650 \mathrm{AD}$, and had a population at its peak of around 125,000 people, although there is an indication of a much larger population of around 450,000 inhabitants (Blanco, 1981, p. 196). They created a monumental art, and their buildings were designed using the "talud-tablero" (slope and panel) system. With this type of design the contrasting horizontal and vertical elements were all rigidly controlled and unified, as were the projecting and recessive structural areas, the light and dark effects, and the illustrative and geometric ornamentation. These factors drove the urban layout to embrace a rigid-grid design (Blanco, 1981, p. 201; INAH, 2011).

The greatness of Teotihuacán architecture is clear in the Pyramid of Quetzalcoatl at Cholula, the largest single pre-Columbian structure, and the Pyramid of the Sun at Teotihuacán, which is second in size (Blanco, 1981, p. 203).

Palace complexes organized around plazas are among the most impressive examples of pre-Columbian residences. All Teotihuacán architecture was thickly covered with stucco, which was usually painted with murals.

Except for the pyramids and other stone buildings there is little information available about residences and urban organization. However there is no evidence that the people from Teotihuacán had a different organization from that of the Olmecs. The public buildings were also placed according to cardinal positions. The forest available made them not so dependent on cropping (Blanco, 1981, p. 201). 


\subsubsection{Maya}

Maya civilization was the most important and strong civilization in southern Mesoamerica in the second half of the first millennium AD. Maya development reached its peak around 600 to about 900AD. The Maya civilization was primarily located in lowland tropical areas, with proportionally more emphasis on ceremonial features due to the fact the Mayas had a theocracy as their governmental system (Blanco, 1981, p. 385). For this reason Mayas dedicated much more time to planning the religious part of the urbis. The material splendor of the Maya culture is respected, more than in any other field, in the architecture and adornment of their cities. These city-states were the centre of power for the king-priests who controlled the submission, the tribute and the manpower of the people who believed in them.

Except for some religious buildings the rest of the city was built randomly as dictated by the topography of each independent location. Some cities located in limestone plains (in the northern of Yucatán) grew into great municipalities (Academic Room, 2006).

For Mayas the most important part of the city was the public plazas which were the gathering places for people, trade and the core of their urban design. The rest of the city was a chaotically relegated set of spaces around the public buildings which were orientated and established in a cardinal direction. Depending on the location of natural resources, such as fresh-water wells, the city grew by using causeways to connect great plazas with the numerous platforms that created the sub-structure for nearly all Maya buildings, as more structures were added and existing structures re-built or remodeled (Blanco, 1979, p. 399). Maya cities were thus disordered and confused and this contrasted sharply with other great Mesoamerican cities such as Teotihuacan and its rigid grid design.

The core of the Maya cities was the largest plaza surrounded by the most important governmental and religious buildings, such as the great pyramid, temples and eventually ball-courts. They were located and built according to the Maya interpretation of the orbits of heavenly bodies. Around these central areas 
were the structures of less importance such as nobles' temples, and individual temples. Outside this religious part there were the permanent and more modest homes of the common people.

\subsubsection{Maya food production}

When the cities became bigger and the forests around the cities were not able to provide food for the whole population, agricultural production improved sharply. The Mayas developed diverse and sophisticated methods of good food production. The shifting cultivation that formed their agriculture provided most of their food although it is now thought that permanent raised fields, terracing, forest gardens, managed fallows, and wild harvesting were also crucial to supporting the large populations of the classic period in some areas (Blanco, 1979, pp. 399-400; Academic Room, 2006).

\subsubsection{Decline of Mayas}

The decline of the Mayas is shown by the cessation of monumental inscriptions and reduction in large architectural construction. There is no universal acceptance of the reasons for the Mayan decline. Social issues have been pointed to as the most important factor for Mayan collapse, however some other factors may have played an important part, such as foreign invasion, the ruin of trade routes, epidemic diseases, thin tropical soils (which decline in fertility and become unviable when destitute of forest cover), and irrregular seasons (Diamond, 2011, p. 175; Blanco, 1979, p. 401).

Some environmental theories for Mayan decline point out the deterioration in rural production. Mayan production was extremely dependent on the slash-andburn system which clearly is destructive for soil, causing its exhaustion. In contrast, before this exhaustion the increase in their food production gave them a competitive advantage over less skillful peoples and explains the high population 
of the classic Mayan sites. Some Mayan practices included making canals, terracing, raised fields, ridged fields, seasonal swamps, using muck from swamps to create fertile fields, dikes, dams, and irrigation. In turn, some of these methods caused deforestation, silting, and decline in biological diversity. However, it cannot exactly be said what the main cause of the Maya decline was (Diamond, 2011, pp. 175176).

\subsubsection{Aztecs and Tenochtlán (Late Civilization)}

"When we saw so many cities and villages built in the water and other great towns on dry land we were amazed and said that it was like the enchantments (...) on account of the great towers and canals and buildings rising from the water, and all built of masonry. And some of our soldiers even asked whether the things that we saw were not a dream? (...) I do not know how to describe it, seeing things as we did that had never been heard of or seen before, not even dreamed about."

Bernal Díaz del Castillo, The Conquest of New Spain in (Castillo, 1928, p. 14)

In contrast to the other civilizations of Mesoamerica, the Aztec culture flourished around $1325 \mathrm{AD}$, when they settled down on an island in Lake Texoco, today Mexico City, founding the city called Tenochtitlán. The Aztecs had been a warring, nomadic tribe of hunters and food collectors, and their origin is probably the semiarid region of the north of Mexico. When they finally settled down in Lake Texoco, they started to produce part of their food. Not deterred by the unfavourable terrain, they set about building their city using the chinampa system (misnamed as "floating gardens") for agriculture and to expand the island. Chinampa was a small rectangular-shaped area of fertile arable land, to live on or grow crops on, in the shallow part of the lake (Conrad G. , 1984, p. 73). Chinampas or "floating gardens" were, in fact, artificial islands that measured around $30 \mathrm{~m} \times 2.5 \mathrm{~m}$. They were made by staking out the shallow lake bed and then fencing in the rectangle with wattle. The fenced-off area was then layered with mud, lake sediment, and decaying vegetation (Conrad G. , 1984, p. 123). 


\subsubsection{Aztec Urban Life}

Tenochtitlán occupied an estimated 8 to $13 \mathrm{~km}$ sq., and was situated on the western edge of Lake Texcoco, in the shallowest part. It was the centre of the Aztec empire and the most important city (Conrad G. , 1984, p. 73). The city was linked to the mainland by causeways. These causeways were interrupted by bridges to allow the canoes to pass freely. In addition these bridges worked as part of the defensive system of the city. The downtown area could be accessed by foot or canoe. Some levees were constructed to avoid having brackish water around the city. The city was provided with water by two aqueducts, each more than $4 \mathrm{~km}$ long and made of terracotta. One of them was just for cleaning and washing and the other for drinking (Blanco, 1979, p. 01).

The city also had a rudimentary sewage system. The houses had latrines and public latrines could be found in the main streets. Small boats went through the city collecting garbage. The excrement was collected to be sold as fertilizer. The city was frequently cleaned and some workers were specialized in this job.

The Aztecs had become farmers and they were distributed in 20 clans (Calpullis) that contained the families in the 4 neighborhoods of the city. Each neighborhood was relatively autonomous with regard to each other. They produced food from their exclusive lands, and part of this production was driven by the need to meet religious expenses and the maintenance of public buildings, such as the marketplace (each Calpulli had its own marketplace), temples and schools (Conrad G. , 1984, p. 24; Blanco, 1979, p. 489).

Aztec homes were designed and influenced by their climate. The common house had only one room. The roofs were flat, covered by mud, and normally they did not have any openings except the doorway. Some Aztec housing units, however, were three storeys high. These Aztec homes were built for the nobles and were usually located in the central courtyard. In addition, the Aztec homes of the nobles had many gardens with flowers nearby and were close to a pool. The Aztec homes of commoners and nobles were most often built of adobe, a type of sun-dried brick. Blanco, describes the Aztec houses for the nobles as higher than the houses for 
poor people. They were multi-storey but not more than 5 metres high. Therefore, it seems probable they were only 2 storeys. The warm climate of the area aided in the creation of this material (Blanco, 1979, p. 501).

Size varied due to the prosperity of the family and location. In the Tenochtitlan the residences tended to be smaller, while in more rural areas houses would be larger. But the same underlying pattern was followed - basically, one large room, occasionally with a small room added on. There were likely to be two doors and no windows. There would be space in one of the walls for a small religious shrine. The rural properties were relatively isolated, and due to the region and the characteristics of the residential architecture there is only a little information about these sorts of houses.

The city was conquered by the Spaniard Hernan Cortez in 1519, and the rest of the empire was not organized enough to resist the coming of the Spanish (Cóttrill, 2006).

The Aztec population was relatively small for the level of resources available. The system of lakes within the valley made it a unique environment. These lakes are both saline and freshwater, giving the Aztecs variety in the resources available to them and also presenting problems for farming. The resources the lakes provided the Aztecs included a wide variety of fish and hunting areas, greater opportunity for collecting plants that grew along and around the lakes, and the ability to perform certain types of intensive farming techniques. The city had a very sophisticated ecological balance, especially the insular part. The clans produced enough food for themselves, however, due to the space limitation they would probably have run into trouble expanding their farming in the future (Cóttrill, 2006). 


\subsubsection{Incas}

The Inca civilization began as a tribe around the Cuzco area. Between the 12th and 13th centuries they expanded their empire absorbing other Andean communities. Around 1412AD, the Incas began a far-reaching expansion under the command of Patchacuti $^{1}$ (Blanco, 1979, p. 365). He founded the Inca Empire, which became the largest empire in pre-Columbian America.

Except for Cuzco, the Inca population was basically rural. People lived nearby and travelled into town for festivals, religious events, or business. The city was mainly for government and religious buildings. The city population was basically composed of metalworkers, carpenters, weavers and other craftsmen who made artwork for the temples. These people lived in the artisans' quarters. Outside the cities were the government storehouses and soldiers' barracks.

The Incas lived in mountainous terrain, which was not good for farming. To solve this problem, terraces were cut into steep slopes, known as andenes, in order to plant crops, sometimes with irrigation (Kendall, 2009, p. 01). The Incas used the dehydration method of storage. They would leave potatoes outside in the cold, then trample on them in the morning to push out the water, and allow them to dry in the sun. This process would be repeated 3 or 4 times, until the dried potatoes were ready for storage (chuños). Francisco Pizarro's conquest of the Inca empire occurred on $16^{\text {th }}$ November 1532AD (Blanco, 1981, p. 01).

\subsubsection{Cuzco}

Cuzco was the centre of the Inca Empire and its most important city. The streets there were narrow, usually straight, and appropriately cemented (Blanco, 1979, p. 378). The central buildings, both religious and governmental, were of stone, however the common residences and other less important buildings were made of adobe with striped walls painted with stucco. Their roofs were made of straw.

\footnotetext{
${ }^{1}$ In 1979, Blanco stated that Patchacuti commanded the Inca expansion in 1412 AD. However, new research has found, using the Carbon-14 method, the date to be 1438 AD (Adamska \& Michczynski, 2012).
} 
Houses did not have many doors or windows so as to maintain the internal temperature during the cold season. Through the beds of the rivers flowed clean water that was drunk by the population (Blanco, 1979, p. 381).

In the city the main activities happened around the great squares. The city was large and it was divided into two sectors by the Saphi (Root) River. The most important political and religious Inca ceremonies were held in one of these sectors, which was called Haukaypata, a word that meant "Ceremonial Sector". The other half of the Square was called Kusipata (Joy Sector), because after the great ceremonies people gathered there in order to celebrate, eat and drink. This great square was paved in different segments with stone labs, and it was covered with sea sand so as to avoid causing slipping during the rainy season. In the centre of these two sectors there was a special high platform known as "Usnu" from where the Incas and priests or other officials spoke to the people. The most vital buildings were located around this place (Blanco, 1979, p. 382).

Cuzco was the biggest metropolis and the one of the most important in the entire continent. It must have been a pleasant city organized according to traditional planning. In 1543AD, the Spanish soldier and secretary of Pizarro, Pedro Sancho de la Hoz, wrote that over 100,000 houses had been found in the city. Based on that it was inferred that the population was 300,000 inhabitants, approximately distributed as 126,000 persons in the urban zone and about 100,000 in the rural zone. In other words, the Tawantinsuyo capital had a total population of approximately 225,000 inhabitants, although this number cannot be confirmed (Blanco, 1979, p. 366).

The city was divided in four sectors, which corresponded to the four nations of Tawantinsuyu (which can be translated as The Four Regions or The Four United Province), and twelve blocks that resulted from the division of each sector into three parts ${ }^{2}$.

\footnotetext{
${ }^{2}$ Tawantinsuyu derives from the Quechua "tawa" (four), to which the suffix "-ntin" (together or united) is added, followed by "suyu" (region or province), which roughly renders as "The four lands together". The four suyos were: Chinchay Suyo (North), Anti Suyo (East: the Amazon jungle), Colla Suyo (South) and Conti Suyo (West) (Martíns, 2012).
} 


\subsubsection{Land Use / Agriculture}

The land was divided into three pieces: one for the aristocracy, another for the religious establishment, and the last for the farmers themselves, who were obligated to farm for all three groups.

Inca farmers had to deal with the difficult terrain of the Andes as usable land was mainly limited to the narrow valleys carved by rivers between the mountains. More flat terrain was afforded by plateaus, but their high altitude and cold weather severely limited their usefulness for farming. To expand the available land, Incas used several Andean techniques which allowed farming on hillsides and at high altitudes; these included the following:

- Andenes: The andenes were artificial agricultural terraces that served to obtain more land for sowing in the steep Andean hills. The Incas used this method to improve the use of water from rain and irrigation. Although their construction demanded the mobilisation of large numbers of the workforce, the Inca state could realize this demand with relative ease (Kendall, 2009).

- Camellones: These were artificial areas built on the banks of the Lake Titicaca. They were the treating of mounds of land that were allowed to store and to take better advantage of the water in places of frequent floods caused by the rains (Pino, 2002, p. 104).

- Cochas: Cochas, or artificial lagoons, were made and used for cultivation and to give the cattle somewhere to drink (Pino, 2002, p. 99).

\subsubsection{Inca Architecture and Construction}

With regard to walls, during the Incan period there were five basic models:

- The Rustic: these were made of stamped irregular stones that were placed without much care. The empty spaces were filled with small stones and a great amount of mud. This type was used for the construction of terraces, storage buildings and residential buildings for the common inhabitant of the cities. 
- The Cell Type: This has an aspect similar to the structure of a honeycomb made of small polygonal limestone.

- The Enchased Type: This was made of igneous stones.

- The Sedimentary or Imperial Inca: Basically, it consisted of stones of a regular height positioned in horizontal lines that appear to be rectangular. They have perfect and polished junctions.

- The Cyclopean Type: Also known as Megalithic, this was characterized by having enormous boulders that in some cases can reach $8.5 \mathrm{~m}$ across (Pino, 2002, pp. 28-34).

\subsubsection{Inca Labour}

The Inca people also kept a strong relationship with the countryside. During the planting season all the men would work in the country. Part of all cropping was taxed to raise money for soldiers, the disabled, and poor people (Blanco, 1979, p. 301; Pino, 2002, p. 207).

\subsubsection{Environmental Issues}

Inca policy conserved natural resources, and tried to assume the continued use of the environment for the benefit of human society. Agroforestry was one conservation measure taken by the Incas. They figured out the importance of protecting soil from erosion, and also providing shade on the roads, and for amenities in the towns. The Inca's wild forest areas were protected by state laws. The wood was regulated to prevent deforestation. Wild life was carefully managed by the Incas because some species were really important for them, such as llama, guanaco and vicuña (Blanco, 1979, p. 301).

\subsubsection{Conclusion about Pre-Columbian Cities}

Although distant and separated by centuries, and with different approaches toward architecture and urban design, there are some remarkable similarities 
between the pre-Columbian civilizations. The civilizations were dependent on local food production, which is also a characteristic of early European civilisations, and they have a profound relationship with agriculture. Indeed, like much of their contemporary cultures, the pre-Columbian civilizations were essentially agrarian and rural. They were dependent on trade, however, this was based on barter or prot-coins (cocoa seed for Aztecs) (Blanco, 1979, p. 56). The Incas and Aztecs were conquered by the Spanish, respectively by Francisco Pizarro (1532) and Hernando Cortes (1521). In contrast, Mayans probably collapsed because of the lack of capacity to manage their empire (Blanco, 1979, p. 01). Prolonged drought and deforestation were possibly one of the causes of this collapse, although it is still not totally clear (Conrad , 2006).

The Incas had a different tactic to deal with trade and its relationship with labour, agriculture and the hinterlands. They did not have an organized monetary system, nor did they create colonies to produce different products, but commercial trade was vigorously controlled by the central government (McEwan, 2006). They were essentially self-sufficient and reliant on local production.

The Aztecs, especially in Tenochtitlan, had a very sophisticated strategy concerning food production and city layout. Because of its floating urban design, with residential areas also being used for food production, sometimes there was no visual boundary between the food production area and the house (Blanco, 1979, p. 89).

In general, the pre-Columbian societies were agrarian, with a strong relationship between countryside and town. The countryside was associated with work, and food production and the town with religion, entertainment and political administration. 


\subsection{China}

\subsubsection{Introduction - Origins and Early Settlements}

Urban development in China is as old as China itself. Settlements in China are considerably older than the urban settlements of the West, and some villages in the lower plains of the Yangtze river are approximately 7000 years old (Hays, 2011). However, despite its current economic growth, China still is a rural society. The origin of urban development in China is related to the second dynasty, also known as the Shang Dynasty (McNamra, 1981, p. 36).

China had a significant tradition in urban design but in fact did not have an urban society. Although the urban tradition is intimately linked with urban antiquity, China's population is classified as rural. In contrast to the majority of western cities, rural inhabitants are not thinly distributed over the landscape on individual land tracts but lived in grouped rural communities (McNamra, 1981, p. 37). These settlements were very convenient for preventing enemy attack or even simply attack from competing villages. There were practical reasons for gathering together in rural settlements, such as ensuring a sufficient clean water supply, and guaranteeing access to the forest (for a wood supply). Such rural conglomerations appeared much later in European history. This partially semi-urban arrangement, that had a very strong web connection, instead of the more common radial European model, was rarely found in other cultures (McNamra, 1981, p. 42). The city was composed of one social centre and many villages around it, where each village had their specific laws and leaders.

At the beginning the settlements took the form of a compact, self-contained, economically autonomous village, grouped around a communal long-house. The first communities with permanent dwellers were formed during a time of agricultural development, such as initiating techniques like irrigation and the rotation of crops, both of which were essential to an increase in production as a starting point for trade (Trewartha, 1952, p. 69).

The crops that grew in the central area basically consisted of grains, although rice had also been incorporated into the crop inventory of the eastern plains. Cattle and 
sheep gradually became more important. The farming development was so intense that some of the inventions are still part of the Chinese agricultural routine, such as the hoe, spade, digging stick, and sickle (Eberhard, 1948, p. 09).

The ancient Chinese city during the Shang Dynasty was probably established in connection with an official building. These settlements primarily had military or political functions. Despite this main function, trade of goods soon came to have a significant position in the new semi-urban society. The cities were occupied by artisans, craftsmen, constructors and merchants (Trewartha, 1952, p. 70).

The urban culture which began under the Shang Dynasty was brought to fulfillment many centuries later, especially between the eleventh and sixth centuries BC. Some cities increased sharply in size for different reasons, such as location, being a port and trading point, or as a defensive spot. However, the greater part of the Chinese people still lived in small villages. There was one China in the cities which had military, religious and political functions and the other in the rural villages, which housed the largest part of people, with a sharp difference between aristocrats and peasants (Trewartha, 1952, p. 70).

The urban aristocrats were normally part of or involved with the government. They were responsible for collecting taxes, laws and religious affairs. The taxes paid by villagers in the form of grain and other products required a place for storage, and this place had to be protected, in other words there was a need for a walled city. This type of organization made for a regional structure of sectors or compartments. Each compartment probably had a walled city and enough surrounding agricultural land to form a self-sufficient unit of local production, commerce and administration. The accumulated grain, the size and characteristics of the wall, the quality and diversity of production, all certainly represented wealth, but also indicated military strength, for food supply made it possible to maintain forts for offensive and defensive warfare. Granaries in the nuclear cities likewise supported the large battalions of conscripted labour necessary for maintaining the state. 

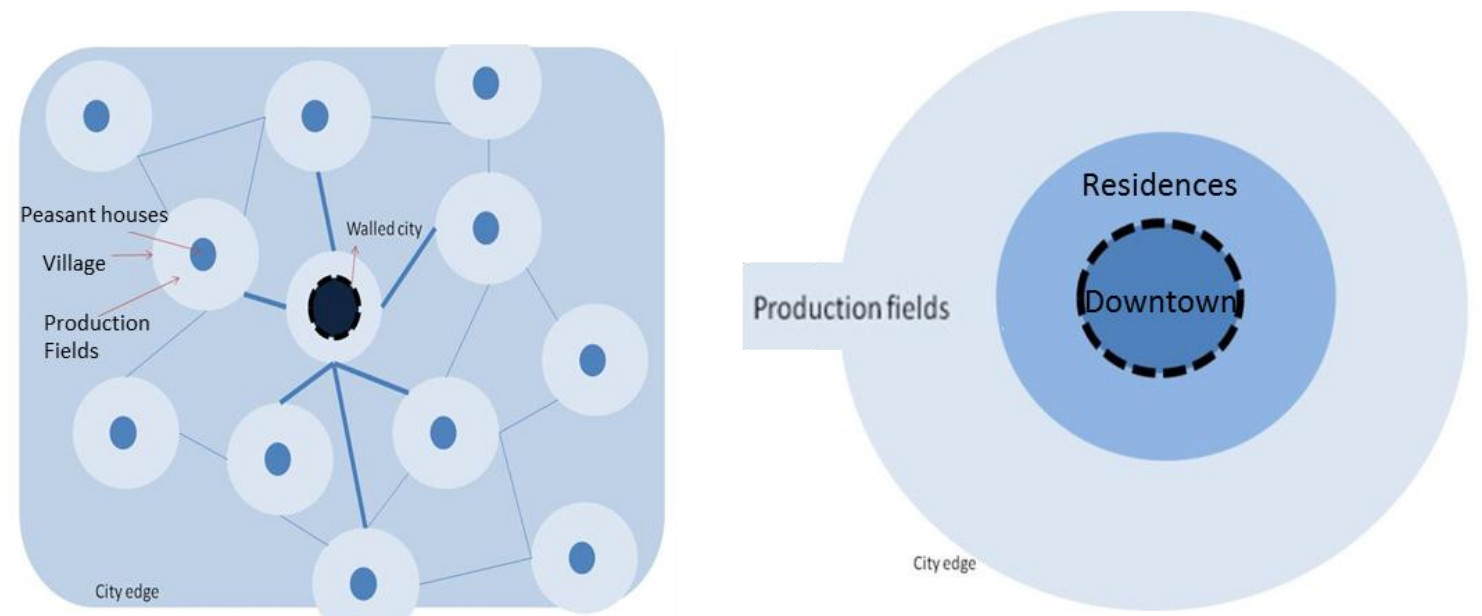

Figure 3 - Simplified comparison between the ancient Chinese (left) and European (right) models of urbanization

As flood control, irrigation projects, and canals became more numerous and complex, the urban settlements became more important as an element of government and administration. Thus a cellular structure of society was established in which each development consisted of a walled semi-urban area, with a central core surrounded by walls that contained the public and religious buildings and the residences of the aristocracy, and outside its tributary agricultural area. This essential structure was multiplied throughout ancient China. The walled "city in the country" was not only an administrative and military centre, but also increased its importance because of its trade and commercial functions. From the un-walled farm villages around the walled cities, inside this tributary area there moved toward the city large amounts of produce for immediate consumption, as well as surplus grain for storage in the city's granaries. An increase in demand for luxury goods by the urban aristocrats, and a developing need for copper and tin, resulted in an increased long-range trade (Trewartha, 1952, p. 71).

With the growing demand for luxury goods, there was an increase in the number of workers in the cities, such as artisans, merchants and blacksmiths. At the same time the cities increased relatively in commercial and industrial activity. Even with the majority of the population living outside the wall, the cities gained importance, becoming an essential part of ancient Chinese structure. 
This social and urban organization had a very strong foundantion and stayed pratically the same until the $19^{\text {th }}$ century (Trewartha, 1952, p. 82).

\subsubsection{Labour Exchange}

The social structure and the exchange of labour was similar in function to that of European cities at the same time. It meant the majority of citizens lived inside, or around the downtown area, or in the villages but they produced in the countryside, travelling during the day (or part of the year) to production fields relatively close to the cities. Due to living in small scale urban settlements, men travelled daily by horseback or walking to a nearby plot of land, while women either accompanied their husbands to the fields or attended to their children. The distances were normally bigger to the downtown area than to the fields (McNamra, 1981, p. 26).

Services, entertainment and social activities were agglomerated in larger urbanized and walled hamlets that were frequently planned for such service. In contrast with Europe, the distances between the villages were quite large giving the "city" a rural impression, however these settlements were extremely dependent on the central area. European peasants did not begin to urbanize in a similar manner until the advent of modern transportation at the beginning of the Industrial Revolution, and arrived in urban areas with little or no urban experience due to the dispersed settlement patterns of the West.

\subsubsection{Downtown Urban Design}

The Chinese people had knowledge of the street and undertood it as a commom area which had to be preserved and conserved. Due to the importance placed on the use of the horse for transportation, the streets were designed to receive both people and animals confortably.

The Chinese applied symbolic meanings to justify their urban design. The cities were designed based on an enlarged "holy field". The "holy field" symbol was essentially numerology applied to the nine in one square. Each square was 
numbered 1-9 to form a magic square. This "system" was largely used to conceptualize many other systems, such as astronomy, geography, and politics. The basic "holy system" was simple. The central square was the main item of the system and around it the other inner squares represented the means through which the subjects acted, amplifying their qualities. The four squares of even integers at the corners are yin and the five axial squares of odd integers are yang. This was considered the correct balance of yin and yang to keep harmony.

Planning in China originated in the very early dynasties. The ideal city was planned based on the "holy system", and this multipurpose diagram was drawn directly over the landscape. The Rites of Zhou codified how the Holy Field would be transformed into a city. The Rites of Zhou, also known as Zhouguan, is one of three ancient ritual texts listed among the classics of Confucianism. This system also dictated planning from the residential to regional scale. The Rites of Zhou, created during Zhou Dynasty (1100 - 221BC) (Xiaoyuan, 1999, p. 09), indicated the origins of the most basic urban planning philosophies in China, including geomancy, fengshui and I Ching. The planners of China imposed an orthogonal and cardinal regimen on the districts, and public buildings. It confirmed the importance of cosmology based philosophies such as directional orientation and symmetry. These concepts were very strongly rooted in Chinese culture. Many centuries after the Zhou Dynasty, around the 7th century AD, Xian was an example of this concept (McNamra, 1981, p. 42). The city was planned as the first Chinese capital city under the Sui Dynasty. Before the construction a vast mapping was made around that region to guarantee a flow of water, resources such as metal and wood, and a strategic location for defense and health. Xian's city walls during the 7th century AD enclosed approximately 80,000ha and housed an estimated half a million people; an accomplishment even the most prominent European cities failed to achieve until the 19th century (McNamra, 1981, p. 56). 


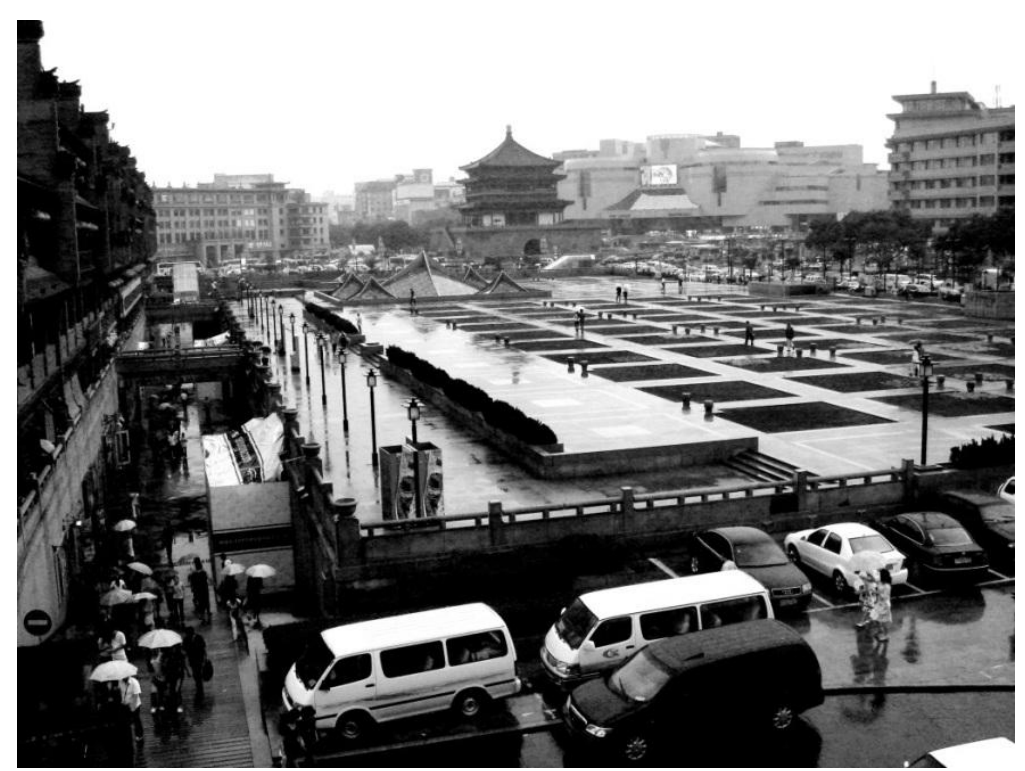

Figure 5 - Xi'an - China, sector 5. Photo: Author: July 2008

According to the Rites of Zhou the capital had to be 9 li $(\sim 3 \mathrm{~km})$ for each side length. Three, sometime four, gates and nine longitudinal and nine latitudinal lines divided the interior of the city with the north to south road nine times the carriage gauge in width. The ancestral temple is on the left of the palace city in the middle, and Sheji altars for the god of land and the god of grains are on the right side. The palace faces the imperial court and is backed on to the market and the court.

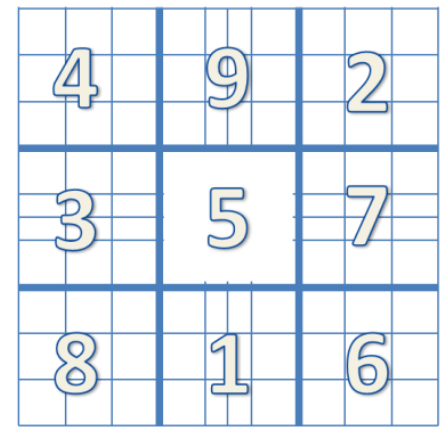

Figure 6 - Diagram of the ancient Chinese urban modulation, the "holy system": Image: Author

The main palace was located in square 5 of the Holy Field. This sector 5 was enclosed by fortifications to form the Inner City. Each sector had a particular function and had a specific type of use, such as:

Sector 7 - The main religious temple (temple of the ancestors) 
Sector 3 - A temple of agriculture

Sector 9 - Market

Sector 1 - An audience hall to avoid the circulation inside the city of people from other cities, or peasants

Even this kind of walled city was dependent on trade. However, the market was not considered of high importance and was placed in square 9 to the north of the palace. The edge of the Holy Field was enclosed in a second ring of fortifications and referred to as the Outer City. The fortifications were ruled to be $20 \mathrm{~m}$ wide and $15 \mathrm{~m}$ high. The wall of the Outer City was pierced by 12 gates aligned with 3 major North-South avenues and 3 major East-West avenues each one with a very restricted function. There were 6 parallel minor ways compounding a total of 9 ways running north-south and the same design was applied to east-west. These 18 avenues were specified as the width of nine chariots (Chinese: $24 \mathrm{bu}$; SI: $30 \mathrm{~m}$ ), and divided the city into wards of 1x1 li (McNamra, 1981, p. 65).

In theory each ward was an individual village, thus the capital was 81 communities (some of them just for food production) within a wall. This design was the origin of the modern hutongs (little villages in the middle of a block in modern China especially in Beijing). Inside each ward individual land was divided out in sections of $8 \mathrm{mu}(66.5 \times 66.5 \mathrm{~m})$. The $8 \mathrm{mu}$ standard lot could accommodate one aristocratic house, or be sub-divided into as many as 6 smaller residential plots. It made the cities have a large diversity in the wards but great homogeny at the city scale. The aristocratic houses used to be located near squares 5 and 1 . This configuration made the squares near the core of the city of lower density than the squares located near the largest walls (Moraes, 1996, p. 96).

This "mathematical" classical standard was extended to the regional planning scale. Cities were part of a modular regional system of urban economics. This reflected the hierarchy of the state at a smaller scale. The Capital should be the largest one, with the whole length $9 \times 9$ li (358 x 358m), decreasing to $5 \times$ 5li (198 $\mathrm{x} 198 \mathrm{~mm}$ ) for lesser cities, and the smallest configuration for an urban settlement being $3 \times 3$ li (118 x 118m). 
This worked for all scales from ancient China until the $19^{\text {th }}$ century. The smallest scale, even that of the site, was built out into standardized Chinese houses (siheyuan) as proscribed in the Rites of Zhou. The siheyuan principles dated back as early as the Zhou Dynasty itself. They occurred across China and are still a template for most Chinese residences. These residences were basically made by a courtyard surrounded by four buildings. Throughout Chinese history, the siheyuan composition was the basic pattern used for residential development (Trewartha, 1952, p. 82).

Although from antiquity a siheyuan is a practically sound, engineered structure, its northwest walls are usually higher than the other walls to protect the buildings inside from the harsh winds blowing across northern China in the winter. Eaves curve upward, so that rainwater will flow along the curve rather than dropping straight down. The rooftop is ridged to provide shade in the summer while retaining warmth in the winter. The layout of a simple courtyard represents traditional Chinese morality and Confucian ethics, and a protection against the wind from the north which brings the dust from the Gobi desert. In Beijing, four buildings in a single courtyard receive different amounts of sunlight. The northern main building receives the most, thus serving as the living room and bedroom of the owner or head of the family. The streets were the main access and the way the siheyuan was faced, and in Beijing, the whole is called the Hutongs. 

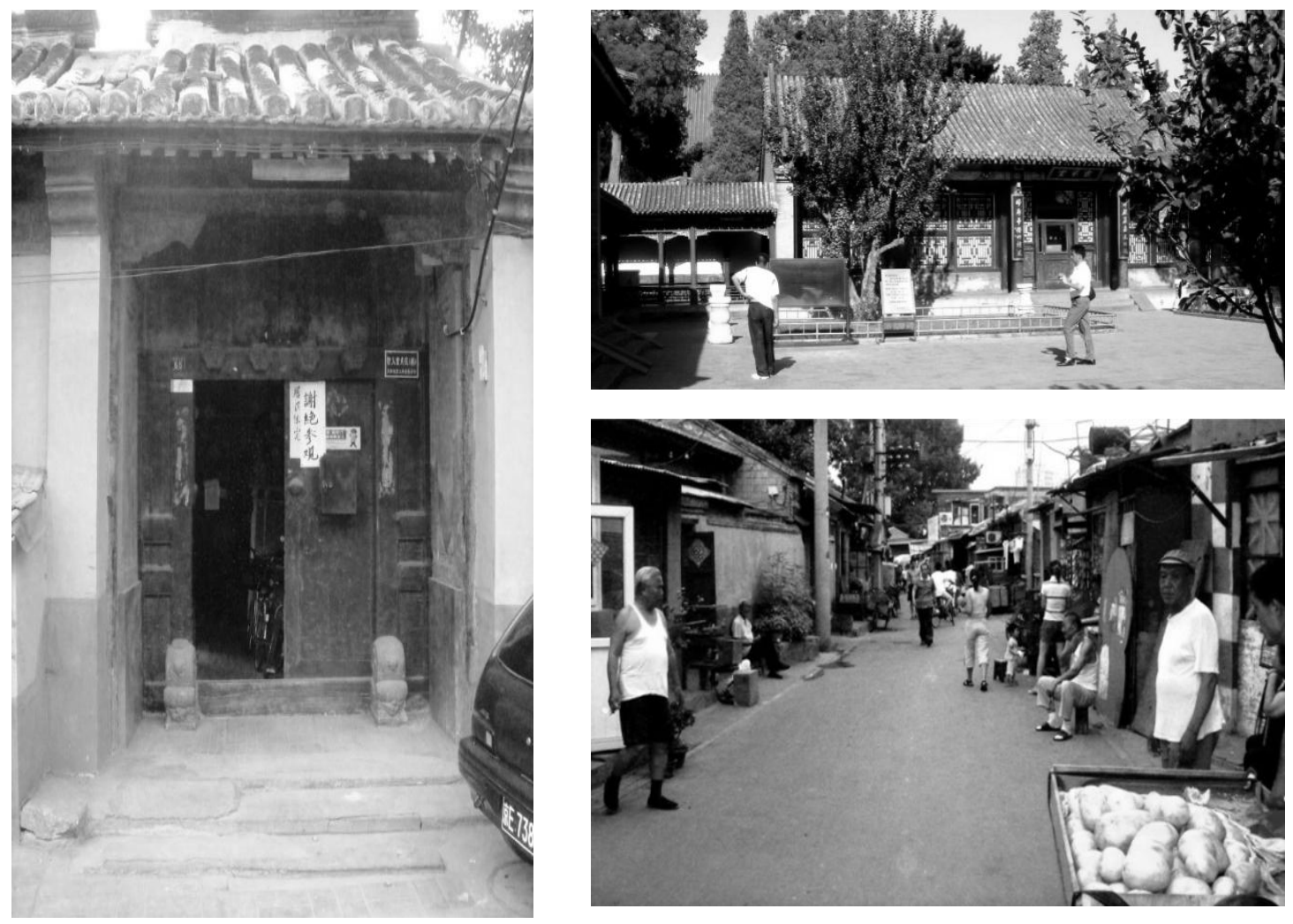

Figure 6 - Letf - Access to group of residences. Hutong - Beijing - June 2008

Figure 7 - Right top - Internal Courtyard. Hutong - Beijing - June 2008

Figure 8 - Right bottom - Street of a Hutong - Beijing - June 2008

\subsubsection{Chinese Relationship with the Environment}

Chinese philosophical thinking based on Taoism and Confucianism was extremely important for the relationship between human beings and the environment. Both Confucian and Taoist philosophies strive to reach a perfect harmony between the cosmos, nature, and human beings. These different "layers" of interaction were understood to be interlocked and constantly interacting with one another in a carefully maintained dynamic equilibrium. According to Confucian thought, human endeavor should not be used for the conquest of the environment, and human efforts had to be aligned as much as possible with natural forces. Any overreaction against any of these layers would cause repercussion throughout the entire system. The ancient Chinese believed that any human abuse will return in the form of nature's retaliation. The most popular Confucian saying was also applied to the environment: "Do not do unto others what you do not wish them do to you". The system of balance, however, accepted and understood a farm as part of it. The relationship existed at any scale and included the small ecosystem around a pond, the larger farmstead and its natural surroundings, and the complex trade system 
created to provide and exchange food among the urban settlements (Dennerline, 2005; Hsin \& Macer, 2002).

\subsubsection{Deforestation}

The deforestation process in China began very early in the Neolithic Age, 7000 $2000 \mathrm{BC}$, due to the wood used to construct houses, especially in the south. The frames were wood, with mud brick and stamped soil to complete the walls, providing good insulation for the residences. However, wood was also the main fuel for many things, such as heating, cooking, pottery and ceramics production, and foundries for bronze. When iron started to be manipulated the wood demand increased dramatically (McNamra, 1981, p. 14).

In the north of China, the arid and extremely cold weather during the winter meant that trees grew much slower than in the south. This meant the new growth had no chance of keeping up with the wood consumption. The topography in the north of China made cities that were surrounded by barren hills. The northern soil was covered by a fine yellow powder (from the Gobi desert) that simply could not be preserved without vegetation, and the phenomenon of rapid desertification was noticed in China from very early days. This powder was washed away by rain water, and went to rivers creating banks and raising the riverbed higher and higher. Because the riverbed had become so high, the rainy season could cause large floods that would invade villages and cities (Eberhard, 1948, p. 62).

Firewood became a very valuable commodity, and the people had to find a creative way of conserving fuel. A very fuel-efficient stove was invented in which a small amount of straw, hay or the stalks of crops could be burned to generate a short but intense heat. The Chinese method of stir-fry cooking was extremely efficient, as the ingredients were chopped and prepared ahead of time, and needed only a minimal time on the fire to be cooked. In north China they also used dried animal dung to provide fuel for heat. 


\subsubsection{China Conclusion}

The size and longevity of the Chinese culture suggests the need for a further investigation in order to completely detail their urban design and social urban organization. However, some general aspects indicate the strong relationship that China has had toward agriculture, self-sufficiency, and its countryside. The web of small production units connected with each other was a remarkable characteristic of the Chinese, and it has kept the population culturally linked and connected to the urban centre, while still preserving some of the aspects of rural life. Life in the countryside remained practically the same from 500BC until the beginning of last century (McNamra, 1981, p. 41). Although there were variations, due to the enormous distances within the Chinese territory, the local tendency of selfsufficiency is a common factor that has culturally moulded the Chinese society (McNamra, 1981, p. 45).

\subsection{Medieval Age}

\subsubsection{Medieval Urban Design: an Overview}

The urban design of the medieval period is included in this discussion because the roots of most of the important cities in Europe today can be found at that point in history (Benevolo, 1975, p. 668). The medieval age was essentially a rural period with a rural society (Benevolo, 1975, p. 256) and urban areas played a very secondary role. Cities, before the renaissance, were to some extent engaged in agriculture, and this was one of the main characteristics of the medieval city. Most inhabitants of medieval cities would have gone to work in the fields every day, returning every evening to the urban settlement, the exceptions including clerics and nobles (Pounds, 2005, p. 02). Some other medieval cities have their origins in the expansionist programme of ancient Greece, like Syracuse in Italy (Pounds, 2005, p. 04). Obviously, medieval cities have their own peculiarities, so this section of the thesis only explores the main general characteristics of the towns of that time, including the relationship between the urban area, its hinterlands, and their natural resources. Towns covered only a few acres and commonly had less than a 
thousand inhabitants. Cities with 50,000 inhabitants, for example were very uncommon. In northern Europe, around 1350 AD, only 15 towns had between 25,000 to 50,000 people, while 3,000 or 4,000 towns had a maximum 2,000 inhabitants.

The medieval period in Europe began with the fall of the Roman Empire in 476 AC (Donnelly \& Forrest, 2007, p. 155). Urban Regions in modern France, Spain, Britain, and Italy experienced a significant loss in infrastructure with the dismantling of the Roman Empire. Additionally the invasion of German tribes from across the Rhine River caused a process of immigration from urban areas to the hinterland. Some cities lost contact with their neighbours or were completely abandoned, such as Augusta Raurica in present Switzerland and Perperikon in Bulgaria (Historvius, 2012). This process continued slowly for around 200 years and the former urban prosperity enjoyed and spread by the Romans was lost (Donnelly \& Forrest, 2007, p. 155). Although some communities would remain, the level of urbanism would not come close to the previous situation for a millennium (Donnelly \& Forrest, 2007, pp. 155-156). Some cities, in Gaul, Italy, Germany and Britain were reoccupied around the fifth century but with different social and architectural aspects, linking them with modern cities, like Paris for example (Benevolo, 1975, p. 253). The ruins of Roman cities have provided some vestigial setting to these new surroundings, as found in places like Priene and Timgad. In contrast, some cities, such as Viterbo, Siena, Chartes, Gubbio and Bruges continued and kept their original aspects, while others grew into a metropolis, such as London and Paris (Benevolo, 1975, p. 253). The Medieval period also observed a fluctuation in its urban population, which was at its lowest with the ruralisation after the fall of the Roman Empire, and rising through a period of progressive urbanization when the economic depression of the early Medieval period began to lift after the ninth century (Pounds, 2005, p. 07). Indeed the population of many towns was in a constant flux. Cities declined in times of economic problems or diseases. One of the major players in the medieval urban population was the Great Plague. In 1348 it may have reduced the population in some urban areas by a half (Pounds, 2005, p. 77). 
Although some cities remained after the collapse of the Roman Empire, the previous commercial and industrial life had been drained, and the process of rebuilding was slow. Cities which remained after the fall of the Roman Empire enjoyed a different condition in the sense that they were founded before the time of feudal expansion, and their citizens had less social restrictions. Some cities that have been going since the medieval period are, therefore, linked with their modern counterparts. Paris, for example, is still basically divided in three parts, as it was in the medieval age: Île de la Cité, The Ville, and the université. London has also retained the old medieval centre that has now become its economic and commercial centre.

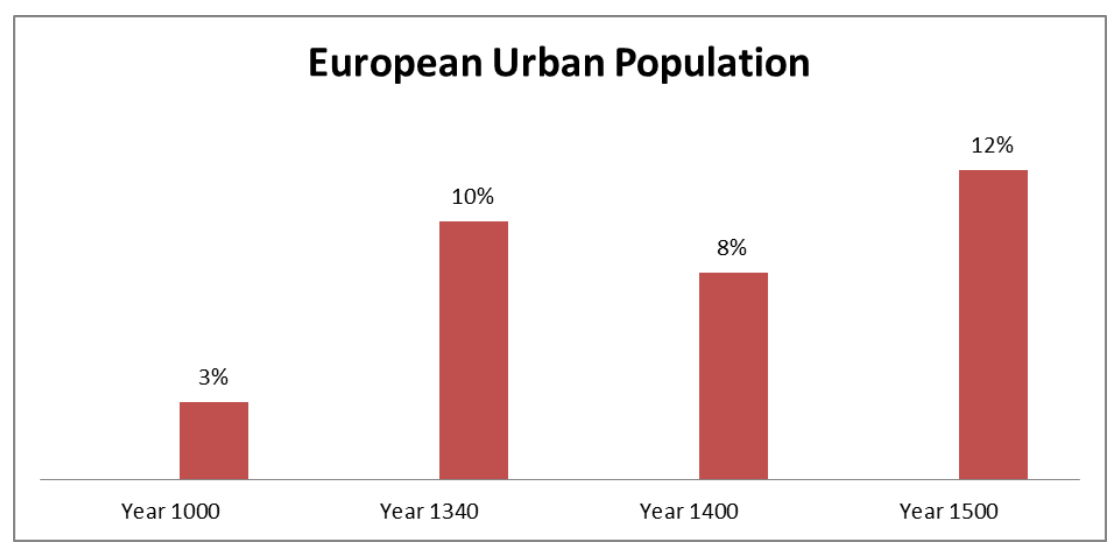

Figure 9 - Percentage of urban population in Europe (Estimated) (Pounds, 2005, p. 81)

The medieval city core normally contained a cathedral, an abbey, and a castle, with houses around, many of which would contain a place for manufacture and trade on the ground floor. In England, the medieval age was never intensively urbanized, with around 90 per cent of its population still rural by the end of 1500 (Platt, 1976, p. 15). English medieval cities rarely had more than 1,000 inhabitants. They normally kept rural characteristics that blurred their distinction from the countryside. However, there were no population censuses before the eighteenth century (expect for some Italian cities, which heavily depend on imported grains, meaning they literally counted how many mouths they had to feed) (Pounds, 2005, p. 76). The medieval city depended on its countryside for food, natural resources and it always controlled a vast territory in consequence (Benevolo, 1975, p. 292). Unlike the ancient Greeks, however, the people from the countryside have not had the same status of those living in cities, and all decisions taken by the lords were favourable to the urban community (Benevolo, 1975, p. 293). 
Some urban settlements did not have their origin in the remnants of the Roman Empire, but were founded by territorial lords. As the lords were entitled to part of the profits from any commercial transactions, cities have helped in this process, although some were only created for protection against possible invaders. This method of urban design was based on the design of the territorial lord. Land was set aside for a town, streets were planned and buildings plots delimited for the anticipated settlers. Even the most ordinary cities would have had a market where some surpluses were traded. These kinds of town were known as planned towns to distinguish them from the organic town which had grown spontaneously (Pounds, 2005, p. 12).

The entire complex process of urban design in Europe is outside the scope of this thesis, however some aspects concerning medieval urban design and the relationship with the countryside are relevant. The relatively closed economic system led entire communities to a straight dependence on their food production regions. The vast majority of cities only had local trade. Craftwork was essentially to produce utilitarian goods for daily use. Later, specialization became more and more important, and the inhabitants developed interdependence with each other. Products were, therefore, made and sold locally.

The evolution of the local market had an effect on urban design. Similar shops were clustered together, and streets have gained names according to their shops, such as Milk St. and Bread St, in London. Shops were open to the street, in full view of the public (Donnelly \& Forrest, 2007, p. 156). Urban life thus led to changes in political and social organization. Socially, once specialization started it led to the creation of a social class, the bourgeoisie, responsible for the production modes that would eventually be responsible for the Industrial Revolution. Politically, the urban population demanded urban bureaucracy and a more organized structure of government (Donnelly \& Forrest, 2007, p. 158).

The European countryside was basically divided into large estates $(5,000$ hectares or even larger) which contained hundreds of farms (Benevolo, 1975, p. 254). The centre of this area contained the common urban buildings, such as the market and cathedral. Around this central section were the grain stores, stables, and other private buildings, such as the houses of the landowner's vassals. The surrounding 
areas were subdivided into three parts: the lord's private domain; the farming land, which was shared by the serfs; and the common land (woods, meadows and marshes), where everyone had their right to graze livestock, pick wild berries and collect wood (Benevolo, 1975, p. 256; Donnelly \& Forrest, 2007, pp. 156-157).

\subsubsection{The Burgs and the Expansion of Countryside Production}

The burgs were formed when the rural population in times of shortage of food migrated to the fortified cities. However those cities could not accommodate the migrant population. Consequently, new settlement spread around the walls, called the suburbs, and eventually these became larger than the original urban core. This effect made necessary the construction of new walls to protect the new suburbs. The development of larger urban settlements led to a progressive collapse of the old medieval model of self-sufficiency. For around a thousand years, the medieval communities aimed to grow enough food for themselves, including food for all who produced the necessary equipment. The newly developed urban areas, including those created by medieval lords, already had fundamental differences with this situation. They guaranteed some individual freedoms, including allowing some citizens to organize themselves with government by magistrates.

\subsubsection{Conclusion}

The medieval urban model indicates a strong relationship between the countryside and urban settlement. The principle of living within resource limits was implicit in the model of self-sufficiency at the start of the medieval period. The limited urban size and the principles of walkable distance from work to home were probably stronger than they were during the Roman Empire. The ancient Roman urban spirit progressively vanished along with a certain exchange of products. The cities had to handle the problem of food supply relying on their own stocks and capacity to produce food. The analysis of a common urban medieval model is impossible due to the diverse characteristic of the urban patterns. Medieval towns have grown 
in different shapes and forms. They were highly adaptive, moulding themselves according to geographical and economic circumstances (Benevolo, 1975, p. 308).

However, two general aspects were common in medieval urban areas:

- The majority of the streets were planned to be used as places to stop, to conduct business or for holding meetings.

- Cities developed into more complex structures to accommodate different authorities: the local bishop, the municipal government, the religious orders, and the guilds.

One remarkable element of the medieval urban-rural organization was the common land around the cities, which the peasants could exploit, although with strict regulation. Although these lands were the properties of the lords of the region, the inhabitants had access to them for food and raw materials production. There was, however, a complex tax system, which worked to collect tax for the regional lord, that was even applied to the lord's land. Regional prosperity could probably be measured by the capacity of its inhabitants to be able to feed themselves and collect taxes for the lord. The expansion of cities was also limited by the fortified walls. A new wall was postponed until there was no more space within the existing walls. This expansion limitation suggests a slow growth that kept the city small and with a high density. The production fields were just outside the walls within a walkable distance. Three prime characteristics - continuity, complexity and concentration - have survived and still define the base of the European cities of today (Benevolo, 1975, p. 326).

Improvement in agricultural techniques was an important factor which helped population growth after the year 1000. The period was known as a time of cerealization, crop rotation, use of draft animals, the addition of iron blades to ploughs, and the spread of water mills and windmills, all of which improved food production, creating some surplus and allowing the urban population to increase. However, the European urban population was still only 9 per cent in 1800 and by 1950 Europe was essentially rural with only 43 per cent of its population living in urban areas (Vries, 1984, p. 349; Bairoch, 1988, p. 495). The phase of colonization and world expansion did not change the vast majority of cities and their 
relationship with their countryside. The Renaissance architects were restricted to making only superficial changes in the cities. Europe kept its medieval model, which essentially fulfilled the needs of Renaissance society, being only partly changed. The Industrial Revolution was the subsequent move that has triggered the large migration from rural communities to work in towns.

\subsection{Early Modernism, the Garden City Concept and Contemporary Urbanism}

\subsubsection{Early Stages}

During the Industrial Revolution cities changed quickly. First came the migration from the countryside to urban areas and the consequent formation of the urban working class. Technological development and innovation, particularly in the energy and water and transport sectors, has been essential for the transformation of cities. In the 1890s in Vienna, Otto Wagner, influenced by James Hobrecht's new sewage system in Berlin 20 years before, introduced innovation in transport, the stadhbahn or light rail, and water treatments. These new concepts helped to produce what was called New Vienna, which was fundamentally urban planning influenced by technology and industrial modernization (Lehmann, 2010, pp. 6568).

The end of the $19^{\text {th }}$ and the beginning of the $20^{\text {th }}$ century introduced the first stage of modernism. Cities were still influenced by the pre-automobile area, and the typology was compact and a strong notion of urban centrality existed. From this period the concept of the Garden City emerged as an influential model of urban development (Lehmann, 2010, p. 68).

\subsubsection{The Garden City - Ebenezer Howard}

Created by Ebenezer Howard, who in 1899 founded the Garden City Association, this model of development also influenced the North American model of the City Beautiful (Robbins, 2007, p. 727). The main idea was to create a balanced regional area of residential, industrial and commercial spaces. Howard was influenced by his reading of Edward Bellamy's socialist utopian novels, Looking Backward 
(1888) and Equality (1897) (Hutchison, 2009, p. 289). The design concept had two main aims: to solve the problems of the congested city, and develop the countryside. The simplification of the concept was that by mixing the town and countryside, residents would get the benefits of both (Robbins, 2007, p. 727).

The Garden City was designed to have 32,000 inhabitants on a site of 6,000 acres $\left(24.28 \mathrm{~km}^{2}\right)$. Six radial boulevards 120 feet (36.5m) wide form the centre creating a radial pattern, with open areas and parks separating areas for residential, industrial and institutional functions (Robbins, 2007, p. 727; Hutchison, 2009, p. 287; Lehmann, 2010, p. 68).

Probably the most important point of City Garden planning was the intention to produce a self-sufficient region, and to include a mix of employment as well as sufficient agricultural land to feed the local population. The Garden City would be separated from the other cities through a green belt of agricultural land. The Garden Cities would be connected by rail transport to each other as well as to the central, larger city. The theoretical goal was to blend city and nature (Hutchison, 2009, p. 287).

\subsubsection{Functional Zoning: Tony Garnier}

The simple principle of functional separation was the essence of Garnier's Citte Industrielle, promoting the moving of industry out of city boundaries (Lehmann, 2010 , p. 69). The design was a web of orthogonal traffic routes, arranged to keep pedestrians and cars separated. It was intended to produce urban regions with a great number of green areas with no enclosed spaces. It also proposed an architecture of stylistic unity from cubic volumes and combinations of simple forms, in which porches played a unifying role. Also, the open plan houses, roof terraces, the bare walls, and the entire region would be built in metal and concrete (Ragot, 2012). 


\subsubsection{The City for Three Million People and La Ville Radieuse: Le Corbusier}

Le Corbusier's proposal for urban living in the Ville Radieuse promoted living in housing slabs and towers situated in parkland making a continuous green space. Cars have an enormous influence on Le Corbusier's design (Lehmann, 2010, p. 69). The automobile enabled an entirely different, dispersed city model. Le Corbusier's first attempt to produce a contemporary design based on a transportation model was the project called "A Contemporary City of Three Million People", exhibited in Paris in in 1922. It was a harmonious plan, with rectangles containing two crossaxial streets meeting at the city centre, which would house the commercial and civic areas of the region. The city centre would have vertical references with highrise buildings soaring above the traffic ways. The centre was surrounded by a green belt, and beyond could be found the housing of the city's workers in dormitory suburbs (Gold, 2006, p. 104). La Ville Radieuse made an attempt to correct the deficiencies for the City for Three Million People, mainly concerning the inhuman scale of the project and lack of social contact. The design was still based on the idea of high-rise housing blocks, free circulation and abundant green spaces. The blocks of housing were laid out in long lines stepping in and out (Curtis, 1986, p. 118 / 207).

\subsubsection{Broadacre City: Frank Lloyd Wright}

Broadacre City represented Wright's utopia. It was the answer to the longing for agricultural life in the city with a decentralized structure and low density. Its inhabitants would grow food and be self-sufficient. It also totally depended on the private vehicle for transportation (Lehmann, 2010, p. 65).

\subsubsection{Conclusion}

The radical idea of a city essentially made for cars and shaped by zoning was proposed by the Charter of Athens after CIAM-1942 (Congrès International d'Architecture Moderne - International Congress of Modern Architecture). Le Corbusier proposed through the Charter of Athens a radical transformation of the 
city (Lehmann, 2010, p. 70). This idea was tremendously influential on contemporary urban design, although it is hard to see exactly how the process happened. However, ideas from La Ville Radieuse, the idea of zoning, suburban dormitory regions, and highways as the main transportation links are still very present in the urban model today. This has probably happened because the economy has structured itself to use cities and their expansion as an essential part of its system. The influence of the economy on urban design will be explored in chapter 7.

\subsection{General Conclusion}

The largest period of urban history occurred in rural or semi-rural areas. Although civilizations have had some of their most important historical processes in urban areas, the importance of the connection between urban and rural areas is undeniable. The development of a vast majority of urban areas has been dependent on the proximity of the hinterland, and food trade. Therefore, since the foundation of humankind, a great amount of urban knowledge has developed and been accumulated under the basic principle of local food production. This essential principle brings not only regional food production, but also determines the scale and size of cities, forces walkability in the urban environment, saves energy in transportation, indirectly limits the local population and food consumption, connects inhabitants with natural, local characteristics, and gives an understanding of water consumption for food production. Food production ultimately regulates and makes explicit local limits. Due to energy and resource limits, this knowledge is adequate for a scenario of limited population growth. However, environmental certifications today are exclusively based on the modern concept of urban development. All historical knowledge and its capacity for lower environmental impact is ignored by the environmental certification label providers of today. Consequently, this thesis has investigated different historical urban models, in order to create a conceptual framework for the environmental prototype assessment tool. In addition, the thesis explores a selection of the major reasons that have diverted urban knowledge from the older and more environmentally efficient model. 


\section{Monetarization in the Ancient World and the Impact on Urban Design}

\subsection{Introduction}

Economic innovations, especially money, speeded up the process of urbanization, breaking the very complicated and refined supply system that had sustained urban development for many years. In addition, these economic transformations probably changed the perception of cities as limited systems. Economic changes were responsible for modifying the relationship the citizens of that time had with the city, countryside and work. When trade enabled cities to be provided with food from distant regions, far from the city's boundaries, the concept of what made an ideal city was also modified. Consequently, urban design, as it is understood today, has also been significantly influenced by these changes.

\subsection{Monetarization as a Catalyst for the Process of Urbanization}

The problems faced by those living in the various megalopolises around the world today are, relatively, similar to those the Romans faced around 2000 years ago. Today cities still draw migrants with the promise of a better quality of life (Backhouse, 2002, p. 12), which was probably one of the reasons that attracted people from the countryside to ancient urban areas. Additionally, most of the problems pointed out by the UN as being associated with the current high level of urbanization can also be observed in ancient societies (Newmann, 1967, p. 59).

Moreover, one of the most serious problems identified by the UN, food production and distribution, was found in ancient Rome, where food supply was a constant problem. Population growth and urbanization were as much an indelible part of some ancient societies as in the modern world. Economic growth, as then, is seen as an essential tool for alleviating poverty. However, the economic model launched in ancient societies, mainly by the Greeks, Romans and Mesopotamians, which modern society essentially still adopts, is not necessarily suggested as being part of the cause of these problems. 
Some of the social and urban problems faced by ancient societies both occurred and increased because of the imbalance caused by the unbridled economic growth brought about by monetarization. The social and urban changes caused by monetarization were so intense that human society even 3000 years later still feels them. Some historians have seen the development of money as an evolution comparable in importance with the domestication of animals and harnessing and cultivation of land (Backhouse, 2002, p. 12). History has shown that economic and population growth are both associated with deforestation and environmental degradation (Gutkind, 1969, p. 448).

The acceleration of the urbanization process in ancient societies was concomitant with the monetarization of their economies. The complete disruption between rural and urban societies that exists today did not happen in all cities in the ancient world, as some cities, such as Sparta and Corinth, kept the relationship between countryside and town as an essential part of their culture. However, in most places, when the base of the economy was changed, the fragile balance between the urban and rural parts of society also changed.

\subsection{From the Pre-Monetary Stage to the Monetary Economy}

Ancient societies tried to produce their food supply from the land immediately around them, but population growth resulted in the need for more agricultural land. When the limit of what a growing city could supply for itself was reached trade became a necessity for these ancient economies. During the early days of ancient civilizations goods were normally made by local producers. This was because land transport was restricted to what a man or animal could carry for short distances. However, when local production was no longer able to supply a growing urban conglomerate, distant trade became more important. Long distance travel, however, was expensive and inefficient. As the population kept increasing the demand for food entailed trade with farther places. As trade became much more necessary the role of the "central market" within the city was also raised in importance. The way of life of the ancient urban citizen was, thus, modified by 
economic factors. In addition, the city market had to be located in a place where it could be easily reached by as many people as possible.

The first stage of economic evolution was obviously barter or exchange of one thing for another, without the use of anything representing an abstract value of the object. This economic process is non-monetary exchange. Although this commercial relationship was found throughout the ancient world it was awkward. The items offered in mutual exchange had to be mutually acceptable. The natural process to increase the success of such dealing was to find a third item which would be mutually accepted by both trading parties. This is the proto-history of money.

Another practice largely known in the ancient world was to use a useful nonmetallic commodity that was approximately constant in value. One of the most frequent items used in this way was grain, but animals were also used, most frequently by the Greeks and Romans (Backhouse, 2002, p. 12).

Subsequently, non-monetary metal began to be used as a third item that was reciprocally accepted. However, even known and desirable metals required considerable effort for the verification processes, to ensure equity in weight, quality, and purity. To avoid weighing, which needed a system of standardization, and proving the metal, various advances were gradually made. The Greeks of Asia used pre-weighed metals, although this practice was not widespread. More frequent was the use of stamps on metal. The metal ingot would be impressed, using something like a seal, thus avoiding quality verification, but it still needed weighing at the point of exchange.

Coinage eventually emerged as the combination of measurement and stamping. A coin is in fact a piece of metal the composition and weight of which is prestandardized and accepted. Therefore, testing and weighing were unnecessary at the point of exchange.

The appearance of early coins suggested they were probably a private invention. For instance, the earliest Greek coins had the phrase stamped on to them, "I am the badge of Phanes", who was a banker (Lévy, 1967, p. 21). Subsequently, the majority of the ancient Greek cities which started to use coins intervened to ensure 
quality, statutory purity, and weight of metal, thus taking on the monopoly of coinage for themselves. The city made the coinage which was the only legal currency and legal tender, which obliged everyone to accept it as payment at the rate set by the state (Lévy, 1967, p. 21-23).

When the state obliged the population to accept a value, this value-stamp became more important than the commodity bearing it. This meant money had become fiduciary. Its acceptance at this stage was based on public confidence, and in fact it was imposed as a system on the public. This imposition opened the possibility for devaluation, which could be carried out in two ways. The first one was reducing the metal in each coin but stamping the same value on it. Devaluation could also be done by changing the valuable metal for an alloy or other less precious metal. The opportunity for devaluation is probably the main difference between a nonmonetary metal economy and a monetary one. A non-monetary economy is based on an amount of precious metal that could be measured and the availability of that resource limited the value of the monetary system. In contrast, the monetary system was made by using an abstract concept of value, related to a particular coin, and set according to the interest of the state.

\subsection{The Mesopotamian Economy and the Invention of Money}

Mesopotamia, "the land between two rivers" was the name that the Greeks gave to the fertile region between the Rivers Tigris and Euphrates, enclosed by desert. The Mesopotamian cities were highly important for the establishment of the concept of urbanism in the ancient world. Within them was founded an evolutionary process for the development of both the urban centre and urban economics (Lévy, 1967, p. 21). The early stages of these cities had a similar background to what was observed some centuries later in ancient Greece or Rome. The origin of these cities was based on the conglomeration of neighbourhoods, in which the tribal members or blood related social groups shared a territory. Economically, agriculture was one of the most important sectors of the local economy (Lévy, 1967, pp. 07-10). The land outside the "land between two rivers" was still a desert where food production was barely possible. These reasons drove the Mesopotamians to trade 
to supply food to some of their cities, thus creating a trade-reliant class of nonfarmers.

Babylon was a commercial city. A system of weights and measures for grains and metal had been developed there, which boosted local and regional commerce, and for 2000 years Babylon was a famous commercial metropolis (Lévy, 1967, p. 09). The Babylonians formulated commercial contracts, written on clay tablets and stamped with the seals of the contracting partners. These commercial foundations were followed by most people in the ancient world. However, Babylon was still a non-monetary economy.

When the use of money arrived it was probably the biggest impact on these ancient economies and consequently influenced their urban design. Before the metal coin, Egypt and Babylonia used grain as a non-metallic commodity, perhaps up to the fourth millennium BC (Lévy, 1967, p. 16). Afterwards, they used metals with all the problems of verification discussed above. However, the advent of these metal trading commodities made it possible to invest in long-distance food trading (Lévy, 1967, p. 21).

Obviously, food from local production was much cheaper than food coming from long-distance trade. Nevertheless, the existence of trade meant that local production was no longer essential to feed the city. Good deals, conquests, or simply existing merchants could keep the city provided with food or anything else required. In addition, as the cities grew faster than local agricultural production (Glotz, 1926, p. 61) inter-regional trading became essential.

The invention of money in the form it is used today probably occurred around 700 B.C, although this date is controversial. Although money probably first occurred in the Ionian towns (Lévy, 1967, p. 19), its use spread rapidly in the Hellenic world. Athens had its own coinage around 600 B.C. This new system and prestandardization of exchange probably gave to the ancient economy a growth never seen before and that was rarely seen afterwards. Around the 6th century BC, the Lydians, called "the Phoenicians of the Land", established a fixed ratio between silver and gold. Historically speaking, the gold silver ratio had been between 15 and 10 to 1 (Morgan, 1965, p. 15; Lévy, 1967, p. 20,25; Glotz, 1926, p. 325), 
reflecting the average supply of each metal. As stated above, coinage, in which a piece of metal received a stamped value, had been created to ease trade, and although it was a monetary abstraction, it reflected the availability of one specific resource. This metal resource was not essential like grains or water, but it enabled cities to supply themselves with these essentials. The ratio between metals differed according to the stock held or the ability to mine for metal. Coins of pure gold and silver were also struck. Babylon, which kept a non-monetary system, did not develop the use of coins before the Persian conquest in 539 BC (Chachi, 2005, p. 08). In the Persian Empire, there were also gold and silver coins, both with the image of the king. The Persians kept the same ratio set by the Lydians. Although this gold coinage gave great prestige to the emperor Darius, it was designed and restricted in use for external dealings, especially those with the Greeks.

The impact of the development of money on a local economy was unique. The ancient world already knew about long-distance trading. Mesopotamia was on one of the major routes of antiquity. Although traders were known in Mesopotamia, money increased the participation of these professionals in society. Originally the traders were also producers but with money they became exclusively merchants and were generally great travellers. Money also contributed greatly to the Mesopotamian economy because it facilitated tax collection. This phase in history saw great civil engineering projects as a consequence, such as making and maintaining the canal between the Nile and the Red Sea, and constructing the great “Royal Road" which led toward Greece (Lévy, 1967, p. 22).

\subsection{The Development of the Ancient Mediterranean Monetary Economy}

\subsubsection{Monetarization in Greece and the Agrarian Dilemma}

While the use of money spread all over the near east, Greece struggled with a philosophical dilemma. The historical economic Greek background was built on the household and agriculture. Although the economy and society had been based on slavery, slaves and owners would work alongside each other. Homer saw prosperity as result of a well ordered and wealthy household, although Greek 
society was also suspicion of excessive wealth. There were local craftsmen and traders but they were less important than those working the landed estates (Backhouse, 2002, p. 12). This was the economic background of the philosophers Xenophon (430-354 BC) and Plato (429-347 BC) (Backhouse, 2002, p. 14). This social and economic structure, based on agriculture, was an indelible part of Greek thought. With the two exceptions of Athens and Sparta (though even Sparta and Athens had deep differences, which were clearly exposed when Athens focused its economy on the market with large scale production and trade while Sparta kept small and mainly agrarian), the cities in Greece were small and most were just villages interlinked under a local power. This meant that several tribes or clans had formed a confederacy and their originally more-or-less discrete and selfsufficient units had gradually grown together but without losing too much of their identity. The Polis, as these groupings were called, was clearly a set of connections between tribes and cities, creating a relationship where each party was provided with some quality of life. Religious reasons, leisure, and protection against invaders were all motives for people to be gathered into cities. Greek urban design, with the limited physical size of cities and the ability of the citizens to walk between settlement and countryside, clearly reflected Greek thought and the agrarian culture of those ancient times.

For the Greeks, the Agora, the gathering place of the citizens, was also in many cases the market square. The market, or place where local producers or merchants could exchange goods, was an evolution of the economy. The first phase of Greek urban development was the self-sufficient city arrangement with no surplus. The people conveniently gathered in communities because of local trade and protection. Sometimes, in accordance with Aristotle`s ideas ${ }^{3}$, movement of people from the countryside to the city was prevented. This happened in Corinth about 600B.C. where the country people were forbidden to leave their land because this would risk the production of adequate food and cause an imbalance in the town

\footnotetext{
${ }^{3}$ Aristotle (384 - 322 BC) was the son of a physician and a student of Plato, by whom he was greatly influenced. Aristotle believed that the ideal city had to be self-sufficient. He though that exchange of goods should be enough to keep the city in balance. He believed that commerce should be of minor importance for the Polis. If cities grew indiscriminately commerce and trade would probably become much more important. What disturbed Aristotle about commerce was that it offered the prospect of an unlimited accumulation of wealth. The thinking of Aristotle on this point could be summarized by the statement: "Evil is a form of unlimited and good of the limited" (Gutkind, 1969, p. 443). There is no reason to not believe that this thought was also not directed at city size, and population.
} 
around water, lack of food, and public services. As mentioned earlier, families were deliberately kept small by abortion, and sometimes infanticide (Gutkind, 1969, p. 476).

In ancient Greece the rural and urban settlements of a region were interdependent. Land availability and the way in which the rural population was distributed and villages were built were all extremely important to the Polis. As some Greek cities developed and grew, the rural villages and some small Polis preserved the original idea behind the development of the Polis, in other words its origination in a union of families, agrarian thought and self-sufficiency.

Ancient Greece was not an urban society, and hence neither were its colonies. The Greeks tried to reproduce the same format for their new towns. Furthermore, the colonies were essentially raw suppliers because the homeland could no longer offer these resources to its citizens.

By the beginning of the 5th century the Polis had reached a final and classical form when the Agora gained its final complexity. However, the growth of the Polis and the Agora brought new issues, such as poverty and hunger, for which answers had to be found.

The Greek ancient communities were originally self-contained and self-sufficient but this changed with the introduction of metal tools produced locally or supplied through trade, as these led to greater efficiency and a certain division of labour. In the process of this development the self-sufficiency of the villages slowly disappeared. It was replaced by an inter-community exchange conducted by the chiefs, and the artisans spread over a wider area.

As a result of these developments Greek life style underwent deep changes. Although the economy was still based on agriculture, as in Homer's days (8th century BC), a tradition kept since the dark ages of Greece, there were enormous economic changes. In Athens Solon (594 B.C.) (Backhouse, 2002, p. 12/21) introduced the idea of a civil head of state, indirectly restricting the power of the aristocracy, and creating the basis for democracy. In addition, land was redistributed and laws were codified. However, when silver currency was established in Athens change happened faster. The merchant fleet was enlarged, 
and there was an expansion of trading. Specialized agriculture developed and Athens became an oil exporter in return for grain. As a result, "The old ideal of selfsufficiency began to break down" (Backhouse, 2002, p. 14). This period, with great prosperity, was known as the Age of Pericles. During this period, trade flourished and agriculture became even more commercial along with many related activities such as banking, credit, money-changing, commodity speculation and monopoly trading. However the monetary changes resulted in prosperity, which modified the city through a number of great buildings projects, such as the new Parthenon.

Xenophon's work Oikonomikos was the origin of the words economy and economist - oikos being the Greek word for household. In fact Oikonomikos is a dissertation about managing an agricultural estate (Backhouse, 2002, p. 16). Natural resources needed to be properly managed to get the most out of them. Even when trade largely overcame the need for local agriculture in Athens, Xenophon kept his view of the need for an economy based on agriculture. He believed productive efficiency was the result of a good relationship between men, nature and agriculture. In his ideal model men interact with nature, not with each other through markets. Plato also agreed with this view. He saw a role for trade and the market, but in his ideal state they were both controlled. He accepted that products could be bought and sold, but profit and interest were condemned. For Plato land had properties which meant it had to be allocated on mathematical principles. He claimed that the optimum number of households in a city was 5040 (Backhouse, 2002, pp. 18-19 and Gutkind, 1969, p. 496). Greek history was consistent with Plato's theory as most cities were relatively small because there was this very strong link between availability of resources and the size of the city. When the population rose, the city had to organize itself to found a colony. In theory, this "new city" would become independent from the original starting point, and the Greek way of life would be preserved.

Athens, however, went in a different direction. Trade expanded and helped to build the greatness of Athens, even though the general feeling was traditionalist and distrustful of what was happening (Lévy, 1967, p. 23). There was a contrast between the chrematistic approach founded on money and the universal feeling for what was right based on agriculture. However, this was not enough to hinder 
the Athenians from participating in commercial enterprises, although the relationship with agriculture and self-sufficiency was probably the reason that food exportation was forbidden in Athens (Glotz, 1926, p. 257). Athens, as a regional metropolis, which progressively lost its relationship with the traditional system based on limits, imported more than it exported. The deficit in its trade balance was offset in part with silver, which was already recognized as "international" money. The main exported products from Athens in that period were wine and olives and the agricultural area around the city was taken over by these products. Although wine and oil sold well, wheat was not always available and the chance of famine was always present, provoking unrest. Evidence suggests that when Athens assumed a trade deficit, and compensated for it with silver, they entered into an irreversible process of decline (Lévy, 1967, p. 29/31). When the main trading product in Athens was renewable, although the system partially depended on trade it was still possible to keep the city reasonably supplied with basic commodities. When a non -renewable product became the means of equalizing the system, Athens faced an entirely new problem.

Even with the enormous economic expansion social problems tended to increase in Greece, as the new wealth was not universally beneficial. The financial system, the basis of the Athenian economy, was no longer able to maintain the city in balance. The country producers were not able to adapt themselves to these economic changes which increased their servitude and poverty. In contrast the various Polis never lost their character as a dense agricultural village although they had many "industrial" activities. The vast majority of the population were farmers who maintained contact with the countryside, rather than consumers, shopkeepers or craftsmen.

In fact agrarian poverty spread all over the countryside around the city of Athens (Lévy, 1967, pp. 29-32,39). The economic changes benefited the big landowners. The small producers emigrated or became mercenaries in foreign armies. The Peloponnesian War also contributed to the decline of Athens and depopulation ensued. During the Age of Pericles Athens had over 41,000 citizens, but by 315 BC the population was no more than 21,000 (Lévy, 1967, p. 31). The Athenian crisis was also provoked by interest-loan debts. The farmer who had borrowed money 
now had to repay in coin rather than by means of commodities, the traditional method. This unstable situation led to the decline of ancient Greece in face of the rise of Rome.

\subsubsection{Monetarization in the Roman Empire and the Urban Character of Ancient Rome}

Rome grew from pastoral settlements around the Palatine Hill (located beside the current Roman Forum ruins). The Republic of Rome was instituted in 509 BC when the Etruscans were expelled from the city. Rome had enjoyed some prosperity under the management of the Etruscan Kings but its real prosperity was to come with a change in its economic system and the rise of urbanisation.

While Greece had developed an agrarian philosophy through Aristotle, Plato and Xenophon, Rome increased its role in the Mediterranean world through expansionist thinking. Rome thrived in a world strongly based on international trade and money and unlike the economies of other ancient societies, which mostly had an agricultural tradition with some part of their development in a nonmonetary world, Rome flourished in a world highly dependent on a monetary economy. Roman expansion also helped to spread coinage. The growth of the Roman Empire was responsible for the money used during the five centuries from 200 B.C. to A.D. 300. (Harl, 1996, p. 1).

The people of what is now Italy used iron spits or cast bars of bronze during the early Iron Age (ca. 900 - 500BC) (Harl, 1996, p. 21). Later people from western Magna-Graecia introduced coinage expertise into this Italian territory, adapting the monetary system, which in Athens was already sophisticated, to local needs. Greek settlers in the south of Italy struck silver coins. The inhabitants of Magna Graecia (the Greek colonies in Italy) received silver in exchange for grain, timber, slaves and others products. The coinage in Italy during the Iron Age was basically an expansion from the Greek model. The cities of Magna-Graecia were also the last consumers in a chain from the North Aegean and Attica to Sicily and, afterwards to the whole of Italy. 
During the Age of Pericles, Athens experienced an imperial expansion. The Athenians were the first to forge fiscal institutions that forced the use of coins throughout the economy, including the colonies. Although Magna Graecia was the last part of this chain, Athenian monetarization was felt and repeated in the cities of Greek, Italy and Sicily, at the opening of the next century, offering a convenient monetary model for Rome. This new model allowed the Romans to move regular citizens to become mercenaries in the army during the century forth $\mathrm{BC}$, and these mercenaries were fundamental to the campaign against the Carthaginians. When the Romans emerged as the dominant power in the vast area of the Italian territory, including Magna-Graecia, they encountered fine silver Greek coins, and discovered the convenience of meeting large-scale payments with these. The scarcity of silver and gold during the first Punic War (264 BC - 241BC) caused the production of bronze coins to increase dramatically. Rome had to pay their citizens serving in the army, and silver coins, with their high value did not serve daily demands. Lesser coins were urgently needed so the colonizers turned to bronze as a coinage metal. The diffusion of bronze currency vastly extended the range of daily transactions and was a major step in the monetarization of all Italy (Harl, 1996, p. 24).

Rome, after victory in the first Punic War, became an imperial power. This new role was to change the Roman economy and society. The process was similar to the one Athens had passed through during the fifth century. However, Rome's financial institutions were not adequate for the task. The victories against Carthage were responsible for providing resources for indemnifying the Roman coinage and the fundamental monetarization of the Roman economy (Harl, 1996, p. 35). Rome had an unprecedented growth as a result, and roads, cities and other major public services were built on an extraordinary scale.

In 323 B.C, when Alexander the Great died the Republic of Rome controlled a small area in the west of current Italy. During the following three centuries Rome grew into a vast empire covering North Africa and most of Europe. In 14 AD, when Augustus died (Backhouse, 2002, p. 12), the Roman Empire stretched from Spain to Syria and from the hinterlands of Egypt to the Rhineland. However, the cultural and social centre of the empire remained in the east around the Hellenized cities, 
such as Antioch and Alexandria, in which the Greeks kept making progress in sciences and philosophy. In contrast, the west remained largely rural.

The Roman constitution linked political power to the ownership of land (Backhouse, 2002, p. 25). War and conquest therefore played an important role for the Empire and were a major source of wealth. When money allowed Rome to have professional soldiers, and conquest became the major route to wealth the relationships between town, countryside, production, local trade, and the local environment were definitely broken. The balance between town and countryside although fragile, which had largely existed in ancient Greece was no longer essential in Rome. As a result, the Roman citizen became a consumer without the responsibility of production.

Agricultural production was still based on subsistence, with small properties and a wide range of products (meat, grains, and milk), when the city of Rome spread the concept of urbanization all over the new lands it had subjugated. Even imports of grain in no way decreased the importance of agriculture. Roman urban life and the relationship between town and hinterland were tremendously influenced by the monetary economy. The Roman Empire flourished at a time when great achievements were funded by money. Some intrinsic characteristics of a monetary market appeared in Rome such as urban speculation, and high economic rents in the towns and regions around them. 


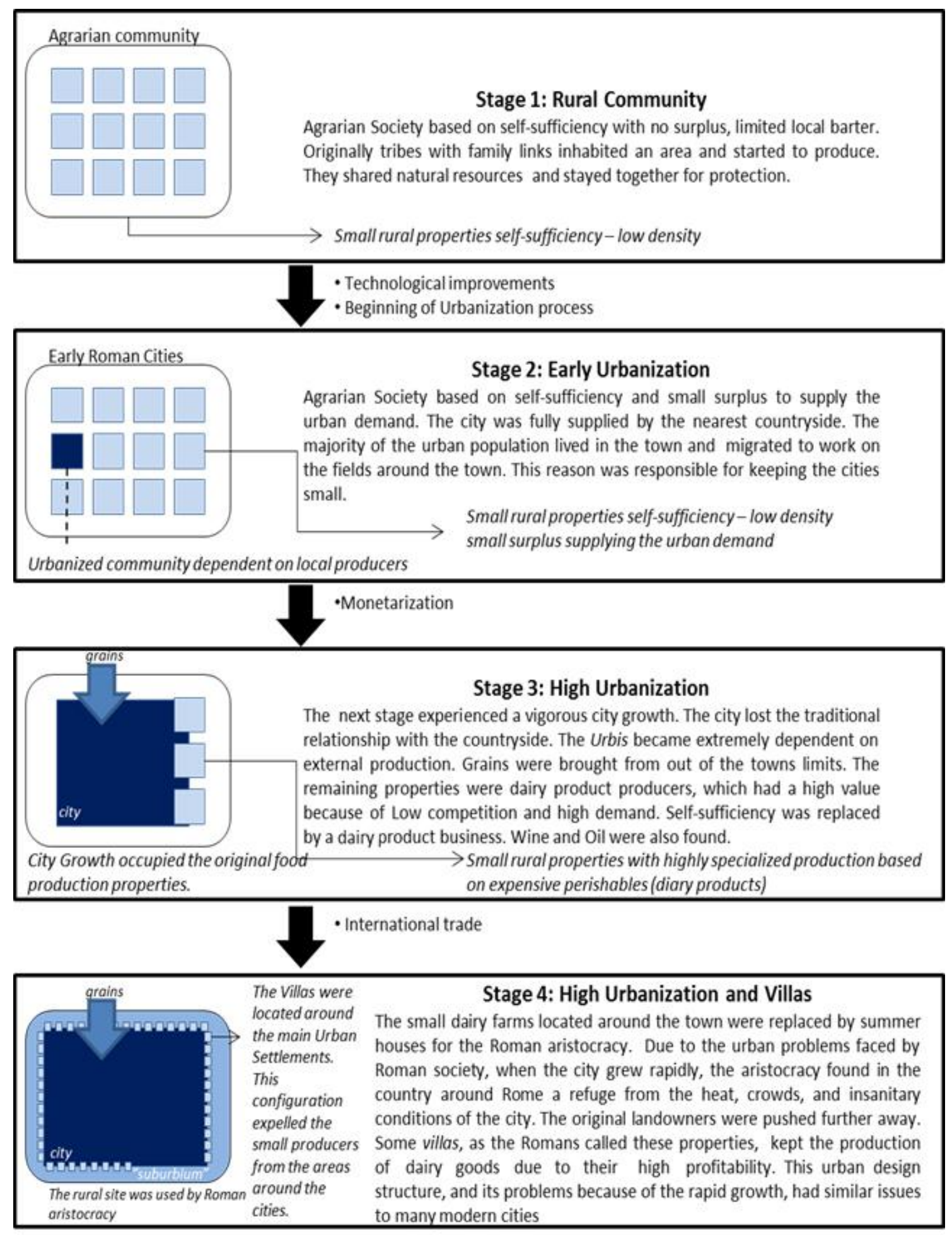

Figure 10 - Simplified model of urban development in ancient Rome 
Due to these factors the food producer located close to the town was forced to have a highly specialized production based on expensive perishables, such as fruit, certain vegetables and dairy products. Self-sufficiency farming and grain production for the local market were no long financially viable due to foreign competition. Local dairy goods production became a profitable business. However, the expansion of this specialized production into the Roman Empire was a complex process. First of all, the creation of market-oriented production involved significant competition, mainly for land, but also for other essential resources. The incipient wealthy land-owning people could respond to the demands of the town. Indeed the resulting increase in prosperity can be seen in the rapid development of the immediate hinterland.

The area immediately out of town was called suburbium. It was a refugee from the heat, crowds, and insanitary conditions of the city. It was a place for leisure. From the second century B.C. the Roman elite built luxurious villas around the towns. The suburban villa filled a very urban need for a temporary refuge, although life was still totally linked with the town. The small producers could not be found in the land around the towns anymore. They were pushed further afield, and although they benefited from the good roads in the Roman Empire, they were out of the centre of Roman life. This situation suggests that the ancient cities of the Roman Empire had a similar structure to many modern cities. The cities had a desirable suburban area while the downtown was a concentration of a working middle-class (in Rome made up by workers) and the furthest districts were where the smallest producers lived.

The countryside was progressively urbanized around the Rome. The constant presence of the Roman elite in these areas also formed a secondary market. The suburban area was originally made up from food producers but the prosperity also brought the urban wealthy class to the countryside, and this was another factor in the expulsion of the former landowners. Some new owners, who had come from the centre of urban Rome, chose to make their suburban villas productive places, mainly for dairy products, although others just kept their villas for relaxation (Harl, 1996, p. 94). 
The demand for new land made the nearest countryside more valuable. Land became extremely expensive, and only the very rich could afford an unproductive property. The hinterland was occupied by a variety of properties each heavily dependent on the presence of the city. Although in other ancient civilizations the country and city were linked, in Rome this dependence was not balanced. Rome grew much faster than the level of food production in the local hinterland level. At that time, the Roman suburb became a place to live rather than the site of food production for the city. The Roman Empire structured itself through long distance trade and military conquest.

The concept of urbis and the demands this entailed were also disseminated to new places. The ancient world before dominated by self-sufficiency and isolated exchange started to experience a very different economic structure.

Every problem which Rome had to cope with for almost a thousand years was taken into account when a new city was established. Those involved analysed the natural resources available and tried to improve the urban design by avoiding the problems faced in Rome in other urban developments. For instance, Rome grew to the point where it relied on Egypt for its supplies of grain, and this could not be repeated throughout the Empire (Lévy, 1967, p. 76; and Weber, 1966, p. 209).

A very sophisticated road system and the monetary economy also boosted Roman industry. Goods produced by local industries and were widely distributed throughout the Empire. The East, for instance, particularly Asia Minor and Phoenicia, remained famous for the production of fine dyed clothes and carpets, found all over the Roman Empire. This process allowed the free movement of money, an important factor for consolidating international monetarization.

Besides commerce, industry and agriculture, which are directly responsible for production, Rome, as in Athens, had bankers and private money-lenders as an important branch of business life. Credit and credit operations were fully developed and spread to the cities of Empire. The bank culture was exported from Greece and the banks of Italy and the Western provinces were managed mostly by men of Greek origin (Rostovtzeff M. , 1976, p. 170). This banking system and the 
movement towards the suburbs around Rome, expelling former farmers, could possibly be viewed as an ancient version of real estate speculation.

\subsection{Conclusion}

Today the urban man is a man who does not supply his own food needs. This is in contrast with the majority of ancient cities. The full urbanite was a semi-peasant in the ancient world (Weber, 1966, p. 71), and agriculture had an enormous role in the ancient economies. The agrarian economy was responsible for 90 per cent (or more) of the market (Morley, 1996, p. 13). Due to the transportation conditions the majority of inland cities were dependent on the agricultural resources of the immediate countryside (Weber, 1966, p. 73). This scenario was understood by the Greeks, as they considered agriculture the source of all civilization (Glotz, 1926, p. 38). The Greeks understood the importance of agriculture and local production, and the whole ancient world was ruled by self-sufficiency and limited exchange. While the pre-monetary period remained, exchanges were something over which the producer had control. Such exchange was essentially made to provide a solution to immediate needs (Backhouse, 2002, pp. 27-28).

The invention of money probably caused the biggest impact on this ancient agrarian world. However, there were many factors before which produced economic change. The facts suggest that money was invented to help commerce through trade. Trade generally begins when there is a surplus. In ancient Greece, the earliest communities were self-contained and self-sufficient. This changes when metal tools, leading to greater efficiency in all sectors of society, were introduced by local or itinerant smiths. The consequence was a certain division of labour. Subsequently, a specialist class grew up including those who were not engaged with agriculture that had to be supplied with food. Technology improved agricultural productivity and the set-up was ready for internal trade. Rural production had reached a sufficient stage of development where a surplus of agricultural commodities could be produced (Gutkind, 1969, p. 467).

City dwellers progressively became more specialized in a particular field of work. According to Xenophon, a product is better made in big cities than small villages 
(Backhouse, 2002, p. 17; Glotz, 1926, p. 223). He believed that in small villas a workman had to make a bed, a door, and often he also had to build his own house, while in a big town, the workman could improve his skill in a single task, and because of a large population and demand he could live by his efforts, trading his skills for food and other goods. Even though labour in the cities was getting more specialized and divided, cities remained eminently agrarian. For this reason Greece had to keep its cities small because some of its citizens were agrarian producers and they had to go to the countryside to work.

The process of identifying the real influence of a developing economy on urban design is enormously affected by the lack of economic data for this period. The analyses here are solely based on political history (Backhouse, 2002, p. 14). Although there was no market economy, commercial activities developed quickly becoming prominent and providing a significant challenge to the existing way of life. Ancient Greek thinkers, such as Plato and Aristotle, were suspicious about the role of commerce in Greek society. Themes like morality and justice were considered by them and linked to economic change. Plato was declared an enemy of trade. He considered traders as agents who interrupted the regular and measured distribution of prosperity produced by nature (Glotz, 1926, p. 288). However, Plato saw a minor importance for money and trade in his ideal state (Backhouse, 2002, p. 18/19). His view of the state fits with the reality of the majority of ancient Greek cities, being small and self-sufficient with a minor trade function. In the early periods the agricultural producer could go to the consumer without any intermediary. The market-gardener came to the centre of town with his fruit and his vegetables. Agriculture as a cultural activity progressively lost importance because of commercialism and trade. When the cities grew the population demanded products and it was necessary to collect these from distant markets where they were abundant. The collection and distribution speeded up the trade process. The original concept was replaced by an inter-community exchange conducted by the chiefs and the artisans, spread over a wide area.

The fine balance between country and city was under pressure and eventually broke down when barter was replaced by a money economy. Trade, basically of grain, had an indirect influence on the rise of the cities as it made the city more or 
less independent of local supplies. The relationship between country and town changed steadily as the economic structure of the city began to be detached from the village economy. With a high rate of non-producers in a town, the problem of feeding the people was at all times the gravest with which the magistrates of a city were faced (Louis, 1965, p. 157).

Cities such as Athens and Rome, for different reasons and historical accident became commercial cities, with a complex economy. Athens was not surpassed until post-Renaissance Europe. Athens during the period between the Persian War and Peloponnesian War had around fifty years of peace and in this time trade flourished, and it became a commercial city around a thousand year later (Backhouse, 2002, p. 21). The increasing scale of ancient Greek society probably went together with the spread of market exchange, especially in Athens. When the population was not high in the Attica peninsula the region was almost selfsufficient in cereals, but as an agglomeration of consumers who were not producers grew up the situation became chaotic.

Athens and Rome were not able to provide local food, mainly grains, for their populations (Weber, 1966, p. 208). This need for foreign products suggests that both cities developed their urban design with no concern for local food production. Athens and Rome were dependent on foreign grain, even though Athens, unlike Rome, kept its agricultural background in view. The ancient city had an urban design policy based on the needs of city consumption (Weber, 1966, p. 71). Attica in 323 B.C. could support between 60,000 and 70,000 residents only, or between 23 per cent and 27 per cent of the total population of ancient Greece (Jardé and Gomme in Peter, 1998, p. 183).

In Athens, the surrounding countryside and the central city grew together into a State. Even so, the ruling class inside the urban communities, the nobles and aristocratic land owners, never lost their dislike of cities and kept their rural spirit. This attitude was strongly alive in Sparta. Aristotle identified the defensive system of the acropolis, as in Athens, with monarchy or oligarchy, while Sparta, which never protected itself with walls but saw the whole city as being a fortified city, was related by him with democracy. Sparta is the best representative city of the 
Greek State (Gutkind, 1969, p. 487 / 506). Its economy was based on agriculture and its army (Backhouse, 2002, p. 15).

Rome developed its empire during the monetary period. Historically speaking, even though Rome had a connection with the countryside, it was probably the first city in which the relationship between the countryside and town was not essential for its creation. A great number of Roman inhabitants did not have a rural background. This can be better explained by the fact that Roman expansion was based on money. The process of devaluation, giving an abstract value for money, unrelated with real resource availability, was a sophistication of the monetarization process that allowed this to happen.

The use of money and its evolution indicated that the idea of limit and system was erased in real life, remaining alive only for thinkers and philosophers. When metal or grain were used in barter, at least both parties involved in the deal had to produce (or extract) a product. There was, therefore, a real exchange of resources. When cities such as Rome and Athens had to buy food, using money, pressure was put on the authorities, which directed efforts into conquests and military expansion. In Rome, any change could cause an increase in stress and internal tensions. For this reason, military expansion and the conquest of new lands through wars was essential to provide food and basic resources. This military need spread all over the Roman Republic and Empire, taking the concept of urbanization all over North Africa and the Middle-east.

The notion of limit was understood by the Greeks and was observed when they had to establish a new colony. The colony was designed and could be understood as a limited Polis in size and numbers, making it a self-contained unity, which had to keep its initial structure for stable equilibrium. The number of inhabitants was fixed in relation to the available food supply, meaning the city could grow, but only within these limitations. If the population increased a new colony had to be founded. Drinkable and sufficient water, fertile soil, and timber were the essential resources for a new colony (Gutkind, 1969, p. 482).

Although only Athens in ancient Greece had commercial characteristics, its legacy remained. Modern comprehension of what a city is still relates to Athens and 
Rome. Definitions such as "A town is a settlement of men who rely for their maintenance on the products of foreign (or alien) agricultural labour" (Werner 1902 in Hamilton, 1991), or "the city is a settlement the inhabitants of which live primarily off trade and commerce rather than agriculture" (Weber, 1966, p. 66) illustrate this. These concepts of a city would not fit with the ancient Greek understanding of urbis as revealed by thinkers such as Aristotle, Plato and Xenophon. Money consolidated the implicit concept that an urban citizen was a consumer of food instead a producer. These various events are summarized in Figure 11 below. Moreover, money has enabled this process to continue unabated, leading to some of the environmental and resource shortage problems currently facing humanity.

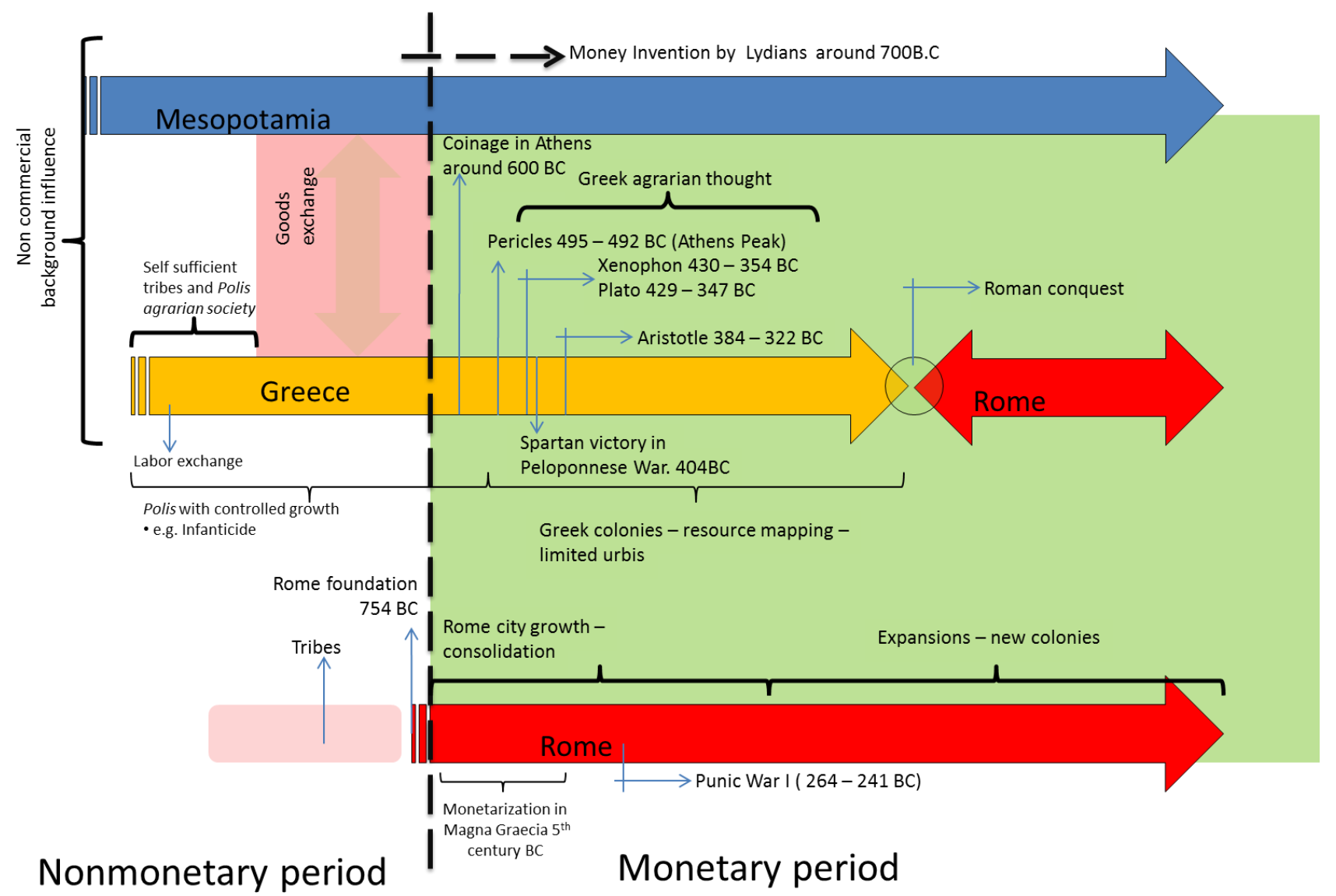

Figure 11 - Timeline representing the development of Mesopotamia, ancient Greece and Rome relating to historical economic milestones 


\section{Modern Urbanization}

\subsection{Introduction}

Cities are a great example of contradictions. On one hand cities are the centre for finance, industry, commerce and communication. The cultural diversity and the ideas provided by the great number of people gathered together have generated a highly productive, creative and innovative space. On the other hand, cities are also a perfect scenario for poverty, exclusion, social discrimination and violence.

The concept of urban sustainability cannot be understood only by the environmental quality of the space for its population or the re-design of that space (Birkeland, 2008, p. 97 and 114). Urban sustainability revolves around economics, and the political and cultural dimensions, as much as the environmental aspects.

As modern society, for the first time in human history, is mainly urban (United Nations, 2011), the progressive phenomenon of urbanization has to be taken as part of present society. However, even though urbanization has been spread all over the world, once the political, cultural and environmental issues are included the problem of the environmental impact of cities has to be considered locally:

“...it is more efficient to treat a problem from the local level, either in terms of effects and/or in terms of participants and authorities, than to start with the same problem at the global level, where frequently the authorities are not present, so there are greater interdependencies between different participants, and there is also a larger uncertainty on the core of the phenomena and the causal chain."

(Camagni 1999 in Munier, 2007, p. 91)

A brief history of urban development and the transformation of the relationship between cities and countryside was presented in the previous chapter. This chapter deals with the present moment of history in which human society is predominantly urbanized. The concepts taken and structured for analysis deliberately exclude discussion of the principles of anti-urbanism. This anti-urban tradition has been built up from the ideas of the socialist utopia, developed 
through the deliberate rejection of the industrialised city. Some authors such as William Morris (1834-1896), A.W. Pugin (1812-1852), John Ruskin (1819-1900) and authors from the Chicago School are traditionally identified with these antiurban principles (Morris, 1890; Pugin, 1836; Ruskin, 1849; Wright, 1932).

However, even though some authors have continued to support the anti-urban theory (Todd, 1984, Vale \& Vale, 1975), the urban population overcame the rural population in 2008 (United Nations, 2011). The numerical gap between rural and urban populations is predicted to increase until 2050 according to the forecasts of the United Nations. The definitions for rural and urban populations as used by the United Nations for their calculation of current levels of urbanisation were taken from national definitions of city and urban area, and this has probably caused some discrepancies. In New Zealand, for example, very small settlements are called cities, as discussed below.

\subsection{Defining the Modern Concept of Rural and Urban}

In New Zealand, the definitions of urban and rural areas according to New Zealand Statistics are divided into (New Zealand Government, 2010):

- Main Urban Areas,

- Satellite Urban Areas

- Independent Urban Areas

- Rural Areas with High Urban Influence

- Rural Areas with Moderate Urban Influence

- Rural Areas with Low Urban Influence

- Highly Rural / Remote Areas

What each of these categories means in terms of size of settlement is briefly explained below to show what might be included in the United Nation's statistics on global urbanisation. The concept of urban and rural are not a consensus, therefore, the New Zealander definition will be used in this thesis. 


\subsubsection{Main Urban Areas}

This is the same as the standard 2001 definition for main urban centres and includes the following places: Whangarei, Auckland, Hamilton, New Plymouth, Palmerston North, Wellington, Nelson, Christchurch, Tauranga, Dunedin and Invercargill. Only five of these main urban areas have a population over 100,000 (Auckland, Hamilton, Tauranga, Wellington, Christchurch and Dunedin). These are very small cities in global terms.

\subsubsection{Satellite Urban Areas}

This category identifies towns and settlements with strong links to main urban centres. This connection is through employment location. Satellite urban communities are defined as urban areas (other than main urban areas) where 20 per cent or more of the people usually resident in the satellite area are employed in a main urban area.

\subsubsection{Independent Urban Community}

This category identifies towns and settlements without significant dependence on main urban centres. Again, employment location is the defining variable. Independent urban communities are urban areas (other than main urban areas) where less than 20 per cent of the usual residents are employed in a main urban area.

\subsubsection{Rural Area with High Urban Influence}

This category identifies rural areas that form a transition between the main urban areas and rural areas, although the meshblocks involved (a meshblock is a unit for counting population) are not necessarily contiguous with main urban centres. The index allows for inclusion of a meshblock in this category only if a significant proportion of the resident population work in a main urban area. 


\subsubsection{Rural Area with Moderate Urban Influence}

This category identifies rural areas with a significant, but not exclusively, main urban area influence. A meshblock can be included in this category if a large percentage of the resident employed population works in a minor or secondary urban area, or if a significant percentage work in a main urban area. However, if the percentage working in a main urban area is too substantial, the meshblock will be included in the high urban influence category.

\subsubsection{Rural Area with Low Urban Influence}

This category identifies rural areas with a strong rural focus. The majority of the population in these areas works in a rural area. It is unlikely meshblocks in this category will have many people employed in a main urban area, although a number may work in a minor urban area.

\subsubsection{Highly Rural/Remote Area}

These are rural areas where there is minimal dependence on urban areas in terms of employment, or where there is a very small employed population.

What this New Zealand example shows is that how a country defines an urban population will have an influence on the UN calculation of global urban populations. More importantly, however, the New Zealand example shows that urban population is defined not by location, density or size of centre but by where a person is employed. Where the majority of people work in an urban centre this is considered to be an urbanized population. What global urbanisation means in these terms is that a majority of people in the world now rely on the city as a source of income, rather than on rural work, whether this is in farming or support services for farming. 


\subsection{Global Urbanisation}

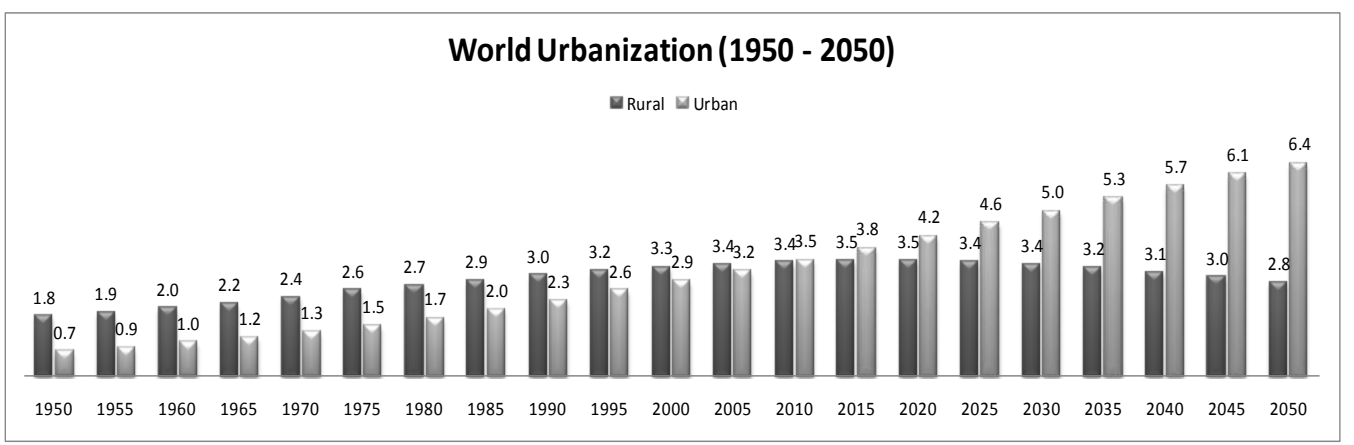

Figure 12 - Urban and rural populations from 1950 and 2050 in billions (United Nations, 2011)

According to figure 12, in 2050 approximately 69.6 per cent of the world's population will be concentrated in urban centres. The rural population will represent 30.4 per cent of total in 2050. Despite the anti-urban theories Figure 12 shows the world has consistently become more urbanized since 1950.

In the least developed countries, however, the population still remains predominately rural, and it will continue to be rural until approximately 2040, when the urban population finally overcomes the rural (Figure 13).

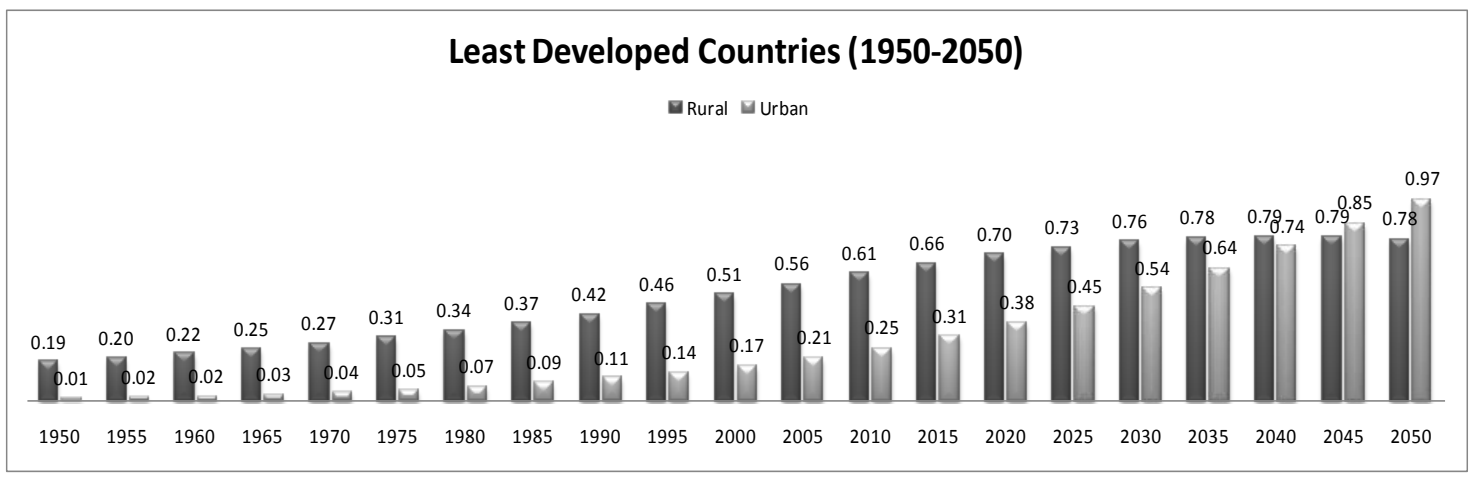

Figure 13 - Urban and rural populations from 1950 and 2050 in billions in the least developed countries. "The group of least developed countries, as defined by the United Nations General Assembly in 2003, comprises 50 countries, of which 34 are in Africa, 10 in Asia, 1 in Latin America and the Caribbean, and 5 in Oceania. The group includes 50 countries - Afghanistan, Angola, Bangladesh, Benin, Bhutan, Burkina Faso, Burundi, Cambodia, Cape Verde, Central African Republic, Chad, Comoros, Democratic Republic of the Congo, Djibouti, Equatorial Guinea, Eritrea, Ethiopia, Gambia, Guinea, Guinea-Bissau, Haiti, Kiribati, Lao People's Democratic Republic, Lesotho, Liberia, Madagascar, Malawi, Maldives, Mali, Mauritania, Mozambique, Myanmar, Nepal, Niger, Rwanda, Samoa, Sao Tome and Principe, Senegal, Sierra Leone, Solomon Islands, Somalia, Sudan, Timor-Leste, Togo, Tuvalu, Uganda, United Republic of Tanzania, Vanuatu, Yemen and Zambia. These countries are also included in the less developed regions." (United Nations, 2011) 
On the other hand, the countries included in the group called "More Developed Countries" have an urban population which rose above the rural population before 1950 (when the United Nations data first became available) (Figure 14).

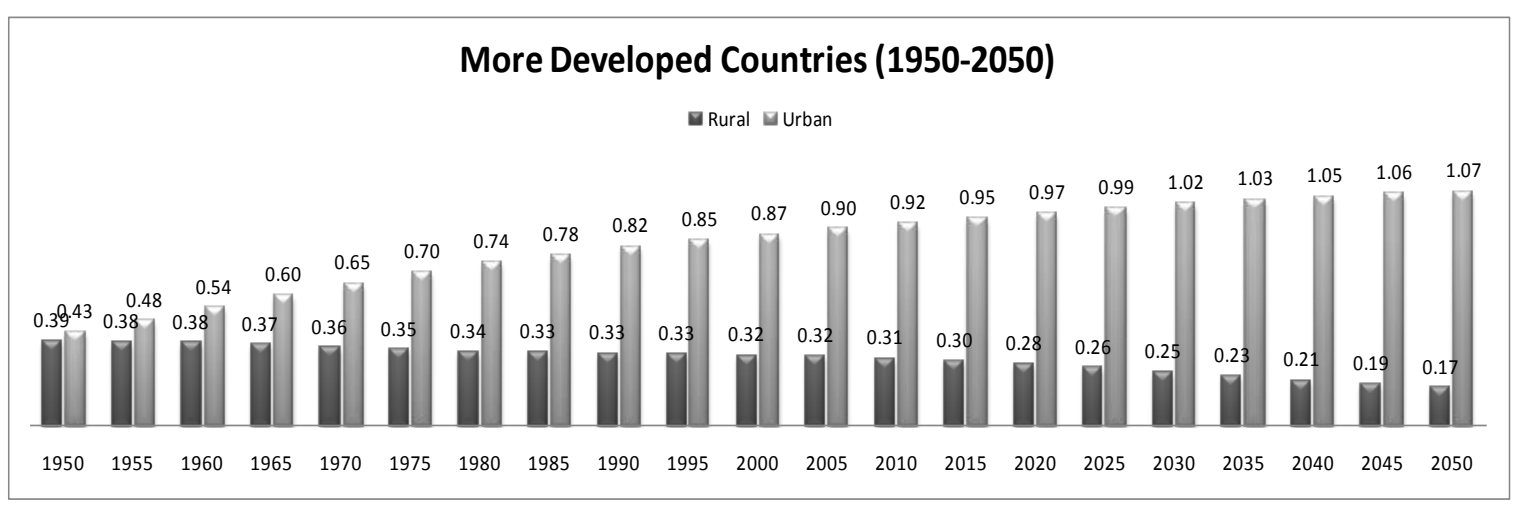

Figure 14 - Urban and rural population from 1950 and 2050 in billions in the more developed countries which comprise all regions of Europe plus Northern America, Australia/New Zealand and Japan (United Nations, 2011)

The graph also shows that the total population in the "More Developed Countries" has virtually kept stable with only a slight but steady decrease from 2020 onwards. The graphs above indicate that urban centres in developed countries have increased in terms of population faster than in other countries. The urban centres in developed countries were essentially already industrialized when the UN started to collect their urban statistics. Although the greater urban conglomerates have also diversified their economies, progressively moving to a service economy, the same cities have dramatically increased in physical size and in terms of population throughout the process of industrialization (United Nations, 2006).

In contrast, the countries that are the least developed are fundamentally agrarian and are the providers of raw materials for more developed economies. They have kept their economies based on primary products. The present distribution of the urban population might possibly be explained through the concept of regional imbalance, as discussed below. 


\subsection{Regional Imbalance - Origin and Consequence for Urban Design}

Regional imbalance can be explained through historical analysis of the city as a system. As a workforce has become specialized in a town or city, the demand for raw products has changed. At first in the history of cities and manufacturing, the raw materials consumed in the manufacturing processes were strictly related with the producer; most of the time the manufacturers were also responsible for growing the raw materials that they used. When monetarization spread and trade became a worldwide business, the regions were transformed as a result.

Some cities such as Rome and Athens could be said to have introduced the concept of international trade to the Western World. These cities have themselves developed according to the commercial relationships they had with other cities and regions. The rural character that these cities once had was progressively lost in this process (see the chapters 3 and 4 ).

Regional imbalance is the consequence of many economic factors such as monetarization, economic growth, and increase in the level of consumption. Moreover, the lack of knowledge about the use of and dependence on local natural resources, together with ignoring the concept of limitation, have built up a strong commercial structure unrelated with local resources. Commerce is primarily an individual, therefore private, enterprise which has a final outcome of profit for those involved. Obviously commerce was not the only factor to determine the characteristics of cities; however, comprehending the commercial influence on cities is fundamental to understanding how the cities have achieved their current design, size and attributes. It may also provide a reason for the current rising rates of urbanisation. This phenomenon is shown in the series of figures below. 


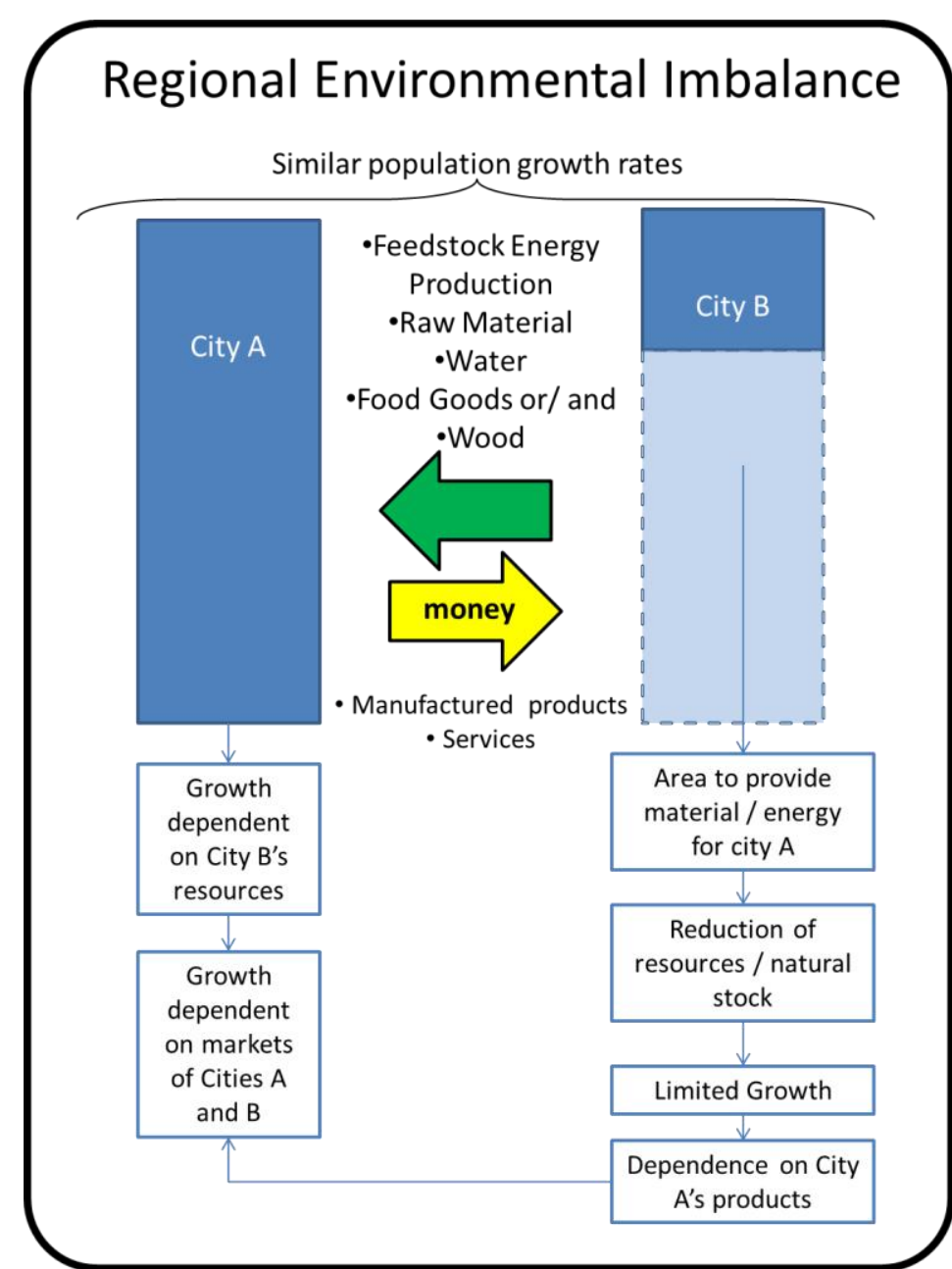

Figure 15 - Regional imbalance and the commercial relationship between cities with different characteristics - static model

The diagram above demonstrates the relationship between cities with diverse economic bases. City A at some point in its history has had its workforce specialized, moving from a self-sufficient way of life to a more industrial/trading based way of life and has started to demand products from another city (B). City A thus has an economic structure dependent on the primary products from city B. In turn City B is also dependent for its growth on the commercial relationship it has with City A. Consequently City A does not need to keep and preserve areas for raw materials production as it imports most of these. In contrast, City B has part of its overall urban design area designated to providing primary products for its inhabitants and to meet the commercial demands of City A. The growth of City B is, therefore, entirely related to what happens in City A and the existence of City A depends upon the existence of City B. 
The model above describes a commercial relationship between two cities with different economic models. The model itself does not show if one or other of the cities is in imbalance. The diagram, indeed, could represent a relatively balanced and hence sustainable model. However, the diagram is only showing a static position. Changes could interfere in the relationship between the two cities, such as climate variations, natural catastrophes and economic fluctuations in A or B. Another factor responsible for showing the static nature of the model is the fact that City B has to be a perpetual provider of raw-materials for City A. In this case, City B has to contain in its portfolio of products only products that are invariably renewable. Moreover, even in the case that City B has strictly renewable products and is able to control their production, City A also has to control its demand for these.

However, the most influential factor to provoke imbalance in this system is population growth, implying that more people are deriving their income from work in the city. This interferes in many factors such as general demand, urban design, the production rates of raw product generation, and the level of consumption. The former model is consequently theoretical and is only provided as an introduction to the more complex dynamic diagram below. 


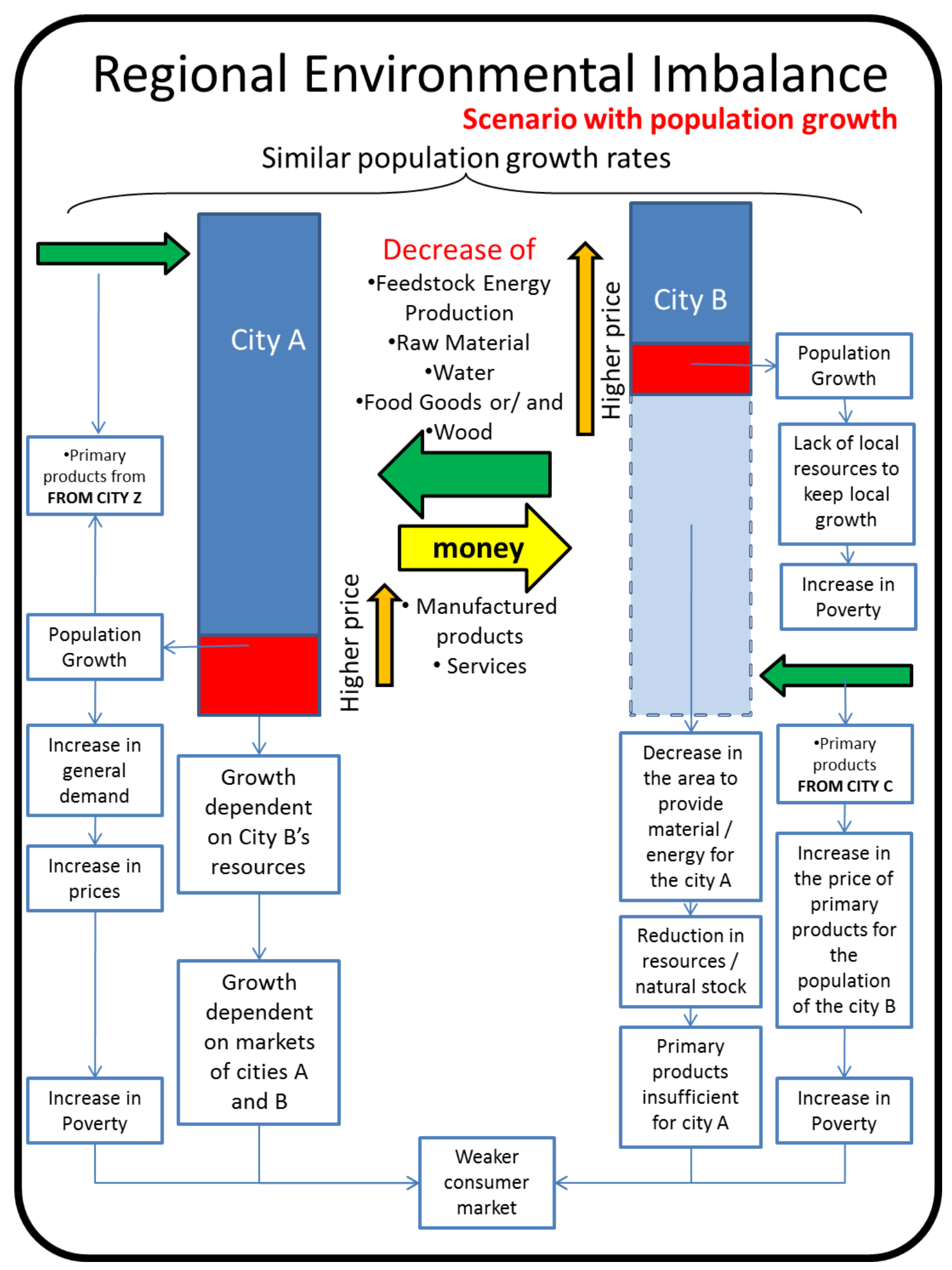

Figure 16 - Regional imbalance and the commercial relationship between cities with different characteristics - non static model (population growth)

Figure 16 describes a model that is non-static. The assumed population growth in Figure 16 modifies the fragile commercial relationship between Cities A and B. One 
of the possible consequences of population growth in City B is a decrease in the area of land available for production of raw materials. This will automatically affect the commercial relationship. The population in $\mathrm{B}$, in order to keep the incoming capital flow from City A, keeps selling primary products. At some point, City B, once self-sufficient for raw products, starts to import primary products from other locations in order to keep the flow to City A going or even to provide primary products to its inhabitants.

City B has based its economy on the commercialization of raw products, but after a population increase City B is not able to produce enough to sustain the local commerce with city A and its population. There are many commercial and social consequences of population growth, such as dependence on products from other cities, transfer of profit to other markets, rise in prices of products once easily available, impoverishment, reduction of natural stock, and pressure on green areas.

Meanwhile, City A will experience similar effects. The products from B become temporarily or permanently more expensive. City A in order to provide goods to its population starts to buy raw products from different cities. While City B is struggling to keep the supply to A, City A starts doing business with other cities enlarging the chain of production and consumption. The capacity of City A to find new suppliers added to its capacity to find new market consumers will probably define the prosperity of the city. The continuing existence of City A now depends on two main factors, a good supply chain and a good and large consumer market. 


\section{Regional Environmental Imbalance}

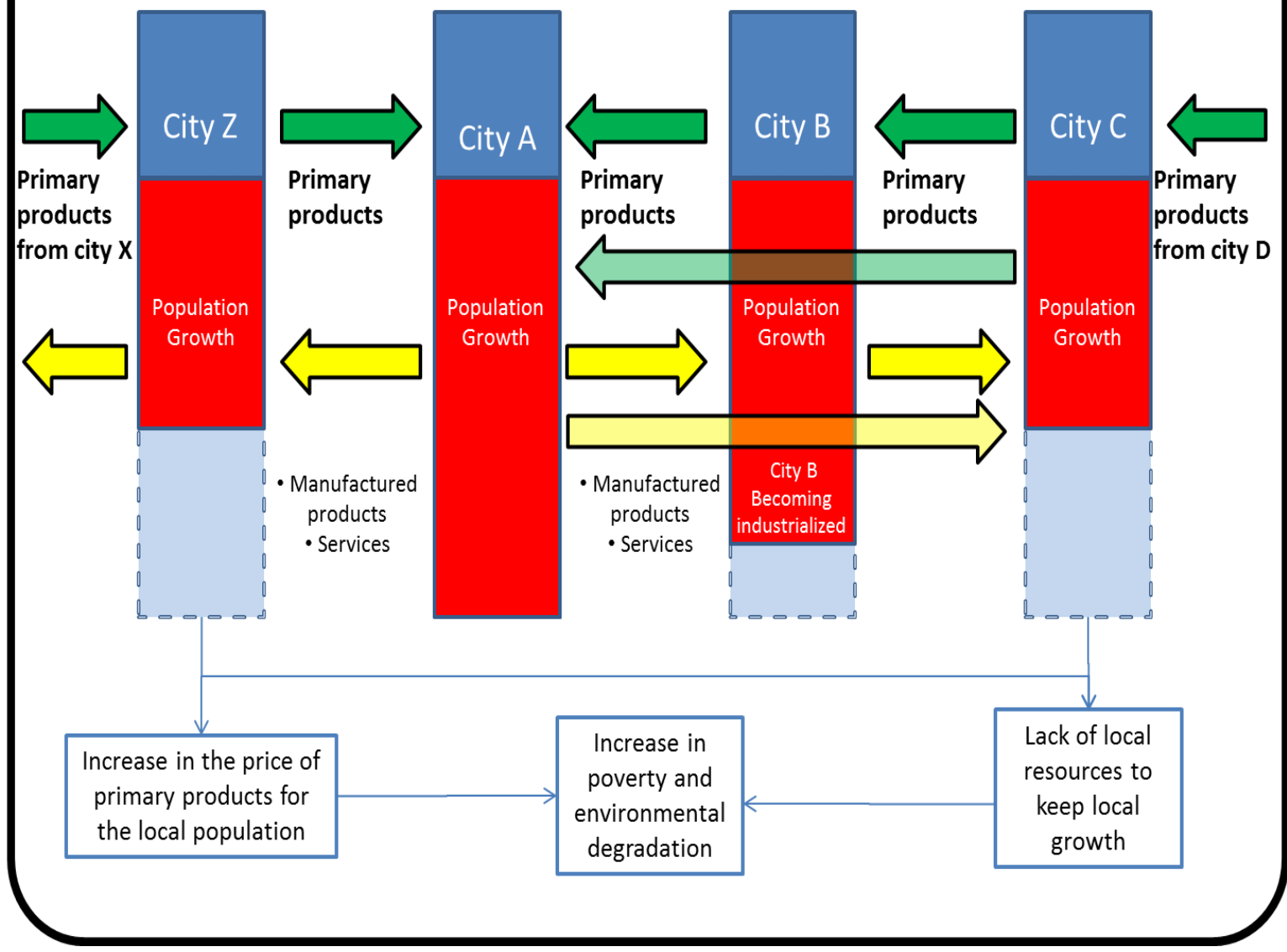

growth and large commercial expansion, increase in poverty, environmental degradation etc.

Although the diagram above shows a non-static model, it is still a schematic. The chain triggered because of the population growth has a propensity to be more complex. Additional to the population growth, the constant rise in the level of consumption also helps to trigger imbalance in the commercial relationships. While the population growth can be predicted with a good level of exactitude, rises in levels of consumption tend to be hard to predict.

Others factors are also able to provoke imbalance in a region, such as natural catastrophes, wars, and political decisions. The discussion here will be primarily focused on population growth and the increase in levels of economic activity that lead to economic growth. These two factors combined directly affect cities and, therefore, urban design is also affected. In order to preserve a regional balance, and consequently city stability, every single change made by a region should be 
based on the capacity to keep the regional resource flow steady. This in turn will affect urban design, and what this affects will be is part of this research.

Consequently economic and population growth should be based on the capacity of a locality to provide food, energy, and raw materials without change to the regional balance. In addition, the cities involved in a regional commerce chain should ideally have a similar quality of life.

In conclusion, it is important to define the environmental limits of any region in order to delineate the restrictions of economic and population growth. Obviously, the functions and reason for the existence of commercial imbalance are extremely hard to enumerate. Moreover, different regions have different reasons to establish an unequal commercial relationship. However, essentially regions try to supply the internal demand using outside resources from adjacent regions because of lack of commercial planning and local limitations. In this situation commercial trade can become highly profitable and keeping a situation of living outside local limitations becomes convenient.

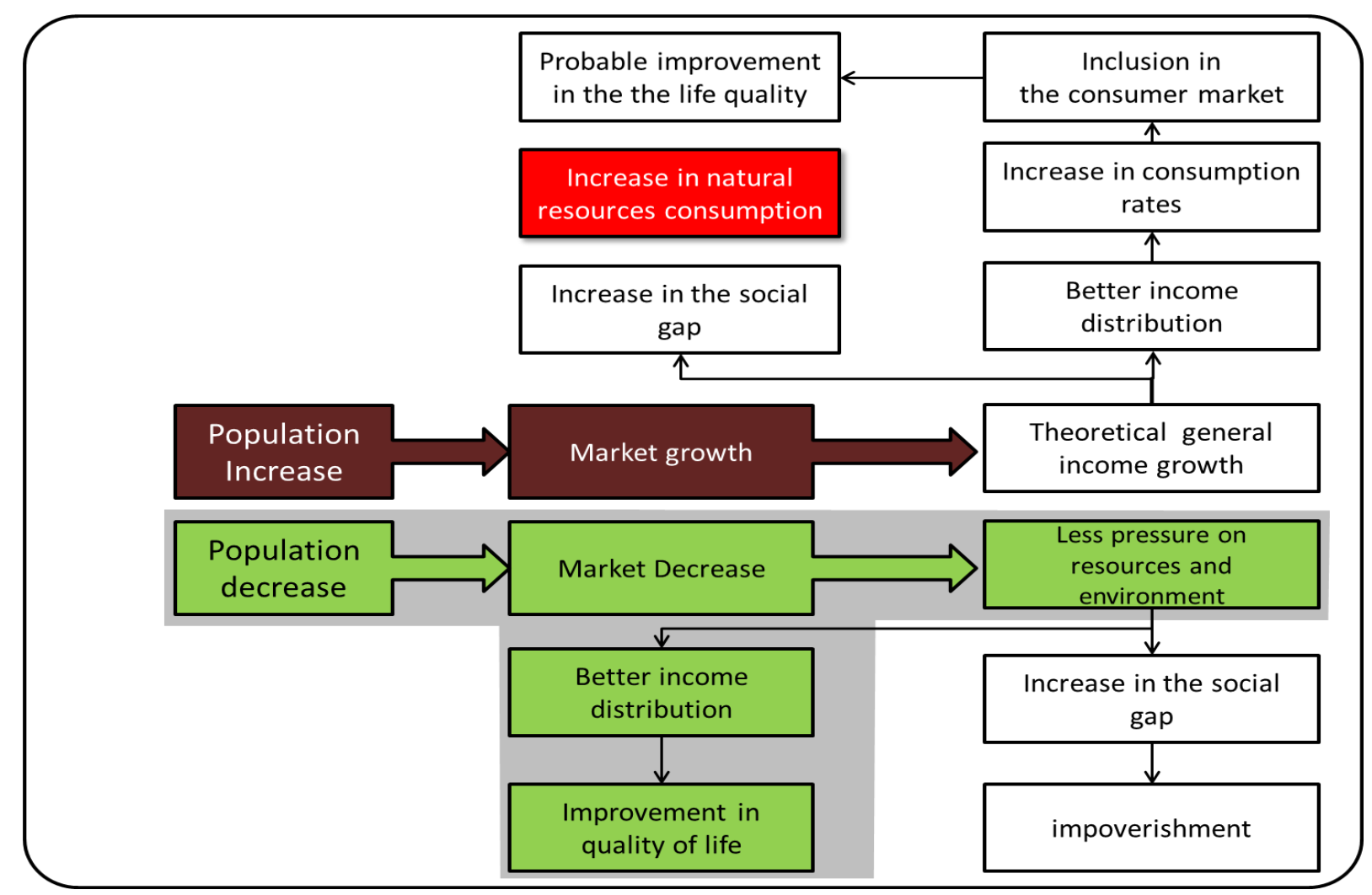

Figure 18 - The consequence of population growth in a stable and sufficient region. The grey area indicates one of the probable effects of population decrease 
The consequences of the commercial imbalance directly impacts on the social urban structure. A great imbalance can lead to a lack of urban social efficiency and can never, therefore, be a sustainable position. 


\section{Eco-Social Urban Design and Urban Social Efficiency}

This research defines urban social efficiency as the process that links together urban sustainability factors in order to eliminate social inequality, provide a healthy life condition, and equal opportunities for all inhabitants in a certain area. Some sustainability factors may change according to the location but it is argued here that critical factors are common to all situations. These common factors are urban design (the physical form of which may change with local conditions), regional trade balance, food and energy production, local natural resources, local commerce and responsible consumption. The aim is to associate the term productivity not only with production, but with social causes and outcomes.

\subsection{Urban Design}

Urban Design is indispensable in order to achieve urban social efficiency. Urban design in a social efficiency regime is essentially the transposition of the concepts into a practical and real environment within which people can have good lives. In the system of social efficiency, the interests of the community are more important than private and individual ones. However, this does not mean that an individual life cannot still be good, although the collective interest has to be respected locally and regionally. Also the acceptance that regions and parts of regions have the same importance is vital. This means that city life and rural life are seen as equally important and interdependent. In order to achieve a good level of urban social efficiency a good regional balance is mandatory. Consequently, even the smallest scale of design requires attention. As described before, regional imbalance is a continuous process which starts at the small scale. Therefore, the concept of regional imbalance cannot only be explained as a commercial disparity. It is a rooted system in which the outcomes are not going to be an adequate quality of life or social equality. Hence, the physical urban conglomeration has to express the desire to achieve and keep the regional balance and inspire its residents to aspire to and achieve social equality and, as a result of achieving this, an enhanced quality of life. The fundamentals of these key points have essentially emerged from the most remarkable aspects of the historical cases previously analysed in this 
research. They are an attempted to summarize important characteristics from the ancient human tradition in urban design. However, they have been intentionally modified in order to respond to social, technological and environmental specificities today. For this research, the key aspects of such an approach in terms of the physical environment are listed below and will be discussed separately:

- Equal access to green areas and urban infra-structure

- Walkable environment

- Commercial areas designed for local commerce

- Priority for public transportation over private transportation

- Reduction of private areas over common areas

- Preservation of ecosystems and green corridors

- Food production - enough to meet significant community demand

- Energy production - enough to meet significant community demand

\subsubsection{Equal access to green areas and urban infra-structure}

For urban social efficiency access to green areas should be shared equally among the inhabitants of any urban area. This is a change to the modern condition. At present it is the wealthy parts of cities that are leafy and green and often the areas of the poorest people have no such attributes. A great number of cities have had their expansion based on private developments and since the time of ancient Rome, the regions around the city that are characterized by containing a considerable number of green areas have been taken by the highest classes for their own use; some of these areas were kept just for relaxation (Harl, 1996, p. 94). Quite simply this is because the rich had the money to pay for this privilege.

In developing countries segregation of social class and green environments is probably more visible. Private properties are generally larger than properties in poorer regions, and tend to have more private green areas. In contrast, the poorer parts of cities frequently suffer from a lack of green areas (Kohle, Romero, Penhalber, Cortes, \& Viviane, 2011). Although through academic research there is recognition of the importance of green areas there is a trend, in countries with a significant social gap like Brazil, for there to be a lack of spaces for leisure in areas 
with low average income (Morero, Santos, \& Fidalgo, 2007, p. 19). The social consequence is creation of a linear relationship between green areas and wealth. One of the urban aspirations among the lower classes is for an increase in green areas per capita, and ensuring leisure areas are equally accessible for all, including the elderly, disabled, and children. In terms of urban design, the lack of urban accessibility to green areas and public infra-structure are powerful factors that indicate social inequality and exclusion. There are different ways to classify green areas. Probably the most common is differentiating spaces for recreation and leisure, for environmental conservation, and areas for educational purposes (Morero, Santos, \& Fidalgo, 2007, p. 20). Although green areas for food and energy production are not commonly acknowledged in this context they are also fundamental in urban social efficiency in order to decrease social inequality. Obviously it is not possible for all food to be grown within a city but the ability to grow at least some food, as happened in the past with provision of green space for rented allotments (UK) and for gardens on the outskirts of the city (Germany and Austria) had two benefits. Firstly, the less wealthy could grow some food and secondly, a visible connection was made in the city between food and where it came from. This maintained the importance of the rural areas to the city as a whole. In an urban social efficiency scenario these areas are indispensable to keep the regional balance as previously explained. Moreover, they should be an essential part of determining the carrying capacity of any region and should be taken into account during any development process where sustainability is the goal (for further discussion see below) (Pizzol, 2006, pp. 04-06).

The Food and Agriculture Organization (FAO) of the United Nations recommends $12 \mathrm{~m}^{2}$ per capita of green area and many urban regions struggle to achieve the minimum required (FAO, 1998). Furthermore, some areas that are included in an inventory of green spaces are inadequate and virtually useless. These areas are often denuded of trees or other planting, being essentially unoccupied land, probably waiting for further development (Morero, Santos, \& Fidalgo, 2007, p. 21). In fact trees have not been integrated into urban planning and design in less developed countries (FAO, 1998). In Asia, urban green areas are underdeveloped and not well organized, particularly in countries with lower development levels. In 
contrast, the wealthiest cities have ambitious urban greening plans. Tokyo is an example of planning to implement greener policies:

"In 1994 the Government adopted the Tokyo Metropolitan Plan for doubling Greenery. This plan is designed to promote comprehensive, systematic policies with regard to urban green areas and bodies of water in Tokyo. Long range goals outlined in the plan include doubling the amount of green space in Tokyo, improving the quality of green space, and promoting activities to achieve these goals."

(FA0, 1998)

In order to fairly allocate green areas, these areas first have to be divided according to use and needs. Secondly, the green spaces have to be studied along with the environmental situation to indicate their ecological potential or ecological restrictions and the human actions which affect or are affected by the environment. Regions have different demands for green areas. Therefore, the balance between natural environment and built environment will change according to the local demand.

The rate of green area per capita as established by the FAO should be taken as the smallest amount acceptable and not the final goal; the aim should be to improve this in new developments to compensate for the absence of green areas in the cities of today.

\subsubsection{Walkable Environment}

In order to minimize energy consumption and provide conditions of equal accessibility, a walkable environment is essential. A walkable environment is not a new concept. Indeed, human society has developed in walkable environments, as has most of human urban history. Only recently have transportation systems taken an important role in the development of cities.

The rationale behind the walkable environment is simple. If an urban system has an efficient walkable design, it means that the majority of the inhabitants can reach 
most of the places by themselves. It will minimize the need for public or private transportation. Although walking also consumes energy, which has to be provided by additional food (Vale \& Vale, 2009, p.102/105) the energy involved is much less than modern forms of transport, such as the car and bus. In a walkable environment the distances have to be designed to provide comfortable access to most of the everyday services people need.

Essentially a walkable environment aims to reduce the use of transportation and the large energy consumption associated with this, particularly in terms of oil. Indeed, providing walkable friendly spaces could be one of the main contributions of the urban designer to the world environment. The process to increase the walkability of an urban system is complex and will inevitably vary from site to site. Some factors such as land (flat, steep, swampy), climate, vegetation, and natural or manmade barriers (rivers, canals), can interfere in the process of achieving a truly walkable space.

The suggestion behind a walkable environment is fundamentally an option for human movement displacement for which an energy supply can be guaranteed in the short term. To minimize the distances, and hence the energy use, means increasing the efficiency of the flow of people and goods. As a result some urban design concepts have to be reviewed.

Private properties have grown larger in the last century (Vale \& Vale, 2009, p. 130). The outcome of this increase is also reflected in recent urban design. Larger houses may determine a larger land area and, therefore, greater distances between them can be created. For example, so called McMansions have appeared at low density around the outskirts of Sydney (Lane \& Murray, 2011, p. 75; Lane and Gorman-Murray, 2011, p.75). In contrast, in many places family sizes have decreased dramatically in the last 50 years. These factors have imposed a fall in the density of cities in wealthier regions (Lane \& Murray, 2011, p. 75; Vale \& Vale, 2009 , p. 130). The combination of low density city areas and private transportation has brought forth a dramatic increase in the distances between services in cities. As a result most cities, particularly new developments within them, have become unfriendly to walking. It is not uncommon to find cities where the downtown (normally the oldest part of the city) is easily accessible by walking. 
In contrast, even when the city has a downtown that is pedestrian friendly, its suburbs are often not walkable.

The process to transform an urban environment from being unwalkable to being walkable is complex. A great number of players are potentially involved in this process and, as a result of their being ignored, many urban conglomerations have progressively become virtually unwalkable. Some of the main factors for this are listed and discussed below with particular reference to conditions in Brazil:

- The highly profitable real estate market and the privatization of green areas Real estate developers have realized the value inherent in regions with a large availability of green areas and have attempted to increase these in projects for the high end of the market. This process of privatization of green areas has been legal and has been partnered by the negligence of the public authorities. The predominantly green regions right beside the cities, which were ideal for preservation as green belts for recreation for all, have been subdivided into large house plots for the wealthy and sold.

- Dependence on private transportation

As a consequence of the suburbanization and privatization of the green areas having some system of transportation has become indispensable to bring people from having the far flung neighbourhoods to the downtown area or other workplaces. Most of the cities in Brazil have not been able to keep up a system of efficient public transportation in the new regions. In contrast, the well-organized automotive industries have encouraged the expansion of the car based models of the suburbs in order to support their own market growth. The day-by-day displacement previously made by walking has gradually been substituted by an automotive trip. The effective combination between two powerful and mutually dependent industries, oil and automotive, has supported this process of private transport dependence. 
- The progressive change from local commerce to the big corporate chains.

The growth of the big commercial chains has suffocated independent local commerce. Consequently local commerce has been in decline. This change in consumption behaviour has helped to consolidate a new life-style where the wealthy suburbs do not have local commerce. The new residents in these partially isolated regions are financially prepared to drive their cars even for the purpose of day-by-day shopping. The poor, who rely on local commerce, are the ones who suffer in this situation.

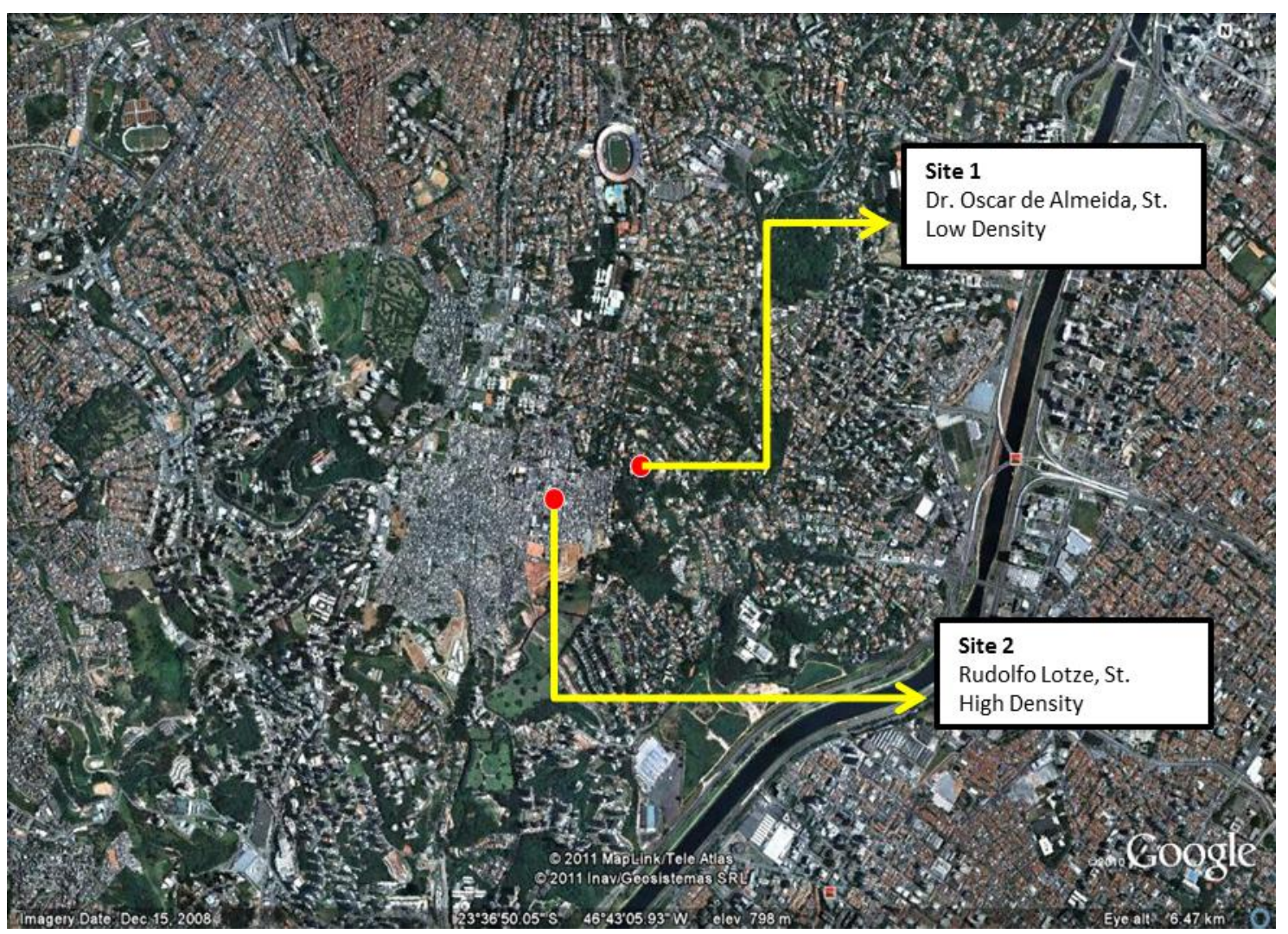

Figure 19 - The contrast between two regions in São Paulo, Brazil. Site 1 is located in a wealthy region (Morumbi) in contrast with site 2 which is located in a recently urbanized slum (Paraisopolis). - (c) 2011 Google $\odot 2011$ Tele Atlas 


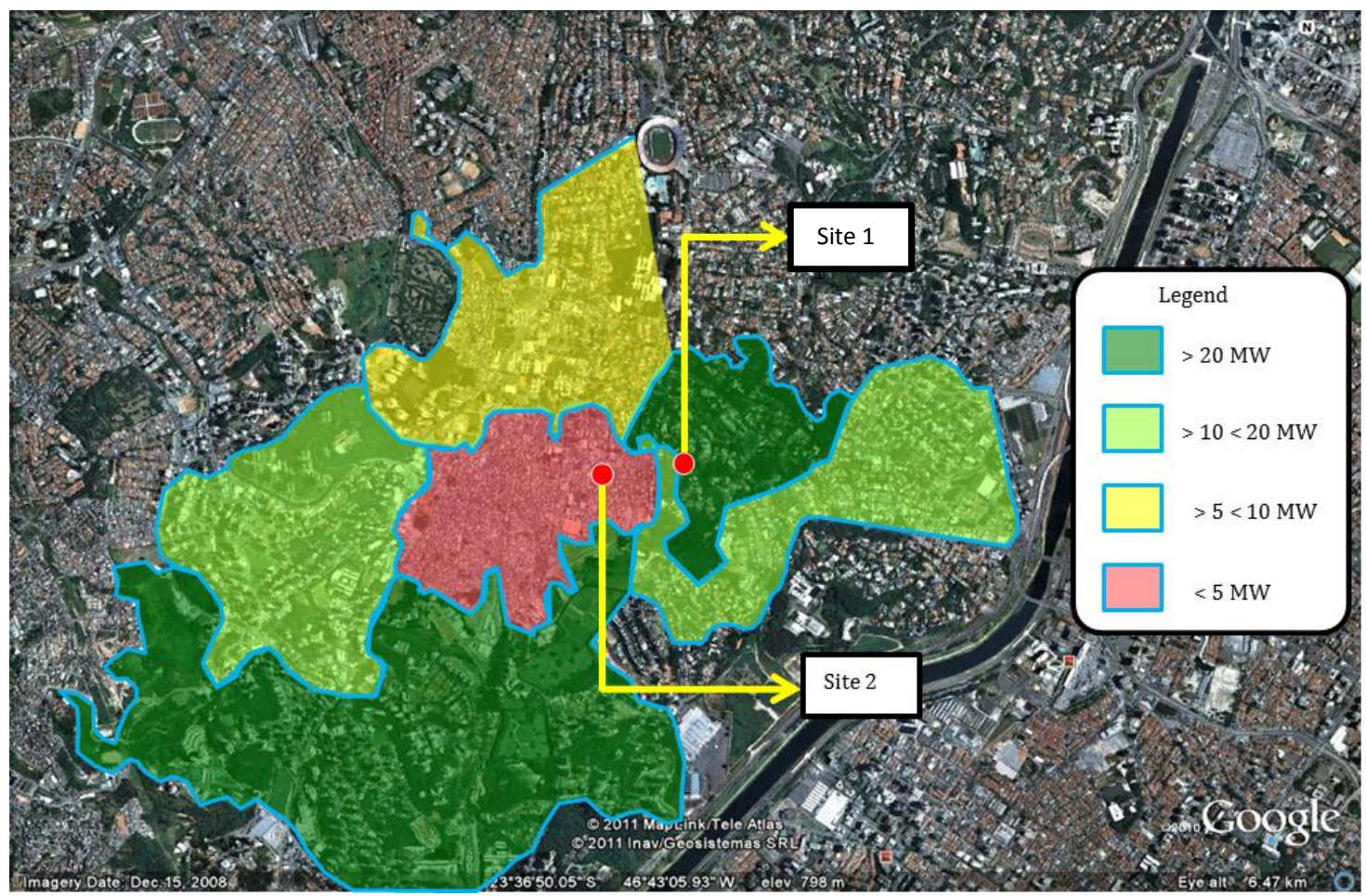

Figure 20 - Family income distribution according to the national 2001 census. Although the distance between Sites 1 and $\mathbf{2}$ is less than $\mathbf{4 0 0}$ metres the map clearly shows the social gap in this part of the town. MW - Minimum Wage in Brazil in 2011 is NZD\$ 354 / month - (c) 2011 Google (c) 2011 Tele Atlas

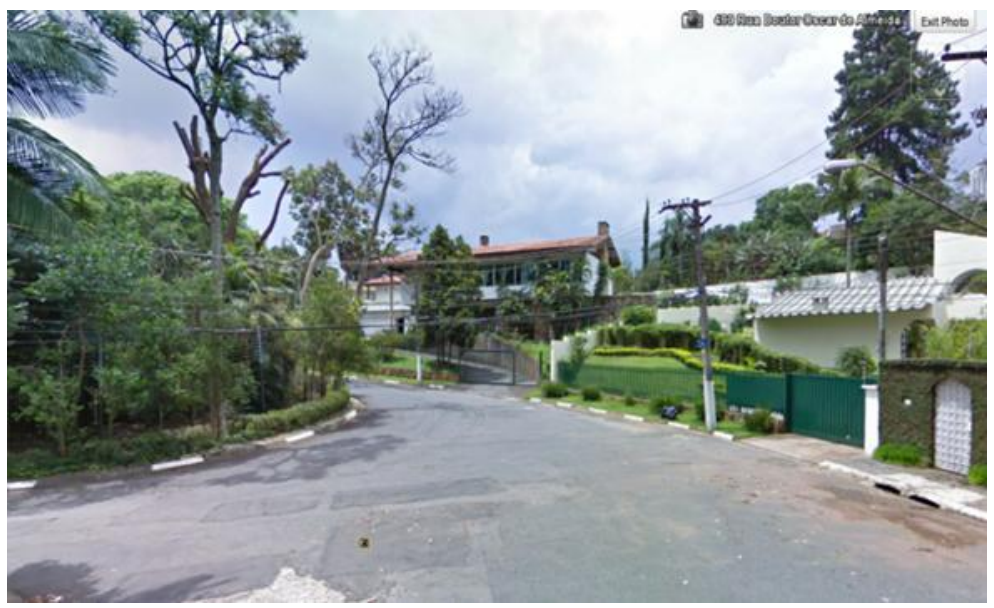

Figure 21 - Site 01, low density, and no commerce - Image: (c) 2011 Google

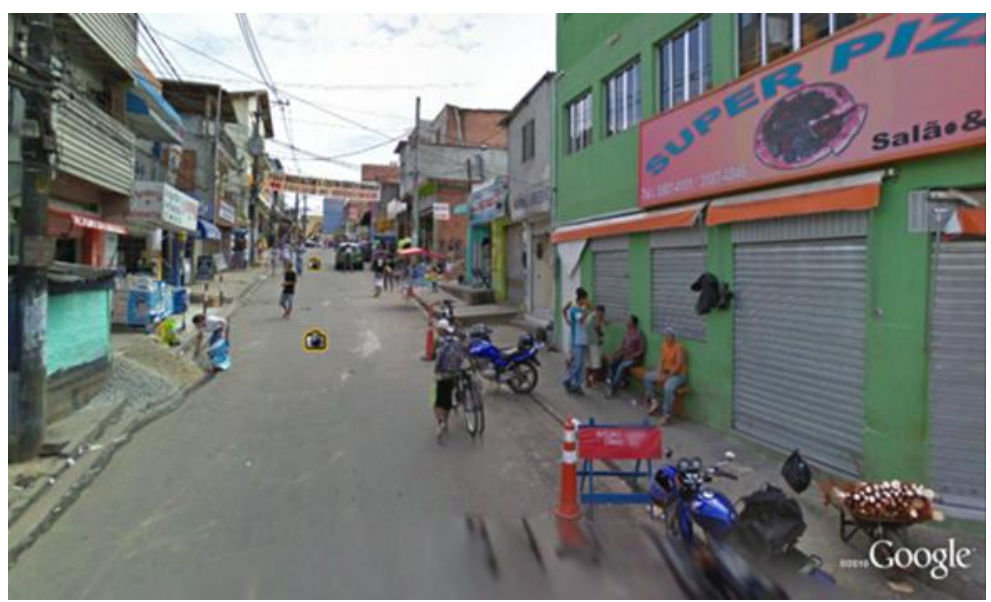

Figure 22 - Site 2 - Higher density than site 01, commerce - (c) 2011 Google 
The examples of sites 01 (Morumbi) and site 02 (Paraisopolis) partially demonstrate the problem of non-application of a policy of equal access to green areas and a walkable environment. Site one is located in a wealthy region. It has a great number of green areas although most of them are private. Although the density has not been calculated in this phase of the research, a visual analysis of the photos indicates that site 01 has a lower density and higher concentration of green areas. The streets are normally wider and there are no visible shops. In contrast, site 02 , although apparently poorer, has a great number of shops. The streets seem narrower than those of site 01 .

Beyond the Brazilian reality, which contrasts two extreme social classes just 400m from each other, the sites typify how profitable the privatization of green areas has become. Green areas have turned out to be an important tool to increase value in real estate properties. Therefore, in regions where there is lack of credit availability, the real estate market has developed for the higher classes and consequently green areas have become important as a low developer cost instrument to increase value.

Another significant contrast between the areas is the population density. Site 01 has a density around 22 inhabitants / ha, while site 02 has approximately 1000 inhabitants / ha (Veja São Paulo, 2009). The regional average density is significantly lower than the density of site 02 . When the regions around are taken into consideration, most of which are relatively wealthy, the average is 28 inhabitants / ha (São Paulo City Council, 2009).

The convenient omission or connivance of the public authorities increases the tendency to boost the population density in regions with easy accessibility to a work market and public infra-structure. Site 02 is thus a well-located provider of cheap labour to site 01 , and around 78 per cent of the local workforce are employed in the region where site 01 is located (Veja São Paulo, 2009). The macroregion where both sites are situated has a reasonably low density. The São Paulo average is 73.28 inhabitants / ha. Fortunately, the neighbourhoods around the sites 01 and 02 offer a great number of work opportunities for non-qualified workers. 
Regions with low density have a propensity to be finically unfeasible from the authorities' point of view concerning the provision of infra-structure. This unfeasibility is remarkable when the parameter concerned is public transportation. In order to provide a comfortable and efficient public transportation service without relevant subsidies, the transportation authorities must satisfy a technical equation. This equation is used to dimension the transport system. The equation relates the population density with the traffic generated in certain regions. The variable used is based on the traffic density created. The equation is DT = N / S; (DT being Traffic Density, $\mathrm{N}$ being the number of trips, and S being the area) (Kneib \& Silva, 2011). Even where this equation can show the feasibility of public transportation, there is no guarantee that any public transport will be good in terms of frequency and linkage to other places. Indeed, most public transportation depends on subsidies to operate it at all (Nobre, 2006, p. 37-39).

\subsubsection{Walkability and Local Commerce}

In addition, the progressive change in the local commerce can also be seen in the region that contains sites 01 and 02 . Site 02 is located in a micro-region with low income, and therefore probably low availability of private transportation. However, the macro-region already demonstrates the influence of the international commerce chains acting in the neighbourhood. Moreover, site 01 and all other regions surrounding it have a greater average income enabling the inhabitants to access private transportation. 


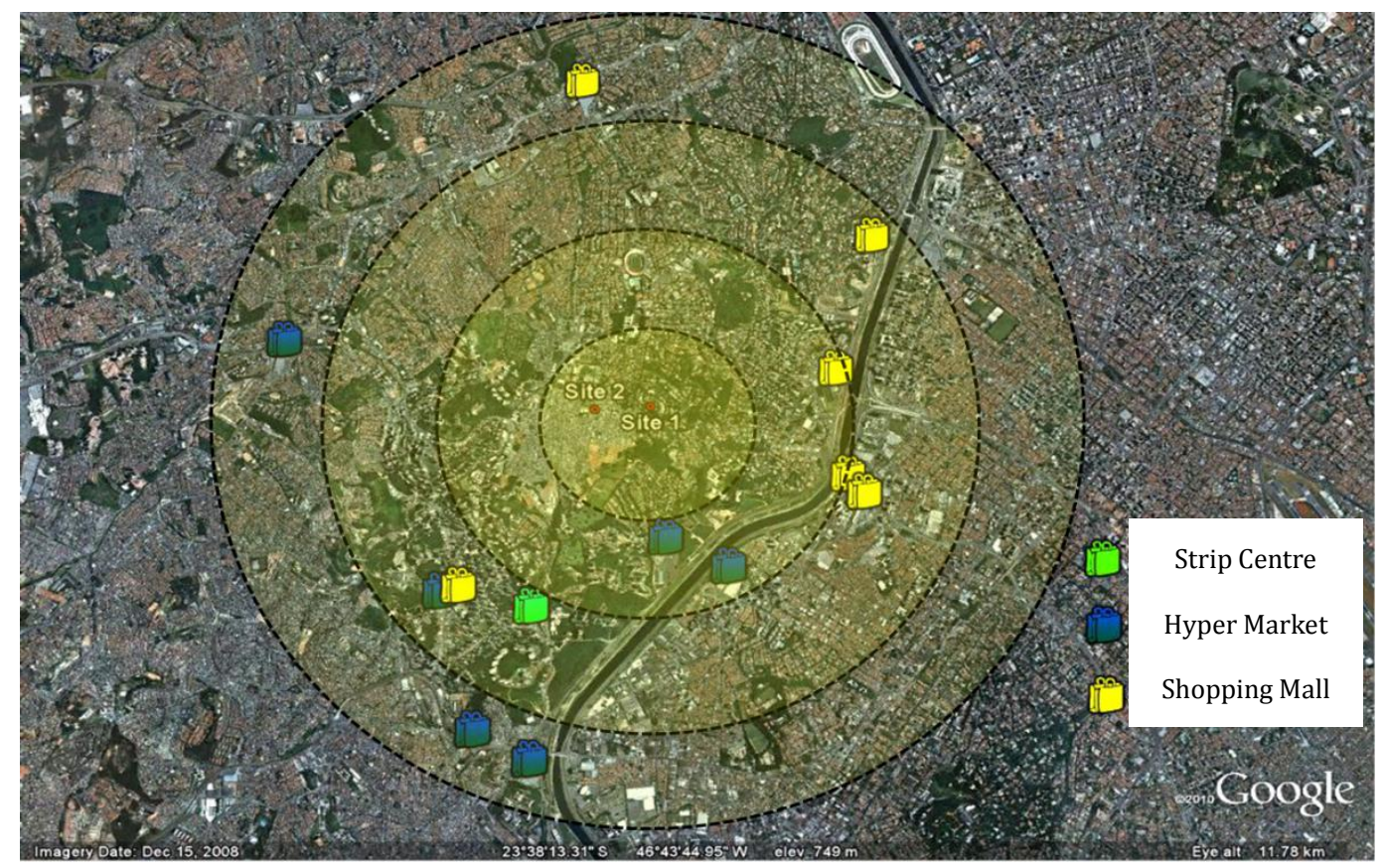

Figure 23- Commercial outlets available around sites 1 and 2. Strip centres are small commercial centres (2 or 3 shops), in Sao Paulo, Brazil, with parking places in front of the stores. The yellow rings represent $2 \mathrm{~km}$ radii steps $($ C) 2011 Google (c) 2011 Tele Atlas.

The local commerce model that historically was widespread has recently been struggling to keep up against competition from the international chains. These chains are mostly based on massive stores with a huge radius of influence. These normally demand consumers reach them by private car. While local commerce has been highly responsible for connecting people and neighbourhoods, the international chains are not closely tied with the local communities.

The progressive change in the characteristics of commerce is an important component of the change in urban morphology. The gradual public acceptance of this commerce model, entirely based on private transportation, has happened in tandem with the real estate development of low density residential areas. The comparison between site 01 and site 02 shows an interesting contrast. Site 01 has a consistent level of private green areas, while site 02 has local commerce which is within walking distance for the users. Neither site achieves both goals. The examples of site 01 and 02 and their close proximity are not rare in developing countries. 


\subsubsection{Case Study Analysis - Carapicuiba and Alphaville}

Another example can be found, at a larger scale, in São Paulo's suburbs (although know as suburbs, these are really satellite cities). The western suburbs also represent a great social and urban contrast as can be seen in the figure 24. In 1973 the new development called Alphaville was launched in the rural area of Barueri city. When Alphaville was launched in 1973, Barueri only had around 30,000 inhabitants. The first part of the project consisted of two residential areas, an industrial park that was stipulated to be non-polluting and a commercial area. According to Renato Albuquerque, the developer responsible for the project along with Yojiro Takaoka, both being partners in the Takaoka S.A. constructor company:

"Alphaville was a great success [commercial success]. We have offered sites, on average, of 560 square metres, in which, as with the commercial sites, all urban infra-structure has been provided. Moreover, we have created an important obstacle to avoid the residential areas becoming a shortcut for through traffic from other places..." ("lançamos Alphaville Residencial $1 \mathrm{em}$ 1975 com grande sucesso. Ofertamos lotes de, em média, 560 metros quadrados, os quais, assim como os lotes do Empresarial, tinham toda a infraestrutura urbana. Além disso, criamos um obstáculo importante para evitar que um residencial se transformasse numa passagem para outros tantos lugares...")

(Guia NewsVille, 2000)

Albuequerque has further stated that the region was not at first able to attract commerce. In order to overcome this problem, some possible solutions were subsidized by the developers, such as a bus route through Alphaville, a fuel station, and a delivery service for goods.

Alphaville can be taken as an example of planned private development in which the environment is not walkable. Even though Alphaville has successfully met the consumer demand becoming a great commercial business success, some basic aspects of environmental sustainability were neglected. 


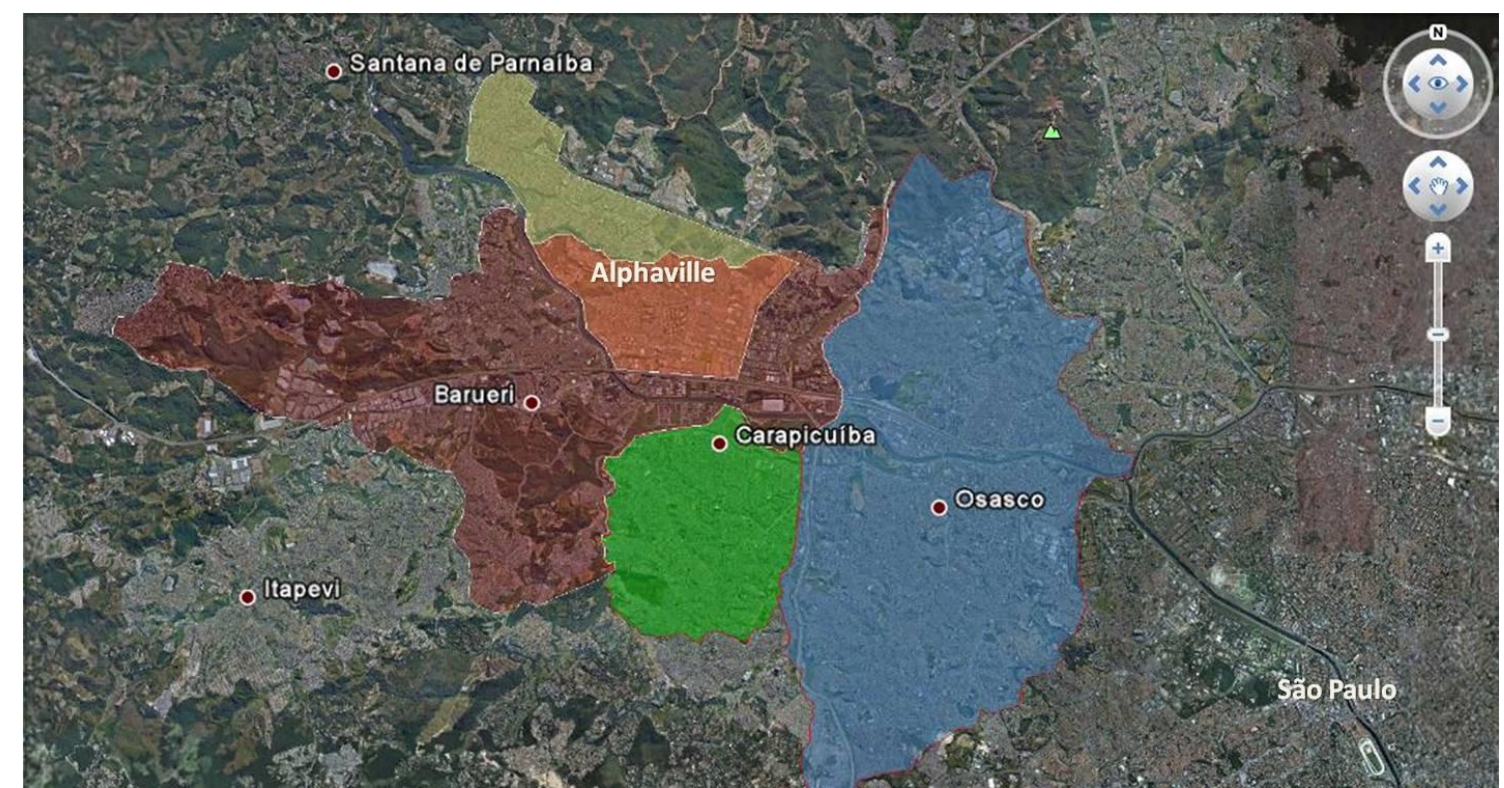

Figure 24 - Western Sao Paulo, including Barueri, Carapicuiba, Osasco Santa do Parnaiba, Itapevi, first Alphaville (orange), and second Alphaville (yellow). Sao Paulo is in the low right corner (C) 2011 Google $(2011$ Tele Atlas . (Imagery from Dec 15, 2008)

Barueri was directly impacted by Alphaville. Originally conceived as a nonpolluting industrial and commercial region, and therefore a large tax contributor, the developers soon realized there was an excellent opportunity to develop a residential area for the executives of the companies who had been established there. Today Alphaville has a population of around 35,000 inhabitants. However, the daily floating population is 200,000 people. The development has also expanded and now has aggregated developments such as nearby Tamboré and Ithayê (Guia NewsVille, 2000).

Alphaville is a private development which has met all legal requirements. Indeed, it has a green marketing approach. The commercial success obtained at Alphaville can be taken as an example of the tendency for there to be a decrease in walkability. Despite being a private and planned development, walkability and connectivity within the bounded regions are neglected, as can be seen in the pictures below. 


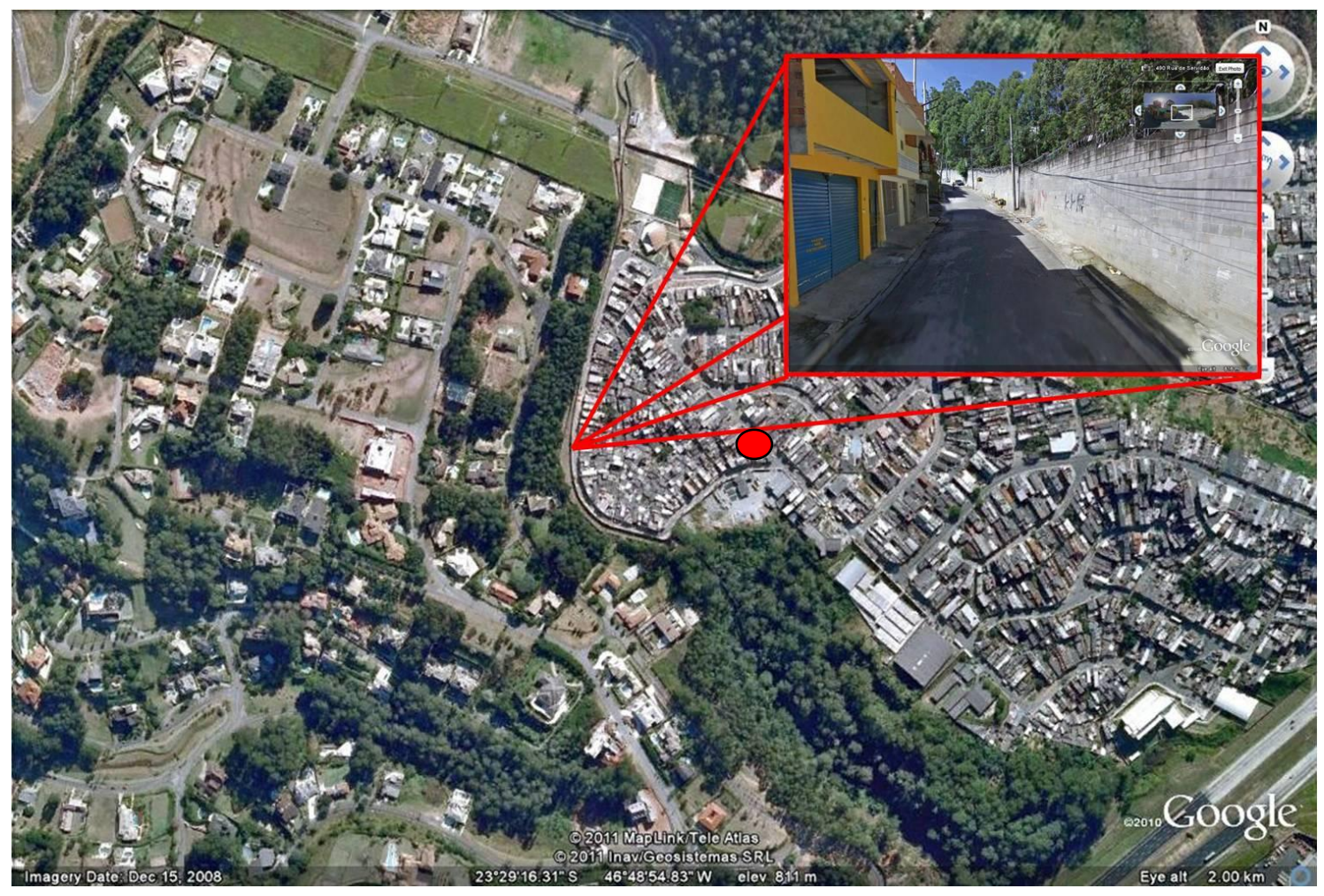

Figure 25 - Junction between one of the Alphaville gated communities and Carapicuiba - The details show the property division made by a high wall (c) 2011 Google @ 2011 Tele Atlas.

The urban design has deepened and emphasized the social segregation. The lack of connectivity has generated a huge waste in energy and resources. Probably the great part of Alphaville's daily floating population comes from the regions around it. The situation shown in figure 26 is an example. One resident at the red spot in the poorer and higher density area (figure 25 and 26) theoretically has to travel $3.6 \mathrm{~km}$ every day in order to access the closest wealthy residential area for work there. This is the problem of having low density, gated communities, designed to exclude through traffic. 


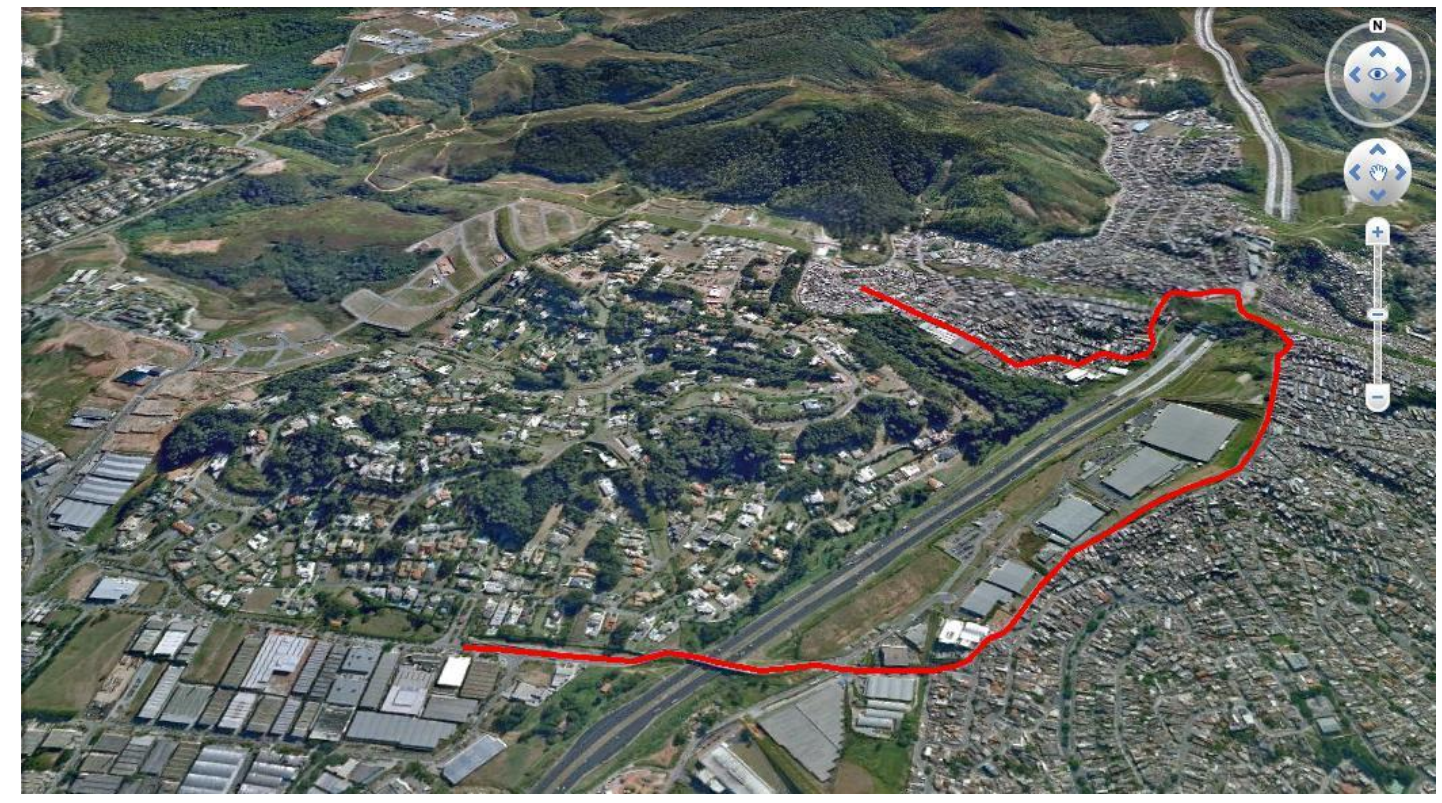

Figure 26 - Distance between the community attached to Alphaville and the closest condominum entry (C) 2011 Google $@ 2011$ Tele Atlas.

Another example of non-walkability can be seen in the distances between some of the wealthy gated residential areas and the locations of day-by-day commerce as can be seen in table 2 .

\begin{tabular}{|l|l|l|}
\hline Colours & Regions & Distance \\
\hline Red Line & $\begin{array}{l}\text { Distance between commercial area and the middle } \\
\text { point of residential area I }\end{array}$ & $1.5 \mathrm{~km}$ \\
\hline Cyan Line & $\begin{array}{l}\text { Distance between commercial area and the farthest } \\
\text { point of residential area I }\end{array}$ & $2.6 \mathrm{~km}$ \\
\hline Yellow Line & $\begin{array}{l}\text { Distance between commercial area and the middle } \\
\text { point of residential area II }\end{array}$ & $1.5 \mathrm{~km}$ \\
\hline
\end{tabular}

Table 2 - Distances between residential condominiums and the closest commercial area 


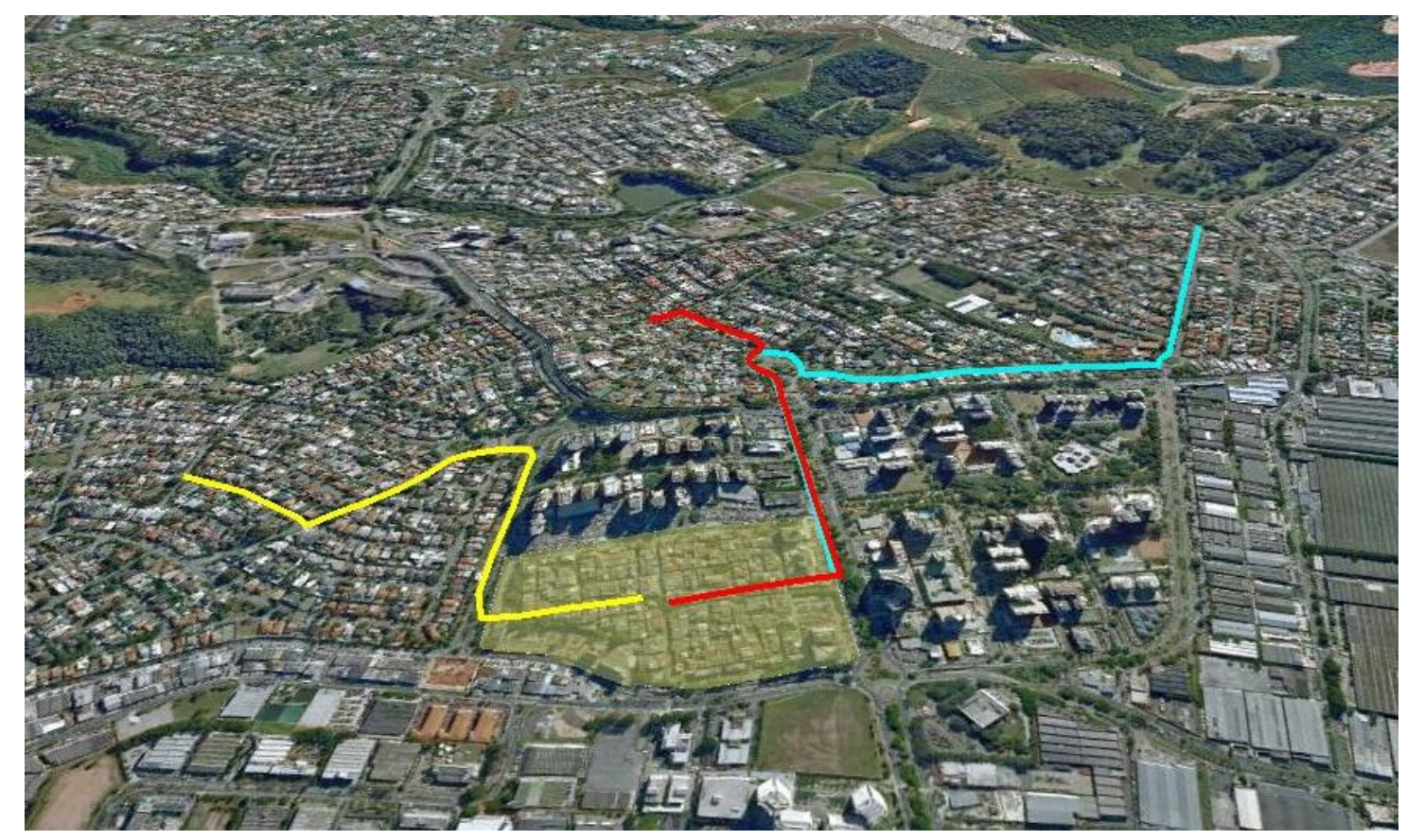

Figure 27- Distances between residential condominiums and the closest commercial area (marked in yellow) (C) 2011 Google $($ C 2011 Tele Atlas

The Alphaville example illustrates one of the most common tendencies of modern planned urban developments. This model of development is largely found in North America and Western Europe (Cox \& Utt, 2004). However, in developing countries this model also presents other factors such as strong social contrast and low connectivity with other regions, and moreover, the privatization of green areas.

The poor regions around these prosperity islands are commonly regulated by the authorities and within them development and growth is often made by the population itself. This sort of vernacular urbanism is likely to be more walkable than the new planned urban models. The relationship between higher densities and local commerce spread all over the neighbourhood is more favourable to walking. In addition, the non-walkable urban models presented in this chapter cannot be associated with urban social efficiency because they demand private transportation and encourage social contrast and segregation. Public transportation in low density areas is normally financially unfeasible, therefore private transportation is essential (Kneib \& Silva, 2011).

Some historic and important aspects of urban design, such as designing for social interaction to reinforce cultural output in cities, are reduced to a subordinate place in this model. These gated communities are commonly designed to be socially 
homogeneous. The scarcity of local commerce and the progressive decline of interaction between different people, socially and culturally, form the antithesis to what cities have been all about. Current human knowledge about urban design has been based on walkable environments (as can be seen in the next chapters). Throughout history, cities have always had niches of prosperity, but probably the level of segregation seen in cities today would be unimaginable in the past. The physical barriers created to demarcate the social limits have produced irrational outcomes. Instead of choosing the shortest way, the pedestrian has to follow a specific track, most of the times making the travel much longer and with no chance of a variety of route.

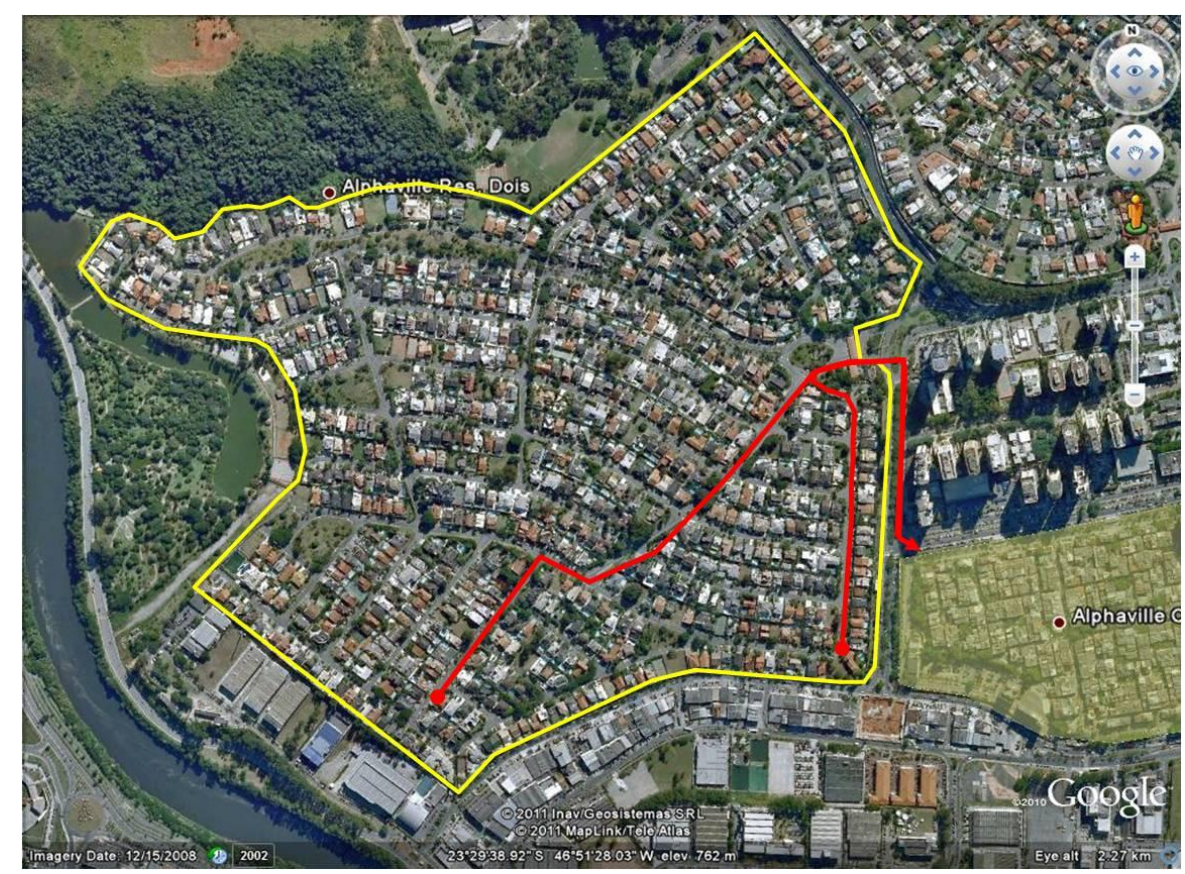

Figure 28 - The walkable route forces the pedestrian to take a longer path $(2011$ Google $\odot 2011$ Tele Atlas

Alphaville has also impacted on social aspects in Barueri through economic issues, as the creation of Alphaville has substantially affected Barueri's Gross Domestic Product (GDP). Although, Barueri has an industrial park, which is relatively small compared with the Eastern suburbs, the local GDP is 51 per cent higher than the second city of Greater São Paulo (Sao Caetano do Sul; Southest Region). 


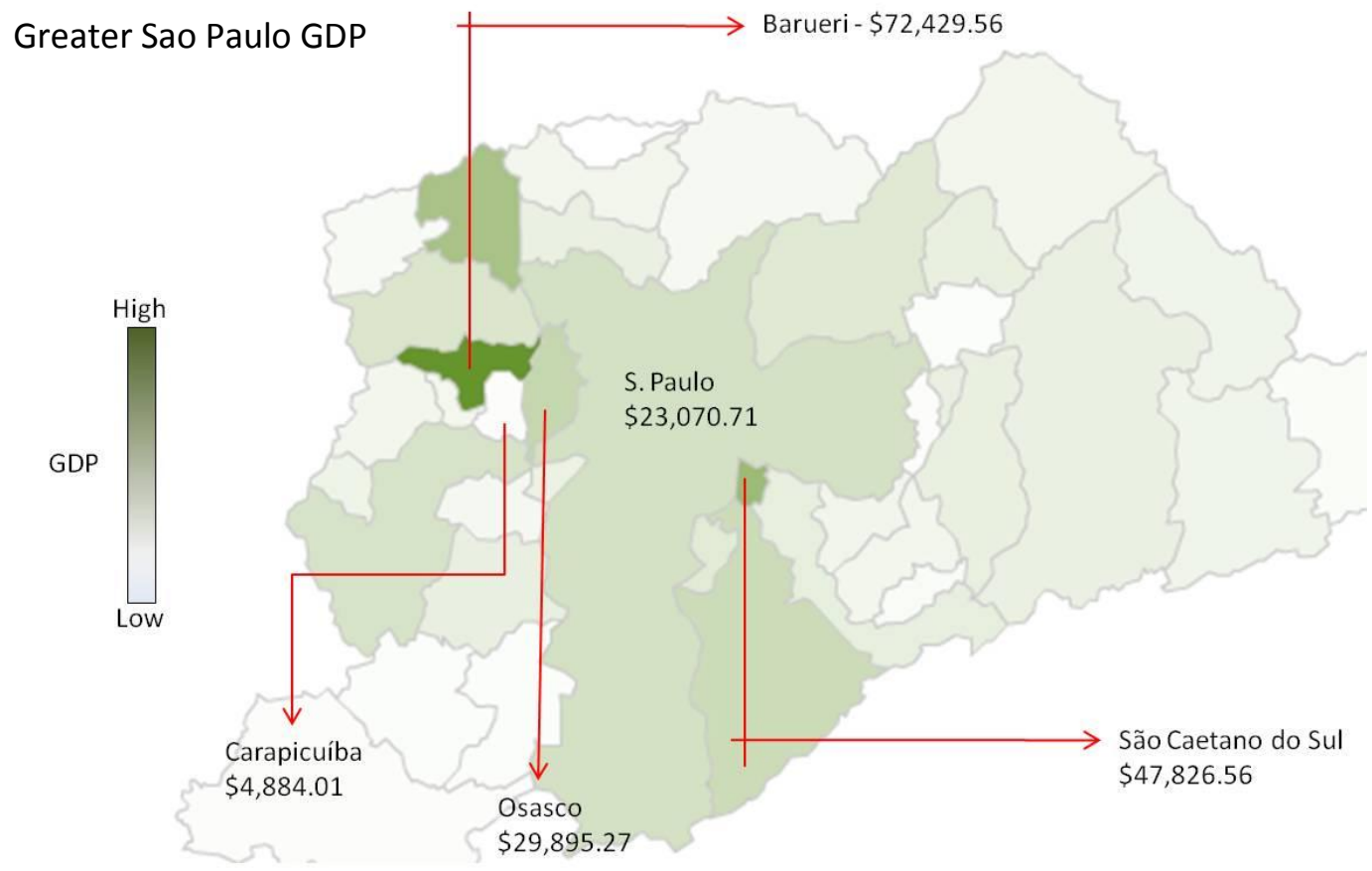

Figure 29 - Greater Sao Paulo GDP (In New Zealand Dollars) (IBGE, 2009)

Alphaville has, therefore, considerably increased Barueri's GDP. While the adjacent Carapicuíba has one of the lowest GDPs in Greater São Paulo, the GDP of Alphaville is about three times higher than the São Paulo city average.

\begin{tabular}{|c|c|}
\hline Sao Paulo Regional GDP & \\
\hline Alphaville Region & GDP / Inhabitant (NZD\$) \\
\hline Barueri & $\$ 72,429.56$ \\
\hline Osasco & $\$ 29,895.27$ \\
\hline Carapicuiba & $\$ 4,884.01$ \\
\hline Alphaville & $\$ 113,046.49$ \\
\hline & \\
\hline Sao Caetano do Sul & $\$ 47,826.56$ \\
\hline Sao Paulo & $\$ 23,070.71$ \\
\hline
\end{tabular}

Table 3 - Comparison between GDPs in Sao Paulo Region (IBGE, 2009) 
In summary, most of the well-planned new urban developments, especially in developing countries, display a trend to be more pedestrian unfriendly. This is because they have been following the consolidated sprawl model from the USA and Western Europe. Moreover, the analysis above, including the economic and social aspects, indicates that the low-density-sprawl and non-walkable model is a recent pattern of development.

The social structure created under this urban concept is segregationist and supportive of making homogeneous urban regions without the diversity which cities have historically enjoyed. Nevertheless, the non-walkable examples analysed here have a great number of green areas; these areas are private and serve a small number of people (low-density model).

Good paradigms for a walkable environment were found in low income regions of the city. Those regions have been feeling the impact of the absence of governmental planning. Despite this, they have developed a walkable friendly region less dependent on energy and public transportation. Even if efficiently developed for walking, the unplanned or non-controlled, normally poor, regions have low rates of green areas.

The international arrangements throughout the global economy have been based on such things as fossil fuel consumption, the automobile industry, international retail chains, and iconic globalization factors, which have singly and together been affecting local commerce. Historically, local commerce has been essential to keep the city walkable. This type of local commerce does not depend on transportation and works to enhance the sense of community. Most importantly it shows that a successful walkable environment also requires commercial changes. Therefore, a walkable environment is not only a simple energy saving device, is an old and successful urban system model, found throughout the historical development of cities. It is also significantly more efficient than the low density model of the new suburbs. 


\subsubsection{Redefining Design Priorities}

\subsubsection{Commercial Areas Designed for Local Commerce.}

The next three relevant aspects to achieving a true urban social efficiency were briefly explored above and will be considered together in more detail here. For example, some economic facets were brought up and the consequences of them for the urban environment outlined. However, the success of local commerce does not exclusively depend on favourable urban design. Probably its success will demand concentrated efforts between different sectors, such as the city council, good urban design, and change in consumption habits. Essentially local commerce has to be competitive in terms of price. One probable reason that local commerce is largely available in poorer neighbourhoods, as mentioned above, is the lack of private or good public transportation and not because the prices are necessarily lower. Indeed most of the large chains have lower prices, which is their primary aspect when it comes to commercial competition. In addition some representative chains have received tax incentives due to the fact they are large tax contributors, making it easy for them to lower prices and still be profitable. Thus, in recent times, local commerce has been pressured to modernize in order to survive.

Although the large commercial chains sell their products with a lower final price, the implicit cost of having such chains is probably disregarded by the consumer. The commercial expansion in Brazil can be taken as an example. In 1968, an important contributory change occurred in Brazil for supermarkets. They were recognized by the federal government as a special segment and the contributory taxes were sharply reduced. These tax reductions have boosted this part of the commercial segment since then. In 1970 the supermarkets were responsible for 2.2 per cent of the commercial sites and 29.3 per cent of the food sales in Brazil. In 2000 supermarkets represented 17 per cent of the commercial sites and sold 86.8 per cent of the food goods in Brazil. In addition, another factor was equally important in order to boost the supermarket expansion in Brazil. A considerable amount of money was offered by the government to aid the supermarket expansion. The loans have had lower market interest and a longer pay-off period (Belik, 2011). 
Although extremely controversial, the tax incentive is largely accepted as a veiled subsidy. In the end, a subsidy helps a commercial segment to be more competitive. The internationally accepted explanation of a subsidy is given by the United Nations Statistics and the World Trade Organization as being a financial contribution by a government or agent of a government, which confers a benefit on its recipients (World Trade Organization, 2011).

To try and deal with the international problem, some good experiments have been made in Europe, following a British model called Town Centre Management (TCM). This is a joint-venture between public authorities and private companies, the desired outcome of which is to renew and revitalize central areas. One of the goals is to increase the vitality and efficiency of traditional commerce. Furthermore the TCMs want to prevent the catastrophic consequences caused by the commercial model of the "out of town shopping centre and one-stop-shopping" (Castro, de Elizagarate, \& Zorrilla, 2006, p. 05). The commercial migration to out of town sites or to sites along a high-speed roadway has been taken as one of the most important contributors to the degradation and diminishing of the importance of local commerce. The decline of local commerce directly affects the urban dynamic; private transportation is universally demanded and the streets have to be adapted to receive a progressive increase in the number of cars; additionally, there is a loss of local centrality caused by the absence of commerce, which in turn affects the sense of community.

In order to draw up an appealing commercial environment the urban designer needs to face the local demand, understand the local consumption behaviour, and obviously the climate and the environment. On top of that urban design cannot neglect the basic and universal demands of commerce such as universal accessibility, good visibility, and shelter against bad weather. 


\subsection{Priority Given to Public Transportation over Private Transportation}

The availability of good public transportation is essential to achieving a satisfactory level of urban social efficiency. Firstly, the function of public transportation when analysed under the aegis of urban social efficiency is to allow the financially underprivileged segment of the population to reach all parts of the urbis. In addition, public transportation also serves the disabled, the elderly, and all people unable to drive. Therefore, public transport also has to have an affordable fare structure. A walkable environment and a good public transportation system combined provide an acceptable base for urban accessibility.

Public transportation has been an important part of government policies to shape cities driven by various obscure interests. Transport authorities commonly face the dilemma between investing resources in highways or public transport, the problem being that the latter needs subsidies to operate. In the USA with an urban structure already strongly based on suburbs the resources are still mainly put into to highways. Between 1992 and 1995, for example, the USA had more than \$33.8 billion available to spend on either public transport or highways. However, the amount spent on public transportation was lower than 15 per cent, and in addition around half of this sum was only spent in two states, California and New York (Lewyn, 2001, p. 264).

Government investments in highways, which indirectly means in private transportation, are larger than the simple investment for the construction of roads. The progressive traffic growth demands an enormous amount of money in strategies and traffic management, medical care resultant from accidents and air and noise pollution. However, unlike public transport subsidies, these costs are seldom connected with driving as a transport system, and the authorities keep investing in highways and roads instead of public transportation. Discouraging private transportation has not been the priority in recent years. New Zealand, for instance, has watched a massive investment in highways and roads while public transportation seems to be left in a secondary role. The Policy Statement on Land Transport Funding 2012/12 - 2021/22 demonstrates a clear intention to increase 
the funds for new and improved infrastructure while public transportation and walking / cycling are to have their funding kept constant, except for 2016 when the funding will decrease by more than 10 per cent (Ministry of Transport - New Zealand, 2010, p. 14).

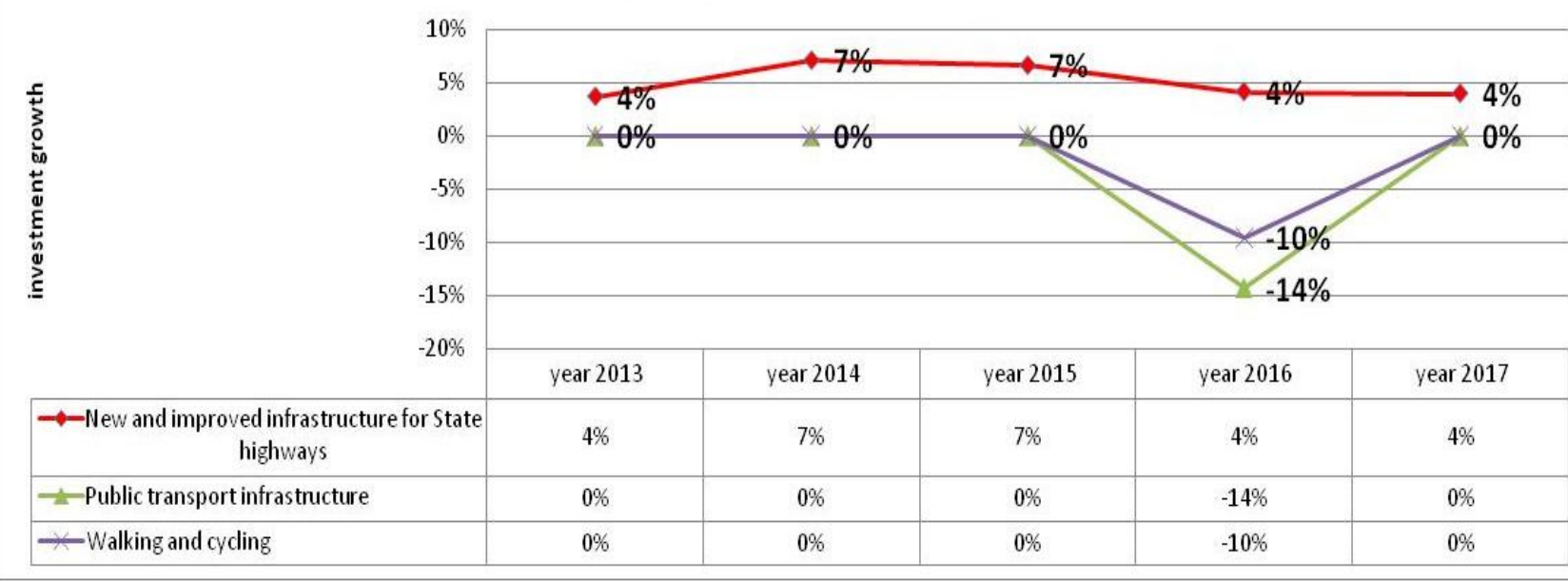

Figure 30 - Comparison between government investment in public transportation and highways in NZ (Ministry of Transport - New Zealand, 2010)

However the situation is more significant when the parameter is the amount of capital invested as can be seen in the chart below. Investment in walking and cycling barely appear on the graph with most money going to new and improving main roads. The amount of investment that will be made in infra-structure is essentially focused on fossil fuel transportation, instead of cycling and walking, indicating the continuity of the current model of transportation.

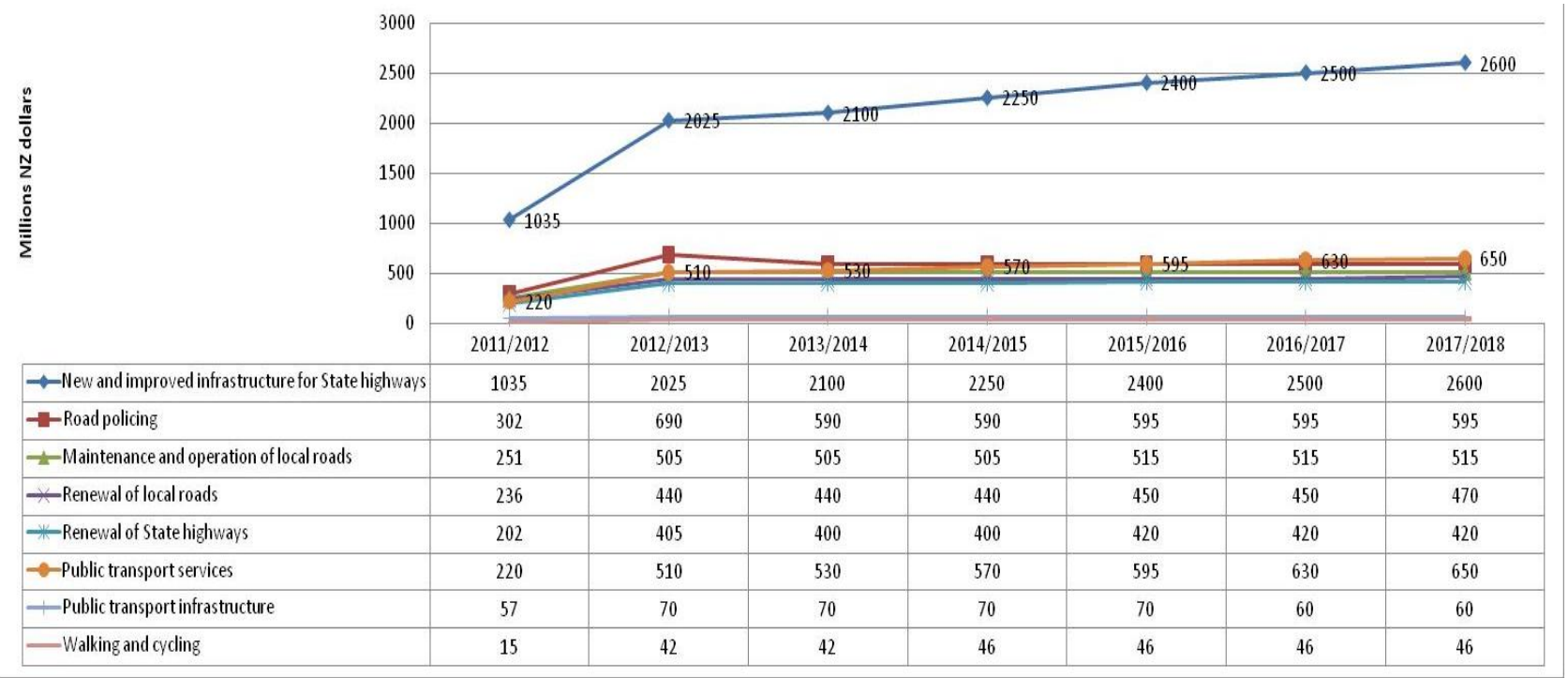

Figure 31 Comparison between government investment in public transportation and highways in NZ 2011 - 2018 (Ministry of Transport - New Zealand, 2010) in million NZ dollars 
The amount of direct capital used in highways and road infrastructure is just part of the real problem. It is the part that can be easily seen. The pro-highways lobby has reduced public transportation ridership and created a transport environment that facilitates people and commerce to move from the walkable environment of the inner city to the far suburbs. This new residential model, based on low density and long distances combined with competition from private cars, has become a battle for public transportation that may be hard to win until petrol really does start to become scarce and expensive.

Analysing the situation from the environmental and social viewpoint the massive investment in highways and roads over public transport seems senseless. However, the economic analysis is easy to understand. A pro-highways and roads policy has supported the relevant industrial sectors such as automotive, steel and oil. Any impact on one of these sectors will also impact on tax collection, and therefore, government revenue. It is an important part of the vicious spiral within which governments and societies have become trapped. As governments have encouraged the middle-class to migrate to far neighbourhoods through investments in roads and highways, the urban tax base has progressively decreased causing the authorities to reduce services and accelerating the migration process to the suburbs. In the example shown below, the total investment in roads and infrastructure, from 2008 to 2018, will be NZD\$ 27 billion, while public transportation will take only 4.4 NZD\$ billion.

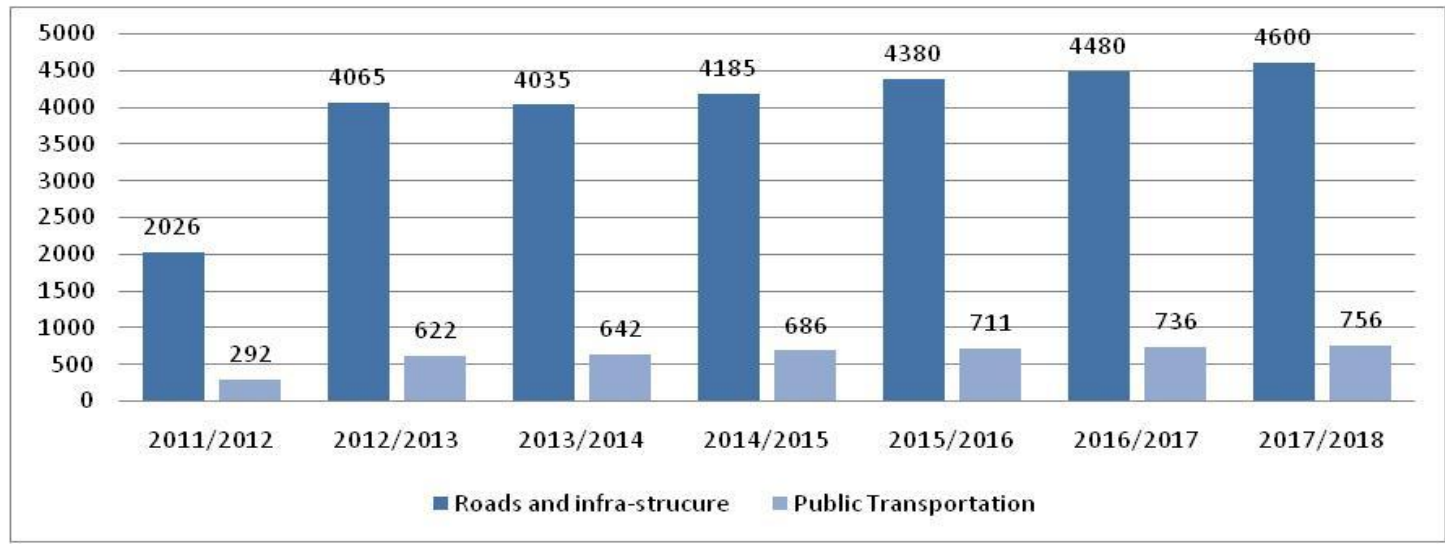

Figure 32 - Investment in Roads and Public transportation in NZ (Ministry of Transport - New Zealand, 2010) in million dollars 
Public transportation was first affected when the public and employers fled from towns and secondly as the ridership has consequently decreased. As a result, the authorities have used this to justify reductions in the services. Consequently, reductions in ridership have decreased the transport revenue, occasioning further reductions or fares increases, which diminish ridership even more.

The whole system seems to be designed for use of private transportation. Employers provide parking to their employees instead of providing financial incentives to employees to use public transportation. In the USA, companies commonly make available parking places which are worth up to U\$ $170 /$ month, while transit passes might be only U\$65/month (Colleman, 2010).

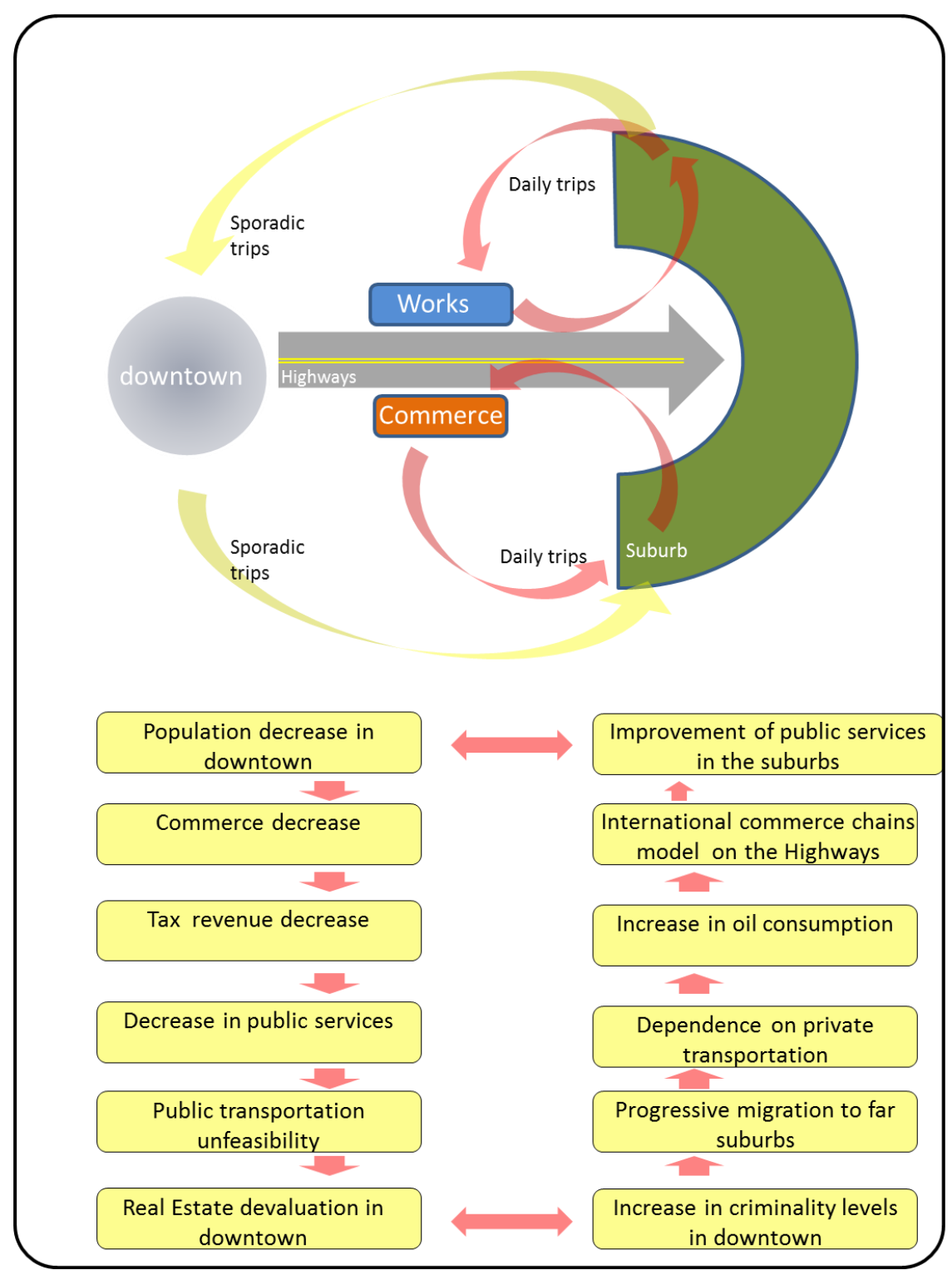

Figure 33 - Transportation cycle and impacts on the social and urban environment 
Local and national governments are partners in policies to decrease the effectiveness of public transportation, even though such a move seems counterproductive. There are many indirect costs associated with private transportation that are normally ignored. Some costs can be easily associated with private transportation such as the maintenance and improvement of existing roads and new infrastructure. On the other hand, some costs that have obviously originated with the growth of private cars are probably not taken into account by society. Examples of these problems are strategies for traffic management (traffic police, traffic engineering, traffic signalization), medical care resultant from accidents (as mentioned above), and environmental problems caused by the whole private transport chain. However, some members of society are now concerned about energy resources, which are a part of current transportation problems. In the USA 83 per cent of the population supports the state development of renewable energy (Opinion Research Corporation, 2006 in Byrne, Hughes, Rickerson, \& Kurdgelashvili, 2007, p. 4566). Nevertheless, the US society desire to achieve more renewable energy generation has stopped with the well articulated lobbies. The influence of the automotive and oil industries in US energy and environmental policy can explain why it has been hard to move towards a national policy to reduce dependence on fossil fuels. In addition, representatives from the oil industries have assumed important positions in the US administration, and have even been some of the main White House advisors (Byrne, Hughes, Rickerson, \& Kurdgelashvili, 2007, p. 4567).

Although, the data presented is related to the USA, there is no reason to believe that the same lobbies or arrangements do not happen in other countries. Most of the companies which act in the USA are transnational and probably expand the same influence worldwide. The car industry, for example, is extremely concentrated with the top 10 global automakers answering for over 77 per cent of world production (Zacks Investment, 2011). The economic structure which supports private transportation is correlated with low-density suburban sprawl. This is a society whose composition originated in the federal sphere and is promoted through federal policies. At local government level, any influence on 
these policies is normally more related with urban design to cope with private transport. One of the most powerful tools for consolidating private transportation are the zoning plans encouraging suburbs with low-density and restricting, for example, the construction of multifamily buildings, like the residential zoning policy in Sao Paulo, called Z1 (SEMPLA, 2012). In addition, significantly some low density districts also restrict commercial areas, and as a result, low density districts are auto-dependent.

Cities have been affected by the progressive growth of private transportation. The new urban developments have to take into account the hierarchy that private transportation implies today. For example, in Brazil, road systems in new urban developments can commonly occupy more than 20 per cent of the total site area.

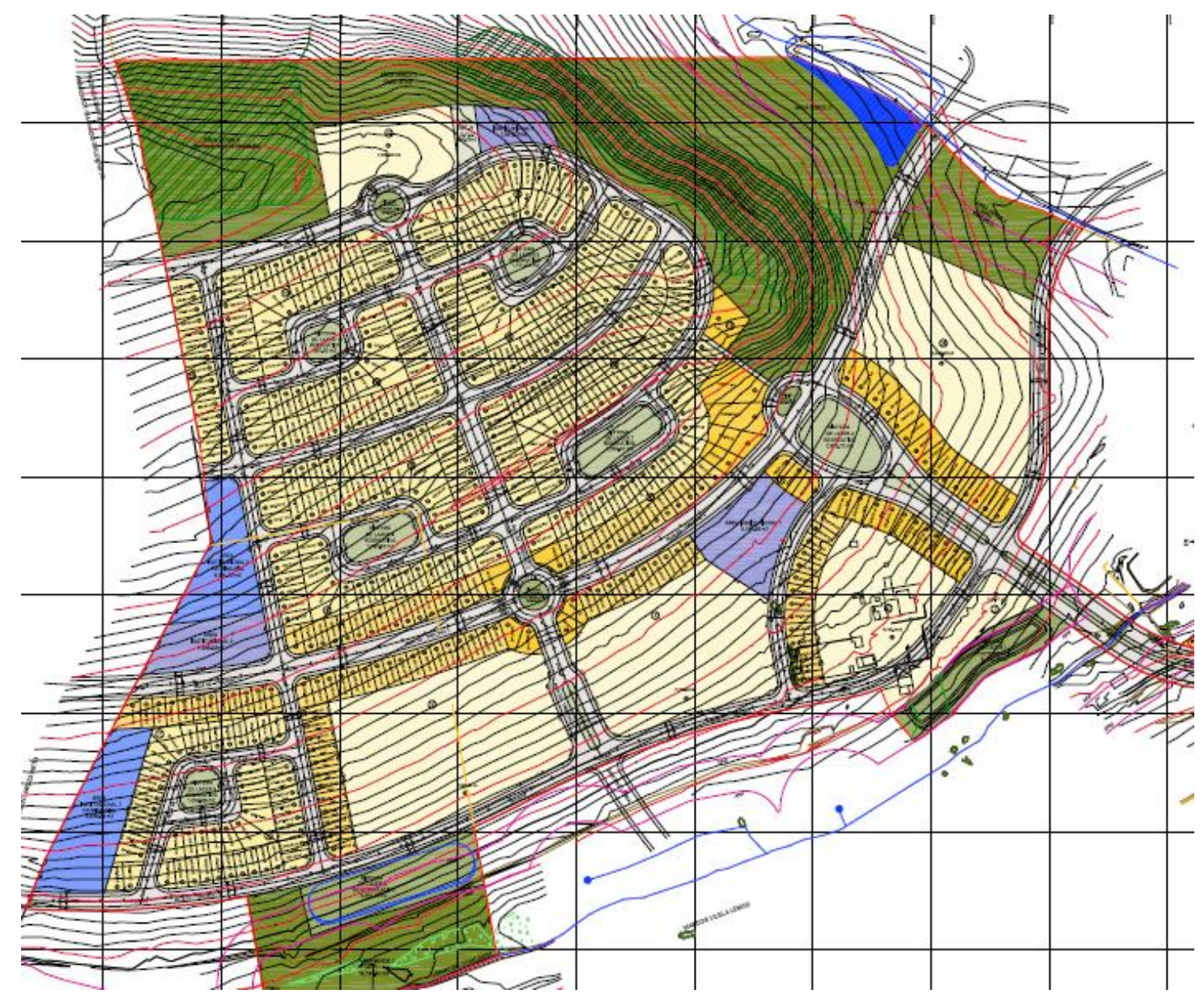

Figure 34 - Subdivision in Ribeirao Preto, Sao Paulo, Brazil developed by the joint-venture CIPASA, SCOPEL and WTB, with 23.63 per cent road cover in its original design 


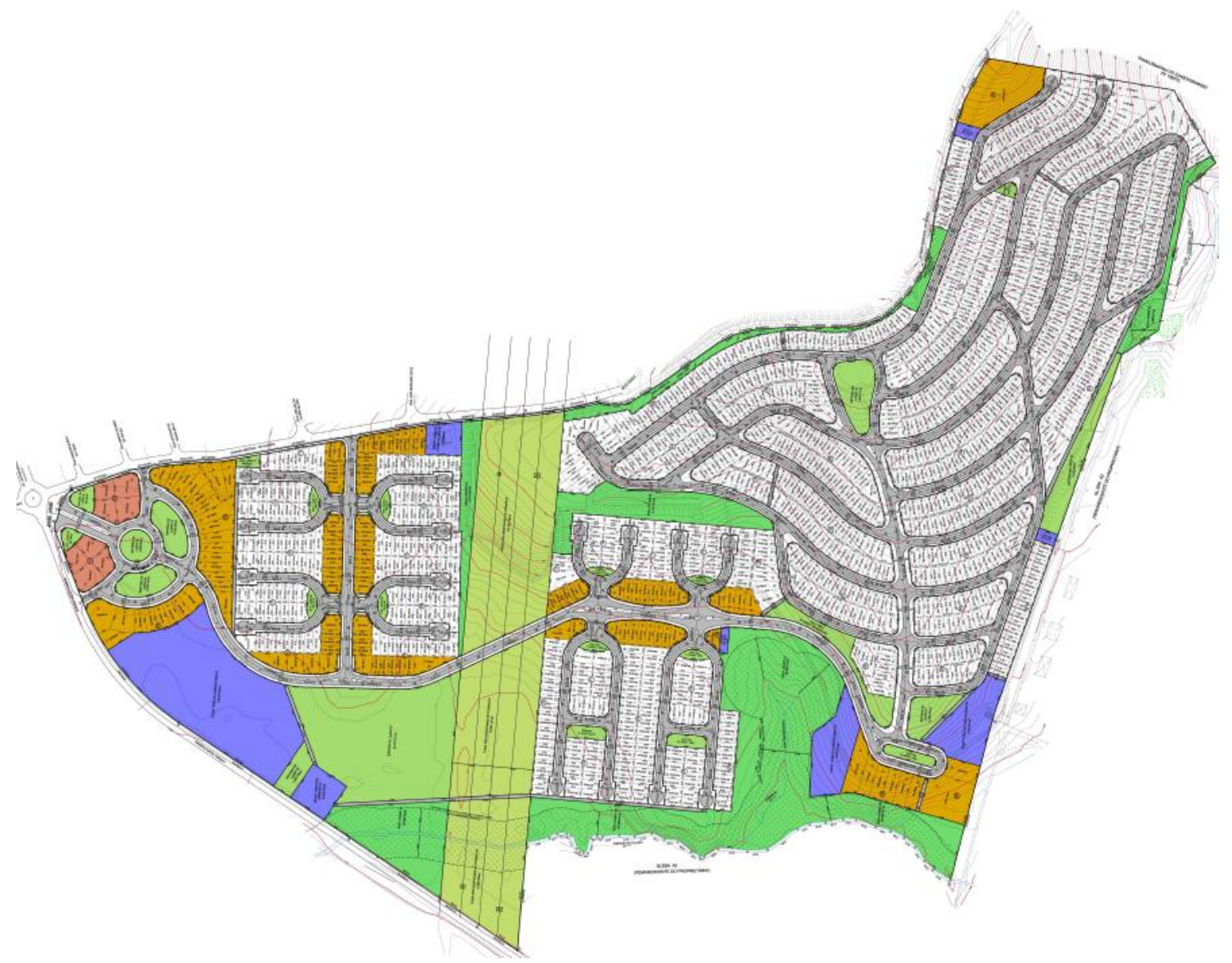

Figure 35 - Subdivision in Mogi das Cruzes, Sao Paulo, Brazil developed by the joint-venture CIPASA, SCOPEL and Helbor has 20.78 per cent road cover in its design

New Zealand follows a similar pattern. According to John Howard from Bayleys Real Estate (2009), new developments in Auckland have between 20 and 30 per cent road cover in their design (Howards, 2010).

Modern society keeps demanding more cars. Even after the recession due to the international financial crisis, the auto industry has had a dramatic growth. In 2010, Ford's sales increased 19 per cent while GM and Chrysler grew 7 per cent and 17 per cent respectively; these three companies combined sold 5.3 million new vehicles that year (Zacks Investment, 2011). While modern society keeps demanding new cars and basing its trips on private transportation developers will keep the present built environment production patterns.

In conclusion, for urban social efficiency public transportation is essential in order to allow people to move around without cars. Moreover, whenever citizens are dependent on private transportation they are also taking part in the whole 
production chain behind it. The consequences of the abundant use of private transport unfortunately overlap on to the car users. The gas emissions by fossil fuels, extraction of iron, and the level of energy demand impact the whole of society. The goal in promoting public transportation is to share the opportunity for all citizens equally to travel around the urbis. The economic interest has been trapping urban design, which needs to propose new egalitarian designs. Urban designers probably need opportunities unrelated with trade and economic pressures in order to produce a different urban design. This design may be based on the effectiveness, ecologically and socially, of public transportation. This new approach might be able to produce the same urban revolution caused by cars a hundred years ago.

\subsection{Reduction of Private Areas over Common Areas}

The progressive growth of the low density suburban model and the privatization of green areas have acted against urban social efficiency. Although the disproportionate house sizes will always be part of the problem, the main problem with urban design efficiency is the privatization of what should be a collective interest, such as green areas, natural water features, or sometimes even vacant land. Whenever urban design creates large private sites automatically there is transference of green area or free areas into these, and ultimately a collective interest has been privatized.

In order to drive society towards urban social efficiency, the urban designer has to reduce the size of private sites. However, again, a decrease in the site affects the interest of developers when some of the development area has to be publicly shared. It means less saleable area. Driven by profit, as the essence of their business, real estate developers satisfy the legal demand for green space, which is the minimum acceptable and far from socially efficient, and nothing more.

The situation becomes even more dramatic when gated communities are scrutinised. Philosophically a gate is a restrictor of access and free transit, which are basic city concepts. On every occasion that a gate is installed in a region with a 
neighbourhood dimension more than green areas are privatized, as streets, sidewalks and any sort of urban equipment also become private.

The illustrations below show a schematic proposal for re-insertion of green areas into the urban grid.
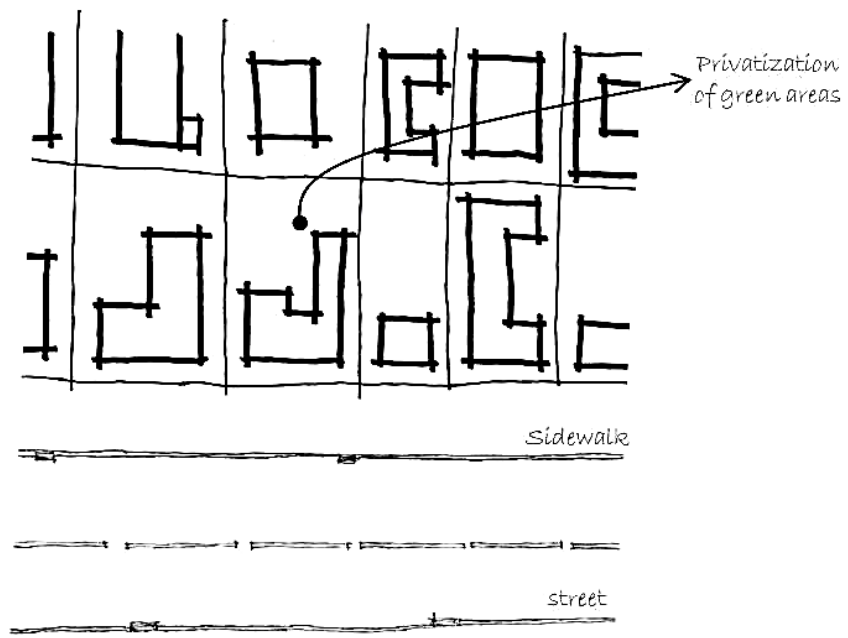

Figure 36 - Common urban block design. Residential site, sidewalk and road

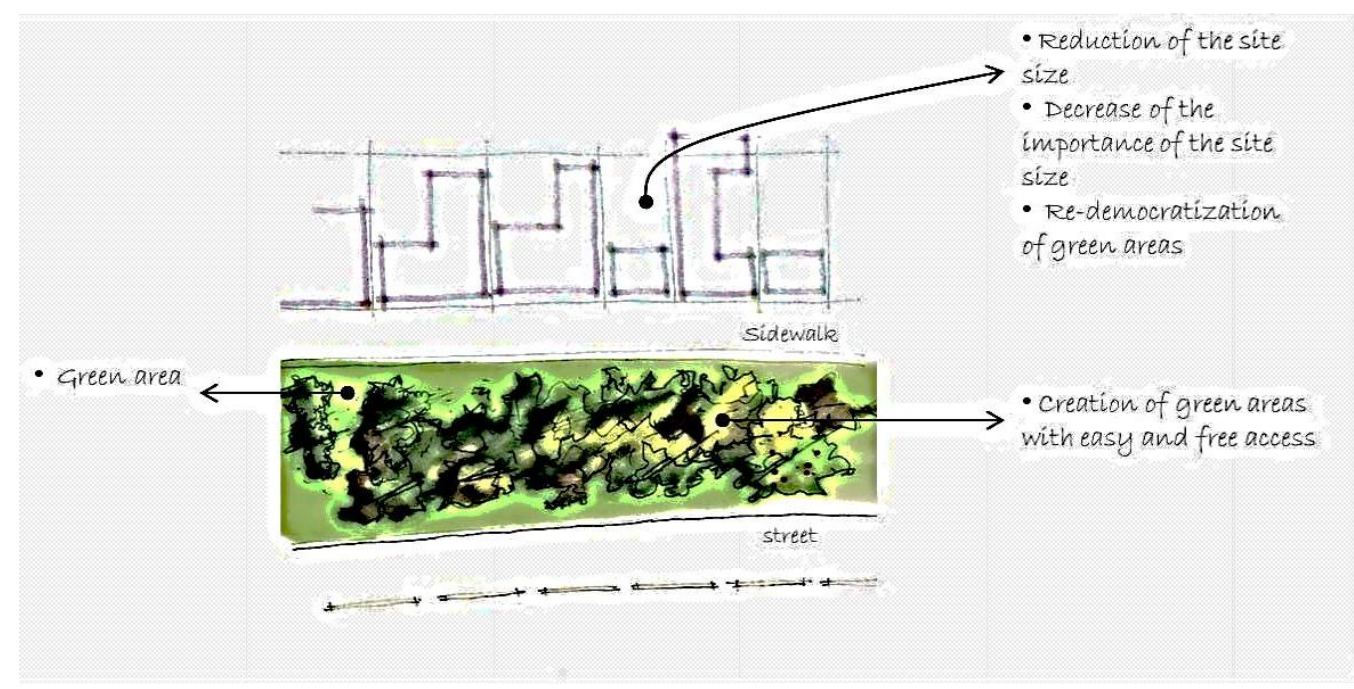

Figure 37 - Example of urban design integrating the principle of green areas and minimizing the importance of road, therefore cars, in a subdivision 
In summary, urban design to have a sustainability dimension has to focus on the collective interest instead of private property. Public and green areas have to be used to reinforce the sense of community. Moreover, these natural elements in accordance with urban social efficiency have to be available to the general public as much as possible. Under this aspect, the public interest clashes with the real estate developer interest. On the one hand, the real estate developer wants to maximize profit by creating more saleable area, while in contrast, the public interest wants to maximize access to green and free areas. This conflict also has one more component; the issue of zoning. Developers produce new developments according to the law, which in some cases is overly permissive of developer interests. Zoning is a great instrument to keep the urban model one of privatizing green areas as part of the spiral described before, but it could also be used as an instrument for creating urban social efficiency.

\subsection{Preservation of Ecosystems and Green Corridors}

Preservation of ecosystems and green corridors are also part of maintaining the collective interest. However, instead of simply delivering these areas to society their ecological relevance may demand access restriction, total isolation or some other preservationist action. This means that ecological green areas may be in conflict with the human need for public green areas.

Green corridors may have to be developed and maintained as part of a larger preservation chain, which in the end will serve the whole of society. In order to minimize the impacts caused by human occupation, the preservation of ecosystems and green corridors are vital to achieve a real social efficiency. Therefore, urban design must act in accordance with this goal. This means even larger green areas may be required in cities (for food as discussed below, for natural eco-systems and for human recreation) so it is essential that those for people are shared by all, rather than being private. 


\subsection{Urban Food Production}

The concept of growing food in urban areas is not a new idea. Indeed, both western and eastern societies have been extensively associated with urban agriculture (see chapter 3). Food production in towns and cities will result in social, environmental and economic benefits. Historically food production has been one of the main products in the creation of regional environmental imbalance. The re-introduction of urban agriculture as a municipality priority policy will be a determinant for reestablishing regional environmental balance and minimizing the consequences of the current imbalance. Moreover, the development of a highly organized structure to grow and produce food inside urban areas will bring to the fore some of the most significant problems seen in modern towns and cities, as briefly described above. Therefore, food production is indispensable for an urban social efficient region.

One of theoretical important aspects of food production in towns or on their fringes, is to reconnect people and food production. The main issue caused by this disconnection is the fact that the urban population has a restricted knowledge about the problems associated with food production. Due to the lack of contact and awareness, most of the urban population cannot properly criticise the status quo. Any food production in the cities will probably bring up other essential notions for the population, especially notions of space and limitation. When consumers purchase their food goods without any realisation of how much land is needed to provide that item, it is relatively easy to understand why part of modern urban society consumes food potentially harmful for the environment and themselves (Viljoen, Katrin, \& Howe, 2005, p. 21).

Consequently, urban food production will minimize the gap created by the polarization between rural and urban areas. These two distinct poles have determined that some relevant nuances that occur in the peri-urban-interface have been lost (Allen 2003 in Redwood, 2009, p. 5). Undeniably, the transition between the dense core of the cities to the low density and more productive suburbs has historically been an indelible part of cities. These city perimeters have been, for most of human history, the first food supplier to towns. In addition, they have also 
been one of the biggest employers and responsible for the main regional dietary characteristics with respect to seasons and climate.

Food production inside the urban fabric has been commonly ignored or discouraged. Because of the European historical context and colonial system, food production for people in towns has been seen as a separate thing from the town itself (Redwood, 2009, p. 5). Indeed, the colonial system, as part of mercantilism, has worked throughout the colonies by treating these as raw-materials suppliers. At some point, monarchies have replaced the agrarian and rural feudalism (despite the fact the towns and cities of this time still had a physically close link with local production), and a progressive urbanization has started in Europe culminating in the Industrial Revolution. During the Middle Ages, settlements in Europe have relied on arable land in order to provide food, as also happened in ancient times in both east and west. As cities have expanded over the agriculture areas, it means an ongoing food demand has continuously been created since the spread began.

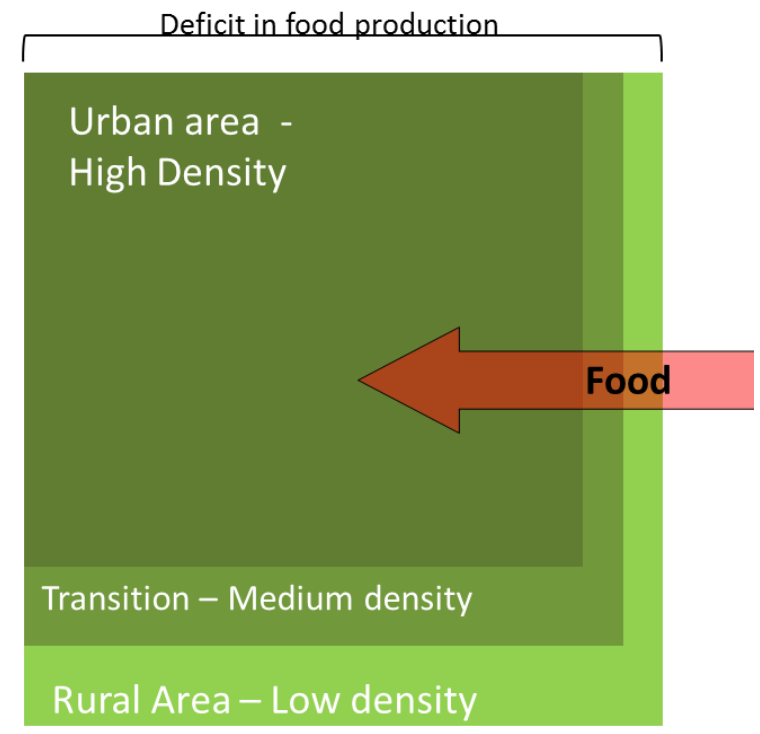

Figure 38 - Present hypothetical model of urban development. Urban area almost totally taken by built-up areas making the city rely on outsourced food supply

This brief historical approach has tried to explain why food production in towns is presently relegated to an irrelevant economic position. Cities all over the world have denied the historical contribution of urban food production and some have 
even forbidden the food production activity, as found in the Sao Paulo ZR1 zoning (Redwood, 2009, p. 1; SEMPLA, 2012). The new model of food supply is different from the traditional and ancient model of food production. This new model is commonly called agribusiness. Agribusiness is a business system which has a wide range of strategies, which aim at profit maximization (MF Rural, 2012).

\subsection{The Social Function of Urban Agriculture}

In order to understand the social importance of agriculture, it is necessary to understand how urban society has been losing space in the town, and why.

Agribusiness is a part, maybe the most relevant one, of the state of regional imbalance. During the 1970s the process of agriculture modernization incorporated the same ideology as found in the industrial, commercial and financial process. This process has triggered the concentration of control to just a few groups, for most of the food production and distribution chain (Vilela \& Macedo, 2000, p. 88). Due to the fact food production has become an enormous industry, the state has also become part of the process. In fact the state has been more than an incentive in agribusiness. It has been negligent in not supporting different scales of agriculture like subsistence and family production (Simão, 1986, p. 23). Although, in the capitalist model subsistence food production has been totally ignored by the state, family production, which can be responsible for employing at least 50 per cent of the family labour in some parts of Brazil, is still relevant and struggles to keep up (Simão, 1986, p. 24; Vilela \& Macedo, 2000, p. 88/89).

Indeed the family and subsistence models have been directly affected by agribusiness. Wherever agribusiness has already been consolidated, local food production will be quickly replaced by large scale food production. The land becomes highly expensive and its cultivation with low aggregated value cannot compete against mass agriculture production. (The progressive increase in the price of land in rural areas is a similar process to that which occurs in urban areas, as will be discussed later.) Worldwide family and subsistence agriculture have had a relevant role in feeding families in poor countries (Giradent in Viljoen, Katrin, \& Howe, 2005, p. L 702). This may demonstrate one of aspects of the social 
importance of this sort of food production, which works to supplement, or even be, the most important food resource for poor families around the world. In addition, when poor families are able to produce a surplus, it normally goes straight to the local market, activating the local economy. If equality is the goal, it may become important to impose a real obstacle in the path of the international food production and distribution monopolies. The dependence on multinational supermarket chains for supplying food may disarticulate part of the local and national economies. Only a small amount of the money will be retained in the area in the form of wages to local people working in food retailing. In contrast, local food production has an economic multiplier effect. Every dollar spent on local food through small initiatives such as family or community production generates approximately two dollars fifty cents because money is spent on other local commerce for goods and services (Paxton in Viljoen, Katrin, \& Howe, 2005, p. L 802).

Although local agriculture competes against international and subsided industries, its final costs may be competitive and attractive. Local food does not depend on middlemen; moreover, it eliminates the profit chain keeping the possible surplus in the community.

More than the social impact due to the changes in the economic aspects, there are significant possible changes at the community level. These include a real possibility for local management of green and free areas, an opportunity for informal and formal education linked to real practice, community enterprise development and training, and creation of social cohesion. Any environmental improvement may also be taken as a social enhancement. Therefore, the ecological benefits that come with local food production are also social improvements. This model of food production will reduce greenhouse gas emissions, improve air quality and humidity, and decrease the food footprint due to a decrease in transportation and packing (Viljoen, Katrin, \& Howe, 2005, p. L 395).

Food transportation is, in fact, a major problem. The process to bring food to the final consumer conceals the number of trips that food makes to be available in the retail outlets. The final consumer probably ignores the inherent seasonality of food production. An efficient distribution system is perfectly able to provide every sort 
of food throughout the year. Indeed the distribution efficiency has become more than a marketing tool to provide every sort of food in all seasons, as it is now an important part of the food business. Supermarkets have to keep the products available all year round. Imported foods do not just fill temporary breaks; now imported food is available even when the same products are in season in the locality.

This has happened because the distribution system, and probably a huge subsidies chain throughout the process, keeps the prices lower even when competing with small local producers. The effects of this process are more complex than the obvious ecological and social problems caused by this system. The permanent distance between the final consumer and producer promotes total ignorance about the limits of food growing as an ecological and social problem. In fact, it has become an educational problem. Simple and cheap political decisions could be helpful in order to inform the public, such as a labelling system informing the distance that food had to make to be available in that supermarket. Apparently lack of information for the consumer is also part of the business. This ignorance is convenient and allows more ecological and social abuses (Viljoen, Katrin, \& Howe, 2005, p. L 710). Also the local food production model will act against the overprocessed, over-preserved, and over-packaged foods, which are now readily available, and which are essentially foods with low nutritional value (Viljoen, Katrin, \& Howe, 2005, p. L 810; Vale \& Vale, 2009, p. 71).

The long distance travel of food consumes a considerable amount of energy, mostly fossil fuel, and moreover, it changes the way food is grown and prepared. It requires that the food stays looking fresh for a longer time and this means overpackaging to protect and keep food, packaging that then goes straight to the waste chain. For urban social efficiency, food production areas need to become part of local and regional urban design. 


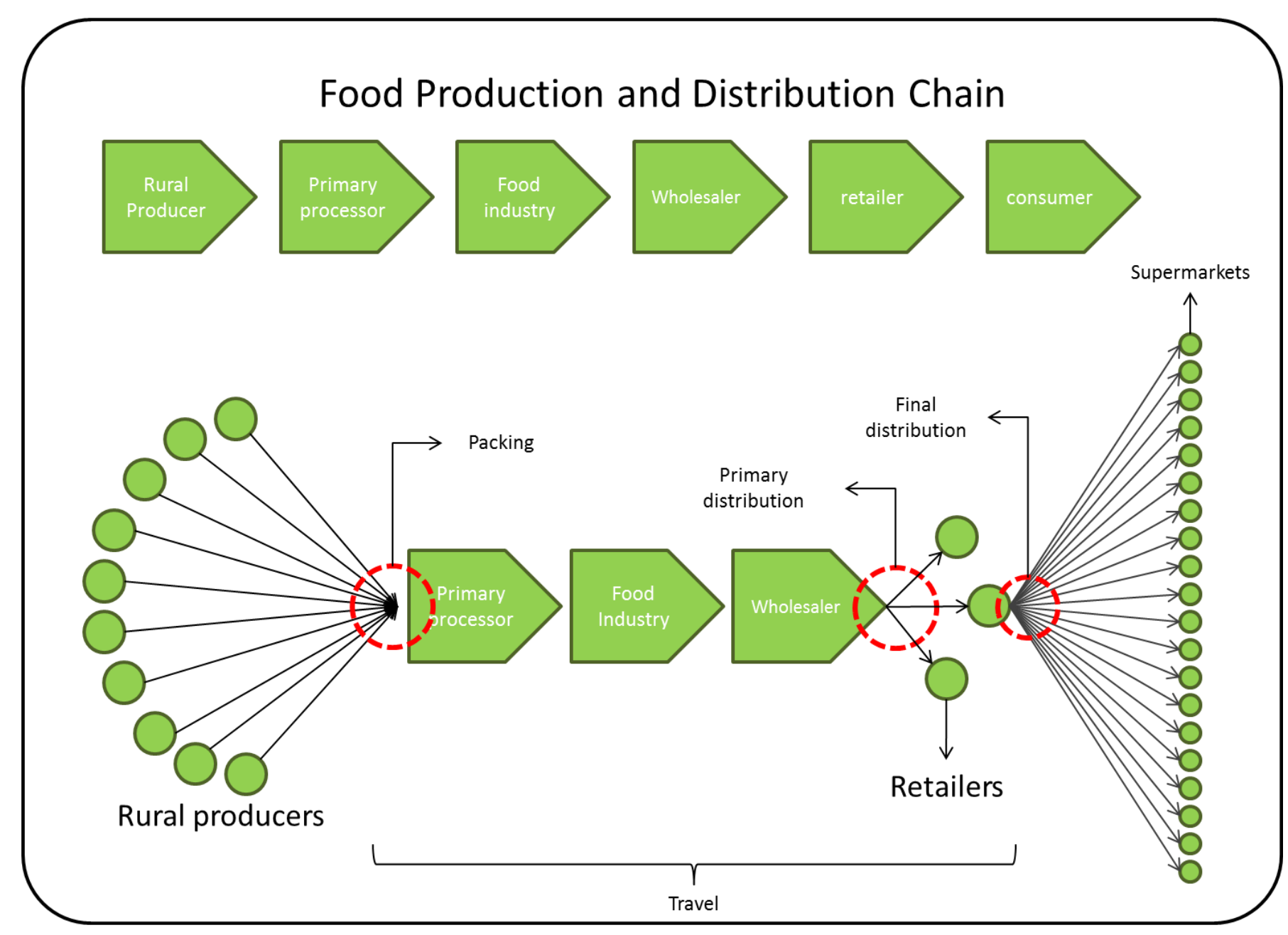

Figure 39 - Distribution chart showing the process of goods distribution and illustrating the importance of distribution for retailers

\subsection{Integrated Transportation Planning and Design}

Urban social efficiency depends strictly on the excellence of the relevant transportation system. This does not mean exclusively people transportation but also goods transportation. Therefore, cities and new development plans have to include these aspects in the design from the start. Because urban food production is also relevant for urban social efficiency, design and transportation planning have to be integrated in order to minimize costs and energy consumption, decrease food delivery time, decrease prices, eliminate middlemen, and reduce the chain and hence the consecutive profits. 
Even a relatively balanced city, in terms of food production, may be inefficient in goods transportation. Pragmatically city expansion and the status-quo designs of today are not functional when or if food production is part of the city system. Most of the cities which have food production relegate the production to the peri-urban areas or even place it outside the accessible urban perimeter.

\section{Comparison between city design according to food production}

\section{Model 1}

Most common city design model. This model is not self sufficient regarding food production. The urban fabric does not take into account local food production. The suppliers are from other regions. This conceptual model is the basis of regional imbalance.

\section{Model 2}

Although model 2 illustrates a self sufficient region in terms of food production, the schematic drawing also demonstrates an inefficient transportation system. Food goods have to be shipped across the region to reach the main market.

\section{Model 3}

Model 3 shows a self sufficient region concerning food production. The design guideline take into account the position of the main market and optimize the transportation efforts in order to save travel, energy and road infrastructure. Food production is intentionally allocated around the main market. This schematic zoning facilitates the transportation and potentially creates employment in food production.

Figure 40 - Comparison between three different models of urban design according to food production and local supply system 
Essentially the transportation system, along with urban design, planning and zoning, have to be developed in order to be energetically and socially efficient. The design and the transportation system have to privilege food production as much as the travel for home - work - home. According to this criterion, placing food production alongside work areas, or residential areas makes ecological sense.

Indeed a transportation system as an inclusive design can promote a new understanding of urban food production. When the design incorporates the transportation system, zoning, and food production, the food production will assume a different dimension inside the urban fabric. Instead of being a disconnected and secondary component of urbis, food production will be an indelible part of the city, representing the essence of the city and its limits. Fundamentally if any region is unable to feed itself, in theory this should be regarded as not a feasible situation.

The proposal of new urban development bringing about the integration of food production and transportation is essential in order to advance towards a balanced region in terms of environment, commerce, and social aspects. Obviously transportation has to be included in all new designs and food production cannot be based on the capitalist hungry-for-profit system. Indeed, the transportation system should serve commuters and food production bringing foodstuffs to high-density population areas, which because of zoning restrictions or unavailability of land do not have food production. These zones were previously called deficit food producers regions. An efficient local transportation system may incorporate local food production in the existing distribution food network. Most of the modern food business relies on an efficient distribution network. The supplier depends on being able to move goods from the origin of their production, through packaging plants, to distribution centres, from where they are finally shipped to the final sales centres (supermarkets). Small producers do not normally have access to such a distribution system, therefore, cannot compete and insert their production in the market. Today the majority of the food that comes to towns relies on integrated large-scale distribution (Viljoen, Katrin, \& Howe, 2005, p. L.579; Pfebve, 2009, p. L.1043). This is the situation that needs to be reconsidered for urban social efficiency, so that small local producers can get their food 
to consumers with the minimum of travel and packaging. It would decrease the consumption of energy, therefore, resources and theoretically decrease the prices, improving purchasing power for poor people.

In conclusion, the transportation system should be an essential part of city plans. It, therefore, should be planned and dimensioned in accordance with the city's inhabitants, new developments and subdivisions. Fundamentally public transportation, in a socially balanced urbanity, should be the primary option for transportation. In contrast, now public transportation is probably just an option to fall back on when individual transportation is not available. Individual transportation, mainly cars, is a major part of both the large production chain based on fossil-fuels (as will be seen below) and consumerism. Promotion of public transportation will play an important role in recovering regional balance. It ultimately decreases energy consumption and the dependence on fossil-fuels. Public transportation demands less area, and consequently reduces traffic and the public clamour for road infrastructure. Its provision should directly impact on urban design and the way that new developments are planned. Today new developments require around 20 per cent of land area for roads based on a private transportation system. There would be a relevant reduction if the transportation model were based on public and mass transportation instead of the private option. This is fundamentally a matter of space (land which could be productive) and energy (the need not to rely on fossil fuels). 


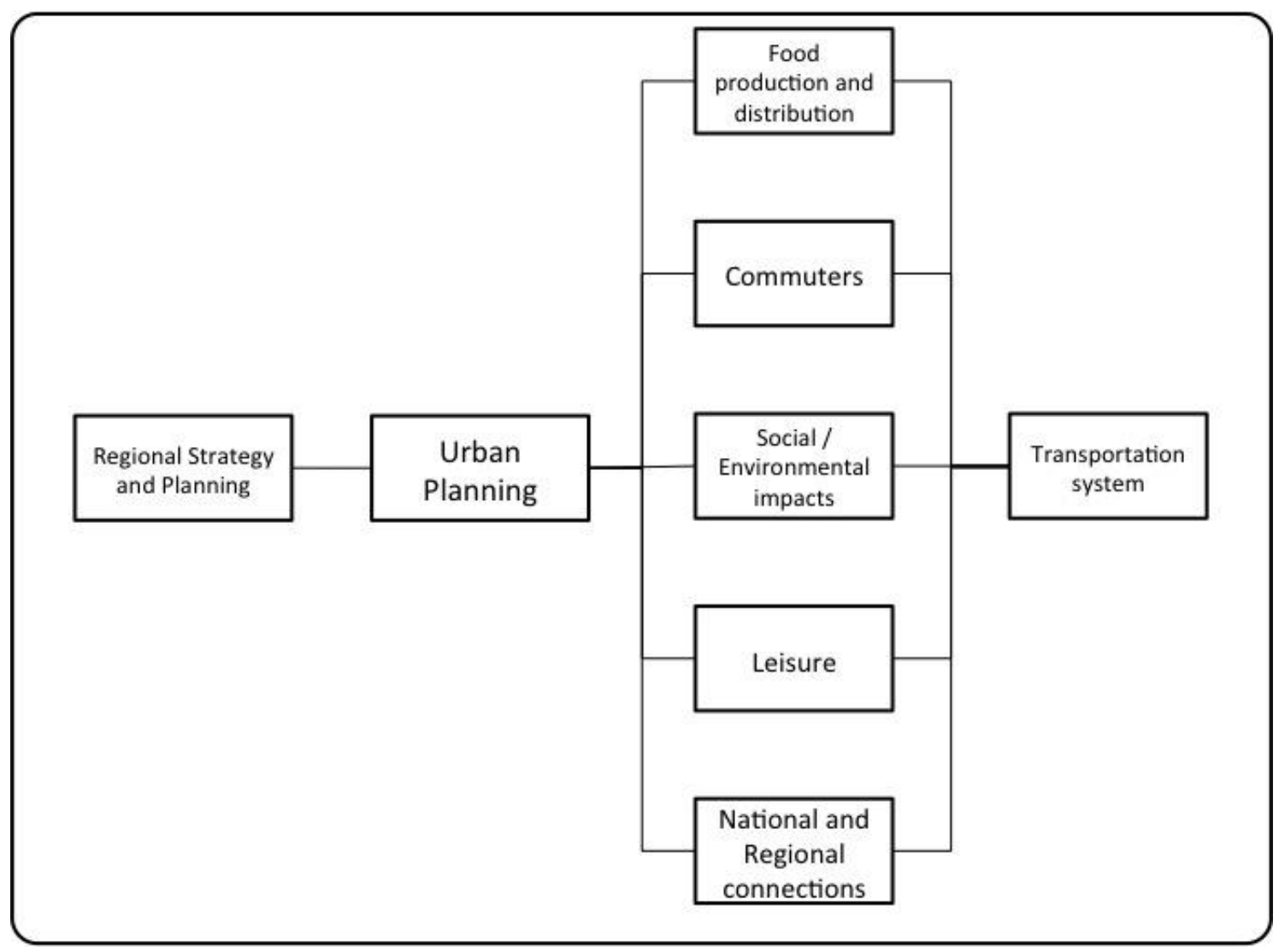

Figure 41 - Conceptual model chart for regional transportation system

Figure 41 illustrates the complexity on which a transportation system has to be planned. In order to have the transportation system acting as a component of an urban social efficient region, planning for it has to emerge at a very early stage. Furthermore, all the analytical processes mentioned above have to be equally taken into account. These processes will naturally drive the transportation system towards a public and mass transportation option. Some factors have been neglected by modern planners and authorities, such as the social and environmental impacts of using cars (as will be seen below). Some others have been ignored because they are out of the agenda, such as the distribution of local food production. Public transportation ought to provide an option for the small food producers, located around the high-density parts of the town, to distribute their products.

Additionally, if these factors are given more equal weightings, this will suggest to planners some feedback about the modern day-to-day routine. The compulsory long daily travel to work, shopping, or school by car would be seen as a contradiction. Such travel is directly acting against the social and environmental regional aspects, therefore sustainable urban design will demand some fundamental changes. Urban designers 
should be aware that even most public transportation journeys could be avoided if the urban design encourages safe walking and bicycle travel and if cities are designed to avoid the need for regular long trips (the energetic aspect of this will be developed below). Indeed, public transportation should the primary transportation option when a journey is inevitable. Under these premises, authorities would encourage short journeys to work. Cities would most likely become polycentric with many small, dispersed centres. Understanding the effects caused by transportation will bring up a different approach to many everyday activities. People would be more likely to work at home or close by it, and this would be encouraged by the authorities (Lopes, 2011). It would cause a deep change in the ways of developing cities and urban design. Finally, these approaches mean an enormous reaction against the model that some nations, such as the U.S. Canada and some European countries, have been developing as their urban models (Shane, 2011, p. 16).

\subsubsection{Urban Energy Consumption and Local Production}

The development of technology has been tied to the availability of energy sources (Wright, 2005, p. 325). From ancient times to modern society cities have been shaped, and have flourished and perished according to the energy sources available. The use of energy, mostly provided by fossil fuels today, is psychologically, culturally and politically attached to society worldwide (Droege, 2006, p. 03).

Energy consumption based on availability of sources has been historically linked with technological and economic development. In ancient societies part of the energy for development was provided by muscle power. Also in the past, the aristocracy has lived in a fairly extravagant way by exploiting the labour of others as an important energy resource, through slaves, indentured servants, and minimally paid workers. Human muscle power was early on supplemented by that of domestic animals, and water, wind and sun (Wright, 2005, p. 325).

Athens and Babylon, and every single settlement that has existed in the last nine millennia have been the consequence of regional arrangements of energy sources and their consumption. These energy resources have been based on biomass, and as already mentioned, animal strength, human strength, water, wind and sun. Obviously other 
factors also affect a city's development, such as climatic response, social structure, commercial organization and trade, and cultural beliefs. However, the role of energy has to be emphasized as an essential factor in human development, and a vital element in urban design. The largest part of human history was based on local energy resources. Until the Industrial Revolution, the world economy has relied on local, non-fossil fuel power. Urban models based on local energy are different from the model on which most cities are now organized. The principle today is fundamentally based on fossil fuel powered cities and their urban design and, seemingly endless, expansion (Droege, 2006, p. 02). Indeed, "the Industrial Revolution was really the Fossil Fuel Revolution" (Heinberg, 2011, p. L 421). The internationalization of energy sources, such as oil, coal and uranium has changed these elements into commodities. As with any other product today, energy resources can be shipped all over the world. Because of the availability of cheap and abundant fossil fuels, human society has seen economic growth at a scale without precedent in human history. The world economy has increased on average around 3 per cent every year for one and half centuries. This means the economy has increased 84 fold in the last 150 years (Heinberg, 2011, p. L 279 / 336).

The impacts on the world's cities have been so dramatic that it would not be an exaggeration to state that practically everything in cities today-economically, culturally and spatially (like most private vehicle friendly neighbourhoods) - have been result of the availability of fossil fuels (Droege, 2006, p. 14). In many countries, especially in developed ones, cities are the core of national economic growth and concentrate the largest number of employment opportunities (Munier, 2007, pp. 315316). Most national economic activities occur in cities. Some highly urbanized countries, for example Australia, have 85 per cent of their inhabitants living in urban areas. A great number of building and infrastructure energy consumption, building and infrastructure embodied energy, and domestic, business, industrial and service energy consumption happens in urban areas (Nelson, 2007, p. 76).

Cities are highly dependent on energy such as oil for transportation and electricity from coal, oil, gas or even hydropower for many urban services. As a consequence, a nation's cities are responsible for consuming between 60 and 80 per cent of national energy production, according to the level of urbanization and industrialization (European Institute for Energy Research, 2011). This emphasizes the relevant role that cities have 
in energy consumption worldwide. Because fossil fuel provides around 80 per cent of the world's energy demand (Munier, 2007, p. 323), cities, therefore, have a substantial responsibility in greenhouses gas emissions. In terms of global energy production hydroelectric facilities have been responsible for a mere 7 per cent of total while only 0.7 per cent comes from biomass, geothermal, solar and wind sources combined (Droege, 2006, p. 17). In contrast, oil and coal combined represent more than 63 per cent of world energy use. Moreover, for the first time in human history the majority of people are now living in towns, and by 2030 this number will probably be around 60 per cent (Munier, 2007, p. 315). "Our time has been declared the age of the cities. Urban centres are heralded as the engines of the global economy" (Droege, 2006, p. 14). As a result cities are consuming most global energy and very rarely do they produce any energy. Freiburg is an exception, producing 2 per cent of its energy in $2003^{4}$ (Solar Region Freiburg, 2003).

Oil is the foremost source of energy in the world. It is found in almost every relevant aspect of modern life. It is responsible for 95 per cent of global transportation, so the majority of goods and people transportation is oil dependent. The economic spiral triggered by this abundant and cheap energy resource has speeded up industrial growth, which is also oil-dependent. As result the oil demand has increased around 7 fold over the past 50 years (Newman \& Jenning, 2008, p. 36).

Modern society has experienced a progressive and constant urbanization probably never seen before. Urbanization, fed by cheap energy, has become an industrial process itself (Droege, 2006, p. 28). Low-density suburbs have been built on a mass scale as a social-cultural and economic feature of the industrial age. The oil dependence and its consequences have had a remarkable impact on urban design. More land has been consumed for highways, parking lots, and garages than for housing (Warren R. , 1998, p. 16). The low-density suburban model has been spread throughout a great number of cities around the world. The Floor Area Ratio (F.A.R. - the per centage of land covered by the equivalent one story building) in some neighbourhoods is as low as 0.05. Floor Area Ratios are used as a measure of the density of a site. This low-density generally

\footnotetext{
${ }^{4}$ The goal was to produce 10 per cent in 2010, however the official website gave this information on June 23 th 2011.
} 
generates no destinations that are walkable on a daily basis, thus maintaining the circle of oil dependence.

However, it is not only urban design that has been affected by the availability of abundant and cheap energy. Perhaps one of the most relevant changes has occurred with food production and distribution. The low cost fossil fuels have allowed local agricultural production to be shared globally. The internationalization of agricultural products has depended on improvements in the transportation networks, also a consequence of the "oil-revolution". Due to irrigation, new crop varieties, fertilizers, herbicides, pesticides and mechanization of agricultural productivity have had an unprecedented increase in the 20th century. In 1900, grain production was under 400 million tons (362 million tonnes) but this has risen to approximately two billion in 2000, an overwhelming 500 per cent increase (Heinberg, 2011, p. L 2339). Obviously, the way food production has been commercialized has also changed. The distribution network has become an essential part of the business, and instead of the local market, huge multinational companies have taken over the majority of the market. In countries such as Belgium, France and the UK only 10 per cent of the food retailers are responsible for more than 80 per cent of food distribution (Viljoen, Katrin, \& Howe, 2005, p. L 453). Most of this distribution takes place in huge hypermarkets conveniently located along the highways, where land is normally cheaper, serving the low-density car dependent suburbs.

Essentially the world economic structure is based on oil. Energy is not only a single commodity; "[it] is a prerequisite for any and all activity. No energy, no economy" (Heinberg, 2011, p. L 1956). Indeed, the demand for oil has increased in a similar proportion to that of the global economy, which has enabled a controlled oil price increase. One of the most revealing economic assumptions states that, "as a resource becomes scarce, prices will rise until some other resource that can fill the same need becomes cheaper by comparison" (Heinberg, 2011, p. L 2171). However, this is not the case for oil, as there is no real replacement for its convenience and portability. The era of low-cost and abundant supplies of oil is coming to an end, demanding a fundamental restructuring of the world's urban energy system, in terms of both production and consumption (Newman \& Jenning, 2008, p. 37). Although, oil will not run out soon, there is little new oil to be found in land, where drilling is relatively inexpensive. Most of the 
areas have already been explored and depleted. From now on, drilling will be progressively more expensive. Offshore oil will be responsible for 40 per cent of the world production in 2020. It directly means more expensive oil as Gilbert, former chief petroleum engineer for BP, noted:

"The current fields we are chasing we've known about for a long time in many cases, but they were too complex, too fractured, too difficult to chase. Now our technology and understanding [are] better, which is a good thing, because these difficult fields are all that we have left."

(Heinberg, 2011, p. L 2007)

Some optimistic research states that peak global oil production will be reached at some point between 2005 and 2015. In contrast, other prominent oil experts say that the peak has already happened or will do so soon (Campbell, 2005 and Post Carbon Institute, 2009). It would be a fair assumption to declare that oil, which is the most important energy resource, will progressively get scarce and, therefore, more expensive. Indeed, in July 2008, oil reached its historical price peak at U\$147.00/barrel (Oil Price, 2011). Economic growth demands more manufacturing, more trade, more transport, and consequently, more energy. This ultimately means that energy supplies that have been exploited today will be more expensive in the future. Economic growth, which has been fed by cheaper energy, will falter. If the assumption that economic growth means a better life for the masses is correct (Firebaugh \& Beck, 1994, p. 631), and the most relevant energy resource is becoming scarce, economic growth will have a problem to keep up continuous improvement in quality of life. In addition, any decrease in social inequality will be hard to bring about in a scarce energy resource scenario.

In conclusion, energy production is a critical process in an efficient urban social structure. However, energy production has been linked with many environmental and social problems. Probably there would not be globalization in the form that exists today without global fossil-fuel supply chains (Droege, 2006, p. 14). The "oil revolution" also created the "urban century" (Droege, 2006, p. 11), and environmental issues caused because of this change are enormous. Fossil fuel is responsible for more than 80 per cent of energy resources (Munier, 2007, p. 316). Urban areas are responsible for a significant level of global energy consumption. Although many countries and cities have 
apparently achieved an acceptable level of urban social efficiency, some important facts have been continuously ignored, especially by the public. The rates of use of dirty fuels such as coal, oil and uranium have been rapidly rising. These energy sources are responsible for most of the environmental problems, such as global warming, fresh water reduction, soil, water, groundwater, and air pollution, and oil spills. Some environmental problems have been directly affecting people around the world. A vast number of diseases and deaths due to cancer and respiratory illness have been caused by toxic gases and air borne particles. China's fossil fuel air pollution is responsible for US $\$ 50$ billion in health costs every year, and this number is estimated at around US\$ 70 billion in the European Union (Droege, 2006, p. 16). Despite all of the problems triggered by fossil fuels, the worst is they are being depleted at an alarming rate (Munier, 2007, p. 316)

In the past decades society, because of the insistent speeches of expert economists, has adopted the impracticable belief that economic growth is necessary and moreover perpetual (Heinberg, 2011, p. L 189). Economic growth is strictly dependent on energy, and oil, which is the main source of energy, will be scarcer every year. According to the financial logic of today, economic growth and improvement in the quality of life will be hard to achieve in the near future. If there is any intention to decrease world inequality, a new source of energy has to be developed. Otherwise, this improvement will bring up new consumers and, therefore, energy consumer competitors. Because energy resources are getting rarer, and new consumers have been created every year due to a rise in consumption levels and population growth, the tendency is the energy becomes more expensive, and the providers, at least while the prices are getting higher, have the opportunity to change the energy sources towards a more sustainable but probably more expensive resource.

A shift in energy resources is consequently vital in order to improve urban social efficiency. Many sources of renewable energy are currently available. Although a change towards a renewable energy resource is essential it does not mean such resources offer a final solution. Even renewable sources have some limitations. The first point is the embodied energy. Photovoltaic panels (PVs), depend on the incidence of sun, and depending on location, can, in some climates, take up to 16 years to recover the energy used to produce them (Vale \& Vale, 2009, p. 139). Although wind turbines are highly 
efficient, they demand large open areas for their installation. The Energy Yield Ratio (EYR) for wind turbines, which means how many times the energy invested in the wind turbine is returned, is around 23 times (Crawford, 2007, p. 115). Hydroelectric schemes are also an unquestionable source of renewable energy. However, there are many environmental impacts related with them. In large plants, vast areas have to be flooded in order to produce a substantial amount of water to run the generators. The Belo Monte scheme in Brazil, recently approved by Brazilian authorities, will flood an area equal to $500 \mathrm{sq} . \mathrm{km}$ in the middle of the Amazon forest. In addition, the $6 \mathrm{~km}$ dam will displace around 30,000 inhabitants of the region, and partially dry up around $100 \mathrm{~km}$ of the Xingu river, one of the most important Amazon River tributaries (The Guardian, 2011). Although there are problems and limitations, renewable energy availability is more than adequate to supply urban energy, although arranging for a constant supply through a gird may be very difficult, as it inevitably involves energy storage. However, use of renewable energy could break the strong oil monopoly and bring energy production close to the town.

City residents are not interested in energy itself but in the service and comfort that it provides (Munier, 2007, p. 315). It ultimately means that the consumers are probably not aware about the limits of fossil fuel energy or the environmental impacts caused by some sources of energy. An important point concerning the limit or capacity of energy production is that any source of energy has a production limit; therefore, any region should have a share of energy to consume in accordance with its energy production capacity. The belief that economic growth is endless and that energy for it will be providentially found and provided is probably wrong. In order to maintain economic growth, energy sources have been dramatically and inefficiently used when it comes to the social and environmental aspects. A shift towards renewable resources is urgently overdue. However, this replacement will not necessarily be able to produce economic growth, but should be viewed as replacing the resources economic growth has made available today. There is still a fundamental need to change the capitalist paradigm based on unlimited growth.

Urban energy production is highly complicated and in most cases unfeasible. To meet urban demands for energy it will probably, like food, be necessary to pass over the city's limits and take into account regional or even national generating capacity. 
Consequently, the urban energy consumption share would be the national capacity of energy production divided by the total number of all inhabitants. An efficient urban area may have part of its inhabitants producing part of their energy, through PVs, wind turbines, biomass, micro-hydroelectric dams or all of them combined. This local production will re-introduce the concept of resource limits currently lost or forgotten (Meadows, Randers, \& Meadows, 2004, p. L 308).

\subsubsection{Water}

It could be argued that the quality of urban water as a resource has been deteriorating since the 19th century. The continuous process of urbanization and its concomitant water borne sewage combined with industrialization have been responsible for most of the water problems in cities. Often polluted waters have been systematically released into urban waterways and streams with no treatment. The most relevant improvement achieved with the latter was essentially to cover the streams to put them out of sight and turn them into sewers. Indeed, water systems have been part of cities since ancient times. Cities have grown connected to water resources, which were ultimately their lifelines and cities and civilizations have perished because of water scarcity. There are many examples of communities, such as Hohokan and Anasazi from southwestern U.S, that were abandoned because of a long dry season or failure of irrigation systems (Novotny, Ahern, \& Brown, 2010, p. 01 / 02).

Urban water management is directly responsible for the relationships between rainfall and runoff, drinking water supply and wastewater systems. It also relates to water and the hydrological environment, particularly in catchment areas. Urban water management also includes design, planning and water systems operation (Munier, 2007, p. 513). The issue is how sustainable urban water management is best achieved.

The urban water system can be categorized according to the way that water has been exploited and wastewater has been managed (see figure 42). An urban water system is different from a rural water system. In an urban water system the water demand and the water inflows have more players interfering in the natural process. There is a complex arrangement of flows and under-flows. Sometimes the supply system is made up of many different resources. Moreover, the waste waters have different 
characteristics and origins (black and grey water, runoff). An urban water system can impact on society in different ways, but basically the aim is to allow citizens to enjoy water and not harm the water resources and ecosystems (Munier, 2007, p. 518). An inefficient urban water system may increase human mortality and restrict people from having water for basic and indispensable human needs, such as drinking, bathing and cooking (Heinberg, 2011, p. L 2254). Whenever a drinking water system fails there will probably be public health issues related with the failure (Munier, 2007, p. 513).

An effective and competent urban water system is essential to accomplish a truly urban social efficient region. A good urban water system can contribute much to people's welfare; it is, therefore, vital to keep cities socially balanced.

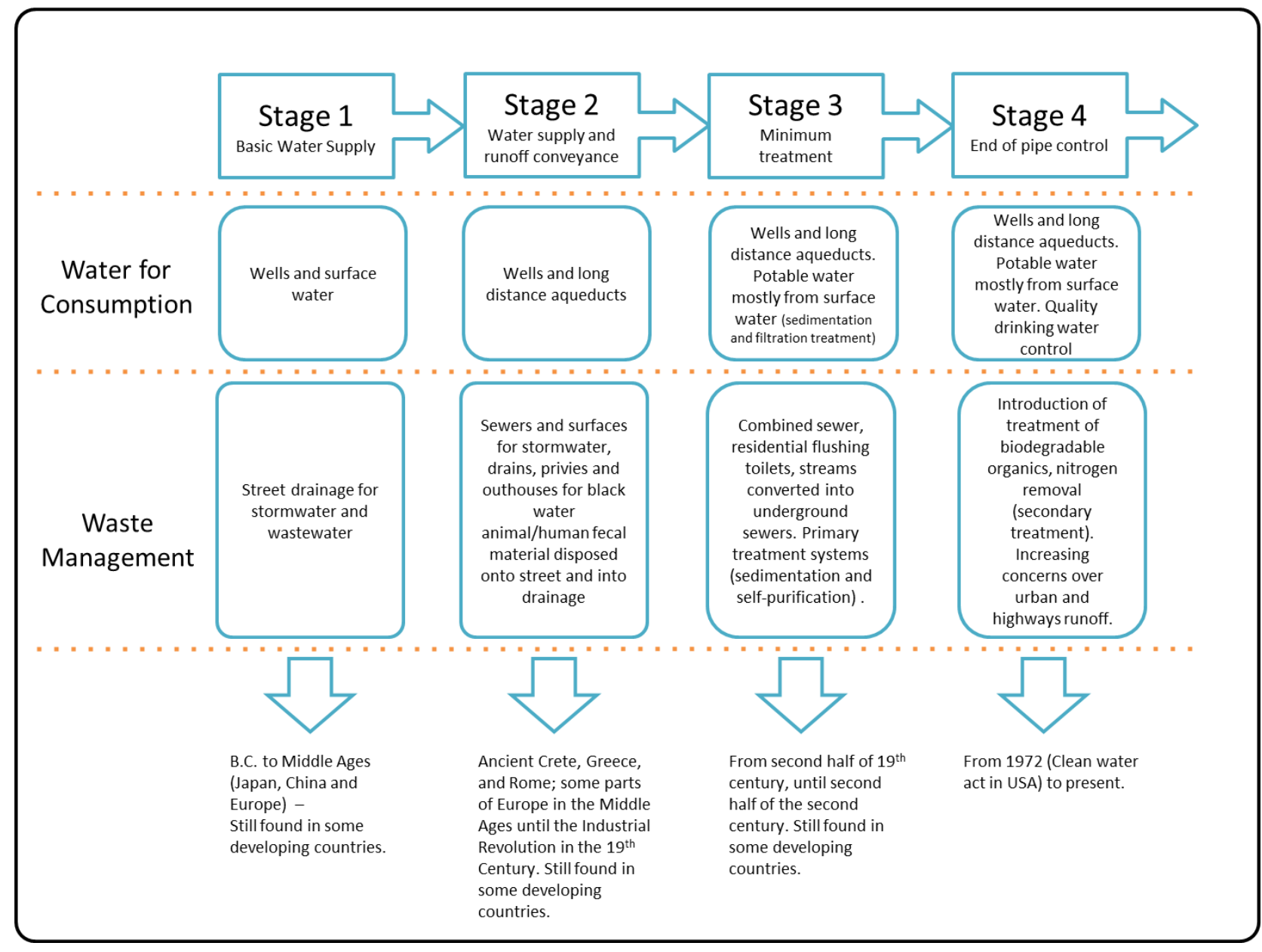

Figure 42- Stages of water management development, Stage 4 being the most developed (Novotny, Ahern, \& Brown, 2010, p. 11) 
Today it is clear that urban water management and infrastructure is struggling to cope with the increasing demand (Novotny, Ahern, \& Brown, 2010, p. 05). The profound urban changes that have occurred in the last century have directly affected urban water availability. Although the changes are not restricted to urban areas, urbanization is the second cause of stream impairment (agriculture is the first) (Paul \& Meyer, 2001, p. 334). Despite atmosphere and climatic conditions that may seem to happen beyond the scale of cities, the latter are responsible for relevant interference in the natural water flows (Droege, 2006, p. 143). Urban design acts as an important factor in the change of natural water flows. The fact urban design has privileged private transportation, thus making the growing city progressively impervious, has caused one of the major water problems in urban areas. Highways, roads and streets are the places where most drainage structures are located. In addition, they receive a substantial amount of detritus, such as dripping oil, street litter, animal fecal deposits, roadwork residues, some residential waste, and dust and heavy traffic emissions. Often some parts of the transport system infrastructure have been built over streams, or close enough to affect the catchment areas. In both cases, they bring serious consequences for the environment (Novotny, Ahern, \& Brown, 2010, p. 34).

Increasing imperviousness is a large and constant process in urban areas. Residential areas, shopping malls, schools, industrial plants, commercial buildings, all often use extremely large sealed areas for parking, in some cases much larger than the establishment they serve (Heaney in Novotny, Ahern, \& Brown, 2010, p. 34). Undeniably, most of the urban changes that directly affect urban water systems are linked together with the existence of an urban social inefficient region. The prioritization of private transportation, which deeply changed cities in the last century, and the associated low-density residential zones, generate more than three times the runoff than a typical family living in a city pre-cars (Novotny, Ahern, \& Brown, 2010, p. 33). Low-density regions connected with highways depend on the commercial infrastructure which relies on large impervious parking lots (Novotny, Ahern, \& Brown, 2010, p. 34). It is notable that the urban expansion cycle conflicts with the water cycle. This conflict has brought social problems in some countries, where only part of the population can reach water. In Brazil, which has a large overall water resource, a great number of cities have systematically had to ration water supply (Torres, 2010). 
There are at least two significant consequences of the spread of impervious surfaces. The first one is the increased runoff. The polluted water generated from runoffs usually ends up in a city's water supplies (in coastal areas it mostly goes to the sea, which can affect the marine environment and those whose livelihoods depend upon it). The second one is the decrease in the recharging of underground water aquifers. This causes a reduction of water release into urban streams (Paul \& Meyer, 2001, p. 335).

Urban Underground Water Recharge and Runoff According to Imperviousness
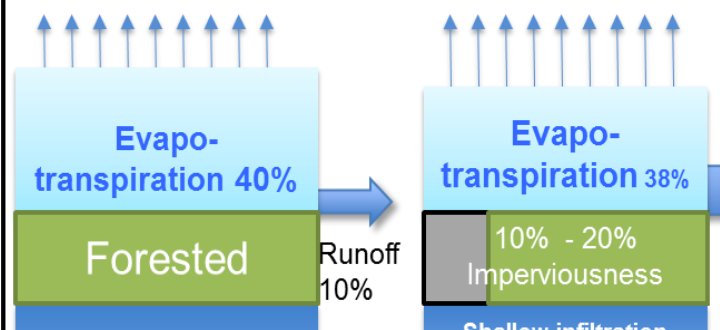

Shallow infiltration $25 \%$

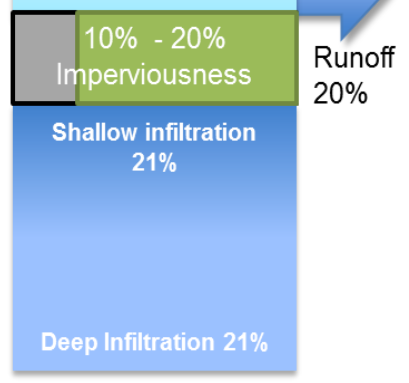

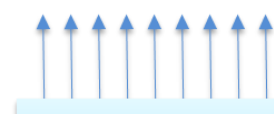

Evapotranspiration $35 \%$

$30 \%-50 \%$ Imperviousness Shallow infiltration $20 \%$

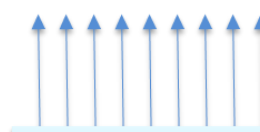

Evapotranspiration $30 \%$

Runoff

$75 \%-100 \%$ Imperviousness Runot $50 \%$

Figure 43 - Water Cycle according to level of imperviousness

The combined effect of agribusiness and urbanization has spread a general concern among experts that freshwater supplies have been critically overused and degraded (Novotny, 2007). Freshwater supplies, surface water, and groundwater sources have been overexploited. Aquifers have not been able to recharge enough in order to keep their original water levels. Today an effective overdraft situation regarding 
underground water and aquifers is common around the world, and this century many aquifers have been exhausted (Novotny, Ahern, \& Brown, 2010, p. 228). In 2025, according to optimistic estimates, 1.8 billion people will be living in countries with water scarcity (Heinberg, 2011, p. L 2264). However, some studies indicate around 2.8 billion people will be living in countries affected by drought. This number may rise to 4 billion by 2050 (Novotny, Ahern, \& Brown, 2010, p. 228). This water shortage will probably be primarily caused by population growth, water demand increase, pollution increase, urbanization, and interferences in water natural cycles. In some cases, water scarcity is an outcome of lack of water management (Novotny, Ahern, \& Brown, 2010, p. 01). However, lack of water is not the only effect of the water cycle change. The progressive imperviousness, which should be considered as an essential component of water management, decreases the time difference between the centres of rainfall and runoff volume. It naturally causes a flood peak to happen more rapidly. In addition, in areas with larger permeable surfaces, such as forests, the flood width can be up to 40 per cent less (Paul \& Meyer, 2001, p. 335). In a sustainable situation, the whole system should be designed to inhibit excess water consumption and especially to keep the quality of the environment and the water cycles intact (Munier, 2007, p. 518).

In conclusion, a sustainable water supply is essential to allow cities to accomplish a reasonable level of urban social efficiency. Indeed, without drinking water social efficiency is impossible, simply because public health depends on water quality. Lack of potable water and wastewater management will affect most urban day-by-day tasks. It will finally lead to urban collapse and abandonment (Novotny, Ahern, \& Brown, 2010, p. 01). The effect on water supplies caused by modern large scale agriculture combined with the process of urbanization could be devastating. Imperviousness is unsustainable; it changes the complex and fragile water cycle. The process for analysing the water cycle and its ecosystems is highly complicated and demands scientific modelling and data collecting (Novotny, 2007, p. 210). Therefore, changes towards a sustainable water system cannot be made simply or quickly. Nevertheless, to avert future problems, this analysis needs to be started immediately.

Water shortage affects the agriculture and energy sectors as well. Agriculture cannot keep utilizing irrigation to guarantee harvests during the whole year; consequently, food production will tend to decrease with water shortages. When water becomes 
scarce in urban areas, authorities tend to bring water in from far away. This water moving takes energy. In dry regions, where water has to be brought in over long distances, energy consumption used in this water moving can reach more than 6 per cent of local consumption. This situation must become an endless spiral. Shortage of water demands more energy to move water around, which will demand more water in order to produce energy (Heinberg, 2011, p. L 2313). Even if there is a remarkable improvement in the water consumption levels, humanity will still face the challenge of having a growing population and economic growth, which will both demand more water. Confronting non-favourable water stocks, industries have been adopting more efficient water systems, but almost always these are more expensive (Heinberg, 2011, p. L 2308), which also affects the economy. Water treatment systems have been created after most of the other urban features, such as housing, infrastructures, commerce and, sometimes, after the squalor and diseases emanating from these. Such systems appear as a reaction to increasing population and urbanization, most likely because the local environment can no longer cope with the load of human fecal material. Cities have been exploiting freshwater resources in many different ways, such as for transportation, drinking, housing, agriculture, industry, religious manifestations, and locally for disposal, "always looking at the river as a means to an end - rarely an end in itself" (Brown P. R., 2007, p. 05).

It is important for the urban population to understand the local water system, including where the wastewater goes and the problems caused by ground impermeability. This knowledge is extremely important so the population will recognize the limits of the system and the necessity for water conservation (Munier, 2007, p. 518).

Ultimately an urban social efficiency will be reached when the basic principle of sufficient drinking quality water is available for the whole urban population. It means that cities will have to consume a share of water in a way that guarantees its natural cycle remains uninterrupted. This will lead to proper underground water recharging, the preservation of catchment areas, rivers, lakes and coastlines. The concept is simple consume and pollute less water. 


\subsection{Conclusion}

The main points of design for urban social efficiency design have come from the adaptation of historical urban patterns and models, with emphasis on the social aspects.

Although primordially rural, human beings have had a long urban history and therefore a tradition of urban design. Some of the most relevant aspects of the historical urban models can be adapted to urban design today. Indeed, the lack of an easy, cheap and widespread energy supply, such as fossil fuels, has produced an urban model less dependent on non-renewable energy. This old urban pattern, with a few exceptions (such as ancient Rome which was a large city), has created a specific urban model in which the sizes of cities were smaller than today and the relationship between cities and their hinterlands were vital for the cities to work properly. The limitations of long distance transportation has made long distance trade expensive and time consuming, and has also helped shape cities; consequently producing fairly small cities, that are energetically more efficient, highly walkable, and with a large capacity for selfsubsistence and raw materials production.

Essentially, the key points discussed here are intended to provide a guideline that can be used to measure environmental performance. The key factors from urban historical knowledge, should be used as a model and could possibly generate better urban designs under an environmental analysis. The idea is to combine these factors, to create a social and environmentally respectable urban design. These key factors are the starting point for good environmental design, and comprise the critical and conceptual elements for socially developed urban areas.

The social differences between ancient urban cities and present urban areas were also taken into account in order to generate environmentally and socially adequate elements for contemporary urban areas. The examples from Morumbi, Paraisopolis and Alphaville, and Carapicuiba illustrate a social and environmental urban imbalance and other major problems of the urban design, while the key aspects of the urban social efficiency attempt to tackle these problems. Wealthier areas have, for instance, more access to green areas and a larger percentage of permeable soil, while the poorer regions have higher densities, local commerce and a walkable environment. The problem is not only a social matter, but, indeed, an intricate combination of social and 
environmental problems. The key points of urban social efficiency assimilate the main problems to provide conceptual support for urban design and controlled city expansion.

The environmental performance measurement is indispensable; however, the use of these principles will probably generate an urban design in which the focus will be social development instead of commercial interests. Under these key aspects the collective interest will prevail over the private one. It also conceptually states that environment privileges, such as green areas and water, must not be commercialized or privatized.

The idea is simple: to create an urban area as socially and egalitarian as possible, and prepare urban conceptualization and planning for subsequent environmental performance analysis. 


\section{How the Economic Status quo affects Urban Environmental Inequality.}

Urbanism has been tremendously affected by changing economic models. Historically, the different designs of cities can be viewed as the consequence of their underlying economic models. Therefore, most recent city designs and urban interventions have been based on the "oil-economy" (Droege, 2006, p. 14).

The unprecedented urbanization brought by the economic shift caused by increase in trade and afterwards by the Industrial Revolution has been one of the major factors to change urban design intentions. Cities have had to organize themselves to cope with a sharp population growth. Paris grew its population from 200,000 in the fourteenth century to around 500,000 by 1700 (Wringley, 1967, p. 44), and London grew dramatically from 317,000 inhabitants in 1632 to about 700,000 by 1700 (Braudel, 1973, p. 431). At that stage in history, the major change may have been because of the introduction of new economic concepts (specialisation and increased trade, and increased agricultural productivity). These concepts have probably caused consistent changes in cities, which can still be seen in current societies and economic models, which in turn then continue to affect urban development

The first change came with the appearance of a sense of society and the clear division between rural and urban, where at the extreme rural has been represented the "rural idiocy" of Karl Marx (Marx saw the rural as being conservative in its values) (Holton, 1986, p. 10). Rural has also been represented as the realm of nature while the urban has been the realm of human endeavour, and hence culture. Cities have, therefore, been associated with the new economic dynamism. The pejorative view of the rural regions and rural economic backwardness is an outcome stemming from the industrial economy and the triumphant urban ideology. From the Industrial Revolution onwards, socialist political philosophy has generally been pro-urban promoting the dominance of cities over the rural regions (Holton, 1986, pp. 11-12). Adam Smith (1723-1790), the Scottish philosopher, who is often described as the father of economics (Gilding, 2011, p. 195), has described cities as places with greater liberty and individual security compared to the dull servility of the countryside. Although Adam Smith recognized the importance of the countryside, he also stated that any major change in the rural areas would be provided by urban capital and intervention (Holton, 1986, p. 34/35). Indeed, 
Adam Smith along with the philosopher John Locke (1632-1704) may be responsible for important concepts, such as the desire to move to the city as a place of opportunity, which can still be found in society today.

\subsection{The Inconsistent Relationship between Economy, Economic Growth and Environmental Limits}

John Locke in his Second Treatise of Government declared that in the State of Nature natural laws rule human behaviour. At this stage, people collect their needs from the environment, however at the start they store only what they need to cover the basic necessities. Eventually people start to produce surplus and barter part of their right over their immediate natural environment. They shortly develop common barter currency rates and subsequently money. Money, therefore, replaces the real limits imposed by the environment and the extraction of simple commodities from it (e.g. livestock, food, and goods based on naturally occurring materials). People essentially exchange their natural rights for the right to enter into a society. They become part of a society ruled by an executive power and then protected by common laws. In a society people need executive power to protect their property. Indeed, many things change with the introduction of the concept of private property. Originally Locke's assumption was based on the idea that everything on the earth belongs to everyone. Therefore, environmental resources should be equally divided between all (the stance still taken by modern interest in fair earth share ecological foot printing). However, he went on to say that everyone had the right to make use of resources, which is a different concept. In fact, some parts of his Second Treatise of Government possibly represent the idea of the abundant and seemingly endless resources available from America. Moreover, the fact that most of America did not yet have a central government and fixed settlement justified its colonization so that the resources would be in good hands (Klausen, 2007, p. 760). There was an underlying unstated assumption of the infinite availability of resources (Lebovies, 1986, p. 568).

The idea of private property was a consequence of the creation of the social contract and the idea that people have the right to appropriate goods and resources by adding labour, thus making them owners of these (Kemerling, 2011). From these ideas 
emerged political obligations and private property (Internet Encyclopedia of Philosophy, 2001). Moreover, Locke declared that the main role of central Government must be to protect private property (Kemerling, 2011).

Along with John Locke, Adam Smith had an important role in the modern economic model and the relationship between wealth and the environment. Conway (2009, p. L155) states Smith was the first economist. He stated that self-interest in a market system produces the solution to an economic problem (Common \& Stagl, 2005, p. 309). In a free-market system there is nothing wrong with people acting in their self-interest; acting this way will bring benefits to of all society, enriching everyone, including the poor (Conway, 2009, p. L 132; Heinberg, 2011, p. L. 766). Adam Smith believed that in the right circumstances individual selfish interest would lead to prosperity. The "invisible hand" of the market would serve to benefit the whole of society. In theory the market would distribute the generosity of nature and the outcome of human labour as fairly as possible. However, because of industrialization and colonialism the market has worked favourably for those who make money as their primary interest in life (bankers, traders, industrialists and investors) (Heinberg, 2011, p. L 757). The invisible hand is in fact shorthand for the law of supply and demand (Common \& Stagl, 2005, p. 03/310; Conway, 2009, p. L 129 / 152):

"By preferring the support of domestic to that of foreign industry, he intends only his own security; and by directing that industry in such a manner as its produce may be of the greatest value, he intends only his own gain, and he is in this, as in many other cases, led by an invisible hand to promote an end which was no part of his intention. Nor is it always the worse for the society that it was not part of it. By pursuing his own interest he frequently promotes that of the society more effectually than when he really intends to promote it. I have never known much good done by those who affected to trade for the public good. It is an affectation, indeed, not very common among merchants, and very few words need be employed in dissuading them from it."

(Smith, 1776, p. 477)

In his time, the economy was still organized around natural primary abundance, where abstracted paper-based wealth was less important. This is probably the reason that 
Smith has overemphasized the importance of well-organized labour, which would lead to wealth (Martenson, 2011, p. L 1418). Smith understood the main components of the economy as being land, labour and capital (Heinberg, 2011, p. L 763). Thomas Robert Malthus (1766-1834) and David Ricardo (1772-1823) with Adam Smith are known as classical economists. Malthus has probably had a great influence in Smith's analysis with his statement which declares that increasing population would inevitably outpace food production and consequently bring famine. Because land and resources are clearly limited Malthus and Smith have assumed that the economy would inexorably reach stability (Heinberg, 2011, p. L 769; Gilding, 2011, p. 195). To achieve this, however, they have placed more reliance on the market and less intervention (Common \& Stagl, 2005, p. 05).

The classical economists, little by little, introduced mathematical ideas to economics and some terminology from science. They began to think of themselves as scientists when in fact their subject remained a branch of moral philosophy (Heinberg, 2011, p. L 748). Economic theory does not require falsifiable hypotheses and demands no repeatable experiments; therefore it is not a science. In contrast, ecology is a science, one that studies the flows of energy and resources through ecosystems. Similarly, economics is the study of the allocation of resources among competing uses in human society. They thus share much the same substantive focus. Economics may then be argued to be human ecology. However, ecology has roots in the real world of chemical reactions and thermodynamic laws. These are the universal regulators of all energy and material changes. In contrast, the study of economy had abandoned its organic roots by the end of the 19th century. Therefore, economics lacks any representation of the different nature of materials, energy sources and physical structures. Moreover, the dependence on time, which is essential for any ecological approach, has constantly been ignored by economics (Brown L. , 2009, p. 15; Portney, 2003, p. L 171). It ultimately means that the essential ecological concept of carrying capacity has been ignored when economic decisions are taken. For human beings carrying capacity can be seen as the maximum rate of resource consumption and waste discharged in a certain area, that can be kept up indefinitely without impairing the integrity and productivity of the relevant ecosystems (Rees, 1994, p. 125). 
Smith did not explain, maybe intentionally, the whole meaning of the word improvement (or progress) mentioned many times in his books. Increasingly "improvement" and "progress" have come to mean growth according to the economic logic of today. However, the major change has been the steady omission of land as an essential ingredient of an economy (Heinberg, 2011, p. 775). Progressively, only labour and capital are seen as important and land became subcategorized as a type of capital, ignoring that fact that land must ultimately be linked with carrying capacity, as explained above. This new approach, an economic refinement, has changed classical economic philosophy into the neoclassical. There is no mention whatsoever about natural environmental limits in neoclassical economic texts (Common \& Stagl, 2005, pp. 03, 119).

Subsequently, another relevant philosopher introduced a new interpretation of the economic phenomenon. Karl Marx (1818-1883), a German philosopher, proposed a new name for the entire system which began in the Middle Ages-capitalism. According to his interpretation, the economic system was designed to expand in an infinite way, meaning it is inherently unsustainable (Heinberg, 2011, p. L 784). The system, in his opinion, had no tendency to reach balance in the market; in fact the way it operates underlies the trade cycle of boom and bust (Wolff, 2011):

"The need of a constantly expanding market for its products chases the bourgeoisie over the whole surface of the globe. It must nestle everywhere, settle everywhere, establish connections everywhere..."

(Marx \& Engels, 1958, p. 35)

"Capitalism is, in its very essence, a process of colonization of countries and people, with the exploitation process as its backbone"

(Hersh \& Brun, 2000, p. 107). 
A more moderate view arose in the late 19th century called social liberalism. It was a response to the incompatible tendencies of capitalism and Marxism. While capitalism has the tendency to believe that the market will be self-regulating, Marx believed in the centralization of credit, and putting the means of communication and transport in the hands of the state. In addition the production modes should also be owned by the state (Marx \& Engels, 1969, p. 26). This new economic view was introduced by sociologist Lester Ward (1841-1913), psychologist William James (1842-1910), philosopher John Dewey (1859-1952) and the physician Oliver Holmes (1809-1894) and was entitled social liberalism. This new system would prevent uncontrolled concentration of wealth and the state was to be responsible for tackling social problems such as unemployment and workers' abuse. The state should also provide universal healthcare and education. Non-Marxists normally had some sympathy for labour unions. They also supported the theory of progressive increases in tax and restrictions against monopolies (Heinberg, 2011, p. L 803). These were the core of John Maynard Keynes' (1883-1946) ideas. He was probably the most influential economist at that stage. According to Keynes, taxation and government investment should be the answers to controlling the economy. Keynes was successful with his theory during the depression of the 1930s, and the New Deal programs of Franklin Roosevelt were commonly attributed to Keynes (Conway, 2009, pp. L 709-725; Heinberg, 2011, p. L 812).

Between 1930 and 1970, the world has seen the contest between social liberals (Keynesians), Marxists, and neoclassical economists. The latter were partially marginalized in between the polarized contest between Marxists and Keynesians. The neoclassical view was essentially different from the social liberals. They believed that the intervention of the state obstructed the efficiency of the market. After the collapse of the Soviet Union at the end of the 1980s Marxism lost its credibility, and this has created space for the rapid ascension of the neoliberals. The USA and British Governments from the 1980s, respectively Ronald Regan and Margaret Thatcher, relied deeply on advice from neoliberal thinkers, most of them influenced by Milton Friedman (1912-2006) and Friedrich von Hayek (1899-1992) (Heinberg, 2011, p. L812).

Friedman's ideas, also called monetarism, declare that the state should only control money flowing around the economy. This will ultimately control inflation, which should be its priority over unemployment. Inflation is a major risk to an economy, probably 
because it directly affects consumption, making it hard for the credit system to expand. In contrast, Keynes had imagined that unemployment was the major risk to an economy (Conway, 2009, p. L795).

Essentially, monetarism re-embraces the idea of the classical economist around total market self-organization. However, unlike Adam Smith's point of view, the monetarists and Keynesians do not foresee a future stable stage of an economy because of resource limits. They believe in perpetual growth, and the divergence between the two views is how this should happen-through state intervention or through omission and the market finding the best way (Heinberg, 2011, p. L 821).

Apparently the idea of perpetual growth without any limit or restriction has taken over modern society. This idea of perpetual increase, already consolidated in most national and local economies, can also be found in urban design and the expansion of cities. Urbanization is a process, which started in the $18^{\text {th }}$ century but which has no limit. The assumption is cities can indefinitely increase in area. While there is population growth, ultimately this means while there are more births than deaths, cities are able to expand and are encouraged to do so (Davis, 1965, p. 18/21 ).

\subsection{Urban Sustainability in an Economic Environment}

It is hard to define which factor is the most important trigger for the processes of urbanization and urban expansion. However, the fact that many things have happened concomitantly is a reasonable and possible explanation, as set out below. Industrialization started attracting people from the countryside from the 18th century onwards (Clark, 2003, p. L 401). Since the Industrial Revolution the world's economy has been growing rapidly, indeed population, food production, industrial production, and resource consumption are growing more and more rapidly (Meadows et al, 2004, p. L. 368). The idea of perpetual urban growth is convenient for the real estate market. The intentional relationship between economic growth and urban growth has been helping real estate companies to gain an important role as urban planners and developers. The current production model has realized that it is essential that investments are not only made in production processes, but also in the built environment. In fact, the built environment is an intrinsic part of the economic model of 
today. It is essential for consumption (Christophers, 2011, p. 1348/1349). The economic model directly affects decision makers, therefore shaping the expansion of urban fabrics all over the world (Lawrence F. , 2004, p. 146/147). The real estate market and its expansionist ideals have conveniently been using the concept that growth is not limited by the environment (Rees, 1995, p. 347). In addition, the unrealistic view adopted by economists that the economy has to grow and perpetually expand (Heinberg, 2011, p. L 190 / 275) gives the opportunity to real estate developers in modern society to consolidate the idea that cities are growth machines (Portney, 2003, p. L 1410). Urban growth, therefore, is perfectly aligned with the idea of "Homo Economicus and growthmania" (Rees, 1995, p. 343; Conway, 2009, p. L 3524).

\subsubsection{The Unsustainable Real Estate Approach to Urban Growth; The Myth of Profit}

Several concepts have been extremely important for keeping the real estate market in a position of notable importance in the market economy. Overall, the single most important concept for real estate is, perhaps, the general neo liberal ideas of deregulation, the free market, and perpetual expansion. In theory, the expansion of the urban fabric and the urbanization process provide a reasonable and sizeable market for real estate developers all over the world. Although the phenomenon of globalization has been seen in the real estate market, some local specificities still exist.

The direct reduction in interference in spatial development promoted by countries at all levels-national, regional and local-according to the neoclassical principles of deregulation, flexibility and privatization has dramatically decreased the importance of the local level in the process of urban planning (Coy, 2006, p. 122). The lack of interference and the profound economic changes are the main reasons why real estate companies as big private investors have been able to increase sharply their control over urban evolution and development (Coy, 2006, p. 122). Because of urbanization and urban growth, expansion of the real estate market is, at least temporarily, assured. This expansion results in a sizable market for all real estate players. However, for the real estate market simple expansion and its associated remarkable increase in numbers is not enough. This simple urban demand does not entirely guarantee prosperity. Each 
single project demands a pre-defined financial result. Each company has its own predefined financial criteria with which to assess the financial performance of its projects. Essentially the companies aim to create a certain amount of profit, in a certain period of time. This simple idea can be converted into a complex and sophisticated index such as E.B.T.I.D.A (Earnings Before Interest, Taxes, Depreciation, and Amortization), R.O.E (Return on Equity) and R.O.I (Return on investment), all of which can easily be found in real estate developers' market reports. Therefore, a property market where the predefined level of profit is not reachable will not be appealing for developers. Developers and investors may thus determine the expansion of the urban fabric according to its capacity to deliver profits in their developments.

Big players in the real estate market are normally large international corporations and these have their stock listed in stock market exchanges all over the world. Globalization has allowed, almost freely, substantial capital flows between markets. The international characteristics of real estate investors and stock market financial requirements have made the issue of financial performance very inflexible. Investors in the real estate market tend to demand financial performance in their investments all over the world.

In order to achieve the investors' demands, real estate developers have based an important part of their financial strategy on sites acquisition. Prospecting for sites and site acquisition are positioned at the very beginning of the real estate chain of production, and there is a responsibility to acquire sites before a project can be developed. Excluding legal matters and zoning restrictions, financial unfeasibility is probably the main reason that developers reject sites. The criteria are straightforward, insufficient profit, no acquisition. However, some other financial criteria are also important. Large developers tend to discard sites for which the net revenue is not relevant. Firstly, some small sites are rejected because they cannot have a sufficiently large marketing budget. Developers normally calculate the marketing budget according to the project revenue. A small marketing budget can lead the project towards a financial failure because it cannot keep up, for instance, against better structured and large advertisement campaigns from competitors. In addition, small projects are unable to cover the basic general and administration costs (G\&A) of large corporations. Therefore, small sites are relegated to small developers, who struggle to compete against bigger and better structured competitors. The acquisition method adopted by 
most of the developers is also not related with the declared aspirations of cities. In fact, as important players in city expansions, real estate developers often have a different aim when compared with city aspirations. Developers, as private institutions, want profit. The real estate site selection process as described here may produce uninhabited sites, and consequently underdeveloped regions, with low density. It basically brings up all sorts of problems of empty sites in the middle on the cities because these are financially unviable. In addition, because larger, viable sites tend to be found in the outer reaches of cities, it brings consequences such as an increase in urban infrastructure expenditure, problems with low density and public transportation costs, and energy waste with increased private transportation.

The process of land acquisition is so vital for developers that some companies have more than five years of project launches guaranteed through their land stock. This process of acquisition and concentration of site stock is normally called land banking for real estate developers. However, it may also play an important role in the expansion of cities. A good launch strategy can lead to an overvaluation of land stock. In a simplistic way, developers may start to sell distant projects, forcing urban development towards these distant projects, consequently ignoring development of sites that are better located. This method is commonly known as real estate speculation. It is also a different facet of the financial strength acting through real estate developers shaping urban expansion. In a progressive deregulated market, residents of the cities experience whatever urban quality results from the real estate developers' expansion (Portney, 2003, p. L 1412). Profit and its economic arrangements are, therefore, undoubted factors in determining the form of the expansion of the cities.

The last few decades have seen an increase in human mobility and the influence of globalization. This has been reinforcing changes already happening in defining lifestyle at local and regional levels towards a more globalized lifestyle. In this scenario businesses have become more decentralized, and low density areas have been created through gated communities, making urban sprawl one of the most remarkable urban characteristics of the twentieth-century (Coy, 2006, p. 122; Haughton \& Hunter, 1994, p. 81). The idea of any sort of constraint or limitation in expansion, which the problem of urban sprawl might suggest, will directly affect and prejudice the real estate market. The situation of political deregulation when combined with land banking policies has 
led cities to incur diverging patterns of fragmentation. Public authorities, therefore, have been left with very little to offer in order to balance socioeconomic, environmental and spatial disparities (Rees, 1994, p. 122; Coy, 2006, p. 123).

New urban developments, through their investors and developers, have been inserted into cities, taking financial advantage of the economic model (Portney, 2003, p. L 1380). Opportunistically, the real estate market has accepted and applied the theory that resource depletion is not a fundamental problem (Rees, 1994, p. 123). Developers and authorities have been relying on the assumed simple mechanics of the free market to ensure sustainability (Rees, 1995, p. 347). In a hypothetical situation, technology would be able to replace resource scarcity, and according to the Nobel Laureate Robert Solow (1974), "if it is very easy to substitute other factors for natural resources, then... [t]he world can, in fact, get along without natural resource (Rees, 1994, p. 123; Rees, 1995, p. 347; Common \& Stagl, 2005, p. 258).

Even when apparently showing concern for the environment, eco-friendly or green building and urban development keeps following the paradigm from neo-liberal economic regulations, taking cities as growth machines (Rees, 1994, p. 123). In this scenario, true pursuit of sustainability is impossible (Portney, 2003, p. 1365). However, such an approach seems to be properly exploring the increased popular appeal for green products, even including greener residential developments.

Real estate developers, like other market segments, have been moving towards green policies. Perhaps because of the increase in importance of cities with their resource demands, and the consequences of the continuous process of urbanization since the nineteenth century, the real estate market has become more aware of its environmental impacts (Stern et al. 2007 in Fuerst \& McAllister, 2011, p. 45). Developers have also realized the benefits and financial gain that can come from adopting green marketing in their developments. Normally such developments increase both prices (and hence often profits) and sales (Noiseux \& Hostetler, 2010, p. 571; Fuerst \& McAllister, 2011, pp. 6566).

The real estate market environmental strategy is normally either a market-approach or simply a mandatory ecological regulation imposed by authorities (Fuerst \& McAllister, 
2011, p. 65). At this point, the major part of the market definition of sustainability is simply an effort to promote some operational version of sustainability (Portney, 2003, p. L 115). This green strategy is essentially there to capture a relevant share of the rising market of environmentally concerned consumers (Oyewole, 2001, p. 239). Whenever a green product is developed, in order to compensate any additional construction cost, investors require a combination of higher income or reduced risk. This ultimately means that investors or real estate developers will be fully compensated for the possible extra costs of providing "green" features (Noiseux \& Hostetler, 2010, p. 571; Fuerst \& McAllister, 2011, p. 50). The deregulated economic climate has led some companies to develop their own approaches to sustainability supported by market rules of supply and demand for greener products (Frame \& Newtom, 2007, p. 574). The process to decode the market consumer, also known as the target consumer, is a helpful instrument to marketers to know what sort of green attributes should be incorporated into the market mix (Ginsberg \& Bloom, 2004, p. 80). When the consumer target is defined, companies analyse if they are a large enough group to be profitable, and then take the decision to appropriate green characteristics into the product (Polonsky, 2005, p. 130). Subsequently, companies contemplate their competitors, how they are approaching the market, and analyse if there still is space for more green products. The growth of the green market has led to the advent of market-based "sustainability" in the form of voluntary environmental certifications. A wide range of labels in different countries cover most of the real estate market products, such as Leadership in Energy and Environment Design (LEED United States), Green Star (Australia), Green Globes (United States), Building Research Establishment Environmental Assessment Method (BREEAM, United Kingdom) (see chapter 1). The certification market has sharply increased and is getting more recognition all over the world (Glenn, 2011, p. 167; Fuerst \& McAllister, 2011, p. 45). The certification market is, indeed, another mechanism to increase profit. Labels yield positive effects on the value of real estate properties (Zheng et al, 2011, p. 04). It also is remarkable that there have been reports that developers have been making fraudulent claims about obtaining certification at the beginning of project construction (Fuerst \& McAllister, 2011, p. 48). Environmental certification has become so popular that some cities have been using it as an environmental building standard, ignoring the market basis of these labels (Stansberry, 2011, p. 98). 
The definition of sustainability has to be more specific. At present the definition of sustainability varies from company to company and institution to institution. In addition the lack of mathematical parameters has provided an enormous scope for the real estate sector to explore the marketability of this idea. Developers have conveniently appropriated aspects of the concept, for instance the idea of being energy efficient, to self-label their products as sustainable or green. Real estate developers have realized the value inherent in regions with a large availability of natural green areas and have attempted to increase these in projects for the high end of the market. Green areas can easily be associated with an ecological or eco-friendly product.

This process of privatization of green areas has been legal and has been partnered by the negligence of the public authorities. The regions right beside the cities, which were predominantly green, instead of having their green areas preserved as a green belt around the towns, have been subdivided into larger house plots and sold.

Local authorities, sometimes misinformed, have often provided incentives for certificated buildings. This essentially means another financial motivation for developers (Fuerst \& McAllister, 2011, p. 49). At the local level the authority is often more concerned about economic stability rather than environmental stability (Girardet, 2007, p. 13). Therefore, a deep analysis of the certification of sustainability efficiency may be lacking. Indeed, the products which claim to be green or sustainable should be subjected to an increased level of inspection. Self-certification or market-based labels are no longer enough to offer a sustainable product (Linstroth, 2009, p. 78).

\subsection{Conclusion}

Maybe as important as the interference in urban design caused by the economic models is the collective change in the public mindset. In fact, at present more land has been allocated to roads, highways, garages, and parking lots than housing in a normal development pattern (Warren R. , 1998, p. 16). In terms of urban form, the real estate market has had as an important role as the urban planner in the last decades. In addition, it also has a central position as an important economic player. Its urban products, such as new developments, demand a high level of resources. However, orthodox economic analysis has become so abstract that some important aspects of 
environmental impact studies have been severely compromised (Rees, 1994, p. 122). The economic model today has to be changed in order to include a better sustainability analysis, instead of the current paradigm of a wealth (well-being) analysis. Another necessary major change is internalizing the concept of externalities into the parameters to measure prosperity. An externality occurs when products or consumption by one party directly affects another party. In addition, the concept can also be used when a product value is not affected, for instance, in terms of not accounting for its environmental impact. The price to recover the environment is paid by a third party today, especially when it comes to social and environmental costs. A relevant environmental catastrophe, for instance caused by urban expansion, may be economically seen as a positive fact. Because of the externality concept, developers are not responsible, and the economy will be boosted by the costs incurred to recover the issues (Heinberg, 2011, p. L 850). Therefore, internalizing an externality would lead to prices that reflect the full costs, including the environmental and social impacts (Meadows, Randers, \& Meadows, 2004, p. L 2794). This suggestion to incorporate the external costs into the price is known as Pivougian theory (Common \& Stagl, 2005, p. 417). Its use would lead consumers to understand the real costs of their behaviour. Indeed, modern consumer well-being should have its sustainability assessed (Stiglitz et al 2010). This aspect cannot be neglected, and companies cannot have or use the term sustainable if they are worsening the situation of a given group in society, even if this group are in a different and far away country (Oyewole, 2001, p. 249). It is, consequently not acceptable that, in order to keep a high level of quality of life in one place, some other region has to be kept under the poverty line (Mcmanus \& Haughton, 2006, p. 116). This concept attests the depth of the urban sustainability principle, which necessarily demands resource conservation and environmentally-friendly strategies at all stages (Johri \& Sahasakmontri, 1998, p. 265). Concern should not only be with the environment, but also with all people in the environment (Oyewole, 2001, p. 240).

Apparently, the corporate mainstream approach of sustainability has failed to undertake analyses that reach the core of the problem. Real sustainability will require a pattern shift in the way that business is done. Companies have been operating opportunistically and not really reducing their impact (Rees, 1994, p. 344; Polonsky, 2005, p. 125). The attention that has been paid to the social and economic aspects of 
sustainable development may be indicative of how its real values and meaning are being ignored. The concepts of ecological footprint and regional carrying capacity are frequently avoided by real estate developers and their products. The concept of ecological footprint clearly shows how the ecological impacts caused by new urban developments go beyond their physical limits. Real estate developers do not tackle the problem of overconsumption of land, in order to supply the life style based on fossil fuel consumption present in their designs. In fact, the process of deregulation, in economic and municipal laws, has been facilitating commerce and trade, which allows the population to appropriate carrying capacity from elsewhere through product consumption. The introduction of ecological footprint in the real estate market would help to disseminate the idea of limit. It would graphically illustrate to consumers the amount of land needed to support a life style in a real estate pseudo-sustainable product. The concept of sustainability should hold the idea of promoting equity, instead of promising more production (Mcmanus \& Haughton, 2006, p. 115). A regional and global sustainability is, therefore, theoretically achievable if all regions live within their own regional carrying capacity (Rees, 1994, p. 126).

Developers may address the concept of technical sustainability, which reflects building materials and construction methods. However, the idea of sustainable behaviour, which represents the behaviour of the residents, is probably seen as an aspect outside the developers' scope. Use of ecological footprint as a measuring tool, however, may lead to the conclusion that a truly sustainable project has to be both of the concepts (material and construction and user behaviour) combined. This ultimately means that marketoriented sustainable projects are, indeed, ineffective in achieving sustainability. Green real estate products are not able to attract and grow sustainable behaviour among their residents (Noiseux \& Hostetler, 2010, p. 240).

The real estate economic model, which demands profit and has helped to shape modern cities, is incompatible with real sustainability. Developers, since the process of land acquisition and land banking is fundamental to their way of working, only have financial objectives. The idea of profit as a main goal over sustainability has led modern society to an unsustainable situation. In ecological terms, cities are nodes of pure consumption existing parasitically on a resource base (Rees, 1994, p. 128; Odum, 1989, p. 49). Cities have been repeating the same compass of expansion, according to the neoclassical 
economic concept of expansion unrelated to environment and resources. Developers and investors are aware of sustainability, and if their green products do not drive to better sales performance or even an increased market share, the strategy will be demoted (Ginsberg \& Bloom, 2004, p. 81). Sustainability is only another attribute for consumers and developers. It is incorporated into products to be considered alongside other attributes, such as obsolescence (Polonsky, 2005, p. 126). For consumers, even if they perceive the appeal of having a green house, when they are required to trade-off product attributes or help the environment, the environment is almost never kept as a priority (Ginsberg \& Bloom, 2004, p. 79). A similar situation may occur when the tradeoff proposed is price. For developers the parameter is simpler. If the green product does not perform according to the pre-defined financial criteria, it is very likely that developers will choose not to engage in such a strategy again. 


\section{Indicators for Urban Design Environmental Assessment}

\subsection{Introduction}

The social structure and mode of production throughout modern developed society have been growing based on an environmentally inefficient model. Consumption and environmental impact have a straight correlation with income, as high income is equal to high environmental impact (Merkel, 2003, p. L 1903). The process to build up a longterm sustainable position may imply a complete change in current developed world lifestyle.

There are three key groups of urban design sustainability indicators; design, sustainable behaviour, and construction processes and materials. Although the indicators can be grouped into these three blocks, they are not restricted to a specific group; sometimes they are interchangeable. For instance, some aspects assessed inside the group 'design' could be also taken as part of 'sustainable behaviour'. Indeed, there is an indivisible relationship between the groups, and a truly sustainable neighbourhood only can be achieved if the essential majority of the items are considered and taken up in any urban development. This integrated approach elucidates, and indirectly criticizes, some gaps in the majority of the environmental labels available in the market. Sustainable urban development, due to the scale of the environmental interference created by any development, demands the effect that comes from combining the indicators; otherwise, the environmental analysis will only be partial. The group of indicators labelled 'sustainable behaviour' is included because a design planned to be sustainable will not be effective if the users keep unsustainable habits. In addition, this group of indicators also encompasses economic aspects and examines the impacts caused by overconsumption and the economic growth paradigm, since the current economic model is essentially unsustainable. Human behaviour very often contributes to diminishing natural resources. Whenever this behaviour is stressed by the marketdriven approach the incentives for behaviour leading to depletion have dramatically increased. The process towards sustainability, therefore, has to challenge every single aspect of the normal routine that has lost the essential idea of limits. The world limit, in this research examined through the ecological footprint, has to be associated with the 
earth's carrying capacity. The current life-style has been based on three fragile factors resource depletion, environmental impacts, and systemic financial failure (Heinberg, 2011, p. L. 417). Therefore, cities and urban development as an important part of the economy are driven to be an unsustainable characteristic of the economy.

The idea of an urban sustainable structure, sustainable development and a sustainable economy are neither new nor lack precedent. Some ancient Greek cities were planned according to the local environmental constraints. Sparta, as well as representing the Greek ideal of development, also controlled its expansion through incorporating the Platonic urban model (Gutkind, 1969, pp. 489-496).

Human behaviour very often contributes to the overconsumption of natural resources. The indicators considered here have individual criteria but are all based on the same principles of limitation and finite resources. Therefore, in order to encompass these notions, the concept of ecological footprint has been used as the basis of the approach. This will allow the internationalization of the concept, although it also covers local aspects, criteria, and their quantitative values. The environmental footprint principle is responsible for determining the territorial limit of the impact caused by an urban development. It has to take into account the regional characteristics, particularly concerning energy resources, to establish the land share that the development is allowed to use in order to be sustainable. In a very restricted analysis, a sustainable development should have a starting footprint lower than the current world footprint, in order for it to remain sustainable as the world average footprint decreases proportionally with global population growth. According to this principle, a sustainable development, at a world scale, has to keep decreasing its footprint. A static examination of footprint and sustainability does not consider the forecast expansion of global population and the permanent increasing demand for resources this implies. Therefore, because of the progressive reduction of land share caused by population growth and overconsumption, new developments have to create opportunities to decrease their impacts. This notion is also a criticism of the labels available in the market, which only consider a static moment and often do not reflect the post construction impacts. In short, the concept is simple; in order to keep being sustainable the development has to decrease its impacts while consumption and population growth are taking more and more land share. 
The new sustainable approach has to challenge the need to move, shop, communicate, and perhaps many other routine modern activities that usually pass unchallenged. This new sustainable approach, centred on the idea of limit and resource scarcity, may ironically apply the same principles of efficiency and productivity largely spread among corporations to limit their resource consumption. However, if the population keeps growing, and the demand for resources also keeps increasing even the fundamental essence of business will have been challenged. A sustainable region, therefore, will need more than low transportation rates, local jobs and food production, and people walking or cycling. It will require that the local businesses are sustainable and engaged in keeping the low footprint. A company may have a very low local environmental impact, however, if its production's chain has any sort of environmental impact, it will consequently be considered regionally sustainable but globally unsustainable. This ultimately means unsustainable. Businesses may experience a fundamental change. They will have to develop sustainable practices among their workers, and production might have to have a different priority than just profit.

This implies a deep change in every single aspect of the current production model. Because this model is entirely based on perpetual economic growth, as soon as resources become scarce the production mode will collapse. It seems that the concept of perpetual economic growth also brings the idea that this current production model will keep going indefinitely. Historically all systems eventually collapse; there is no reason to believe that the present one will not fail one day.

Due to human population growth, humanity's footprint has been increasing with less land per capita, and consequently a more emergency approach is now needed. The main problem, which cannot be avoided by a simple adjustment, such as giving up private transportation, is the population expansion, which leads to increasing scarcity of many resources essential to sustain human life. Apparently, the first prop of the economic system that will probably fail will be oil production, and hence energy, although land may also be very scarce. This is the main reason that transportation plays such an important role in a sustainable picture, but it is not the only one. The equation of change is simple - if the population grows, the footprint increases, and the required changes will be more dramatic (figure 44). 


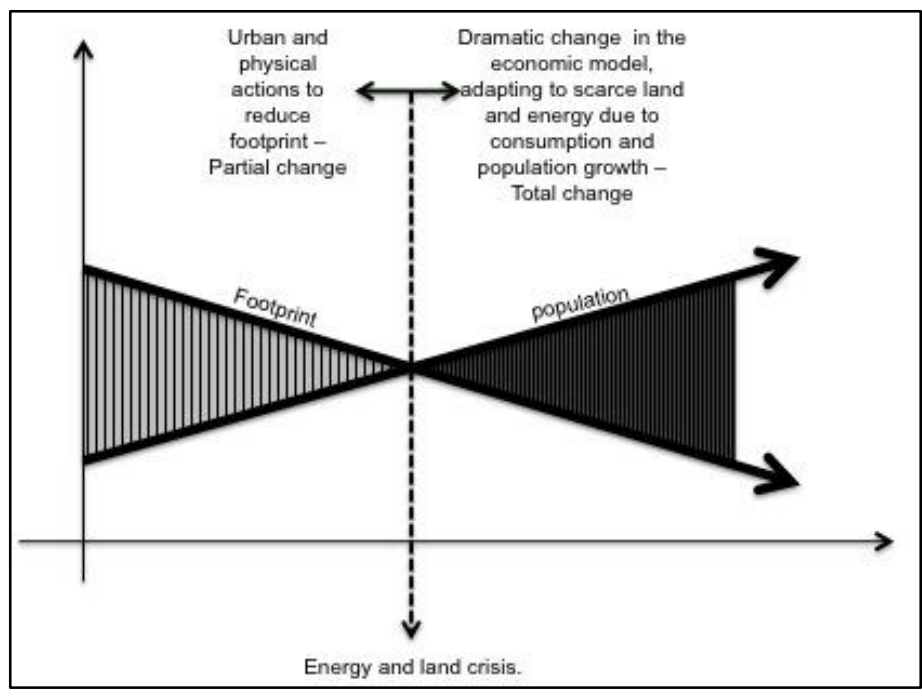

Figure 44 - Theoretical relationship between population growth and footprint and transformation after an energy and land crisis, the vertical axis indicates the growth and units while the horizontal axis indicates timeline.

The footprint analysis is given through the unit of global hectares to take account of world average land productivity. It is, therefore, a mathematical unit, which is easily measurable. However, its characteristic, which permanently varies according to population growth and consumption level, dictates how the developments have to be analysed because of the problem of dealing with a varying quantity. Instead of only measuring the footprint of the development, this research suggests using a best practice approach, in which the best practice is based on both the environmental impact and the footprint. The footprint methodology is consequently the most consistent guideline in this research for the development of best practices. It has influenced all indicators discussed her but the indicators are not all expressed in global hectares. The research therefore does not present a methodology for calculating the footprint of an urban development. Through the suggestion of best environmental practices, new developments will consequently have the lowest footprint possible. This process indicates that the footprint analysis has to be permanent and has to happen during the lifetime of the development. It has numerous variations, such as the seasons, economic variations and environmental changes and even catastrophes. Essentially the environmental efficiency of an urban development is its capacity to keep itself permanently under the global land share determined by the global footprint and global 
carrying capacity. It ultimately means that most of the sustainable developments today, even if they keep up an excellent performance, will become unsustainable in the future due to the reduction in land share. It also means that some developments, due to their locations, will permanently be unsustainable, even when based on the best sustainable practices.

The adoption of best environmental practices also works to create urban development with very low impact. Even if an urban development theoretically has its footprint under the global hectare limit the best environmental practices are essential. If some of the essential indicators have been neglected, but the urban development is under the footprint limit, best practice will guarantee that the development will have a long sustainable life. The best environmental practice is, therefore, more than the simple mathematical adoption of the footprint analysis, it the guarantee that an urban development will have the lowest possible impact in a certain region.

\subsection{The Unreal Handiness of the Car Exchanged for the Real Convenience of not Going}

Cars have been progressively replacing the energetic efficiency of walking and cycling. Even the simplest activities, like going to school, have been switched from walking to driving (Ministry of Transport - New Zealand, 2010). The process of moving to sustainability at the transportation level may not simply mean the giving up of cars as this alone may not be enough. Due to population growth a more emergency approach to the transportation problem is needed.

Obviously the way that people move around can be redesigned in order to save more energy and resources, but this, difficult as it is, might not be enough. The way that people and goods are transported, which is responsible for shaping modern convenience, has to be re-thought. However, the change is not exclusively in the way that people and goods move, nor the distances between work-house-leisure. The technological development brought about by cheap energy has also improved the whole communications system. The only probably reason that electronic communication is not widespread among companies is because the whole system is not totally set up and some sectors still demand a physical presence in order to control their employees. 
Working from home, even for one day a week, has already been shown to mean significant lessening of environmental impacts (Chapman, 2007, p. 359). Although, communication demands some use of energy, it seems more efficient than transporting a large proportion of the population every day between house-work-shopping-house. However, a switch of this sort will still not change the essence of business, which would still be profit, and probably the core of business would still be, directly or indirectly, based on resource depletion.

In consequence of the unavoidable collapse in oil supply, therefore, revising the transportation system as a whole is essential whenever the topic of sustainability is brought up. Apparently, even in the current relative resource scarcity with oil prices going up, measurements indicate that people are using cars even more (Ministry of Transport - New Zealand, 2010). This goes against the obvious global interest of environmental preservation. New Zealand demonstrates this tendency. Travel for social events plays an important part in all travel, and 82 per cent of these trips are made by private transport. Private transportation is also responsible for more than 80 per cent of all travel to work (Ministry of Transport - New Zealand, 2010). The tendency to motorization can easily be seen when comparing travellers' behaviour during the late 1980 s and today. In the late 1980s 6 per cent of travel to work was walking, and today this is only 4 per cent, while driving has increased 15 per cent over the same period (Ministry of Transport - New Zealand, 2010). The journey to school has suffered an even more relevant unsustainable impact. In the late 1980s, 40 per cent of journeys to school were accomplished by walking, whereas today only 25 per cent of such journeys are walking. Cycling, comparing the same periods has dropped 66 per cent. The only hope is bus travel has risen from 31 per cent to 58 per cent of journeys to work (Ministry of Transport - New Zealand, 2010).

\subsection{Urban Environment towards Walkability}

Walkability in urban design can be defined as a built environment that supports and encourages walking by providing comfort and safety, and connecting people with different destinations for a reasonable expenditure of effort. Walking, in a walkable environment, has to be taken as the main transportation mode. It also has to offer visual 
interest, a safe environment, connectivity of path networks, linkage with other modes of transportation, and good quality paths. However, the main factor that defines whether people decide to walk or not is distance (Funihashi, 1985; Komanoff \& Roelofs 1993; Handy 1996; Smith and Butcher 1994 in Southworth, 2005, p. 249). Although, the influences of the built environment on the decision to walk are not totally understood (Sallin \& Owen, 1999, in Leslie, Coffee, Frank, Owen, Bauman, \& Hugo, 2005, p. 113), connectivity, as a design decision, may have a role as an important factor in reducing distances.

Connectivity is based on the design of the street network. It measures the directness of the path between households, shop, schools and place of employment (Leslie, Coffee, Frank, Owen, Bauman, \& Hugo, 2005, p. 113). It is determined by the presence of sidewalks, pedestrian paths, and absence of barriers (Southworth, 2005, p. 249). The relationship between distance and connectivity is rather important. Lack of connectivity may lead to a poor walkable environment, and even a short distance can be unreachable. It can be analysed according to the number of street intersections and size of the blocks. However, a high number of intersections does not necessarily mean a good walkable environment. A highly walkable environment has to be appealing, and provide a richly connected path network that provides access to everyday places. Intersections have to be combined with the other walkable environment factors mentioned above. Moreover, intersections can be categorized according to their physical characteristics. An intersection can be exclusively for cars, cars and pedestrians, or only for pedestrians. An intersection just for cars is indeed a barrier to pedestrians; consequently these contribute to an unwalkable environment. Thus a simple numerical analysis of intersections may lead to some paradoxes. Ideally, intersections have to be analysed one-by-one at a micro-local context. Some of the main pedestrian barriers, which work to decrease connectivity, are culs-de-sac, dead end streets, busy roads and arterial roads, railroads, power line rights-of-way, rivers and lakes, high slopes and any element which blocks the shortest way in the everyday routine. These elements must be avoided. Culs-de-sac and dead end streets have to be planned in order to keep the ability of pedestrians to access different areas, thus providing walking and cycling systems. Urban design has to be planned in order to 
understand and integrate natural barriers and railroads, minimizing the obstacles caused by them.

An intersection, therefore, can be analysed according to its quality, quantity and positioning. In an ideal scenario for urban design, each $1 \mathrm{~km}$ sq. should have at least 100 intersections in order to promote a walkable environment, and therefore a sustainable one. This can be visualised as a block with a side of $100 \mathrm{~m}$ on average, and the block average perimeter would be $400 \mathrm{~m}$.

Figure 45 illustrates different urban patterns in different countries. These places were randomly selected to show how diverse an urban fabric can be concerning connectivity. Victoria and Lisbon were chosen to demonstrate the contrast between European pre World War II design and more recent design. In Beijing, a traditional group of hutongs, only 500m from Tiananmen Square, were selected.

The most remarkable result is from Beijing. The hutongs and their residences have the best results in terms of connectivity level. Hutongs are ancient alleys, in fact pathways. They are formed by many quadrangles and a rectangular house model (siheyuans) that are a type of enclosure of buildings. Each is composed of four houses in the four sides around a courtyard. The result of the combination of these sorts of residence forms a set of pathways - the hutongs. This traditional dwelling can be traced back to the Han Dynasty (206 BC - 220 AD) (Wan, 1997, pp. 574-575). 


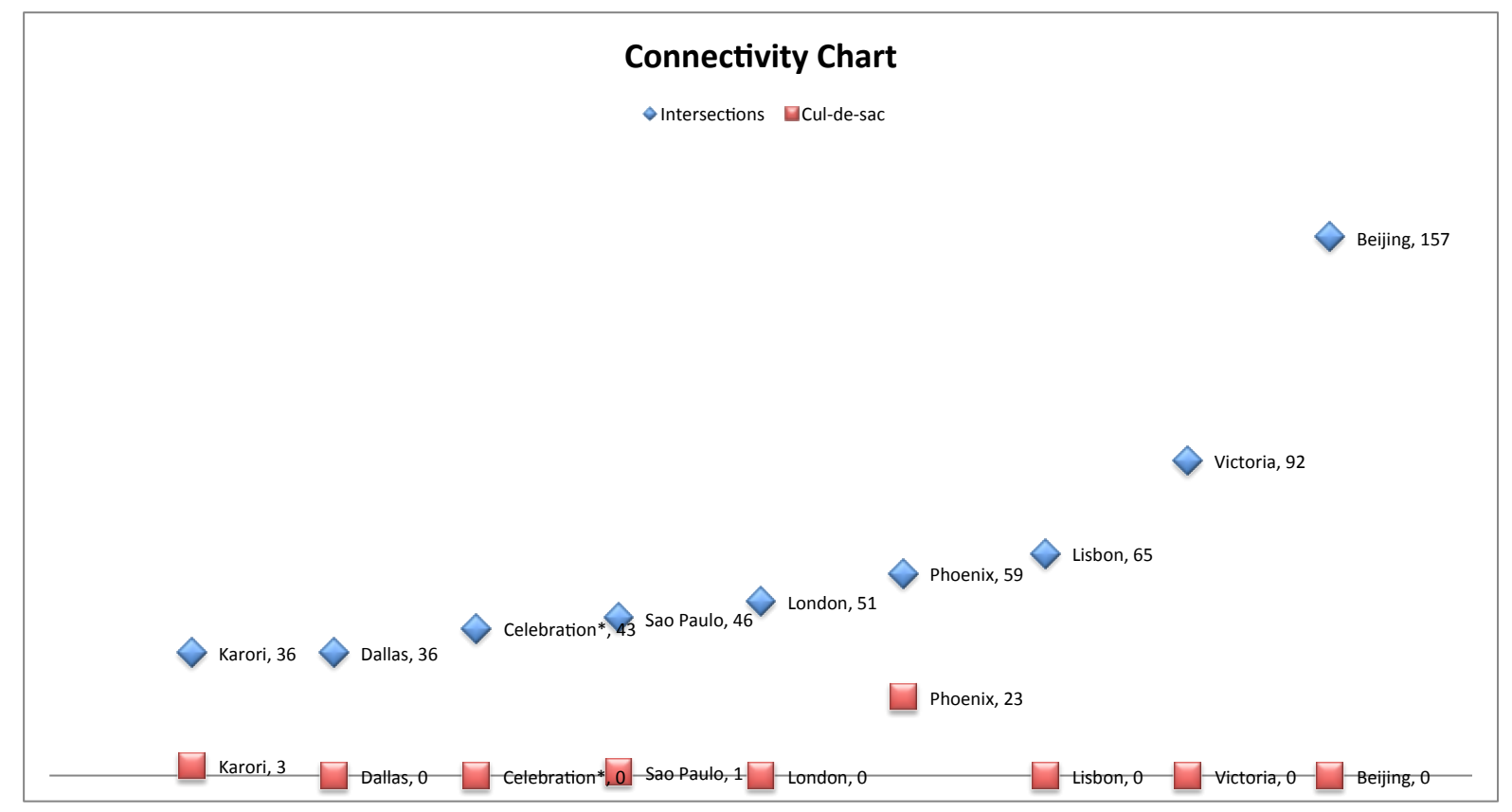

Figure 45 - Connectivity comparing the number of intersections in different models of urban environment

Another important area analysed was the Celebration development. "Celebration is perhaps the most prominent and certainly the most controversial of the secondgeneration New Urbanism communities" (Duany, 2011). Controversially the Celebration development scores very low in connectivity when compared with a traditional walkable designed Hutong.

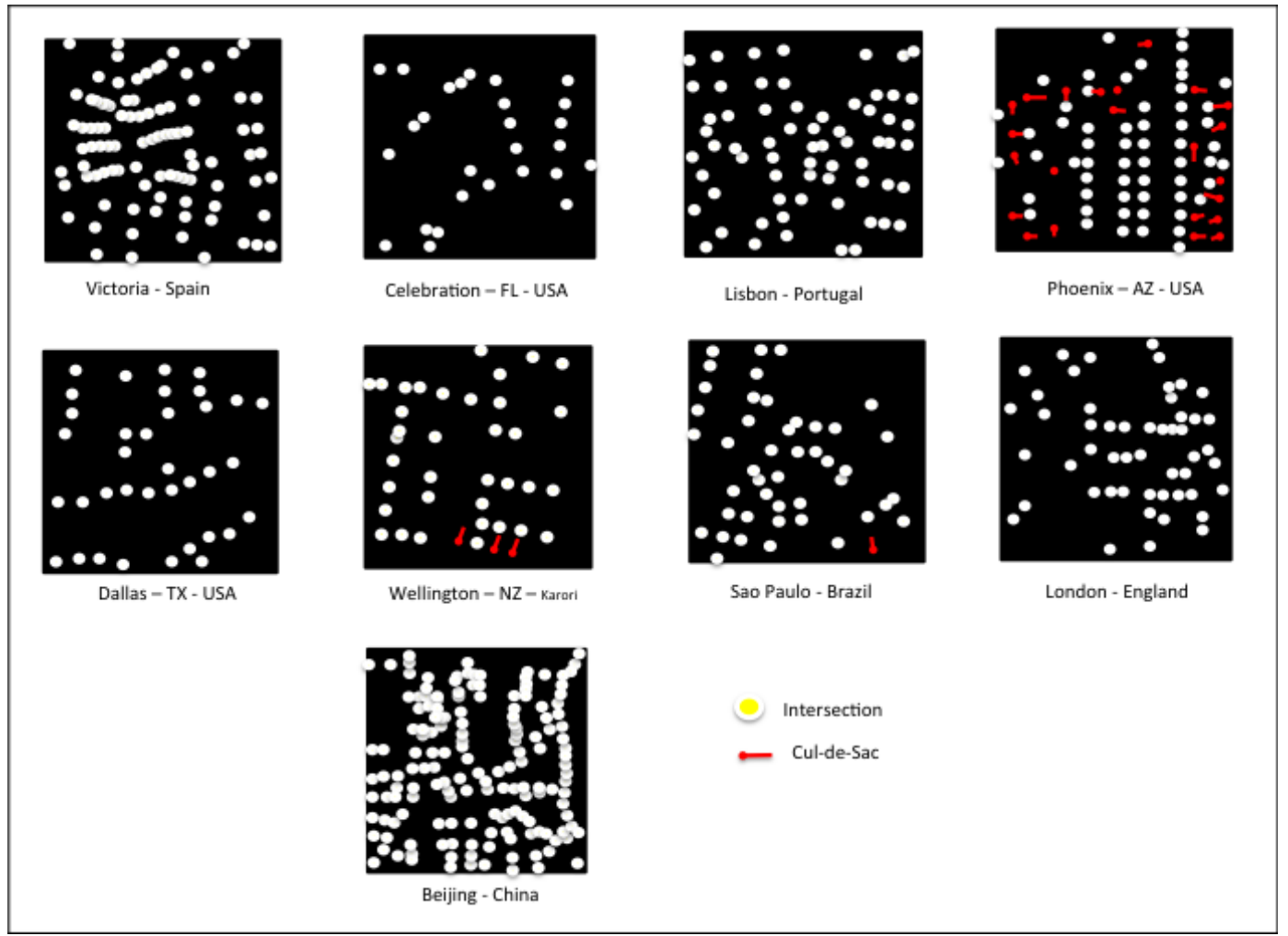

Figure 46 - Comparison of the urban intersection dispositions in different urban models -the analysis was made using google earth $(c) 2011$ Google Earth 
In order to facilitate the assessment, some conventions were adopted. The sites do not have highways crossing them, and the measurements of blocks were taken considering the axes of streets.

\begin{tabular}{|l|c|c|c|c|c|}
\hline Connectivity Analysis & $\begin{array}{c}\text { Highly } \\
\text { Unwalkable }\end{array}$ & Unwalkable & Walkable & Highly Walkable & $\begin{array}{c}\text { Sustainable } \\
\text { Level }\end{array}$ \\
\hline Intersections & $>0<40$ & $>40<60$ & $>60<80$ & $>80<100$ & $>100$ \\
\hline Car Intersections & $>2$ & $>2$ & 1 & 0 & 0 \\
\hline Block Perimeter Ave. & $>632 \mathrm{~m}$ & $>632>516 \mathrm{~m}$ & $<516>447 \mathrm{~m}$ & $<447>400 \mathrm{~m}$ & $<400$ \\
\hline Cul-de-Sac & $>10$ & $<10>5$ & $<5>2$ & 0 & 0 \\
\hline Pedestrian Barriers & $<4$ & $<4$ & $<2$ & 1 & 0 \\
\hline
\end{tabular}

Table 4 - Minimum requirements for urban sustainability related to walkability

The intersection analysis is only a single criterion, which isolated does not represent any significant indicator of real sustainability. It essentially determines if the built environment is walkable, and has the potential to have a sustainable transportation approach. The intersection analysis indicator combined with density (table 5) can be a more powerful tool to analyse the built environment and its transportation approach.

Urban density was ranked according to the table below.

\begin{tabular}{|l|l|}
\hline \multicolumn{2}{|c|}{ Inhabitants $/ \mathrm{km}^{2}$} \\
\hline Low & $>386$ \\
\hline Medium & $>386<1544$ \\
\hline High & $>1544<3860$ \\
\hline Very & $<3860$ \\
\hline
\end{tabular}

Table 5 - Urban density expressed in inhabitants / square kilometre

The effect of the combination of low densities and lack of connectivity leads to a highly unwalkable environment. This model, largely spread after World War II, is essentially unsustainable (Shane, 2011, p. 12). It takes a large amount of land, which demands oilbased transportation. However, high densities and a high level of connectivity are not enough to assure a sustainable environment, even though high density normally results 
in less usage of car, more walking, cycling, and public transportation (Acker, Witlox, \& Wee, 2007, p. 333). However, even high-density regions demand structural planning to be sustainable. The design, which privileges high density, has to take into account the distances between the every day activities. Large areas with high density cannot be exclusively residential. Each has to include within its region, shopping, work areas and leisure. This is directly related with zoning. High-density areas need a zoning policy that encourages the development of regions with mixed uses.

It has been claimed that in order to encourage walking, the distances from home to work or commerce cannot be longer than 800 metres (roughly 1/2 mile), and this was a typical distance found in medieval settlements (Southworth, 2005, p. 247). In addition, others have claimed the distance from home to public transport cannot be longer than 400m (Hoback, Anderson, \& Dutta, 2008, p. 681). This means that density and connectivity have to be analysed along with the distances that the inhabitants have to walk to reach all everyday services.

However, a walkable environment designed to achieve an optimal relationship between consumption of energy and land only guarantees efficiency in transportation and land occupancy. On its own, this is not enough to declare a region sustainable. Energy efficiency and lowering land consumption are essential attributes of moving toward a sustainable environment; however, in isolation they are inefficient for measuring sustainability. Therefore, settlements designed on the principles of New Urbanism cannot be accepted as the paradigm of sustainability in urban design. Although New Urbanism projects have a relatively high density, criticisms have been made of them because of the lack of public transport at connections and consequent oil dependence (Shane, 2011, p. 103 and 286; Southworth, 2005, p. 250). This demonstrates that isolated parameters are only partial and incapable of defining sustainability. However, they are extremely convenient for promoting an ecological approach in real estate developments. Consequently, real estate sales are boosted when these ideas are included, probably because of public demand for environmentally correct projects. 


\subsection{Food - Integrating Food in Urban Planning.}

The process toward sustainability in urban design has to add new permanent parameters according to their impacts on the ecological footprint. Therefore, food and its consumption and production, has to be taken into account as an important parameter. Consequently, density becomes a criterion, which demands an intergrated analysis with food production. It means that a region can have low density if it produces food as overall this will tend to lower the ecological footprint. The combination of a walkable environment, considering the range of distances which encourage walking and cycling, density, food production and public transportation are, in contrast with considering these factors in isolation, when taken together a relevant indicator of sustainability.

In order to develop a mathematical parameter for food production and density, some constraints were adapted from the Global Footprint Network (GFN). According to the GFN, the earth's total biocapacity was 1.8 global hectares (gha)/person in 2007. Biocapacity is defined as

"The capacity of ecosystems to produce biological materials useful for people, and to absorb waste they generate (including carbon dioxide from fossil fuel... Biocapacity is usually expressed in units of global hectares (gha). The gha is a weighted area used to report both the biocapacity of the earth, and the demand on biocapacity (the ecological footprint). The global hectare is normalized to the areaweighted average productivity of biologically productive land and water in a given year. Because different land types have different productivity, a global hectare of, for example, cropland, would occupy a smaller physical area than the much less biologically productive pasture land, as more pasture would be needed to provide the same biocapacity as one hectare of cropland. Because world bioproductivity varies slightly from year to year, the value of a gha may change slightly from year to year. The biocapacity of an area is calculated by adjusting the area for its productivity. This is achieved by multiplying the actual physical area by the area specific yield factor and the appropriate equivalence factor."

(Global Footprint Network, 2011) 
In order to create a mathematical base for the density calculation, some assumptions from the GFN were made, shown in table 6 below.

\begin{tabular}{|l|r|}
\hline Global Population (billion) - 2007 & 6.7 \\
\hline Cropland Footprint & 0.6 \\
\hline Grazing Land Footprint & 0.2 \\
\hline Forest Footprint & 0.3 \\
\hline Fishing Ground Footprint & 0.1 \\
\hline Carbon Footprint & 1.4 \\
\hline Built-up Land & 0.1 \\
\hline Total Ecological Footprint Average (gha) & 2.7 \\
\hline Total Biocapacity (gha) & 1.8 \\
\hline
\end{tabular}

Table 6 - World Biocapacity and the ideal share that each item should have in order to have a non-land deficit (Global Footprint Network, 2012)

Table 6 above gives a total biocapacity of 1.8 global hectares. It includes around 0.8 global hectares entirely dedicated to food production from cropland and grazing land. In order to provide a consistent indicator, local productivity has to be analysed and measured in accordance with the GFN. This is essentially the analysis of the biocapacity of a region in a certain period of time, which will give the land weighting. The indicator suggested below has assumed a hypothetical productivity, which makes the global hectare the same as the conventional metric hectare. Otherwise, the indicator should measure the productivity, and therefore the biocapacity, of the site. Consequently, this is what has to be done in a real situation when applying the indicator.

The amount of land necessary to provide food becomes essential to the development of a sustainable urban environment. In contrast with the irrelevant sustainability parameter provided by density in isolation, the combination of density and food production using a measurable unit, can deliver a trustworthy gradient of sustainability. Food production may be responsible for something between 18.33 per cent of biocapcity in Brazil (Global Footprint Network, 2011), 24 per cent in Wales (Vale \& Vale, 2009, p. 36) and 87.69 per cent in the UK (Global Footprint Network, 2011) (Figure 47). 


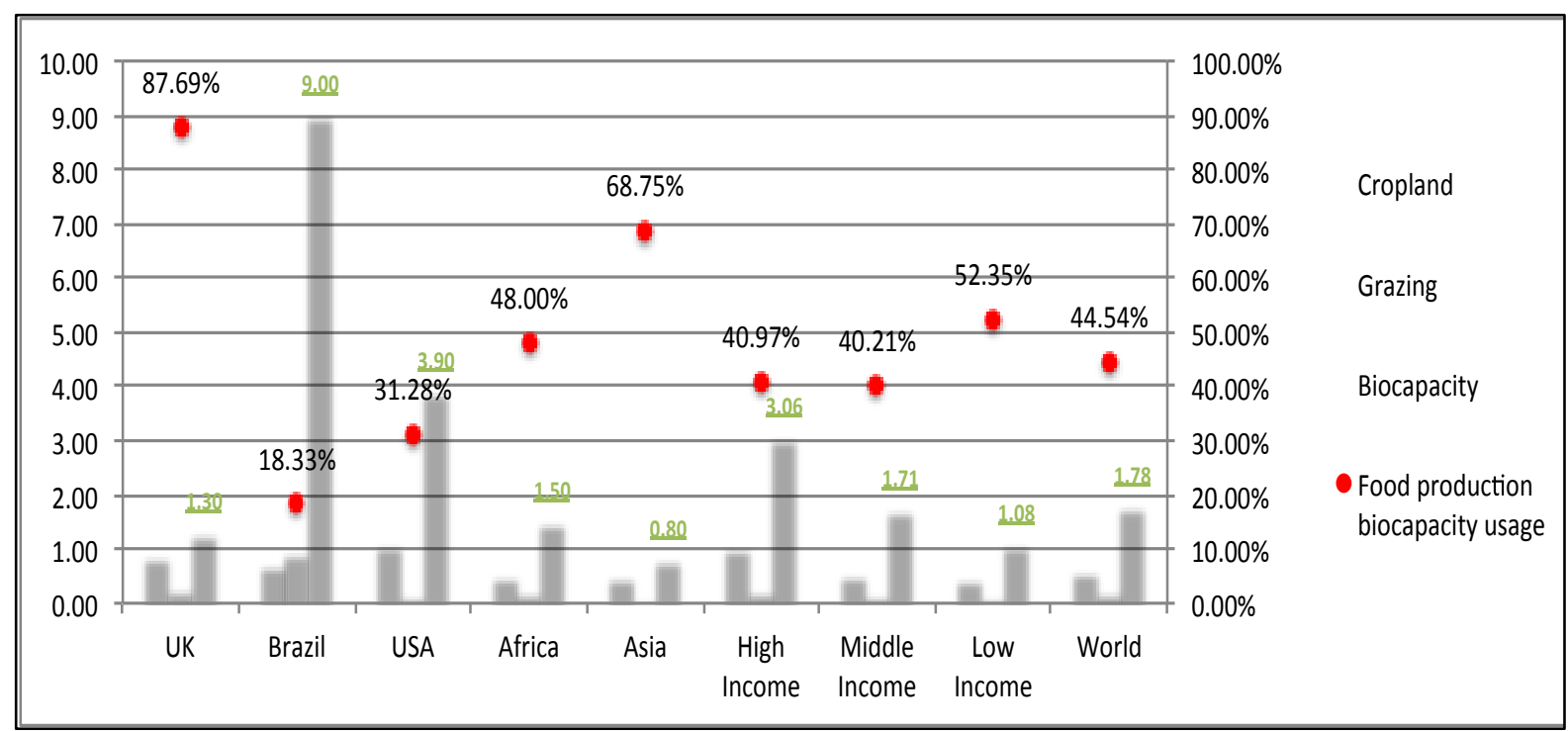

Figure 47 - Comparison of different countries and their ecological footprint and its components (Global Footprint Network, 2012)

In order to provide an indicator from the combination of density and food production, the parameters were developed using the assumptions below:

1. The world average percentage dedicated to food production has been used as parameter; therefore, 44.54 per cent of the footprint, expressed in global hectares, is directly used to provide food.

2. The earth's biocapacity is 1.78 global hectares.

3. The productivity of the sites when weighted to the productivity index levels provided by GFN makes them equivalent to the global hectare. Consequently 1 metric hectare is equal to 1 global hectare due to their assumed productivity levels.

4. Each person consumes 25 sq. metres of land for housing

5. On top of housing, 5 per cent of this area has been added in order to provide circulation and access and another 5 per cent for public infrastructure.

6. There are no natural obstacles.

7. The hypothetical site is flat.

8. The site is not responsible for generating energy. 
With these assumptions, a formula was created in order to calculate how much food a certain site has to produce to be environmentally efficient, in accordance with the local density.

$$
100 * F p=\frac{S t-S o}{(P * F F)}
$$

Where:

$F p=$ Necessity for food production expressed as a percentage of available land

$S t=$ Total area of the region studied

So $=$ Occupied area

$P=$ Persons

$F F=$ Food Footprint to supply human beings' needs. This research will assume 44.54 per cent of 1.78 gha

The equation for land associated with housing is given below:

$$
\text { So }=(P * I h)+P(I c+I i)
$$

Where:

$I h=$ Housing Index - indicates how many hectares a person consumes for housing. According to assumption 4 , this research takes 0.0025 hectares $\left(25 \mathrm{~m}^{2}\right)$, although different values could be used.

$I c=$ Circulation Index - indicates land percentage dedicated to circulation; this research assumes 5 per cent on top of the housing index, although other values could be used. This assumption is based on the number of houses / inhabitants and the required space for circulation, therefore, more houses and people will need more circulation area, although the results show that it is a relatively negligible figure. Therefore $I c=0.05 \mathrm{Ih}$ 
$I i$ = Urban Infrastructure Index - indicates percentage of land dedicated to public infrastructure, such as urban furniture, roads, schools etc. This research assumes 5 per cent of total land although different values could be used. Therefore $I i=0,05 I h$.

Therefore, according to the formula above, densities have to provide a certain amount of food for those who live there, as can be seen in the table below.

\begin{tabular}{|c|c|}
\hline Urban Density & Local Food Production \\
\hline $1 \mathrm{p} / \mathrm{ha}$ & 125.79 per cent \\
\hline $3.86 \mathrm{p} / \mathrm{ha}$ & 32 per cent \\
\hline $15.44 \mathrm{p} / \mathrm{ha}$ & 7.5 per cent \\
\hline $38.60 \mathrm{p} / \mathrm{ha}$ & 3 per cent \\
\hline $100 \mathrm{p} / \mathrm{ha}$ & 0.35 per cent \\
\hline
\end{tabular}

Table 7 - The relationship necessary between Urban Density and Local Food Production in order to achieve local food production sustainability. Lower densities have to have high levels of food production.

This implies that lower densities, in order to be sustainable according to the criteria for food production, have to have a substantial amount of area dedicated to food production. A region with 3.86 inhabitants per hectare, has to produce roughly a third of its needs in food. The equation can create a relevant comparison about how much area different countries require to meet the food needs of their inhabitants.

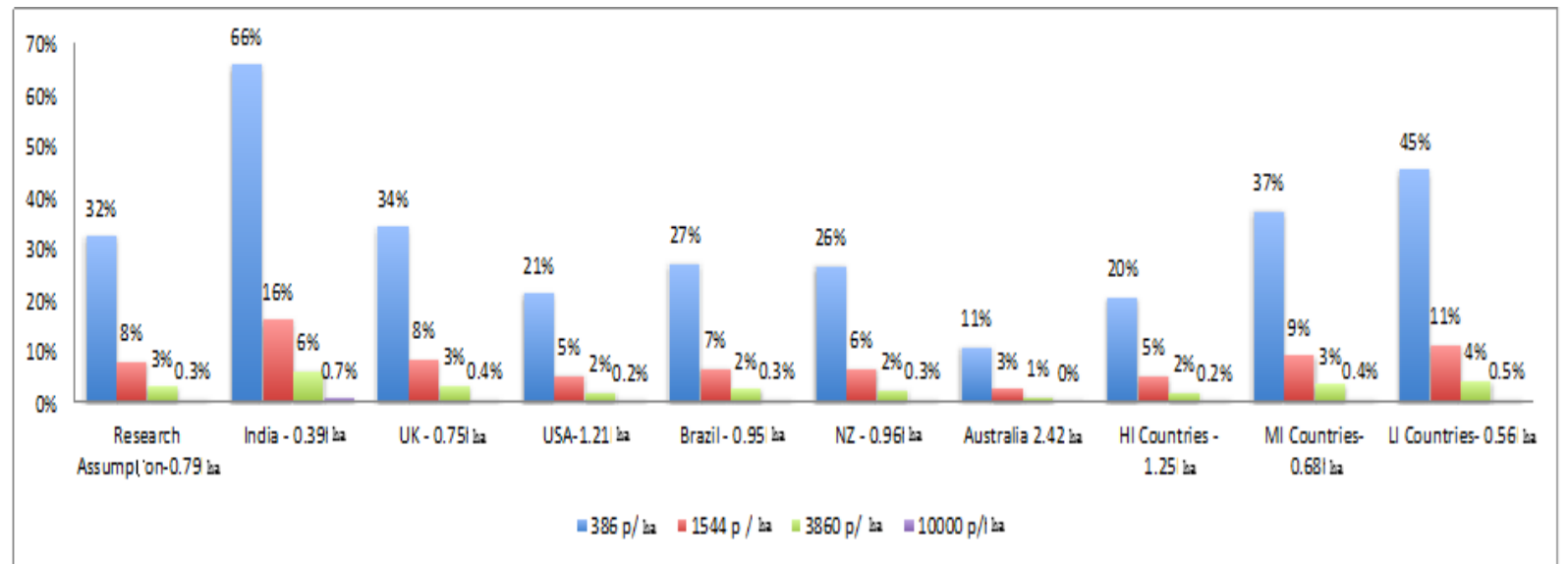

Figure 48 - Comparison of the capacity of different countries to produce food according to their diet habits and ecological footprint. It means that, in India for example, a region with low density ( $386 \mathrm{p} / \mathrm{ha}$ ) would be able to produce 66 per cent of their food, while in Australia, due to the diet, even using the free space in regions with low density, only 11 per cent would be locally produced. 
According to Figure 48, the simulation indicates that, even assuming that countries have the same areas for housing and circulation areas, food consumption and eating behaviour is a dominant factor in 'unbalancing' a region and making it unsustainable. The food consumption, therefore, may invalidate all efforts, including those in urban design, to maintain a sustainable region. This can also be extended as a criticism against environmental labels, which do not tackle the food production footprint.

Despite having a mathematical approach to combining food production and density, different regional and local constraints can directly affect the model and the outcome from the equation. Therefore, it becomes a guideline towards a best practice. It suggests that food production has an essential role in the urban scenario, and empty urban spaces must be covered by food production. It stands against the progressive privatisation of green areas and turban sprawl. The best practice is essentially the process of designing urban spaces with a focus on decreasing the footprint impact of the items which really matter.

In conclusion, in order to achieve a sustainable model some actions have to be taken according to the ecological footprint pressures. The first stage towards the sustainability is to decrease the distances and dramatically change the way that people move around. Transportation has to be based on renewable energy, and travel has to be significantly reduced. Due to the constant increase in population, the next stage, in order to keep the sustainable model after the implantation of the first stage, is to change the entire production model and avoid, as much as possible, any travel which will consume a great amount of energy

\subsection{Mobility: Circulation of People and Goods}

Mobility is an important issue in achieving a sustainable region. Transportation, food production and energy combined are responsible for more than 85 per cent of the average world footprint (Global Footprint Network, 2011). Therefore, an urgent shift in societies' circulation and transportation systems seems mandatory. Energy utilized for transportation is basically based on fossil fuels. The United Kingdom is an example of this; 99 per cent of cars in the UK are moved by petrol and 1 per cent by diesel (Chambers, Simmons, \& Wackernagel, 2009, p. 85). Only a few regions have a different 
scenario. In Brazil, more than 90 per cent of the car fleet is 'flex', which means cars that can drive on petrol, ethanol or both at the same time in the same tank (UNEP - United Nation Environment Program, 2012; UNICA, 2012). Because Brazil has a large car fleet dependent on bio-fuel, and its petrol is blended with 20 to 25 per cent ethanol, Brazil has one of the lowest $\mathrm{CO}_{2}$ car emissions in the world (William \& La Rovere, 2010). However, most of the world has transportation fleets based on fossil fuel. Not only are fossil fuel supplies finite, but also, in footprint terms, transportation demands a great area of land to sequester the carbon dioxide realised when the fuels associated with it are consumed. Consequently the main issue related with energy is the impact on footprint, and therefore land usage (as will be seen further in this chapter). Dealing with this ultimately means an important change in urban design. Consumption patterns in modern society have been extremely dependent on transportation and therefore dependent on energy (Droege, 2006, p. 14). Industrial production and goods transportation represent a significant share of the footprint of developed society. The transportation system has been designed following the principle of the economic logic (Vale \& Vale, 2009, p. 42 / 43). The way that food, goods and people are transported causes a serious impact on the ecological footprint. Commuting is another important factor that has an important relevance for footprint calculation. As with any other element of ecological footprint, commuting energy consumption consumes a certain amount of land. There are three basic approaches to measure how much land energy demands: (Wackernagel \& Rees, 1996, p. 72)

- Approach 1 - A yield of 3,800 l/ha of ethanol (Kohlhepp, 2010, p. 229), the most optimistic forecast, indicates $80 \mathrm{GJ} /$ year/ha for ethanol (Wackernagel \& Rees, 1996, p. 72).

- Approach 2 - Land required to sequester $\mathrm{CO}_{2}$ emitted by burning fossil fuels, shows 1 hectare of average forest sequesters the emissions generated from consuming $100 \mathrm{GJ}$ of fossil fuel (Wackernagel \& Rees, 1996, p. 73).

- Approach 3 - Land required to rebuild natural capital in the same proportion as the fossil fuel has been used gives $100 \mathrm{GJ} /$ ha (Wackernagel \& Rees, 1996, p. 73).

Any of the approaches mentioned above may be used to represent how much land is consumed in order by modern energy consumption. The process ends up by revealing 
the land necessary to support the transportation system, and consequently the urban design development and strategy. Any of these approaches can show how many hectares a certain kind of transport system consumes per passenger kilometre travelled. This sort of information allows calculation of the real impact caused by the way the people, food and goods are transported. The urban designer has to consider these figures and produce a design, which encourages the most environmentally efficient way to travel. It is a primary function of planners that, through their design and policies, the inhabitants of certain regions will be led to the best environmental practice when it comes to transportation. Moreover, it is clear that a region cannot be entirely sustainable if the transportation system does not include a regional and national program of ecological efficiency.

Different transportation models need different amounts of land to supply the energy demand. The overall situation is simple, however. In order to achieve a sustainable region, the total ecological footprint has to be lower than the global biocapacity of 1.8 gha/person in 2007 (Global Footprint Network, 2011). Therefore, transportation has to be planned to take just the minimum amount needed, thereby saving land for other essential items, such as food growing.

\subsection{The Matter of Distance-High-Density or Low Density-Transportation and Urban Design}

The ecological analysis that includes transport, density, commuting distance and mode, food production and consumption, shows these parameters are intrinsically related. It indicates that a transportation system has to include food distribution along with passengers. Food production and consumption and their concomitant energy demand are responsible for the largest amount of land in the ecological footprint. At the same time, the urban pattern defined by the urban designer has to consider the effects of the decision of having high-density or low density. Apparently there is no single answer for achieving a sustainable urban region. It has to be a concentrated effort focused on

saving land through decreasing the ecological footprint. A low-density region can be highly sustainable if it produces its own food and energy, and if its population does not have to commute for work and services. However, apparently most of the existing 
suburbs are not engaged in food production and they are highly dependent on fossil fuel. This is an unfavourable combination under an ecological analysis, although highly favourable when considering the economic aspects of the present production model. High-density regions can be more efficient because in theory they reduce travel distances. Public transportation is more feasible and, therefore, more efficient. In contrast, high density regions are generally more dependent on distant food producers and the essential relationship between society and food production has been lost. Consequently urban design has to list and prioritize the indicators, which will save more land and decrease the footprint. According to this condition, low-density regions are not sustainably tolerable if they do not produce either food, energy, or wood to sequester $\mathrm{CO}_{2}$. On the other hand, high-density regions cannot grow indefinitely because this would cause interruption in the notion of resource limits and totally disconnect people from the site of food production. Ultimately, it would make the region unaware of its ecological limits.

The optimum relationship between density and these other parameters may vary for each region. Many factors are directly responsible for altering the density pattern such as: climate, land fertility, topography, and cultural aspects. Indeed the list is virtually immeasurable; each site will have its specificities, which are able to change the point of optimum density.

However, some analysis can be done for a hypothetical case study. It is possible to analyse the amount of energy for transportation, therefore, it is also possible to measure the amount of land (ecological footprint) needed. All transportation energy demand and consequently all transport can be measured on a daily basis. In order to be sustainable, a region cannot have its inhabitants only dependent on fossil fuels to accomplish the day-to-day tasks. This is an implicit indicator. It directly states that cars, as an energy inefficient transportation model when compared with public transportation, cannot be the design priority.

According to the second approach for measuring land for energy consumed (see above), table 8 below was made considering daily transportation for a year (220 day considering only working days, one month for annual leave and 10 days of public holidays). 


\begin{tabular}{|l|c|c|c|c|c|c|}
\cline { 4 - 7 } \multicolumn{1}{c}{} & \multicolumn{5}{c|}{ Distances } \\
\cline { 2 - 7 } \multicolumn{1}{c|}{ Mode } & $\begin{array}{c}\text { MJ/ passenger } \\
\mathrm{km}\end{array}$ & $0.8 \mathrm{~km}$ & $1 \mathrm{~km}$ & $5 \mathrm{~km}$ & $10 \mathrm{~km}$ & $25 \mathrm{~km}$ \\
\hline Cycling (slow, bread) & 0.500 & 0.00088 & 0.0011 & 0.0055 & 0.011 & 0.0275 \\
\hline Walking & 0.900 & 0.001584 & 0.00198 & 0.0099 & 0.0198 & 0.0495 \\
\hline Electric Train & 1.770 & 0.0031152 & 0.003894 & 0.01947 & 0.03894 & 0.09735 \\
\hline Cycling (fast / shower) & 2.200 & 0.003872 & 0.00484 & 0.0242 & 0.0484 & 0.121 \\
\hline Tram / light rail & 2.280 & 0.0040128 & 0.005016 & 0.02508 & 0.05016 & 0.1254 \\
\hline Trolleybus & 2.610 & 0.0045936 & 0.005742 & 0.02871 & 0.05742 & 0.14355 \\
\hline City Bus & 3.500 & 0.00616 & 0.0077 & 0.0385 & 0.077 & 0.1925 \\
\hline Ferryboat & 9.060 & 0.0159456 & 0.019932 & 0.09966 & 0.19932 & 0.4983 \\
\hline
\end{tabular}

Table 8- Land used to supply the demand for energy for daily transportation (220 days a year) including embodied energy. Electric commuter train has $\mathrm{MJ} /$ passenger calculated from a renewable energy model multiplied by 1.25 (for diesel) and then multiplied by 3 for a non-renewable electricity value (Vale \& Vale, 2009, p. 111).

Table 8 shows the land necessary for different distances using different transport modes, and suggests urban design that is significantly different from the present standard model.

If urban designs were exclusively based on land preservation, the urban fabric would prioritize cycling, walking and renewable electric trains instead of cars. The urban fabric designed for pedestrians and cyclists would also save land by decreasing the size of paths, thereby potentially increasing soil permeability.

Highways and roads are extremely flexible allowing passengers and goods to be transported at the same time without complex regulations. Although flexible, this does not necessarily mean being energy efficient. However, the logic behind goods and people sharing transportation space seems completely assimilated by society. Although public transportation may struggle to keep a good financial performance when a region has low density, this can be minimized if the same logical applied to highways and roads is applied to it. This means that public transportation must share its potential between goods and people, which would actually be convenient. Goods and food could be transported when public transport is underused by commuters. Apparently New Zealand authorities have followed this energetic logic in the past. Transport licensing regulations restricted how far goods could be carried by trucks rather than by rail. In 1936, this was only $48 \mathrm{~km}$, being progressively relaxed, so that by 1977 , trucks were allowed to carry goods $150 \mathrm{~km}$. The restriction was repealed in 1982 (Vale \& Vale, 2009, p. 117; Rail Trail Services, 2011). Therefore, goods transportation regulations are not new, and apparently society has coped with these limitations. The best transportation 
practice would suggest that goods and people are transported using the most energy efficient system available for each region. This sort of regulation has to be flexible enough to be adapted to different circumstances, and the focus has to be on the footprint and land consumption. While there is no energy resource available able to supply the current demands of society indefinitely, the best practice has to be based on cycling and walking and saving as much energy and land as possible, through only travelling just the minimum distances necessary.

Cars, as private transportation, have been destroying the balance between the forces that shape the growth and metabolism of cities. Cars and what comes with them are important agents of resource depletion, because, they are part of a huge chain, which contains the production of gasoline, grease, antifreeze, transition fluid, oils, rubber, and plastic parts (Register, 2006, p. 141). Indeed, 45 per cent of the fuel consumption can be added on for the resources to maintain the car system, with 15 per cent for the car and 30 per cent for roads and transport infrastructure (Chambers, Simmons, \& Wackernagel, 2009, p. 85) 5 .

Due to progressive population growth, which places great pressure on land availability, a transportation system has to have strategies to avoid unnecessary travel, which will probably influence society's habits. The regular routine of moving from residential areas to workplace, permanently consuming resources, will be challenged in a more sustainable model. The best practice, therefore, will be based on a travel necessity analysis. If the travel is inevitable, it has to be analysed using the ecological footprint and added on the other items that also impact the ecological footprint.

The analysis of the travel needs, and how they will be accomplished is a major input for urban design and planning. It will require a depth of understanding of cultural habits and economic models. Cycling and walking have to be taken as important and essential transport modes instead of recreational activities (Southworth, 2005, p. 246), because they usually are the most energy efficient transportation modes. In current modern urban design just a few destinations are easily reached without motorized transportation (Lawrence, 2004, p. 147). Indeed, the solution is not as simple as banning or minimizing motorized transport. Cars, if well driven, using their full

\footnotetext{
5 estimated for the UK.
} 
passenger capacity, may be more efficient than some public transportation options, while cycling fast, fuelled by a burger and taking a shower afterwards, may have a really higher impact per person than a 1.6 litre engine car with 4 people inside (Vale \& Vale, 2009, p. 107). The analysis always will come down to the amount of land indirectly used to move around.

Transportation investments have normally been based on short-term analysis, and are often directly responsible for determining where city growth happens. The built environment and therefore, urban design decisions, are responsible for which transportation models are available (Lawrence F. , 2004, p. 146 / 149).

Best practices in transportation can be summarized as:

- Everyday travel distances have to be analysed in depth, to determine the best mode.

- Environmental impacts are more important than economic interests.

- Local urban planning and design have to work with regional transportation systems. It can lead to a very unsustainable model, if the regional transportation system is based on fossil fuel and private transportation. This suggests a sustainable transportation system needs regional planning, in which the priority has to be resource saving.

- Residential densities

- Low densities are normally inefficient for public transportation, however, can provide areas for food production or forestry.

- High densities are normally more energy efficient, and public transportation is more feasible, however, food and goods distributions gain importance and the population looses contact with the notion of limits. Short distances and simple distribution processes normally lead to low ecological footprints.

- Topography, climate, environment and cultural aspects can influence public transportation.

- The transportation system has to be designed to encourage the most efficient transportation model considering these factors. 
- The built environment must also be designed taking into account all these aspects, and the principle of maximization of resources use.

- The urban environment has to be able to flexible, in order to adapt according to resource availability.

\subsection{Energy and Consumption}

The discussion about energy is intrinsically related with consumption, and therefore the economy, because consuming demands energy. Modern society is familiarized with energy use in houses, and from now on this type of energy will be called residential energy. In developed societies this energy is mainly in the form of electricity for lights, appliances and heating, gas for heating and cooking, and firewood for heating (Lenzen, Wood, \& Foran, 2008, p. 91). Obviously, as seen before, total household energy use is not exclusively electricity, for instance transport energy (the vast majority based on fossil-fuels) is part of the equation of household energy consumption. Because the transportation topic was explored before, this section will focus on residential energy. However, it is important to highlight the importance of what is called direct household energy consumption. This is the sum of energy used in the house and household transportation energy (Bin \& Dowlatabadi, 2005, p. 199).

The process of consumption demands energy in different parts of the production process. It can be roughly divided in physical terms into items such as: clothes, food, cars, water, and all sorts of appliances, or classified as immaterial in items such as: entertainment, transportation, and personal care. All these items are normally received by people in a state such that they are ready to be consumed. They do not evoke, in most cases, the association with energy. Indirectly, consumers may guess that the final price reflects the amount of energy and resources demanded to produce these items, but the consumer knows that many things can influence the final price, and the energy used to produce these items may be relegated to a secondary level of importance.

The energy cycle, which starts from the transformation of raw material and goes to the final product disposal, is normally called embodied energy. If it can be traced from the product origins and transformation to the disposal process, the amount of energy can be measured for all these processes. From the energy spent in the processes, the land 
needed to accommodate the energy production can also be calculated to give a footprint. Because the information about embodied energy is not explicit, practically, it is impossible to determine if the direct energy used to prepare or use a product is higher than the embodied energy used to produce and dispose of this item (Lenzen, Wood, \& Foran, 2008, p. 91).

Most of the world's energy is consumed by North America, East Asia and Europe, and around 87 per cent is non-renewable, made up from 80 per cent fossil-fuels and 7 per cent nuclear (Meadows, Randers, \& Meadows, 2004, p. L 1086; Lenzen, Wood, \& Foran, 2008, p. 92; Girardet H. , 2004, p. 130). In the world the consumption patterns are similar, as can be seen in the figure 49 .

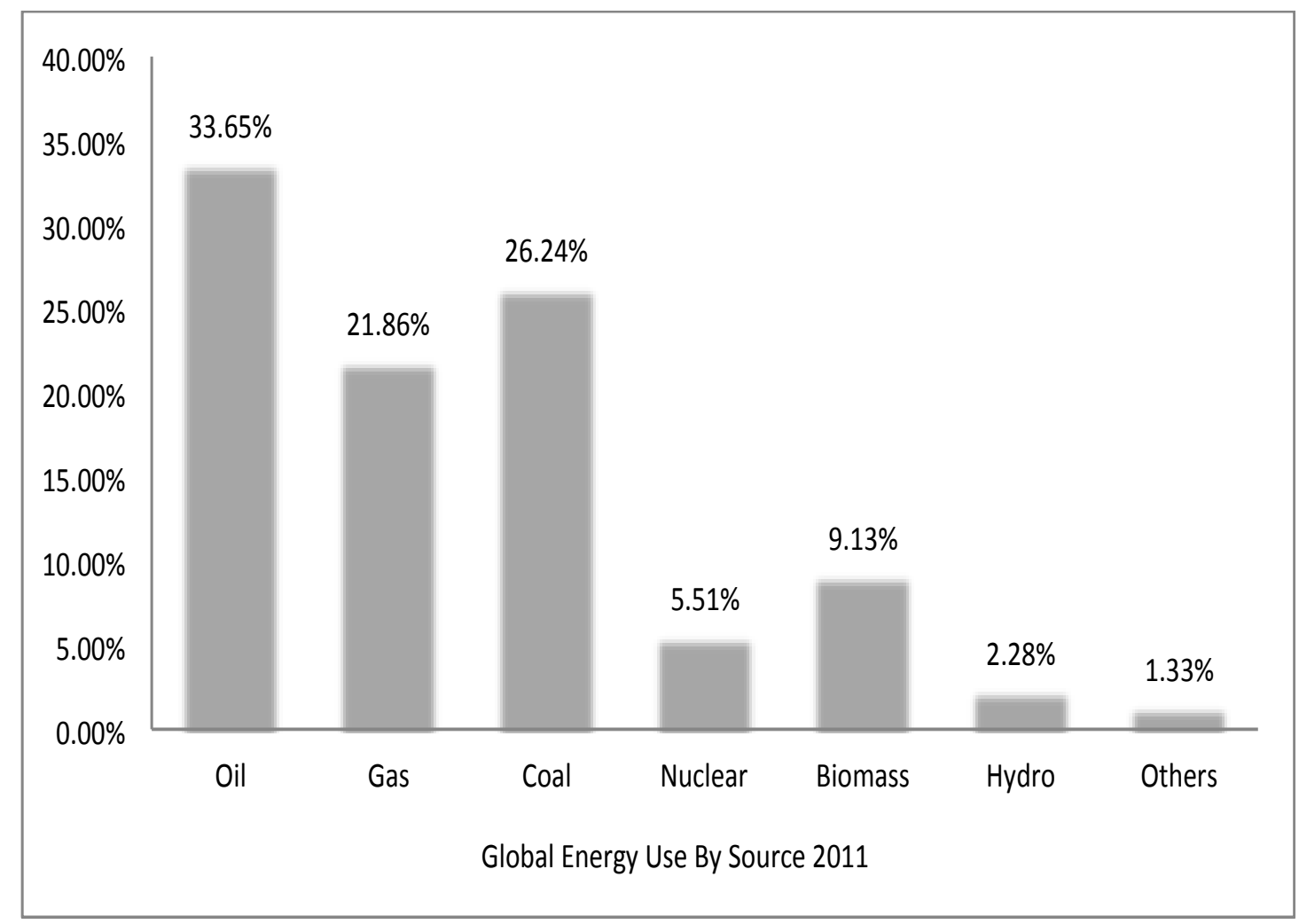

Figure 49 - World energy use by sources (ExxonMobil, 2012)

Interestingly the proportion taken by residential energy can vary dramatically from 20 per cent to 60 per cent of total energy, depending on the per capita income (Lenzen, Wood, \& Foran, 2008, p. 92). Normally a higher income means a lower relevance for residential energy consumption. The embodied energy used by a consumer in a highincome country normally exceeds the direct energy consumed, which is the residential 
energy added to the energy used for transportation (Lenzen, Wood, \& Foran, 2008, p. 94). Consequently, the focus on decreasing energy consumption has to include the embodied energy. There is a significant variation in consumption patterns, and therefore, the amount of energy used, stemming from differences in population size, income, and cultural beliefs. However, the global economic model with its enormous reliance on international trade also has a relevant impact on global energy statistics.

Residential energy consumption may be proportionally low in high-income countries. However, when income increases, the consumption of goods also increases and the energy used for goods production can become progressively detached from the final market consumer. Industrial production far from the final consumer, often in developing countries, may help to blur the understanding about the energy involved in industrial products. It may lead to ecological alienation, in which the consumer is totally unaware of the energy needed and the impacts caused by consumption habits.

Therefore, because embodied energy is not normally listed in the core analysis of energy consumption, the consumption of energy may appear lower that it really is. Developed post-industrial countries have been outsourcing energy consumption for production of goods, and even water, from less developed countries (The Royal Society, 2012, p. L1252). Assuming that embodied energy also includes the process of disposal of products, China represents an important international player in energy for the disposal of garbage, due to receiving a great amount of refuse from developed countries (Diamond, 2011, p. L 6761). The embodied energy brings up the discussion of scarcity of resources, pollution, and ecological footprint at an international level. It clarifies the real discussion about energy, which is not a local problem but an international issue which could possibly interfere in the whole consumption chain. Essentially, the economy is linked with production, consumption and possession of commodities (Jenks \& Dempsey, 2005, p. 25), therefore, it is extremely dependent on energy. Consequently, the economic prosperity enjoyed after World War II has caused a sharp increase in energy demand (Jackson, 2011, p. 60).

Energy supply is directly associated with abundance. A vast supply of energy can help to solve water scarcity problems, and address many health problems (Diamandis \& Kotler, 2012, p. L 2860), and possibly, for this reason, energy and electricity have been used as 
an indicator of prosperity. This can be proved comparing consumption by regions. Western Europe uses 5.5 times as much commercial energy as the average African, while the average North American consumes 9 times more energy than an Indian on average. More than a billion people have no access to electricity, and this could possibly reach 1.4 billion people in 2030 (Meadows, Randers, \& Meadows, 2004, p. L 1076).

The understanding of the reality of energy production and consumption suggests that sustainability in energy terms has to include embodied energy. In addition, the analysis exclusively of residential energy may be inaccurate for determining how sustainable a house or community is. Certainly it is an incomplete picture. To analyse energy consumption effectively the measurement of consumption has to include embodied energy. Consequently this means revising consumption habits. However, material progress and subsequent rising living standards have been demanding a consistent increase in consumption, then energy, and land (Droege, 2006, p. 45).

The source of the energy is also a very important aspect to be considered. Some sources demand more land than others. The current comparison basis for this is rather simplistic being based on land use and area for sequestering carbon dioxide emissions, which are perhaps not directly comparable. This approach means that a community for which the main energy resource is coal, even though nominally consuming less energy, may be more unsustainable than another with a much larger consumption that has its energy from a low-impact energy strategy. It implies that the impact caused by energy consumption is much more complex than the first simple consumption comparison may suggest.

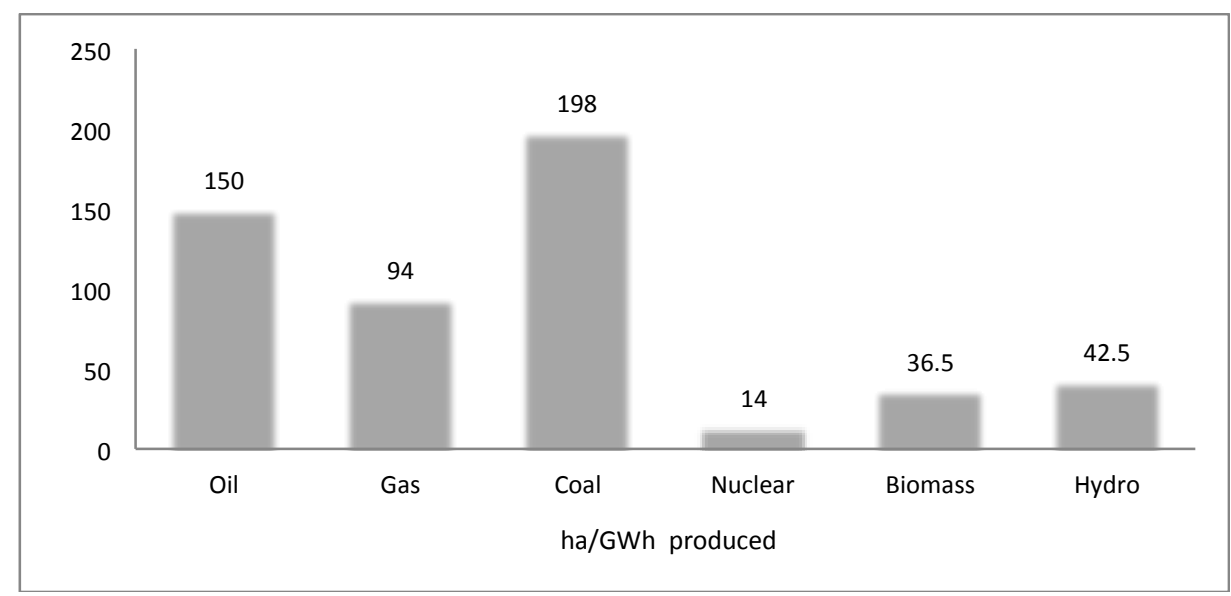

Figure 50 - Ecological footprint by energy source (Chambers, Simmons, \& Wackernagel, 2000, p. 83; Wackernagel \& Rees, 1996, p. 69) 
On the other hand, the theory for an energy sustainability indicator is relatively simple. In theory, the amount of direct energy added to the embodied energy, after the footprint calculation, has to be added to the rest of footprint items to then produce a footprint area smaller than the world biocapacity. This exposes a very convenient weakness of the environmental certifications available worldwide. They do not measure the total energy consumption including embodied energy. Therefore, they exclude the consumption impact and focus on the small picture, which is the residential energy, or sometimes direct energy, which is usually lower than the embodied energy in highincome countries. A consistent method to determine if a community is truly energy sustainable would be analysing the sum of the all energy used in transportation, residential, and embodied energy. This analysis would imply a radical shift in habits and, in order to have a sustainable approach, the community would have to dramatically decrease consumption in general, and decrease the impact of transportation in its footprint.

One of the obvious suggestions to decrease the energy footprint would be a massive investment and shift towards the local economy. However, more than reducing the footprint, local production would have an additional role in the community. It may lead the local community to be more aware about the energy used to produce goods, particularly if industry and the people share the same energy source and also share its limitations and restrictions.

The earlier view that scarcity of fossil fuels would produce a technologically driven salvation has quickly become stalled in the environmental cost dilemma (Droege, 2006, p. 45), and it is very unlikely that this will happen soon. The peak of oil production was reached in 2006 (Smith P. F., 2010, p. 118) and has not brought a significant improvement in urban areas, just as the vision of a more orderly, healthier and socially more equitable society was not accomplished with industrial development (Droege, 2006, p. 45). Today the vision of social improvement based on an endless energy source has been redirected to renewable energy sources. However, even with a lower impact, this approach also requires some analysis. Renewable energy sources are not totally environmentally inoffensive and, moreover, they are not unlimited. Wind turbines 
require roads for access to appropriate, often distant, sites, and steel for the blades and towers. Some solar cells are made up from toxic materials, require large collection areas, and need a very difficult storage mechanism (Meadows, Randers, \& Meadows, 2004, p. L 1171). Additionally, to extract materials indispensable for the renewable energy sources requires more resources, which then require more energy. This spiral may lead society to an energetic collapse. The hope that solar and wind energy will solve the energy crisis in the future may be not entirely right, at least in the short term. The recent history of technology suggests a different scenario. Every major energy shift has demanded several decades for re-adjusting the system. For instance from candles to oil lamps, or from wood, to coal to petroleum all took time. Moreover, the replacements have normally happened because they were a more energy efficient option (Diamond, 2011, p. 507). Although fossil fuels are not about to run out immediately, population increase and economic growth are constantly putting pressure on these resources and the limits of supply are becoming more apparent. Figure 51 below indicates a tendency for a progressive decrease in the Energy Returned relative to the Energy Invested (EROEI) in fossil fuels. It is reasonable to expect to observe the opposite tendency for the renewable energy resources. 


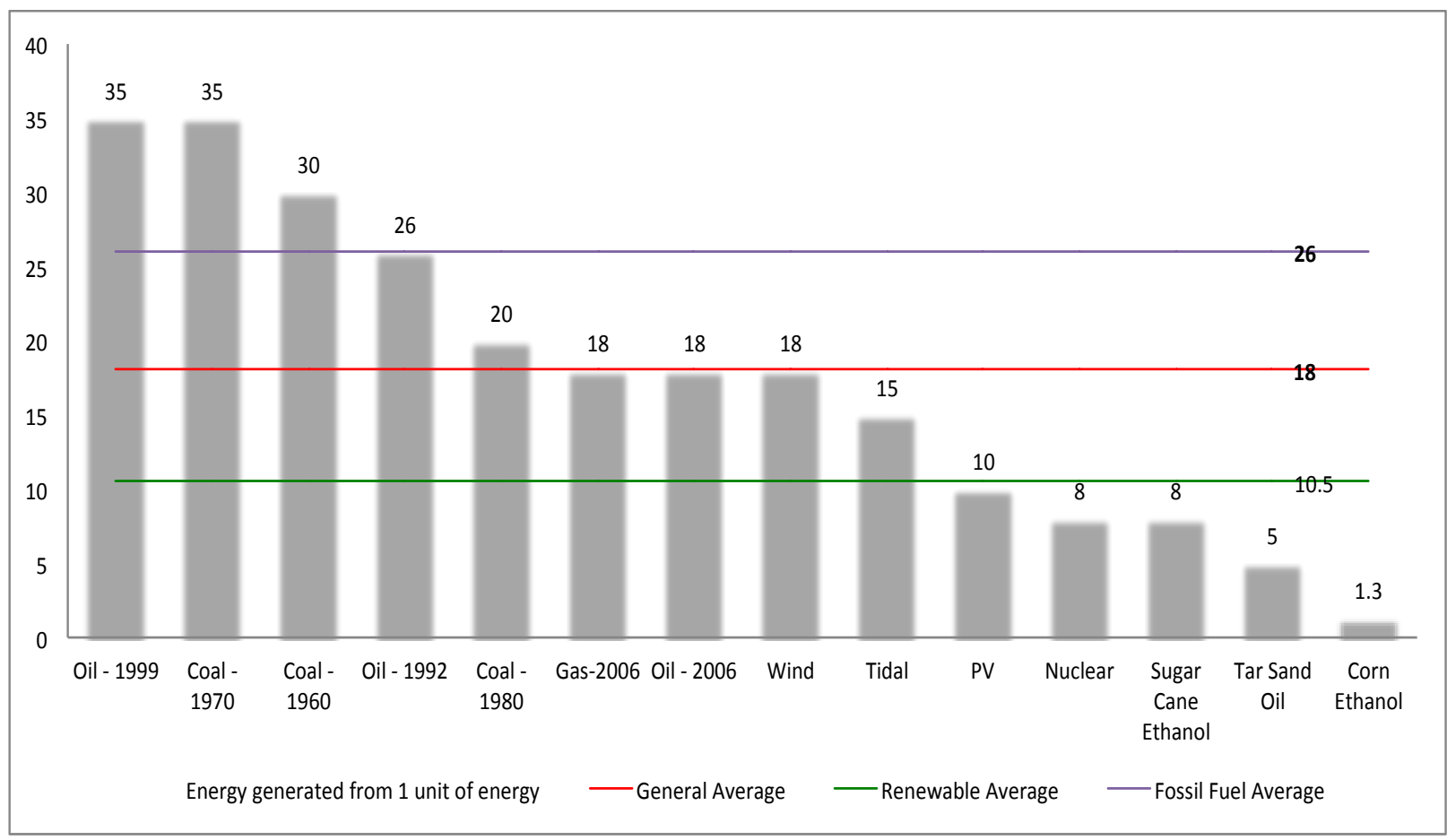

Figure 51 - Comparison between EROEI from different energy sources - (Murphy \& Hall, 2010, p. 109; Wackernagel \& Rees, 1996, p. 69)

Because fossil fuels are becoming progressively rare, more energy is demanded to extract them, so the EROEI goes down. On the other hand, because of technological improvements, renewable sources are becoming more efficient, therefore the EROEI goes up.

Sustainability in terms of energy has to be analysed along with the other indicators. Some regions may demand more energy because, for example, of climate, but the food footprint could be low because of the local diet. Sustainability is, therefore, the amount of energy direct or embodied used that, when added on the other sustainability indicators, keeps the total footprint area below the world biocapacity. This indicator may vary enormously according to the energy origin, climate, and consumption level. This indicator directly impacts on the economy due to suggesting a reduction in consumption and a shift toward a local and low impact economy.

Another problem is related with construction materials and operating energy. Operating energy represents by far the largest part of energy demand in a building lifespan (Sartori \& Hestness, 2006, p. 256; Mithraratne \& Vale, 2003). The energy demanded for construction, although important, has to be divided throughout the 
lifespan of the building. A good insulation material can exemplify the situation between the energy used for materials and construction and the operational energy. Although insulation traditionally demands more energy for its production, it will save energy for heating in the long term. Notwithstanding, the materials used to build a house are important, although user behaviour and the operational energy will be more significant. In order to provide an indicator, the recommendation is to assess the entire energy used including the embodied energy of the construction materials, and the life time operational energy of the building.

In order to minimize the drastic impact caused by energy consumption, urban design has to privilege local energy production. Moreover, even when the energy consumed is based on renewable sources, a limit has to be agreed. There are some examples of an energy limit. In 1994 the Forum Vauban Association in Germany was created, which aims to create an ideal eco-city of the future. In Vauban green living is compulsory, and all buildings had to be built first to reach an energy consumption of $65 \mathrm{kWh} / \mathrm{m}^{2} /$ year and then progressively to a reduced $40 \mathrm{kWh} / \mathrm{m}^{2} /$ year. These figures are not enough to determine if the region is sustainable, however, the point is the fact that people can, in the modern world, have an energy consumption limitation (Smith P. F., 2010, p. 72). The proposal for a real sustainable region is to extend the measurement to include all embodied energy including goods, food production and transportation and entertainment.

Fundamentally, the best practice in energy should be treated as a local problem, responding to local climate and resource conditions. The best practice in energy would prioritize a truly walkable environment and zero fossil fuel energy buildings. A competent urban design, based on energy efficiency, would directly tackle relevant energy uses, which are transportation and house energy consumption.

A walkable environment demands more than a comfortable sidewalk or trees to provide shade or wind protection along the pathways. It implies in a deep change in urban design desire distances, altering zoning restrictions in order to create more mixed spaces with availability of local commerce and jobs. The urban design goal would be to decrease the number of journeys under a walkable distance to day-by-day services, avoiding hence transportation based on fossil fuel. 
In addition, all buildings and especially house should be designed to be zero fossil fuel energy. This means designing ways for houses to produce their energy, for instance allowing enough space for solar panels or solar access for passive heating and ventilating of buildings. Basically, urban design has to be combined with good architecture to achieve ultimate energy efficiency. In summary, the best practice in energy should be maximum limitation of energy consumption according to the local capacity to provide energy. 


\section{General Global Footprint: Prototye Tool Development, Results and Analysis}

\subsection{Urban Ecological Footprint Measurement Prototype Tool}

\subsubsection{Description of Prototype Tool 1 Components}

The prototype tool is essentially a spread sheet with an interpolation of data from different resources, generating a mathematical unit expressed in global hectares. The spreadsheet fields are set out below.

Field 1: Total Population - the quantity of people that will be used to calculate the footprint. The prototype tool can be used to assess an individual, or an entire community.

Field 2: Diet - the type of diet that the individual or population has. This field has in total 27 predetermined Ecological Footprint components, according to income or country. The options for income are world average food footprint, high income countries diet footprint, middle income countries diet footprint, low income countries diet footprint, and world biocapacity for food footprint. The countries included are: Australia, New Zealand, Papua New Guinea, USA, UK, France, Italy, Germany, Japan, Canada, Brazil, Russia, India, China, South Africa, Argentina, Burundi, Zambia, Egypt, Kenya, Nigeria, and African average. In addition, there is an empty field, for which the unit is in global hectares (gha), in case a specific footprint is to be assessed. All data comes from Global Footprint Network, 2011.

Field 3 - Housing size - how many square metres per person of housing floor area is found in the community. The limitation in this field is the maximum size accepted in the prototype tool of 25 square metres per person for conjoined housing, as greater than this makes the use of detached houses mandatory in field 8.

Field 4 - Construction - materials used for the house(s). There are 6 options preloaded into the prototype tool (light weight, concrete or brick (masonry), superisulated, timber frame and brick veneer, strawbale and non-impact). The data is from Vale \& Vale, 2009, p. $130-148$. 
Field 5 - Embodied energy in GJ/m2. This field allows the user to insert a different value for the energy embodied in the house construction. It also serves as the way of adding extra energy use in case of high impact construcion.

Field 6 - Life Cycle - house lifespan average expressed in years.

Field 7 - Energy for construction describes the proportion of all energy sources used to produce the construction materials and for the construction itself. The data is from Chambers, Simmons, \& Wackernagel, 2000, p. 71.

Field 8 - Housing types - the number of houses, expressed in number of residents, has to match the total population from field 1 . The limitation is that if the area per resident is greater than $25 \mathrm{~m} 2$, only detached house models can be used.

Fields 9 and 10 - Transportation system and private transportation - these fields describe how the resident or resident population move around. There are 3 entries for each model. The first one - \# persons - is associated with the number of people who use that specific mode. The second one - \# trips/week - describes the number of trips in that specific mode per week. The last one describes the average distance for each trip. The yellow cell at the end of each row shows the total kilometres per week for each transport mode. In order to calculate the total Ecological Footprint, the total travel is calculated per year. The data is from Vale \& Vale, 2009, p. 80 and 111

Field 12 - Residential Energy Use / Person / Year - this fields allows the user to select between 8 preloaded consumer levels (Zero, HI - High Income Countries average, MI Middle Income countries average, LI - Low Income Countries average, Brazil, NZ - New Zealand, UK - United Kingdom, and USA). The user can also select the exact amount of energy consumed, leaving a gap in the Zero, and filling the cell below with the energy used per year in GJ. The yellow cells on the right show the energy consumed in $\mathrm{GWh} /$ person and the total for the community respectively.

Field 13 - The proportion of each energy source used to produce electricity for residential consumption. The data is from Chambers, Simmons, \& Wackernagel, 2000, p. 71.

Field 14 - Embodied Energy Factor related to lifestyle - this field adds the amount of energy used indirectly to produce goods for consumption, infrastructure, industries and 
so on. It is proportional to the amount of electricity used per person (if the number is 1 , it means that the indirect amount energy used is the same as the residential electricity use). According to Lenzen, Wood, \& Foran, 2008, p. 91, the indirect energy, or embodied energy, is significantly higher than the residential electricity, and in some countries the residential electricity makes up only 25 per cent of the total energy. This indicates that a realistic number for high-income countries Ecological Footprint analysis would be 3 for field 14. This field is extremely important as it encompasses the energy used for all sorts of demands within a society, and also includes citizenship impact. Food exemplifies the importance of this field. If a country has a high level of processed food consumption or high food miles, part of the energy used for processing and transportation is allocated to this field. This may explain why in some countries, the expectation that the highest single Ecological Footprint category will be for food does not happen. Therefore, this field in this prototype tool has a high share of the total footprint, because it encompasses many social aspects.

Field 15 - The proportion of the various energy sources used to produce the embodied energy of consumption. The data is from Chambers, Simmons, \& Wackernagel, 2000, p. 71.

\subsubsection{Advantages and Disadvantages of Prototype Tool 1}

The outcome provided by the measurement prototype tool is a single number. The methodology has tried to encompass all the concepts and theory discussed in the research. The concept provided by Brundtland Commission is not accurate enough, being too vague. The concept that has been used to support the prototype tool outcome, tries to embrace a wider range of topics, such as diet, distances, public and private transportation, construction materials and housing lifespan, domestic energy consumption and indirect (embodied) energy consumption. Relevantly, the prototype tool developed here is not market subservient. While the environmental certifications available and their analysis are partially restricted by needing to support the market, the concepts that underpin the new prototype tool embrace serious constraints, such as resource limitation (probably land being one of the most critical), population growth, water scarcity, pollution, energy shortage and economic stagnation or depression. 
However, is recognized that the total measurement of all these parameters requires more research. For instance, water, which is one of the most relevant and important items (Novotny, Ahern, \& Brown, 2010, p. 04), has only been marginally considered in this research. Also, pollution is an item, which would benefit from further research. Although greenhouse emissions have been included in the footprint calculation, other pollution factors require supplementary investigation.

It is critical to highlight that the outcome is largely based on assumptions from different sources. The process can appear to be extremely exact but the results are only as good as the assumptions. However, the comparative methodology is the key to providing an environmental assessment since the assumptions are the same for all case studies.

This research prototype tool does not restrict its effort to an urban design and planning analysis, but also engages with the ecological impact of the modern life style, with its consumption and lack of knowledge about resource and environmental limitations. The over consumption of resources, if they cannot be replaced, will lead any society to collapse. Historically collapse has happened for over use of resources and lack of planning in population and economic expansion, as was seen in the Ur Dynasty in Ancient Mesopotamia (Tainter, 1988, p. 07). Indeed, the rise and fall of civilizations has been associated with climate change and resource depletion, which are the most relevant factors in collapse studies (Tainter, 1988, p. 45). Therefore, one of the mandatory items to consider for anything to be sustainable is the use of a renewable resource at a rate less than the capacity of its replacement, which has to also consider human population growth. Consumption has to decrease proportionally with population growth. Additionally, non-renewable resource consumption has to decrease faster than its depletion (Heinberg, 2010, p. L 518 / 601). However, the most important conceptual approach in this research is assessing the total ecological impact.

The criterion taken for considering whether urban development is sustainable is world biocapacity. The land, expressed in global hectares, needed to provide all items consumed by the world's population, has to be less than the Earth's area. Obviously some resources, such as food can come from the sea, but the same principle applies, of a resource not being extracted at a rate that exceeds the replenishment rate. Although this approach can lead to some controversies, because the area available varies 
according to each country, modern countries are economically linked and their borders are more permeable today than ever before (Kresl \& Fry, 2005, p. 48). The international flows of goods have progressively increased, which has been described as a weakness of today's economic system. Ekholm, 1980 in Tainter, 1988 (p. 45), has stated that an economic system becomes fragile when it becomes progressively dependent on external exchange over which it has a little control. The fragility caused by the economic system, which promotes international trade, is the justification for the use here of the international unit of global hectare per capita for the carrying capacity of the planet. Consequently the value taken from the Global Footprint Network was 1.78gha per person (Global Footprint Network, 2011). This number, or land limit, will ultimately be used to support a method, which can be tested and adjusted for the majority of urban settlements. The measurement prototype tool has to provide a reliable figure, including most of the aspects that may impact the footprint. Essentially the prototype tool does not accept urban characteristics separated from life itself of those living in cities. Urban life, and its consumption model oriented landscape (Dear, 2011, p. 189), has been leading, and progressively globalizing, society towards an over-consumption model (Heinberg, 2011, p. L.4609). However, although consumption and urban living are apparently linked, there is no indication that an urban lifestyle causes a larger impact. The increase in environmental impact is associated with behaviour, habits and consumption. Because urbanization and increasing consumption have been happening concomitantly, this fogs the origins of the real environmental problem.

The analysis of the tables provided by the Global Footprint Network has pointed out the necessity of including aspects related to diet, social behaviour and life style in this research measurement prototype tool. A simplification of this tool, which ultimately means excluding all the aspects just mentioned, might conveniently yield a useful figure to a market demanding some sort of sustainability certification but would not be a true reflection of the situation. Hence, no urban development is accepted as being sustainable in this research if the per capita result is larger than 1.78gha. However, this number also requires permanent adjustment according to global population growth, consequently the tool only provides a static examination, which requires a permanent parameter update, hence the use of the second prototype tool. 


\subsubsection{Description of Prototype Tool 2 Components}

Prototype tool 2 is also a spread sheet based on interpolation of data from different sources. The result is the ecological footprint per person, and the biocapacity per person expressed in global hectares (the red column on the right).

Field 1: Fossil Fuel Consumption - the difference in fossil fuel consumption based on average income of similar countries (HI, MI, LI - high income, middle income and low income countries respectively), expressed as a percentage average fossil fuel consumption. The data comes from Global Footprint Network, 2011, EarthTrends, 2011 and the World Bank, 2012.

Field 2: Food Consumption - the difference in food ecological footprint by average income of similar countries, as a percentage of global average food footprint. The data comes from Global Footprint Network, 2011, EarthTrends, 2011, the World Bank, 2012 and United Nations 2011.

Field 3: Housing - the difference in housing ecological footprint by average income of similar countries as a percentage of global average. The data comes from Global Footprint Network, 2011.

Field 4: Population Growth - the rates of population growth by average income of similar countries in two stages. The first is from 2012 to 2050 and the second from 2051 to 2100 , as a percentage of global average rate of population increase. The data comes from Global Footprint Network, and United Nations 2011.

\subsection{Cases Studies - Contemporary Urban Developments}

The urban case studies selected were chosen for different reasons. Firstly three case studies, Tassafaronga, SALT and Mapleton-Fall Creek, were chosen because they already have, or will soon have, a rating from one of the leaders in environmental certification (LEED) currently available on the market. Among the case studies one needs special comment. The Seaside project, in Florida (Duany Plater-Zyberk \& Company-1978) was not arbitrarily included. It has been acknowledged as an important example of American new urbanism (Katz, 1994, p. 03), which has become self-nominated as an important urban planning movement toward sustainability (CNU - Congress for New 
Urbanism, 2012). This was the reason that one of the most prestigious examples of new urbanism was tested here, although it has no LEED certification.

In addition, because the flexibility of the prototype tool developed here allows for this, some historical cases were analysed. This has generated a powerful comparative table between wide ranges of urban examples in different times in history. The details about the assessment of the case studies using the prototype tool 1 are in the appendix 1.

\subsection{Using the Prototype Tool}

A diverse variety of urban environments were tested. Firstly, some historical models were examined, followed by some contemporary urban models ranging from under developed communities, slums, middle class communities, three LEED certified projects, and a new urbanism community. Some minor adaptations to the prototype tool and many assumptions have allowed the analysis of the historical civilizations. Some premises were assumed for all models. The first one is related with the amount of food consumed by the ancient communities. The assumption utilized was that every resident of an ancient, medieval, and under developed community consumes $2000 \mathrm{kcal}$ a day. Therefore, the Ecological Footprint was calculated according to the local diet and this calorific intake. However, the figures used for the food footprint have used current values for the land impact of agricultural production. More precise numbers will require further investigation. Even though, these values really demand more research the figures are sufficient for an understanding of the environmental impact, and even with a possibly higher footprint because of the contemporary values used, their outcome is still dramatically lower than for a modern diet. Still, with some reservation, the numbers reveal a consistent outcome that, even with a much greater biocapacity, ancient societies were more sustainable by using less land, and therefore by having a lower footprint.

The process of investigating the footprint was started by analysing the diet of ancient civilizations. Because the use of energy in these was restricted to wood and biomass, food would naturally be responsible for the largest share of the footprint. However, the analysis has some limitations. The process to measure the food footprint of these societies was based on contemporary data. In contrast, the use of contemporary values 
can aid the study of current under developed societies, which still live in similar conditions to those of some ancient civilizations. Indeed, rural India and China are examples of a society in which the modus-operandi has barely changed in the last few centuries (China International Travel Service, 2012).

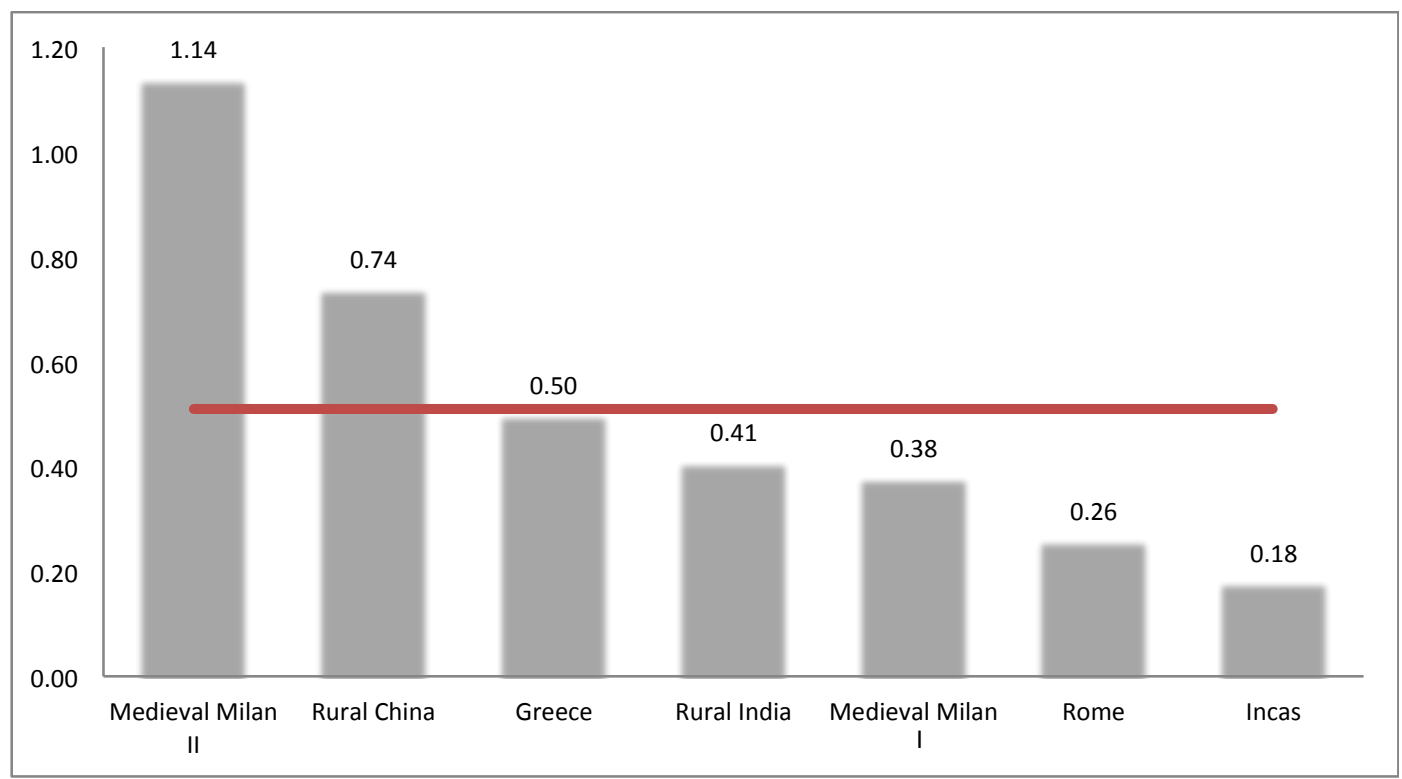

Figure 52 - Comparison between the Ecological Footprints of different ages and communities all around the world. The red line represents the group average

\subsubsection{First Analysis Group - Ancient Societies, Incas, Medieval Milan, and Contemporary Rural India and China}

\subsubsection{Ancient Rome}

The ancient Roman diet was based on porridge, vegetables and bread, although small amounts of meat and fish were sporadically part of the diet (see Table 9) (Deviller Donegan, 2006). The ancient houses, known as insulae, were poorly made of wood and brick. They had no sanitation or heating (Deviller Donegan, 2006; Pounds, 2005, p. 38). Energy was basically supplied by burning wood, and on some rare occasions came from a geothermal source (Ecoist, 2012; Migliaccio \& Rotondi, 2011). The distance taken for the transport calculation was $2 \mathrm{~km}$ for each trip, which was the same distance taken for the other civilizations, except the contemporary rural societies, for which the distances were measured by Google-Earth, or on the spot. The information for field 3 was taken 
from the ruins of Pompeii through photo analysis. A negligible amount of energy was considered in order to cover possible wood heating, and some consumption items that would need energy, such as pottery.

\begin{tabular}{|l|c|}
\hline Rome & $\mathrm{kg} /$ day \\
\hline Porridge & 0.40 \\
\hline Milk & 0.07 \\
\hline Bread & 0.40 \\
\hline Vegetables* & 1.50 \\
\hline Fish & 0.07 \\
\hline Wine & 0.03 \\
\hline Meat & 0.01 \\
\hline & \\
\hline Total kcal/day & 2091.00 \\
\hline
\end{tabular}

Table 9 - Typical Ancient Roman diet. *kcal and gha of 7 different vegetables and fruits (carrots, asparagus, tomatoes, cabbage, apples, figs and bananas (Berners-Lee, 2010, pp. L 580, 839, 1359 ; Calorie Count, 2012; Global Footprint Network, 2011)

\subsubsection{Ancient Greece}

The Ancient Greek diet was based on bread, cheese, some vegetables and a good variety of fruits, and rarely meat and fish, although some island communities had more fish and seafood in their diets (BBC, 2012; Lambert, 2008). The houses were simply made from sun dried mud and straw (BBC, 2012). A negligible amount of energy was considered in order to cover possible wood heating and food transportation.

\begin{tabular}{|l|r|}
\hline Greece & kg/day \\
\hline Bread & 0.4 \\
\hline Wine & 0.6 \\
\hline Cheese & 0.1 \\
\hline Fish & 0 \\
\hline Vegetables / fruits* & 0.5 \\
\hline eggs (unit) & 1 \\
\hline Porridge & 0.25 \\
\hline & \\
\hline Total kcal/day & 2036.00 \\
\hline
\end{tabular}

Table 10 - Typical Ancient Greek diet. * kcal and gha of 7 different vegetables and fruits (carrots, asparagus, tomatoes, cabbage, apples, figs and bananas (Berners-Lee, 2010, pp. L 580, 839, 1359 ; Calorie Count, 2012; Global Footprint Network, 2011) 


\subsubsection{Incas}

The Inca diet was based on potatoes, tomatoes, peanuts, and quinoa, and in the lowlands, maize which was the staple food. In the highlands the staple was potatoes. Incas also ate peppers, tomatoes and avocados (Lambert, 2008; Cowen, 1989, p. 13). The distance and the isolation have possibly contributed to the simplicity and lack of variety in the diet. The houses were made of bricks for the walls, with wooden beams and rafters for the roofs covered by straw. Some houses were also made of stone, as can still be seen in Machu-Pichu (Hemming \& Ranney, 2010, p. 34/36). The calculation here was made based on the Machu-Picchu ruins, therefore, a greater amount of energy $\left(2 \mathrm{GJ} / \mathrm{m}^{2}\right)$ was included in field 5 of the prototype tool, because of the effort needed to cut move and build the house using stones in that topography. A negligible amount of energy was also included to cover possible wood heating and food transportation from the low lands to the town plateau.

\begin{tabular}{|l|r|}
\hline Inca & kg/day \\
\hline Potatoes & 0.60 \\
\hline Tomatoes & 0.30 \\
\hline Maize & 0.30 \\
\hline Avocados & 0.30 \\
\hline & 2049.00 \\
\hline Total kcal/day & Table 11 - Typical Inca diet
\end{tabular}

\subsubsection{Rural China - Ping'an and Weigan, Guangxi Province, July 2006}

In order to analyse the Chinese footprint out of a large metropolis, a partially isolated community in Guangxi province was chosen. The community is located around two hours by car from the city of Longsheng. The community has been growing rice and vegetables in the mountains for many decades. Ping'an is one of the most developed villages in the region, however, more remote communities such as Lenji and Weigan still remain fairly isolated. When the villages were visited in June 2006, Ping'an had part of the house shown below served with electricity for some hours per day, and the other part was still without electricity. In contrast Weigan, reached by four hours walking from Ping'an, and all small communities on the way, did not have access to any public services, including water and electricity. During 11 days in the summer of 2006, the 
community in the village of Weigan ate three meals a day all of which were made of rice and pork cooked inside a length of bamboo and served with vegetables. After the rice harvest, the community would sell and barter its surplus in Longsheng, Guilin and Yangzhou.
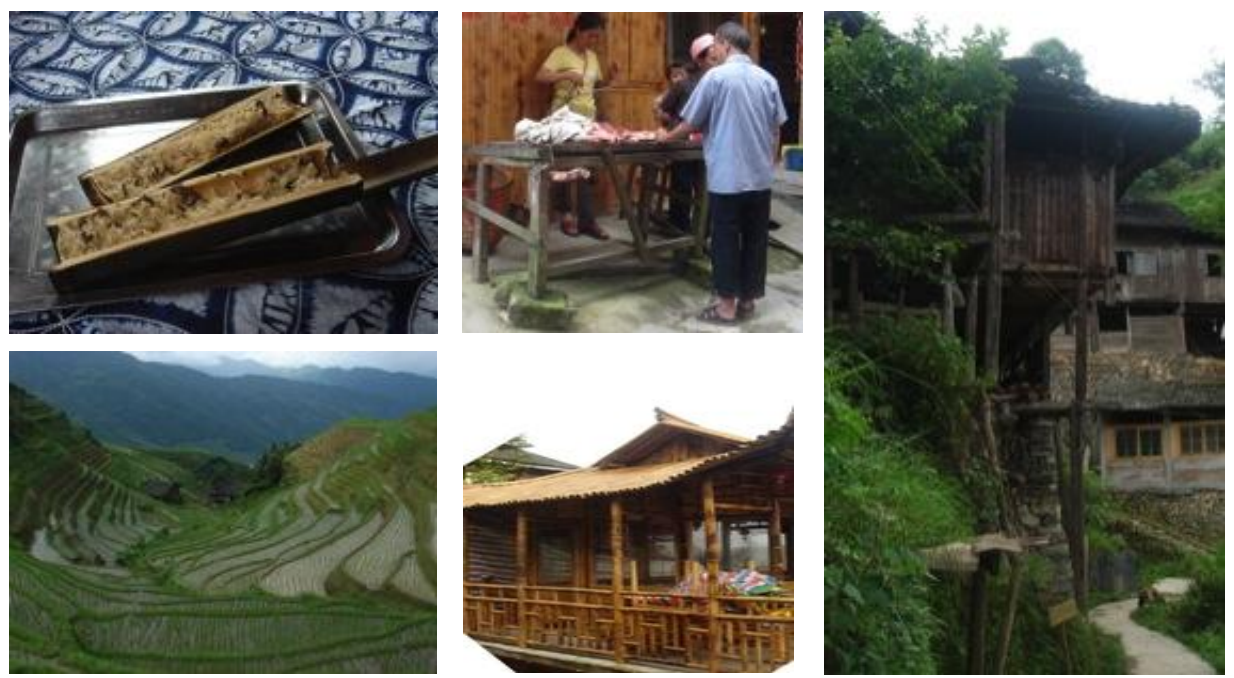

Figure 53 - Top left - Every day meal - rice and pork cooked inside bamboo

Figure 54 - Right - Timber house

Figure 55 - Top middle - Pork slaughter and its commercialization - barter is largely accepted.

Figure 56 - Bottom middle - Bamboo House

Figure 57 - Left bottom - Rice production on wet terraces All Photos from the Author - July 2006

\begin{tabular}{|l|r|}
\hline Rural China & $\mathrm{kg} /$ day \\
\hline Rice & 0.75 \\
\hline Vegetables & 0.75 \\
\hline Pork & 0.3 \\
\hline & \\
\hline Total kcal/day & 1916.00 \\
\hline
\end{tabular}

Table 12 - Typical Rural Chinese Diet (Guangxi - Province). * kcal and gha of 7 different vegetables and fruits (carrots, asparagus, tomatoes, cabbage, apples, figs and bananas (Berners-Lee, 2010, pp. L 580, 839, 1359 ; Calorie Count, 2012; Global Footprint Network, 2011)

The materials used in the house construction are essentially timber and bamboo; the foundations are made from river rocks collected from the river at the foot of the mountains. More recently some rather poor concrete has been used in some 
construction foundations. Although the rice fields are located next to the community, the $2 \mathrm{~km}$ distance was kept in the footprint measurement because of the sloping surface, and the distances to some fields.

\subsubsection{Rural India - Khajuharo, Madhya Pradesh , January 2011}

The community chosen is located in the outskirts of Khajuharo, which is locally known as Old City, in Madhya Pradesh Province, in India. The daily routine of a family was analysed for a week.

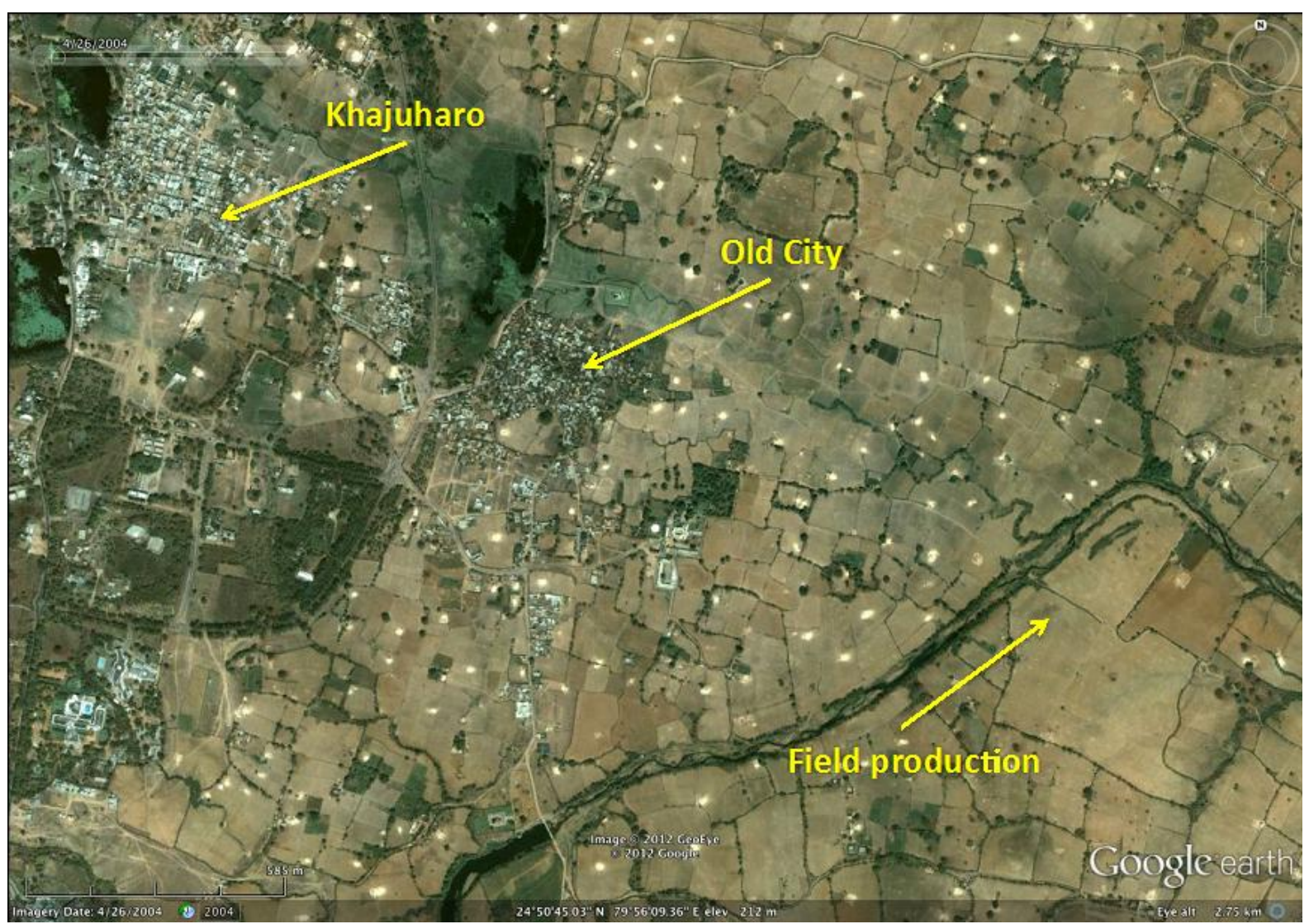

Figure 58 - Khajuharo Region, including the old city, and production fields $(2012$ Google $\subset 2011$ GeoEye

The family's house has no internal access to electricity and potable water, and the latter was collected from rain stored in a reservoir beside the house. One of the residents worked in Khajuharo, and another worked in the community agriculture field $1.2 \mathrm{~km}$ distant from the house. The diet is exclusively vegetarian and with few variations. Rice, chickpeas, potatoes, and spinach are the main components of the diet. A domestic goat sometimes provides milk. 


\begin{tabular}{|l|c|}
\hline India & $\mathrm{kg} /$ day \\
\hline Rice & 0.50 \\
\hline Vegetables & 0.75 \\
\hline Bread & 0.42 \\
\hline & \\
\hline Total kcal/day & 1818.00 \\
\hline
\end{tabular}

Table 13 - Typical Rural Indian Diet (Madhya Pradesh - State). * kcal and gha of 7 different vegetables and fruits (carrots, asparagus, tomatoes, cabbage, apples, figs and bananas (Berners-Lee, 2010, pp. L 580, 839, 1359 ; Calorie Count, 2012;

Global Footprint Network, 2011)

The house was built in 1987, made from brick and timber, and it is only a single space without any partitioning.

The distances utilized to measure the footprint were the total walked by the family in a week. The amount of energy utilized in the study was the same as that used for an ancient society, because the family essentially uses a wood fire, and the work in town is paid for in food or the money is used in its totality to acquire food.
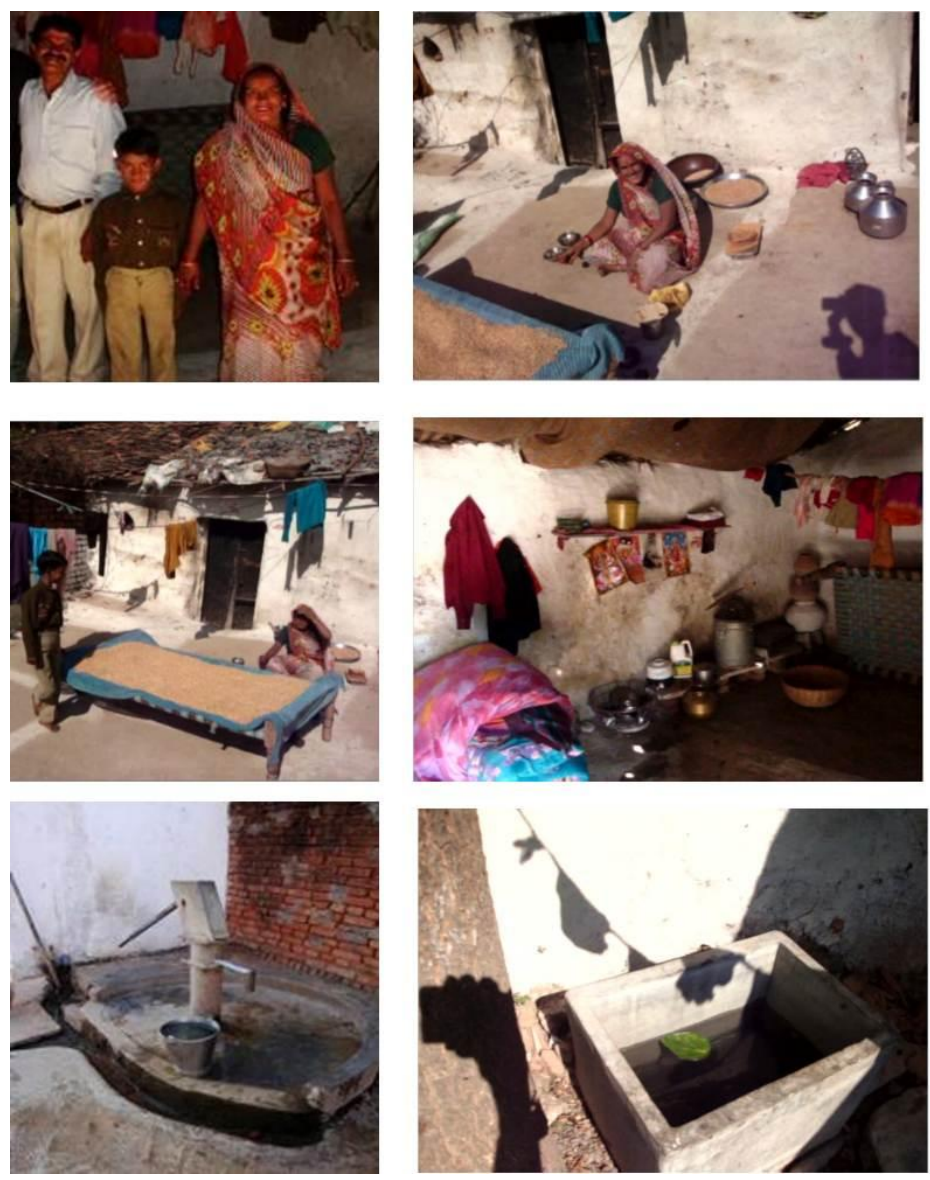

Figure 59 - Overview of an analysed family from Khajuraho. Left middle, woman working on the family harvest. Bottom right a communal well, and bottom left a small reservoir to collect rain water. 


\subsubsection{Medieval Milan}

The medieval Italian diet has a similar pattern to that of ancient societies. The diet was based on vegetables, with some meat, bread and porridge. They had only one cooked meal a day. Medieval diets lacked Vitamins A, C and D and were not high in calories, therefore, the calories used to describe the diet were the same as those used in the ancient societies (Lambert, 2008). The medieval diet was really low in fat and high in fibre. The houses were described as really small and precarious, made from wood and built over stone foundations (Pounds, 2005, p. 39). The walking distances were rounded from $1.9 \mathrm{~km}$ to $2.0 \mathrm{~km}$, which is the approximate distance from the city centre to just beyond the city walls, measured by photo analysis from Google Earth. A second medieval diet hypothesis was tested using the footprint numbers from Vale \& Vale, 2009 p. 49 (4800 kcal/day and 1.1gha).

\subsubsection{Ecological Footprint Comparison}

The footprint of these communities varies from 1.14gha/person for the second medieval diet scenario to as low as $0.18 \mathrm{gha}$ /person for the Incas. Food represents on average 89 per cent of the total footprint averaged across the case studies.

Although the diet had some similarities, the environmental impact (Calorie Count, 2012) may vary dramatically, as can be seen in Table 14, where the different foods are compared according to weight and footprint. The total footprint for this group is essentially the outcome from the different diets. Although, biocapacity in the ancient world would naturally be higher than in the current one, the life-style also provided a lower environmental impact than in the world today. Presumably, the final footprint for this group may be even lower, if an investigation was taken in order to calculate precisely the real footprint from past production methods. As can be seen in figure 52, all communities would potentially be classified as sustainable. 


\begin{tabular}{|c|c|c|c|c|c|}
\hline & $\begin{array}{l}\mathrm{CO}_{2} / \mathrm{kg} \text { (in } \\
\mathrm{kg})\end{array}$ & $\mathrm{GAEF} / \mathrm{kg}$ & References & Calories / kg & References \\
\hline Oats & 0.8 & 0.0004 & (Berners-Lee, 2010, p. L.907) & 3700.00 & $\begin{array}{llr}\text { (Berners-Lee, } & 2010, & \text { p. } \\
\text { L.907) } & & \end{array}$ \\
\hline Bread & 0.9 & 0.0005 & $\begin{array}{l}\text { (Berners-Lee, } 2010, \quad p . \\
\text { L.1285) }\end{array}$ & 2250.00 & (Vogel's, 2012) \\
\hline Carrot & 0.3 & 0.0002 & (Berners-Lee, 2010, p. L.839) & 450.00 & (FAAC-UNESP, 2006) \\
\hline Porridge & 0.2 & 0.0001 & (Berners-Lee, 2010, p. L.899) & 981.00 & \\
\hline Potato & 0.6 & 0.0003 & $\begin{array}{l}\text { (Berners-Lee, 2010, } \\
\text { 1172) }\end{array}$ & 850.00 & \\
\hline Milk & 1.4 & 0.0008 & $\begin{array}{lll}\text { (Berners-Lee, } & 2010, & \text { p. } \\
\text { L.1211) } & & \end{array}$ & 608.00 & \\
\hline Wine & 0.6 & 0.0003 & $\begin{array}{l}\text { (Berners-Lee, } \quad 2010, \quad p . \\
\text { L.1310) }\end{array}$ & 480.00 & (C.H.I., 2012) \\
\hline Asparagus & 0.5 & 0.0003 & (Berners-Lee, 2010, p. 1359) & 201.00 & (Calorie Count, 2012) \\
\hline Rice & 2.5 & 0.0014 & (Berners-Lee, 2010, p. 1465) & 1100.00 & \\
\hline Eggs & $\begin{array}{r}0.15 \\
\text { (unit) }\end{array}$ & 0.0000 & (Berners-Lee, 2010, p. 1562) & 888.00 & \\
\hline Tomatoes & 0.4 & 0.0002 & (Berners-Lee, 2010, p. 1580) & 160.00 & \\
\hline Cheese* & 12.0 & 0.0148 & (Vale \& Vale, 2009, p. 40) & 3720.00 & \\
\hline Leg of lamb & 38.0 & 0.0211 & (Berners-Lee, 2010, p. 1739) & 1620.00 & \\
\hline Apple & 0.6 & 0.0003 & (Berners-Lee, 2010, p. 580) & 450.00 & \\
\hline Banana & 0.5 & 0.0003 & (Berners-Lee, 2010, p. 598) & 850.00 & \\
\hline Orange & 0.5 & 0.0003 & (Berners-Lee, 2010, p. 620) & 530.00 & \\
\hline Fish & 0.5 & 0.0003 & (Berners-Lee, 2010, p. 1602) & 3633.00 & \\
\hline Meat* & 18.0 & 0.0209 & (Vale \& Vale, 2009, p. 40) & 1400.00 & \\
\hline Avocado** & & & (McEwen, 2012) & 1770.00 & (C.H.I., 2012) \\
\hline
\end{tabular}

Table 14 - Food ecological footprint (global average - GAEF) and Calorie Comparison - *Final Footprint (global average), ${ }^{*}$ Number computed from productivity - tonne/ha 


\subsection{Second Analysis Group - Contemporary LEED Certified Projects}

\subsubsection{Tassafaronga, SALT District and Mapleton-Fall Creek - Analysis of the scores from LEED}

The Tassafaronga, SALT District and Mapleton-Fall Creek developments are all located in the United States and have, or will soon have, environmental certifications provided by USGBC (United States Green Building Council). Tassafaronga is a new development, while SALT District and Mapleton-Fall Creek have been retrofitted in order to achieve the certification. The LEED certification for Neighbourhood Development, LEED-ND, divides its assessment analysis into four blocks - Smart Location and Linkage, Green Infrastructure and Buildings (GIB), Neighborhood Pattern and Design (NPD) and Innovation and Design.

Although LEED has this certification assessment for a neighbourhood, it does not strictly define what a neighbourhood is, using a loose definition appropriated from the charter of the Congress for New Urbanism (CNU) - "compact, pedestrian-friendly, and mixed-use" (U.S. Green Building Council, Inc., 2012, p. XVI). Indeed, the document that contains the procedures and general information about the certification credits part of its creation to the CNU, Natural Resources Defense Council, and finally the U.S. Green Building Council.

The first block of items to be analysed by LEED-ND (April 2012) is Smart Location and Linkage, which includes six required items (Smart Location, Imperilled Species and Ecological Communities, Wet Land and Body Conservation, Agricultural Land Conservation, and Floodplain Avoidance). Without scoring points in one of these items, the development cannot be certificated. This block is responsible for 27 points out of 106. Additional to the required items, another item responsible for 10 points is called Preferred Locations (SLL Credit 1). This criterion investigates connectivity with the existing city. According to LEED this is, "to conserve natural and financial resources required for construction and maintenance of infrastructure". This item encompasses aspects related to location type, connectivity or designated high priority location. For Location Type, which is responsible for up to 5 points and is part of Preferred Locations, even a previously developed site that is not an adjacent site earns one point if it is 
within $1 / 2$ mile $(0.8 \mathrm{~km})$ from the proposed development. The item, which investigates connectivity, is essentially an index regarding the number of intersections per square mile, with more points for more connections. The last item designated high-priority locations, gives points whenever the location is part of the city council plans to expand provision of affordable houses. The scores can be combined to provide the total score for this credit.

Another critical item in the Smart Location Block is the SLL credit 3 - Location with Reduced Automobile Dependence, which can provide 7 points in total. There are two ways to achieve high scores here. The first relates to the number of public transport journeys and the distances from residences to public transportation stops. The criteria demands at least 50 per cent of the dwellings and non-residential units are within $1 / 4$ mile $(0.4 \mathrm{~km})$ of bus or streetcar stops or within $1 / 2$ mile $(0.5 \mathrm{~km})$ walking distance of bus rapid transit stops, light or heavy rail stations, or ferry terminals, and there is also a minimum number of public transport trips that the development has to have. The second way to achieve points is to have a proportional number of car trips lower than the local average.

Housing and Jobs Proximity - SLL credit 5 - is responsible for up to 3 points in the Smart Location parameters. This credit awards points for projects located within less than a mile $(1.6 \mathrm{~km})$ of full time job opportunities. Others items concerning SSL and awarding projects up to 2 points are, in the guide updated in 2012, Brownfield Redevelopment (2 points), Bicycle Network and Storage (1 point), Steep Slope Protection (1 point), Site Design for Habitat or Wetland and Water Body Conservation (1 point), Restoration of Habitat or Wetlands and Water Bodies (1 point), and Long-term Conservation Management of Habitat or Wetlands and Water bodies (1 point).

The subsequent block of items is called Neighbourhood Pattern and Design (NPD). NPD can provide up to 44 points out of the 106 total. According to LEED, this block of parameters tries to analyse and award design aspects that encourage walking and daily physical activity. The NPD block has three required items, Walkable Streets, Compact development, and Connected and Open Community. The first one, Walkable Streets addresses aspects concerning house access to streets through a front door, relationship between building height and street width, and length of continuous sidewalks. The 
second required parameter in the NPD block is called Compact Development, which encourages the development of more densely occupied projects, which according to LEED promote liveability, walkability and transport efficiency to reduce Vehicle Miles Travelled (VMT). This item primarily tackles project density. The next required one, Connected and Open Community, addresses the internal urban design, intersections and connections, and promotes interconnection with other developments. It suggests a project should have at least 140 intersections per square mile $\left(2.6 \mathrm{~km}^{2}\right)$, or when the project does not have internal streets, the region has to have at least 90 intersections within $1 / 4$ mile $(0.4 \mathrm{~km})$ of the project boundary.

Apart from being a required item, the Walkable Streets category can award the project with up to 12 points. The points are given according to a list of items the project has to have, such as specific distance between façade and entries and the sidewalk, amount of glass on the ground-floor (minimum 60 per cent of clear glass façades between 1 and $2.5 \mathrm{~m}$ above the ground), design speeds for safe pedestrian and bicycle travel, and street parking on both side of the streets. If the project reaches 15 or 16 of these items, it receives 12 points, while projects, which achieve only 2 or 3 items, only earn 1 point. The next highest parameter, Mixed-Income Diverse Communities, can award projects with up to 7 points. It determines that the development has to have a diversity of economic levels. In order to analyse this, the criterion is essentially the diversity of house types, including a certain level of affordable houses. The next parameter, Compact Development, can award the project with up to 6 points. It is investigated by measuring the density of the development and awarding higher densities, which is defined by dwelling / ha value. Then, Mixed-used Neighbourhood Centres can provide up to 4 points for design that is near regional centres to encourage daily walking or biking thereby reducing VMT, such that 50 per cent of the units are within a $1 / 4$ mile $(0.4 \mathrm{~km})$ walking distance of a regional centre. The diversity of uses within the regional centre may also increase the points. Others items in the NPD block are: Reduced Parking Footprint (1 point), Street Network (2 points), Transit Facilities (1 point), Transportation Demand Management (2 points), Access to Civic and Public Spaces (1 point), Access to Recreation Facilities (1 point), Visitability and Universal Design (1 point), Community Outreach and Involvement (2 points), Local Food Production (1 point), Tree-Lined and Shaded Streets (2 points), and Neighbourhood Schools (1 point). 
The next block of items, which may give up to 29 points, is called Green Infrastructure and Buildings (GIB). In a very simplistic way, LEED has defined this block of parameters in order "to encourage the design, construction and retrofit of building that utilize green building practices" (U.S. Green Building Council, Inc., 2012, p. 77). It has 4 required parameters; Certified Green Buildings, Minimum Building Energy Efficiency, Minimum Building Water Efficiency, and Construction Activity Pollution Prevention. The first, Certified Green Buildings, demands that at least one whole building within the project be certified by LEED or another third-party certification institution. The second, Minimum Building Energy Efficiency, demands a reduction in energy consumption. This is applied to 90 per cent of the total building area of non-residential buildings, mixedused buildings, and multi-unit residential buildings with four or more stories. The buildings have to comply with the energy reduction goal of at least 10 per cent over the ANSI/ASHRAE/IESNA standard. ANSI/ASHRAE/IESNA calculates energy performance using the following formula:

Percentage improvement $=100 \times$ (Baseline building performance - Proposed building performance)/Baseline building performance.

ANSI/ASHRAE/IESNA provides the baseline building performance, and the proposed building must follow their instructions for calculating the building energy use (ANSI/ASHRAE/IESNA, 2009, p. 3). This is assessment at the design stage, not the building in use stage.

The next GIB criterion, Minimum Building Water Efficiency, is included to encourage reduction of adverse effects on natural water resources. The units have to have at least 20 per cent reduction in water consumption compared with the base line buildings. The baseline usage is based on the Energy Policy act of 1992 (U.S. Green Building Council, Inc., 2012, p. 81), and only encompasses water consumption in toilets, urinals, lavatory faucets, shower, kitchen sink faucets, and pre-rinse spray valves. The next required item is Construction Activity Pollution Prevention, which essentially lists a number of procedures to avoid construction pollution. As might be expected, the item awarded with more points, up to 5 , is Certified Green Buildings. It fundamentally gives more points to projects that have a greater number of LEED certified constructions. Subsequently the item that awards the next largest number of points, up to 4 , is 
Stormwater Management. It is included to encourage projects to reduce pollution and hydrologic instability from stormwater. It credits points according to the volume of water retained on-site. Another important item inside the GIB block is On-Site Renewable Energy Source, which awards up to 3 points if the project produces 20 per cent of its energy consumption (residential electricity or commercial consumption). The rest of the items, awarding up to 2 points, are; Building Energy Efficiency (2 points), Building Water Efficiency (1 point), Water-Efficient Landscaping (1 point), Existing Building Reuse (1 point), Historic Resource Preservation and Adaptive Use (1 point), Minimized Site Disturbance in Design and Construction (1 point), Heat Island Reduction (1 point), Solar Orientation (1 point), District Heating and Cooling (2 points), Infrastructure Energy Efficiency (1 point), Wastewater Management (2 points), Recycled Content in Infrastructure (1 point), Solid Waste Management Infrastructure (1 point), and Light Pollution Reduction (1 point).

The last block called Innovation and Design Process, awards up to 6 points to innovations and excellence in performance, 1 extra point being awarded when at least one principal member of the project is a LEED accredited professional. 
Total Score

\begin{tabular}{|c|c|c|}
\hline Tassafaronga & SALT District & Mapleton-Fall \\
\hline 66 & 62 & 53 \\
\hline
\end{tabular}

\begin{tabular}{|c|c|c|c|c|}
\hline \multirow{4}{*}{ SLL } & \multirow{4}{*}{$\begin{array}{l}\text { Preferred Location } \\
\text { Reduced Automobile Dependence } \\
\text { Housing and Jobs Proximity } \\
\text { Total SLL }\end{array}$} & 8 & 8 & 9 \\
\hline & & 5 & 4 & 7 \\
\hline & & 3 & 3 & 0 \\
\hline & & 21 & 17 & 20 \\
\hline
\end{tabular}

\begin{tabular}{|c|c|c|c|c|}
\hline \multirow{5}{*}{ NPD } & \multirow{5}{*}{$\begin{array}{l}\text { Walkable Streets } \\
\text { Compact Development } \\
\text { Mixed-Income Diverse Community } \\
\text { Mixed-Use Neighbourhood Centres } \\
\text { Total NPD }\end{array}$} & 0 & 0 & 7 \\
\hline & & 3 & 1 & 0 \\
\hline & & 3 & 4 & 3 \\
\hline & & 4 & 4 & 0 \\
\hline & & 22 & 20 & 21 \\
\hline
\end{tabular}

\begin{tabular}{|c|c|c|c|c|}
\hline \multirow{4}{*}{ GIB } & \multirow{4}{*}{$\begin{array}{l}\text { Certified Green Building } \\
\text { Stormwater management } \\
\text { On-Site Renewable Energy Source } \\
\text { Total GIB }\end{array}$} & 3 & 1 & 0 \\
\hline & & 0 & 5 & 0 \\
\hline & & 0 & 0 & 0 \\
\hline & & 17 & 20 & 4 \\
\hline
\end{tabular}

\begin{tabular}{|l|l|l|l|}
\hline Innovation & 6 & 5 & 4 \\
\hline
\end{tabular}

\begin{tabular}{|l|l|l|l|}
\hline Regional Priority Credit & 0 & 0 & 4 \\
\hline
\end{tabular}

Table 15 - Comparison between 3 real estate developments certified with LEED-ND. The table only shows the total score by blocks and the highest scores for each block of credits

The minimum score to receive the lowest certification is 40 points, which means that any of the three developments above would be able to be certified when scoring in only two blocks of credits. The Table 15 analysis brings up some important aspects. Firstly, even with relevant differences in the points awarded in each of the credit blocks (the GIB block being the most obvious with Mapleton-Fall only scoring 4 points) all projects have achieved a similar certification (two gold and one silver). Secondly, the numerical result from the simple summing of points may give a misleading notion of sustainability to the final user, the market, and the authorities. Because the total score provides a certain level of certification, possible environmental issues are automatically hidden by the accreditation. For instance, Tassafaronga and SALT District have received a gold certification, which should imply a high level of sustainability. However, both projects have not earned points in On-Site Energy Source, which could cause an enormous impact on the site footprint as calculated by the prototype tool developed for this thesis. 
The final score does not show the reality of the environmental performance. It is not, therefore, a holistic assessment. This may represent a major flaw in the LEED system, as it allows a project to accommodate possible environmental degradation by only working with the points in the other blocks, where credits may be less expensive to accumulate. This numerical approach allows real estate companies to develop certified projects through a scoring strategy to obtain points without compromising profit. The LEED system also gives them the opportunity to explore possible market niches, such as that of the green consumer, but without truly reducing environmental impacts.

For instance, Tassafaronga and Mapleton-Fall have scored zero points in Stormwater management, while SALT district has scored the maximum total points for this item. Without a pluviometric analysis, it is impossible to assess the possible damage caused by the lack of stormwater management. In a region highly susceptible to storms, a project without stormwater management and with low water soil permeability could cause a high environmental impact. The same approach works in the opposite direction. There is no reason to penalize a project without such a system, if it is located in a very arid region, with few storms. Basically, the LEED-ND certification indirectly states that lack of stormwater management has the same effect on the environment in both Tassafaronga and Mapleton, disregarding the local climate. The climate differences and the possible impacts caused by these are not assessed by LEED.

The comparison has pointed out an analysis issue regarding green certified buildings. LEED gives points according to the number of certified buildings within the project. It does not, however, assess the real impact caused by the buildings. A building can be highly efficient, but not certified, which will penalize the whole project even if such buildings have less impact in terms of overall energy use than certified ones.

The last two blocks, Innovation and Regional Priority have a short description in the LEED-ND guide (U.S. Green Building Council, Inc., 2012, p. 107/109) but when combined are responsible for 8.5 per cent of the total score, or 25 per cent of the minimum amount of points needed to guarantee certification.

The Tassafaronga, Oakland, California project in the US, scored 66 points out of 106, achieving gold certification. It is a project started from scratch and was designed to receive a LEED certification (David Braker \& Partners architects, 2008). There are 
minor alterations in the criteria for each block when compared with the latest version of LEED, however, as the USGBC states, the changes are relatively small, being related to names, as all aspects assessed are the same (USGBC, 2011). Tassafaronga scored 21 points in the first SLL block of points. Location and Reduced Automobile Dependence received 13 points in total. However, in the GIB block, called at the time Green Construction and Technology, only 17 points were given, while NPD was awarded 22 points. Additionally, the Innovation section provided 6 points out 6 . The Tassafaronga project therefore reached the intermediate level of certification.

The SALT district, in Syracuse New York, had a similar score of 62 points and also received a gold certificate. Rather than being planned as a LEED certificated project, the SALT district was refurbished. Coincidently, SALT reached the same high scores for the same items. The SLL block was given 17 points. Location and Reduced Automobile Dependence were given 12 points in total. The GIB block, then called Green Construction and Technology, was only given 20 points. This development scored 5 points out of 5 in stormwater management (while Tassafaronga scored no points in this item). NPD was given 20 points in the SALT district assessment. Additionally, the Innovation section provided 5 points out 6. SALT district, along with Tassafaronga, reached the gold certification level.

The Mapleton-Fall Creek was designed for LEED certification. A 2010 summer preassessment gave a potential gold certification, with 53 points. The development is still happening, and the expected score has dropped to 47 or 48 points (depending on the analysis) in the worst scenario, but reaching the maximum of 64 in the most optimistic situation, according to the most recent pre-assessment. However, the numbers considered on this research are those of the summer 2010 pre-assessment, because the whole score breakdown was available. The development would reach 20 points in the SLL, with 16 points coming from Location and Reduced Automobile Dependence. NPD would provide 21 points, with 7 points from Walkable Streets, and understandably, because Mapleton-Fall Creek is an existing development, the block GIB provided only 4 points. Innovation would give 4 points out of the 6 possible. 


\subsubsection{Seaside}

As there was no LEED-ND assessment of Seaside this case study was only investigated using the prototype tool 1 . The result obtained was the same as the Mapleton-Fall Creek (see table 16).

\subsubsection{LEED: Revealing Important Flaws}

In order to assess fairly the effectiveness of LEED Neighbourhood in measuring sustainability, the most environmentally impacting credits were analysed and compared with the results from the prototype tools presented in this research. Whereas these latter prototype tools offer a holistic environmental analysis, the LEED assessment method only partially covers the most relevant environmental issues caused by urban developments. At this point, LEED has been assessed to measure the efficiency in environmental impact evaluation. Previously, this research has shown how the LEED certification has been working to accommodate at least some market demands (refer to chapter 1).

A complete analysis of LEED-ND demands further research; however, the items examined here are enough to confirm some significant LEED-ND flaws regarding environmental impact assessment. Although LEED-ND represents some evolution and improvement in both the community sense and energy saving, it fails to deliver what it proposes. It states that it aims to achieve high performance in key human and environmental areas, such as sustainable site development, water saving and energy efficiency (USGBC, 2011). One of required items of LEED-ND is a certain level of LEED certified buildings, however, when it comes to such certified buildings, 28-35 per cent of LEED buildings use more energy than their conventional counterparts (Newsham, Mancini, \& Birt, 2009, p. 904). The prototype tool developed in this research analyses the relationship between energy efficiency and sustainability. A building or region may be, according to a certification institute, highly energy efficient, but still not sustainable. Efficiency is essentially measured by comparison and indicates that, if the average energy consumed is high, efficiency can be reached without achieving a sustainable level. The research prototype tool, in contrast, suggests parameters based on the earth's 
biocapacity. The prototype tool assesses the most relevant energy consumption at the urban level.

\subsubsection{SLL - Credit 1 - Preferred Location 1-10 points}

This credit is to encourage urban developments within and near existing communities (U.S. Green Building Council, Inc., 2012, p. 22). The points are provided by combining any of the 3 options below:

Option 1: Location Type

Location of the project in one of the following:

- A former developed site that is not an adjacent site or infill site (1 point)

- Next to site that is also a previously developed site (2 points)

- An infill site that is not a previously developed site (3 points)

- An infill site that is also a previously developed site (5 points)

Option 2: Connectivity

The project should be located in an area that has existing connectivity within $1 / 2$ mile $(0.8 \mathrm{~km})$ of the project boundary. The scoring varies from 1 point for $\geq 200$ and $<250$ intersections per square mile $\left(2.6 \mathrm{~km}^{2}\right)$, to 5 points for $\geq 400$ - intersections per square mile $\left(2.6 \mathrm{~km}^{2}\right)$.

Option 3: Designated high-priority Locations

To achieve the following ( 3 points): earn at least 2 points under NPD Credit 4, MixedIncome Diverse Communities, Option 2, affordable Housing. In addition, the project to be located in one of the high-priority redevelopment areas suggested (US-version), such as: Federal Empowerment Zone, Federal Enterprise Community, Federal Renewal Community, Department of Justice Weed and Seed Strategy Community, Department of the Treasury Community Development Financial Institutions Fund Qualified LowIncome Community.

Although this credit establishes straight definitions for connectivity, use of infill sites, and minimum boundary with adjacent sites, there are potential flaws. For example, the definition of an adjacent site does not demand any particular use of the adjacent site 
therefore, the use of the adjacent site may not help to achieve the sense of connectivity. An urban development may be able to achieve a high score in this credit although located in a very distant suburb, if it has been planned and located following the guidelines for the credit and is beside an existing subdivision. Another suggestion to obtain credits in this item is to develop communities following the government guideline for urban growth. However, zoning, probably the ultimate guideline, is often produced to match real estate industry demand. Although the effort to promote connectivity, which is essential to promote a walkable environment and support efficient public transportation and decrease public infrastructure, is recognised the assessment is vague and demands more restrictions and analysis. This credit seems too flexible and is responsible for almost 10 per cent of all possible points.

Under a real estate analysis the overvaluation made by the LEED scores of a specific type of site location can be exploited by the developers, and the process is simple. LEED has been working to spread its Neighbourhood Development regulations through local government. Although it is a volunteer program, local governments have backed it, offering incentives for those who participate. According to LEED, the ND guide is to explore one tool in particular - the LEED for Neighborhood Development rating system - focusing specifically on the ways it can be best used by local governments to achieve sustainability goals (Fuerst \& McAllister, 2011, p. 46; Green Building Council Brasil, 2012). This movement towards local government using LEED certification to orientate or even regulate the local urban policies allows real estate companies to map all possible sites, creating landbanks (site stock) and monopolizing the market. As soon as the process of adopting LEED regulation starts, large developers, with greater financial reserves, rush to acquire sites, possibly taking smaller, local developers out of business. In the worst scenario, real estate developers, using an 'environmental' voice, support LEED implementation and acquire most of the urban sites, thus being able to score high points in this credit. 


\subsubsection{SLL Credit 3: Locations with Reduced Automobile Dependence 1-7 points}

The name of the credit is accurate because it obligates developers to locate new urban development in areas served by public transportation. The walkable distances are sufficiently short ( $1 / 2$ to $1 / 4$ of mile) $(0.8 \mathrm{~km}$ to $0.4 \mathrm{~km})$. However, there are substantial problems when it comes to assessing sustainability. There are two options to obtain points:

Option 1:

The first option gives points according to the number of journeys made by public transportation. It simply means, more public transportation more points.

\section{Option 2:}

The second way to obtain points in this score is locate the development in regions served by Metropolitan Planning Organization (MPO) low Vehicle Miles Travelled (VMT). It provides points if the community average VMT is lower than the regional average, from 1 point for a 10 per cent reduction up to 7 points for reductions equal or higher than 70 per cent.

Apparently the Reduced Automobile dependence credit is another handy tool for developers to exploit the market. It allows developers to trace down and map all possible high scoring sites in a city (most of the SLL credits also allow the same sort of pre assessment and mapping). Additionally, this sort of allowance for mapping is a useful tool for developers implementing landbank policies to guarantee future project launches. The situation may be more dramatic if the local authorities adopt LEED-ND as the guideline for new developments. For instance, if the local authority starts to require a minimum score based on LEED-ND, regions previously cheap and ignored by developers may become financially attractive if those regions comply with some high scoring LEED credits, because it will be easier when it comes it achieving the local approvals requirements. Real Estate speculation may also work in a different way. Some developers could sharply increase their landbank, acquiring sites according to potential SLL credits, and waiting until local authorities implement LEED-ND as the local 
guideline, when their sites become worth more because they comply with the new regulations.

Although the score specifies different walkable distances for different types of transportation, no difference is made between public transportation types. Moreover, there is no reference to proportionality between the number of trips and size of development. It indirectly assumes that different types of public transport have the same impact on the environment. The second option does indicate a reduction in mileage travelled, which possibly leads to an environmental impact reduction, but this is made by comparison with the region, which may have very high private transport use. It simply cannot be accepted as an efficient tool to measure sustainability, because assuming a region with an extremely high average mileage, even a 70 per cent reduction may not be enough to make the transportation mode sustainable.

\subsubsection{SLL Credit 5: Housing and Job Proximity 1 - 3 points}

According to LEED, this credit is meant to encourage balanced communities with a diversity of employment opportunities. There are 3 options to earn points under this category.

This credit combines the requirement of a 30 per cent affordable residential component, walkable distance to full time jobs and additionally at least 1 point is demanded under NPD Credit 4, Mixed-Income Diverse Communities and Option 2, Affordable Housing. It progressively gives fewer points if the amount of jobs in the region goes down, or the project does not earn points in NPD Credit 4, or Mixed-Income Diverse Communities and Option 2, Affordable Housing.

Although the certification relates the number of dwellings with jobs in the region, there is no requirement for job creation, or even job availability. It seems, therefore, an inappropriate relationship between sustainability and economics. For instance, an industrial plant close to the development, even without any jobs available, may be able to provide more full-time-equivalent jobs than the number of dwelling units in the project. A region with a high level of unemployment, high density, and a possible industrial plan, may provide a full score in this credit, and still be extremely 
unsustainable. It may increase the unemployment of the region and obligate further transportation. Additionally the credit provides a static analysis. Possible economic shifts may dramatically change the region, improving or worsening the score. However, the major flaw is not measuring the real impact of the transportation to work of the project's residents.

\subsubsection{NPD Credit 13: Local Food production - 1 point}

According to LEED, this credit was created to promote community based food production. It includes a table relating density and food growing space, which for densities around 7 dwellings per acre is $18 \mathrm{~m}^{2}$ per dwelling, going down to $5.5 \mathrm{~m}^{2}$ when the density is around 35 dwelling per acre. It also awards points for proximity to a farmer's market and for purchase of shares in a community-supported agriculture scheme located within 150 miles $(241 \mathrm{~km})$ of the project site.

This credit represents one of the major failures of LEED-ND to measure sustainability. The proportion of site for food production is negligible in terms of supplying food for the community. This research has shown how important food is as a component of the total environmental footprint. This credit does not help to educate the project community or wider society concerning the need to have land for food. Additionally, the insignificant proportion of the site for agriculture may give the impression that the neighborhood has dealt with this aspect of sustainability, but without any relevant

reduction in the community footprint. This credit excludes any possibility of educating the community about the amount of land necessary to provide its food. Moreover, it does not suggest any kind of diet limitation. This item may be responsible for making the whole neighbourhood unsustainable, depending on the average diet of the development's residents.

\subsubsection{NPD Credit 4: Mixed-Income Diverse Communities 1 - 7 points}

This item is meant to promote a socially equitable community. The project earns points according to the diversity of dwelling options. More diversity guarantees more points (up to 3). Another way to get points is defining a range of products in which the rental 
prices given are for members of the public whose income is up to 60 per cent lower than the Area Median Income (AMI) and the sales prices given are for members of the public whose income is 20 per cent higher than the AMI. This is explained in a table called "Points for Affordable Housing" (U.S. Green Building Council, Inc., 2012, p. 59). The project earns up to 3 points, if, for instance, 15 per cent of the rental prices were priced for a population with 60 per cent of the AMI, and 2 points for sales price 20 per cent higher than AMI.

This credit may be able to guarantee a relative diversity in the income of project residents, but seems an inefficient indicator for affordability. The average perhaps will not be accurate enough, if the region has a large income gap. The example provided in this research of Alphaville and Carapicuiba, in São Paulo, Brazil, perfectly illustrates the possible distortion in this credit. While Alphaville has a per capita annual average income around NZD 113,046.00 Carapicuiba has an average NZD 4,884.00 per year per capita (IBGE, 2009). This huge difference will lead to an inevitable distortion in the AMI. Therefore, in a region with such characteristics a development may reach really high scores and have some diversity, but will not provide affordable options.

A similar problem happens with the items for which the indicators are made up by using a local average such as GIB Credit 2: Building Energy Efficiency for 2 points, which also provides points for considering the ANSI/ASHRAE/IESNA Standard 90.1-2007. Indeed, as previously mentioned, there is no guarantee that LEED certified buildings will perform better energetically (Newsham, Mancini, \& Birt, 2009, p. 904). The same distortion is possible if the region has a high existing energy consumption or a relevant social gap.

Additionally, one aspect which may be able to make difference, On-Site Renewable Energy Sources, GIB Credit 11 (1 - 3 points), will provide only 3 points if the site produces up to 20 per cent of its energy. It seems inefficient, for instance, that if a project has reduced its consumption of energy from the national grid, and started to produce 100 per cent of its electricity on-site, it would still be rewarded with 3 points, although effectively significantly decreasing its impact. 


\subsubsection{Conclusions about LEED-ND as a Tool for Environmental Assessment}

Essentially LEED-ND presents some contradictions and has not covered all important topics in order to assess environmental impacts effectively. LEED-ND does not assess items which would guarantee the prosperous and sustainable future it promises. This is a relevant issue, as LEED is promoted on the possibility of a prosperous and sustainable future as a result of its efforts (CRGBC, 2012). Additionally, this research has not found a sufficient conceptual structure in LEED-ND to guarantee an efficient measurement of environmental impact. LEED certification has largely been used as a tool by developers to explore the market niche for green products. For instance, the Green Building Brazil website has in its front page the slogan: "Building a Sustainable Future" (Green Building Council Brasil, 2012), and essentially endorses LEED certification as a tool to achieve this. This is extremely convenient for developers, as it provides a great marketing increment. The rise in public demand for environmental growth has led to many certification schemes emerging, among them LEED (Fuerst \& McAllister, 2011, p. 45). Developers have understood the need for certification, and green markets have expanded dramatically in response to pricing signals, and the consumer has also chosen certified products because of possible tax incentives and other advantages linked to marketing and image (Fuerst \& McAllister, 2011, p. 46). LEED certification has an enormous importance in the pricing composition, increasing property value. Residential Real Estate sells in areas with a green approach. Labels still yield positive effects in terms of building value (Zheng, Wu, Kahn, \& Deng, 2011, p. 04). This research concludes that LEED-ND is a green marketing tool, and as such attempts to minimize the perception of the impacts caused by real estate growth rather than successfully minimizing environmental impact. This is because consumers want to incorporate environmental criteria as an attribute to be considered along with other more conventional items (Polonsky, 2005, p. 126) but without significant changes to the consumer life style.

\subsection{Using LEED to Environmentally Assess Low Ecological Footprint Communities}

It would be expected that if LEED-ND was a tool to measure urban sustainability, developments with a recognizably low impact would be able to be certified and would 
score highly. In order to confirm the effectiveness of the LEED, some of the case studies measured earlier in this research were analysed to check if they would be able to be certified. Although a whole LEED analysis would be demanded to test the LEED certification method, only the most relevant items were applied in these test cases to see if they would comply with the LEED requirement.

The lowest footprint analysed, the Incas, and the two modern cases (rural India and China) were used as models. Firstly, the required items were analysed and a general overview made in order to assess their LEED rating.

For the Smart Location and Linkage criteria, the required items are Smart Location, Imperilled Species and Ecological Communities Conservation, Wetland and Water Body Conservation, Agricultural Land Conservation and Floodplain Avoidance. These are discussed below.

\subsubsection{Smart Location}

This is hard to apply due to the need take account of nearby community. Therefore, an isolated community would have a problem meeting this demand. This brings up another possible flaw of the rating system proposed by LEED, as self-sufficient communities in relative isolation would not be certified. According to this category, the Chinese and Inca cases would not score. The possible score for India would depend on a deeper study, although the distance between the community and the town (1.2 miles / 3.2km) may exclude India as well, even though the distance is walked regularly.

\subsubsection{Imperilled Species and Ecological Communities Conservation}

Because this item demands consultation with the State of Heritage Program, it would be hard to apply. Essentially it requires that the location does not affect but rather conserves imperilled species and ecological communities. It would require further research, however, to state that all three cases could potentially comply with the demand. 


\subsubsection{Wetland and Water Body Conservation}

This has the same assessment problems pointed out for the previous item, given the reference to a US programme, so would demand a deeper hydrologic analysis. Theoretically, the three case studies would conform, depending on the cultural behaviour and some infra-structure changes. In India and China there is no piped water. In India water is essentially collected from rainfall, or pumped out from community wells. It can be assumed that the community depends only on rainfall and the local underground water supply, which indicates lack of waste. Local observation in India, shows water usage is restricted to drinking and cooking, with a shower every another day limited to a 20 litre bucket. In summer, however, the community stated there is an increase in consumption because of the monsoon and the need for daily showers. In rural China the situation is similar, as the community depends on local water supply. The water is collected from higher spring water and is conducted through bamboo pipes to the border of the community.

\subsubsection{Agricultural Land Conservation}

This credit depends on the federal authority demarking agriculturally relevant sites. However, because the case study communities are extremely dependent on local production, it could be assumed that all locations would conform with some adaptation with the LEED demands.

\subsubsection{Floodplain Avoidance}

The Incas and Chinese, due to location, would have no problem conforming with this item. India, though different, would also conform because of lack of water bodies and the low risk of flood.For Neighbourhood Pattern and Design the mandatory items are: Walkable Street, Connect and Open Community. 


\subsubsection{Walkable Streets}

This item has the intention of promoting transportation efficiency, including reduced VMT. Possibly all cases would comply with this item due to the focus on street walkability as in all cases there is no other use for streets than walking.

\subsubsection{Compact development}

If only the conceptual aspect of the credit applied, all the case studies would comply with the LEED requirements. All are fairly compact and with an apparent high density.

\subsubsection{Connect and Open Community}

In contrast, the location and characteristic of the case studies would mean they would not comply with this aspect of LEED. The Inca, Indian and Chinese communities have a relatively isolated location and would not meet the LEED demand for local communities. However, isolation is probably one of the reasons that the communities have a relatively low impact. They have had to learn how to live with their limitations and local resources. In India and China rural communities barter is still part of daily life. In these cases, the connectivity is sufficient for their sustainable habits. This indicates the conclusion that this credit only examines certain models of urban design, mostly western orientated and linked with current urban models. Moreover, intersections, although vital for a truly walkable environment, demand a more accurate description of their usage. Intersections, due to visibility, are liked by retailers (Hibshoosh, 1988, p. 580). Intersections may lose urban value if they are restricted to a residential scheme. It is not clear if the case studies would comply with the demand of internal connectivity.

The block called Green Infrastructure and Building has four required credits, Certified Green Building, Minimum Building Energy Efficient, Minimum Building Water Efficiency and Construction Activity Pollution Prevention. 


\subsubsection{Certified Green Building}

None of the projects have any certified building. Further research is necessary to analyse if the buildings would comply with LEED for New Construction of buildings.

\subsubsection{Minimum Building Energy Efficiency}

It is relevant to emphasize that energy efficiency is related with energy consumption and not only electricity. All the case studies have no access to electricity meaning the measurements would be hard to make. LEED requires a 5 per cent improvement over ANSI/ASHARAE/IESNA Standard 90.1-2007, which would not be feasible.

\subsubsection{Minimum Building Water Efficiency}

Apparently the way that the case studies manage water supplies indicates they would find it difficult to be more cautious about water consumption.

\subsubsection{Construction Activity Pollution Prevention}

Further research is necessary to analyse if the buildings would comply with the demands of LEED for the construction process.

\subsubsection{Conclusion on Using LEED for Low Ecological Footprint Communities}

Apparently, without greater flexibility in interpretation, the projects would fail to achieve some of the required credits. Other credits, which are relevant for the sustainability prototype tool offered by this research, were verified such as Local Food Production and Onsite Renewable Energy Source. These two items are essential in order to measure environmental impacts. Local Food Production should award the neighbourhood with a high score, because, as this research has tried to point out, food has a high impact on the Ecological Footprint. The amount of embodied energy contained in food, may be up to 10 times larger than the energy contained in the food 
itself (Vale \& Vale, 2009, p. 31). The prototype tool developed in the research has shown how important food is to the Ecological Footprint composition, and this also applies to On-Site Renewable Energy Source. Domestic energy is also a relevant factor impacting the ecological footprint, and in both cases, the numbers reflect the importance of both items.

The case studies used as models would fail to achieve a high score in some of the highest scoring categories, such as Preferred Location (10 points) and Housing and Jobs proximities, although the scoring could be adjusted to the local reality. In the case of India, the distances walked are greater than the LEED suggests, but are suitable for the local reality. Some points would be lost in the walkable street credit, because the projects do not comply with some requirements, such as minimum glass areas in retail projects and restrictions on blank facades (without windows and doors), there are no parking lots, there are no elevated accesses to the ground floor units, and there are no design speeds for creating a safe pedestrian zone. Indeed, even a modern urban development, designed exclusively for pedestrians, would lose some important points in this credit. Cultural and climate aspects which might affect provision of window and door openings are ignored, because there is no mention in the LEED brochure about these characteristics. The Mixed-Use Neighbourhood Centre has a similar problem as previously pointed out, and does not apply to communities with low commerce needs, extremely low incomes, dependence on community agriculture, and with barter being important in the commercial relationship (as seen in India and China). It means that LEED does not take in account local culture, economy and climate. The communities studied possibly have a very similar internal income. It exposes another facet of LEED, which indicates that LEED might measure income diversity, but the way this is done would produce a lack of points in an entirely affordable community. Although it is recognizable that LEED intends to blend diverse incomes in the same project, some old communities have established themselves using a more equalitarian base, as seen in the China and India examples.

In conclusion, the application of LEED as a sustainability measurement tool is limited and restricted. Indeed it does not effectively assess the two major aspects of urban impact, food and energy. Additionally, it does not indicate any major human behaviour change and or any environmental constraints. As an environmental urban measurement 
tool, it might be expected that present urban behaviour, particularly in the countries with recognizable environmental impact, would be challenged. There is no relevant movement towards a better relationship between urban design, urban inhabitants and the environment. It has important and relevant considerations about income diversity, urban connectivity, walkable environment, and density, but still lacks consistency in the environmental analysis. Because of its origins and upper management it is natural to suggest that LEED is an instrument used by developers to expand the market towards a progressively, but marginally, environmentally aware consumer.

Developers along with other economic sectors have understood the importance of the green market, and this has gained wide acceptance as being a viable competitive strategy. The term green has been widely used and also connects a product with proenvironmental attitudes (Oyewole, 2001, p. 239). The research from Newsham, Mancini, \& Birt (2009) pointed out that around 30 per cent of the LEED certified buildings consume proportionally more than their counterparts. Because these are part of the Neighbourhood Certification, which demands a certain amount of certified buildings, this contradiction is also incorporated in LEED-ND. The IDP credit 2 indicates the internal market expansion commitment by giving a point to urban projects which have a LEED accredited professional involved. The possible environmental improvement from adopting LEED-ND as a new local urban development regulation tool is also in question. It may be used as a real estate speculation tool, allowing developers to map and acquire landbank.

However, the most important aspect of the ineffectiveness of LEED is the fact, as stated by Noiseux \& Hostetler, 2010, (p. 240) that the "green" offered by the developers does not affect the residents' behaviour. They have concluded that " [it] is necessary to ensure that residents are sufficiently educated and empowered to embrace sustainable behaviour." Their research has pointed out no consistent behaviour change in people who live in green-developments compared with normal ones. Therefore, it can be assumed that the footprint, apart from the potential improvement given by the green structure provided by the developer, is essentially the same in a green and non-green development. The research shows that the cultural background and attitude toward sustainability is more relevant than the structure provided by the development. This can be confirmed with the results from the prototype tool developed in this thesis. In all 
cases, the most relevant factors impacting the footprint are those related with behaviour, consumption and habits. Although some aspects related with urban design reflect the outcome, these are fundamentally minor in the overall measurement. LEED fails in assessing and connecting the urban relationships and lifestyle associated with the present model of urban development. The historical examples are, indeed, a powerful information tool by suggesting which direction has to be taken in order to improve urban sustainability.

\subsection{General Conclusion}

Table 16 sets out the results of using both prototype tools on the selected case studies.

\begin{tabular}{|c|c|c|c|c|}
\hline Case Study & $\begin{array}{l}\text { High } \\
\text { Income } \\
\text { Country EF } \\
\text { (GFN) }\end{array}$ & $\begin{array}{l}\text { First } \\
\text { Protot } \\
\text { ype } \\
\text { Tool } \\
\text { Result }\end{array}$ & $\begin{array}{l}\text { Scenario simulated in the } \\
\text { secondary prototype tool in } \\
\text { order to make the average EF } \\
\text { of high income countries } \\
\text { equal to the case studies }\end{array}$ & $\begin{array}{l}\text { Results from the secondary prototype tool } \\
\text { assuming that the entire world population would } \\
\text { have the same EF as the case study }\end{array}$ \\
\hline \multicolumn{5}{|c|}{ LEED and Contemporary Cases } \\
\hline $\begin{array}{l}\text { Mapleton-Fall } \\
\text { Creek and } \\
\text { Seaside }\end{array}$ & & 5.8 & $\begin{array}{l}-5.5 \text { per cent of fossil fuel } \\
\text { consumption and Food EF } \\
\text { or } \\
-7.5 \text { per cent of fossil fuel } \\
\text { consumption }\end{array}$ & $\begin{array}{l}\text { World Population Limit: } 2.04 \text { Billion } \\
\text { (EF 5.8gha) } \\
\text { - If the population decreases } 1 \text { per cent } \\
\text { per year from 2012, in } 2100 \text { the land } \\
\text { deficit will be } 30 \text { per cent. } \\
\text { If the population decreases } 3 \text { per cent } \\
\text { per year from 2012, in } 2052 \text { the land } \\
\text { deficit will be } 0 \text { per cent }\end{array}$ \\
\hline SALT District & 6.09 & 4.5 & $\begin{array}{l}-27.5 \text { per cent of fossil fuel } \\
\text { and food } \mathrm{EF} \text { and }-25 \text { per } \\
\text { cent in house EF } \\
\text { or } \\
-38 \text { per cent of fossil fuel }\end{array}$ & $\begin{array}{l}\text { World Population Limit: 2.6 Billion } \\
\text { (EF 4.5gha) } \\
\text { - If the population decreases } 1 \text { per cent } \\
\text { per year from 2012, in } 2100 \text { the land } \\
\text { deficit will be } 9 \text { per cent. } \\
\text { If the population decreases } 3 \text { per cent } \\
\text { per year from 2012, in } 2044 \text { the land } \\
\text { deficit will be } 0 \text { per cent }\end{array}$ \\
\hline Tassafaronga & & 4.2 & $\begin{array}{l}\text {-33 per cent of fossil fuel, } \\
\text { food EF and housing }\end{array}$ & World Population Limit: 2.85 Billion \\
\hline
\end{tabular}




\begin{tabular}{|c|c|c|c|c|}
\hline & & & $\begin{array}{c}\text { or } \\
-48 \text { per cent of fossil fuel }\end{array}$ & $\begin{array}{l}\text { (EF 4.2gha) } \\
\text { - If the population decreases } 1 \text { per cent } \\
\text { per year from 2012, in } 2100 \text { there will } \\
\text { be } 3 \text { per cent of land surplus } \\
\text { - If the population decreases } 3 \text { per cent } \\
\text { per year from 2012, in } 2041 \text { the land } \\
\text { deficit will be } 0 \text { per cent }\end{array}$ \\
\hline \multicolumn{3}{|c|}{ Historical cases, Rural China and India } & $\begin{array}{l}\text { Comparison between the case } \\
\text { studies and contemporary } \\
\text { countries with some possible } \\
\text { adaptation }\end{array}$ & $\begin{array}{l}\text { Results from the secondary prototype tool } \\
\text { assuming that the entire world population would } \\
\text { have the same EF as the case study }\end{array}$ \\
\hline $\begin{array}{c}\text { Medieval } \\
\text { Milan II } \\
\text { (4800kcal/day) }\end{array}$ & $\mathrm{N} / \mathrm{A}$ & 1.1 & Similar to Kenya today & $\begin{array}{l}\text { World Population Limit: } 11.1 \text { Billion } \\
\text { (EF 1.1gha) } \\
\text { - If the population increases } 1 \text { per cent } \\
\text { per year from 2012, in } 2100 \text { the land } \\
\text { deficit will be } 51 \text { per cent. } \\
\text { If the population increases } 1 \text { per cent } \\
\text { per year from 2012, in } 2059 \text { the land } \\
\text { deficit will be } 0 \text { per cent }\end{array}$ \\
\hline Rural China & $\begin{array}{l}\text { China EF } \\
2.21 \text { gha } \\
\text { (2007) }\end{array}$ & 0.7 & $\begin{array}{l}\text {-75 per cent in fossil } \\
\text { fuel consumption and } \\
\text { food EF compared with } \\
\text { China average in } 2007\end{array}$ & $\begin{array}{l}\text { World Population Limit: } 16.8 \text { Billion } \\
\text { (EF 0.7gha) } \\
\text { - If the population increases } 1 \text { per cent } \\
\text { per year from 2012, in } 2100 \text { the land } \\
\text { deficit will be } 0 \text { per cent }\end{array}$ \\
\hline Greece & $\mathrm{N} / \mathrm{A}$ & 0.5 & $\begin{array}{c}\text { Similar to Bangladesh } \\
\text { today }\end{array}$ & $\begin{array}{l}\text { World Population Limit: } 18+\text { Billion } \\
\text { (EF 0.5gha) } \\
\text { - If the population increases } 1 \text { per cent } \\
\text { per year from 2012, in } 2100 \text { there will } \\
\text { be } 32 \text { per cent land surplus }\end{array}$ \\
\hline Rural India & $\begin{array}{c}\text { India } \\
\text { actual EF } \\
0.91 \text { gha } \\
\text { (2007) }\end{array}$ & 0.4 & $\begin{array}{l}45 \text { per cent reduction } \\
\text { in current Indian } \\
\text { average EF }\end{array}$ & \multirow{2}{*}{$\begin{array}{l}\text { World Population Limit: } 18+\text { Billion } \\
\text { (EF 0.4gha) } \\
\text { If the population increases } 1 \text { per cent } \\
\text { per year from 2012, in } 2100 \text { there will } \\
\text { be } 79 \text { per cent land surplus }\end{array}$} \\
\hline $\begin{array}{c}\text { Medieval } \\
\text { Milan I } \\
\text { (2000kcal/day) }\end{array}$ & $\mathrm{N} / \mathrm{A}$ & 0.4 & $\begin{array}{l}\text { Similar to East-Timor } \\
\text { today }\end{array}$ & \\
\hline Rome & $\mathrm{N} / \mathrm{A}$ & 0.2 & $\begin{array}{l}50 \text { per cent reduction } \\
\text { in the current EF of }\end{array}$ & \\
\hline
\end{tabular}




\begin{tabular}{|c|c|c|c|c|}
\hline & & East-Timor & \multirow{2}{*}{$\begin{array}{c}\text { World Population Limit: 18 + Billion } \\
\text { (EF 0.2gha) }\end{array}$} \\
\hline Incas & N/A & 0.2 & $\begin{array}{c}50 \text { per cent reduction } \\
\text { in the current EF of } \\
\text { East-Timor }\end{array}$ & $\begin{array}{c}\text { If the population increases 1 per cent } \\
\text { per year from 2012, in 2100 there will } \\
\text { be 243 per cent land surplus }\end{array}$ \\
\hline
\end{tabular}

Table 11 - The table shows the combined results of the prototype tools developed in this thesis. The right column explores the results from the second prototype tool, calculating the scenarios of land deficit or surplus according to the Ecological

footprint of the case studies.

Although the prototype tool offered in this research guarantees a more precise and effective environmental performance measurement, it has some limitations. Although the process of measurement is undeniably accurate, due to being a simple mathematical operation, it relies on third party data. As an example, food and diet information has come from GFN (Global Footprint Network, 2012), and the impacts from private transportation were from Vale \& Vale (2009).

However, in testing, its results were fairly similar to those of the Global Footprint Network. For example the average American in 2010, according to GFN had an ecological footprint of 8.0gha, while according to this prototype tool, using the American average the Ecological Footprint varies from 4.82gha when using a very low consumption patterns to 8.58gha using a more realistic figure, based on consumption being up to 3 times higher than the direct energy consumed at home (Lenzen, Wood, \& Foran, 2008). Although it seems to be the most relevant change, the source of energy is also a relevant. Another limitation of the prototype tool is the lack of precision regarding the nuclear energy footprint. According to Wackernagel \& Monfreda (2004) nuclear footprints are often used as the equivalent of those of fossil fuels, while in contrast, Simmons \& Lewan (2001) suggest that the nuclear energy footprint is as low as 0.00002 ha/GJ. To overcome these problems, the figure used here was an intermediate value, equivalent to the impact of hydroelectricity.

Despite some limitations, the process developed by this research adequately measures the true sustainability of an urban development. At this stage, it requires many parameters and assumptions; however, the process follows a mathematical method. The criterion basically gauges the Ecological Footprint generated by any urban development, and moreover, the habits and behaviour of the inhabitants of the site. However, it demands a continuous investigation and the progressive replacement of assumptions with real measurements. 
The combination of the two prototype tools can generate a relevant environmental analysis. The footprint calculation prototype tool used to analyse the historical models and the LEED certified buildings offers a static examination, which requires the secondary analysis in order to keep its sustainable performance. When the two results are combined, as is demonstrated in table 16 , it is possible to understand that the reductions proposed by LEED, although relevant, are not enough to qualify any project as sustainable. Additionally, the combination of the prototype tools was helpful in confirming that historical models were as sustainable as contemporary rural India and China. The impact caused by the ancient societies and rural India and China have a very low ecological footprint, allowing for population growth, while remaining sustainable.

In conclusion, it is possible to assess environmental performance in urban developments through measurement of Ecological Footprint. This research demands continuity. A long process of measuring the real ecological footprint of all eras in an urban development is needed, instead of using parameters and assumptions. 


\section{General Conclusion}

Land is the ultimate resource and the most obvious limit (Meadows, Randers, \& Meadows, 2004, p. L 776). Therefore, this research has used the ecological footprint as a main indicator of sustainability. However, sustainability cannot be taken in isolation, as it encompasses a wide range of concepts and indicators, that ultimately have to conform with the land limitation. This research has suggested that the influence and environmental impact caused by urban settlement reaches areas beyond its physical limit. Therefore, it is acceptable to admit that any criteria to assess urban sustainability have to encompass the extension of this impact. It is relatively easy to find tools to assess urban or building sustainability through measuring physical and infrastructural aspects, such as LEED or BREEAM. However, this research has suggested that the physical analysis is not sufficient to measure the environmental impact caused by urban settlement usage. The process of environmental evaluation must go beyond the physical performance, and assess a group of behaviour and cultural attitudes which are, by far, more impacting than, for instance, urban electricity consumption.

The process of assessment of environmental performance has gone further than simply suggesting a handful of indicators. It has implicitly advised the need for a deep change in modern lifestyle in order to tackle environmental problems. The investigation which indicates these changes has brought up relevant influences caused by the economic model and its work relationships, consumption patterns, and diet. These aspects have been, according to the prototype tool developed in this research, the most environmentally impacting issues. Consequently a significant effort was made to understand the origin of these issues and how to assess them. This investigation has additionally brought up some suggestions for how to mitigate some of these problems.

The progressive decline of the earth's biocapacity, due to population growth, also supports the need for a dramatic change in modern lifestyle. The secondary prototype tool developed here was created to indicate the decline in the world's biocapacity per capita. The outcomes of this supplementary prototype tool are essential for pointing out the urgency in the need for change, and moreover, how superficial most of the environmental analyses that have been made lately are. The combined result from the two prototype tools indicates the need for periodic analysis and reassessment. 
Indirectly it also suggests that static assessments are ineffective in the long term. This thesis, consequently, postulates that most of the tools available in the market are not truly prepared to offer an option to society for preventing unwanted and damaging environmental impacts.

The historical examination has been helpful in highlighting the contradictions of modern society. The extraordinary technological evolution from the last centuries has not brought a reduction, in general, of the footprint of modern society. Generally and contradictorily, the countries that are apparently more developed (certainly in terms of material consumption) have a larger environmental impact. Under an environmental analysis, in contrast, countries taken as under developed have smaller impacts, and therefore are more environmentally developed. This suggests that the current model of development does not include the environment as part of the process. Indeed, it seems to be the opposite: an African consumes $10 \mathrm{~kg}$ of resource/day on average, while an Australian consumes $100 \mathrm{~kg}$ on average (Gilding, 2011, p. 51). Bangladesh, for instance, has an Ecological Footprint of 0.66gha, while New Zealand scores 4.31gha, Australia has 6.68gha and USA has 7.19gha (Global Footprint Network, 2012). It is a fair assumption to state that lack of development (under the current of standard of development assessment) suggests lower environmental impact. This suggests that, instead of looking exclusively to developed countries to find solutions for reducing environmental impact, some examples from under developed countries also have to be considered. Consequently, the understanding of the environmental impacts and the economic model points out relevant aspects related to urban design. The historical and economic parts of this research have indicated that current urban design and growth and the adaptation that cities have been making to accommodate cars, are the consequences of an economic model based on consumption. The historical urban model, based on a walkable environment involving relatively short distances, has been progressively replaced by immense urban settlements. This model of urbanization is dependent on fossil fuels, which are limited, and is also responsible for a large part of total greenhouse gas emissions. Consequently, the car-dominant model of urban and suburban development is not sustainable (Karlenzig, 2010, p. L. 4492).

However, cities are often taken as one of the most important creations of humankind. They allow collaboration, joint production of ideas, and a constant flow of information 
(Glaeser, 2011, p. L. 4270). This apparent contradiction between the capacity that cities have to produce ideas and development and the current model of their growth has suggested the brief investigation into historic urban settlements throughout history at the start of this research. One of the first conclusions from the historic investigation is that complex forms of human organization and stratification are a recent phenomenon and an anomaly of history (Tainter, 1988, p. 193). Since the initial principle of the urbanization process as a place where people have gathered to barter a little surplus and the subsequent invention of currency, through international trading and the Industrial Revolution, urbanization has evolved from a phenomenon of very simple structures of small cities to a very large and complex society, based on international commerce. Essentially, however, the most prominent characteristic of modern society is the dependence on economic growth and physical expansion to keep it going. As long the economy is expanding, which means more money and credit are available, consumption increases and as a result resource depletion occurs much faster, and at a rate beyond natural ecosystems to replace these resources. Historically regions have faced periods of economic expansion and retraction, while the world economy has grown slowly throughout history. The exploitation of fossil fuels and the technological development that followed have provided an ideal condition for an unprecedented economic growth that has never before occurred in human history (Heinberg, 2011, p. 275).

One of the most important postulates from this research, is the fact the need for economic expansion has been an important factor in making urban expansion so disconnected from its history and so dependent on unsustainable models. For instance, in the current paradigm, carbon emissions should be cut and fossil fuel dependence reduced, but only to the extent these two actions do not affect economic growth. Ancient societies also depended on expansion. Rome may be a good example of the dependence on expansion and conquest to keep its economy going. The city imported grains from distant places, as far away as Egypt, and also expended a huge amount of resources to keep its legions patrolling the borders, and hence the resources that supported the city and empire. But even Rome and its extraordinarily large empire eventually collapsed. "Civilization can die, because it has already died once" (Mazzarino, 1966, p. 174) in (Tainter, 1988, p. 02). 
However, history has shown some good examples of the understanding of limitations. Sparta, although obscured by Athens, was a major example of the modest Greek ideal. Sparta has been said to represent the ideal State (Gutkind, 1969, p. 487). The major principles of Greek city planning were limitations and good use of the urban space (Gutkind, 1969, p. 504). Although, cities from the Neolithic in Greece have grown protected by concentric walls, Sparta never had walls, and its citizens could access the hinterland, keeping a physical relationship with the land. In contrast, elsewhere in Europe, a strong antagonism has grown up between people from the countryside and townspeople, whereas in Greece the countryside and central city grew together into a State. Ancient cities have had up to 90 per cent of their population involved with agriculture, and therefore with the cities' surroundings (Morley, 1996, p. 13).

Human history experienced a massive change when money was introduced (Lévy, 1967, p. 21). The balance achieved with barter was lost, and civilizations had to adapt their skills in order to keep the city supplied with food, and to commercialize and deal with its products. This was, therefore, a point of major change in urban design, where urban societies possibly faced the first disruption between the city and its rural heritage and hinterlands. The principle that a city has to be permanently fed initially brought cities and their hinterlands into a balanced relationship of connection and interdependence. Money profoundly changed these relationships, which directly affected the size of cities, the scale of the streets, the permeability of the soil, increase in runoff, and the size of the population. Money speeded up the trade process, allowing cities to grow without the restriction of the food production fields around them, and allowing the work specialization of their citizens. The balance, although fragile, that cities had achieved, and in which the concepts of self-sufficiency and limitation were present, was progressively lost as a consequence of the introduction of money. The slow barter deal was replaced by the abstraction of money and the increased speed of exchange that came with this. The limitation of local resources could then be circumvented by resources from overseas provided by money raised from 'a good deal'. Obviously, this research does not suggest that sustainability must be achieved through isolation and forced self-sufficiency, but rather that the main knowledge that can be taken from the historical analysis is the idea of limitations. Civilizations have flourished by coping with their environmental limits and sometimes perished by not doing so. However, the idea 
of limitlessness is apparently recent in human history despite the fact the history of humankind has shown many examples of collapse due to lack of understanding, or respect for, environmental limits. The tremendous expansion of irrigation systems in Mesopotamia, under the Ur dynasty for instance, in an attempt to maximize economic and political power, led to rapid collapse. The number of settlements and the irrigated area dropped 40 and 77 per cent respectively over the subsequent millennium (Tainter, 1988, p. 07). The Mayan civilization almost totally vanished probably because of environmental mismanagement. Cook proposed in 1931 that:

“...collapse here was caused by soil erosion and land scarcity, encroachment of grasses, silting of lakes with consequent destruction of water transportation, a decline of water supply in dry years, and an increase in mosquito populations along with increase or introduction of malaria."

(Cook, 1931, pp. 283-284)

The same conclusions were reached approximately thirty years later by Sander (1962, 1963) after an extensive study of lowland ecology in the region (Tainter, 1988, p. 45).

The theory of resource depletion is a perennial favourite in historical investigations of collapse, but it is both hard and complex to establish that mismanagement of resources was the only thing responsible for the collapse of various societies. It seems more plausible that a chain of issues was trigged by environmental problems. Collapses triggered in this way have been predominantly accepted for Mesoamerica, but progressive acceptance has begun for downfalls in eastern North America, Europe and Near East societies (Tainter, 1988, pp. 45-46).

This research has found historical correlations between economic changes and urban patterns, and moreover, how the economic changes have acted as a relevant factor in shaping cities. Historically urbanization and its rural counterpart have appeared to be linked by economic fluctuations. However, just recently the process of urbanization has speeded up. Only in 2008 has the urban population overcome the rural one (United Nations, 2008, p. 06). This level of urbanization indicates a unique moment in history, in which people cluster themselves in towns at a level never before observed, at the same moment that economies are growing at a rate without precedent in history (Heinberg, 2011, p. L. 284). 
The investigation process has been divided, therefore, into looking at changes in cities before and after the Industrial Revolution. The first stage was to look at the physical changes when cities have expanded through receiving internal migrants from the hinterlands to work in the industries at the beginning of the Industrial Revolution. This first stage is related with industrialization. However, increasing urbanisation indicates that migrations are still happening and there is tendency for this process to keep going. The second stage is essentially the evolution of the first stage, and cities become a tool for consumption.

For instance, in China internal migration has been growing dramatically. The urbanization process in China is alone responsible for 50 per cent of Chinese economic growth. This process has demanded an increase in highways, car production, and fuel consumption. This is the fastest and largest economic growth and has no precedent in world history (Heinberg, 2011, p. L. 3885). This rapid urbanization, which brings along industrialization of food systems, the building of highways and other basic infrastructure, causes a sharp expansion of the economy in the short term, but creates a societal vulnerability over the long term. This economic expansion in a world after peak oil, and an impending scarcity of fresh water, could make China a vulnerable and fragile society (Heinberg, 2011, p. L. 3888).

Globally, slums have been growing at a fast rate around big cities (Heinberg, 2011, p. L 3731), turning these areas into centres of misery and poverty. These changes in the urban environment are not new, as was observed by Friedrich Engels in his book "The Condition of the Working Class in England in 1844". He described the poor conditions of the workers in Manchester during the process of industrialization. He also observed that every great city had one or more slums, where the working-classes were crowded together. He suggested that poverty often dwelt in hidden alleys close to the palaces of the rich, something still true today. By giving the poor a separate territory they were removed from the sight of the richer classes. Engels saw that these early slums were almost equally arranged in all the great towns of England, with the worst houses in the worst quarters of the towns, these usually being one or two-storied cottages in long rows, perhaps with cellars used as dwellings: 
"These houses of three or four rooms and a kitchen form, throughout England, some parts of London excepted, the general dwellings of the working-class. The streets are generally unpaved, rough, dirty, filled with vegetable and animal refuse, without sewers or gutters, but supplied with foul, stagnant pools instead. Moreover, ventilation is impeded by the bad, confused method of building of the whole quarter, and since many human beings here live crowded into a small space, the atmosphere that prevails in these working-men's quarters may readily be imagined. Further, the streets serve as drying grounds in fine weather; lines are stretched across from house to house, and hung with wet clothing."

(Engles, 1844, p. L 608)

In another part of the book, Engels uses a description from Mr. G. Alston, a preacher at St. Philip's, Bethnal Green, on the condition of his parish. Alston states his parish is a place with 1,400 houses, inhabited by 2,795 families, meaning about two families to a dwelling. The space where this great population resided was less than 400 metres square, it being very usual to find a husband and wife, four or five children, and sometime both grandparents sharing a single room. Alston suggested that people from the rich part of London knew as little about the conditions of his parish as they did of the savages of Australian or the South Seas Islands. He also described the lack of nutrition, clothes, furniture and sewage treatment (Engles, 1844, p. L 650). The conditions observed and described by Engels sadly match the present conditions found in some of the most important industrial cities of today. Rapid urbanization is already making it harder for the poor to access education and medical facilities, because local authorities struggle to keep the public services increasing at the same rate as that of urban population growth (Heinberg, 2011, p. L 3734).

In summary, the first stage of the impact of economic expansion on cities meant an extraordinary growth in attracting people from the countryside, normally because of industrialization, although any increase in economic activity may cause migration. Maybe the best way to summarize what has been happening in towns and cities is given by Karl Marx and Friedrich Engels: “The more rapidly capital accumulates in an industrial or commercial town, the more rapidly flows the stream of exploitable human material" (Marx \& Engels, 1887, p. 726). 
The second stage of change in cities can be understood as an evolution of the first model, even though both models may happen in the same town at the same time, in different locations. This stage is essentially the materialization of urban design as an agent of consumption. Urban design has become a player in the economic model. Although this aspect of the research deserves more investigation, this thesis has presented an overview of the consequences for urban design caused by economic drivers. It has pointed out, sometimes without following the historical sequence, the main modifications in urban design since the upwelling of the influence of the economic players in city planning. Cities started to receive investments in infrastructure, such as highways and only later in the social needs of cities. Under these aspects, one of the most relevant factors shaping cities since the intensification of the participation of economic players in urban planning, is transportation. The cost, speed, quality and capacity of the transportation system is directly related to capital accumulation. Transportation, public or private, may alone be the most important cause of change in contemporary urban design. Cities have been able to extend themselves way beyond old boundaries, with suburbs designed further and further away, all meaning fossil fuel has become essential to keep cities working. The first step was simply designing cities to accommodate the financial demand for investments from investors, simply by building more houses, roads and infrastructure. Under this economic model, there is a tendency to "drive beyond all spatial barriers" (Harvey, 1985, p. 24). This process to overcome spatial barriers is disruptive of any urban configuration. It ultimately means that the economic system is actively destroying and erasing the urban design and planning knowledge accumulated throughout human history. The urban planners' response is that these changes are based on a process of rationalization, including all facets of urban agents, such as private investors, real estate developers, landlords, the financial institutions, and the environment (Harvey, 1985, p. 181; pp. 174-177). Considering all aspects, the definition of rationalization has become essential to understand how the economy acts to interfere in urban design. Rationalization, under the economic model, is the central core of an economic ideology, and is essentially the reproduction of the social model of consumption, "doing whatever must be done to re-establish the conditions for a positive accumulation" (Harvey, 1985, p. 181; pp. 174-177). It suggests an economic model protection mechanism under crisis situations. During a crisis, the economic players suggest what is going wrong and the way to right it. For instance, in a 
particular urban environment physical infrastructure may be overcrowded; therefore, it has to be replaced generating investments and their associated profits through its rebuilding. The economic model has imposed a condition in which capital builds a physical landscape appropriate to its own condition at a particular moment in time, only to have to destroy it at some point, normally during the course of a crisis (Harvey, 1985, p. 25).

The economic model has defined and arranged a distinction between the places of work and home for two main reasons. The first is related with the rationalization described above. The second has its roots in the revolutions of 1848, the Paris Commune of 1871, and the great railroad strikes of 1877 in the United States, when the clustered working class population made a claim for social change. Suburbanization has become an important tool for avoiding and minimizing the chances of the working classes banding together, whether through strikes or revolutions. This is not just planning towards an increase in consumption and flow of capital, but design to keep a population under control, making the whole a mix of repression and control (Harvey, 1985, p. 179).

In addition, the consumption analysis is also served by making urban planning based on the physical separation of the place to work and the place to live. The process to allocate the place to live apart from the place to work is economically convenient, because it demands a permanent investment in infrastructure, with its essential consumption of resources and energy. Roads and highways have to be built to keep improving the traffic flow during the rush hours, cars have to be sold, and consequently fossil fuels have to be exploited and commercialized. This is a massive economic arrangement to fuel growth, and this research could not find any aspect of this economic process that takes regard for the environment.

The conceptual structure of the economic system, when analysed under an urban design perspective, has shown how the morphology of cities changes according to the economic players. For instance, the progressive decrease in local commerce against the massive increase in chains of international retailers came along with the construction of highways, and conveniently serves the suburbs. This illustrates how opportune it is, in terms of modern economics, to have work and living separated. The complex arrangement involving the distance between home and work with investment in 
infrastructure is based on an urban model of sprawl, highways, cars, and consequently fossil fuels. Therefore, it upholds the idea that the built environment has become part of the system and serves as the physical infrastructure for production and flow of commodities. This research investigation suggests that the expansion of cities is essentially the design result of a structure made to serve the consumption patterns of present society, a result also endorsed by Harvey (1985, p. 15). The historical examination shows the important role that cities had for economic growth in the last century. Cities have also become a place for private investment, as part of the economic model of today. The examples from Site 1 and 2 (see chapter 6), Alphaville and Carapicuiba confront two different realities of the influence of the economy in urban design. While Carapicuiba and Site 2 have a very low average family income, their respective neighbours Alphaville and Site 1 are much higher. Carapicuiba and Site 2 apparently still remain based on local commerce, while Site 1 and Alphaville have based their consumption patterns in the massive commercial chains primarily located along the highways. Although still relevant, the local commerce has been struggling because of price competition from the huge chains.

Even though there are differences in the consumption patterns between Carapicuiba and Alphaville, the idea of separation between place of work and home is still there. Although Carapicuiba has some local commerce, and therefore some local jobs, observation suggests a lack of local employment. Alphaville, however, has a relevant number of jobs available, but they cannot be described as local jobs. The same number of people who go to Sao Paulo every day for work also come from there to work in Alphaville (Tavares \& Brancatelli, 2011).

Alphaville also supports other conclusions from this research. It is a fairly recent neighbourhood, designed in the middle of the 1970s, although the residential areas became more established from the 1980s onwards, being composed of gated communities, commercial centres and light industries. Alphaville's developers have always declared Alphaville to be a model of a highly planned urban development (Alphaville, 2011), and a large investment has been made to improve access and local infrastructure. This project is called "Better traffic in Alphaville" (melhor transito em Alphaville). It is essentially a group of improvements in road infrastructure (including a fly-over crossing the main highway beside the project) which serves the region. It is a 
car based investment to improve the accessibility to the region, and hence jobs elsewhere. Summarizing, Alphaville does not provide the right jobs for its residents; therefore its population has to commute to Sao Paulo, demanding, because of Alphaville's economy and population growth, permanent investment to update the local infrastructure. In addition, because the type of jobs created there (low paid service industry jobs) are not wanted by the local population who need to earn a good wage to live in Alphaville, people have to commute to Alphaville to work there.

This physical separation was not possible in the past because of the lack of transportation systems, such as those currently based on fossil fuels. It is important to stress that the urban pattern has been planned on economic principles, which apparently do not consider environmental limitations as important in urban and social development. This has exposed an undeniable flaw in the economic model. In order to keep the status quo and its apparent wellbeing, the system demands permanent growth. Although permanent growth is essential, it is impossible. It is impossible because the resources on which the system bases its growth are finite. The same restrictions and beliefs can be applied to urban design. Cities cannot grow indefinitely or, in order to preserve the economic model mechanism, be built and re-built to allow a state of permanent capital investment, through trying new and different models. In contrast, many historical models have been proved efficient when it comes to environmental issues and limitations.

The critical insight that comes from using this viewpoint brings the understanding that continued economic growth is both absolutely essential and also impossible. It is essential because the human economic system was designed to grow and performs horribly when it cannot, and impossible because nothing can grow forever. According to the principles of economic growth, population growth plays an important role. In theory it will guarantee market expansion and, therefore, an increase in consumption. Population growth forces intensification of agricultural production and the expansion of farming areas. This leads to land scarcity, pushing up the price of land, which benefits those who have invested in it, but not the majority who have not.

This thesis has shown the large influence caused by economic agents in urban design. It has also pointed out some of basic factors which support the model, such as the 
consumption of goods and energy, the choice of diet, and the economy based on limited raw materials and fossil fuels.

After briefly showing some of the important economic influences on urban design and their main environmental impacts, the next stage was to find a way to assess theses impact, regarding their influence on the built environment. The thesis has shown how the real estate market often uses environmental certification to increase sales. Consequently, it was necessary to examine some of the environmental performance certification labels available on the market. After an overview, LEED was chosen to compare results in selected case studies. The results, although expected, were sufficiently discrepant to bring up some important issues for answering the third subquestion academic questions of this thesis: Is it possible to develop a sustainable neighbourhood under the current economic model?

The answer is rather simple; under the economic tenets it is not possible. Current economic and urban growth models are in their majority unsustainable. Additionally, the institutionalization of urban environmental assessment tools, which are essentially unable to measure urban environmental performance effectively, will ultimately allow the expansion of the current model of urban development. Urban development is not only a simple expansion of urban settlement, it demands a massive investment in urban infrastructure, housing, and public transportation. Moreover, the modern consumption pattern has been consolidated within this model of expansion. The need for economic expansion assumes a physical dimension in urban terms. Cities are growing as never before, not only from human population growth, but through increased rates of urbanization.

The result obtained from using the prototype tool developed for this thesis aims to answer the first sub-question which arose after the initial research question: What criteria should be used in measuring sustainability in urban environments? The criteria are simple, urban development has to generate an ecological footprint per capita lower than the world's biocapacity. If an urban development has achieved an ecological footprint under the world's biocapacity, it is sustainable at that specific moment. This lead to answering the second sub-question: Are there any true example of urban sustainability, either in the past or now? The answer is that there are clear historical 
examples of urban societies with very low ecological footprints. However, to achieve these cities were very different from modern urban models. This suggests a need for a profound change in what cities are and the lifestyles they offer if there is ever to be such a thing as a sustainable city, based on sustainable urban design. This leads on to the key research question: Is it possible to develop a way of measuring the true sustainability of an urban development? The answer to this question hinges around the discussion of sustainability in the thesis. True sustainability has been linked to available biocapacity. It is possible to measure the impact of urban developments in these terms, but the results suggest very large changes in the way urban developments are created and the way people will live in them.

Sustainability is also not a final and static answer; the development has to keep its ecological footprint permanently under the world's biocapacity. It suggests that the pressure caused by population and economic growth will ultimately force sustainable urban developments to keep decreasing their impacts. Otherwise they will consequently become unsustainable ones. It indicates that even a model of sustainability in urban development tends to become unsustainable in the future; therefore, the solution lies not only in urban efforts, but a profound change in economic models and consumption habits. A sustainable urban environment is possible as mentioned above. Some examples from the past, such as Sparta and the Incas, as well as India and China, offer a real example of a low impact ecological footprint. Therefore, although called 'rural' India and China, these areas perhaps illustrate an ideal size and, behaviour, for a sustainable future.

The idea advocated by post classical economists that nature is merely a subset of the human economy, an inexhaustible set of resources waiting to be transformed into riches, does not take into account resource limitations. The blind trust in the idea that technology can solve problems caused by the economic patterns of consumption hides the fact that some resources, even the most basic ones such as land and water, do not have a realistic substitute in a short time. During the process to generate the measurement prototype tool itself, this thesis has tried to show how detrimental the urban expansion model has been. 
This research has concluded that urban development cannot have profit as its main goal. It suggests that private companies are not the best economic sector to design the expansion of cities. Urban growth demands a balance of interests and ultimately has to aim at urban social efficiency, therefore, making sustainability factors and indicators more important than capital return rates, profit and private interests in general. 


\section{Bibliography}

Academic Room. (2006, June 05). Academic Room History of Central America. Retrieved August 21, 2011, from Academic Room Website: http://ns1.academicroom.com/topics/about-mayas

Achsah Nesmith. (1985, March 01). A long, arduous march toward standardization. Smithsonian, Digital Version.

Adamska, A., \& Michczynski, A. (2012, May 05). Warsaw University. Retrieved August 14, 2012, from Warsaw University -Department of History: http://maa.uw.edu.pl/es/base-de-datos-c14/82towards-radiocarbon-chronology-of-the-inca-state.html

Alphaville. (2011, August 21). Historico Alphaville. Retrieved July 30, 2012, from Alphaville Official website: http://www.alphaville.com.br/institucional/historico.php

American National Standards Institute. (2008, May 12). ANSI overview. Retrieved August 29, 2009, from ANSI website:

http://www.ansi.org/about_ansi/overview/overview.aspx?menuid=1\#.UD7AbtbizYg

Backhouse, R. E. (2002). The ordinary business of life. Princeton: Princeton University Press.

Bairoch, P. (1988). Cities and Economic Development from the Dawn of History to the Present. Chicago: Chicago University Press.

Bairro Novo. (2010). Sobre o Bairro Novo. Retrieved 2010 October,10 from Bairro Novo website: http://www.bairronovo.com

Barros, J. L. (2010, February 01). Importância de selos ecológicos para tomada de decisão das empresas em mudança. (Personal Communication)

Bartlett, B. (1994). How Excessive Government Killed Ancient Rome. The Cato Digital Journal. www.cato.org/pubs/journal/cjv14n2-7.html

Beckerman, W. (1994, August 03). Sustainable development: is it a useful concept? Environmental Values , pp. 191-209.

Belik, W. (2011, 2004). Sober Palestras. Retrieved June 21, 2011, from Sober Website - Sociedade Brasileira de Economia, Administração e Sociologia Rural:

http://www.sober.org.br/palestra/12/070078.pdf

Benevolo, L. (1975). The History of the City. Rome: Latereza.

Berners-Lee, M. (2010). How Bad are Bananas? The Carbon Footprint of Everything. London: Profile Books.

Beyer, D. (2002, November). Sustainable Building and Construction Implementing Green Building in Western Australia. Perth, Western Australia, Australia: Murdoch University.

Big Switch Projects. (2008). Big Switch Projects. Retrieved 03 12, 2010, from Big Switch Projects NABERS: http://www.bigswitchprojects.com.au/services/nabers-ratings.aspx 
Birkeland, J. (2008). Positive Development. London: EarthScan.

Blanco, J. M. (1979). Historia da America Central. Lisboa: Barões Assinalados .

Blanco, J. M. (1981). Nova História da América Central. São Paulo: Ativas.

Bloor, R. (1952). Ancient Rome Economy. New York: New York Press.

Bohn, k., \& Viljoen, A. (2005). More Space With Less Space: An Urban Design Strategy. In A. Viljoen, k. Bohn, \& J. Howe, CPULs Continuous Productive Urban Landscapes (pp. 10-15). Oxford: Elsevier.

Bosselman, K. (2008). The Principle of Sustainability: Transforming Law and Governance. Hampshire: Ashgate.

Boyle, C. (2004, March). http://www.ipenz.org.nz. Retrieved August 2012, 12, from IPENZ website: http://www.ipenz.org.nz/ipenz/practicesupport/Sustainability-combined.pdf

Bradley, K. (2009, September 12). Resisting Slavery in Ancient Rome. Retrieved July 17, 2011, from BBC History: http://www.bbc.co.uk/history/ancient/romans/slavery_01.shtml\#four - in

Braudel, F. (1973). Capitalism and Material Life 1400-1800. London, England: Weidenfel \& Nicholson. BRE, Building Research Establishment. (2009). BREEAM around the world. Retrieved February 13, 2010, from BRE web site: http://www.breeam.org/filelibrary/BREEAM_Around_The_World_A4.pdf Brown, L. (2009). Plan B 4.0 Mobilizing to Save the Civilization. Nwe York: W.W. Norton \& Company. Brown, P. R. (2007). The Importance of Water Infrastrucure and the Environment. In V. Novotny, \& P. R. Brown, Cities of the Future - Towards Integrated Sustainable Water and Landscape Management. London, England.

Byrne, J., Hughes, K., Rickerson, W., \& Kurdgelashvili, L. (2007). American policy conflict in the greenhouse: Divergent trends in federal, regional, state, and local green energy and climate change policy. Energy Policy, 4455-4573.

Campbell, E., \& Hood, I. (2006). Assessment of Tools for Rating the Performance of Existing Buildings: A Report on the Options. Great Vancouver Regional District.

Castillo, B. D. (1928). The Discovery and Conquest of Mexico. Ciudade de Mexico: Genaro Garcia.

Castro, D., Castilho, S., \& Miranda, S. (2004, May). A Rotulagem Ambiental no Contexto do Comercio. Retrieved february 03, 2010, from Centro de Estudos Avançados em Economia Aplicada: http://www.cepea.esalq.usp.br/pdf/cma_maio04_rotul_amb.pdf

Castro, G. A., de Elizagarate, V., \& Zorrilla, P. (2006, February). Universidade del país vasco. Retrieved May 29, 2011, from www.inzepe.com: http://www.izenpe.com/s15-

4812/es/contenidos/informacion/estudiosestadisticaspu/es_estudios/adjuntos/estudioestrategias.pdf

Cerchiai, L., Janelli, L., \& Longo, F. (2004). The Greek Cities of Magna Graecia and Sicily. Los Angeles: Getty. 
Chachi, A. (2005). Origin and Development of Commercial and Islamic Banking Operations. J.KAU: Islamic Economy, 3-25.

Chambers, N., Simmons, C., \& Wackernagel, M. (2000). Sharing Nature's Interest Ecological Footprint as an Indicator of Sustainability. London: Earthscan.

Chapman, L. (2007). Transport and Climate Change: a review. Journal of Transport Geography, 354367.

China International Travel Service. (2012). China Highlights. (C. D. Gov., Producer) Retrieved July 18, 2012, from China Highlights Website: http://www.chinahighlights.com/tour/guilintour/gl-23m/

Christophers, B. (2011, July 27). Revisiting the Urbanization of Capital. Annals of the Association of American Geographers, 1347-1364.

Clark, D. (2003). Urban Growth / Global City. New York, USA: Routledge.

Colleman, S. (2010, January). Popular Transportation Commons Sense. Retrieved November 01, 2011, from PTCS website: www.ptcs.com/articles.interin.research//\%collemann

Common, M., \& Stagl, S. (2005). Ecological Economy - An Introduction. London: Cambridge University Press.

Conrad, D. (2006, January 01). MexConnect. Retrieved June 30, 2011, from MexConnect website: http://www.mexconnect.com/articles/1574-the-ancient-maya-a-commercial-empire

Conrad, G. (1984). Religion and Empire; The Dynamic of Aztec and Inca Expansionism. Cambridge: Cambridge University Press.

Costanza, R. 2000. The Dynamics of the Ecological Footprint Concept Ecological Economics 32:341345.

Conway, E. (2009). 50 Economic Ideas. London, England: Quercus.

Cook, W. (1931). Why the Maya Cities of Guatemala were Abandoned. Journal of the Washington Academy of Sciences, 283-287.

Cóttrill, J. (2006, June 21). Aztec History Population. Retrieved November 01, 2009, from Aztec History website: http://www.aztec-history.com/

Cox, W., \& Utt, J. (2004, June 05). Backgrounder. Retrieved May 31, 2011, from http://www.demographia.com: http://www.demographia.com/costsofsprawlreconsidered.pdf

Coy, M. (2006). Gated communities and urban fragmentation in Latin America: the Brazilian experience. GeoJournal, 66, 121-132.

Curtis, W. (1986). Modern Architecture since 1900. London: Phaidon.

Curwell, S. (1999). Environmental Assessment of Buildings,. Manchester: University of Salford. 
Dantzig, G. B., \& Saaty, T. L. (1973). Compact City - A plan for a liveable environment. San Francisco: W.H.Freeman and Company.

Danzer Group. (2012, August). Danzer Group. Retrieved August 11, 2012, from Danzer Website: http://www.danzergroup.com/fileadmin/files_group/docs/history-of-sustainability_en.pdf

Davis, K. (1965). The Urbanization of the Human Population. In R. Legates, \& F. Stout, The City Reader (4th Edition ed.). Abungdon: Routledge.

Delgado, A. (2010, February 19). BREEAM and others eco-labels. (Personal Communication)

Dennerline, J. (2005, January). New Dictionary of the History of Ideas. Retrieved August 12, 2011, from The Encyclopedia.com: http://www.encyclopedia.com/topic/Confucianism.aspx

Diamond, J. (2005). Collapse? How Society Choose to Fail or Succeed. London, Penguin Books.

Donnelly, A., \& Forrest, B. (2007, September 15). Cities, Medieval. Retrieved August 01, 2012, from Sage References: http://knowledge.sagepub.com/view/community/n65.xml

Droege, P. (2006). Renewable City - A Comprehensive Guide to an Urban Revolution. London: WileyAcademy.

Dupuy, T. N. (1993, August 13). International Military and Defense Encyclopedia. Retrieved August 2012, from World History in Context:

http://ic.galegroup.com.helicon.vuw.ac.nz/ic/whic/ReferenceDetailsPage/ReferenceDetailsWindow? failOverType $=\&$ query $=\&$ windowstate $=$ normal $\&$ contentModules $=\&$ mode $=v i e w \&$ displayGroupName $=$ Reference \&limiter $=\&$ currPage $=\&$ disableHighlighting $=$ true $\&$ source $=\&$ sortBy $=\&$ display $G$

Eberhard, W. (1948). A History of China. Los Angeles: UCLA Press.

Elkington, J. (2012). John Elkington - Ideas. Retrieved August 09, 2012, from John Elkington webiste: http://www.johnelkington.com/activities/ideas.asp

Endo, J., Murakami, S., Ikaga, T., Iwamura, k., Yashiro, T., \& Bogaki, K. (2005). Extended Framework od CASBEE; Designing an Assessment System of Buildings for All Lifecycles Stages Based on the Concept of Efficiency. The 2005 World Sustainable Building (pp. 1856 - 1863). Tokyo: In-House.

Engles, F. (1844). The Condition of the Working-Class in England in 1844 with a Preface written in 1892. Manchester: Public Domain.

Environment \& Society Portal. (2011). Environment \& Society Portal. Retrieved August 08, 2012, from Environment \& Society Portal:

http://www.environmentandsociety.org/tools/keywords\#/id/1820

ESCO. (2012, August 10). Clientes. Retrieved August 10, 2012, from Esco website:

http://www.cside.pt/c_escos.asp

European Institute for Energy Research. (2011). EIFER. Retrieved June 01, 2012, from EIFER Website: http://www.eifer.uni-karlsruhe.de/spip.php?rubrique12 
ExxonMobil. (2012). Exonn Mobil. Retrieved July 01, 2012, from Exonn Mobil Website:

http://www.exxonmobil.com/Corporate/files/news_pub_eo.pdf

FAO - Food and Agriculture Organization of the United Nations. (1998, August). FAO Corporate Document Repository. Retrieved April 13, 2011, from The FAO Corporate Document Repository houses: http://www.fao.org/docrep/003/x1577e/X1577E00.htm\#TopOfPage

Fay, R. (2003). NABERS: Environmental Rating as a Reporting Strategy. Fraunhofer - Institute for Applied Information Technology , 01-09.

Felix, J. (2005). Ganhos de Mercado por Meio do Marketing Ambiental. Revista da Faculdade de Ciências - Universitas, 2.

FIESP. (2007 Octuber, 22). Indústria Aposta em Novo Salto da Construção. Retrieved 2010 15-July from FIESP Wesite:

http://www.fiesp.org.br/clipping.nsf/5b56c69712d7723983256c7d0060a3c9/45d67fd734530a4083 25737c0069d260?OpenDocument

Finley, M. I. (1977, July). The Ancient City: From Fustel de Coulanges to Max Weber and beyond. Comparative Studies in Society and History, 19, 305-327.

Frame, B., \& Newtom, B. (2007). Promoting Sustainability Through Social Marketing: Examples from New Zealand. International Journal of Consumer Studies, 571-581.

Frischer, B. (2008). Rome Reborn Aqueducts. Retrieved July 02, 2011, from Rome Reborn - Institute for Advanced Technology in the Humanities:

http://archive1.village.virginia.edu/spw4s/RomanForum/GoogleEarth/AK_GE/AK_HTML/AQ002.html

Fuerst, F., \& McAllister, P. (2011). Green Noise or Green Value? Measuring the effects of Environmental Certification on Office Values. Real Estate Economics, 39, 45-69.

Gifford, H. (2009). A Better Way to Rate Green Buildings. The Magazine of the Northeast Sustainable Energy Association, 19-27

Gilding, P. (2011). The Great Disruption. New York: Bloomsbury Press.

Gilk, P. (2002). The Meaning of Green Agriculture. Retrieved January 12, 2011, from http://www.greens.org/s-r/28/28-10.html

Ginsberg, J. M., \& Bloom, P. (2004). Choosing the Right Green-Marketing Strategy. MIT Sloan Management Review, 79-84.

Giradert, H. (2004). Cities People Planet. Chichester: John Wiley \& Sons.

Girardet, H. (2007). Creating Sustainable Cities. Bristol, UK: Green Books Ltd.

Glaeser, E. (2011). The triumph of the City. New York: Penguin Press. 
Glenn, M. (2011). Salt Lake City Turns Old Building into Green Buildings. In R. L. Kemp, \& C. J. Stephani, Cities Going Green. Jefferson, USA: McFarland \& Company, Inc.

Global Footprint Network. (2012, April 27). Glossary. Retrieved August 01, 2012, from Global Footprint Institute website: http://www.footprintnetwork.org/pt/index.php/GFN/page/glossary/

Global Footprint Network. (2012, May 08). Trends. Retrieved July 19, 2012, from Global Footprint Network website: http://www.footprintnetwork.org/en/index.php/GFN/page/trends

Glotz, G. (1926). Ancient Greece at Work. London: Kegan Paul, Trench, Trubner \& Co., Ltd.

Gold, J. (2006). A world of organized ease: the role of leisure in Le Corbusier's La Ville Radieuse. Leisure Studies, 101-110.

Green Building Council Brasil. (2012, January 03). Green Building Council Brasil website. Retrieved July 07, 2012, from Green Building Council Brasil website:

http://www.gbcbrasil.org.br/?p=world\&M=3\&O=1

Guia NewsVille. (2000). Geomundo Geografia . Retrieved August 14, 2012, from Geomundo Website: http://www.geomundo.com.br/geografia-30194.htm

Gutkind, E. A. (1969). Urban develpment in Southern Europe: Italy and Greece. Toronto, CA: Collier Macmillian.

Halsall, P. (2000). Aristotle: The Polis, from Politics. Internet Ancient History Sourcebook.

Hamilton, P. (1991). Max Weber (2) - Critical Assessments. London: Routledge.

Harl, K. W. (1996). Coinage in the Roman Economy 300 B.C. to A.D. 700. London: The John Hopkins University Press.

Harvey, D. (1985). The Urbanization of Capital: Studies in the History and Theory of Capitalist Urbanization. Oxford: Basil Blackwell.

Haughton, G., \& Hunter, C. (1994). Sustainable cities. London: Regional Studies Association.

Hays, J. (2011, March). Facts and Details. Retrieved July 16, 2011, from Facts and Details website: http://factsanddetails.com/world. php?itemid=1508\&catid=56\&subcatid=362

Heinberg, R. (2011). The End of Growth: Adapting to Our New Economic Reality. Gabriola Island, BC, Canada: New Society Publisher.

Hersh, J., \& Brun, E. (2000, January 15-21). Globalisation and the Communist Manifesto. Economic and Political Weekly, 35, 105-108.

Hibshoosh, A. (1988). A Principle for Corner Store Positioning under Intrinsic Modeling for Traffic Orientation. Decision Sciences, 580-597.

Historvius. (2012, August 14). Historvius Dead Cities. Retrieved August 12, 2012, from Historvius website: http://www.historvius.com/ancient-cities/fr246 
Holton, R. J. (1986). Cities, Capitalism and Civilization. London: Allen \& Unwin.

Howards, J. (2010, March 05). Road Coverage in new subdivisions in NZ. Personal Communication. Auckland - NZ.

Hsin, D. H.-C., \& Macer, D. (2002). 4.3. Confucian and Taoist influences on the images of life among seniors in Taiwan. Retrieved January 06, 2010, from Eubios Ethics Institute :

http://www.eubios.info/ABC4/abc4084.htm

Hutchison, R. (2009). Garden City. Encyclopedia of Urban Studies, 287-290.

IBGE. (2009, July 01). Estimativa das Populações Residentes em Municípios Brasileiros. Retrieved August 2012, 14, from IBGE:

http://www.ibge.gov.br/home/estatistica/populacao/estimativa2009/POP2009_DOU.pdf

IBGE. (2009 10-March). IBGE - Sala de Imprensa :: Contas Nacionais Trimestrais-Indicadores de Volume e Valores Correntes. Retrieved 2011 02-July from IBGE website:

http://ibge.gov.br/home/presidencia/noticias/noticia_visualiza.php?id_noticia=1330\&id_pagina=1

INAH. (2011, July 27). Insituto nacional de Antropologia e Historia - Press Releases. Retrieved August 01, 2011, from INAH - Website: http://inah.gob.mx/index.php/english-press-releases/50-museumsand-exhibitions/5155-teotihuacan-city-of-gods-open-in-its-last-european-seat

International Organization for Standardization. (2010). ISO members. Retrieved March 01, 2010, from ISO website: http://www.iso.org/iso/home/about/iso_members.htm

International Organization for Standardization. (2012). About ISO. Retrieved July 05, 2012, from ISO website: http://www.iso.org/iso/home/about/about_governance.htm

International Organization for Standardization. (2012). ISO membership manual. Genève 2: ISO.

Internet Encyclopedia of Philosophy. (2001, April 12). IEP . Retrieved November 21, 2011, from IEP Website: http://www.iep.utm.edu/locke/\#SH2c

Januzzi, G. (2005). Breve Historia de Italia. Buenos Aires: Latemendia.

Japan Sustainable Building Consortium . (2011). CASBEE - Brief Version. Tokyo: Japan Green Building Council.

Japan Sustainable Building Consortium. (2011, May 22). CASBEE overview. Retrieved July 07, 2011, from CASBEE website: http://www.ibec.or.jp/CASBEE/english/overviewE.htm

Johnston, P., Everard, M., Santillo, D., \& Robert, K.-H. (2007). Reclaiming the Definition of Sustainability. Environmental Science and Pollution Research International, 60-66.

Johri, L., \& Sahasakmontri, K. (1998). Green marketing of Cosmetic and Toiletries in Thailand. Journal of Consumer Marketing, 265 - 281.

Kahn, M. (2006). Green Cities - Urban Growth and Environment. Washington: Brookings Institute. 
Karlenzig, W. (2010). The Death of the Sprawl. In R. Heinberg, \& D. Lerch, The Post Carbon Reader Managing the 21st Century's Sustainability Crises

Kemerling, G. (2011, November 12). The Philosophy Pages . (G. Kemerling, Producer) Retrieved November 20, 2011, from Philosophers web page: http://www.philosophypages.com/hy/4n.htm

Kendall, A. (2009, July 03). Cushicana. Retrieved 23 May, 2011, from Cusichaca Trust Website: http://www.cusichaca.org/pdf/1-Presentacion_de_la_Institucion.pdf

Kiewiet, D., \& F. J. Vos, J. (2007). Organisational Sustainability: A Case for Formulating a Tailor-Made Definition. Journal of Environmental Assessment Policy and Management, 1-18.

Klausen, J. C. (2007, August). Room Enough: America, Natural Liberty and Consent in Locke's Second Treatise. The Journal of Politica, 69, 760-769.

Kneib, E. C., \& Silva, F. M. (2011). Rede Íbero-Americana de Estudos em Polos Geradores de Viagens . Retrieved May 10, 2011, from Documentos web site:

http://webcache.googleusercontent.com/search?q=cache:KWC5SR20b90J:redpgv.coppe.ufrj.br/ind ex.php\%3Foption\%3Dcom_docman\%26task\%3Ddoc_details\%26gid\%3D406\%26Itemid\%3D64\%26lan g\%3Des+DENSIDADE+POPULACIONAL+E+GERA\%C3\%87\%C3\%83O+DE+VIAGENS:+AN\%C3\%81LISE+E XPLORAT\%

Kohle, M. C., Romero, M. d., Penhalber, E. d., Cortes, T. M., \& Viviane, C. (2011). Biblioteca virtual de desarrollo sostenible y salud ambiental. Retrieved April 2011, 12, from Biblioteca virtual de desarrollo sostenible y salud ambiental web site: http://www.bvsde.paho.org/bvsaidis/impactos/vi050.pdf

Kuhlman, T., \& Farrington, J. (2010, November 01). What is sustainability? Sustainability Journal, pp. 3436-3448.

Lane, R., \& Murray, A. (2011). Material Geographies of Household Sustainability. London: Ashgate Press.

Lanni, A. (2009). Social Norms in the Courts of Ancient Athens. Oxford Journal, 691-736.

Lawrence, F. (2004). Economic Determinants of Urban Form. American Journal of Preventive Medicine, 146-153.

Lebovies, H. (1986, Oct). The Uses of America in Locke's Second Treatise of Government. Journal of the History and Ideas, 47, 567-581.

LeGates, R. T., \& Stout, F. (2011). Towards Sustainable Development. In R. T. LeGates, \& F. Stout, The City Reader (377-381). London: Taylor \& Francis.

Lehmann, S. (2010). The Principles of Green Urbanism - Transofrming the City for Sustainability. London, England: Earthscan.

Lenzen, M., Wood, R., \& Foran, B. (2008). Direct Versus Embodied Energy - The Need for Urban Lifestyle Transformation. In P. Droege, Urban Energy Transition (91-120). Oxford: Elsevier. 
Lévy, J. P. (1967). The Economic life of the Ancient World. Chicago: The University of Chicago Press. Lewyn, M. (2001). Campaign of Sabotage:Big Government's war Against Public Transportation. Columbia Journal of Environmental Law, 261-287.

Linstroth, T. (2009). Green From Inside Out. In M. Melaver, \& P. Mueller, The Green Building Bottom Line (77-108). Chigaco: McGraw-Hill.

Louis, P. (1965). Ancient Rome at work. London: Routledge.

Manfredini, A. (2007). Centro da Metropole Pesquisas. Retrieved March 02, 2010, from Centro da Metropole Website:

http://www.centrodametropole.org.br/pdf/2007/manfredinil_corrosao_social.pdf

Martenson, C. (2011). The Crash Course. Hoboken, New Jersey, USA: John Wiley \& Sons.

Martin, A. (1945). La Ciudade Antigua. Madrid: Perlas Graphicas.

Martíns, A. (2012, April 13). crw flag - Incas. Retrieved August 14, 2012, from CRW website: http://www.crwflags.com/fotw/flags/xi.html

Marx, K., \& Engels, F. (1887). Capital: A Critique of Political Economy. Progress Publishers. Moscow

Marx, K., \& Engels, F. (1958). The Manifesto Comunista (Vol. 1). Moscow: Publishing House.

Marx, K., \& Engels, F. (1969). Manifesto of the Communist Party (Vol. 1). Moscow: Progress

Publishers.

Mazzarino, S. (1966). The End of the Ancient World. London: Faber and Faber.

McEwan, G. F. (2006). The Incas, New Perspective. Santa Barbara: ABC-Clio.

McFarland, R., Guerti, J., \& Pelizza, S. (1996, October). North American Tunneling '96: what is sustainability? Tunnelling and Underground Space Technology, pp. 373-376.

Mcmanus, P., \& Haughton, G. (2006). Planning with Ecological Footprint: A Sympathetic Critique of Theory and Practice. Environment and Urbanization, 18, 113-126.

McNamra, J. (1981). Lo Urbanismo Oriental. Montevideo: Orientes.

Meadows, D., Randers, J., \& Meadows, D. (2004). Limits to Growth - 30 years update. White River, VT, USA: Chelsea Green Publishing Company.

MF Rural. (2012, July 03). MF Rural. Retrieved August 14, 2012, from MF Rural Website Agronegocio: http://www.mfrural.com.br/agronegocio.asp

Ministry of Transport - New Zealand. (2010). The Government Policy Statement on Land Transport Funding. Wellington, Wellington, New Zealand: newzealand.govt.nz.

MIT - Massachusetts Institute of Technology. (2012, May 31). Solar. Retrieved August 10, 2012, from solar decathlon main site: http://mit.edu/solardecathlon/solar1.html 
Mithraratne, N., \& Vale, B. (2003). Life Cycle Analysis Model for New Zealand Houses. Building and Environment, 483-492.

Montillo, P. (1956). Historia Antigua. Buenos Aires: Buenos Aires Libre.

Moraes, J. (1996). China Urbana - Uma realidade para o século 21. Rio de Janeiro: Vivicitudes.

Morero, A. M., Santos, R., \& Fidalgo, E. (2007, June). Planejamento Ambiental de Áreas Verdes: Estudo de Caso em Campinas - SP. Revista Instituto Florestas, pp. 19-30.

Morley, N. (1996). Metropolis and Hinterland - The city of Rome and Italian economy 200 B.C. - A.D. 200. Cambridge: Cambridge Press.

Mumford, L. (1947). The Culture of Cities. London: Secker \& Warburg.

Munier, N. (2007). Handbook on Urban Sustainability. Sevilla: Springer.

Murphy, D., \& Hall, C. (2010). Year in Review - EROEl or Energy Return on (energy) Invested. Annals of the New York Academy of Sciences, 102-118.

NABERS Project Scope. (2001, December). Retrieved 2001, from NABERS web site: www.ea.gov.au/industry/waste/construction/scope

NABERS - Home Page. (2008). Retrieved February 20, 2010, from NABERS - Website: http://www.nabers.com.au/

Napoli, F. (2009, July 05). Environmental Certifications. (Personal Communication)

Nardo, D. (1994). The Decline and Fall of Ancient Greece. San Diego: GreenHaven.

Nardo, D. (2000). Ancient Greece. San Diego: Lucent Books.

Nash, E. (1944). Roman Towns. New York: J.J. Augustin Publisher.

Nelson, A. (2007). Steering Sustainability in a Urbanazing World. Hampshire, England: Ashgate Publishing Limited.

New Zealand Government. (2010). New Zealand: An Urban/Rural Profile. Retrieved March 20, 2011, from Statistics New Zealand:

http://www.stats.govt.nz/browse_for_stats/people_and_communities/geographic-areas/urbanrural-profile.aspx

Newman, P., \& Jenning, I. (2008). Cities as Sustainable Ecosystems. Washington, D.C., USA: Island Press.

Newmann, F. C. (1967). História do Mundo Antigo. Rio de Janeiro: Liberdade Livros Nacionais.

Newsham, G., Mancini, S., \& Birt, B. (2009, January 13). Do LEED-Certified buildings Save Energy? Yes, but... Energy and Buildings, 41, 897-905.

Noiseux, K., \& Hostetler, M. (2010). Do Homebuyers Want Green Features in Their Communities? Environment and Behavior, 42, 551-580. 
Novotny, V. (2007). Effluent Dominated Water Bodies, Their Reclamation and Reuse. In V. Novotny, \& P. Brown, Cities of Future Towards Integrated Sustainable Water and Landscape Managment. London, England: IWA Publishing.

Novotny, V., Ahern, J., \& Brown, P. (2010). Water Centric Sustainable Communities - Planning, Retrofiting, and Building the Next Urban Environment. Hoboken, New Jersey, USA: John Wiley \& Sons, Inc.

NY City Council. (2009, January 01). Official New York City info. Retrieved October 15, 2009, from Official New York City website: www.nyc.gov/info

Odum, E. P. (1989). Ecology and Our Endangered Life-Support Systems . Sunderland, MA: Sinauer Associates.

Orwell, G. (1989). The Road to Wigan Pier. London: Penguin.

Owens, S. (2003). Is there a meaningful definition of sustainability? Plant Genetic Resources Characterization and Utilization, 5-9.

Oyewole, P. (2001). Social Costs of Environmental Justice Associated with the Practice of Green Marketing. Journal of Business Ethics, 239-251.

Paris City Council. (2009, July 05). Official Paris Website. Retrieved October 21, 2009, from www.paris.fr

Pfebve, E. (2009). Africa and Sustainable Development. Karlstad: Karlstad Unviersity.

Pino, I. d. (2002). La Ciudad Inca de Quito. Quito: Eskeletra.

Pizzol, K. M. (2006, February). A Dinamica Urbana: Uma Leitura da Cidade e da Qualidade de Vida no Urbano1. Caminhos de Geografia - revista on line, pp. 1-7.

Platt, C. (1976). The English Medieval Town. London: Martin Secker \& Warburg.

Polonsky, M. (2005). Green Marketing. In R. Staib, Environmental Management and Decision Making for Business (pp. 124-135). New York: Plagrave Macmillan.

Portney, K. E. (2003). Taking Sustainable Cities Seriously. London: MIT Press.

Pounds, N. (2005). The Medieval City. Westport: Greenwoods Press.

Ragot, G. (2012, August 12). Tony Garnier. Retrieved August 12, 2012, from Grove Art Online: http://www.oxfordartonline.com/subscriber/article/grove/art/T03089

Redwood, M. (2009). Introduction. In M. Redwood, Agriculture in Urban Planning - Generating Livehoods and Food Security (pp. 1-20). London: International Development Research Center.

Rees, W. (1994). Ecological Footprint and Appropraited Carrying Capacity: What Urban Economics Leaves out. Environment and Urbanization, 121-130. 
Rees, W. (1995). Achieving Sustainability: Reform or Transformation? Journal of Planning Literature, 343-361.

Robbins, P. (2007). Garden Cities. Encyclopedia of Environment and Society, SAGE Publications, Inc, (727-728).

Roebuck, J. (1974). The Shaping of Urban Society. New York: Charles Seribner's Son.

Rostovtzeff, M. (1976). The Social \& Economic History of the Roman Empire. Oxford: Oxford University Press.

Rostovtzeff, M. (1986). The Social and Economic History of the Hellenistic World. New York: Oxford University Press.

Rubnicu, A. (2012). Advancement of Knowledge and Use of Solar Energy. Universitatea Tehnică "Gheorghe Asachi" din laşi, 189-196.

Rutherford, B. (2012, February 23). A Definition For Sustainability Is Elusive. Retrieved August 02, 2012, from http://search.proquest.com.helicon.vuw.ac.nz/docview/954944317?accountid=14782

Sandys, S. J. (1910). A Companion to Latin Studies. Cambridge: University Press.

São Paulo City Council. (2009). Fundação Seade - Projeção Populacional 2009. Retrieved May 07, 2011, from infocidade: Fundação Seade - Projeção Populacional 2009

Scheidel, W. (2007, July). Roman population size: the logic of the debate. Princeton/Stanford Working Papers in Classics. Stanford University.

SEMPLA. (2012). Zoneamento da cidade de Sao Paulo. Retrieved August 15, 2012, from Sempla: http://www.prodam.sp.gov.br/sempla/zone.htm

Seo, S. (2002). International review of environmental assessment tools and databases. CRC Contruction Inovation, (1-14).

Sheehan, B. (2009, September). What is Sustainability? Control Engineering, (12).

Simão, E. (1986). Repensando a produção e distribuição de alimentos no Brasil. Perspectivas, 21-35.

Simmons, C., \& Lewan, L. (2001). The use of Ecological Footprint and Biocapacity Analyses as Sustainability Indicators for Subnational Geographical Areas: A Recommended Way Forward. Ambiente: ECIP.

Smith, A. (1776). An Inquiry into the Nature and Causes of the Wealth of Nations (Vol. IV). Dublin: Whitestone.

Smith, P. F. (2010). Building For a Changing Climate - The Challenge For Construction, Planning and Energy. London: Earthscan.

Solar Region Freiburg. (2003). Solar City. Retrieved June 23, 2011, from Solar City: http://www.solarregion.freiburg.de/solarregion/freiburg_solar_city.php 
SparkNotes Editors. (2011, November 16). SparkNote on Locke's Second Treatise on Civil

Government. (S. Editors, Producer) Retrieved November 20, 2011, from SparkNotes.com:

http://www.sparknotes.com/philosophy/locke/

Stansberry, M. (2011). Eugene and Other Cities Create Energy Efficient Buildings. In R. Kemp , \& C. J. Stephani, Cities Going Green (pp. 98-100). Jefferson: McFarland \& Company.

Stoglehner, G. (2003). Ecological footprint - a tool for assessing sustainable energy supplies. Journal of Cleaner Production, 267-277.

Tainter, J. (1988). The Collapse of Complex Societies. Cambridge: Cambridge University Press.

Tavares, B., \& Brancatelli, R. (2011, February 27). Alphaville: da vida calma ao pesadelo de trânsito e filas. O Estado de Sao Paulo.

Tokyo Metropolitan. (2009, 28 January). Population of Tokyo. Retrieved September 6, 2009, from Tokyo Metropolitan Government website:

http://www.metro.tokyo.jp/ENGLISH/PROFILE/overview03.htm

Tomé, F. (2007). Tudo que você precisa saber sobre sêlo verde e ecoetiqueta. São Paulo: Conselho Nacional de Defesa Ambiental.

Trewartha, G. T. (1952). Chinese Cities: Origins and Functions. Annals of the Association of American Geographers, 69-93.

United Nations. (2006). A world of cities. Retrieved June 20, 2011, from United Nation - Habitat: http://www.un.org/ga/Istanbul+5/10-11.pdf

United Nations. (2008). An Overview of Urbanization, Internal Migration, Population Distribution and Development in the World. New York: United Nations.

United Nations. (2011, February). Population Division - Home Page. Retrieved March 12, 2011, from Department of Economic and Social Affairs: http://www.un.org/esa/population/unpop.htm

United Nations. (2012). Global Isses. Retrieved August 08, 2012, from UN website:

http://www.un.org/en/globalissues/environment/

United Nations. (2012). World Urbanization Prospects - The 2011 Revision. New York: Department of Economic and Social Affairs.

United States Environmental Protection Agency. (2012, July 05). Our Mission. Retrieved August 10, 2012, from EPA Website: http://www.epa.gov/aboutepa/whatwedo.html

U.S. Green Building Council, Inc. (2012, April). LEED 2009 for Neighborhood Developmets.

Washington, USA: U.S. Green Building Council, Inc.

USGBC. (2011). USGBC Commercial Real Estate. Retrieved August 2012, 04, from USGBC - LEED

website: http://www.usgbc.org/DisplayPage.aspx?CMSPagelD=1935 
Vale, B., \& Vale, R. (2009). Time to Eat the Dog? The Real Guide to Sustainable Living. London: Thames \& Hudson.

Vale, B., \& Vale, R. (1975). The Autonomous House: Design and Planning for Self-Sufficiency. Thames and Hudson.

Vale, R. (2010, March 8). NABERS. (Personal Communication)

Vasconcelos, Y. (2008, September). Quais são os principais selos ecológicos no mercado? Retrieved February 12, 2010, from Planeta Sustentável:

http://planetasustentavel.abril.com.br/noticia/desenvolvimento/conteudo_298573.shtml

Veja São Paulo. (2009, february 11). Veja São Paulo - Revista - Violência em Paraisópolis. Retrieved May 08, 2011, from Veja São Paulo: http://vejasp.abril.com.br/revista/edicao-2099/violencia-emparaisopolis-segunda-maior-favela-da-cidade

Vilela, N., \& Macedo, M. (2000, July). The Scientific Electronic Library Online. Retrieved August 10, 2011, from SciELO Brazil: http://www.scielo.br/pdf/hb/v18n2/v18n2a02.pdf

Viljoen, A., Katrin, B., \& Howe, J. (2005). More Food with Less Space: Why Bother? In A. Viljoen, B. Katrin, \& J. Howe, CPLUs Continuous Productive Urban Landscapes (pp. 19-31). Oxford: Elsevier.

Vries, J. (1984). European Urbanization 1500-1800. London: Methuen.

Wackernagel, M., \& Monfreda, C. (2004). Ecological Footprints and Energy. Encyclopedia of Energy, 1-11.

Wackernagel, M., \& Rees, W. (1996). Our Ecological Footprint. Gabriola Island, BC: New Society Publisher.

Warren, C. (2009). Who needs a Green Star? Pacific Rim Real Estate Society Conference, 1-9.

Warren, R. (1998). The Urban Oasis. New York, NY, USA: McGraw-Hill.

Weber, M. (1966). The City. London: Collier-Macmillan LTD.

Weber, M. (1976). The Agrarian Sociology of Ancient Civilisations. Bristol: NLB.

William , W., \& La Rovere, E. L. (2010, November). Light vehicle energy efficiency programs and their impact on Brazilian $\mathrm{CO}_{2}$ emissions. Energy Policy, 6453-6462.

Willson, M. (2008 November). McGraw Hill Construction. Retrieved 2010 20-January from McGraw Hill Construction features: -

http://intermountain.construction.com/features/archive/0811_feature2d.asp

Wirth, L. (2007). Urbanism as a Way of Life. In R. T. LeGates, \& F. Stout, The City Reader (4th ed.). Oxon, England: Routledge.

Wiser. (2008, February 18). Wiser.org. Retrieved July 05, 2012, from Wiser.org - The Social Network for Sustainability: http://www.wiser.org/article/5533ddc0e2cadba2dae55900780a0b0/section/main 
Wohlmeyer, H., \& Quendler, T. (2002). The WTO, Agriculture and Sustainable Development. Vienna: Greenleaf Publishing.

Wolff, J. (2011, June 2011). The Stanford Encyclopedia of Philosophy (Summer 2011 Edition). (E. N. Zalta, Producer) Retrieved November 24, 2011, from Stanford Encyclopedia of Philosophy: <http://plato.stanford.edu/archives/sum2011/entries/marx/>.

World Commission on Environment and Development. (1987). Our Common Future. Oxford: Oxford University.

World Trade Organization. (2011). WTO search. Retrieved May 13, 2011, from WTO website: http://search.wto.org/search?q=\%22A+subsidy+is+a+financial+contribution+by+a+government\%22 \&site=English_website\&btnG=Search\&entqr=0\&output=xml_no_dtd\&sort=date\%3AD\%3AL\%3Ad1\& client=english_frontend\&numgm=5\&ud=1\&oe=ISO-8859-1\&ie=ISO-8859-1\&proxystylesheet=e Wright, R. (2005). Environmental Science. Upper Saddle River, New Jersey: Pearson Prentice Hall. Wringley, E. A. (1967). A Simple Model of London's importance in Changing English Society. Past and Present, 37, 44-70.

Xiaoyuan, J. (1999, January 15). Culture notes. China Daily, 9-9.

Zacks Investment. (2011, May 24). Zacks Investment Research. Retrieved July 22, 2011, from Zacks Investment website: http://www.dailymarkets.com/stock/2011/05/24/analyst-interviews-autoindustry-outlook-and-review-4/

Zheng, S., Wu, J., Kahn, M. E., \& Deng, Y. (2011). The Nascent Market for "Green" Real Estate in Beijing. National University of Singpore. Singapore: Institute of Real Estate Studies. 
Appendix 1:

LEED Certified Projects 


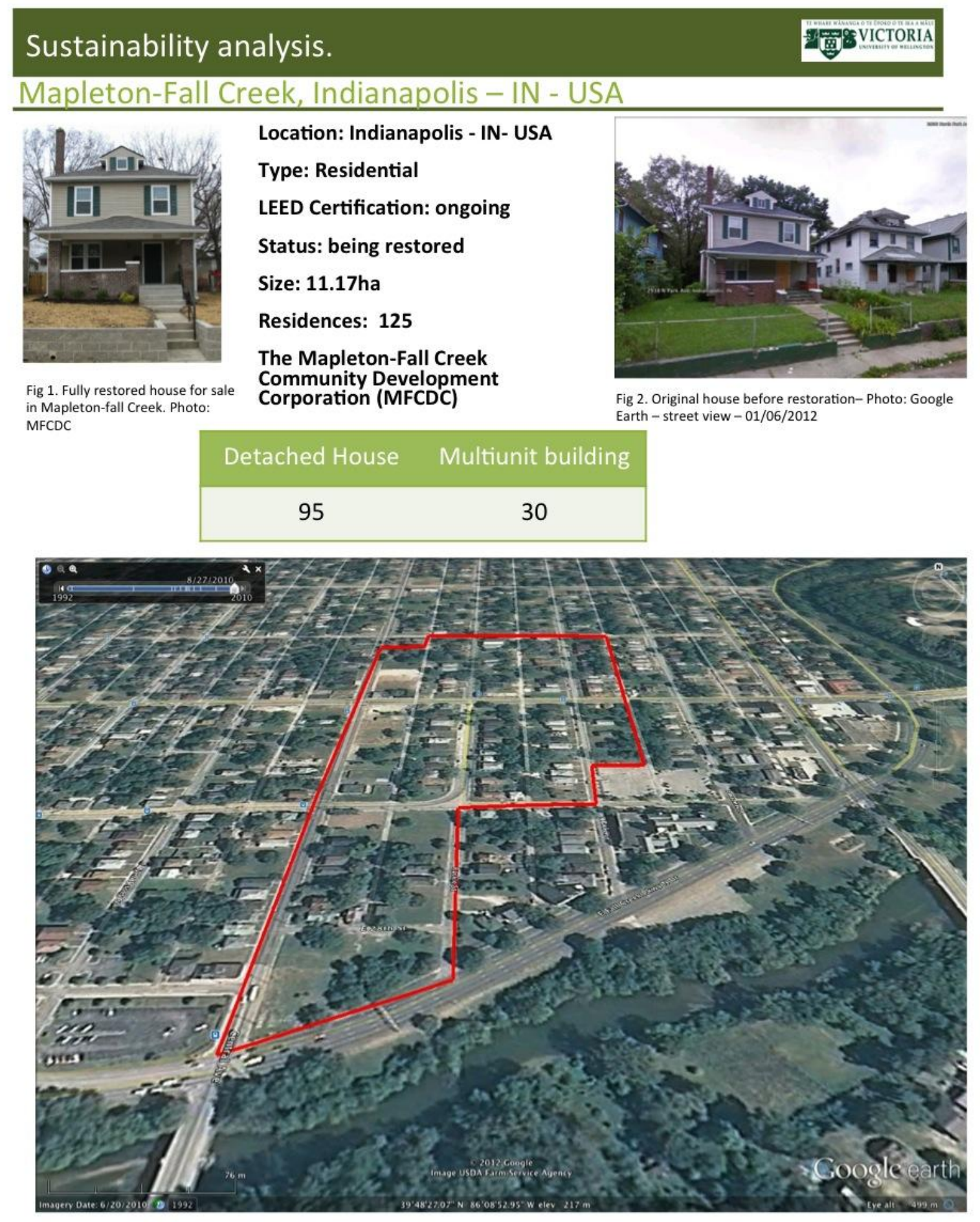

Fig 3. Mapleton-fall Creek aerial view - Google Earth 


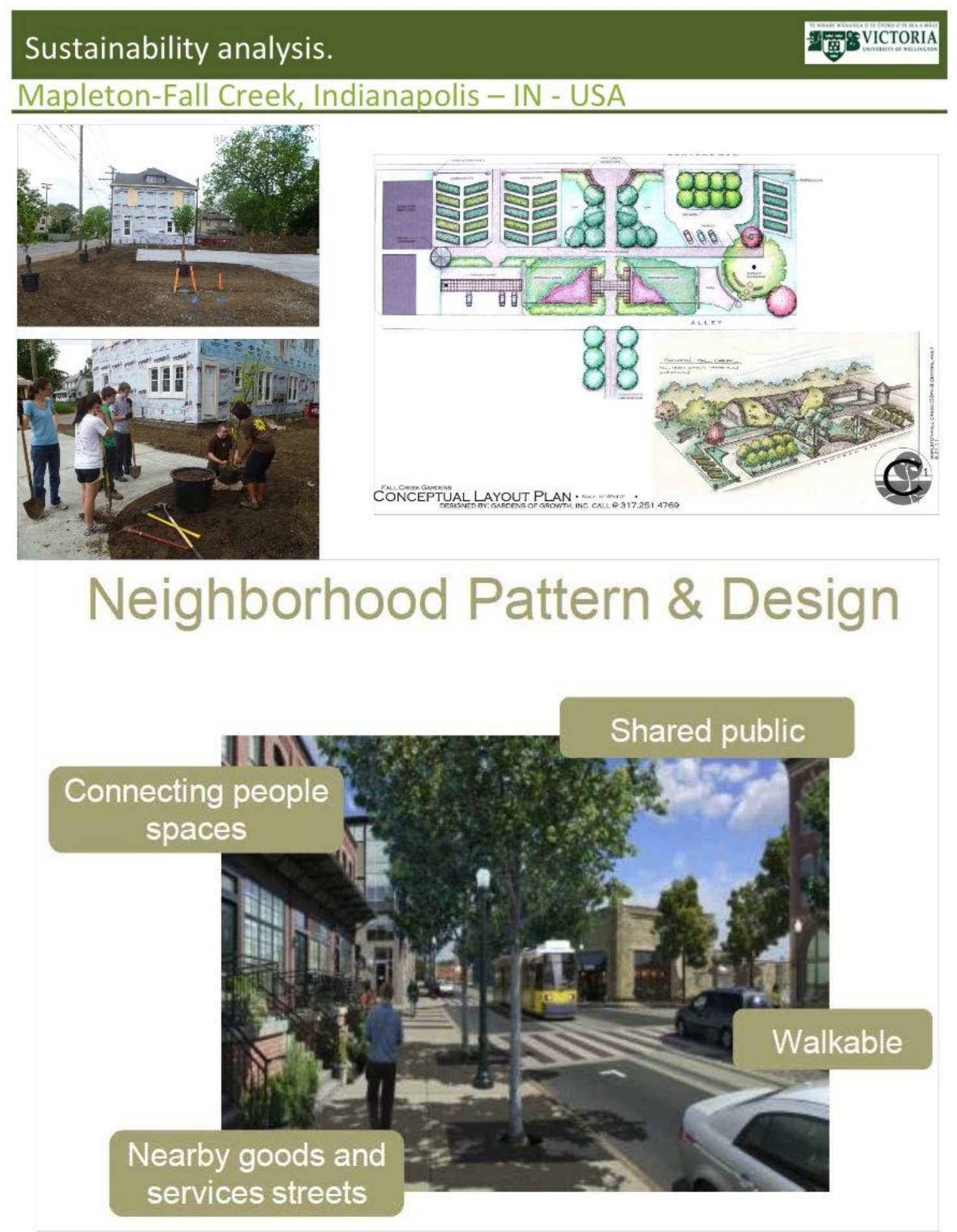

Fig 4 and 5 (left top) - Preparation of pocket park in Mapleton-Fall Creek photo: MFCDC.

Fig 6 (right top) - Pocket park design Fig 7 (Bottom) - General view of Mapleton-Fall Creek after the intervention - Image: MFCDC 


\section{Sustainability analysis.}

\section{Mapleton-Fall Creek, Indianapolis - IN - USA}

\section{LEED rating after interventions}

\begin{tabular}{|c|c|c|}
\hline Points possible & Points Accepted & SLL - Smart Location and Linkage \\
\hline \multicolumn{2}{|c|}{ Required } & $\begin{array}{l}\text { Smart Location } \\
\text { Proximity to Water and Wastewater Infrastructure } \\
\text { Imperiled Species and Ecological Communities } \\
\text { Wetland and Water Body Conservation } \\
\text { Farmland Conservation } \\
\text { Floodplain Avoidance }\end{array}$ \\
\hline 2 & 2 & Brownfield Redevelopment \\
\hline 1 & 0 & High Priority Brownfields Redevelopment \\
\hline 10 & 9 & Preferred Location \\
\hline 8 & 7 & Reduced Automobile Dependence \\
\hline 1 & 0 & Bicycle Network \\
\hline 3 & 0 & Housing and Jobs Proximity \\
\hline 1 & 1 & School Proximity \\
\hline 1 & 0 & Steep Slope Protection \\
\hline 1 & 1 & Site Design for Habitat or Wetlands Conservation \\
\hline 1 & 0 & Restoration of Habitat or Wetlands \\
\hline 1 & 0 & Conservation Management of Habitat or Wetlands \\
\hline 30 & 20 & \\
\hline \begin{tabular}{|l|} 
Points possible \\
\end{tabular} & Points Accepted & NPD - Neighborhood Pattern \& Design \\
\hline \multicolumn{2}{|c|}{ Required } & $\begin{array}{l}\text { Open Community } \\
\text { Compact Development }\end{array}$ \\
\hline 7 & 0 & Compact Development \\
\hline 4 & 0 & Diversity of Uses \\
\hline 3 & 3 & Diversity of Housing Types \\
\hline 2 & 1 & Affordable Rental Housing \\
\hline 2 & 2 & Affordable For-Sale Housing \\
\hline 2 & 1 & Reduced Parking Footprint \\
\hline 8 & 7 & Walkable Streets \\
\hline 2 & 2 & Street Network \\
\hline $\begin{array}{l}1 \\
2\end{array}$ & 1 & $\begin{array}{l}\text { Transit Facilities } \\
\text { Transportation Demand Management }\end{array}$ \\
\hline $\begin{array}{l}2 \\
1\end{array}$ & 0 & $\begin{array}{l}\text { Transportation Demand Management } \\
\text { Access to Surrounding Vicinity }\end{array}$ \\
\hline $\begin{array}{l}1 \\
1\end{array}$ & $\begin{array}{l}1 \\
0\end{array}$ & $\begin{array}{l}\text { Access to Surrounding Vicinity } \\
\text { Access to Public Spaces }\end{array}$ \\
\hline 1 & 1 & Access to Active Public Spaces \\
\hline 1 & 1 & Universal Accessibility \\
\hline 1 & 1 & Community Outreach and Involvement \\
\hline 1 & 0 & Local Food Production \\
\hline
\end{tabular}

\section{\begin{tabular}{|l|l|l|}
\hline Points possible Points Accepted & GC\&T - Green Construction \& Technology \\
\hline
\end{tabular}}

\begin{tabular}{|cll|}
\hline Points possible Points Accepted & \multicolumn{1}{c|}{ GC\&T - Green Construction \& Technology } \\
\hline \multicolumn{2}{|c|}{ Required } & Construction Activity Pollution Prevention \\
3 & 0 & LEED Certified Green Buildings \\
3 & 0 & Energy Efficiency in Buildings \\
3 & 1 & Reduced Water Use \\
2 & 1 & Building Reuse and Adaptive Reuse \\
1 & 0 & Reuse of Historic Buildings \\
1 & 0 & Minimize Site Disturbance through Site Design \\
1 & 1 & Minimize Site Disturbance during Construction \\
1 & 0 & Contaminant Reduction in Brownfields Remediation \\
5 & 0 & Stormwater Management \\
1 & 0 & Heat Island Reduction \\
1 & 1 & Solar Orientation \\
3 & 0 & On-Site Energy Generation \\
1 & 0 & On-Site Renewable Energy Sources \\
1 & 0 & District Heating \& Cooling \\
1 & 0 & Infrastructure Energy Efficiency \\
1 & 0 & Wastewater Management \\
1 & 0 & Recycled Content for Infrastructure \\
1 & 0 & Construction Waste Management \\
1 & 0 & Comprehensive Waste Management \\
1 & 0 & Light Pollution Reduction \\
\hline 31 & 4 & \\
\hline
\end{tabular}

Local Initiatives Support Corporation (LISC), along with Mapleton-Fall Creek Development Corporation (MFCDC), Raimi + Associates, the Natural Resources Defense Council (NRDC), and the United States Green Building Council (USGBC) are developing a substantial change in the the Mapleton-Fall Creek neighborhood, in order to transform 27-acres into a certificated neighborhood using LEED-ND. Still under development, the region intends to reach at least 53 points on the LEED rating. The rating shows the score reached during summer 2010.

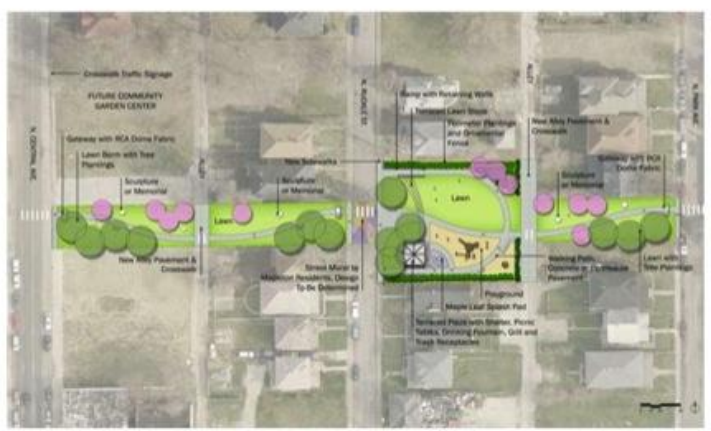

Fig 8. Design for a pocket park in Mapleton-Fall Creek.

\begin{tabular}{|cc|c|}
\hline Points possible & Points Accepted & \multicolumn{1}{c|}{ Innovation and Design Process } \\
\hline 1 & 1 & Exemplary Performance NPD \\
1 & 1 & Exemplary Performence Green infrastrucuture and Building, GII (now GCern) \\
1 & 1 & Exemplary Performance, GIB \\
1 & 0 & Innovation and Design \\
1 & 0 & Innovation and Design \\
1 & 1 & LEED accredited Professional \\
\hline 6 & 4 & \\
\end{tabular}

\begin{tabular}{|c|c|}
\hline Total Possible & Total Achieved \\
\hline 106 & \\
\hline
\end{tabular}

\begin{tabular}{l|l}
106 & $53^{*}$
\end{tabular}

\section{Potential Gold Certification}

* Four additional points for Regional Priority 


\section{Sustainability analysis.}

\section{Mapleton-Fall Creek, Indianapolis - IN - USA}

\section{Sustainability analysis.}

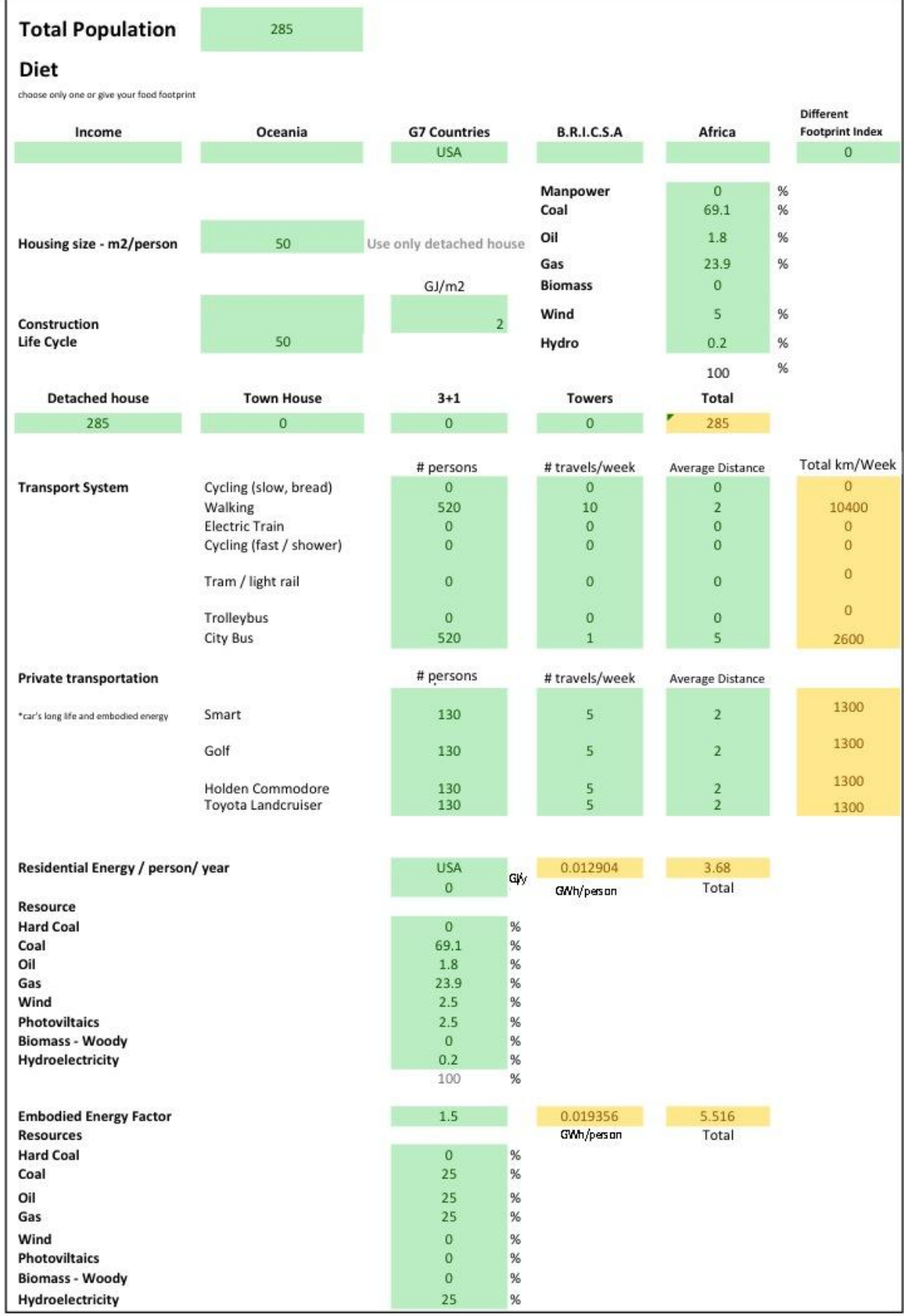




\section{Sustainability analysis.}

\section{Sustainability Results}
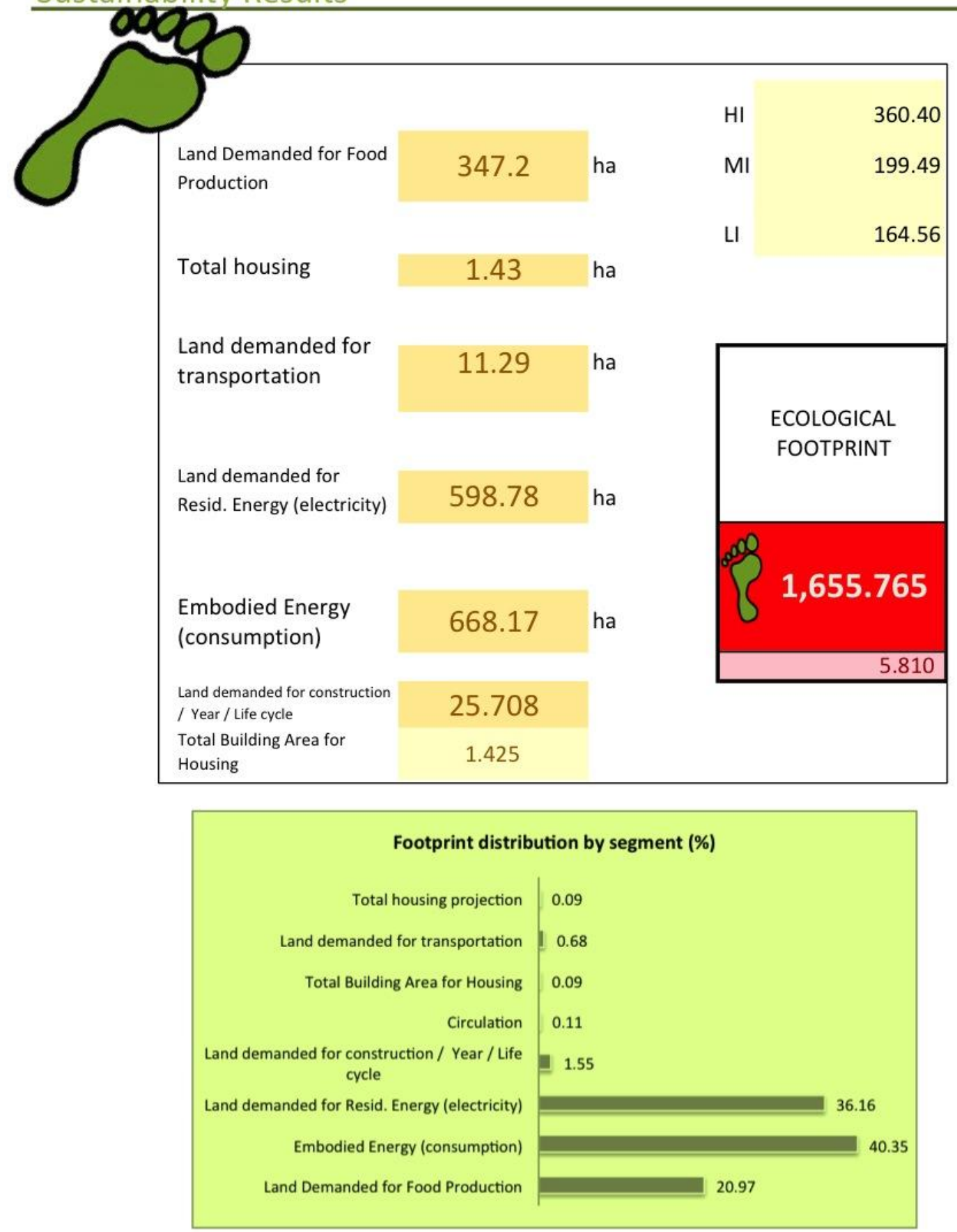
Sustainability analysis.

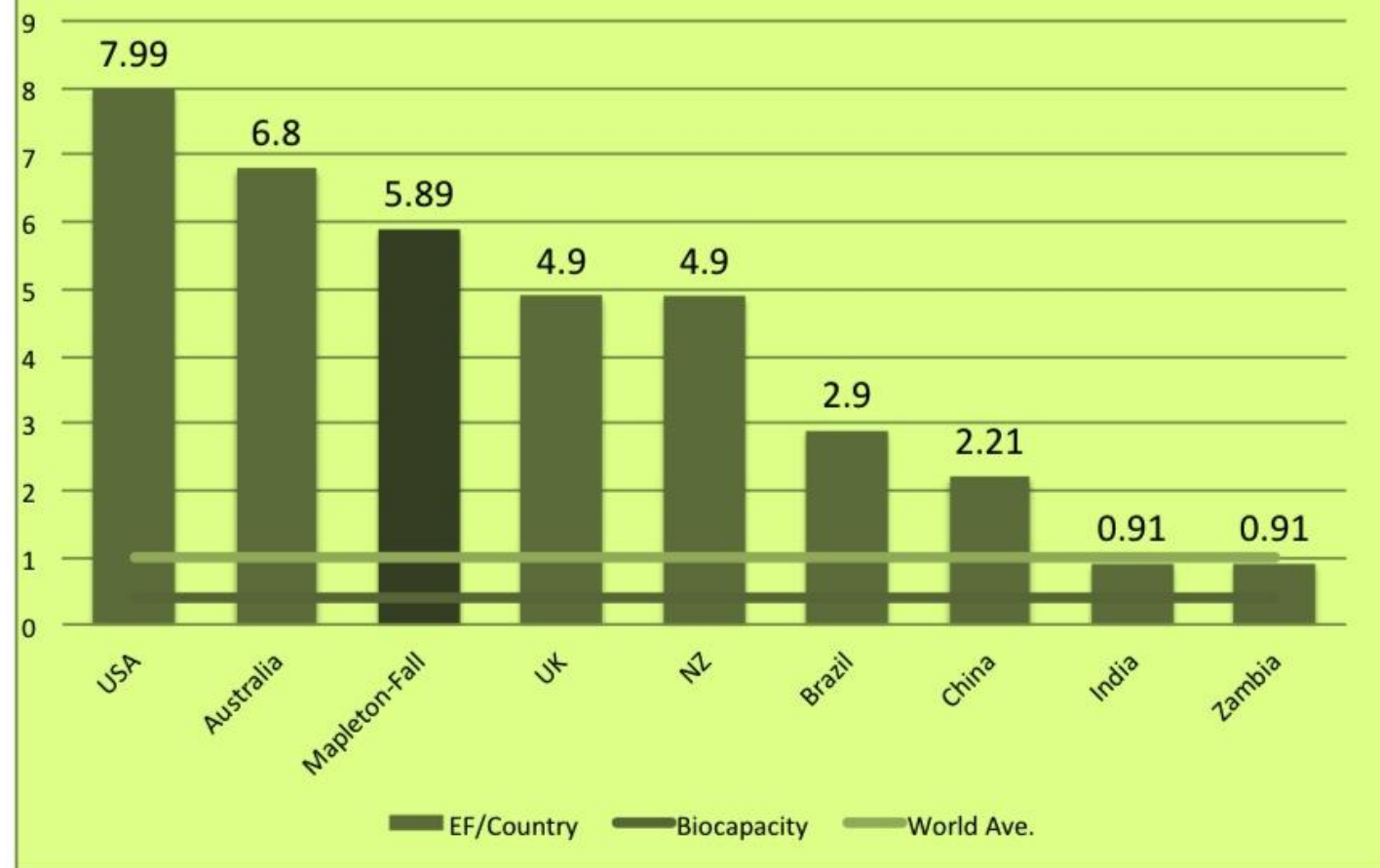

Comparison between the project and Ecological Footprint of some countries in gha - (Global Footprint Network, 2011)

Although based on many assumptions, the project has a higher Ecological Footprint than the world average and biocapacity. The two main components, food and energy, are based on American averages.

The assumptions made for energy consumption are environmentally optimistic. The consumption energy is only $50 \%$ higher than the domestic energy. 


\section{SALT district, Syracuse NY - USA}

Location: Syracuse, NY - USA

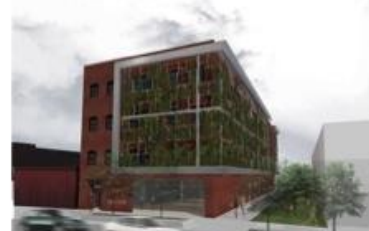

Fig 9. Lincoln Supply Building, after adaptive reuse - Photo: Raimi Associates
Type: Residential / mix

LEED Certification: 2008

Status: Largely Complete

Size: 63.1 ha

Residences: 961

Design: Raimi + Associates

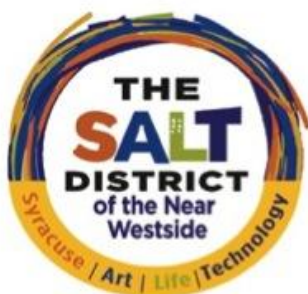

Art | Lirelre

\begin{tabular}{|ccccccccc|}
\hline $\begin{array}{c}\text { Detached } \\
\text { Small }\end{array}$ & $\begin{array}{c}\text { Detached } \\
\text { Large }\end{array}$ & $\begin{array}{c}\text { Duplex } \\
\text { Large }\end{array}$ & $\begin{array}{c}\text { Duplex } \\
\text { Small }\end{array}$ & $\begin{array}{c}\text { Multifamily } \\
\text { Small }\end{array}$ & $\begin{array}{c}\text { Multifamily } \\
\text { Large }\end{array}$ & $\begin{array}{c}\text { Multifamily } \\
\text { Towers }\end{array}$ & $\begin{array}{c}\text { Live Work/ } \\
\text { Small }\end{array}$ & $\begin{array}{c}\text { Live Work/ } \\
\text { Large }\end{array}$ \\
\hline 91 & 72 & 54 & 138 & 23 & 333 & 227 & 6 & 17 \\
\hline
\end{tabular}
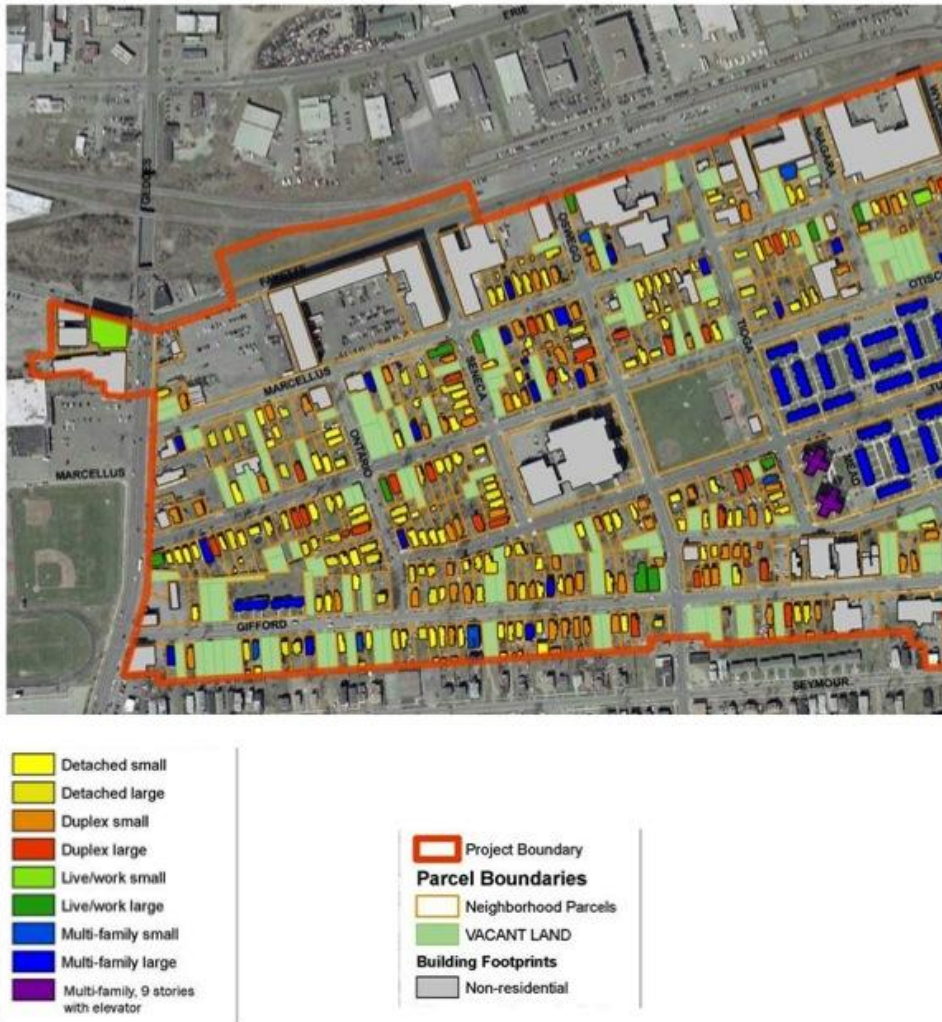

\section{帮}

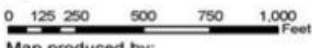

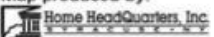

Fig 10. Diversity of Housing Types - Image: Raimi + Associates. 
Sustainability analysis.

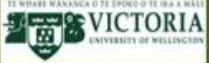

SALT district, Syracuse NY - USA
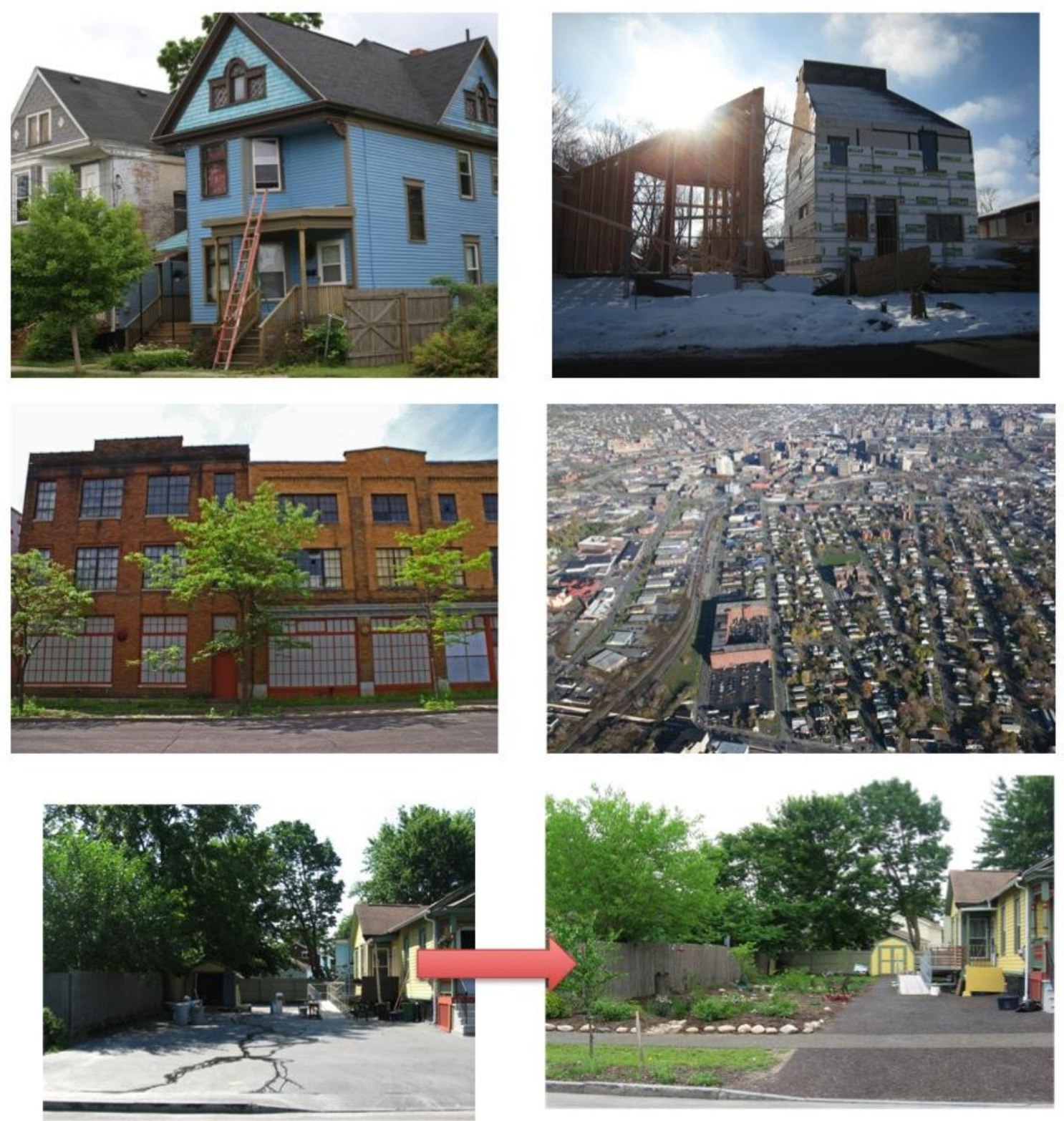

Fig 11 - 12. Different aspects of Syracuse District: Photos: Raimi + Associates

Fig. 13 and 14 - Before and after - improvement in impervious surfaces: Photos Raimi + Associates 


\section{SALT district, Syracuse NY - USA}

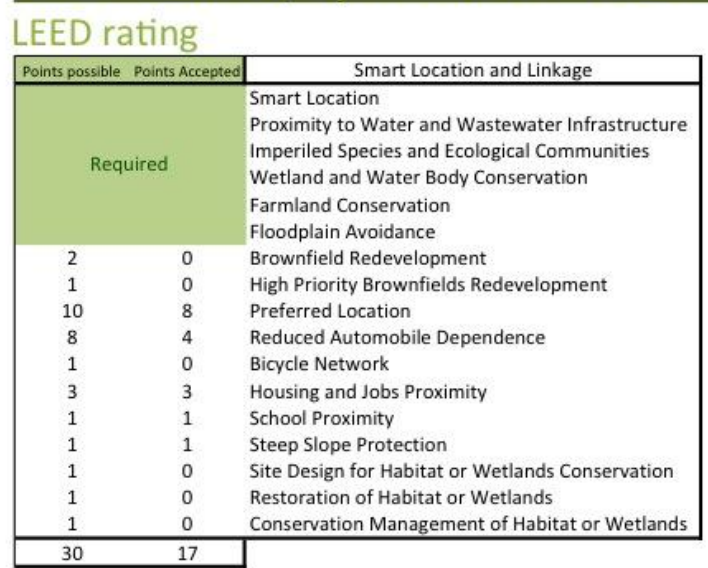

\begin{tabular}{|cll|}
\hline Points possible Points Accepted & \multicolumn{1}{c|}{ Green Construction \& Technology } \\
\hline \multicolumn{2}{|c|}{ Required } & Construction Activity Pollution Prevention \\
\hline 3 & 1 & LEED Certified Green Buildings \\
3 & 3 & Energy Efficiency in Buildings \\
3 & 2 & Reduced Water Use \\
2 & 2 & Building Reuse and Adaptive Reuse \\
1 & 0 & Reuse of Historic Buildings \\
1 & 1 & Minimize Site Disturbance through Site Design \\
1 & 1 & Minimize Site Disturbance during Construction \\
1 & 0 & Contaminant Reduction in Brownfields Remediation \\
5 & 5 & Stormwater Management \\
1 & 1 & Heat Island Reduction \\
1 & 1 & Solar Orientation \\
3 & 0 & On-Site Energy Generation \\
1 & 0 & On-Site Renewable Energy Sources \\
1 & 0 & District Heating \& Cooling \\
1 & 0 & Infrastructure Energy Efficiency \\
1 & 0 & Wastewater Management \\
1 & 1 & Recycled Content for Infrastructure \\
1 & 1 & Construction Waste Management \\
1 & 1 & Comprehensive Waste Management \\
1 & 0 & Light Pollution Reduction \\
\hline 31 & 20 & \\
\hline
\end{tabular}

\begin{tabular}{|ccl|}
\hline Points possible Points Accepted & \multicolumn{1}{c|}{ NPD - Neighborhood Pattern \& Design } \\
\hline \multicolumn{2}{|c|}{ Required } & $\begin{array}{l}\text { Open Community } \\
\text { Compact Development }\end{array}$ \\
\hline 7 & 1 & Compact Development \\
4 & 4 & Diversity of Uses \\
3 & 3 & Diversity of Housing Types \\
2 & 2 & Affordable Rental Housing \\
2 & 2 & Affordable For-Sale Housing \\
2 & 0 & Reduced Parking Footprint \\
8 & 0 & Walkable Streets \\
2 & 2 & Street Network \\
1 & 1 & Transit Facilities \\
2 & 0 & Transportation Demand Management \\
1 & 1 & Access to Surrounding Vicinity \\
1 & 1 & Access to Public Spaces \\
1 & 1 & Access to Active Public Spaces \\
1 & 0 & Universal Accessibility \\
1 & 1 & Community Outreach and Involvement \\
1 & 1 & Local Food Production \\
\hline 39 & 20 & \\
\hline
\end{tabular}

SALT stands for Syracuse Arts, Life and Technology According to the report, prepared by The Syracuse Centre of Excellence, in association with Home Headquarters and the Near Westside Initiative, LEED certification for the region is: "to promote environmental sustainability, provide economic opportunity, promote appropriate redevelopment and retrofits, and create a cutting edge arts, technology and green jobs district. An ongoing neighbourhood planning process for the SALT District will coordinate these efforts." The SALT district is located west of downtown Syracuse. It was a former industrial salt making area. The SALT district has suffered from a long period of disinvestment.

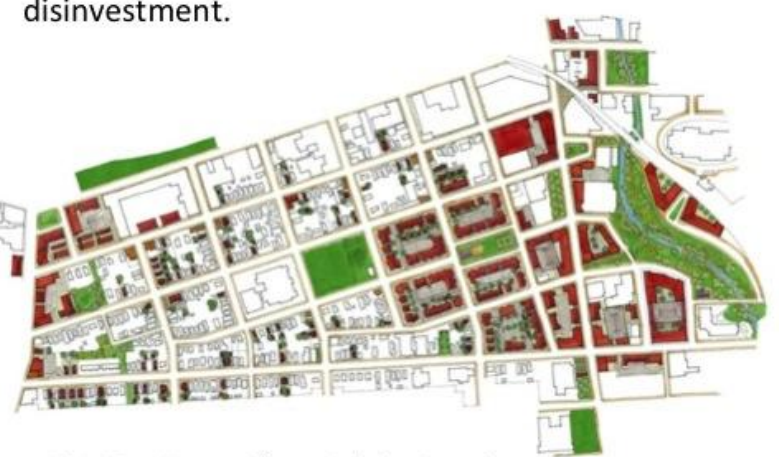

Fig 15 - Master Plan - Raimi + Associates

\begin{tabular}{|cc|c|}
\hline Points possible Points Accepted & \multicolumn{1}{c|}{ Green Construction \& Technology } \\
\hline 1 & 1 & Building Reuse and Adaptive Reuse Exemplary Performance \\
1 & 1 & Housing and Jobs Proximity Exemplary Performance \\
1 & 1 & Rental Affordability Exemplary Performance \\
1 & 1 & From the Ground Up International Design Competition \\
1 & 1 & LEED Accredited Professional \\
\hline 5 & 5 & \\
\cline { 1 - 2 } & &
\end{tabular}

\begin{tabular}{|l|l|}
\hline Total Possible & Total Achieved \\
\hline
\end{tabular}

\begin{tabular}{l|l}
106 & 62 \\
\hline
\end{tabular}

\section{Gold Certification}


Sustainability analysis.

\section{SALT district, Syracuse NY - USA}

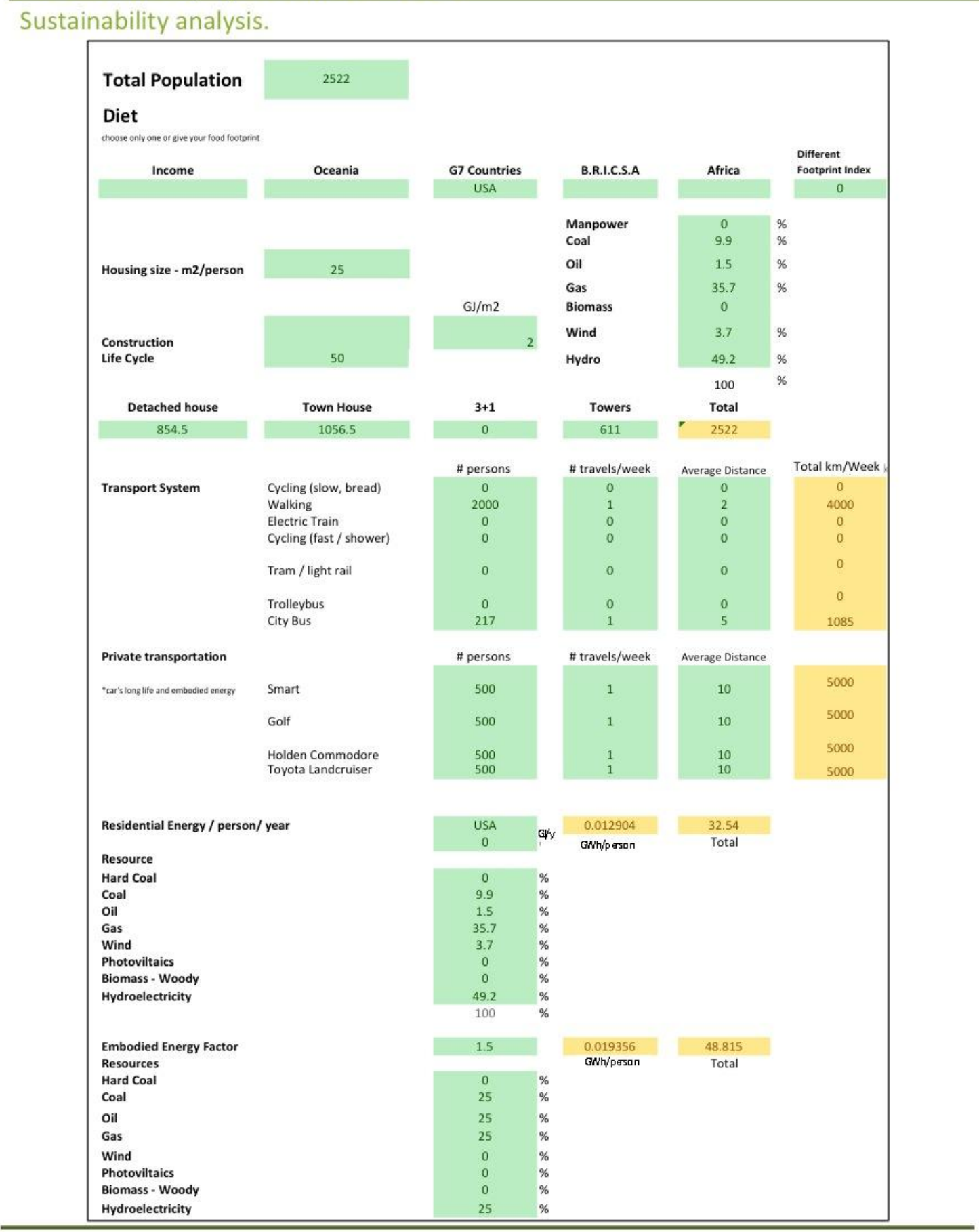




\section{Sustainability analysis.}

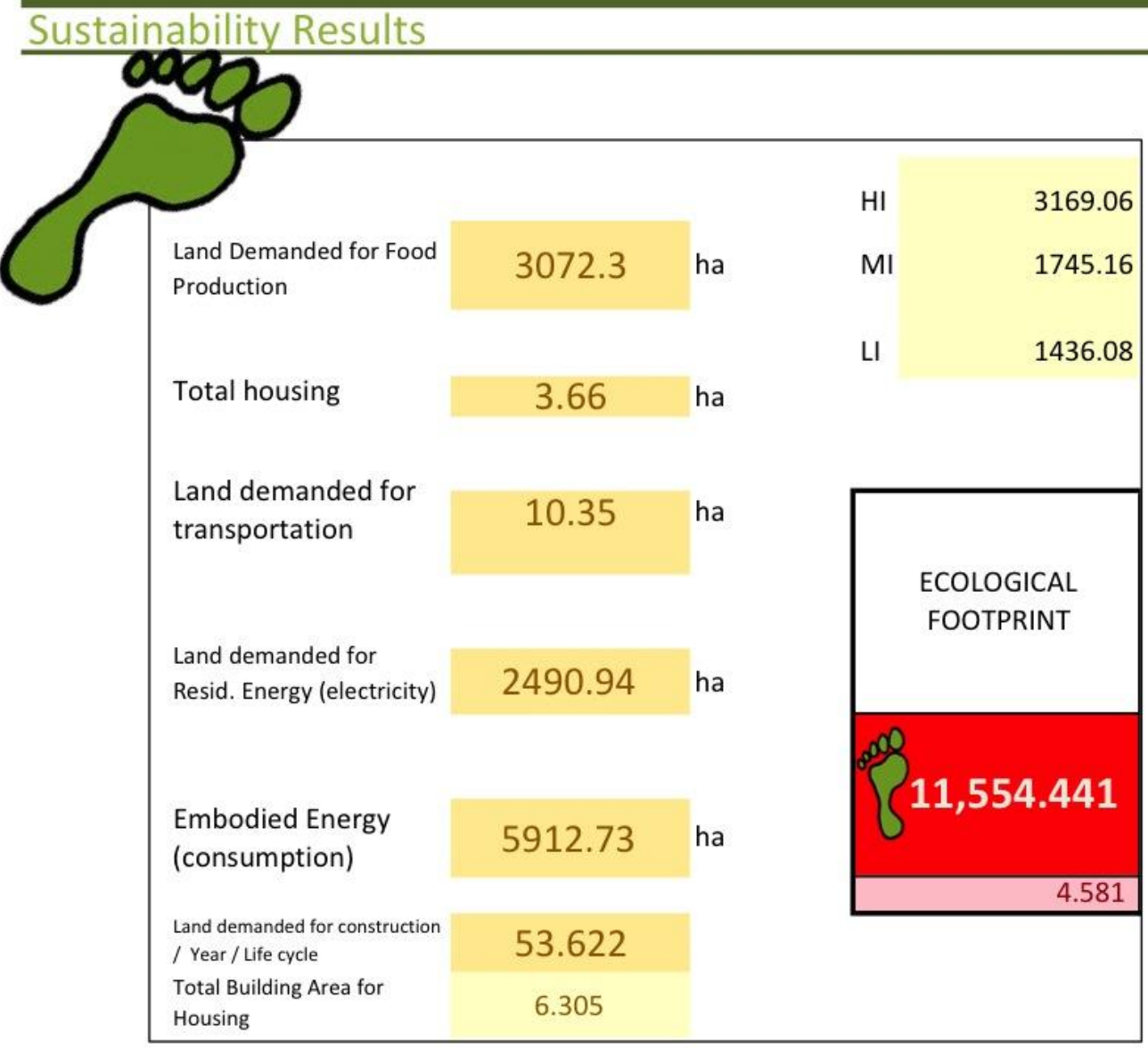

Footprint distribution by segment (\%)

Total housing projection

Land demanded for transportation

Total Building Area for Housing

Circulation

Land demanded for construction / Year / Life cycle

Land demanded for Resid. Energy (electricity)

Embodied Energy (consumption)

0.09

0.05

0.04

0.46

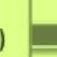


Sustainability analysis.

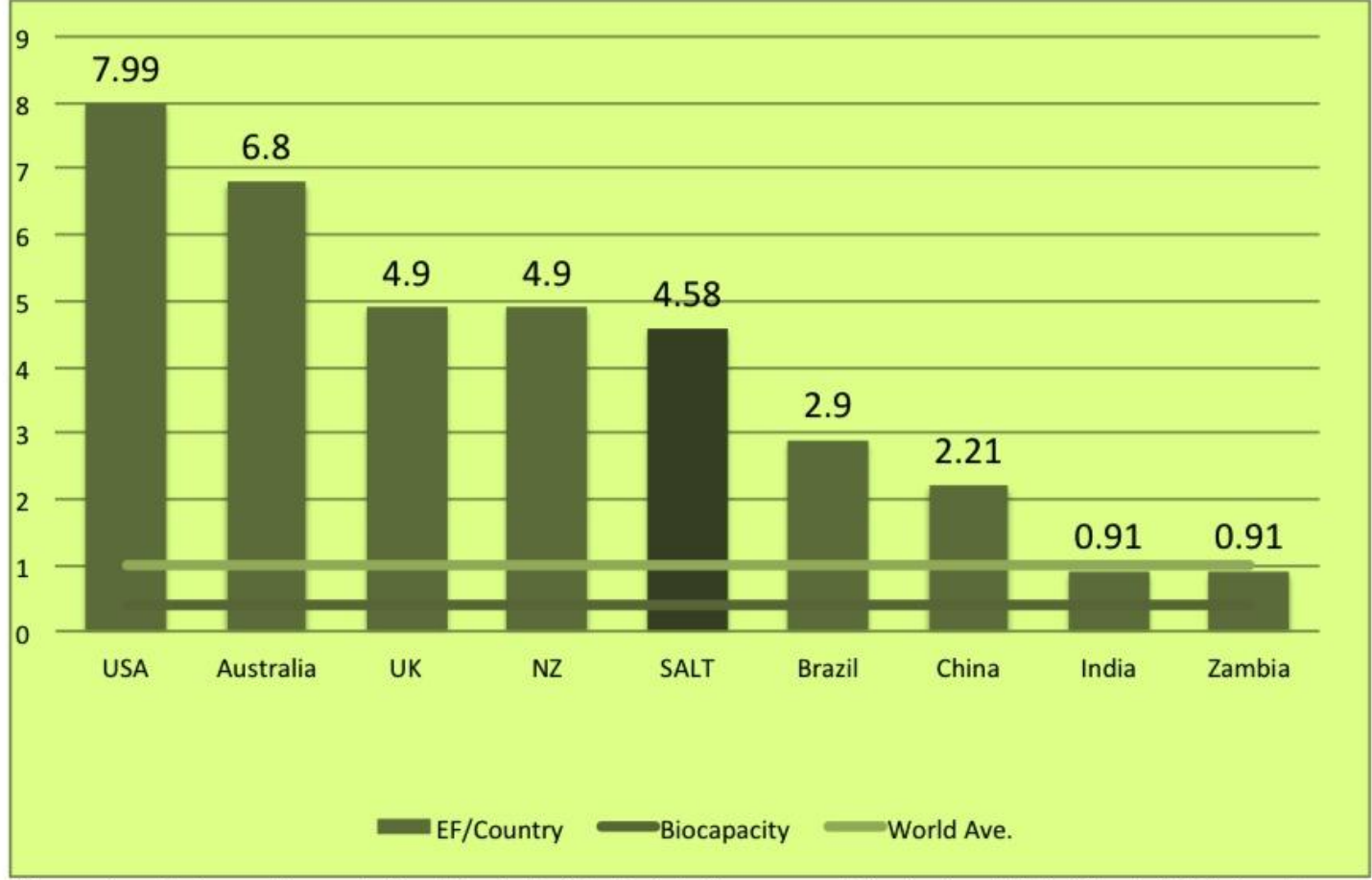

Comparison between the project and Ecological Footprint of some countries in gha - (Global Footprint Network, 2011)

Although based on many assumptions, the project has higher Ecological Footprint than the world average, and moreover, the world biocapacity. The two main components, food and energy, are based on American averages.

The assumptions made for energy consumption are environmentally optimistic. The consumption energy is only $50 \%$ higher than the domestic energy. 


\section{Sustainability analysis.}

\section{Tassafaronga Housing, Oakland CA - USA}

\section{Location: Oakland, California - USA}

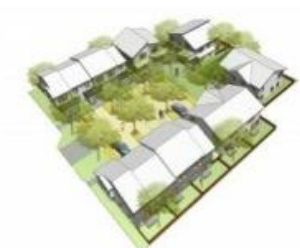

Fig 16. Habitat for Humanity from David Baker + Partners
Type: Residential

\section{LEED Certification: 2008}

Status: Largely Complete

Size: $\mathbf{3 . 0 3}$ ha

Residences: 157 + 22 Habitat for Humanity

Design: David Baker + Partners Architects

\section{j)}

\begin{tabular}{|cccccccc|}
\hline Studio & Townhome & 1 Bedroom & 2 Bedroom & 3 Bedroom & Total & $\begin{array}{c}\text { Habitat for } \\
\text { Humanity }\end{array}$ \\
\hline 7 & 77 & 16 & 34 & 23 & 157 & 22 \\
\hline
\end{tabular}

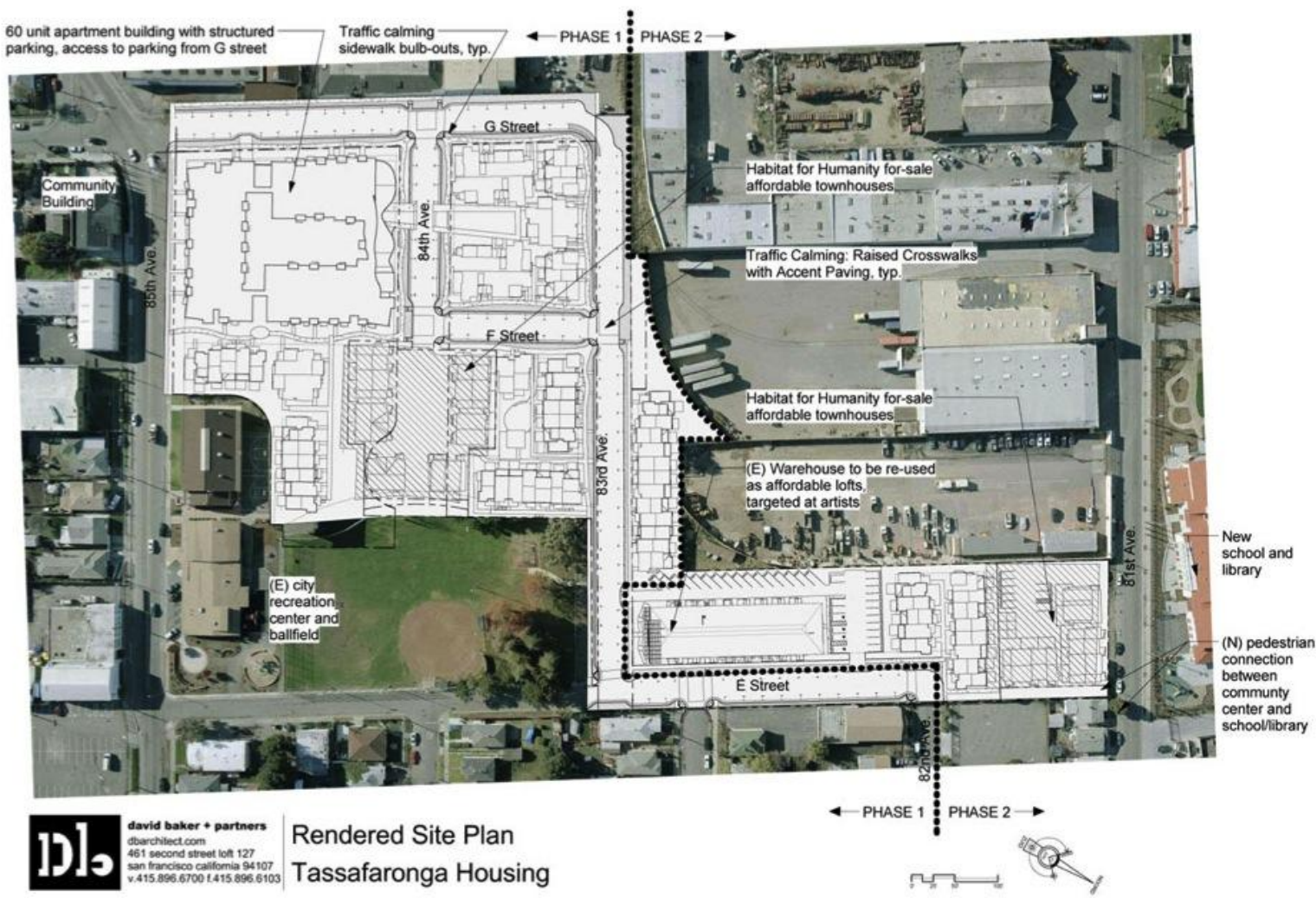

Fig 17. Master Plan reproduced with Permission from David Baker + Partners. 
Sustainability analysis.

Si

Tassafaronga Housing, Oakland CA - USA

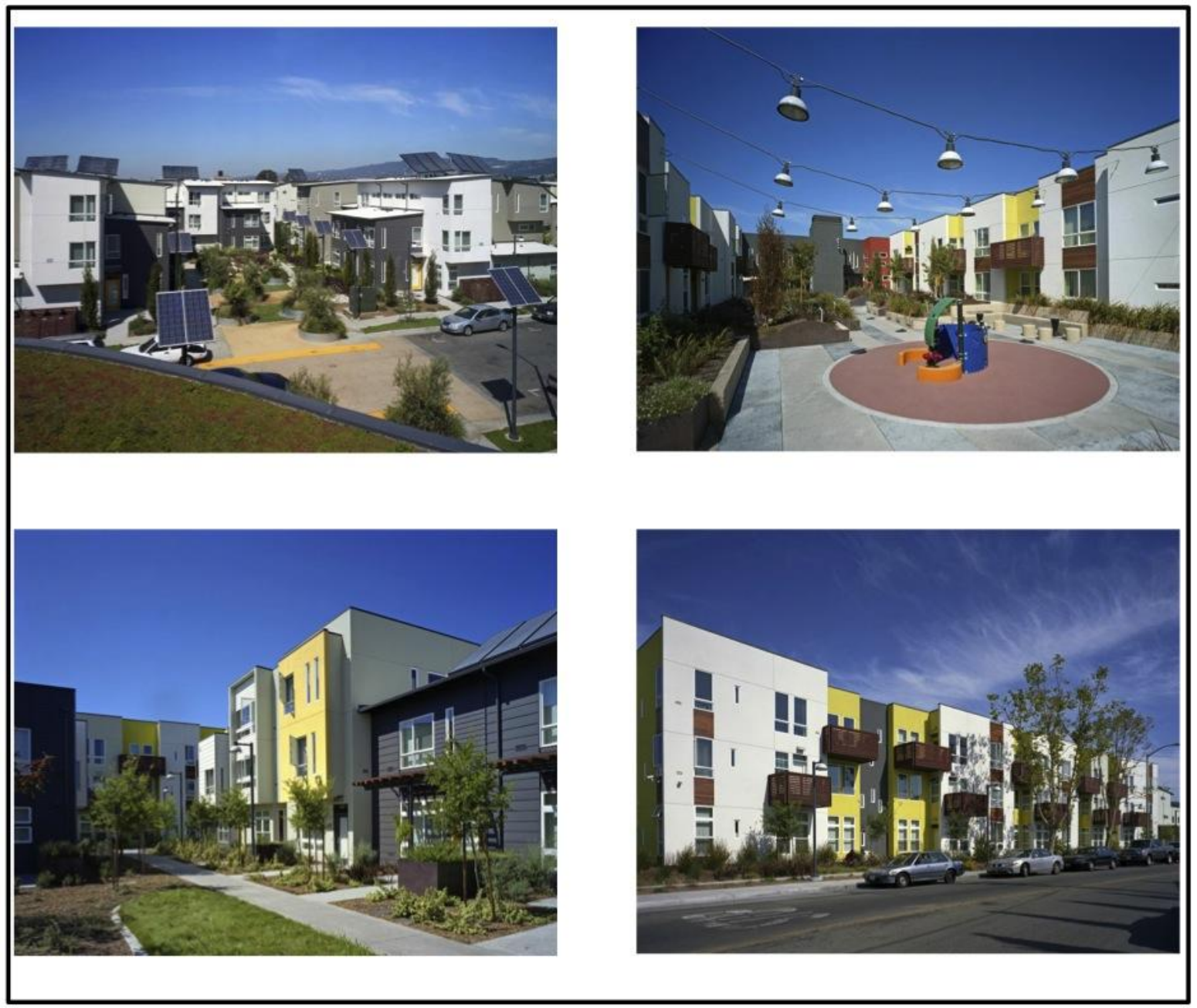

Fig 18 - 6. Different aspects of Tassarafornga Village: Photos: Brian Rose from David Baker + Partners. 


\section{Sustainability analysis.}

\section{Tassafaronga Housing, Oakland CA - USA}

\begin{tabular}{|c|c|c|}
\hline Points possible & Points Accepted & Smart Location and Linkage \\
\hline \multicolumn{2}{|c|}{ Required } & $\begin{array}{l}\text { Smart Location } \\
\text { Proximity to Water and Wastewater Infrastructure } \\
\text { Imperiled Species and Ecological Communities } \\
\text { Wetland and Water Body Conservation } \\
\text { Farmland Conservation } \\
\text { Floodplain Avoidance }\end{array}$ \\
\hline 2 & 2 & Brownfield Redevelopment \\
\hline 1 & 1 & High Priority Brownfields Redevelopment \\
\hline 10 & 8 & Preferred Location \\
\hline 8 & 5 & Reduced Automobile Dependence \\
\hline 1 & 0 & Bicycle Network \\
\hline 3 & 3 & Housing and Jobs Proximity \\
\hline 1 & 1 & School Proximity \\
\hline 1 & 1 & Steep Slope Protection \\
\hline 1 & 0 & Site Design for Habitat or Wetlands Conservation \\
\hline 1 & 0 & Restoration of Habitat or Wetlands \\
\hline 1 & 0 & Conservation Management of Habitat or Wetlands \\
\hline 30 & 21 & \\
\hline Points possible $P$ & Points Accepted & Green Construction \& Technology \\
\hline \multicolumn{2}{|c|}{ Required } & Construction Activity Pollution Prevention \\
\hline 3 & 3 & LEED Certified Green Buildings \\
\hline 3 & 3 & Energy Efficiency in Buildings \\
\hline 3 & 2 & Reduced Water Use \\
\hline 2 & 2 & Building Reuse and Adaptive Reuse \\
\hline 1 & 1 & Reuse of Historic Buildings \\
\hline 1 & 0 & Minimize Site Disturbance through Site Design \\
\hline 1 & 1 & Minimize Site Disturbance during Construction \\
\hline 1 & 1 & Contaminant Reduction in Brownfields Remediation \\
\hline 5 & 0 & Stormwater Management \\
\hline 1 & 2 & Heat Island Reduction \\
\hline 1 & 1 & Solar Orientation \\
\hline 3 & 0 & On-Site Energy Generation \\
\hline 1 & 0 & On-Site Renewable Energy Sources \\
\hline 1 & 0 & District Heating \& Cooling \\
\hline 1 & 0 & Infrastructure Energy Efficiency \\
\hline 1 & 0 & Wastewater Management \\
\hline 1 & 0 & Recycled Content for Infrastructure \\
\hline 1 & 0 & Construction Waste Management \\
\hline 1 & 1 & Comprehensive Waste Management \\
\hline 1 & 0 & Light Pollution Reduction \\
\hline 31 & 17 & \\
\hline
\end{tabular}

\begin{tabular}{|c|c|c|}
\hline Points possible & Points Accepted & NPD - Neighborhood Pattern \& Design \\
\hline \multirow{2}{*}{\multicolumn{2}{|c|}{ Required }} & Open Community \\
\hline & & Compact Development \\
\hline 7 & 3 & Compact Development \\
\hline 4 & 4 & Diversity of Uses \\
\hline 3 & 3 & Diversity of Housing Types \\
\hline 2 & 2 & Affordable Rental Housing \\
\hline 2 & 2 & Affordable For-Sale Housing \\
\hline 2 & 2 & Reduced Parking Footprint \\
\hline 8 & 0 & Walkable Streets \\
\hline 2 & 2 & Street Network \\
\hline 1 & 0 & Transit Facilities \\
\hline 2 & 0 & Transportation Demand Management \\
\hline 1 & 1 & Access to Surrounding Vicinity \\
\hline 1 & 1 & Access to Public Spaces \\
\hline 1 & 1 & Access to Active Public Spaces \\
\hline 1 & 0 & Universal Accessibility \\
\hline 1 & 1 & Community Outreach and Involvement \\
\hline 1 & 0 & Local Food Production \\
\hline 39 & 22 & \\
\hline
\end{tabular}

The Tassafaronga Housing project is a Gold LEED-USGBC certificated New Development located in the southern end of Oakland city, in the outskirts of San Francisco - California. All houses are also LEED certificated. The project occupies 3 ha. It has a good diversity of units from single studios to 3 bedrooms, in townhouses and 3 story buildings. The project incorporates on-site generation of electricity and hot water. It has a public plaza known as the Village Square.

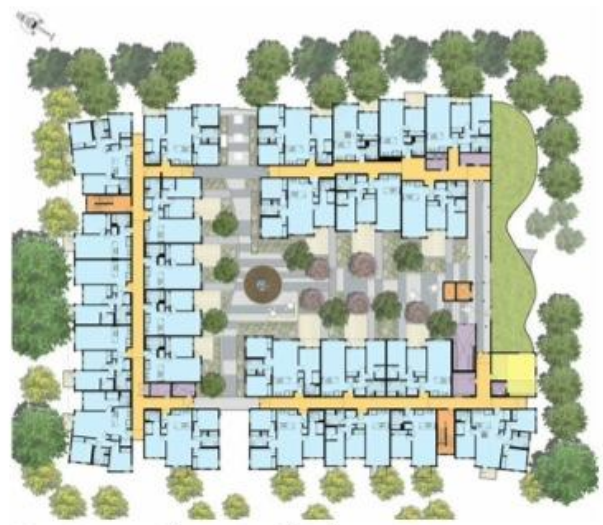

Fig 19 - Master Plan - David Baker + Partners

\begin{tabular}{|c|c|c|}
\hline Points possible & Points Accepted & Green Construction \& Technology \\
\hline 1 & 1 & Increased Affordability for Rental Housing \\
\hline 1 & 1 & Increased Affordability of For Sale Housing \\
\hline 1 & 1 & Further Reduced Parking Footprint \\
\hline 1 & 1 & Increased Increased Housing \& lobs Proximity Housing \& Jobs Proximity \\
\hline 1 & 1 & Bay Friendly Landscape Maintenance Plan \\
\hline 1 & 1 & LEED Accredited Professional \\
\hline 6 & 6 & \\
\hline
\end{tabular}

\begin{tabular}{|c|c|}
\hline Total Possible & Total Achieved \\
\hline
\end{tabular}

\begin{tabular}{l|l}
106 & 66
\end{tabular}

Gold Certification 


\section{Sustainability analysis.}

\section{Tassafaronga Housing, Oakland CA - USA}

\section{Sustainability analysis.}

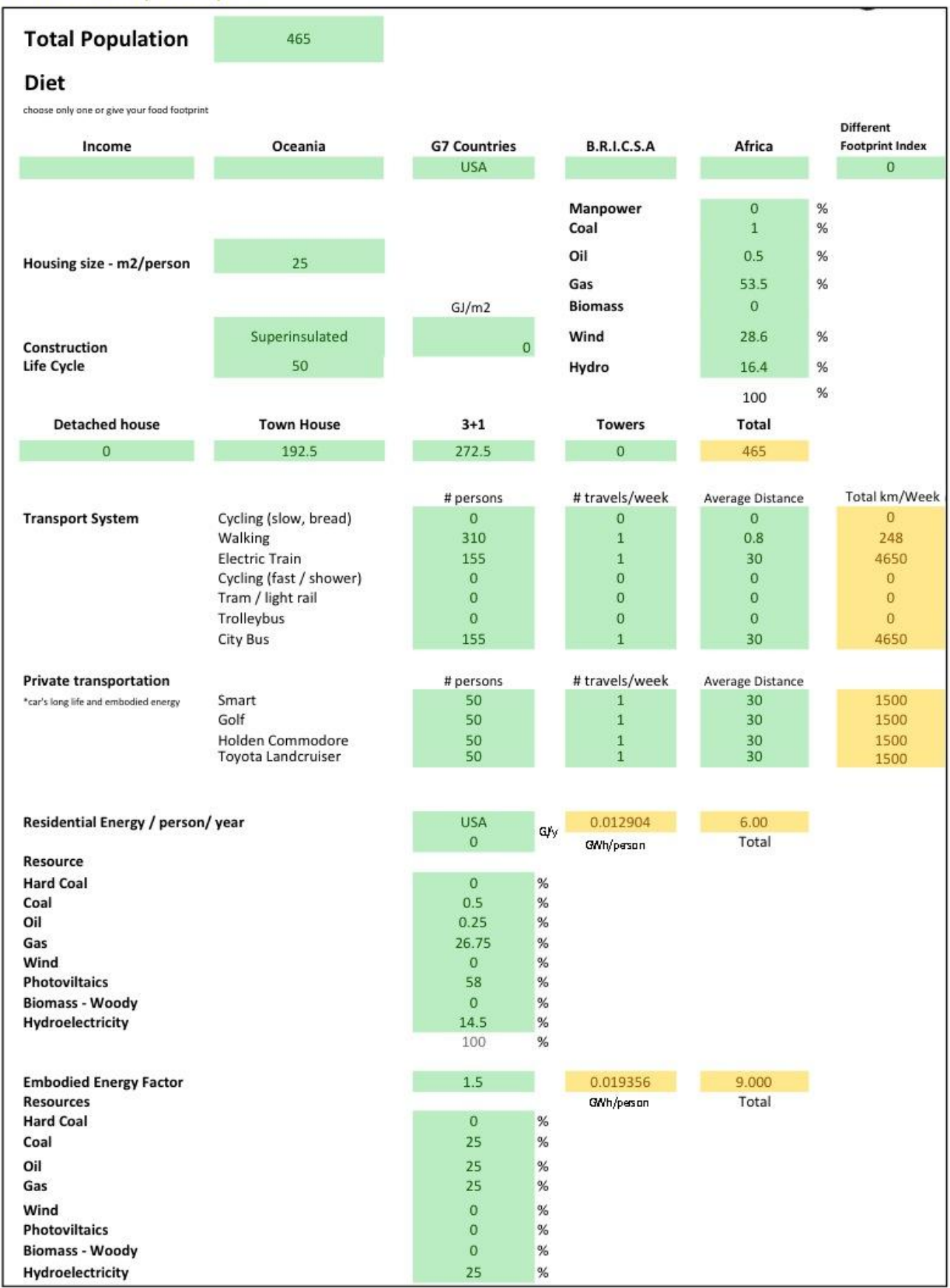


Sustainability analysis.

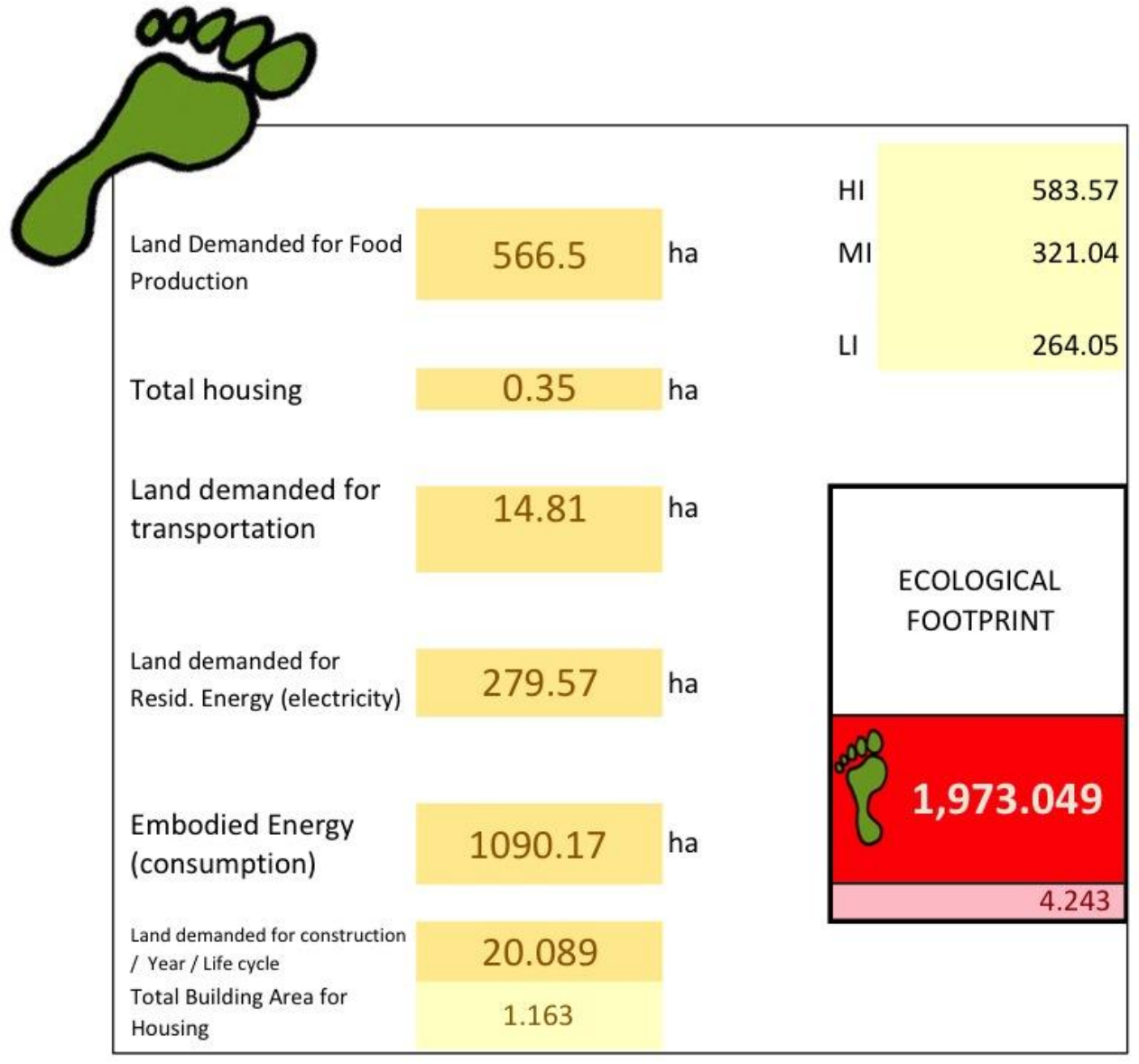

Footprint distribution by segment (\%)

Total housing projection $\quad 0.02$

Land demanded for transportation 0.75

Total Building Area for Housing $\quad 0.06$

Circulation $\quad 0.02$

Land demanded for construction / Year / Life 1.02

Land demanded for Resid. Energy (electricity) 14.17

Embodied Energy (consumption)

Land Demanded for Food Production

28.71 


\section{Sustainability analysis}

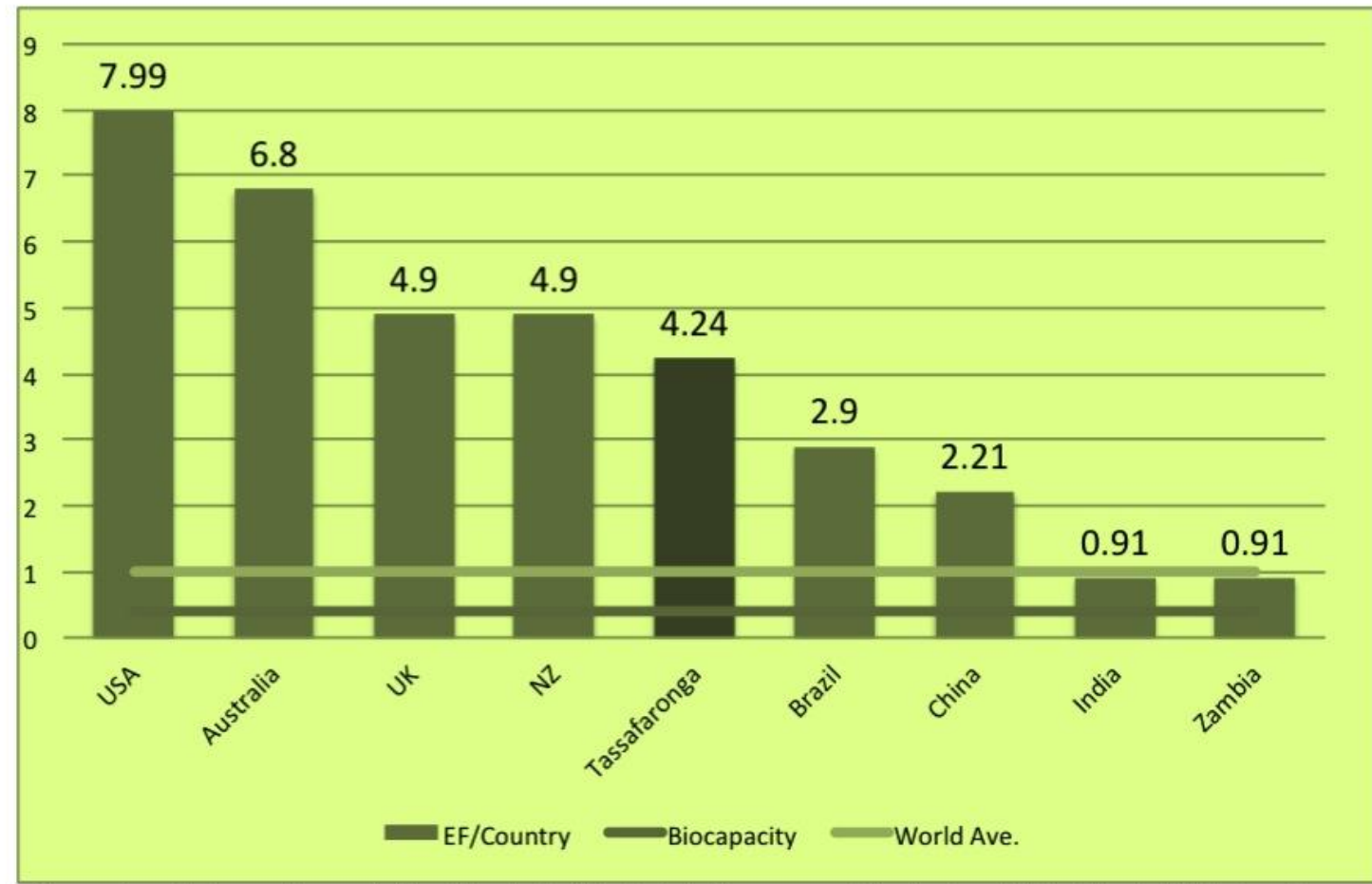

Comparison between the project and Ecological Footprint of some countries in gha - (Global Footprint Network, 2011)

Although based on many assumptions, the project has higher Ecological Footprint than the world average, and moreover, the world biocapacity. The two main components, food and energy, are based on American averages.

The assumptions made for energy consumption are environmentally optimistic. The amount of solar panel needed in order to supply the American average consumption is high and it is very unliky that the project would be able to produce 50 per cent of the electricity as assumed in the analysis. On the other hand, the transportation assumption is based on the LEED number and seems feasible. According to the analysis the project has not achieved a minimum level of sustainability. 
Appendix 2:

New Urbanism - Seaside 


\section{Seaside - FL}

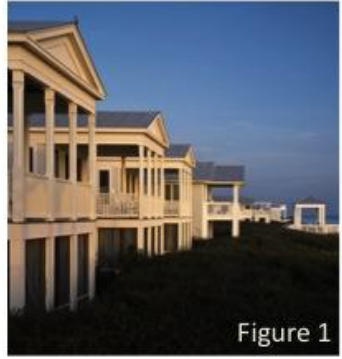

\section{Location: Walton County, Florida}

Type: Resort Village

Year Design: 1978

Status: Largely Complete

Size: 32ha

Residences: $\mathbf{5 0 0}$

Design: Duany Plater-Zyberk \& Company

Seaside is probably one of the most influential new urbanism developments, located along the beachfront in the Florida Panhandle, about a hundred miles west of Tallahassee. The project was started in 1978.
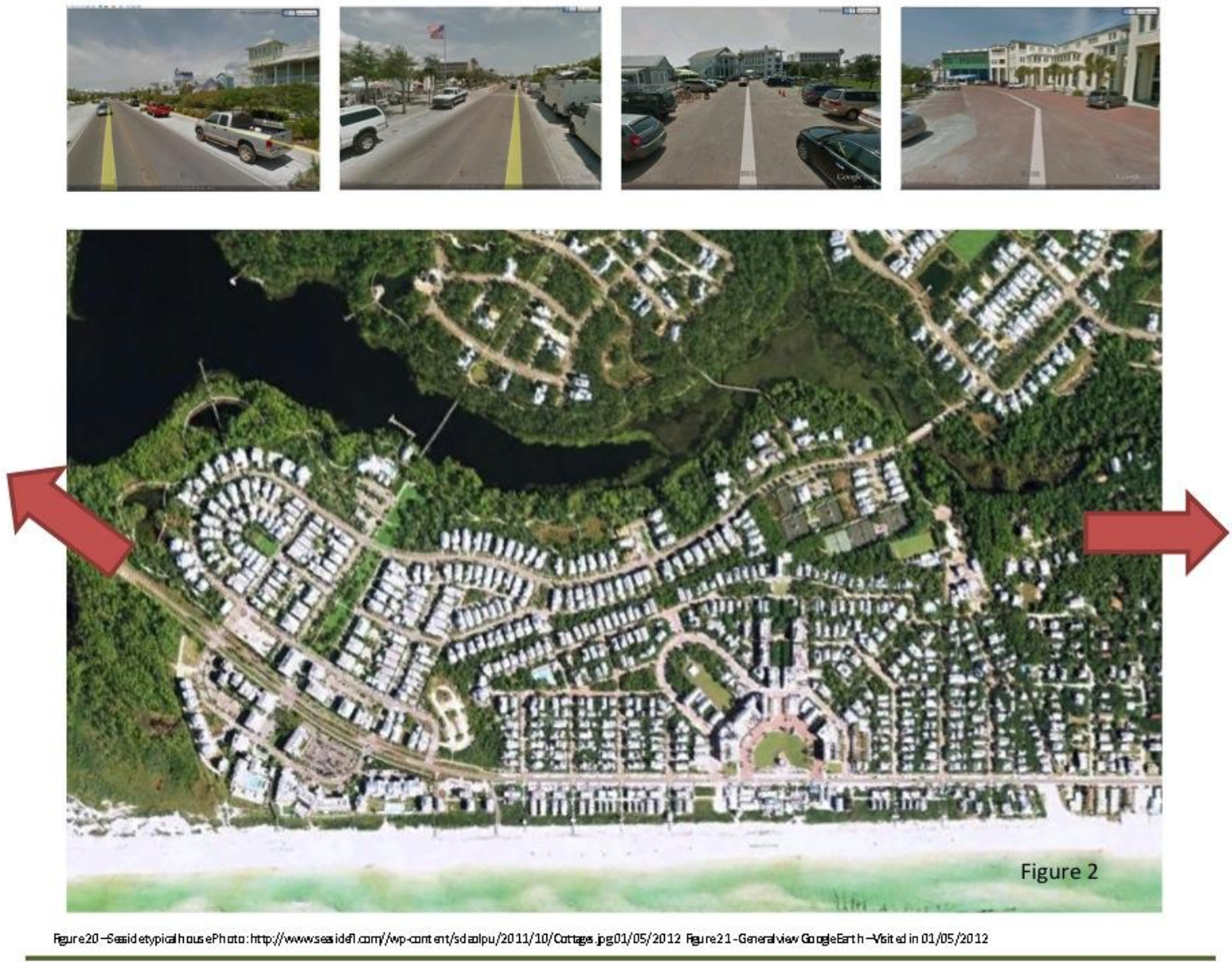


\section{Sustainability analysis.}

Seaside - FL

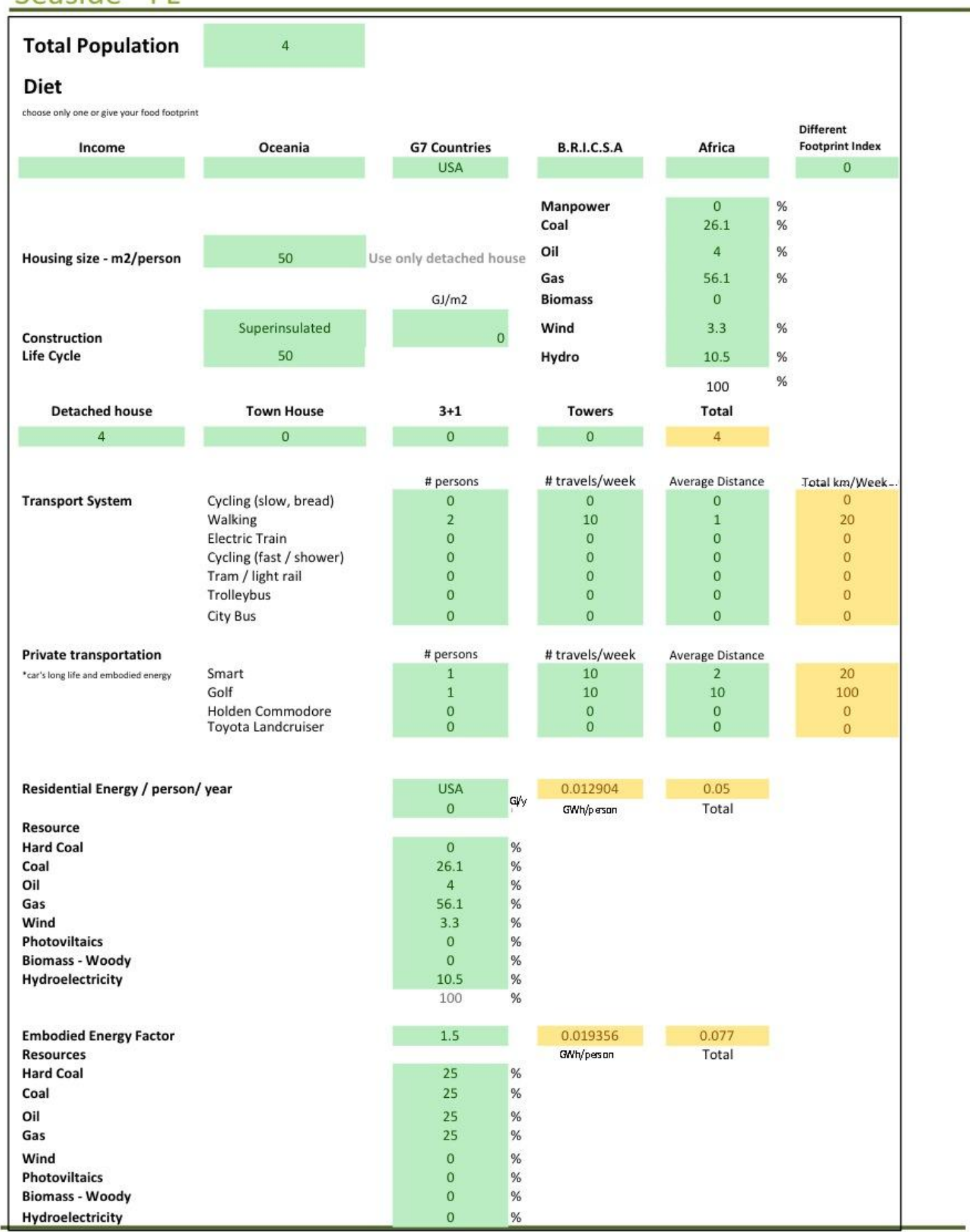



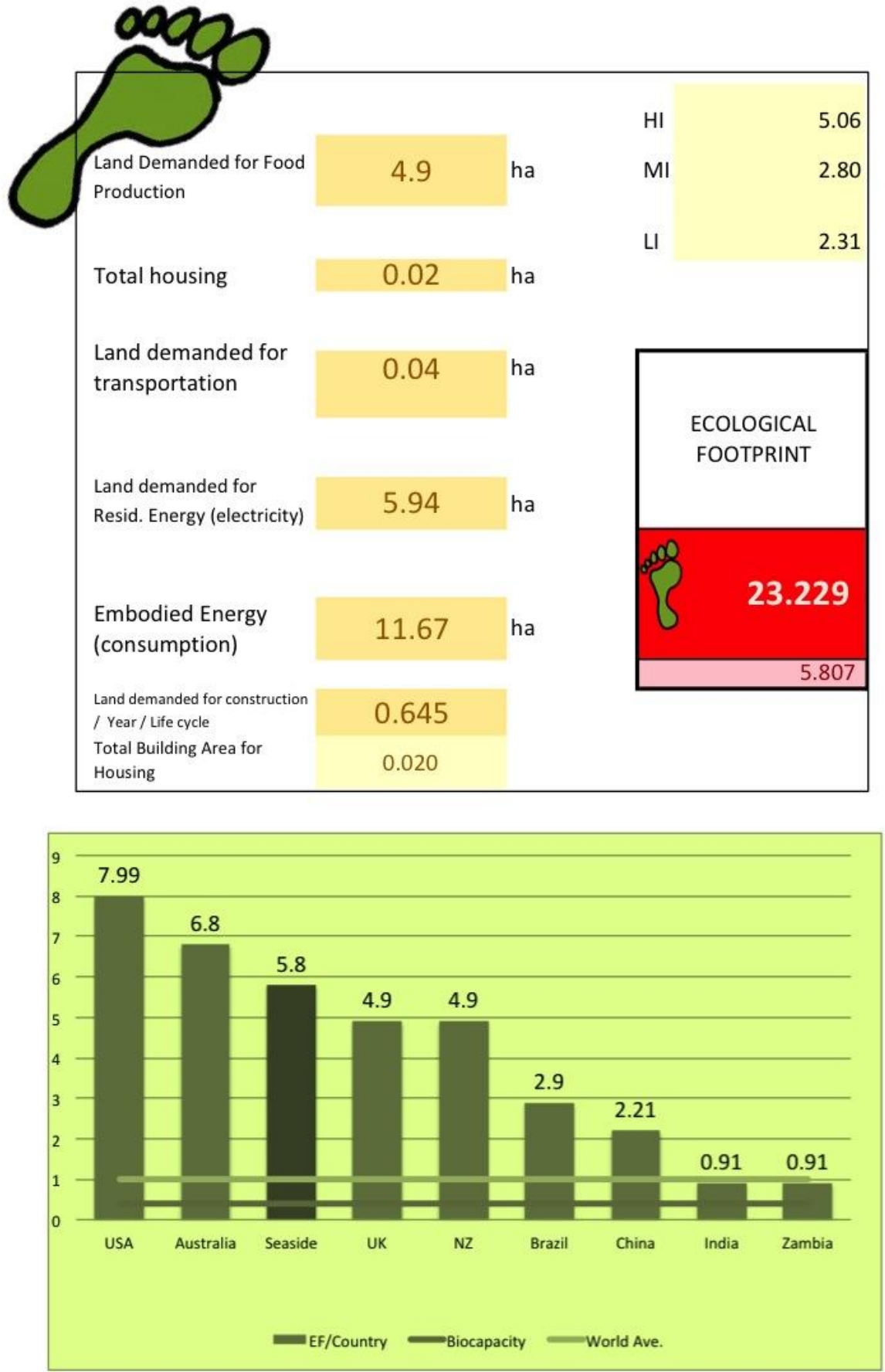
Appendix 3:

Historical Case Studies 


\section{Sustainability analysis.}

Ancient Rome

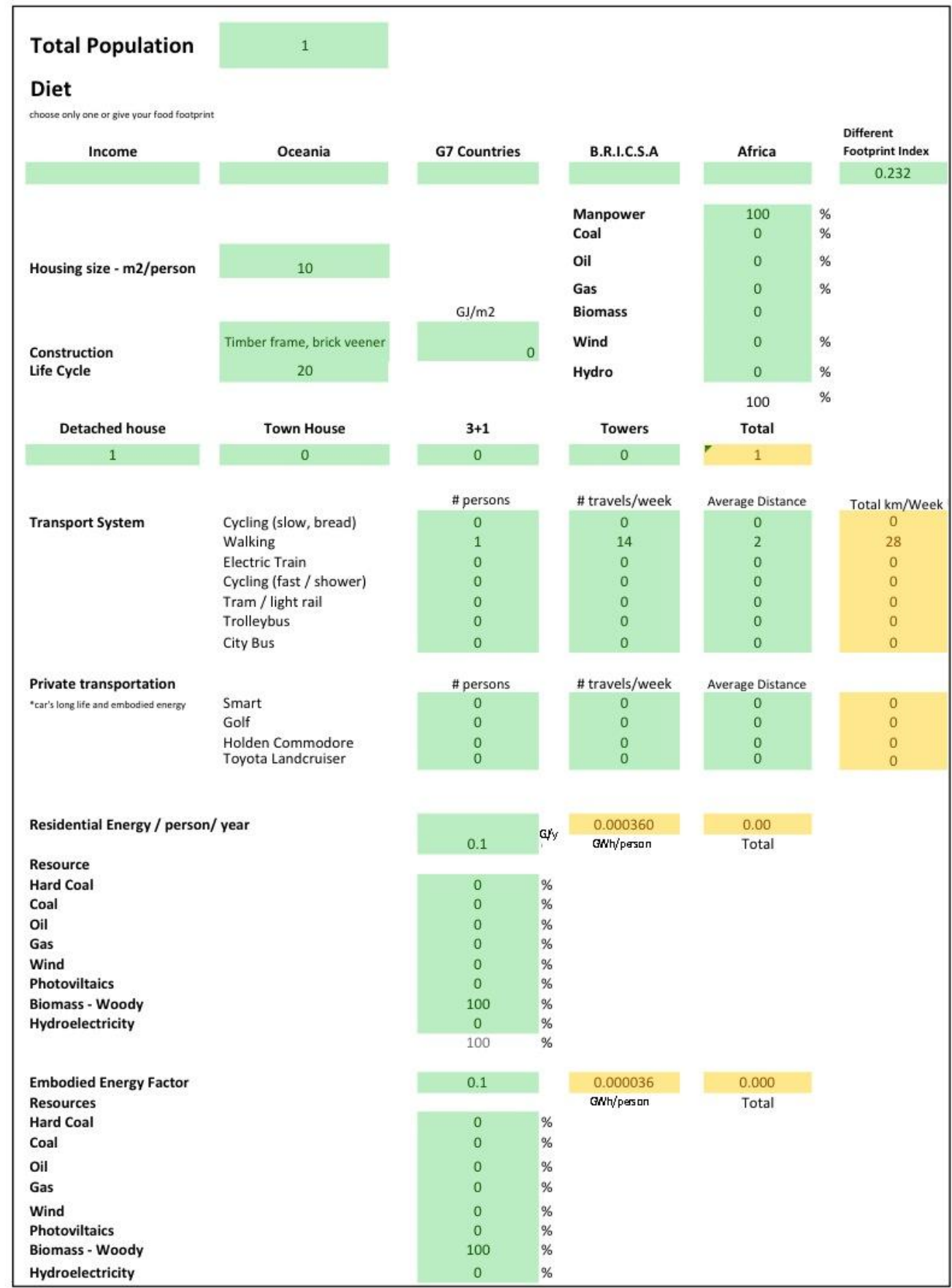




\section{Sustainability analysis.}

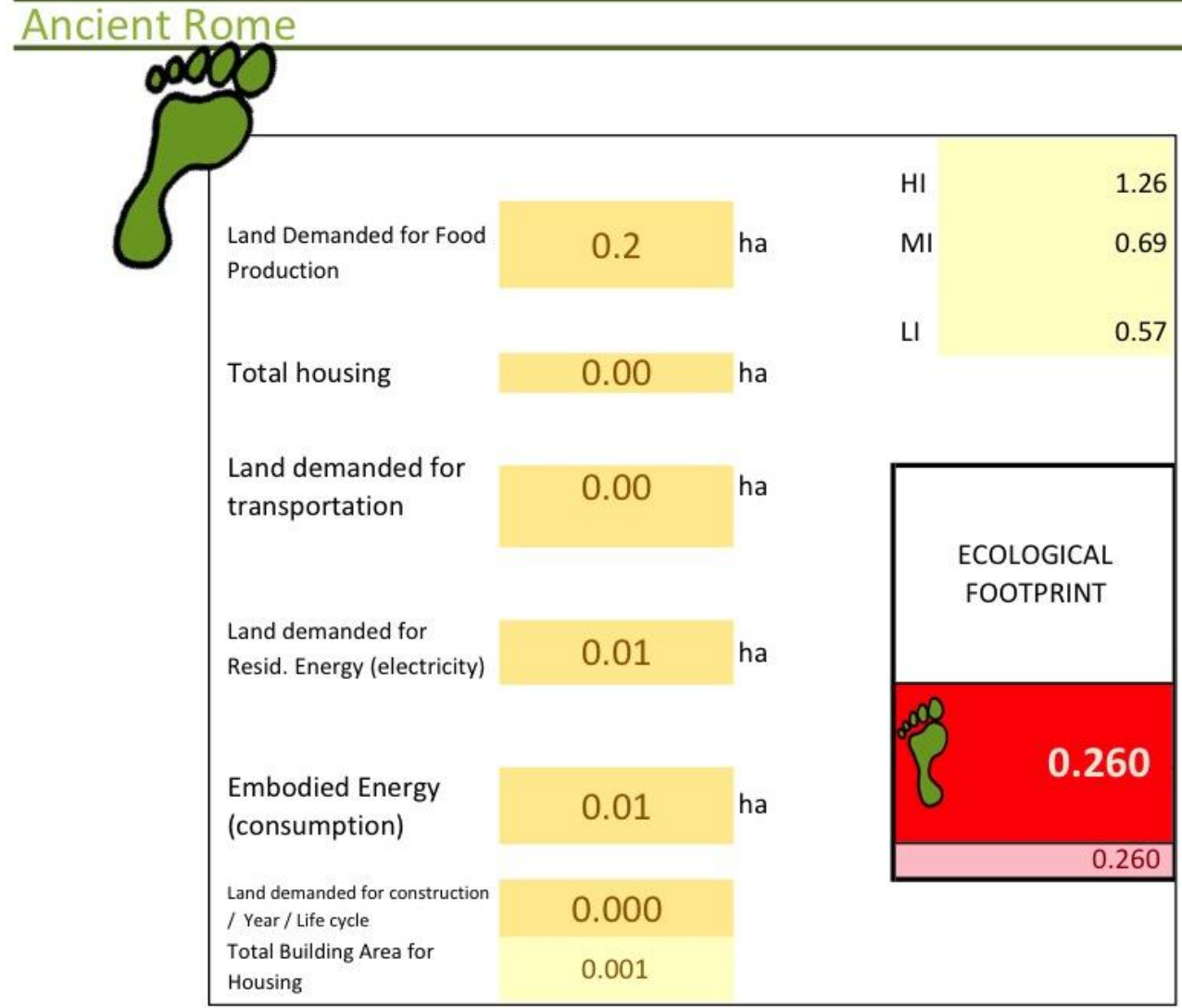

\section{Footprint distribution by segment (\%)}

Total housing projection $\quad 0.38$

Land demanded for transportation $\quad 0.00$

Total Building Area for Housing 0.38

Circulation $\quad 0.48$

Land demanded for construction / Year / Life 0.11

Land demanded for Resid. Energy (electricity) 5.06

Embodied Energy (consumption) $\quad 5.06$

Land Demanded for Food Production 
Sustainability analysis.

Ancient Rome-Diet description

\begin{tabular}{|c|c|c|c|c|c|c|c|c|}
\hline \multicolumn{9}{|l|}{ Rome } \\
\hline & $\mathrm{CO} 2 /$ unit & Breakfast & Lunch & Supper & Total day & $\mathrm{CO2}$ & kcal & kcal day \\
\hline Porridge & 0.16 & 0.20 & 0.00 & 0.20 & 0.40 & 0.06 & 981.00 & 392.40 \\
\hline Milk & 1.44 & 0.00 & 0.00 & 0.07 & 0.07 & 0.10 & 608.00 & 43.43 \\
\hline Bread & 0.94 & 0.00 & 0.20 & 0.20 & 0.40 & 0.38 & 2250.00 & 900.00 \\
\hline Vegetables* & 0.30 & 0.50 & 0.50 & 0.50 & 1.50 & 0.45 & 315.25 & 472.88 \\
\hline Fish & 0.50 & 0.00 & 0.00 & 0.07 & 0.07 & 0.04 & 3633.00 & 259.50 \\
\hline Wine & 0.57 & 0.00 & 0.00 & 0.03 & 0.03 & 0.02 & 480.00 & 16.00 \\
\hline \multirow[t]{4}{*}{ Meat } & 18.00 & 0.00 & 0.00 & 0.01 & 0.01 & 0.10 & 1400.00 & 7.67 \\
\hline & & & & & Day & 1.15 & & \\
\hline & & & & & Year & 419.37 & & \\
\hline & & & & & gha & 0.23 & & \\
\hline \multicolumn{5}{|c|}{ Average of carrots, aspargus, Apple, tomatoes CO2 0.3025 / kcal } & kcal day & 2091.87 & & \\
\hline
\end{tabular}




\section{Sustainability analysis.}

\section{Incas}

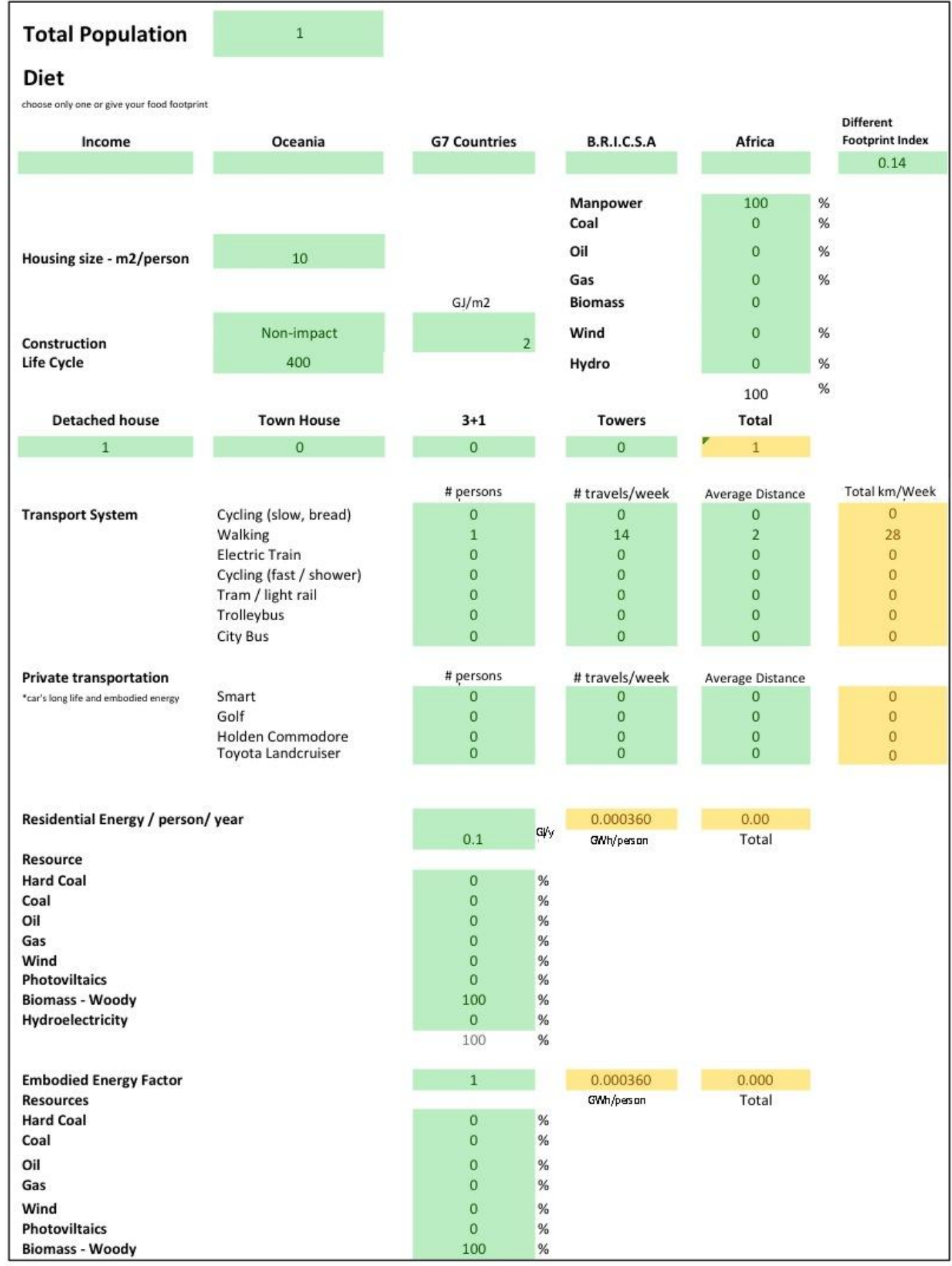




\section{Sustainability analysis.}

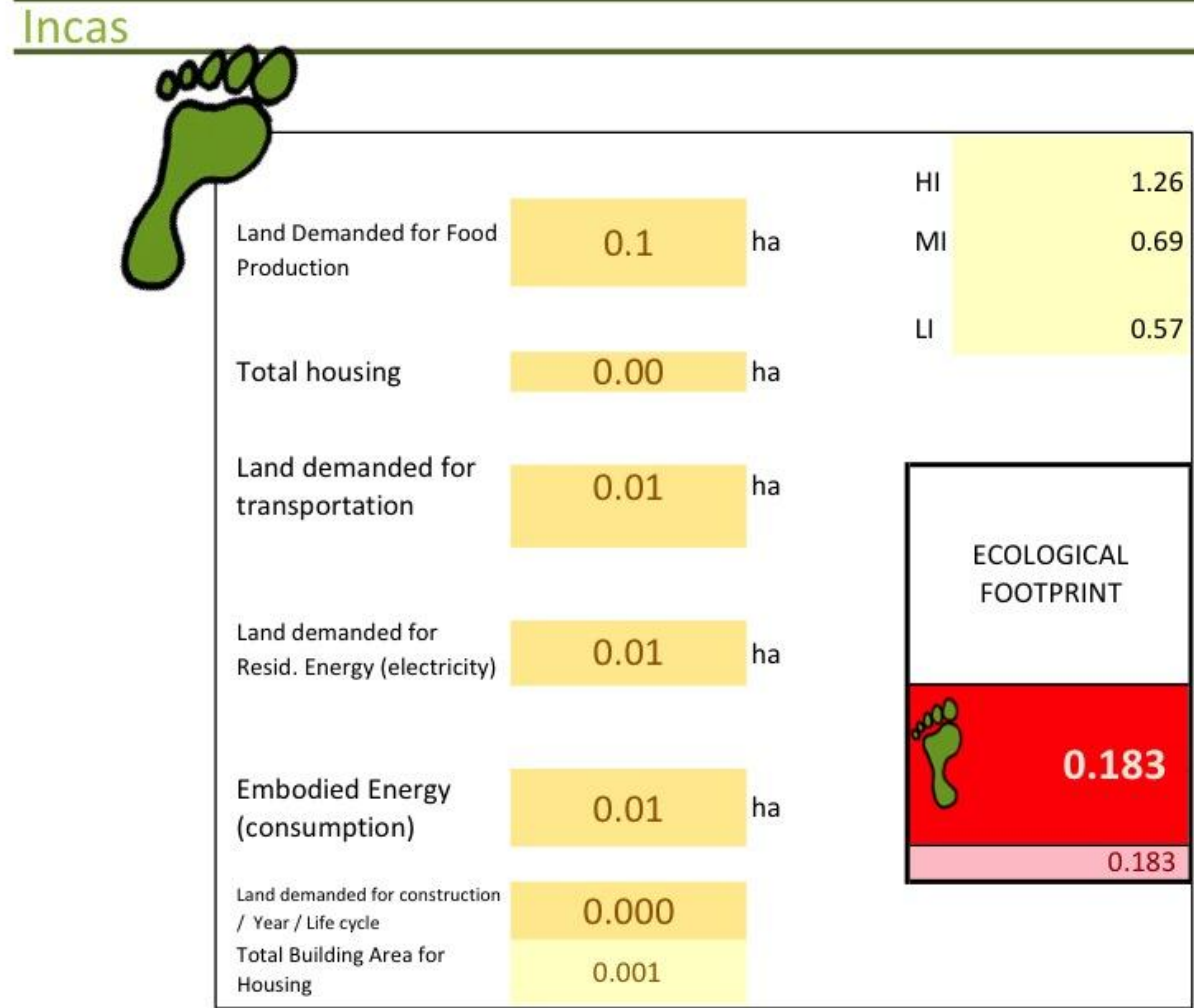

\section{Footprint distribution by segment (\%)}

\begin{tabular}{r|c} 
Total housing projection & 0.55 \\
Land demanded for transportation & 7.17 \\
Total Building Area for Housing & 0.55 \\
Circulation & 0.68 \\
manded for construction / Year / Life & 0.01 \\
Embodied Energy (consumption) & 7.19 \\
Land Demanded for Food Production & 7.19
\end{tabular}


Sustainability analysis.

\begin{tabular}{|c|c|c|c|c|c|c|c|c|}
\hline \multirow[t]{2}{*}{ Incas } & \multirow[b]{2}{*}{$\mathrm{CO} 2 /$ unit } & \multirow[b]{2}{*}{ Breakfast } & \multirow[b]{2}{*}{ Lunch } & \multirow[b]{2}{*}{ Supper } & \multirow[b]{2}{*}{ Total day } & \multirow[b]{2}{*}{$\mathrm{kg} /$ Year } & \multirow[b]{2}{*}{ Footprint $\mathrm{CO} 2$} & \multirow[b]{2}{*}{ Production land } \\
\hline & & & & & & & & \\
\hline Potatoes & 0.62 & 0.20 & 0.20 & 0.20 & 0.60 & 219.00 & 135.78 & \\
\hline Tomatoes & 0.40 & 0.10 & 0.10 & 0.10 & 0.30 & 109.50 & 43.80 & \\
\hline \multicolumn{9}{|l|}{ Peanuts } \\
\hline Maize & 0.00 & 0.10 & 0.10 & 0.10 & 0.30 & 109.50 & & 0.02 \\
\hline \multirow[t]{2}{*}{ Avocadoes } & 0.00 & 0.10 & 0.10 & 0.10 & 0.30 & 109.50 & & 0.02 \\
\hline & & & \multicolumn{2}{|c|}{ Total CO2 / year } & & & 179.58 & 0.00 \\
\hline \multirow[t]{3}{*}{ kcal } & 2049.00 & & \multicolumn{3}{|c|}{ Total land for production } & & 0.00 & 0.04 \\
\hline & & & \multirow{2}{*}{\multicolumn{3}{|c|}{ Total footprint $=\mathrm{CO} 2$ footprint + La }} & & 0.10 & \\
\hline & & & & & & roduction & 0.00 & 0.14 \\
\hline
\end{tabular}




\section{Sustainability analysis.}

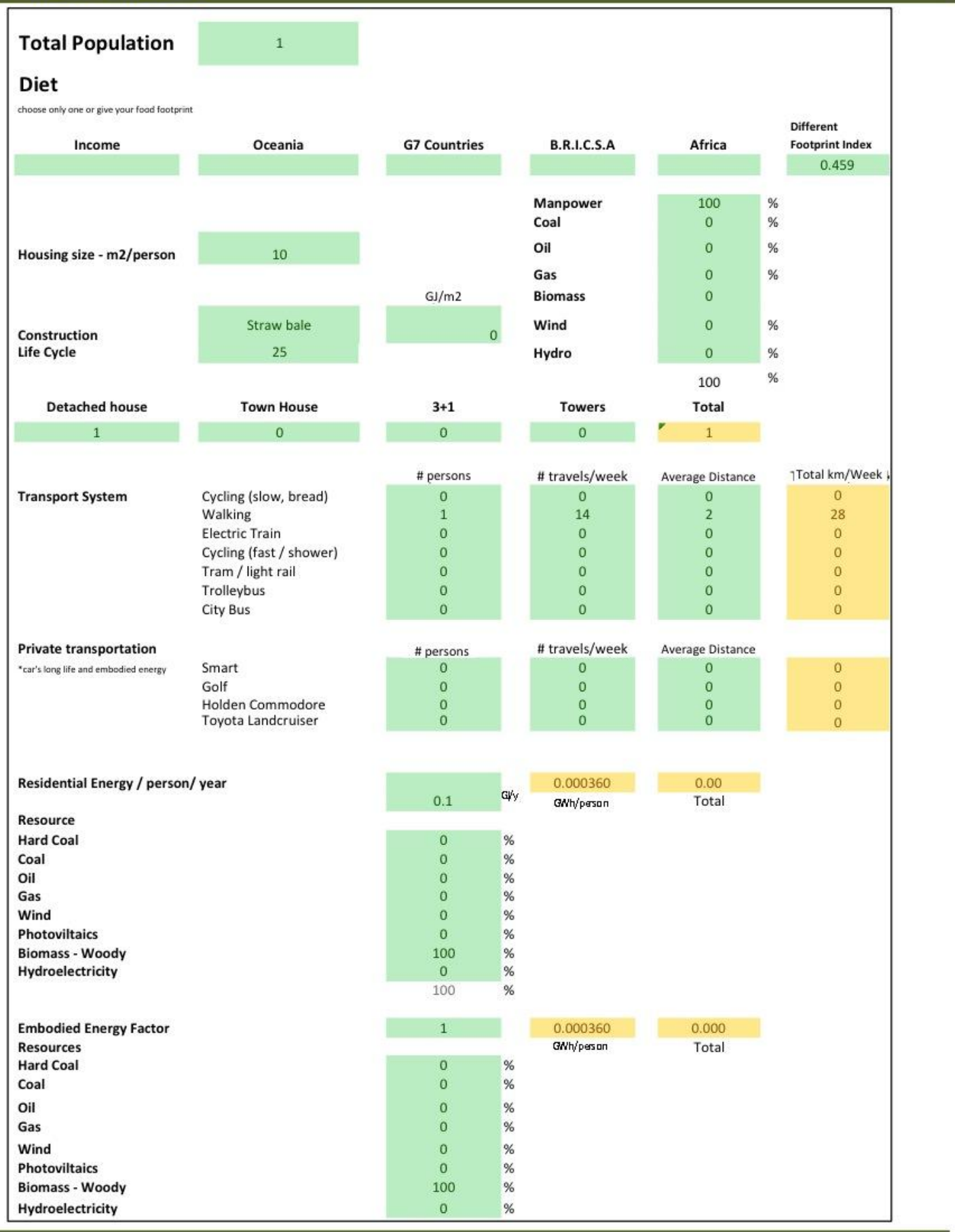




\section{Sustainability analysis.}

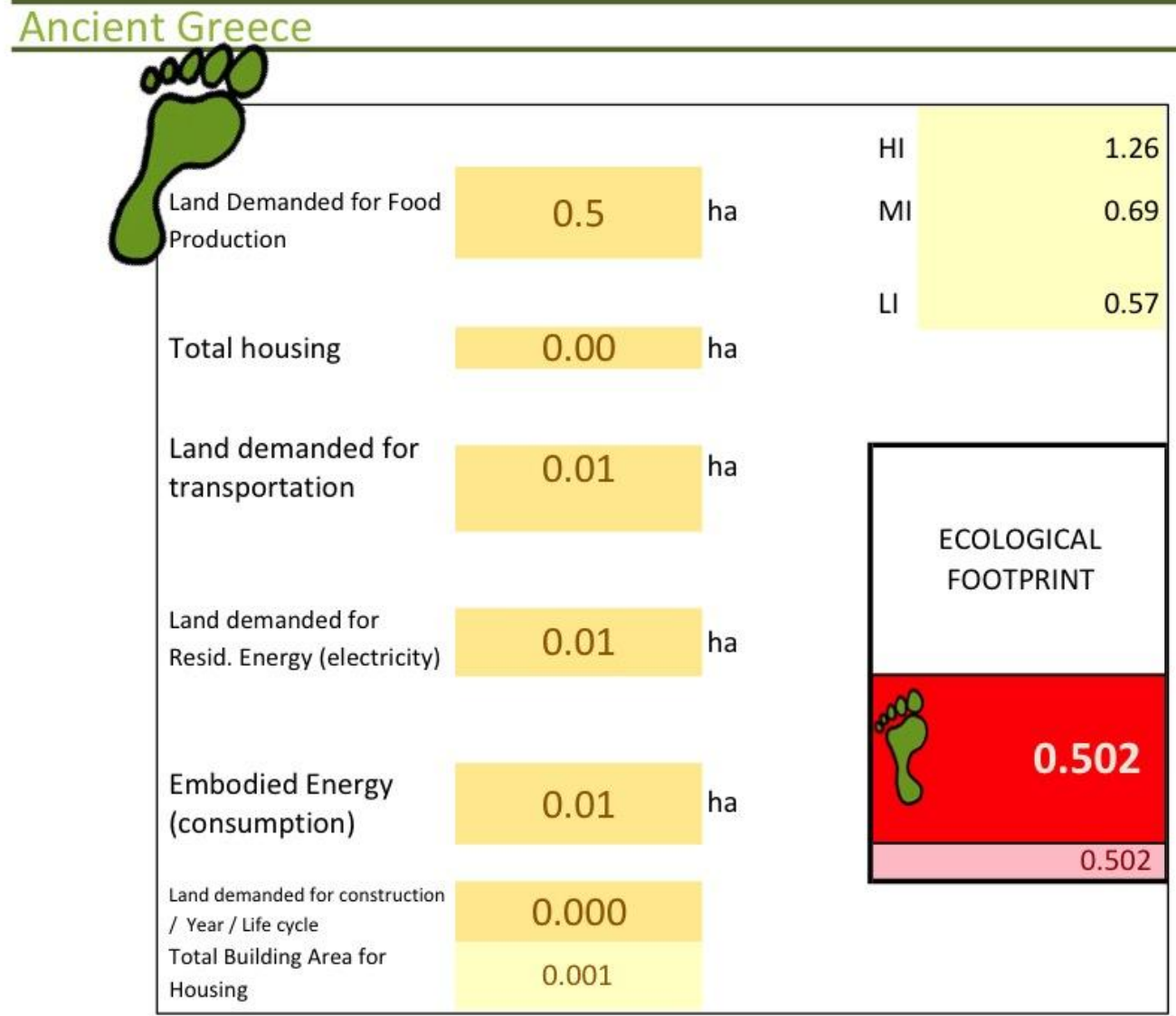

\section{Footprint distribution by segment (\%)}

\begin{tabular}{r|c} 
Total housing projection & 0.20 \\
Land demanded for transportation & 2.61 \\
Total Building Area for Housing & 0.20 \\
Circulation & 0.25 \\
anded for construction / Year / Life & 0.04 \\
anded for Resid. Energy (electricity) & 2.62 \\
Embodied Energy (consumption) & 2.62 \\
and Demanded for Food Production &
\end{tabular}


Sustainability analysis.

Ancient Greece

\begin{tabular}{|c|c|c|c|c|c|c|c|c|c|}
\hline \multicolumn{10}{|l|}{ Greece } \\
\hline & Unit $\mathrm{kg}$ & $\mathrm{CO} 2$ & kcal & Breakfast & Lunch & Dinner & $\mathrm{kg} /$ Day & $\mathrm{CO} 2 /$ day & kcal \\
\hline Bread & 1.00 & 0.94 & 2250.00 & 0.20 & 0.20 & 0.00 & 0.40 & 0.38 & 900.00 \\
\hline Wine & 1.00 & 0.57 & 480.00 & 0.20 & 0.20 & 0.20 & 0.60 & 0.34 & 288.00 \\
\hline Cheese & 1.00 & 12.00 & 3720.00 & 0.00 & 0.10 & 0.00 & 0.10 & 1.20 & 372.00 \\
\hline Fish & 1.00 & 0.50 & 3633.00 & 0.00 & 0.00 & 0.00 & 0.00 & 0.00 & 0.00 \\
\hline Vegetables / fruits & 1.00 & 0.32 & 315.00 & 0.00 & 0.00 & 0.50 & 0.50 & 0.16 & 157.50 \\
\hline eggs & 1.00 & 0.15 & 74.00 & 0.00 & 0.00 & 1.00 & 1.00 & 0.15 & 74.00 \\
\hline \multirow[t]{5}{*}{ Porridge } & 1.00 & 0.16 & 981.00 & 0.00 & 0.00 & 0.25 & 0.25 & 0.04 & 245.25 \\
\hline & & & & & & & & 2.27 & \\
\hline & & & & & & & & 826.91 & \\
\hline & & & & & & & gha & 0.46 & \\
\hline & & & & & & & kcal & 2036.75 & \\
\hline
\end{tabular}


Sustainability analysis.

Rural China - Ping'an - Guangxi - China

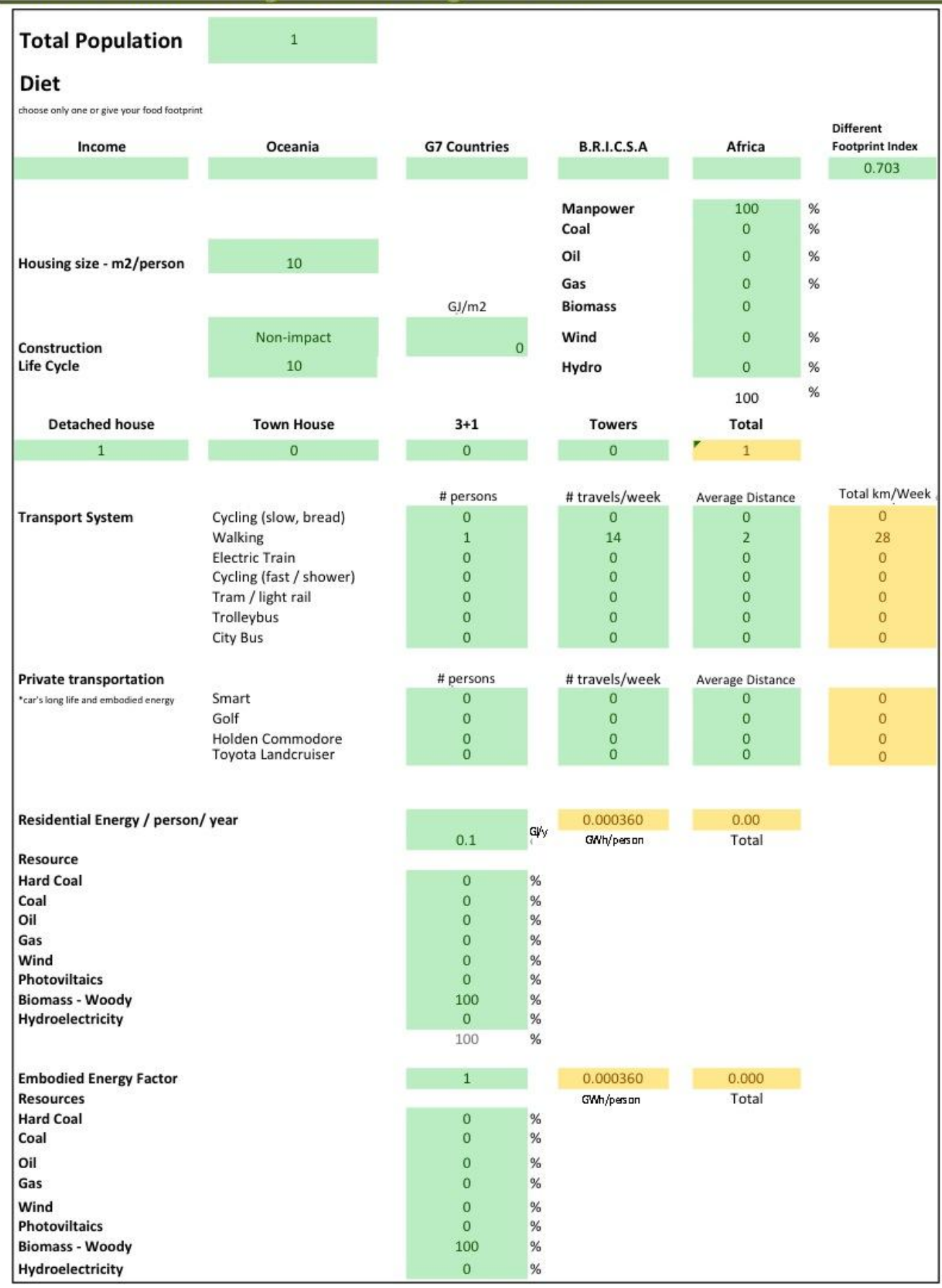


Sustainability analysis.

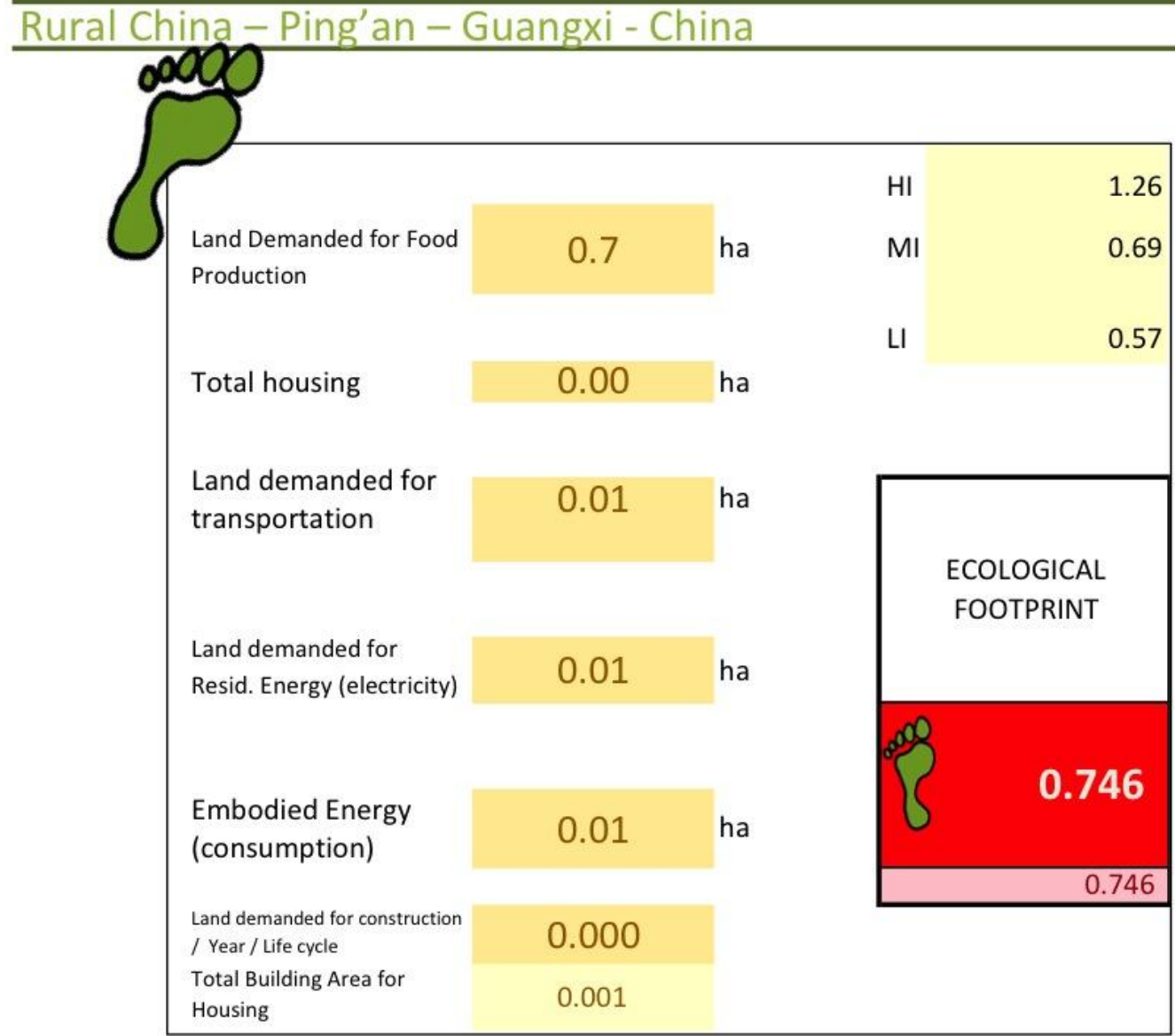

\section{Footprint distribution by segment (\%)}

Total housing projection

Land demanded for transportation

Total Building Area for Housing

Circulation

1.76

0.13

0.17

Land demanded for construction / Year / Life

Land demanded for Resid. Energy (electricity)

0.00

Embodied Energy (consumption)

1.76

Land Demanded for Food Production 
Sustainability analysis.

Rural China - Ping'an - Guangxi - China

\begin{tabular}{|c|c|c|c|c|c|c|c|c|c|}
\hline \multicolumn{10}{|l|}{ China } \\
\hline & Unit kg & $\mathrm{CO} 2$ & kcal & Breakfast & Lunch & Dinner & $\mathrm{kg} /$ Day & $\mathrm{CO} 2 /$ day & kcal \\
\hline Rice & 1.00 & 2.50 & 1100.00 & 0.25 & 0.25 & 0.25 & 0.75 & 1.88 & 825.00 \\
\hline Vegetables & 1.00 & 0.32 & 315.00 & 0.25 & 0.25 & 0.25 & 0.75 & 0.24 & 236.25 \\
\hline \multirow[t]{8}{*}{ Pork } & 1.00 & 0.00 & 2850.00 & 0.10 & 0.10 & 0.10 & 0.30 & 0.00 & 855.00 \\
\hline & & & & & & 0.00 & 0.00 & & \\
\hline & & & & & & kcal day & 1916.25 & & \\
\hline & & & & & & $\mathrm{CO} 2 /$ day & 2.11 & & \\
\hline & & & & & & $\mathrm{CO} 2 /$ Year & 770.61 & & \\
\hline & & & & & & gha / CO2 & 0.43 & & \\
\hline & & & & & & gha / Pork & 0.28 & & \\
\hline & & & & & & Total gha & 0.70 & & \\
\hline
\end{tabular}




\section{Sustainability analysis.}

Rural India - Khajuharo - Madhya Pradesh

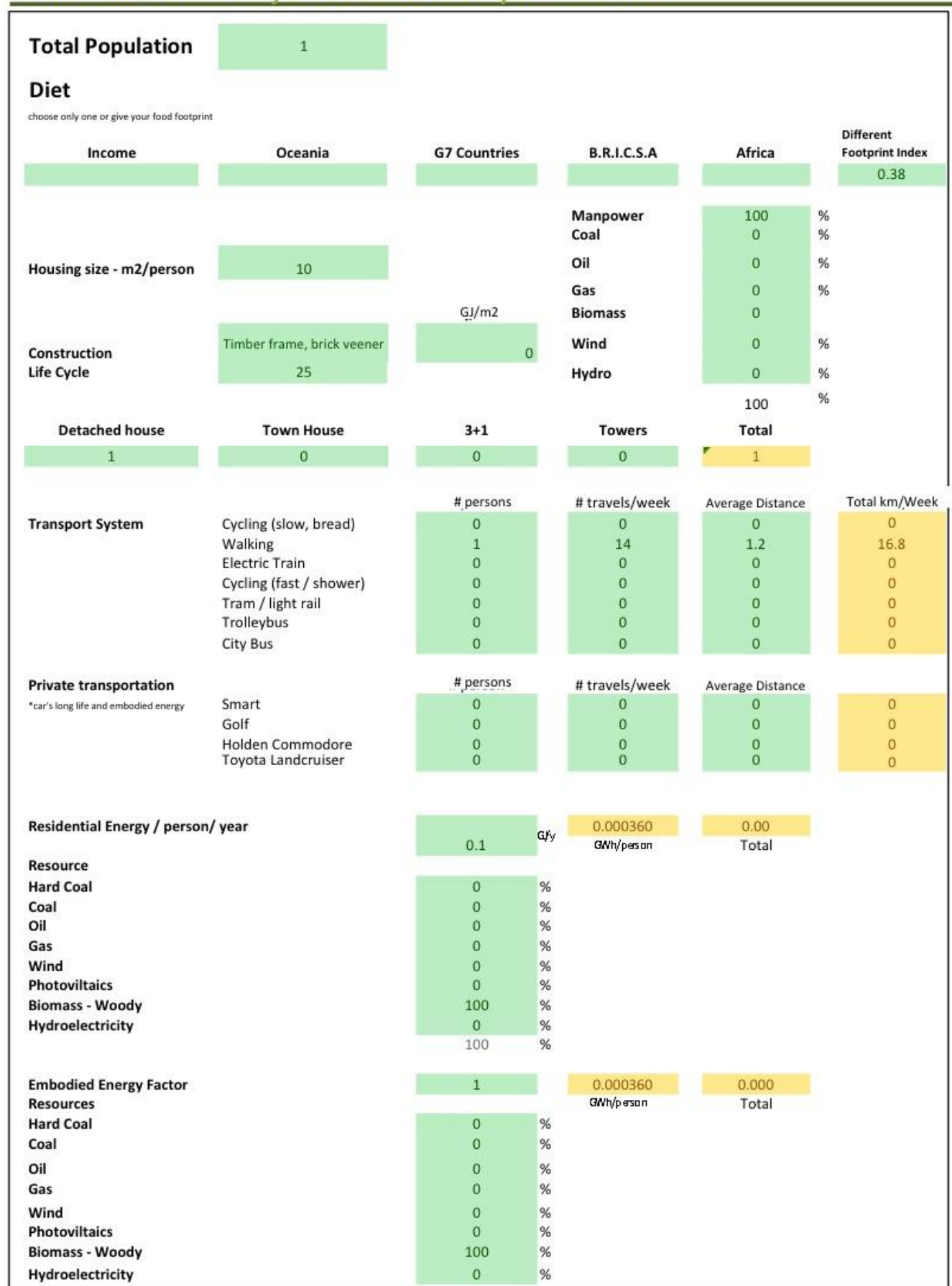


Sustainability analysis.

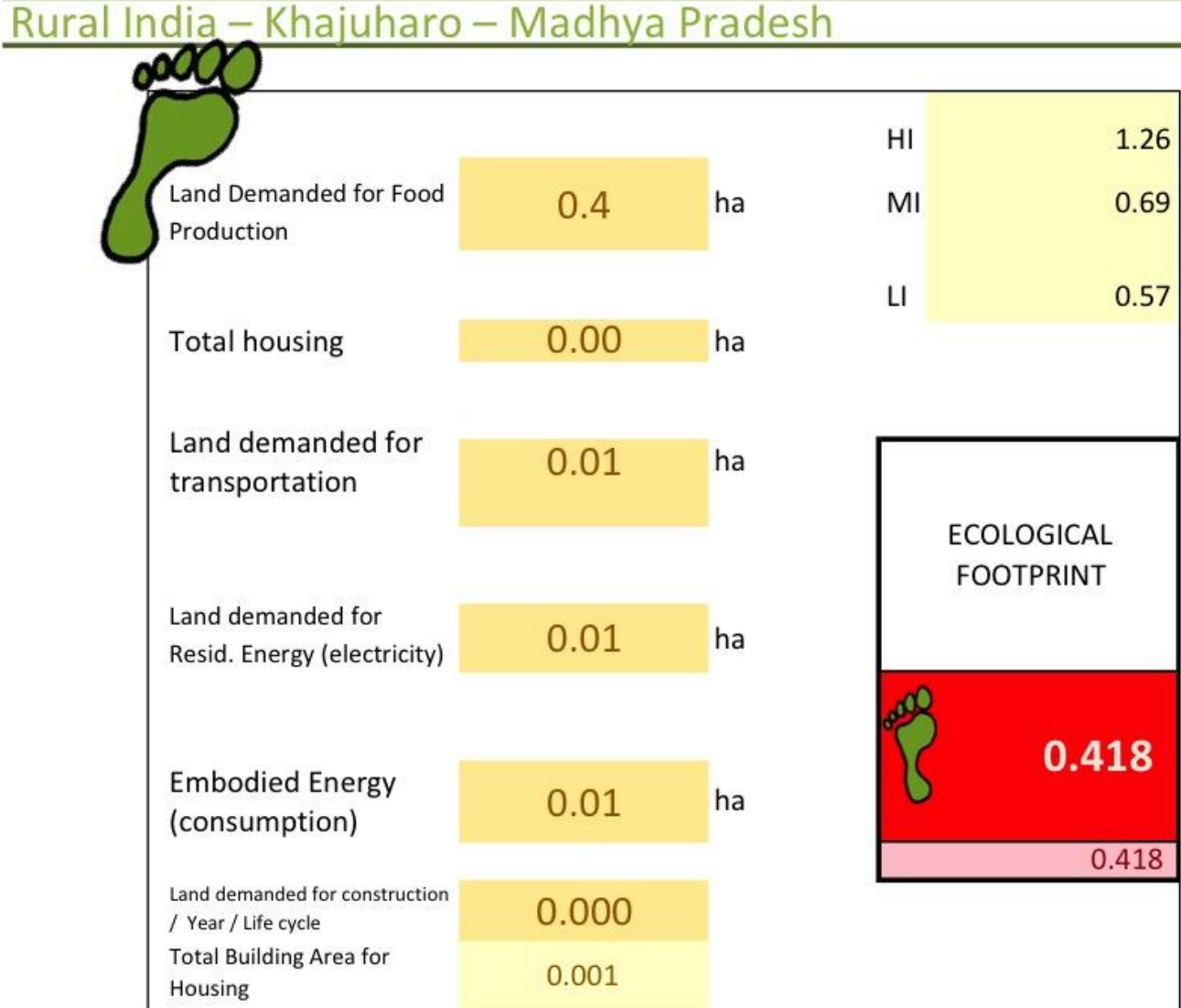

Footprint distribution by segment (\%)

\begin{tabular}{r|c} 
Total housing projection & 0.24 \\
Land demanded for transportation & 1.88 \\
Total Building Area for Housing & 0.24 \\
Circulation & 0.30 \\
manded for construction / Year / Life & 0.05 \\
Embodied Energy (consumption) & 3.15
\end{tabular}

Land Demanded for Food Production 
Sustainability analysis.

Rural India - Khajuharo - Madhya Pradesh

\begin{tabular}{|c|c|c|c|c|c|c|c|c|c|}
\hline \multirow[t]{2}{*}{ India } & \multirow[b]{2}{*}{ Unit kg } & \multirow[b]{2}{*}{$\mathrm{CO} 2$} & \multirow[b]{2}{*}{ kcal } & \multirow[b]{2}{*}{ Breakfast } & \multirow[b]{2}{*}{ Lunch } & \multirow[b]{2}{*}{ Dinner } & \multirow[b]{2}{*}{ kg/Day } & \multirow[b]{2}{*}{$\mathrm{CO} 2 /$ day } & \multirow[b]{2}{*}{ kcal } \\
\hline & & & & & & & & & \\
\hline Rice & 1.00 & 2.50 & 1100.00 & 0.00 & 0.25 & 0.25 & & 1.25 & 550.00 \\
\hline Vegetables & 1.00 & 0.32 & 315.00 & 0.25 & 0.25 & 0.25 & & 0.24 & 236.25 \\
\hline \multirow[t]{6}{*}{ Bread } & 1.00 & 0.94 & 2600.00 & 0.14 & 0.14 & 0.14 & & 0.39 & 1092.00 \\
\hline & & & & & & & kcal day & 1878.25 & \\
\hline & & & & & & & $\mathrm{CO2}$ & 1.88 & \\
\hline & & & & & & & $\mathrm{CO} 2$ year & 686.58 & \\
\hline & & & & & & & Footprint & 0.38 & \\
\hline & & & & & & & & & \\
\hline
\end{tabular}




\section{Sustainability analysis.}

\section{Medieval Milan II}

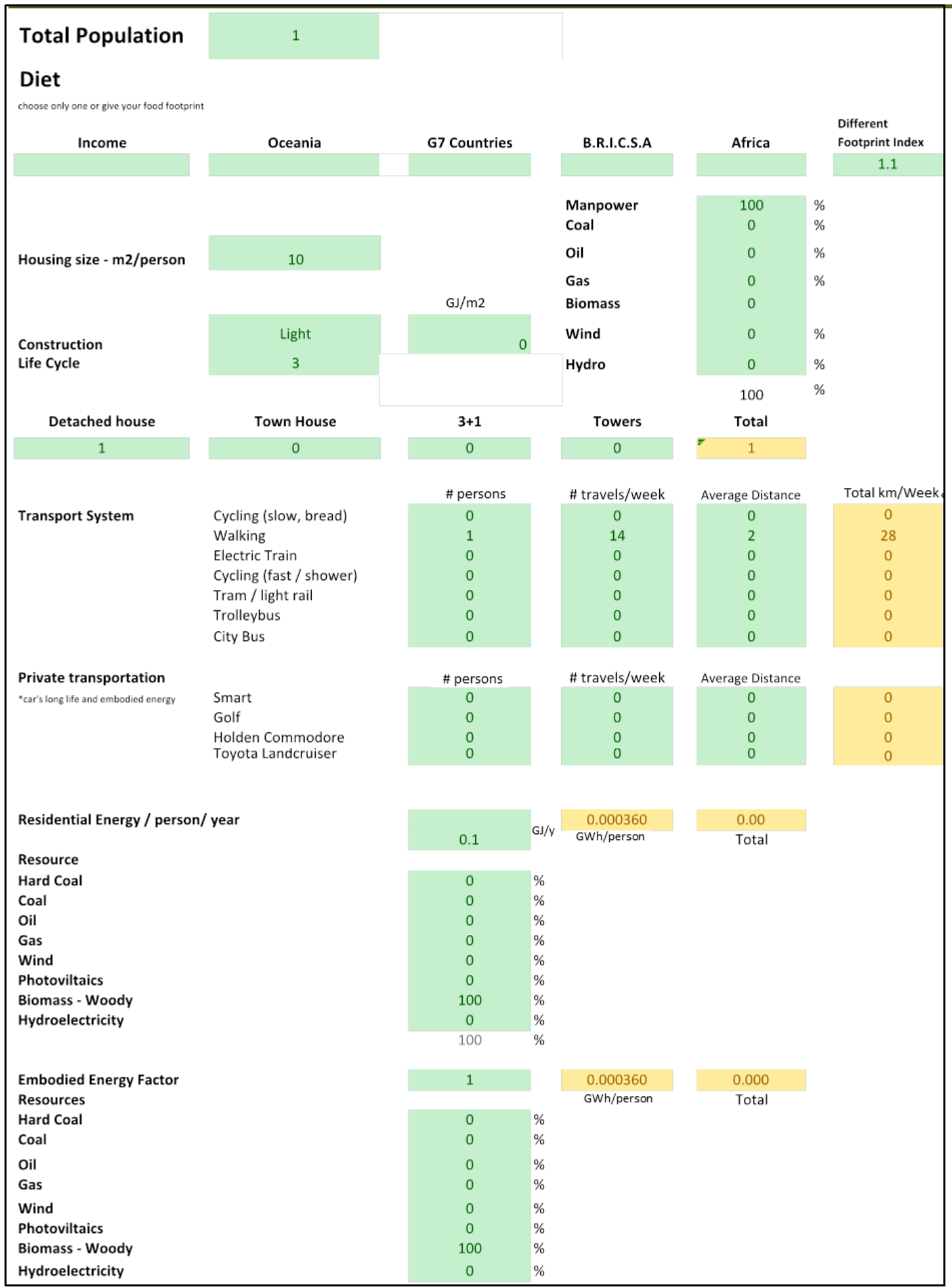




\section{Sustainability analysis.}
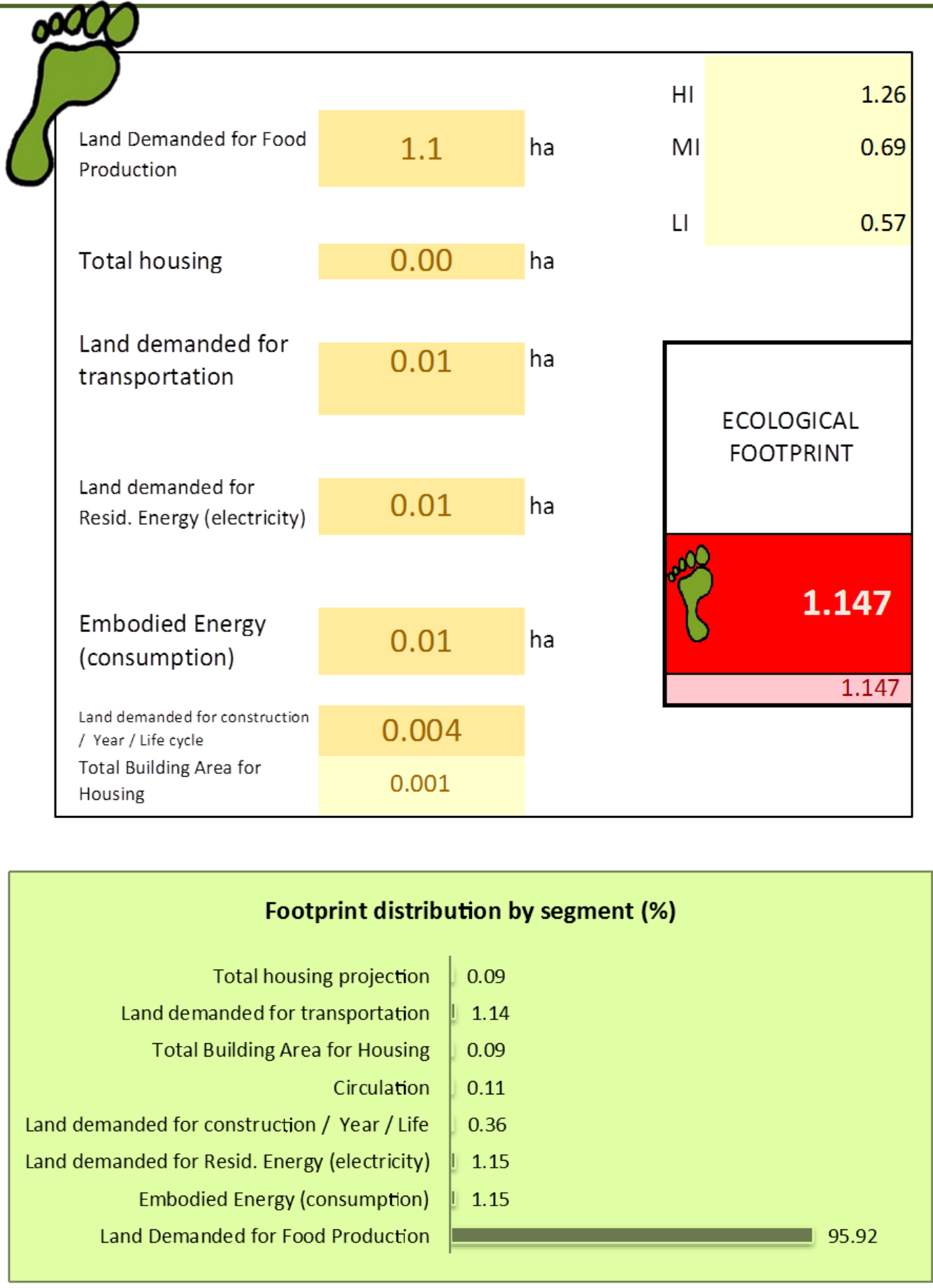
Sustainability analysis.

\begin{tabular}{|l|c|c|c|c|c|c|c|c|c|c|}
\hline & & & & & & \\
\hline
\end{tabular}




\section{Sustainability analysis.}

\section{Medieval Milan I}

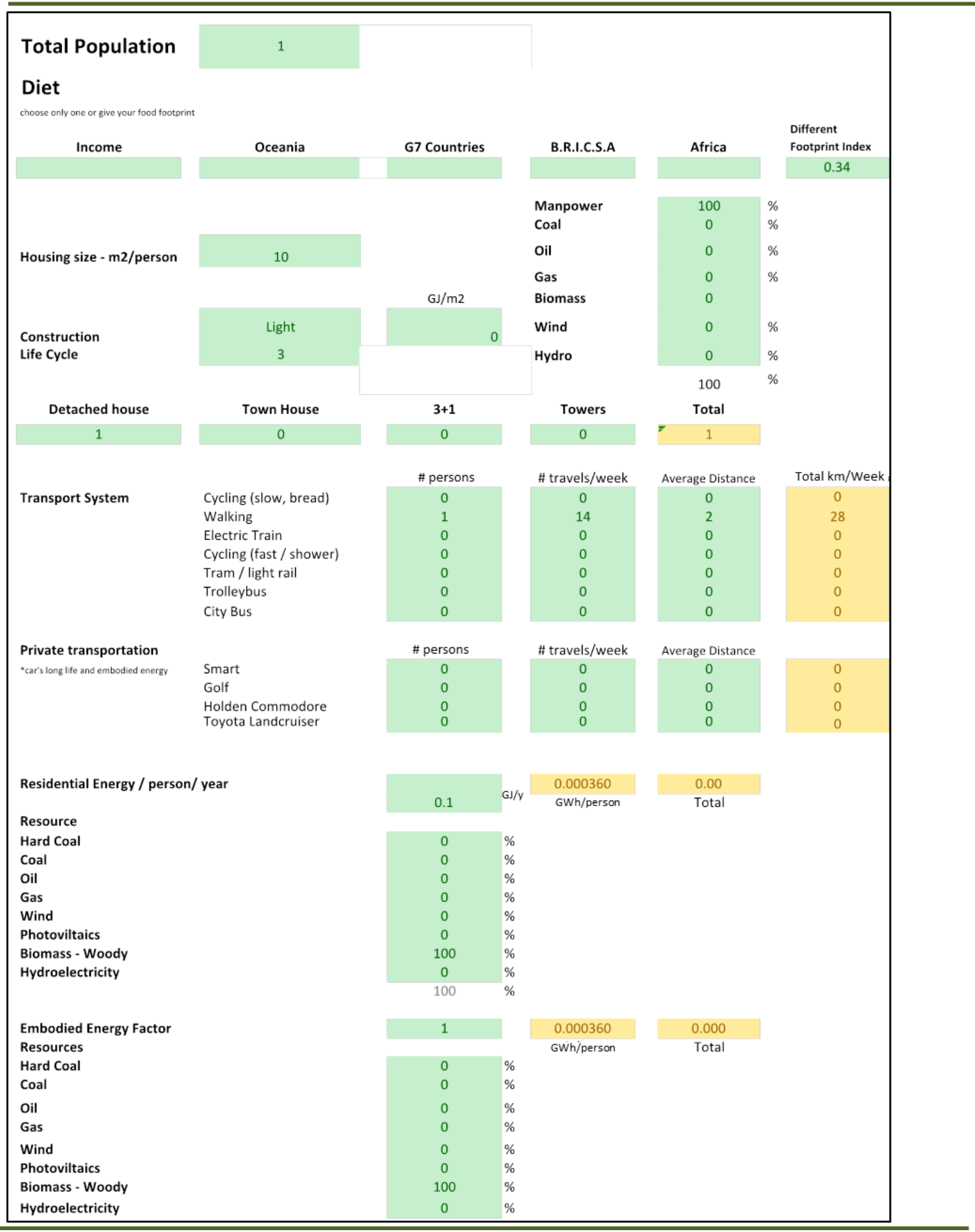




\section{Sustainability analysis.}

\section{Medieval Town I}
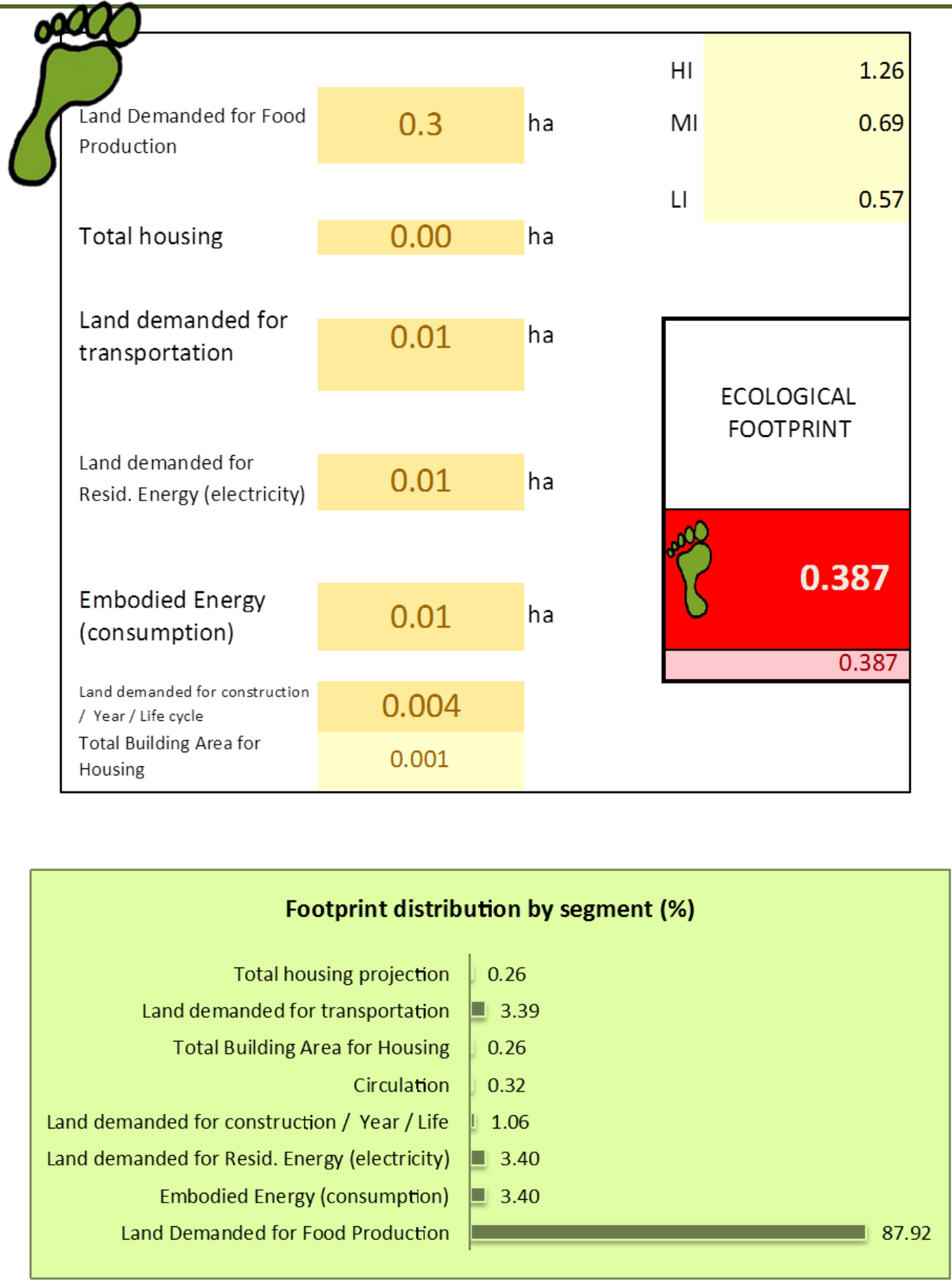
Sustainability analysis.

\begin{tabular}{|l|c|c|c|c|c|c|c|c|c|c|}
\hline & & & & & & & \\
\hline
\end{tabular}

